\title{
Hanford Double-Shell Tank Thermal and Seismic Project - Buckling Evaluation Methods and Results for the Primary Tanks
}

\author{
Author: TC Mackey \\ WRPS \\ Richland, WA 99352 \\ U.S. Department of Energy Contract DE-AC27-08RV14800 \\ $\begin{array}{lll}\text { EDT/ECN: } & \text { ECN-725883 } & \text { UC: } \\ \text { Cost Center: } & & \text { Charge Code: } \\ \text { B\&R Code: } & & \text { Total Pages: } 2\urcorner 4\end{array}$
}

Key Words: DST, Double-Shell Tanks, dynamic response, waste elastic properties, increased fluid level, sludge level, DST comments

Abstract: After releasing Revision 0 of this report, an independent review of the Double Shell Tanks (DST) Thermal and Operating Loads Analysis (TOLA) combined with the Seismic Analysis was con $\neg$ ducted by Dr. Robert P. Kennedy of RPK Structural Mechanics Consulting and Dr. Anestis S. Veletsos of Rice University. Revision 1 was then issued to address their review comments (included in Appendix D). Additional concerns involving the evaluation of concrete anchor loads and allowables were found during a second review by Drs. Kennedy and Veletsos (see Appendix G). Extensive additional analysis was performed on the anchors, which is detailed by Deibler et al. (2008a, 2008b). The current report (Revision 2) references this recent work, and additional analysis is presented to show that anchor loads do not concentrate significantly in the presence of a local buckle.

TRADEMARK DISCLAIMER. Reference herein to any specific commercial product, process, or service by trade name, trademark, manufacturer, or otherwise, does not necessarily constitute or imply its endorsement, recommendation, or favoring by the United States Government or any agency thereof or its contractors or subcontractors.

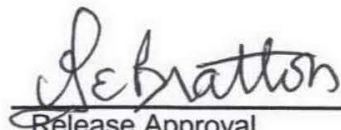

Release Approval

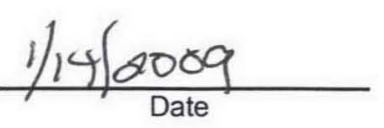

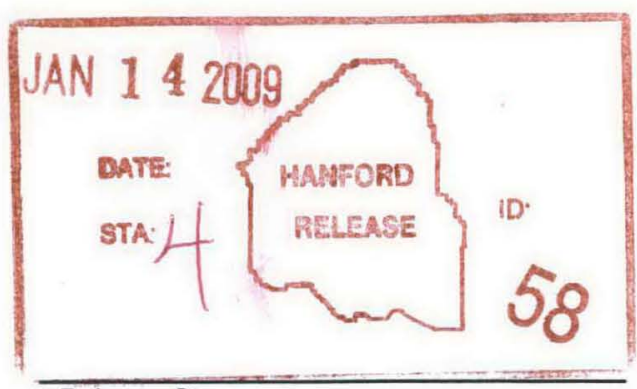

Release Stamp

\section{Approved For Public Release}




\begin{tabular}{|c|c|c|c|}
\hline \multicolumn{2}{|r|}{$\begin{array}{l}\text { Tank Farm Contractor (TFC) } \\
\text { RECORD OF REVISION }\end{array}$} & $\begin{array}{l}\text { (1) Document Number: } \\
\text { RPP-RPT-28967 }\end{array}$ & Page 1 \\
\hline \multicolumn{4}{|c|}{$\begin{array}{l}\text { (2) Title: } \\
\text { Buckling Evaluation Methods and Results for the Primary Tanks }\end{array}$} \\
\hline \multicolumn{4}{|c|}{ Change Control Record } \\
\hline \multirow{2}{*}{$\begin{array}{c}\text { (3) } \\
\text { Revision }\end{array}$} & \multirow{2}{*}{ (4) Description of Change - Replace, Add, and Delete Pages } & \multicolumn{2}{|c|}{ Authorized for Release } \\
\hline & & (5) Resp. Engr. (print/sign/date) & (6) Resp. Mgr. (print/sign/date) \\
\hline 2 RQ & Incorporate ECN 725883 Rev. 0 & T.C. Mackey $1 / 8 / 09$ & $\begin{array}{l}\text { D.J. Washenfelder } \\
\text { og wathenfeld } \\
0,108 \% 9\end{array}$ \\
\hline
\end{tabular}




\section{Pacific Northwest}

National Laboratory

Operated by Battelle for the

U.S. Department of Energy

\section{Hanford Double-Shell Tank Thermal and Seismic Project - Buckling Evaluation Methods and Results for the Primary Tanks}

\author{
K. I. Johnson J. E. Deibler \\ S. P. Pilli M. W. Rinker \\ N. K. Karri
}

September 2008

Prepared for

CH2M HILL Hanford Group, Inc.

in Support of the

Double-Shell Tank Integrity Program

Prepared for the U.S. Department of Energy under Contract DE-AC05-76RL01830 


\title{
DISCLAIMER
}

This report was prepared as an account of work sponsored by an agency of the United States Government. Neither the United States Government nor any agency thereof, nor Battelle Memorial Institute, nor any of their employees, makes any warranty, express or implied, or assumes any legal liability or responsibility for the accuracy, completeness, or usefulness of any information, apparatus, product, or process disclosed, or represents that its use would not infringe privately owned rights. Reference herein to any specific commercial product, process, or service by trade name, trademark, manufacturer, or otherwise does not necessarily constitute or imply its endorsement, recommendation, or favoring by the United States Government or any agency thereof, or Battelle Memorial Institute. The views and opinions of authors expressed herein do not necessarily state or reflect those of the United States Government or any agency thereof.

\author{
PACIFIC NORTHWEST NATIONAL LABORATORY \\ operated by \\ BATTELLE \\ for the \\ UNITED STATES DEPARTMENT OF ENERGY \\ under Contract DE-AC05-76RL01830
}

This document was printed on recycled paper. 


\section{Hanford Double-Shell Tank Thermal and Seismic Project - Buckling Evaluation Methods and Results for the Primary Tanks}
K. I. Johnson
J. E. Deibler
S. P. Pilli
M. W. Rinker
N. K. Karri

September 2008

Prepared for

CH2M HILL Hanford Group, Inc.

in Support of the

Double-Shell Tank Integrity Program

Pacific Northwest National Laboratory

Richland, Washington 99352 



\section{Executive Summary}

This report documents a detailed buckling evaluation of the primary tanks in the Hanford double-shell waste tanks (DSTs), which is part of a comprehensive structural review for the Double-Shell Tank Integrity Project. This work also provides information on tank integrity that specifically responds to concerns raised by the Office of Environment, Safety, and Health (ES\&H) Oversight (EH-22) during a review of work performed on the double-shell tank farms and the operation of the aging waste facility (AWF) primary tank ventilation system.

The current buckling review focuses on the following tasks:

- Evaluate the potential for progressive anchor bolt failure and the appropriateness of the safety factors that were used for evaluating local and global buckling. The analysis will specifically answer the following questions:

- Can the EH-22 scenario develop if the vacuum is limited to -6.6-inch water gage (w.g.) by a relief valve?

- What is the appropriate factor of safety required to protect against buckling if the EH-22 scenario can develop?

- What is the appropriate factor of safety required to protect against buckling if the EH-22 scenario cannot develop?

- Develop influence functions to estimate the axial stresses in the primary tanks for all reasonable combinations of tank loads based on detailed finite element analysis. The analysis must account for the variation in design details and operating conditions between the different DSTs. The analysis must also address the imperfection sensitivity of the primary tank to buckling.

- Perform a detailed buckling analysis to determine the maximum allowable differential pressure for each of the DST primary tanks at the current specified limits on waste temperature, height, and specific gravity.

Based on the concrete anchor bolt loads analysis and the small deformations that are predicted at the unfactored limits on vacuum and axial loads, it is very unlikely that the EH-22 scenario (i.e., progressive anchor bolt failure leading to global buckling of the tank under increased vacuum) could occur.

Based on the buckling analysis contained in this report, the current limits on the maximum vacuum level of 6 inches water gauge (w.g.) for the AY, AZ, SY, AN, and AW tanks and 12 inches w.g. for the AP tanks are acceptable given the current lack of corrosion in the tanks and the expectation that the maximum waste temperature will not exceed $160^{\circ} \mathrm{F}$ in the $\mathrm{AY}, \mathrm{AZ}, \mathrm{SY}, \mathrm{AN}$, and $\mathrm{AW}$ tanks and $135^{\circ} \mathrm{F}$ in the AP tanks. These limits are predicated on maintaining the minimum allowable waste level at 6 inches for the AY, AZ, SY, AN, and AW tanks and 12 inches for the AP tanks to preclude bottom uplift from occurring.

Previous buckling evaluations of the double-shell primary tanks used the analysis method in ASME Code Case N-284-1, which is based on the buckling of a constant thickness cylindrical shell with unsupported length, L. The cylindrical shells of the DST primary tanks do not have constant wall thicknesses and they 
do not have clearly defined lines of support due to the varying wall thicknesses and the upper and lower knuckle geometries.

The present buckling analysis used large displacement finite element analysis to predict the limiting vacuum load for the DST primary tanks under combined axial and vacuum loads. The detailed finite element analysis included models of the AY and the AP tanks. The AY results are also representative of the $\mathrm{AZ}, \mathrm{SY}, \mathrm{AW}$, and $\mathrm{AN}$ tanks because they have very similar wall thickness distributions. The current buckling evaluation method uses the ASME NB-3213.25 stiffness reduction method to conservatively estimate the vacuum and axial load limits on the primary tank. Comparison with N-284-1 calculations showed that Pacific Northwest National Laboratory's (PNNL's) large displacement method better accounts for the effect of the wall thickness variation on the limiting vacuum and axial loads. The finite element analysis also predicts that the tank deformations are small at the limit loads and they increase stably at loads beyond the limit loads. A large matrix of analyses was run that covers the expected range of axial forces and vacuum loads on the primary tanks. Influence functions were then fit to the limit load data to allow calculating the limiting vacuum and axial loads for all reasonable combinations of axial load, corrosion allowance, specific gravity, and waste height.

An ANSYS ${ }^{\circledR}$ thermal model was developed that is directly node-to-node compatible with the ANSYS DST structural model. The ANSYS thermal model supports the tank buckling analysis by allowing easy prediction of tank stresses due to different combinations of thermal and operating loads. This capability was required to calculate the allowable net vacuum loads as a function of the waste height and temperature. The ANSYS thermal model includes the effects of radiation and convection in the annulus and the dome space, and the thermal solution compared very closely with the previous TEMPEST thermal results. The two temperature solutions also gave very similar stresses throughout the thermal transient.

Influence functions were also developed to estimate the applied axial force in the primary tank wall, which is required for evaluating buckling of the primary tank. The ANSYS thermal and structural models were used to predict the axial thermal stresses in the wall of the primary tanks for a large matrix of waste height and temperature conditions. Analyses were conducted for both the AY and AP tank models. The axial forces for the applied load components were curve fit to allow estimating total axial force as the sum of the following loads:

- Differential thermal expansion

- Gravity

- Surface loads

- Concrete thermal degradation and creep

- Seismic excitation

- Effect of hydrostatic waste pressure on the confined axial force.

The variation in concrete anchor loads in and near a local buckle was calculated to address the concern of the EH-22 safety panel that an initiating buckle may locally overload the outer ring of anchors and lead to progressive anchor failure and global buckling of the primary tank. Finite element analysis showed that the variations in the anchor axial and shear displacements in the buckle are very small; $0.06 \%$ and $1.2 \%$ of the axial and shear displacement allowables. Therefore, the differential vacuum from the tank

\footnotetext{
${ }^{8}$ ANSYS is a registered trademark of ANSYS, Inc., Canonsburg, Pennsylvania.
} 
ventilation systems will not cause local failure of anchor bolts in or near a buckle. Since the anchors are not expected to fail, it is unlikely that the EH-22 scenario could occur.

A buckling evaluation was also performed to calculate the allowable vacuum limits for the DST primary tanks. The safety factors for the ASME Section III service levels are applied to calculate the allowable tank vacuum limits. Each service level has required factors of safety for local and global buckling:

Level $\mathrm{A}=$ Normal operating conditions

Level B $=$ Upset conditions

Level $\mathrm{C}=$ Emergency conditions

Level $\mathrm{D}=$ Faulted conditions

\begin{tabular}{cc}
\multicolumn{2}{c}{ Factors of Safety } \\
\cline { 1 - 1 } Local Buckling & Global Buckling \\
2.0 & 2.4 \\
2.0 & 2.4 \\
1.67 & 2.0 \\
1.34 & 1.61
\end{tabular}

An Excel ${ }^{\mathrm{TM}}$ spreadsheet was constructed to perform the above calculations and apply the safety factors. The spreadsheet was used to evaluate each of the DST primary tanks for their current operating conditions (waste temperature, height, and $\mathrm{SpG}$ ) and corrosion allowances of $0.000,0.060$, and $0.100 \mathrm{inch}$. The calculated vacuum limits for the specified 0.060 inch corrosion allowance are greater than the current vacuum limits for all of the tanks except the AP tanks. The current AP vacuum allowable is 12 inches w.g. compared to the calculated allowable of $10.53 \mathrm{inch}$ w.g. This vacuum limit is based on global buckling assuming a minimum waste height of 12 inches. The calculations show that although the AP tank is slightly thicker in the upper tank wall, this is not enough to double the vacuum limit compared to the other tanks.

Additional cases were analyzed with corrosion levels from 0.000 to 0.120 inches and a more realistic maximum waste temperature of $250^{\circ} \mathrm{F}$ for future operations. The calculated allowable vacuum limits for the AY, AZ, SY, AW, and AN tanks are above the current vacuum limit of 6 inch w.g. for all the cases. The allowable vacuum limit for the AP tank is above the current 12 inch w.g. limit for corrosion allowances of 0.000 to 0.025 inches. Therefore, the minimum wall thickness for buckling in the AP tanks is estimated to be 0.475 inch in the upper section of the primary tank wall.

The corrosion allowance for the AY, AZ, SY, AW, and AN tanks was also increased to identify the maximum value where the calculated vacuum limit was nearly equal to the 6 inch w.g. vacuum limit. The maximum allowable corrosion for these tanks was estimated to be $0.120 \mathrm{inch}$. Therefore, the minimum wall thickness for buckling in these tanks is estimated to be 0.255 inch in the thinnest upper section of the primary tank wall. These calculations conservatively assume uniform general corrosion.

The spreadsheet provides a convenient tool for quickly calculating the applied loads, the vacuum and axial load limits, and the code-based allowable vacuum loads. The buckling evaluation method contained in this work uses curve fitting to condense many detailed analyses into a quick evaluation tool. As such, it includes necessary conservatisms in the influence functions to ensure that the applied loads are not under-predicted or that the unfactored vacuum limit is not over-predicted for the range of input parameters that define the tanks. In addition, the ASME stiffness reduction method used to calculate the limiting vacuum and the axial loads is also judged to be conservative. The finite element results show that the unscaled tank deformations are barely visible on the tank geometry at the ASME limits for vacuum and axial loads. The models also predict that stable deformation will occur beyond these limits. Therefore, the buckling evaluation tool provides a conservative evaluation of the DST primary tanks. In 


\section{RPP-RPT-28967, Rev. 2}

cases where the calculated allowable vacuum is predicted to be below the current vacuum limit, then additional, more detailed analysis would be required to qualify the tank for the higher vacuum limit.

Tank farms operations staff recently reviewed all of the Occurrence Reports from 1990 to the present. This information will be released in the next revision of RPP-11413, Technical Basis for the Ventilation Requirements Contained in Tank Farm Operating Specifications Documents, authored by L. Payne. No incidents were found where the primary tank differential vacuum has exceeding the 6 inch w.g. maximum. Therefore, not only are the tanks able to withstand the expected loads without buckling, there are no recorded occurrences where the maximum vacuum has been achieved. There are also safety systems and operating procedures in place to ensure that the maximum vacuum loads are not achieved in future operations.

After releasing Revision 0 of this report, an independent review of the Double-Shell Tanks (DST) Thermal and Operating Loads Analysis (TOLA) combined with the Seismic Analysis was conducted by Dr. Robert P. Kennedy of RPK Structural Mechanics Consulting and Dr. Anestis S. Veletsos of Rice University. Revision 1 was then issued to address their review comments (included in Appendix D). Additional concerns involving the evaluation of concrete anchor loads and allowables were found during a second review by Drs. Kennedy and Veletsos (see Appendix G). Extensive additional analysis was performed on the anchors, which is detailed by Deibler et al. (2008a, 2008b). The current report (Revision 2) references this recent work, and additional analysis is presented to show that anchor loads do not concentrate significantly in the presence of a local buckle. Revisions to the buckling analyses in response to the reviewer comments are contained in the Executive Summary and in Sections 6.0, 7.1, 7.2, and 8.0 of this report. The results of the Revision 1 and 2 analyses do not change the overall conclusions of the original report.

Appendixes A, B, and C contain examples of the ANSYS finite element model input files used in this study.

Appendix D contains the Revision 0 review comments.

Appendix E contains an independent review of the methods used to calculate the vacuum limits on the DST waste primary tanks. The review specifically confirms the correct calculation of the axial tank force, the unfactored vacuum limit at incipient buckling, and the application of the safety factors for the ASME Service Levels A, B, C, and D.

Appendix F summarizes buckling evaluations from the body of this report that address the resistance of the Hanford DST primary tanks to buckling when in the full condition. These results were compiled in response to a question by CH2M HILL staff regarding the potential for primary tank buckling to occur when the tank is full and being drawn down during waste treatment efforts.

Appendix G contains the Revision 1 review comments. 


\section{Contents}

Executive Summary

iii

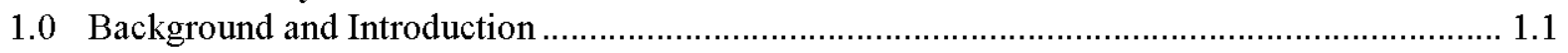

2.0 Assessment of Buckling Evaluation Methods for the DST Primary Tanks.............................. 2.1

2.1 ASME Code Case N-284-1 Method for Evaluating DST Primary Tank Buckling ................... 2.1

2.2 Sensitivity of Critical Buckling Loads to the Size and Number of Tank Imperfections ............ 2.11

3.0 Buckling Evaluation Method for the DST Primary Tanks Based on Large Displacement Instability Analysis

3.1 Vacuum Limit Equations for the AY Primary Tank ...................................................... 3.13

3.2 Vacuum Limit Equations for the AP Primary Tank .......................................................... 3.19

3.3 Comparison of Buckling Evaluations Using ASME N-284-1 and the DST Primary Tank Specific

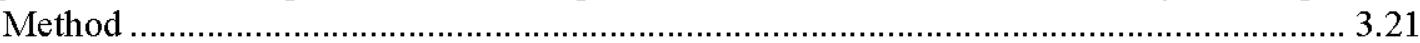

4.0 ANSYS Thermal Model of the Double-Shell Waste Tanks ..................................................... 4.1

4.1 Comparison of Previous Double-Shell Tank Thermal Models ............................................ 4.1

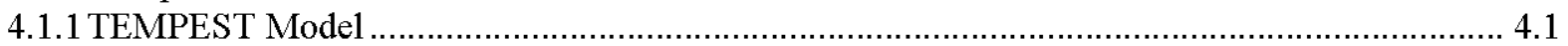

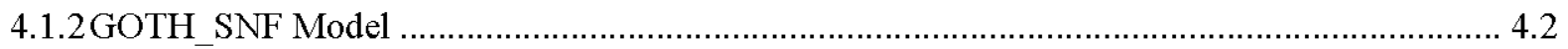

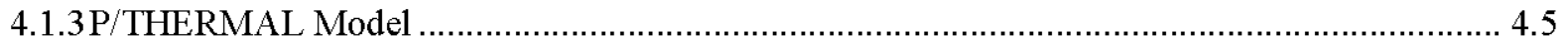

4.1.4 Summary of the Previous DST Thermal Models and the Objectives of the Buckling Analysis 4.5

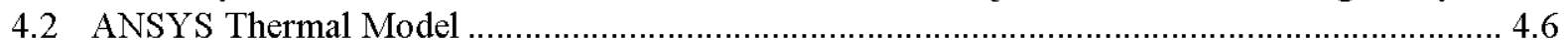

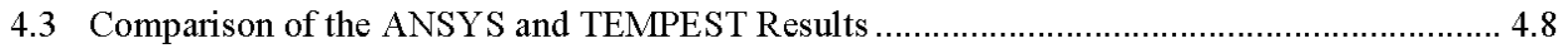

4.4 Calculated Boiling Temperatures for the Different Double-Shell Waste Tanks ...................... 4.13

5.0 Influence Functions for Calculating the Applied Axial Force on the Primary Tank Wall ........ 5.1

5.1 Axial Compression in the Primary Tank Wall Due to Concrete Thermal Degradation and Creep 5.2

5.2 Differential Thermal Expansion Forces for Current Operating Conditions ............................ 5.5

5.3 Axial Load Components Due to Gravity ............................................................................ 5.9

5.4 Axial Load Components Due to Surface Loads ................................................................. 5.9

5.5 Axial Load Component Due to Waste Hydrostatic Pressure.................................................. 5.11

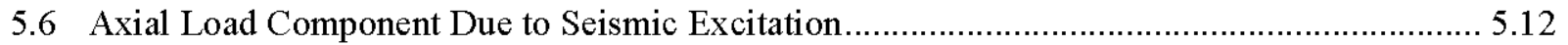

5.7 The Total Axial Force in the Primary Tank Wall ............................................................... 5.13

6.0 The Potential for Progressive Anchor Bolt Failure Under Thermal Operating and Seismic Loads 6.1

6.1 Anchor Bolt Evaluations for the Bounding (AY) and AP Tank Designs ................................ 6.1

6.2 Does Initiation of Primary Tank Buckling Concentrate Anchor Bolt Loads? .......................... 6.2

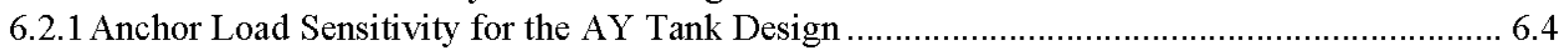

6.2.2 Anchor Load Sensitivity for the AP Tank Design ............................................................... 6.6

6.3 Addressing the EH-22 Findings on the Potential for Progressive Anchor Bolt Failure and the Appropriate Safety Factors for Evaluating Local and Global Buckling ........................... 6.9

6.3.1 Can the EH-22 Scenario Develop if the Vacuum is Limited to -6.6 Inch Water Gage by a Relief

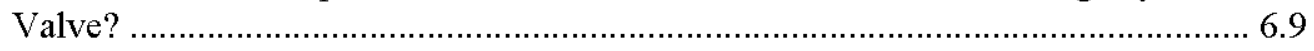

6.3.2 What is the Appropriate Factor of Safety Required to Protect Against Buckling if the EH-22 Scenario Can Develop? ............................................................................ 6.9

6.3.3 What is the Appropriate Factor of Safety Required to Protect Against Buckling if the EH-22 Scenario Cannot Develop? .......................................................................... 6.10

7.0 Buckling Evaluation of the DST Primary Tanks ............................................................ 7.1

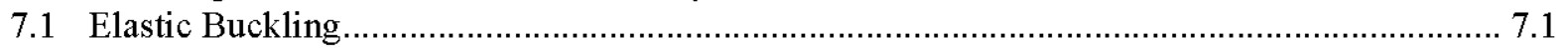

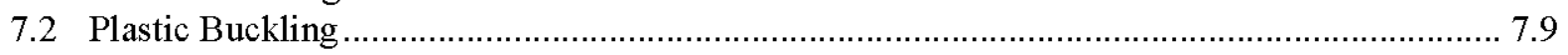

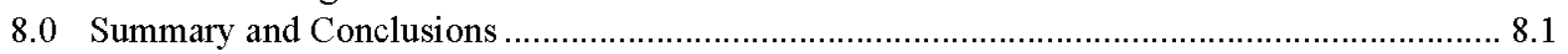

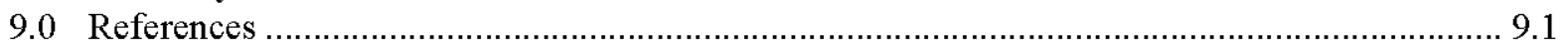


Appendix A - Analysis Files Used in the Chapter 2 Assessment of Buckling Evaluation Methods

Appendix B - ANSYS Input and Post Processing Files for Buckling Analysis.

Appendix C - ANSYS Input and Post Processing Files for Thermal, Hydrostatic and Dead Load Stress Contributions to Primary Meridional Stress...

Appendix D - Reviewer Comments and Discussion

Appendix E - Independent Confirmation of PNNL's Use of N-284-1 Safety Factors in Computing the Double-Shell Primary Tank Allowable Vacuum Level Governed by Buckling

Appendix F - Buckling Resistance of the DST Primary Tanks Under Internal Vacuum When in the Full Condition.....

Appendix G - Reviewer Comments and Discussion on Revision 1 of RPP-RPT-28967.

G.1 


\section{Figures}

Figure 2-1. Cross-Section View of the Hanford DST Primary Tank Designs

Figure 2-2. Predicted First Eigenvalue Buckling Mode for a Uniform Cylinder with Fixed

Displacements (in the plane of the cylinder), Added at the Top and Bottom Edges of the Cylinder

Figure 2-3. Predicted First Eigenvalue Buckling Mode for the AY Primary Tank Geometry with Fixed Displacements (in the plane of the cylinder) at the Tangent Points of the Top and Bottom Knuckles

Figure 2-4. Predicted First Eigenvalue Buckling Mode for the AY Primary Tank Geometry with Fixed Displacements and Rotations at the Tangent Points of the Top and Bottom Knuckles

Figure 2-5. Predicted First Eigenvalue Buckling Mode for a Uniform Cylinder Loaded with External Pressure and Fixed Displacements (in the plane of the cylinder), Added at the Top and Bottom Edges of the Cylinder.

Figure 2-6. Predicted First Eigenvalue Buckling Mode for a DST Cylinder with External Pressure Loading, Plus Fixed Displacements (in the plane of the cylinder), Added at the Top and Bottom Edges of the Cylinder

Figure 2-7. Predicted First Eigenvalue Buckling Mode for a Uniform Cylinder with Fixed Displacements (in the plane of the cylinder), Added at the Top and Bottom Edges of the Cylinder

Figure 2-8. Predicted First Eigenvalue Buckling Mode for a DST Cylinder with Fixed Displacements (in the plane of the cylinder), Added at the Top and Bottom Edges of the Cylinder

Figure 2-9. Uniform Cylinder with Imperfections.

Figure 2-10. AY Tank with Imperfections (The imperfection amplitudes are exaggerated in the plots to make them visible.)

Figure 3-1. Double-Shell Primary Tank Model Used in the Large Deflection Buckling Analysis (The imperfection size was 1 inch out of roundness in a 7-foot circumferential arc.)...................... 3.2

Figure 3-2. Loads Applied to the Large Deflection Buckling Model ................................................ 3.2

Figure 3-3. Effect of Increasing Dome Load on the Axial Stress in the AY Primary Tank ................... 3.3

Figure 3-4. Load Deflection Curve for Increasing Vacuum Load Applied to the Large Displacement Tank Buckling Model (The results are for the AY tank model, with specific gravity $=1.7$, waste height $=144$ inches, and compressive dome displacement $=0.3$ inches.) $\ldots . . .3 .3$

Figure 3-5. Displaced Shape of the AY Model at the Limit Vacuum Defined by the ASME Slope Reduction Method (The influence of the geometric imperfection is evident in the upper left of the plot. The results are for the AY tank model, with specific gravity $=1.7$, waste height $=250$ inches, and compressive dome displacement $=0.3$ inches. The displacements are magnified 50 times so that they are visible.).

Figure 3-6. Contour Plot of the Maximum Surface Stress in the Upper Knuckle of the AY Tank (This large displacement elastic model shows that the surface stresses are above the $32 \mathrm{ksi}$ yield strength. The displacements are magnified 50 times so that they are visible.) ............................. 3.5

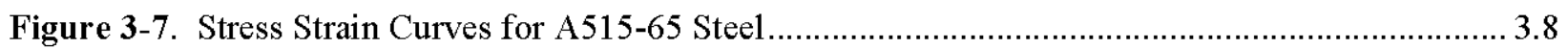

Figure 3-8. Load Deflection Curves of the AY and AP Primary Tanks Under Axial Compression Alone (These results are for a uniform corrosion allowance of 0.060 inches. Note that bending stresses in the upper knuckle of the elastic AY model exceeded the $32 \mathrm{ksi}$ yield 
strength. The model was re-analyzed with elastic/plastic stress strain curves for A515 steel at $\leq 100^{\circ} \mathrm{F}$ and $350^{\circ} \mathrm{F}$.)

Figure 3-9. Surface Stress in the Upper Knuckle Region of the AY Tank at the Maximum Axial Compressive Load (dome deflection $=0.75$ inch) $($ The yield curve corresponds to A515-65 steel at $350^{\circ} \mathrm{F}$. The displaced shape is for a scale factor of 1.0.)

Figure 3-10. Surface Stress in the Upper Knuckle Region of the AY Tank at a Dome Deflection = 1.0 Inch (The yield curve corresponds to A515-65 steel at $350^{\circ} \mathrm{F}$. The displaced shape is for a scale factor of 1.0.).

Figure 3-11. Load Deflection Curves for the AY Primary Tank Under Axial Compression for a Range of Yield Strengths and Wall Thicknesses (corrosion allowances) in the Nominal 0.5 Inch Wall Section

Figure 3-12. Nonlinear Load Deflection Curves for the AY Tank Plus the Linear Elastic Projected Stiffness, Showing the Definition of the Equivalent Linear Elastic Compressive Force3.11

Figure 3-13. Nonlinear Load Deflection Curves for the AP Tank Plus the Linear Elastic Projected Stiffness, Showing the Definition of the Equivalent Linear Elastic Compressive Force.

Figure 3-14. Calculated Vacuum Limit Versus Waste Heights for a Range of Axial Compressive Loads (These results are for the $\mathrm{AY}$ tank with waste $\mathrm{SpG}=1.7$ and corrosion allowance $=$ 0.060 inch.)

Figure 3-15. Axial Compression Scale Factor of Adjusting the Vacuum Limit for the AY Primary Tank

Figure 3-16. Wall Thickness Scale Factor for the AY Tank

Figure 3-17. Specific Gravity Scale Factor for the AY Tank

Figure 3-18. Comparison of the Analytical Equations for Vacuum Limit with the Discrete Valued Predicted with Large Deformation Finite Element Analysis

Figure 3-19. Effect of Wall Thickness and Yield Strength on the Axial Limit Load for the AY Primary Tank

Figure 3-20. Effect of Wall Thickness on the Axial Limit Load for the AP Primary Tank

Figure 3-21. Typical Displacement Shape of the AY and AP Primary Tanks at the Axial Limit Load (The displacements have been magnified 50 times in the plot.)

Figure 3-22. Comparison of the PNNL Large Displacement Buckling Evaluation Method with the ASME N-284-1 Method (The comparison is made for the AY tank with a waste height of 6 inches.)

Figure 3-23. Comparison of the PNNL Large Displacement Buckling Evaluation Method with the ASME N-284-1 Method (The comparison is made for the AY tank with a waste height of 144 inches.)

Figure 3-24. Comparison of the PNNL Large Displacement Buckling Evaluation Method with the ASME N-284-1 Method (The comparison is made for the AY tank with a waste height of 144 inches and an average wall thickness of 0.315 inches.) .

Figure 4-1. TEMPEST DST Model Configuration.

Figure 4-2. GOTH_SNF DST Model Configuration

Figure 4-3. P/THERMAL DST Model Configuration

Figure 4-4. Example Waste Temperature Transient Showing the Limiting Waste Surface Temperature

Figure 4-5. TEMPEST Temperatures Mapped onto the ANSYS DST Model (Steady State temperature solution, Waste Height $=422$ inches, Twaste $=350^{\circ} \mathrm{F}$.) 
Figure 4-6. $\quad$ ANSYS Thermal Solution with Bulk Waste and Waste Surface Boundary Temperatures (Steady State temperature solution, Waste Height $=422$ inches, Twaste_bulk $=350^{\circ} \mathrm{F}$, Twaste_surface $=222^{\circ} \mathrm{F}$. Maximum temperature of the dome surface $=$ $217^{\circ} \mathrm{F}$.)

Figure 4-7. ANSYS Contour Plot Showing Temperatures Around and Beneath the Tank for a Waste Depth of 422 Inches (Bulk waste and waste surface boundary temperatures applied. Steady State, Twaste_bulk $=350^{\circ} \mathrm{F}$, Twaste_surface $=222^{\circ} \mathrm{F}$. Maximum temperature of the dome surface $=217^{\circ} \mathrm{F}$.)

Figure 4-8. ANSYS Contour Plot Showing Temperatures Around and Beneath the Tank for a Waste Depth of 144 Inches (Bulk waste and waste surface boundary temperatures applied. Steady State, Twaste_bulk $=350^{\circ} \mathrm{F}$, Twaste_surface $=222^{\circ} \mathrm{F}$. Maximum temperature of the dome surface $=229^{\circ} \mathrm{F}$.)

Figure 4-9. Comparison of the TEMPEST and ANSYS Temperature Predictions at the Inside Surface of the Concrete Tank (Steady State, Twaste_bulk $=350^{\circ} \mathrm{F}$, Twaste_surface $=222^{\circ} \mathrm{F}$. Temperature at the inside dome center $=244^{\circ} \mathrm{F}$.) .

Figure 4-10. Comparison of the TEMPEST and ANSYS Temperature Predictions at the Outside Surface of the Concrete Tank (Steady State, Twaste_bulk $=350^{\circ} \mathrm{F}$, Twaste_surface $=222^{\circ} \mathrm{F}$. Temperature at the outside dome center $=244^{\circ} \mathrm{F}$.)

Figure 4-11. Comparison of Maximum Meridional Membrane Stresses During Heatup for the TEMPEST and ANSYS Temperature Distributions (Maximum stresses occur at heatup cycle H4.)

Figure 4-12. Vapor Pressure Data Used to Estimate the Boiling Temperature of Different Tank Wastes (The data for Tank AY-102 is shown.)

Figure 5-1. Relationship of Maximum Axial Thermal Expansion Force During the Heatup Cycle in the AY Primary Tank Wall for a Range of Waste Heights and Temperatures (The data point are the finite element results and the solid lines represent the curve fits of the data.) ................... 5.6

Figure 5-2. Relationship of the Steady State Axial Thermal Expansion Force in the AY Primary Tank Wall for a Range of Waste Heights and Temperatures (The data point are the finite element results and the solid lines represent the curve fits of the data.)

Figure 5-3. Relationship of the Maximum Axial Thermal Expansion Force During the Heatup Cycle in the AP Primary Tank Wall for a Range of Waste Heights and Temperatures (The data points are the finite element results and the solid lines represent the curve fits of the data.) ..........5.8

Figure 5-4. Relationship of the Steady State Axial Thermal Expansion Force in the AP Primary Tank Wall for a Range of Waste Heights and Temperatures (The data point are the finite element results and the solid lines represent the curve fits of the data.)

Figure 5-5. Comparison of the Axial Force Components in the AY Primary Tank Wall Due to the Different Tank Loads

Figure 5-6. Comparison of the Axial Force Components in the AY Primary Tank Wall Due to the Different Tank Loads

Figure 5-7. Axial Force in the Primary Tank Wall Due to Waste Hydrostatic Pressure ..................... 5.11

Figure 5-8. Effect of Specific Gravity on Axial Force in the AY Tank Wall .................................... 5.12

Figure 5-9. Meridional (axial) Membrane Stress in the AY Tank Wall for the Four Different Combinations of Soil and Concrete Properties

Figure 5-10. Stiffness Scale Factors to Estimate the Seismic Axial Force for the AY and AP

Tanks with Different Corrosion Allowances ........................................................................ 5.14

Figure 6-1. Buckling Model Showing the Location of the anchor bolts Attached to the Tank Dome..... 6.3 
Figure 6-2. Axial Displacement Variation Along the Outermost Anchor Bolt Circle as a Function of Internal Vacuum. Bounding (AY) Tank with 25 Inch Waste Depth.

Figure 6-3. Shear Displacement Variation Along the Outermost Anchor bolt Circle as a Function of Internal Vacuum. Bounding (AY) Tank with 25 Inch Waste Depth.

Figure 6-4. Axial Displacement Variation Along the Outermost Anchor Bolt Circle as a Function of Internal Vacuum. Bounding (AY) tank with 400 inch waste depth.

Figure 6-5. Shear Displacement Variation Along the Outermost Anchor bolt Circle as a Function of Internal Vacuum. Bounding (AY) tank with 400 inch waste depth.

Figure 6-6. Axial Displacement Variation Along the Outermost Anchor Bolt Circle as a Function of Internal Vacuum. AP Tank with 25 Inch Waste Depth.

Figure 6-7. Shear Displacement Variation Along the Outermost Anchor bolt Circle as a Function of Internal Vacuum. AP Tank with 25 Inch Waste Depth.

Figure 6-8. Axial Displacement Variation Along the Outermost Anchor Bolt Circle as a

Function of Internal Vacuum. AP tank with 400 inch waste depth

Figure 6-9. Shear Displacement Variation Along the Outermost Anchor bolt Circle as a Function of Internal Vacuum. AP tank with 400 inch waste depth.

Figure 7-1. The Axial Distribution of Hoop Stress in the Primary Tank Wall Due to Thermal +

Operating + Seismic Loads 


\section{Tables}

Table 2-1. Summary of Design Data and Operating Limits for the DST Primary Tanks

Table 2-2. Comparison of Eigenvalue Critical Buckling Loads for the Approximate Uniform Cylinder and the AY Primary Tank Geometry

Table 2-3. Summary of the Eigenvalue Buckling Comparisons of the Uniform Cylinder and the DST Primary Tank Geometry for Axial, Hoop, and Combined Axial and Hoop Loads ................ 2.7

Table 2-4. Comparison of the Construction Imperfection Tolerances Specified in ASME NE4220 and the AY Tank Construction Specifications

Table 2-5. Matrix of Imperfection Sizes That were Simulated

Table 2-6. Summary of the Critical Buckling Loads for the Sensitivity Study on the Number and Size of the Tank Imperfections

Table 3-1. Large Deformation Tank Analyses for the AY Vacuum Limit Equations .......................... 3.6

Table 3-2. Large Deformation Tank Analyses for the AP Vacuum Limit Equations ............................ 3.7

Table 3-3. Yield Strength at Temperature for the Primary Tank Steels .............................................. 3.8

Table 3-4. Summary of Maximum Dome Displacements and Maximum Equivalent Linear Elastic Compressive Forces for the AY Primary Tank ............................................................ 3.12

Table 3-5. Summary of Maximum Dome Displacements and Maximum Equivalent Linear

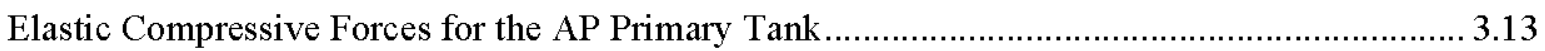

Table 3-6. Excel ${ }^{\circledR}$ Spreadsheet for Calculating the Vacuum Limit of the AY Primary Tank ................ 3.17

Table 3-7. Excel ${ }^{\circledR}$ Spreadsheet for Calculating the Vacuum Limit of the AP Primary Tank................ 3.20

Table 3-8. Buckling Evaluation Cases for Comparing the N-284-1 Method with the PNNL

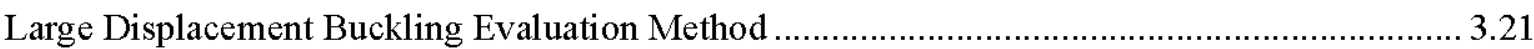

Table 3-9. ASME N-284-1 Calculated Section Properties and Allowable Stresses............................ 3.21

Table 4-1. Example Vapor Pressure Data from Ogden et al. (2002) for Tank AY-102...................... 4.13

Table 4-2. Estimated Boiling Temperature for the 28 Double-Shell Tanks....................................... 4.14

Table 5-1. Load Conditions for the Baseline DST Analysis ............................................................... 5.1

Table 5-2. Example Creep and Thermal Degradation Calculations ....................................................... 5.4

Table 5-3. Estimated Axial Force Due to Creep and Thermal Degradation of the Elastic Modulus for a Range of Tank Waste Temperatures and Waste Heights (The force calculations assume a 0.060 inch corrosion allowance and a 60 -year operating history.) ............................... 5.5

Table 5-4. Matrix of Waste Tank Models That were Analyzed to Estimate the Axial Thermal Expansion Forces for the AY Tank Design (The table lists the thermal expansion forces at the end of the heatup cycle and at the steady state temperature distribution.) .................................. 5.6

Table 5-5. Matrix of Waste Tank Models That were Analyzed to Estimate the Axial Thermal Expansion Forces for the AP Tank Design (The table lists the thermal expansion forces at the end of the heatup cycle and at the steady state temperature distribution.) ................................... 5.7

Table 6-1. Maximum load conditions addressed in the AY and AP anchor bolt evaluations.................. 6.2

Table 7-1. Calculation of Axial Applied Force for the AY Primary Tank ......................................... 7.2

Table 7-2. Calculation of Unfactored Vacuum Limit for the AY Primary Tank .................................. 7.3

Table 7-3. Evaluation of the Allowable Vacuum Limit for the AY Tank Based on the ASME Section III Service Level Safety Factors ............................................................................... 7.4

Table 7-4. Summary of the DST Primary Tank Buckling Evaluations for the Specified Maximum Operating Conditions (corrosion allowance is 0.060 inches) ..................................... 7.5 
Table 7-5. Summary of the DST Primary Tank Buckling Evaluations for the Reduced Maximum Waste Temperatures Based on Anchor Integrity (corrosion allowance is 0.060 inches)

Table 7-6. Summary of DST Primary Tank Buckling Evaluations for a Range of Corrosion Allowances and Operating Conditions.

Table 7-7. Reevaluation of Plastic Buckling for the DST Primary Tanks 
RPP-RPT-28967, Rev. 2

\subsection{Background and Introduction}

This report documents a detailed buckling evaluation of the primary tanks in the Hanford double-shell waste tanks (DSTs). The analysis is part of a comprehensive structural review for the Double-Shell Tank Integrity Project. This work also provides information on tank integrity that specifically responds to concerns raised by the Office of Environment, Safety, and Health (ES\&H) Oversight (EH-22) during a review (in April and May 2001) of work being performed on the double-shell tank farms, and the operation of the aging waste facility (AWF) primary tank ventilation system (CH2M HILL 2002).

The EH-22 review team assessed the adequacy of the nuclear facility hazard analysis by performing an essential system review of the AWF primary tank ventilation system. Several concerns with the hazards analyses performed on the AWF tanks were identified with respect to potential non-conservative assumptions in the tank structural analysis, analysis of scenarios involving high efficiency particulate air (HEPA) filter failure, and the potential for tank airlift circulators to over-pressurize tanks and negate the requirement for sub-atmospheric tank operation. With respect to the tank structural analysis for vacuum reported in HNF-1838, Assessment of Project W-030 Relief Valve Pressure Setting on Internal Vacuum Specification Limits for AY and AZ Tank Farm Primary Tanks (Julyk 1997), the EH-22 panel had the following findings:

- The AY/AZ tank structural analysis for vacuum conditions is potentially non-conservative. A structural analysis on the AY/AZ primary tanks (the inner shells of the double-shell tanks) determined the ability of the tanks to withstand all negative pressures associated with operation of the ventilation system. A single vacuum relief valve on each tank protects against excessive vacuum and would limit vacuum to minus 6.6 inches water gage (w.g.). Normal operating vacuum is minus 1.0 to minus 3.0 inches w.g.

- The structural analysis was based on an American Society of Mechanical Engineers (ASME) Code Case N-284-1, Metal Containment Shell Buckling Design Method, Class MC, Section III, Division 1, that addressed tank buckling due to vacuum (ASME 1995). This Code Case required that the factor of safety used for the local buckling failure mode be increased by 20 percent when local buckling would lead to a total collapse failure mode. The higher safety factor was not used in the analysis, based on the assumption that total collapse would not occur because the primary tank wall is supported through structural interaction between the primary tank steel shell dome, the secondary tank reinforced concrete dome and connecting embedded anchor bolts. The review team identified that this assumption was probably invalid. The load path would initially be only through the outer ring of anchor bolts, because the primary tank dome would likely peel away from the underside of the concrete dome because of the downward pull of the buckling sides. Each succeeding inboard bolt circle could assume load only after the outboard bolts had failed, and thus the anchor bolt failures would be progressive until complete detachment of the steel dome from the concrete dome, with the resultant total collapse of the primary tank. The anchor bolts or their attachments were the unanalyzed weak link in the load path. Therefore, the factor of safety that was used is potentially non-conservative with respect to the ASME Code Case requirements.

The first finding by the EH-22 panel describes the focus of the previous analysis and simply states that it may be non-conservative. No specific recommendations are given in the first finding that require further analysis or review. The second finding details the panel's concerns regarding non-conservative 
assumptions in the analysis and it postulates that progressive anchor bolt failure may occur which could cause local buckling (and local anchor bolt failure) to progress to global buckling. The anchor bolts or their attachments were identified as the unanalyzed weak link in the load path.

The allowable vacuum with regard to buckling under combined vacuum and axial stress is sensitive to the compressive axial membrane stress in the tank vertical wall. The axial stress results from: 1) dead loads (soil overburden, concrete structure, and self weight of the primary tank), 2) waste hydrostatic pressure, 3) differential thermal expansion between the primary steel tank and the concrete tank, 4) concrete creep down loads on the primary tank with time, and 5) seismic loads. Variations in these conditions can lead to high axial compressive stress in the primary tank vertical wall. The buckling analysis in Julyk (1997) relied on the tank stresses reported in the ASA Phase III analysis (see Appendix A of Rinker et al. 2004) that considered only a limited number of load cases. Scaling functions were used by Julyk to estimate the tank axial membrane stresses for load combinations other than those specifically evaluated in the Phase III analysis.

Because of the concerns raised by the EH-22 panel and the approximate nature of the stress solutions used in the previous buckling analysis, the current buckling review focuses on the following tanks:

- Evaluate the potential for progressive anchor bolt failure and the appropriateness of the safety factors that were used for evaluating local and global buckling. The analysis will specifically answer the following questions:

- Can the EH-22 scenario develop if the vacuum is limited to -6.6 inches w.g. by a relief valve?

- What is the appropriate factor of safety required to protect against buckling if the EH-22 scenario can develop?

- What is the appropriate factor of safety required to protect against buckling if the EH-22 scenario cannot develop?

- Based on detailed finite element analysis, develop influence functions to estimate the axial stresses in the primary tanks for all reasonable combinations of tank loads. The analysis must account for the variation in design details and operating conditions between the different DSTs. These variations include operating temperature, waste level, primary tank material thickness, creep of the secondary concrete tank, secondary tank concrete degradation, waste specific gravity and soil overburden. Note that from a buckling perspective the worst condition is when the waste level is low, the waste specific gravity is low and the temperature is high. Note also that the compressive stresses are secondary, driven by differential thermal expansion and creep down of the concrete. The analysis must also address the imperfection sensitivity of the primary tank to buckling.

- Perform a detailed buckling analysis to determine the maximum allowable differential pressure for each of the DST primary tanks at the current specified limits on waste temperature, height, and specific gravity.

This report is organized in the following manner. Chapter 2 compares the buckling analysis method in the ASME Code Case N-284-1 (used in the previous tank buckling analyses) with detailed finite element analysis of the specific geometry of the DST primary tanks. The analysis also evaluates the sensitivity of the calculated critical buckling loads to the number and size of the geometric imperfections that are assumed. 


\section{RPP-RPT-28967, Rev. 2}

Chapter 3 presents an alternate buckling evaluation method based on large displacement finite element analysis of the DST primary tanks. Limit values on internal vacuum and axial compression loads are defined using an ASME criterion for establishing structural collapse loads. Influence functions are developed to calculate the unfactored limit loads (vacuum and axial compression) as a function of the applied axial force, corrosion allowance, waste height, and specific gravity. Different influence functions are presented for tanks with thickness distributions comparable to the AY primary tanks (including AZ, $\mathrm{SY}, \mathrm{AN}$, and $\mathrm{AW}$ ) and the AP primary tanks.

Chapter 4 describes the ANSYS thermal model that was developed to provide temperature solutions from which to estimate the differential thermal expansion stresses for different waste heights and temperatures. The modeling methods are checked by comparing the ANSYS temperature solutions with previous results from the TEMPEST code.

Chapter 5 details the development of influence functions for estimating the applied axial forces in the primary tank, which are necessary for estimating the limit vacuum. The influence functions were implemented in Microsoft Excel ${ }^{\mathrm{TM}}$ to allow easily estimating the applied force as continuous functions of the tank-specific operating parameters. Separate influence functions were developed for the AY and AP tank thickness distributions.

Chapter 6 presents a detailed analysis of the anchor bolt shear and normal forces that are predicted for the possible loading conditions on the primary tank. The analysis estimated the maximum allowable axial compression in the tank wall that corresponds to the anchor bolt allowable forces for normal (operating) and abnormal (operating + seismic) loads. Chapter 6 also addresses the concerns of the EH-22 panel and recommends the appropriate safety factors for the buckling analysis.

Chapter 7 uses the buckling criteria developed in Chapter 3 and the influence functions for estimating the applied loads (Chapter 5) to calculate the allowable vacuum loads for each of the DST primary tanks at the currently specified operating limits on waste heights, temperatures and specific gravities.

Chapter 8 summarizes the conclusions of this buckling analysis.

Appendix A contains examples of the ANSYS finite element model input files used in this study.

Appendix B contains the ANSYS input and post processing files for buckling analysis of the AP and AY primary tanks under combined axial compression and vacuum loads.

Appendix C includes ANSYS model input files for estimating the individual contributions of various load components (gravity, surface loads, hydrostatic loads and differential thermal expansion loads) to the total meridional stress in the tank wall. Input files for the ANSYS DST thermal model are contained here.

Appendix D documents an independent review of the Double Shell Tanks (DST) Thermal and Operating Load (TOLA) and Seismic analyses that was conducted by Dr. Robert P. Kennedy of RPK Structural Mechanics Consulting and Dr. Anestis S. Veletsos of Rice University. Their review included an evaluation of the initial release of this report on the potential for buckling of the DST primary tanks.

Appendix E documents an independent review that confirmed the correct calculation of the axial tank force, the unfactored vacuum limit at incipient buckling, and the application of the safety factors for the ASME Service Levels A, B, C, and D. 
Appendix F summarizes buckling evaluations from the body of this report that address the resistance of the Hanford DST primary tanks to buckling when in the full condition. These results were compiled in response to a question by CH2M HILL staff regarding the potential for primary tank buckling to occur when the tank is full and being drawn down during waste treatment efforts. 


\subsection{Assessment of Buckling Evaluation Methods for the DST Primary Tanks}

\subsection{ASME Code Case N-284-1 Method for Evaluating DST Primary Tank Buckling}

Buckling of the primary tank is of concern due to compressive stresses that occur in both the meridional and hoop directions. Meridional (axial) compression results from differential thermal expansion between the primary tank and the concrete over-structure, plus creep-down of the concrete structure over time. Hoop compression results from net vacuum loads in the tank. These loading conditions (displacement controlled in the meridional direction and load controlled in the hoop direction) are unique compared to the vacuum-induced stresses in typical free-standing storage tanks, and are a direct result of the unique design of the underground double-shell waste storage tanks.

The buckling evaluation method defined in Code Case N-284-1, Metal Containment Shell Buckling Design Methods, of the American Society of Mechanical Engineers (ASME) Boiler and Pressure Vessel Code, Section III, Division 1 (ASME 1995) has been used in previous evaluations of the DST primary tanks because it considers the interaction of independent levels of compressive stress in both the meridional and hoop directions. By comparison, the ASME Code Case N-530 method (ASME, 1994) that is described in the Brookhaven report, BNL 52361, (Bandyopadhyay et al. 1997) only addresses buckling of thin walled tanks loaded with hoop tension. The N-530 method is not applicable to tanks subjected to vacuum loads.

The N-284-1 method provides an acceptance criteria with respect to buckling instability for defining the allowable loads for a given tank design. The method is based on theoretical critical buckling loads (hoop and axial limit stresses) that are adjusted by knockdown factors to account for geometric imperfections, the height of the tank, the radius-to-thickness ratio, and material plasticity. The intent of these calculations is to accurately estimate the actual bifurcation buckling load for a specific tank geometry. These loads are then reduced by safety factors (specified for four different service levels) to set the allowable combination of axial compressive load and tank vacuum. The bifurcation buckling solutions and knock down factors used in N-284-1 are for simplified geometries that are intended to conservatively apply to typical storage tank geometries. This section reviews the analytical basis for N-284-1 and compares the solutions with finite element models that include the specific geometric features of the DST primary tanks.

Although the DST designs vary somewhat between tank farms, the primary tanks typically consist of a 75 -ft-diameter by $34-\mathrm{ft}-\mathrm{high}$ cylindrical portion that is connected to a flat bottom through a 1-ft-radius lower knuckle (Figure 2-1). The wall thickness of the tank cylinder is graduated to counteract the hydrostatic stress of the contain waste (see Table 2-1). The tanks are capped by a shallow spherical dome that transitions to the cylindrical section through a radiused upper knuckle. The dome is attached to the concrete over-structures with anchor bolts that are imbedded in the concrete. The total height of the tank is approximately $46.8 \mathrm{ft}$.

The formulas presented in Section 1710 of ASME Code Case N-284-1 are based on the buckling of a constant thickness cylindrical shell with an unsupported length, $\mathrm{L}$. The length, $\mathrm{L}$, is defined between 


\section{RPP-RPT-28967, Rev. 2}

"lines of support that provide sufficient stiffness to act as bulkheads." In previous analyses, L has been defined as the vertical distance from the waste-free surface to the tangent point between the upper knuckle and the dome. The wall thickness used in the N-284-1 equations was then calculated as the weighted average over this length. However, the primary tank cylindrical shell does not have a constant wall thickness and it does not have clearly defined lines of support due to the upper and lower knuckles.

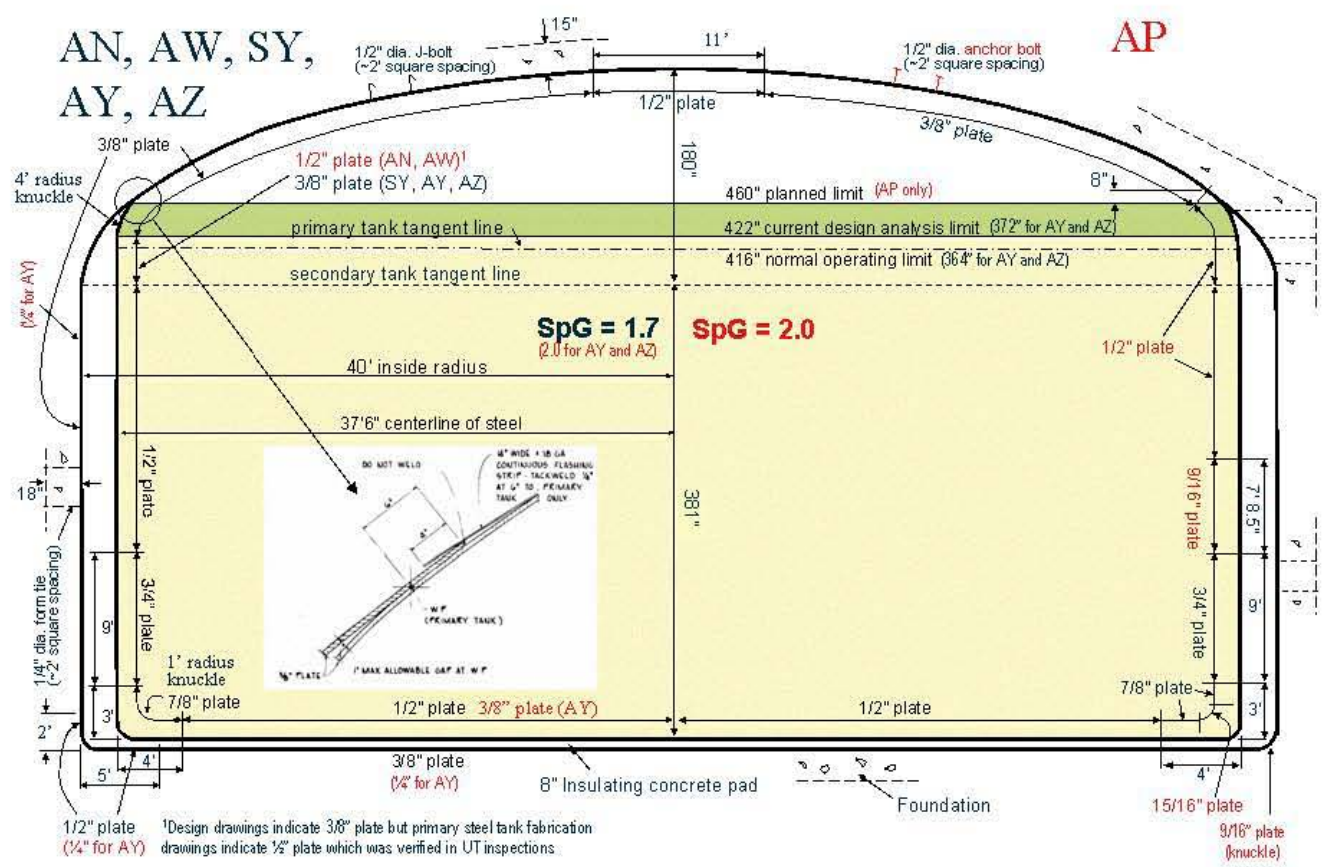

Figure 2-1. Cross-Section View of the Hanford DST Primary Tank Designs

Table 2-1. Summary of Design Data and Operating Limits for the DST Primary Tanks

\begin{tabular}{|l|r|r|r|r|}
\hline & \multicolumn{3}{|c|}{ The Different Tank Farm Designs } \\
\hline Design Data and Operating Limits & AYIAZ & SY & AWIAN & AP \\
\hline Primary Tank Thickness, inches & & & & \\
\hline Upper Haunch & 0.375 & 0.375 & 0.375 & 0.5 \\
\hline Vertical Wall, Top & 0.375 & 0.375 & 0.5 & 0.5 \\
\hline Vertical Wall, Mid & 0.5 & 0.5 & 0.5 & 0.563 \\
\hline Vertical Wall, Bottom & 0.75 & 0.75 & 0.75 & 0.75 \\
\hline Lower Knuckle & 0.875 & 0.875 & 0.875 & 0.9375 \\
\hline & & & & \\
\hline Max Allowable Waste Temp., F & 350 & 250 & 350 & 210 \\
\hline Max Historical Waste Temp, F & $247 / 263$ & 155 & $135 / 150$ & 118 \\
\hline & & & & \\
\hline Yield Strength @ Room Temp, ksi & 32 & 35 & 50 & 45 \\
\hline Ultimate Strength, ksi & 60 & 65 & 70 & 70 \\
\hline Sm at Max. Allow Temp, ksi & 18.6 & 21 & 21.3 & 21.7 \\
\hline Sm at Max Hist Temp, ksi & 19.2 & 21.4 & 21.7 & 21.7 \\
\hline & & & & \\
\hline Specified Max. Waste Height, inch & 370 & 422 & 422 & 422 \\
\hline Maximum Specific Gravity & 1.7 & 1.7 & 1.7 & 2 \\
\hline
\end{tabular}




\section{RPP-RPT-28967, Rev. 2}

Therefore, finite-element-based, eigenvalue buckling models were constructed to compare the bifurcation buckling loads for the theoretical approximation and the actual tank geometries. Additional models were also constructed to investigate the sensitivity of the results to the imperfection size and the number of imperfections. The ANSYS input files for this work are listed in Appendix A.

First, a model was constructed to confirm that the ANSYS finite element code could accurately predict the eigenvalue buckling mode of a uniform thin-walled cylinder. The model was constructed using the basic dimensions of the AY primary tank in the DST bounding model ( $\mathrm{R}=450$-inch, average wall thickness $=0.507$-inch, height $=460$-inch). A $180^{\circ}$ arc was modeled to ensure that the minimum eigenvalue was not increased artificially by simulating too small a section of the tank. Symmetry boundary conditions were applied to the cut edges of the $180^{\circ}$ model. The critical buckling loads predicted by ANSYS were compared against the theoretical buckling stress used in N-284-1:

$$
\sigma_{\varphi \varrho L}=0.605 E t / R
$$

This is equivalent to the equation derived in Timoshenko and Gere (1961) for a cylindrical shell that is uniformly compressed and assumed to buckle symmetrically with respect to the axis of the tank (i.e., the cylinder ends are simply supported, but they remain circular). Table 2-2 lists the predicted critical buckling load in the uniform cylindrical wall from the finite element model. The table shows that the critical buckling load predicted by the finite element model (with the end displacements fixed to remain circular) matches the theoretical value within $0.1 \%$. Therefore, the ANSYS solution reproduces the theoretical buckling solution very accurately. Figure 2-2 shows the predicted mode shape from the ANSYS uniform cylinder buckling model.

Next the actual primary tank geometry and wall thickness variation of the AY design were substituted into the model to compare the critical buckling load and the resulting buckling mode shape with that of Figure 2-2, the uniform cylindrical approximation assumed in the ASME N-284-1 evaluation. Table 2-2 gives the eigenvalue buckling load for the AY tank geometry with the in-plane displacements of the cylinder ends fixed. These are the same end constraints assumed in the theoretical solution. The critical load for this case is only $20.7 \%$ of the theoretical buckling load for the uniform cylindrical tank section assumed in N-284-1. Figure 2-3 shows that the corresponding buckling mode shape is confined to the upper section of the tank with the thinnest wall $(0.375$-inch minus the 0.060 -inch corrosion allowance $=$ 0.315 inch). The AY primary tank model was also run with the in-plane displacements and the edge rotations fixed, which closely approximates the actual conditions of the primary tank. The eigenvalue buckling load for this case is $34.1 \%$ of the theoretical buckling load, and the buckling mode shape is again confined to the top thinnest course of the tank wall (Figure 2-4). 
Table 2-2. Comparison of Eigenvalue Critical Buckling Loads for the Approximate Uniform Cylinder and the AY Primary Tank Geometry

\begin{tabular}{||c|l|c|c|}
\hline No. & \multicolumn{1}{|c|}{ Top and Bottom Edge Constraints } & $\begin{array}{c}\text { Total Buckling } \\
\text { Load for a 360 } \\
\text { cylinder }(\mathbf{l b})\end{array}$ & $\begin{array}{c}\text { Percent of the } \\
\text { theoretical buckling } \\
\text { load in N-284-1 }\end{array}$ \\
\hline \hline 1 & $\begin{array}{l}\text { Theoretical buckling solution - Ends fixed to remain } \\
\text { circular }\left(\sigma_{\mathrm{c}}=0.605 \mathrm{Et} / \mathrm{R}\right)\end{array}$ & $2.883 \mathrm{E}+07$ & 100 \\
\hline & ANSYS uniform cylinder model & & 100.1 \\
\hline 2 & Ends fixed to remain circular & $2.885 \mathrm{E}+07$ & 20.7 \\
\hline & ANSYS AY primary tank geometry & $5.962 \mathrm{E} 6$ & 34.1 \\
\hline 3 & Ends fixed to remain circular & $9.831 \mathrm{E} 6$ & \\
\hline 4 & $\begin{array}{l}\text { Ends fixed to remain circular } \\
+ \text { top and bottom edge rotations fixed to approximate the } \\
\text { primary tank conditions }\end{array}$ & & \\
\hline
\end{tabular}

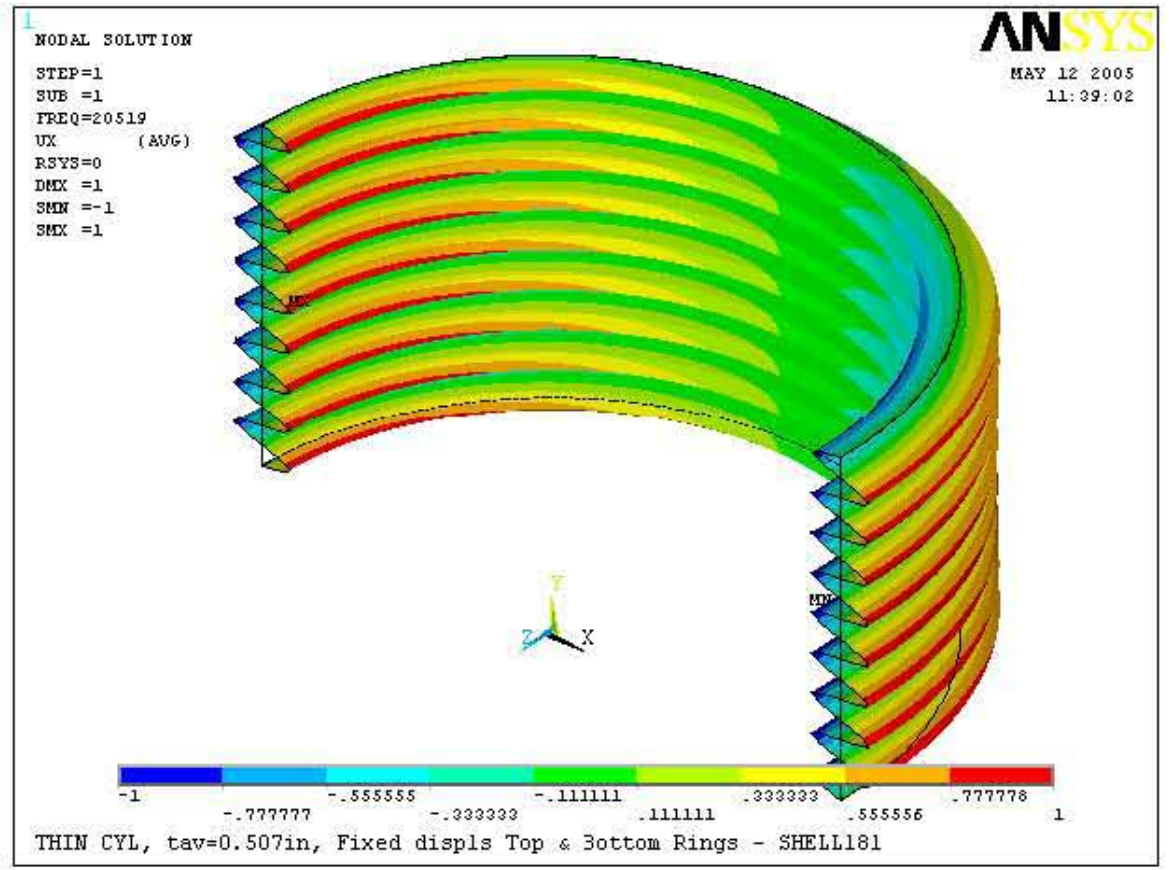

Figure 2-2. Predicted First Eigenvalue Buckling Mode for a Uniform Cylinder with Fixed Displacements (in the plane of the cylinder), Added at the Top and Bottom Edges of the Cylinder 


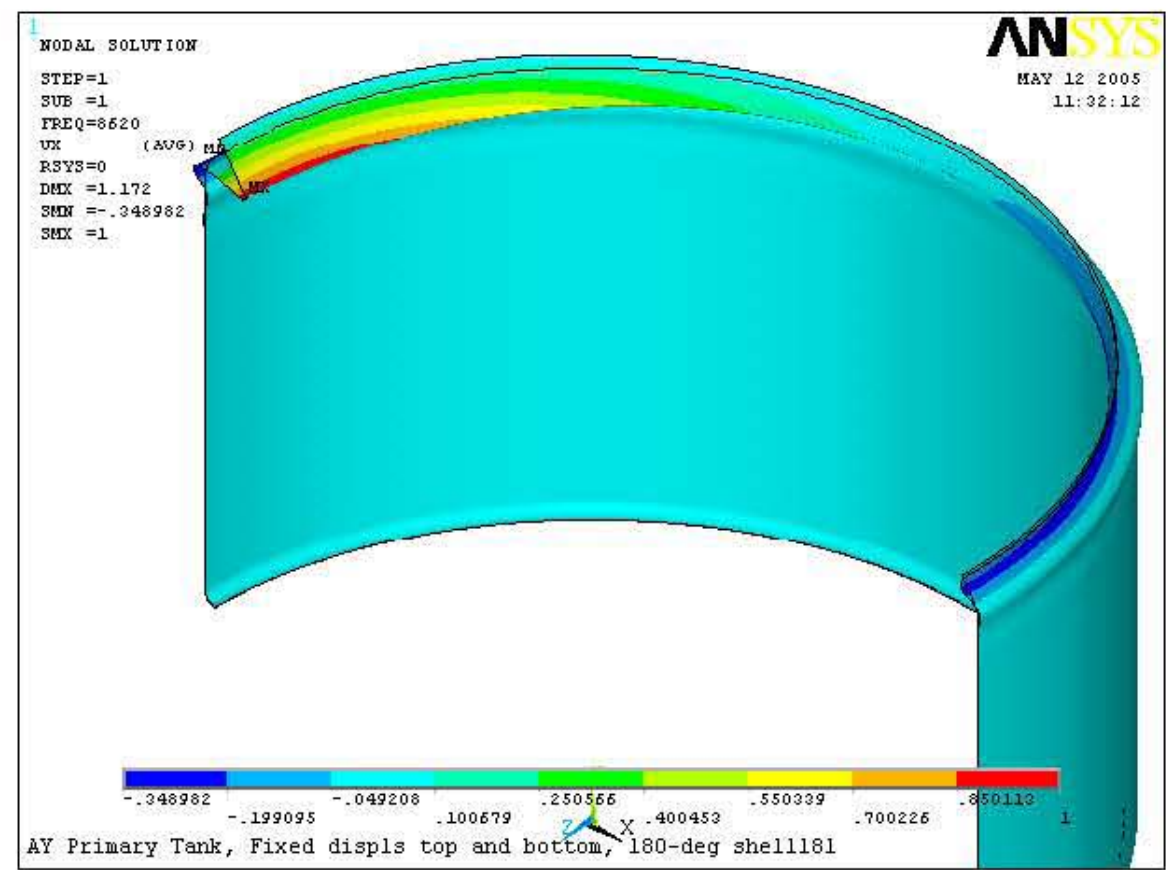

Figure 2-3. Predicted First Eigenvalue Buckling Mode for the AY Primary Tank Geometry with Fixed Displacements (in the plane of the cylinder) at the Tangent Points of the Top and Bottom Knuckles

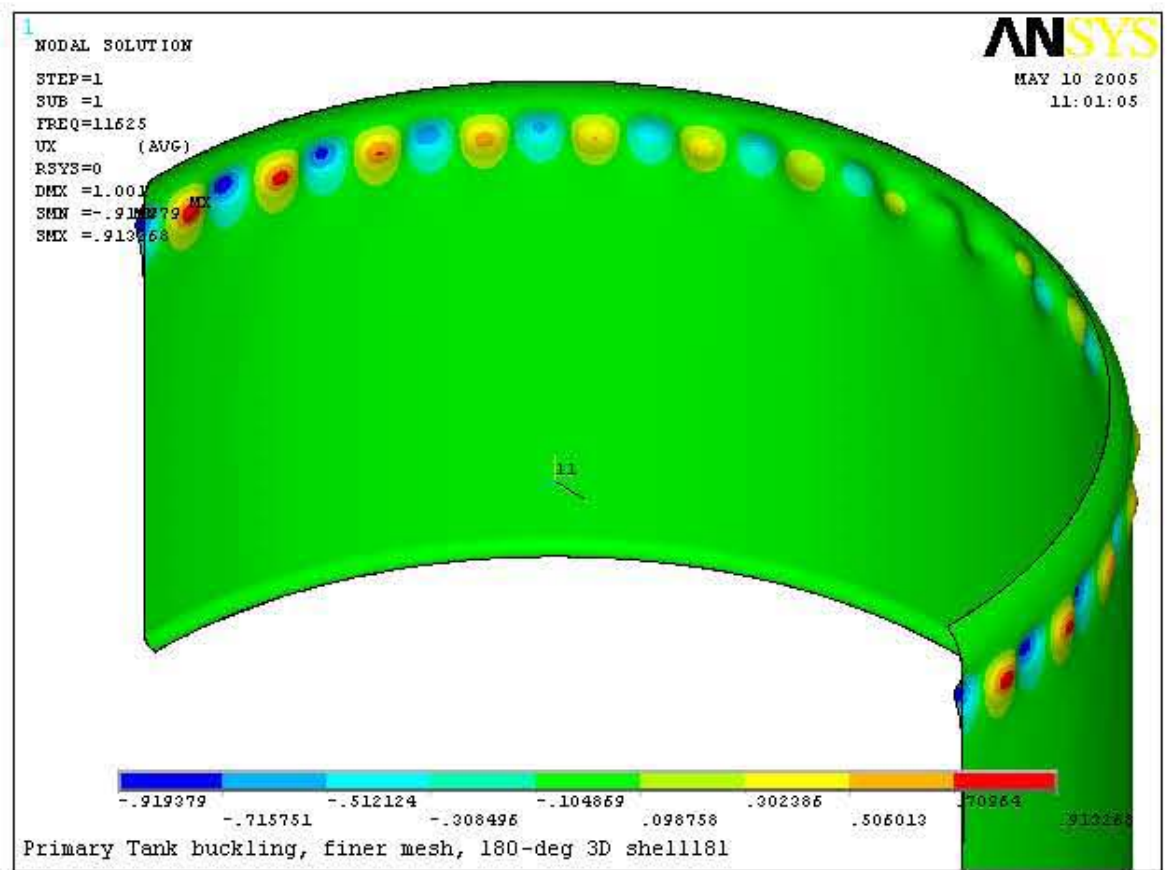

Figure 2-4. Predicted First Eigenvalue Buckling Mode for the AY Primary Tank Geometry with Fixed Displacements and Rotations at the Tangent Points of the Top and Bottom Knuckles 
This comparison shows that using an average wall thickness and a buckling length from the waste level to the dome tangent point does not conservatively approximate the theoretical buckling load of the actual tank geometry. If one assumes that buckling is localized to the upper ring of the tank with the minimum wall thickness $\left(\mathrm{t}_{\mathrm{av}}=0.315\right.$-inch, height $=78.75$-inch $)$, then the estimated critical buckling load is $1.82 \mathrm{E} 7 \mathrm{lb}$. This is still a factor of 1.82 greater than the critical buckling load predicted for the AY primary tank geometry. Therefore, the radiused shape of the upper knuckle significantly reduces the axial critical buckling load of the actual tank geometry.

External pressure boundary conditions were also applied to the above finite element model to predict the "harmonic" buckling mode. Symmetry boundary conditions were applied to the cut edges of the $180^{\circ}$ model. The critical buckling loads predicted by ANSYS were compared against the theoretical buckling loads used in ASME code case N-284-1. The equation used in ASME code case N-284-1 is a simplification of the classical solution and it is independent of the number of lobes ' $n$ ' into which the cylinder collapses. A comparison with the classical solution showed that the simplified equation in N-284-1 is sufficiently accurate. Table 2-3 lists the predicted critical buckling load in the uniform cylindrical wall from the finite element model. The table shows that the critical buckling load predicted from the finite element model matches the theoretical value within 5\%. Therefore, the ANSYS solution reproduces the theoretical buckling solution accurately, considering the fact that the theoretical solution involves trial and error substitutions for the number of lobes ' $n$ '. Figure 2-5 shows the predicted buckling mode shape for the uniform cylinder loaded with external pressure. 
Table 2-3. Summary of the Eigenvalue Buckling Comparisons of the Uniform Cylinder and the DST Frimary Tank Geometry for Axial, Hoop, and Combined Axial and Hoop Loads

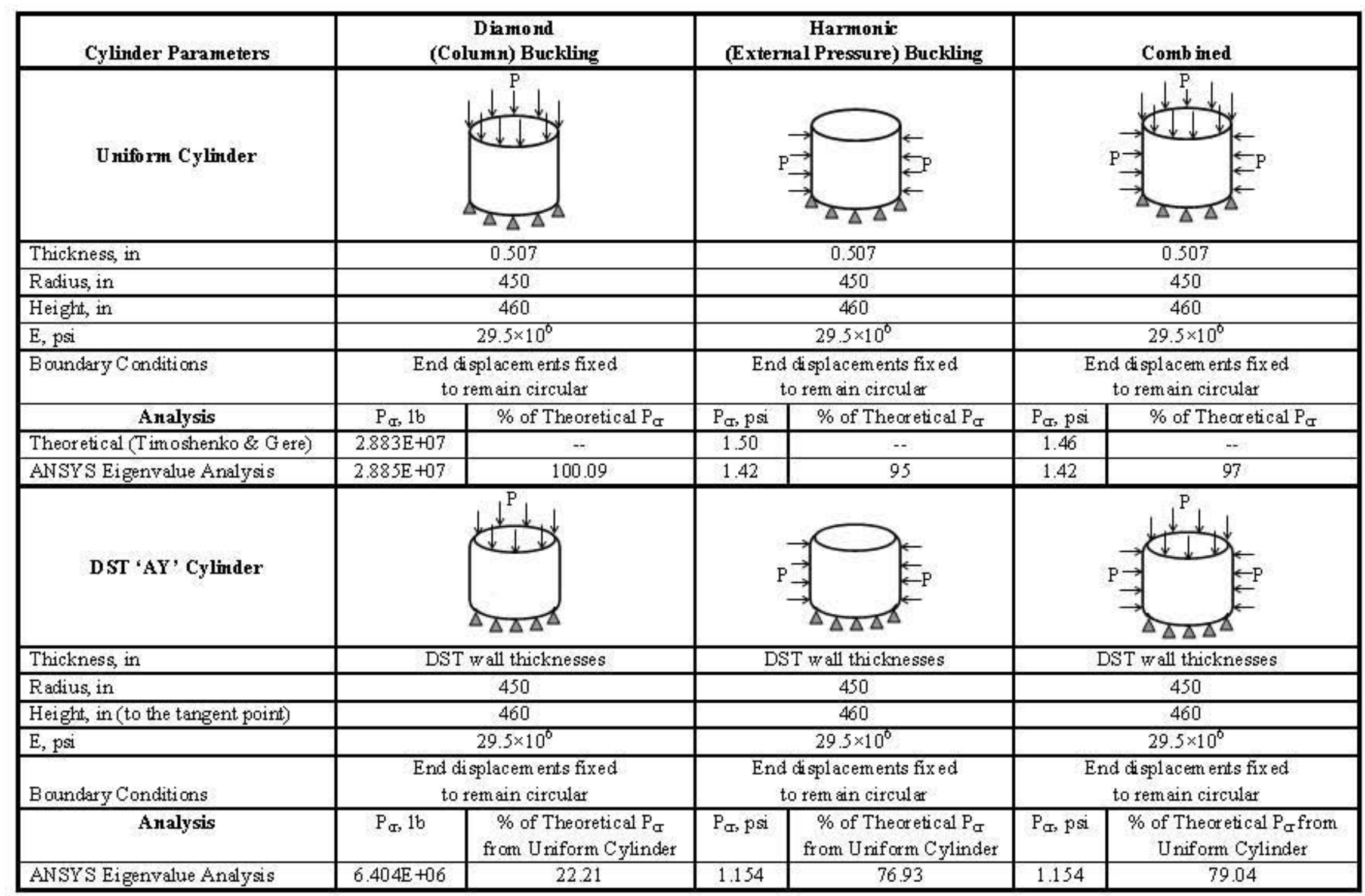




\section{RPP-RPT-28967, Rev. 2}

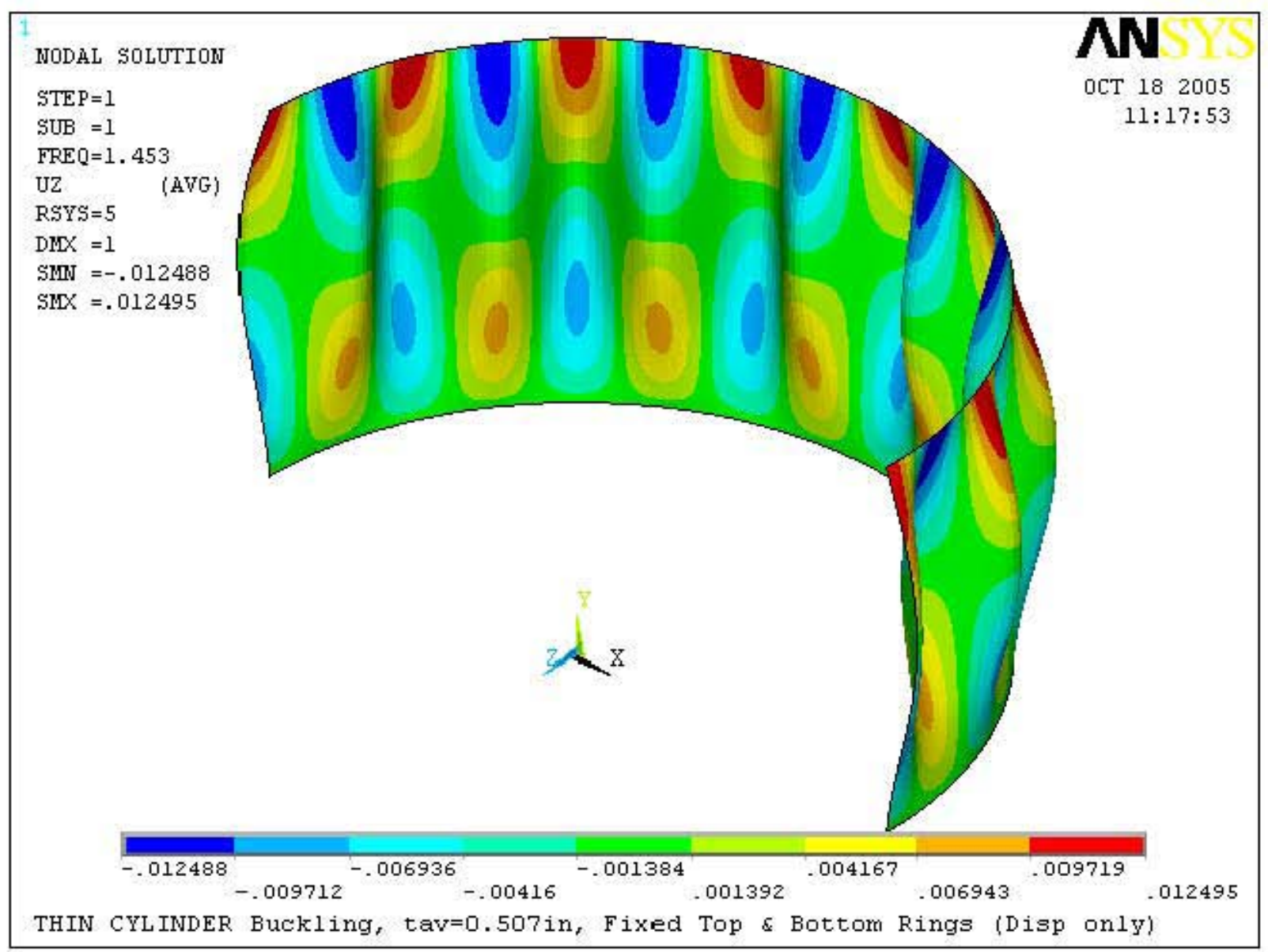

Figure 2-5. Predicted First Eigenvalue Buckling Mode for a Uniform Cylinder Loaded with External Pressure and Fixed Displacements (in the plane of the cylinder), Added at the Top and Bottom Edges of the Cylinder

The primary tank geometry and wall thickness variation of the AY design were again substituted into the model to compare the critical buckling load and the resulting buckling mode shape with that of the cylindrical approximation assumed in the ASME N-284-1 evaluation. Table 2-3 gives the eigenvalue buckling load for the AY tank geometry with the in-plane displacements of the cylindrical ends fixed (the same end constraints assumed in the theoretical solution). The critical load for this case is only $76.93 \%$ of the theoretical buckling load from N-284-1. Figure 2-6 shows that the corresponding buckling mode shape is very similar to the uniform cylinder tank

This comparison shows that using an average wall thickness and a buckling length from the waste level to the dome tangent point does not conservatively approximate the theoretical buckling load of the actual tank geometry even though they have similar mode shapes. Therefore, the gradation in wall thickness and the radiused shape of the upper knuckle reduces the critical buckling load of the actual tank geometry.

Combined external pressure and axial compression loads were also applied to the above finite element model to predict the combined buckling mode. This simulates the vacuum loading of a closed-ended cylinder where the axial stress is $1 / 2$ the hoop stress. The critical buckling loads predicted by ANSYS were compared with the theoretical buckling loads predicted using the N-284-1 equations. Table 2-3 lists 


\section{RPP-RPT-28967, Rev. 2}

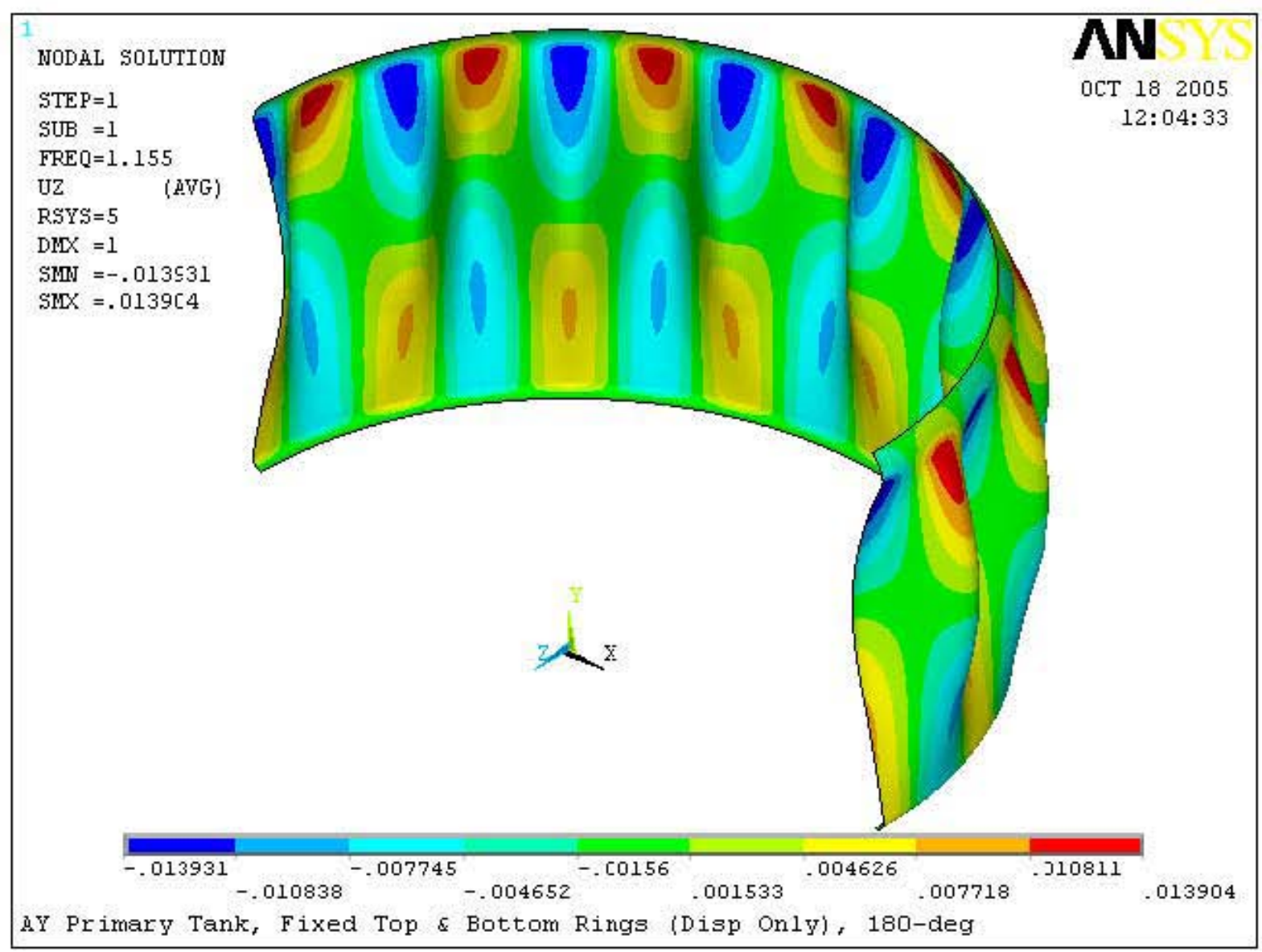

Figure 2-6. Predicted First Eigenvalue Buckling Mode for a DST Cylinder with External Pressure Loading, Plus Fixed Displacements (in the plane of the cylinder), Added at the Top and Bottom Edges of the Cylinder

the predicted critical buckling load in the uniform cylindrical wall from the finite element model. The table shows that the critical buckling load predicted from the finite element model (with the end displacements fixed to remain circular) matches the the oretical value within $3 \%$. Therefore, the ANSYS solution reproduces the theoretical buckling solution accurately. Figure 2-7 shows the predicted mode shape for ANSYS uniform cylinder buckling model case in Table 2-3.

The primary tank geometry and wall thicknesses of the AY design were substituted into the model to compare the critical buckling load and the resulting buckling mode shape with that of the cylindrical approximation assumed in the ASME N-284-1 evaluation. Table 2-3 shows that the eigenvalue buckling load for the AY tank geometry is $79 \%$ of the theoretical buckling load from N-284-1. Figure $2-8$ shows that the corresponding buckling mode shape is again very similar to the uniform cylinder tank.

This comparison shows that using an average wall thickness and a buckling length from the waste level to the dome tangent point does not conservatively approximate the theoretical buckling load of the actual tank geometry but have the same mode shapes. Therefore, it is again shown that the gradation in wall thickness and the radiused shape of the upper knuckle tend to reduce the critical buckling load of the actual tank geometry. 


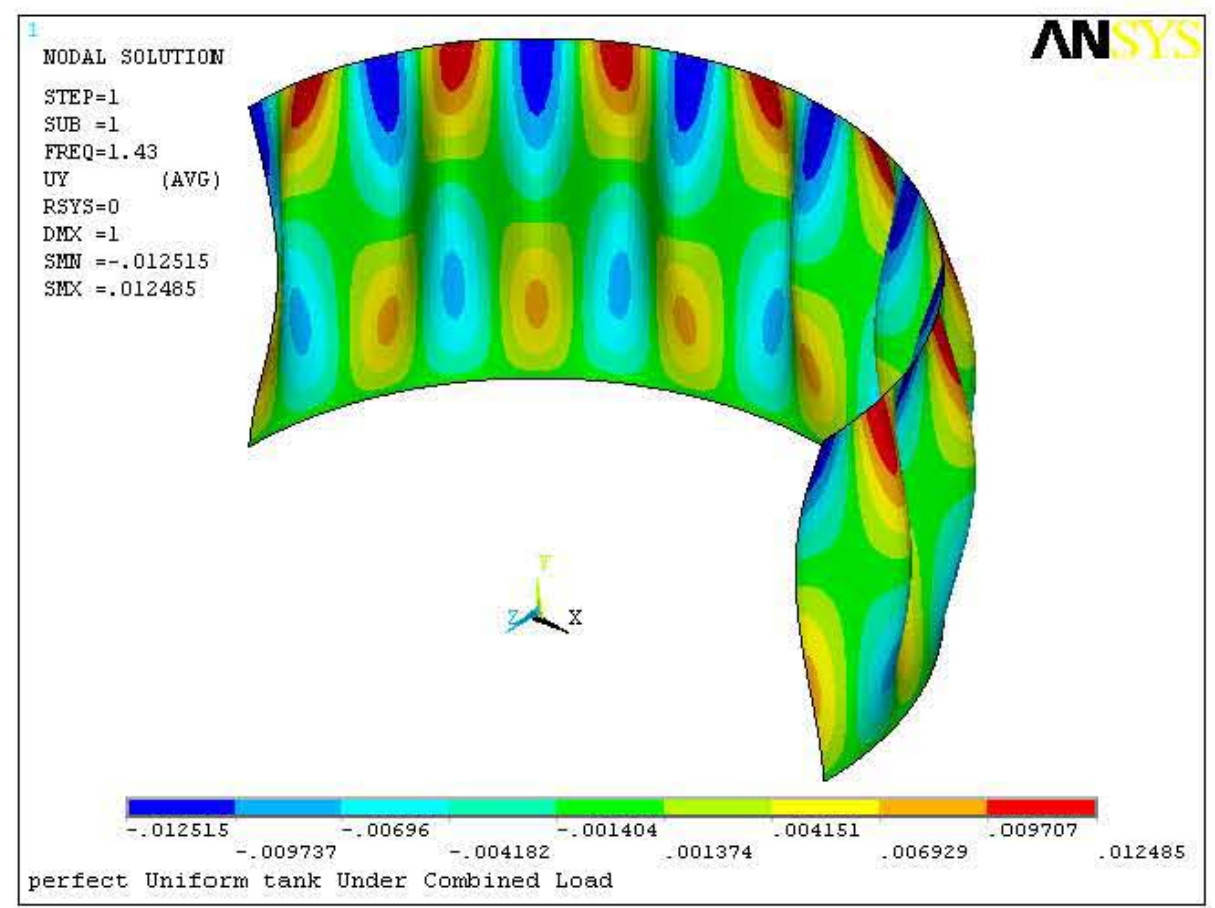

Figure 2-7. Predicted First Eigenvalue Buckling Mode for a Uniform Cylinder with Fixed Displacements (in the plane of the cylinder), Added at the Top and Bottom Edges of the Cylinder

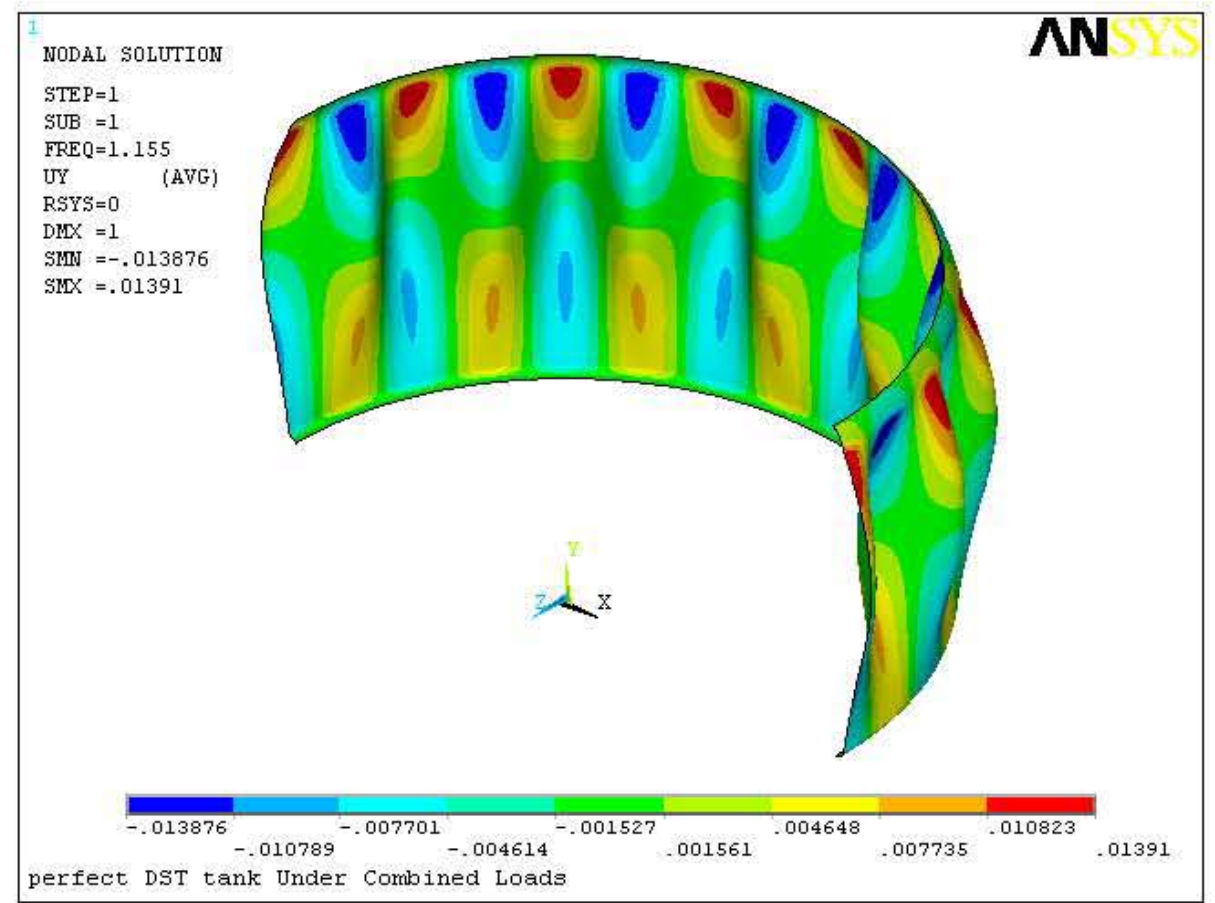

Figure 2-8. Predicted First Eigenvalue Buckling Mode for a DST Cylinder with Fixed Displacements (in the plane of the cylinder), Added at the Top and Bottom Edges of the Cylinder 
In summary, the following observations were made from the above eigenvalue buckling solutions:

- Previous buckling analyses of the DSTs used the methodology in ASME Code Case N-284-1, which is based on the buckling of a constant thickness cylindrical shell with unsupported length, L. N-284-1 requires that the user estimate the length, $\mathrm{L}$, as the distance "between lines of support with sufficient stiffness to act as bulk heads." The DST primary tank cylindrical shell does not have constant wall thickness and it does not have clearly defined lines of support due to the varying wall thickness and the upper and lower knuckle geometries.

- The ANSYS finite element code is able to very accurately predict the theoretical buckling loads of a uniform cylinder under axial, hoop and combined loadings.

- Using an averaged wall thickness and a buckling length from the waste level to the dome tangent point does not conservatively approximate the theoretical buckling load of the actual tank geometry.

- The varying wall thickness and the radiused shape of the upper and lower knuckles significantly reduces the critical buckling load of the actual tank geometry (approximately $78 \%$ reduction in the column buckling load, $23 \%$ for harmonic buckling, and $21 \%$ for the combined loading case).

- The tank buckling loads deviate more from the N-284-1 solutions for column buckling (under pure axial compression) than they do for harmonic buckling (external pressure only) or buckling due to combined axial and hoop loads.

\subsection{Sensitivity of Critical Buckling Loads to the Size and Number of Tank Imperfections}

A study was also performed to determine the sensitivity of the buckling load to the size and number of geometric imperfections that act to initiate the buckling response. ASME code case N-284-1 uses geometric knockdown factors that are based on the allowable construction imperfection size given in ASME Section III NE-4220 whereas the tolerance on construction imperfections given in the DST tank construction specifications is somewhat different. Table 2-4 compares the NE-4220 dimensional tolerance with the maximum out of roundness allowed in the AY tank farm construction specifications, HWS-7789 (Hanford Engineering Services 1968).

Three different imperfection amplitudes $\left(1 / 10^{\text {th }}, 1\right.$, and 10 times the specified imperfection depths $)$ were modeled using ANSYS and are shown in Table 2-5 and Figures 2-9 and 2-10. For comparison purposes the amplitude of two times the ASME imperfection ( 0.5 inch deep) is equal to the amplitude of the specified AY tank fabrication imperfection (1 inch deep) and is shown in Table 2-5.

The uniform cylinder and DST 'AY' tank models were analyzed for the different imperfection sizes, multiple numbers of imperfections and the three different loading cases listed in Table 2-3. Table 2-6 summarizes the variation in the buckling limits of axial compressive force and external pressure. 
Table 2-4. Comparison of the Construction Imperfection Tolerances Specified in ASME NE-4220 and the AY Tank Construction Specifications

\begin{tabular}{|c|c|c|}
\hline Requirement & $\begin{array}{c}\text { ASME NE-4220 Fabrication } \\
\text { Requirement }\end{array}$ & $\begin{array}{c}\text { Typical Primary Tank Fabrication } \\
\text { Specification }\end{array}$ \\
\hline $\begin{array}{l}\text { Maximum difference in cross- } \\
\text { sectional diameter }\end{array}$ & $\begin{array}{l}\text { Shall not exceed } 1 \% \text { of the nominal } \\
\text { diameter }\end{array}$ & $\begin{array}{l}\text { Shall not exceed } 1 \% \text { of the nominal } \\
\text { diameter }\end{array}$ \\
\hline $\begin{array}{l}\text { Maximum deviation from true } \\
\text { Theoretical form }\end{array}$ & $\begin{array}{l}\text { Maximum plus-or-minus deviation } \\
\text { from the true circular form shall not } \\
\text { exceed the maximum permissible } \\
\text { deviation obtained from Fig. } \\
\text { NE-4221.1-1 (i.e., } 0.5 \text { in. when } \\
\text { extrapolated for primary tank } \mathrm{D} / \mathrm{t} \text { ) } \\
\text { over an arc length equal to twice the } \\
\text { arc length obtained from Fig. } \\
\text { NE-4221.2-2 (i.e., } 9.75 \mathrm{ft} \text { when } \\
\text { extrapolated for primary tank D/t) }\end{array}$ & $\begin{array}{l}\text { Maximum deviation from design curvature } \\
\text { on } 7 \text { foot shall be } 1 \text { in. at center if less than } \\
\text { design and at end if greater than design. } \\
\text { Measurements shall be made at } 3 \text { foot } \\
\text { vertical intervals. } \\
\text { Circumference of the shell section at any } \\
\text { horizontal plane shall not deviate from the } \\
\text { theoretical by more than plus or minus } \\
2 \text { in. } \\
\text { Top of shell shall be plumb within } 2 \text { in. of } \\
\text { the bottom of the cylindrical section when } \\
\text { measured from any point on the } \\
\text { circumference. } \\
\text { In any vertical plane cutting the cylindrical } \\
\text { section the maximum deviation of the line } \\
\text { of intersection from a true straight line } \\
\text { shall not exceed } 1 / 2 \text { in. in any } 5 \mathrm{ft} \text { length }\end{array}$ \\
\hline \multicolumn{3}{|c|}{$\begin{array}{l}\text { AY/AZ primary tank geometric parameters } \\
\mathrm{L} \quad=459 \mathrm{in} . \text { (between bottom knuckle and primary tank tangent line at weld to dome cap) } \\
\mathrm{D} \quad=75 \mathrm{ft} \\
\mathrm{t} \quad=0.508 \mathrm{in} . \text { (weighted average over length with corrosion allowance of } 1 \mathrm{mil} / \mathrm{yr} \text { for } 50 \mathrm{yrs} \text { applied) } \\
\mathrm{L} / \mathrm{D}=0.51 \\
\mathrm{D} / \mathrm{t}=1770\end{array}$} \\
\hline
\end{tabular}

Table 2-5. Matrix of Imperfection Sizes That were Simulated

\begin{abstract}
ASME
Specifications

0.5 in over $9.75 \mathrm{ft}$ arc

Tank Fabrication

Specifications

$\mathbf{1}$ in over $7 \mathrm{ft}$ arc
\end{abstract}

\section{(1/10) times \\ ASME Specs}

0.05 in over $9.75 \mathrm{ft}$ arc

(1/10) times

Tank Fab Specs

$\mathbf{0 . 1}$ in over $7 \mathrm{ft}$ arc

Imperfection Size

\section{(2) times \\ ASME Specs}

$\mathbf{1}$ in over $\mathbf{9 . 7 5} \mathrm{ft}$ arc

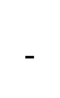

\section{(10) times ASME Specs} 5 in over $9.75 \mathrm{ft}$ arc

(10) times

Tank Fab Specs

$\mathbf{1 0}$ in over $\mathbf{7 f t}$ arc 


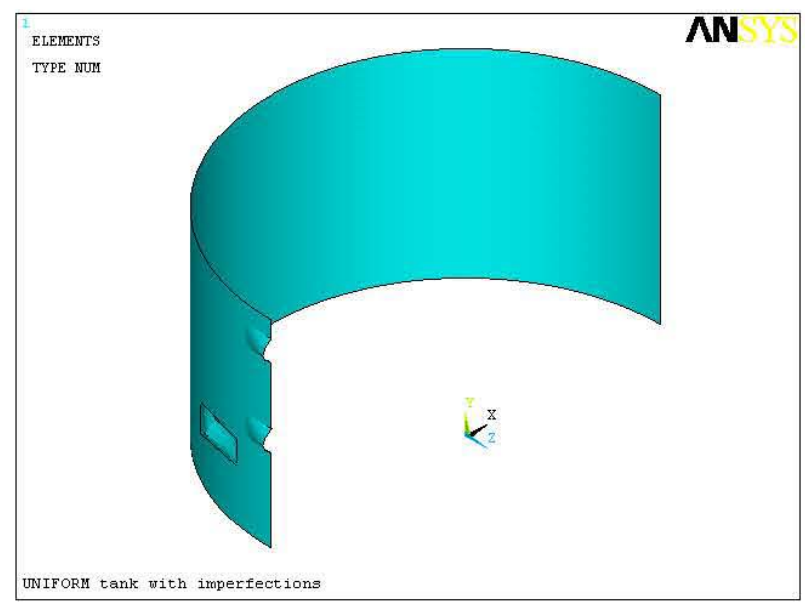

Figure 2-9. Uniform Cylinder with Imperfections

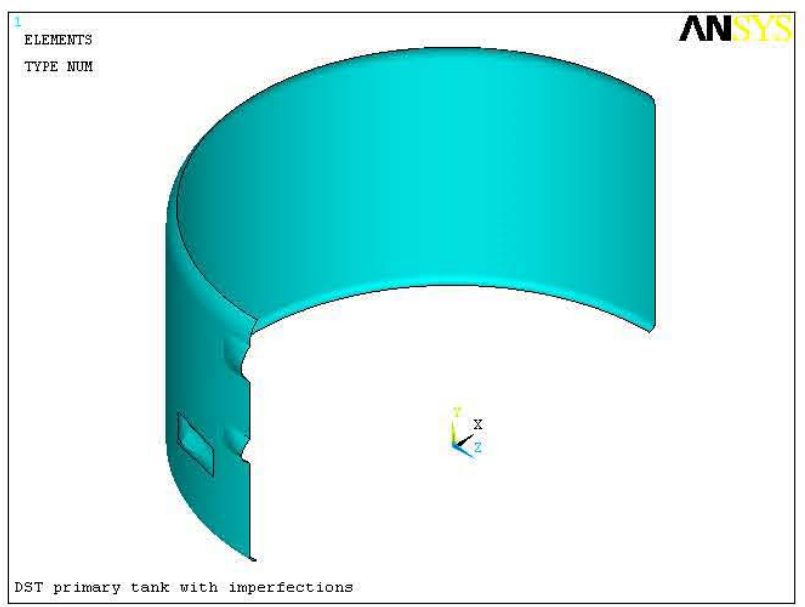

Figure 2-10. AY Tank with Imperfections (The imperfection amplitudes are exaggerated in the plots to make them visible.)

The following observations were made from the imperfection sensitivity study:

- The buckling limit loads for axial, hoop, and combined loadings are insensitive to the number of imperfections.

- The axial limit load is sensitive to the amplitude of the imperfection, but the imperfection lengths from ASME NE-4220 and the AY specifications ( 9.75 and 7 feet, respectively) are similar and do not give different buckling limits. The 1-inch over 7-foot out-of-roundness from the AY construction standard gives a lower axial load limit than the 0.5 -inch over 9.75 foot imperfection limit specified in NE-4220. Therefore, the limiting imperfection size from the AY construction specification will be used in predicting the buckling limits for the DST primary tanks.

- The limit pressure for both the pressure only and the combined loading (for a closed ended cylinder where the axial stress is $1 / 2$ the hoop stress) are not sensitive to the amplitude or number of imperfections. The limit pressure is $1.42 \mathrm{psi}$ for the uniform cylinder and $1.14 \mathrm{psi}$ for the AY tank geometry. The tank has a very large $\mathrm{R} / \mathrm{t}$ ratio $(450 / 0.375=1200$ in the $3 / 8$ inch upper section of the tank wall) and any imperfection is enough to initiate buckling. The addition of a small amount of axial compression in the combined loading case is not enough to reduce the limiting external pressure load.

- Comparing the buckling limits for the AY tank geometry and the uniform cylindrical tank again shows that the AY tank geometry has significantly lower critical buckling loads than the uniform equivalent cylinder. 
Table 2-6. Summary of the Critical Buckling Loads for the Sensitivity Study on the Number and Size of the Tank Imperfections

\begin{tabular}{|c|c|c|c|c|c|c|c|c|c|c|c|c|c|c|}
\hline \multirow{8}{*}{ 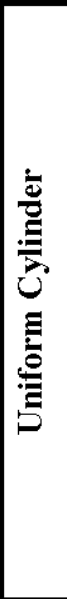 } & & $\begin{array}{c}\text { Cylinder } \\
\text { with No } \\
\text { Imperfection }\end{array}$ & \multicolumn{4}{|c|}{$\begin{array}{c}\text { Cylinder with one } \\
\text { ASME *times imperfection }\end{array}$} & \multicolumn{4}{|c|}{$\begin{array}{c}\text { Cylinder with two } \\
\text { ASME *times imperfection }\end{array}$} & \multicolumn{4}{|c|}{$\begin{array}{c}\text { Cylinder with four } \\
\text { ASME *times imperfection }\end{array}$} \\
\hline & Axial Load, lb/in. & 10204 & 10196 & 8045 & 6279 & 3263 & 10190 & 8024 & 6378 & 3436 & 10188 & 7993 & 6328 & 3387 \\
\hline & Combined, psi & 1.419 & 1.419 & 1.418 & 1.417 & 1.424 & 1.419 & 1.418 & 1.417 & 1.426 & 1.418 & 1.417 & 1.416 & 1.428 \\
\hline & & & & & & & & & & & & & & \\
\hline & & & \multicolumn{4}{|c|}{$\begin{array}{c}\text { Cylinder with one } \\
\text { Tank Fab *times imperfection }\end{array}$} & \multicolumn{4}{|c|}{$\begin{array}{c}\text { Cylinder with two } \\
\text { Tank Fab *times imperfection }\end{array}$} & \multicolumn{4}{|c|}{$\begin{array}{c}\text { Cylinder with four } \\
\text { Tank Fab *times imperfection }\end{array}$} \\
\hline & Axial Load, lb/in. & & 10119 & - & 6846 & 5188 & 10093 & - & 6941 & 5403 & 10081 & - & 6828 & 5354 \\
\hline & Lateral Pressure, psi & & 1.419 & - & 1.418 & 1.424 & 1.419 & - & 1.418 & 1.426 & 1.419 & - & 1.416 & 1.429 \\
\hline & Combined, psi & & 1.419 & - & 1.418 & 1.424 & 1.419 & - & 1.418 & 1.426 & 1.418 & - & 1.415 & 1.429 \\
\hline \multirow{11}{*}{ 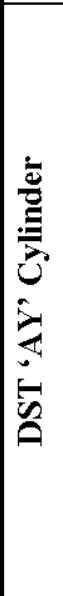 } & & \multirow{2}{*}{$\begin{array}{c}\text { Cylinder } \\
\text { with No } \\
\text { Imperfection }\end{array}$} & \multicolumn{4}{|c|}{$\begin{array}{c}\text { Cylinder with one } \\
\text { ASME *times imperfection }\end{array}$} & \multicolumn{4}{|c|}{$\begin{array}{c}\text { Cylinder with two } \\
\text { ASME *times imperfection }\end{array}$} & \multicolumn{4}{|c|}{$\begin{array}{c}\text { Cylinder with four } \\
\text { ASME *times imperfection }\end{array}$} \\
\hline & & & $*(1 / 10)$ & $*(1)$ & $*(2)$ & $*(10)$ & $*(1 / 10)$ & $*(1)$ & $*(2)$ & $*(10)$ & $*(1 / 10)$ & $*(1)$ & $*(2)$ & $*(10)$ \\
\hline & Lateral Pressure, psi & 1.154 & 1.154 & 1.152 & 1.145 & 1.152 & 1.154 & 1.151 & 1.136 & 1.157 & 1.154 & 1.147 & 1.129 & 1.159 \\
\hline & \begin{tabular}{|l|} 
Combined, psi \\
\end{tabular} & 1.154 & 1.154 & 1.152 & 1.145 & 1.151 & 1.154 & 1.151 & 1.135 & 1.157 & 1.154 & 1.146 & 1.129 & 1.159 \\
\hline & & & & & & & & & & & & & & \\
\hline & & & \multirow{2}{*}{\multicolumn{4}{|c|}{$\begin{array}{c}\text { Cylinder with one } \\
\text { Tank Fab *times imperfection }\end{array}$}} & \multirow{2}{*}{\multicolumn{4}{|c|}{$\begin{array}{c}\text { Cylinder with two } \\
\text { Tank Fab *times imperfection }\end{array}$}} & \multirow{2}{*}{\multicolumn{4}{|c|}{$\begin{array}{c}\text { Cylinder with four } \\
\text { Tank Fab *times imperfection }\end{array}$}} \\
\hline & & & & & & & & & & & & & & \\
\hline & & & $*(1 / 10)$ & - & $*(1)$ & $*(10)$ & $*(1 / 10)$ & - & $*(1)$ & $*(10)$ & $*(1 / 10)$ & - & $*(1)$ & $*(10)$ \\
\hline & Axial Load, lb/in. & & 2265 & - & 2265 & 1791 & 2265 & - & 2265 & 1836 & 2265 & - & 2265 & 1829 \\
\hline & \begin{tabular}{|l} 
Lateral Pressure, psi \\
\end{tabular} & & 1.154 & - & 1.151 & 1.157 & 1.154 & - & 1.146 & 1.158 & 1.154 & - & 1.138 & 1.159 \\
\hline & Combined, psi & & 1.154 & - & 1.151 & 1.157 & 1.154 & - & 1.146 & 1.157 & 1.154 & - & 1.138 & 1.159 \\
\hline
\end{tabular}




\subsection{Buckling Evaluation Method for the DST Primary Tanks Based on Large Displacement Instability Analysis}

Large displacement finite element analysis was used to predict the limiting vacuum load for the DST primary tanks under combined axial and vacuum loads. Figure 3-1 shows the model of the primary tank that was used in this analysis. The ANSYS model input files are listed in Appendix B. A downward deflection was applied to the dome of the tank (the area in contact with the concrete tank structure) to simulate the displacement controlled axial compression of the tank wall that occurs due to concrete thermal degradation and creep, plus the confined thermal expansion of the steel tank inside the concrete shell. The model includes a geometric imperfection to initiate the buckling instability under the radially symmetric vacuum load. The imperfection was sized to the maximum out of roundness (1-inch deviation in a 7-foot arc length) allowed in the AY tank farm construction specifications, HWS-7789 (Hanford Engineering Services 1968). Additional loads on the model include gravity and hydrostatic pressure of the waste at height, h, and specific gravity, SpG (see Figure 3-2).

The vacuum in the primary tank also increases the downward deflection of the concrete dome and tank walls, which increases the compression on the primary tank walls. Because the concrete tank structure is not included in the buckling model, this effect is not included in the current analysis. However, PNNL's previous work quantifying the effect of increased concentrated load on tank integrity (Rinker et al. 2005) provides information to estimate the increase in axial compression in the primary tank wall caused by the increased dome load due to vacuum. The area of the tank dome is about $637,000 \mathrm{inch}^{2}$. Therefore, the AP vacuum limit of 12 inch w.g. (0.43 psi) would increase the total load on the dome by 276 kips. Figure 3-3 shows axial (meridional) stresses in the nominal $1 / 2$ inch wall section at several increased loads. (Note that the wall thickness in the model is 0.44 inches because of the 0.060 inch corrosion allowance). The figure shows that increasing the concentrated load by 400 kips increases the wall compression by less than 20 psi. The AP vacuum limit of 12 inch w.g. would increase the primary tank axial compression by less than $15 \mathrm{psi}$. This is a small effect compared to the total wall compression that is estimated to be on the order of 1,000 to $1,400 \mathrm{psi}$ for the combined operating and seismic loads. Therefore, the increased downward deflection of the concrete dome due to tank vacuum is a minor effect in determining the vacuum limits for the tank.

The onset of the buckling instability was predicted by applying an increasing vacuum load on the inside surface of the tank while monitoring the maximum radial displacement of the tank wall as a function of the increasing vacuum load. The onset of instability is signaled by an increasing rate of radial deflection for a constant increment in the applied vacuum load. Figure 3-4 shows an example load deflection curve from one of the cases that was analyzed. Because vacuum is a primary load, the stresses are not self limiting and the model eventually fails to converge (numerically) as the physical load carrying capacity of the tank is reached. Figure 3-5 shows the distorted tank geometry at the final converged load step of the finite element analysis. However, using the final converged vacuum load as the buckling limit is not a reliable measure of the onset of instability because the final convergence is sensitive to non-physical factors including the load step size, the convergence tolerance, and the numerical precision of the computer. Therefore, the ASME code was reviewed to find an appropriate method for defining the limiting vacuum load. 


\section{RPP-RPT-28967, Rev. 2}

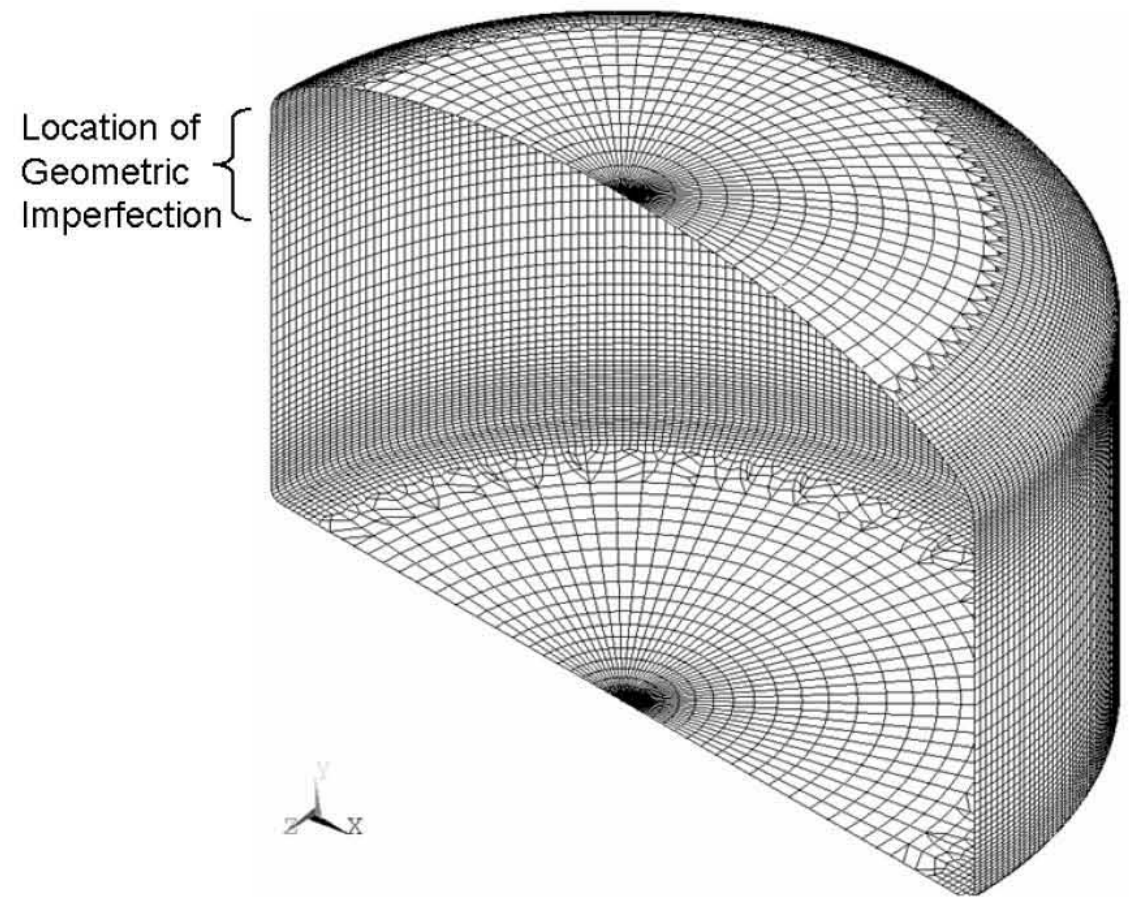

Figure 3-1. Double-Shell Primary Tank Model Used in the Large Deflection Buckling Analysis (The imperfection size was 1 inch out of roundness in a 7 -foot circumferential arc.)

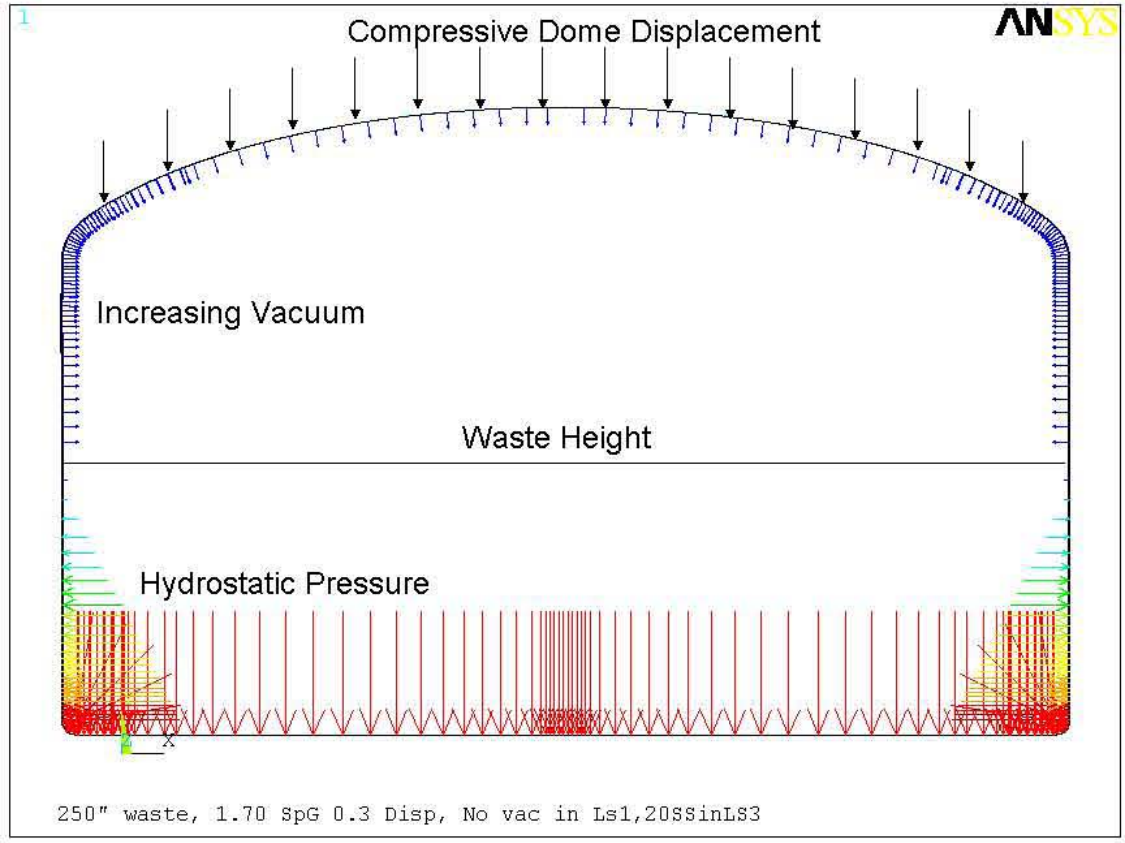

Figure 3-2. Loads Applied to the Large Deflection Buckling Model 


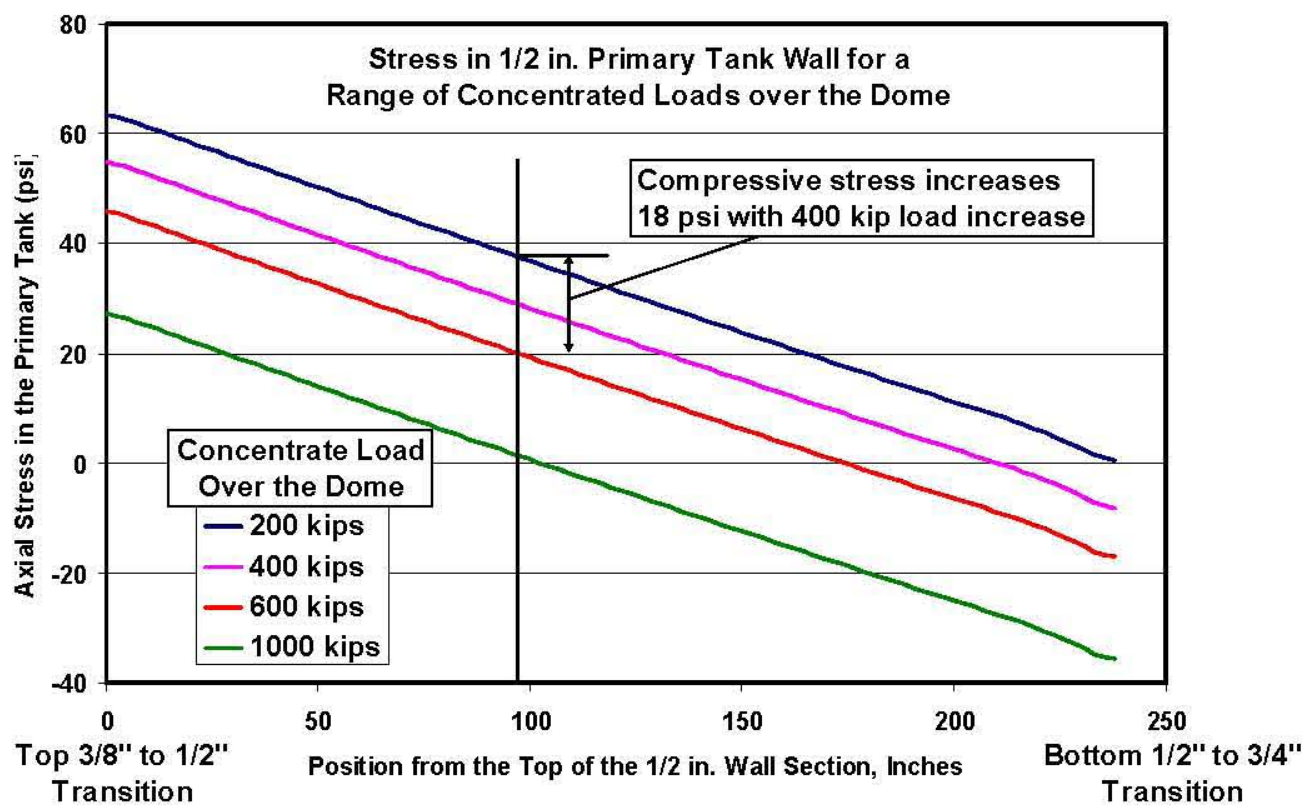

Figure 3-3. Effect of Increasing Dome Load on the Axial Stress in the AY Primary Tank

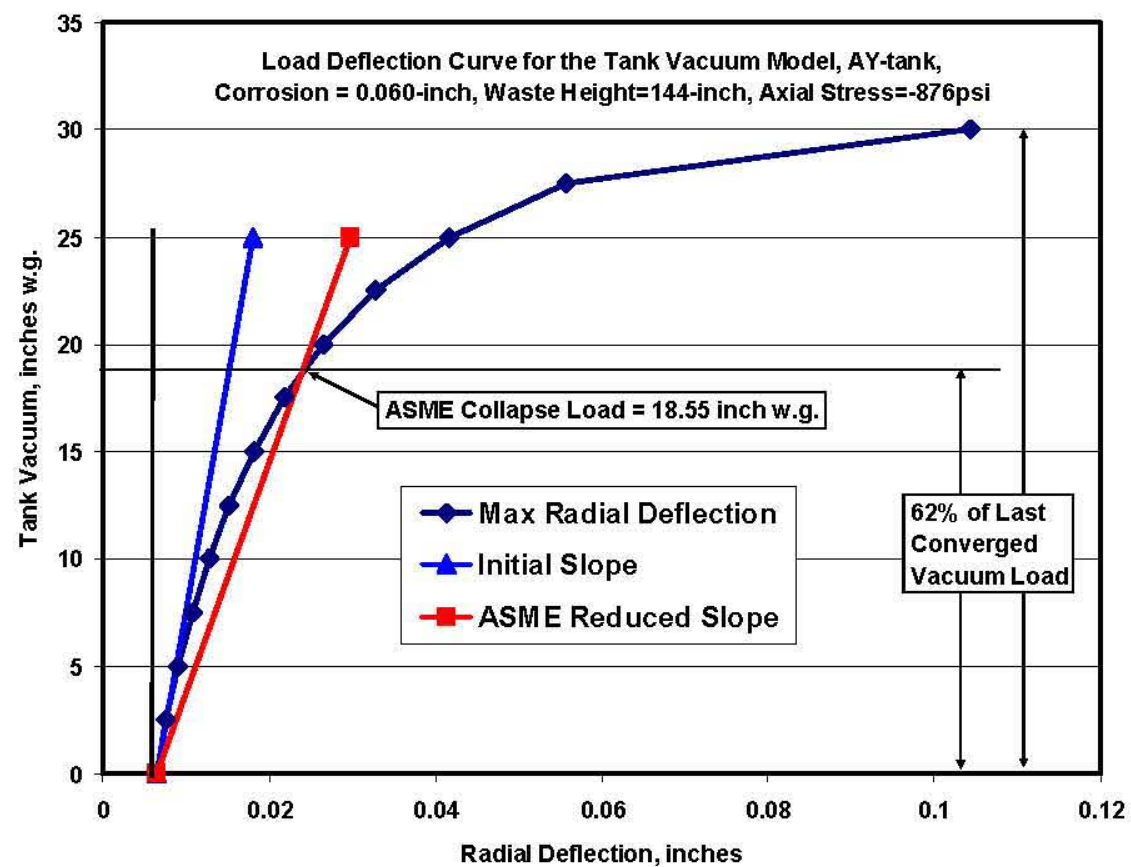

Figure 3-4. Load Deflection Curve for Increasing Vacuum Load Applied to the Large Displacement Tank Buckling Model (The results are for the AY tank model, with specific gravity $=1.7$, waste height $=144$ inches, and compressive dome displacement $=0.3$ inches.) 
The ASME Boiler and Pressure Vessel Code, Section III, NB-3213.25 provides guidance on establishing a reasonable collapse load for a structure undergoing controlled plastic deformation (ASME 2004a). Although we are evaluating an elastic buckling phenomenon (the buckling models predict that the tank membrane stresses are well below the elastic limit), the increasing rate of distortion in the tank wall (for a constant increasing vacuum load) represents a gradual decrease in structural stiffness that is similar to what occurs in a structure undergoing progressive plastic deformation. In the former case the stiffness reduction is due to the large deformations of the tank geometry that progressively decrease the load carrying capacity of the tank. In the later case it is due to plastic softening. The ASME code method establishes the collapse load by limiting the reduction in structural stiffness under increasing load.

NB-3213.25 Plastic Analysis - Collapse Load. A plastic analysis may be used to determine the collapse load for a given combination of loads on a given structure. The following criterion for determination of the collapse load shall be used. A load-deflection or load-strain curve is plotted with load as the ordinate and deflection or strain as the abscissa. The angle that the linear part of the load-deflection or load-strain curve makes with the ordinate is called $\theta$. A second straight line, hereafter called the collapse limit line, is drawn through the origin so that it makes an angle of tan ${ }^{-1}$ $(2 \tan \theta)$ with the ordinate. The collapse load is the load at the intersection of the load-deflection or load-strain curve and the collapse limit line. If this method is used, particular care should be given to ensure that the strains or deflections that are used are indicative of the load carrying capacity of the structure.

Figure 3-4 graphically illustrates the ASME code method based on the factor of two stiffness reduction. The radial displacement is offset from zero (at zero vacuum) because the initial loads (axial compression, hydrostatic pressure, and gravity) cause an initial radial deflection in the tank wall. The initial load/deflection slope was calculated and a second line was drawn at an angle with twice the tangent measured from the vertical axis. The vacuum limit was then calculated by interpolating to find the vacuum load where the second line crossed the load/deflection curve (Figure 3-4). In this case, the ASME collapse load is about $62 \%$ of the last converged vacuum load. This is typical of the other load cases that were run. Figure 3-5 shows the displaced shape of the tank model at the ASME collapse load. For the tank geometry, the ASME method results in a minor amount of tank distortion.

A matrix of tank models was run to develop equations for the tank vacuum limit as a function of waste height, specific gravity, wall thickness, and axial compressive load. Equations were developed for both the AY and AP primary tank designs. The AY equation also applies to the AZ, SY, AW, and AN primary tank designs because they have essentially the same geometry and wall thickness distributions. The different yield strengths of the different tank materials do not affect the predicted vacuum limits significantly because the membrane stresses are within the elastic range (the maximum membrane compression was about 2,500 psi in the $3 / 8$ inch section of the AY tank wall). The AY and AP primary tank designs differ only by the wall thickness in the upper cylinder, where the AY tank is $3 / 8$ " thick and the AP tank is $1 / 2$ " thick. Table 3-1 lists the vacuum limits that were predicted for the load combinations that were analyzed for the AY tank design, and Table 3-2 lists similar results for the load combinations that were analyzed for the AP tank design. The approach used to curve fit these data for the AY tank design is described in detail below with the final results of the AP tank analysis following. 


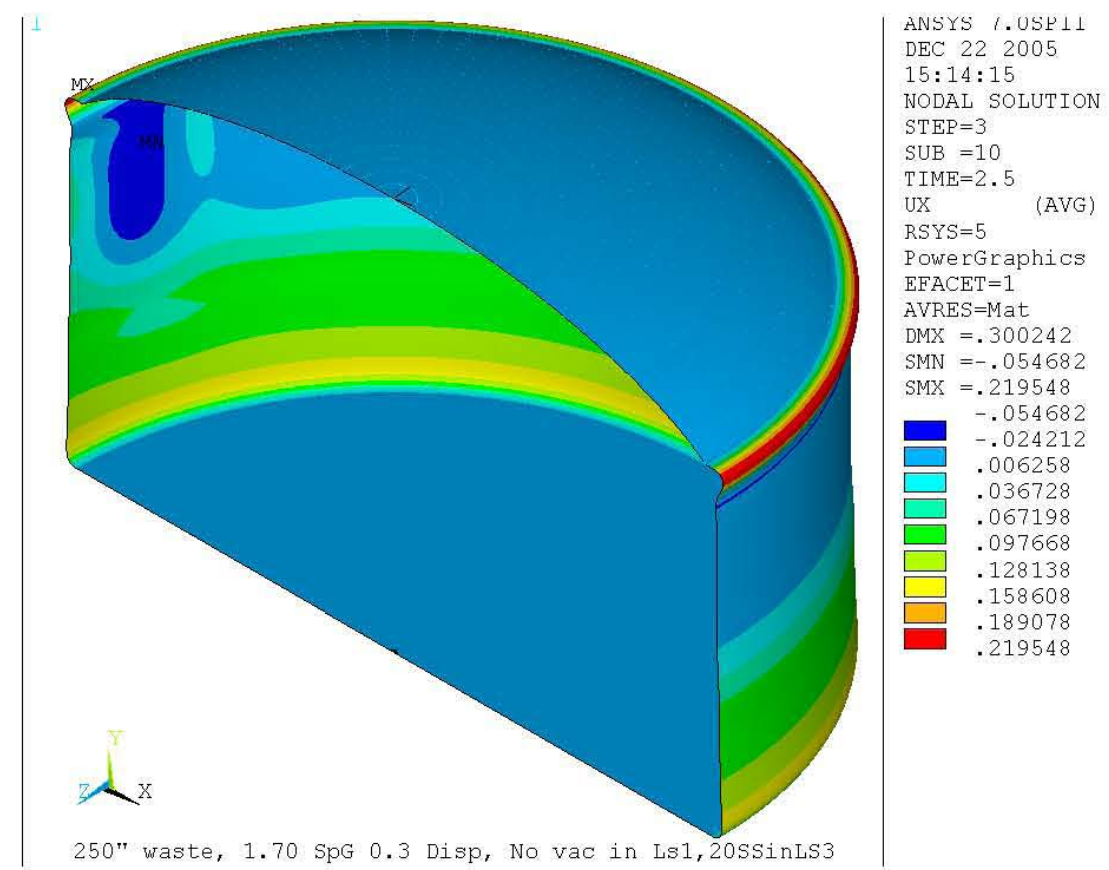

Figure 3-5. Displaced Shape of the AY Model at the Limit Vacuum Defined by the ASME Slope Reduction Method (The influence of the geometric imperfection is evident in the upper left of the plot. The results are for the AY tank model, with specific gravity $=1.7$, waste height $=250$ inches, and compressive dome displacement $=0.3$ inches. The displacements are magnified 50 times so that they are visible.)

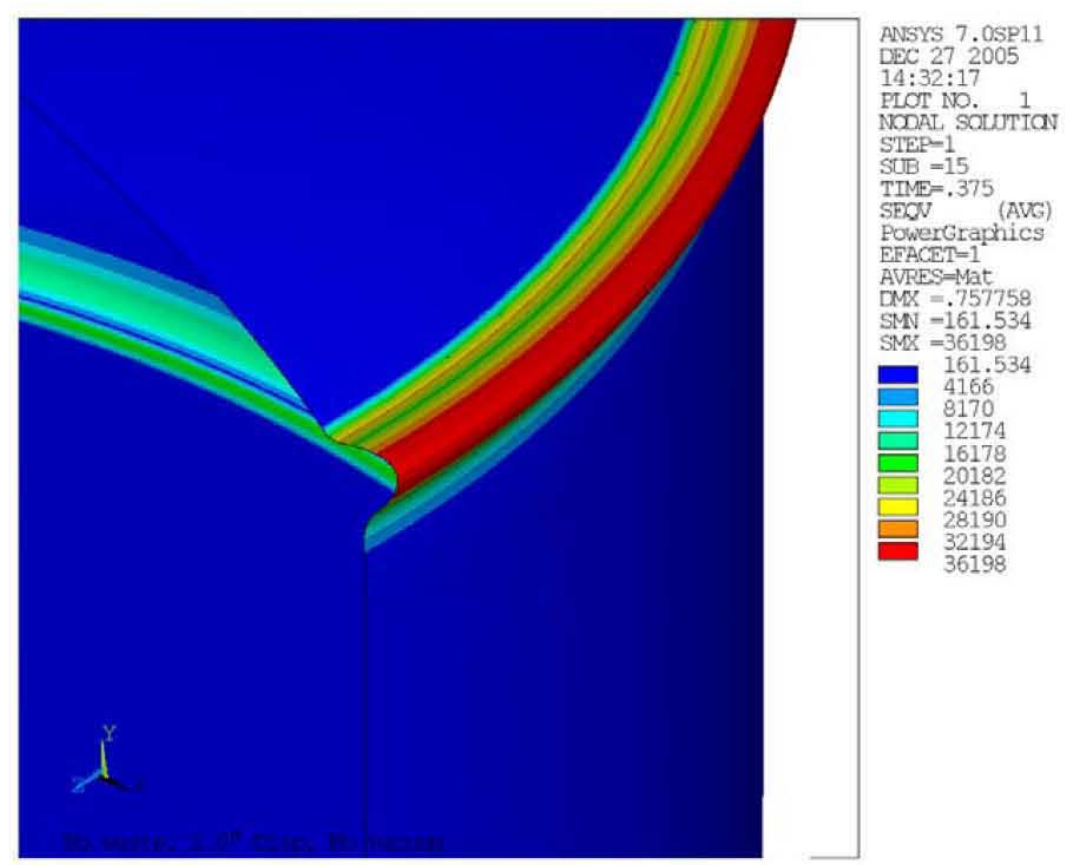

Figure 3-6. Contour Plot of the Maximum Surface Stress in the Upper Knuckle of the AY Tank (This large displacement elastic model shows that the surface stresses are above the $32 \mathrm{ksi}$ yield strength. The displacements are magnified 50 times so that they are visible.) 
Table 3-1. Large Deformation Tank Analyses for the AY Vacuum Limit Equations

\begin{tabular}{|c|c|c|c|c|c|c|c|c|}
\hline & $\begin{array}{r}\text { Dome Displ, } \\
\text { inches } \Rightarrow\end{array}$ & $0.0^{\prime \prime}$ & $0.2^{\prime \prime}$ & $0.3^{\prime \prime}$ & $0.4 "$ & $0.5^{\prime \prime}$ & $0.6^{\prime \prime}$ & $1.0^{\prime \prime}$ \\
\hline & $\begin{array}{r}\text { Equivalent } \\
\text { Linear Elastic } \\
\text { Axial Force, } \\
\text { kip/inch => }\end{array}$ & 0.000 & -0.290 & -0.435 & -0.580 & -0.726 & -0.871 & -1.45103 \\
\hline \multicolumn{9}{|c|}{ AY Primary Tank, Corrosion $=0.060$ inches, $S p G=1.7$} \\
\hline & Waste Height & & & & & & & \\
\hline & inches & \multicolumn{6}{|c|}{ Primary Tank Vacuum Limits, Inches of Water } & \\
\hline & 6 & 18.85 & 17.97 & 17.55 & 16.80 & 16.03 & 14.93 & 10.150 \\
\hline & 25 & 18.86 & 17.98 & 17.56 & 16.82 & 16.03 & & \\
\hline & 50 & 18.91 & 18.02 & 17.59 & 16.88 & 16.08 & & \\
\hline & 75 & 19.02 & 18.11 & 17.67 & 17.00 & 16.19 & & \\
\hline & 100 & 19.29 & 18.32 & 17.85 & 17.28 & 16.42 & & \\
\hline & 144 & 20.19 & 19.12 & 18.55 & 17.96 & 17.26 & 16.30 & \\
\hline & 200 & 22.83 & 21.62 & 20.95 & 20.28 & 19.36 & & \\
\hline & 250 & 27.23 & 25.71 & 24.97 & 23.93 & 22.90 & & \\
\hline & 300 & & & 32.10 & 30.85 & & & \\
\hline & 350 & & & 50.50 & 56.21 & & & \\
\hline & 400 & & & 94.59 & 87.43 & & & \\
\hline \multicolumn{9}{|c|}{ SpG Runs, Waste Height $=250$-inches, 0.0 and 0.5 inch Tank Dome Displacem ent } \\
\hline & SpG & & & & & & & \\
\hline & 1.0 & 25.74 & & & & 21.59 & & \\
\hline & 1.5 & 26.85 & & & & 22.64 & & \\
\hline & 1.7 & 27.23 & & & & 22.90 & & \\
\hline & 2.0 & 27.67 & & & & 23.26 & & \\
\hline \multicolumn{9}{|c|}{ Wall Thickness Runs, Waste Height $=6$-inches, 0.3 inch Dome Displacem ent } \\
\hline Thickness, & Corrosion, & & & & & & & \\
\hline inches & inches & & & & & & & \\
\hline 0.375 & 0.000 & & & 22.51 & & & & 17.46 \\
\hline 0.345 & 0.030 & & & 19.97 & & & & \\
\hline 0.315 & 0.060 & & & 17.55 & & & & \\
\hline 0.296 & 0.079 & & & 15.47 & & & & \\
\hline 0.278 & 0.098 & & & 13.54 & & & & \\
\hline
\end{tabular}

Additional models were run to determine a reasonable load limit for axial load alone. The compressive displacement of the tank dome was increased gradually until the maximum reaction load was reached and the load began to decrease. In this case, the finite element solution continues to converge beyond the peak load because the loading is fully displacement controlled. Figure 3-8 shows the load displacement curves for several cases with the AY and AP tank models. The load/displacement curves show that the maximum load is reached before the ASME factor of 2 slope reduction is achieved. Surface stress plots showed that the AY tank would yield in bending at the maximum compressive load (Figure 3-6). Therefore, the AY model was re-analyzed using the yield curves for A515-65 steel at temperatures of $100^{\circ} \mathrm{F}$, $250^{\circ} \mathrm{F}$, and $350^{\circ} \mathrm{F}$ (Figure 3-7). The model was also run with a yield strength of $35 \mathrm{ksi}$ to represent the A516-65 steel used in the SY primary tank. The elastic response of the AY model is representative of the $\mathrm{AN}$ and $\mathrm{AW}$ tanks where higher strength material was used (see Table 3-3). Figure 3-8 shows that including plastic deformation reduces the maximum axial compression from 1800 psi to $1692 \mathrm{psi}$ (for temperatures up to $100^{\circ} \mathrm{F}$ ). Using the yield curve for the maximum $\mathrm{AY}$ operating temperature of $350^{\circ} \mathrm{F}$ further reduces the maximum axial compression to $1500 \mathrm{psi}$ in the 0.5 inch wall of the primary tank. 
Table 3-2. Large Deformation Tank Analyses for the AP Vacuum Limit Equations

\begin{tabular}{|c|c|c|c|c|c|c|c|c|}
\hline & $\begin{array}{r}\text { Dome Displ, } \\
\text { inches }=>\end{array}$ & $0.0^{\prime \prime}$ & $0.2 "$ & $0.3^{\prime \prime}$ & $0.4 "$ & $0.5^{\prime \prime}$ & $0.6^{\prime \prime}$ & $1.0^{\prime \prime}$ \\
\hline & $\begin{array}{r}\text { Equivalent } \\
\text { Linear Elastic } \\
\text { Axial Force, } \\
\text { kip/inch }=>\end{array}$ & 0.000 & -0.422 & -0.634 & -0.845 & -1.056 & -1.267 & -2.112 \\
\hline \multicolumn{9}{|c|}{ AP Primary Tank, Corrosion $=0.060$ inches, $\mathrm{SpG}=1.7$} \\
\hline & \begin{tabular}{|l|} 
Waste Height \\
\end{tabular} & & & & & & & \\
\hline & inches & \multicolumn{6}{|c|}{ Primary Tank Vacuum Limits, Inches of Water } & \\
\hline & 6 & 20.59 & 19.62 & 19.03 & 18.48 & 17.99 & 17.47 & 16.125 \\
\hline & 25 & 20.60 & & 19.03 & & 18.00 & & \\
\hline & 50 & 20.64 & & 19.08 & & 18.02 & & \\
\hline & 75 & 20.74 & & 19.19 & & 18.17 & & \\
\hline & 100 & 20.96 & & 19.45 & & 18.32 & & \\
\hline & 144 & 21.79 & & 20.25 & & 19.07 & & \\
\hline & 200 & 24.43 & & 22.68 & & 21.36 & & \\
\hline & 250 & 28.77 & & 26.65 & & 25.25 & & \\
\hline & 300 & & & 35.08 & & & & \\
\hline & 350 & & & 68.51 & & & & \\
\hline & 400 & & & & & & & \\
\hline \multicolumn{9}{|c|}{ SpG Runs, Waste Height $=250$-inches, 0.0 and 0.5 inch Tank Dome Displacement } \\
\hline & \begin{tabular}{|c|} 
SpG \\
\end{tabular} & & & & & & & \\
\hline & 1.0 & & & & & & & \\
\hline & 1.5 & & & & & 24.97 & & \\
\hline & 1.7 & & & & & & & \\
\hline & 2.0 & & & & & 25.62 & & \\
\hline \multicolumn{9}{|c|}{ Wall Thickness Runs, Waste Height $=6$-inches, 0.3 inch Dome Displacement } \\
\hline Thickness, & Corrosion, & & & & & & & \\
\hline inches & inches & & & & & & & \\
\hline 0.5 & 0 & & & 24.36 & & & & 21.68 \\
\hline 0.47 & 0.03 & & & 21.62 & & & & \\
\hline 0.44 & 0.06 & & & 19.03 & & & & \\
\hline 0.421 & 0.079 & & & 17.60 & & & & \\
\hline 0.402 & 0.098 & & & 15.96 & & & & \\
\hline
\end{tabular}

The maximum surface stress in the AP model was $45.6 \mathrm{ksi}$, which is just above the yield strength of the AP A537 steel at room temperature ( $\mathrm{Sy}=45 \mathrm{ksi}$ ). Therefore, the elastic response is used for the AP tank.

When defining the limit load for axial compression it is important to recognize that the primary tank is fully confined within the concrete over-structure and it cannot collapse due to axial compression alone. Rather it will continue to deform stably under increasing compression beyond the maximum load. The stiffness reduces due to flexing (and plastic deformation in the case of the AY tank) of the upper knuckle, which acts to relieve the load and limit the contact force between the steel inner tank and the concrete over-structure. Figure 3-8 shows that this limits the compressive membrane stress in the 0.5 inch wall section to less than $2 \mathrm{ksi}$ for the AY tank and less than $3 \mathrm{ksi}$ for the AP tank. The maximum load is truly a maximum possible reaction force rather than a collapse load. In the case of tank AY (with a room temperature yield strength of $32 \mathrm{ksi}$ ) this includes a controlled amount of surface plasticity in the upper 
RPP-RPT-28967, Rev. 2

Table 3-3. Yield Strength at Temperature for the Primary Tank Steels

\begin{tabular}{|c|c|c|c|c|}
\hline & \multicolumn{4}{|c|}{ Yield Strengths at Temperature, ksi } \\
\hline $\begin{array}{c}\text { Temperature, } \\
{ }^{\circ} \mathbf{F} \\
\end{array}$ & $\begin{array}{l}\text { A515-65 } \\
(A Y, A Z)\end{array}$ & $\begin{array}{c}\text { A516-65 } \\
\text { (SY) }\end{array}$ & $\begin{array}{c}\text { A537-Class } 1 \\
(\mathrm{AW}, \mathrm{AN})\end{array}$ & $\begin{array}{c}\text { A537-Class } 1 \\
\text { (AP Derated to } \\
\text { Sy }=45 \mathrm{ksi} \text { ) }\end{array}$ \\
\hline 100 & 32 & 35 & 50 & 45 \\
\hline 200 & 29.2 & 31.9 & 44.1 & 39.7 \\
\hline 300 & 28.3 & 31 & 40.5 & 36.5 \\
\hline 400 & 27.4 & 30 & 37.5 & 33.8 \\
\hline 500 & 25.6 & 28.3 & 35.2 & 31.7 \\
\hline
\end{tabular}

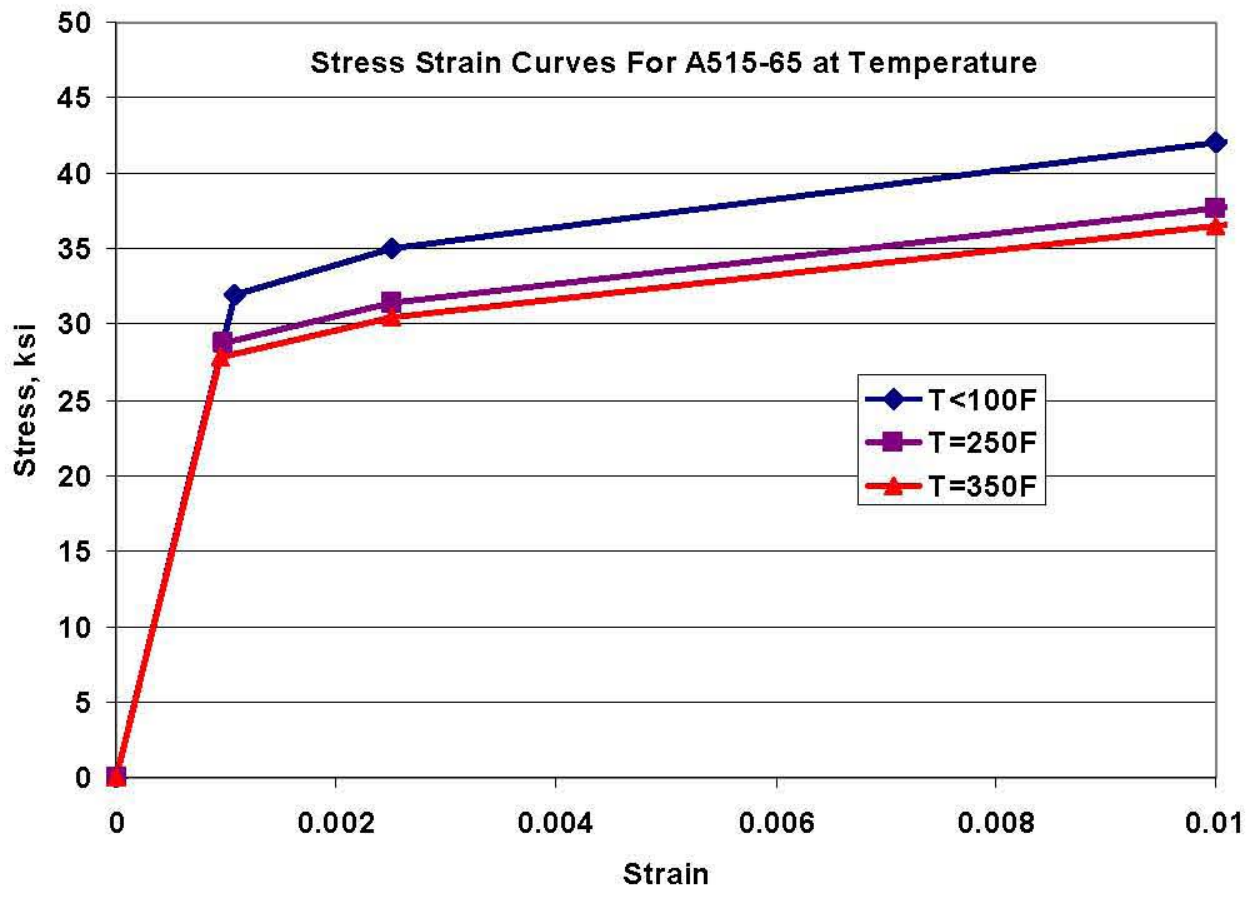

Figure 3-7. Stress Strain Curves for A515-65 Steel

knuckle region. Figure 3-9 shows the deformed shape of the AY primary tank at the maximum load for the elastic/plastic analysis at $350^{\circ} \mathrm{F}$ (dome deflection $=0.75$ inch). Figure $3-10$ shows a similar deformed shape at a dome deflection of $1.0 \mathrm{inch}$, well beyond the maximum load point. Even this rather severe loading condition does not result in gross distortions of the tank geometry. Therefore, the AMSE stiffness reduction method was used to define the allowable equivalent dome compressive displacement even though this is somewhat beyond the displacement that corresponds to the maximum load. This is justified because the axial deformation of the primary tank is fully displacement controlled and it is stable well beyond the maximum load. 


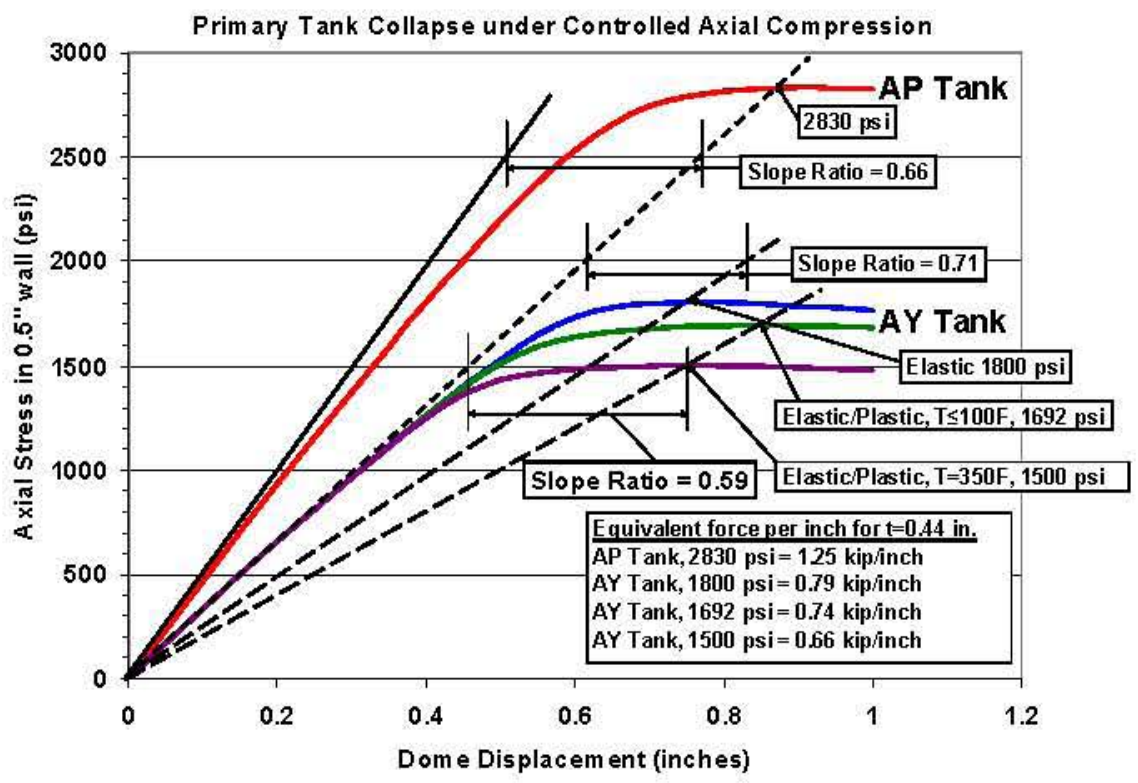

Figure 3-8. Load Deflection Curves of the AY and AP Primary Tanks Under Axial Compression Alone (These results are for a uniform corrosion allowance of 0.060 inches. Note that bending stresses in the upper knuckle of the elastic AY model exceeded the 32 ksi yield strength. The model was re-analyzed with elastic/plastic stress strain curves for A515 steel at $\leq 100^{\circ} \mathrm{F}$ and $350^{\circ} \mathrm{F}$.)
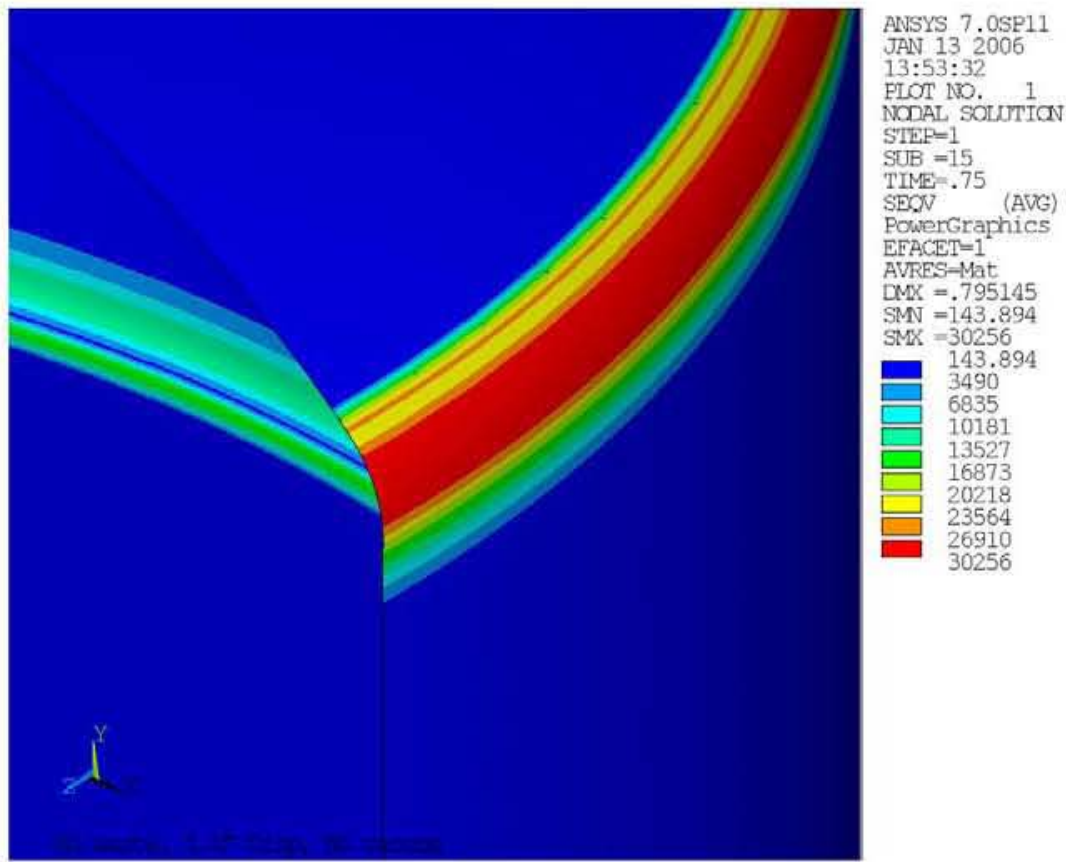

Figure 3-9. Surface Stress in the Upper Knuckle Region of the AY Tank at the Maximum Axial Compressive Load (dome deflection $=0.75$ inch) (The yield curve corresponds to A515-65 steel at $350^{\circ} \mathrm{F}$. The displaced shape is for a scale factor of 1.0 .) 
RPP-RPT-28967, Rev. 2

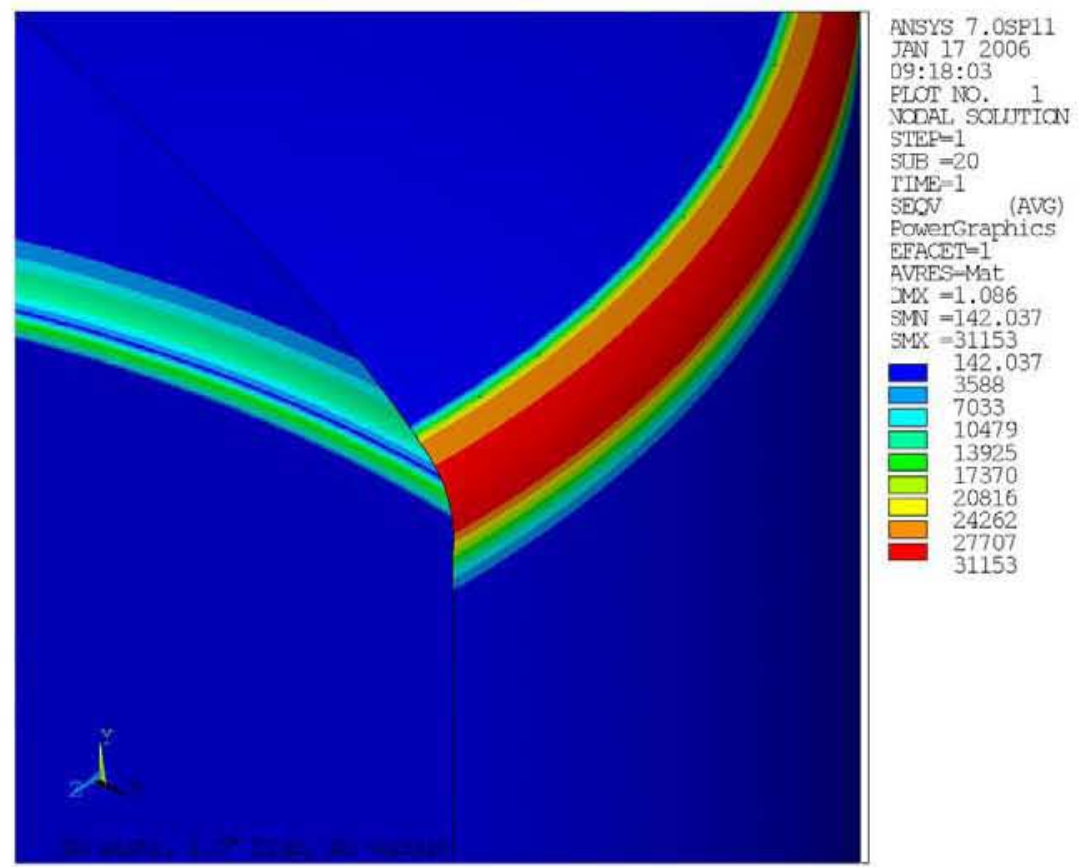

Figure 3-10. Surface Stress in the Upper Knuckle Region of the AY Tank at a Dome Deflection= 1.0 Inch (The yield curve corresponds to A515-65 steel at $350^{\circ} \mathrm{F}$. The displaced shape is for a scale factor of 1.0.)

Figure 3-11 shows the ASME 50\% stiffness slopes for the three corrosion allowances $(0.000,0.060$ and $0.100 \mathrm{inch}$ ) that were modeled. Note that the assumed level of wall thinning significantly affects the stiffness of the tank. Figure 3-12 shows the family of nonlinear force/deflection curves for the AY tank geometry with 0.060 inch corrosion allowance and stress/strain curves corresponding to several different operating temperatures. The limiting equivalent dome deflections are defined where the ASME 50\% slope intersects the load/deflection curve. Figure 3-13 shows the similar response of the AP tank. Figures 3-12 and 3-13 also define the equivalent linear elastic force, $F_{\varphi}(\max )$, which would correspond to the limiting dome deflection if the tank deformed at the initial linear elastic stiffness. The equivalent linear elastic force is needed when correlating the applied axial force (the sum of the different axial load components) to the allowable vacuum. Finite element models were used to estimate the incremental axial force components due to individual loads such as concrete thermal degradation and creep, hydrostatically induce axial stress, surface loads, seismic loads, and differential thermal expansion. Each of these load components are relatively small and result in a linear response of the structure. However when combined, these loads can deform the tank into the nonlinear range. Therefore, the equivalent linear elastic force accounts for the sum of the force components and it corresponds to the sum of the linear dome deflections that the axial load components would apply to the tank. This assumes that the deformation of the primary tank is fully determined by the loads on the primary tank plus the deformations of the concrete overstructure. The equivalent linear elastic force is used in the curve fitting to correlate the axial compression in the tank with the allowable vacuum limit. It should be emphasized that the equivalent linear elastic force is not the maximum allowable force on the primary tank. It is simply defined to:

1. provide a limit on the sum of the axial load components that corresponds to the maximum tank deformation defined by the ASME stiffness reduction method, and

2. define the vacuum limit for the tanks as a function of the sum of the axial loads. 


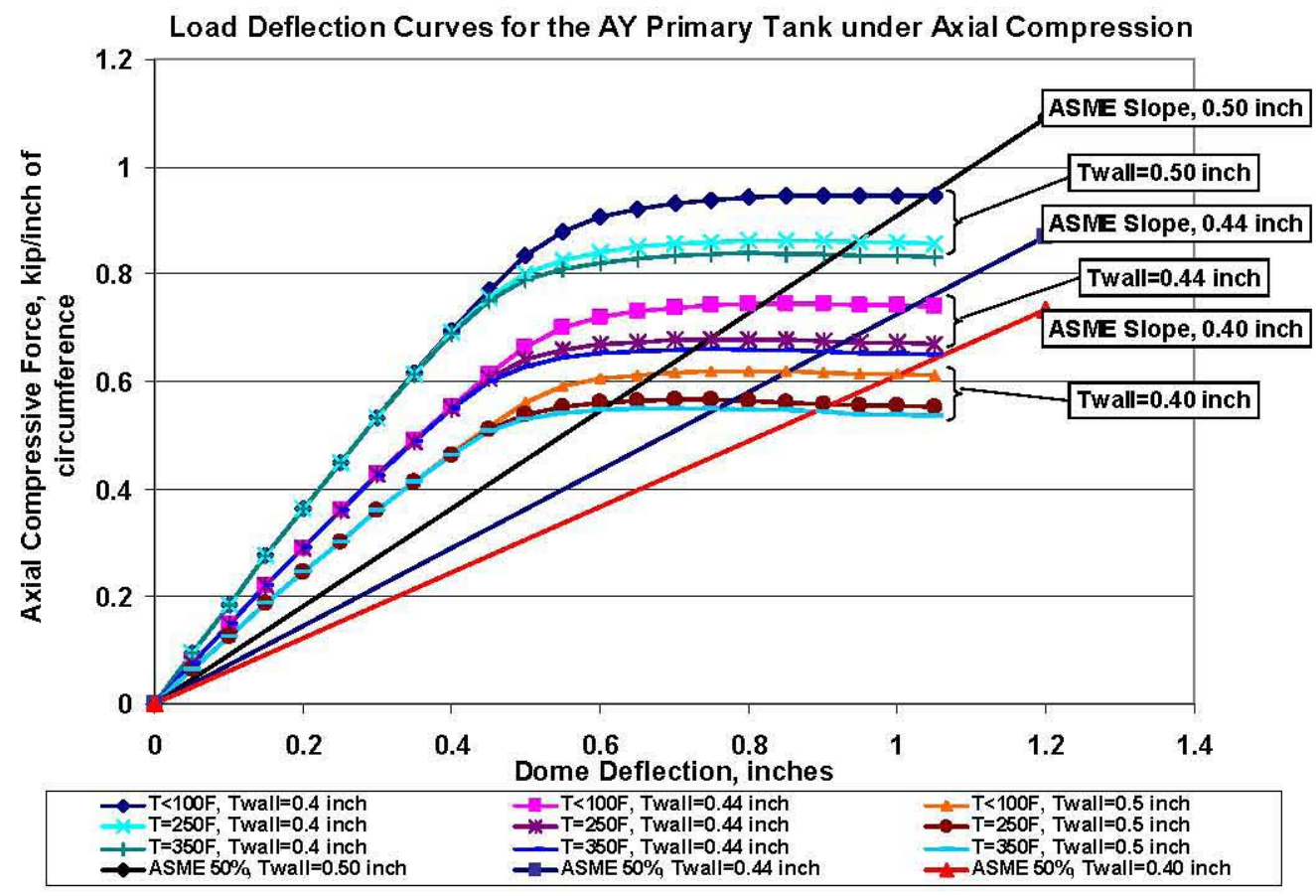

Figure 3-11. Load Deflection Curves for the AY Primary Tank Under Axial Compression for a Range of Yield Strengths and Wall Thicknesses (corrosion allowances) in the Nominal 0.5 Inch Wall Section

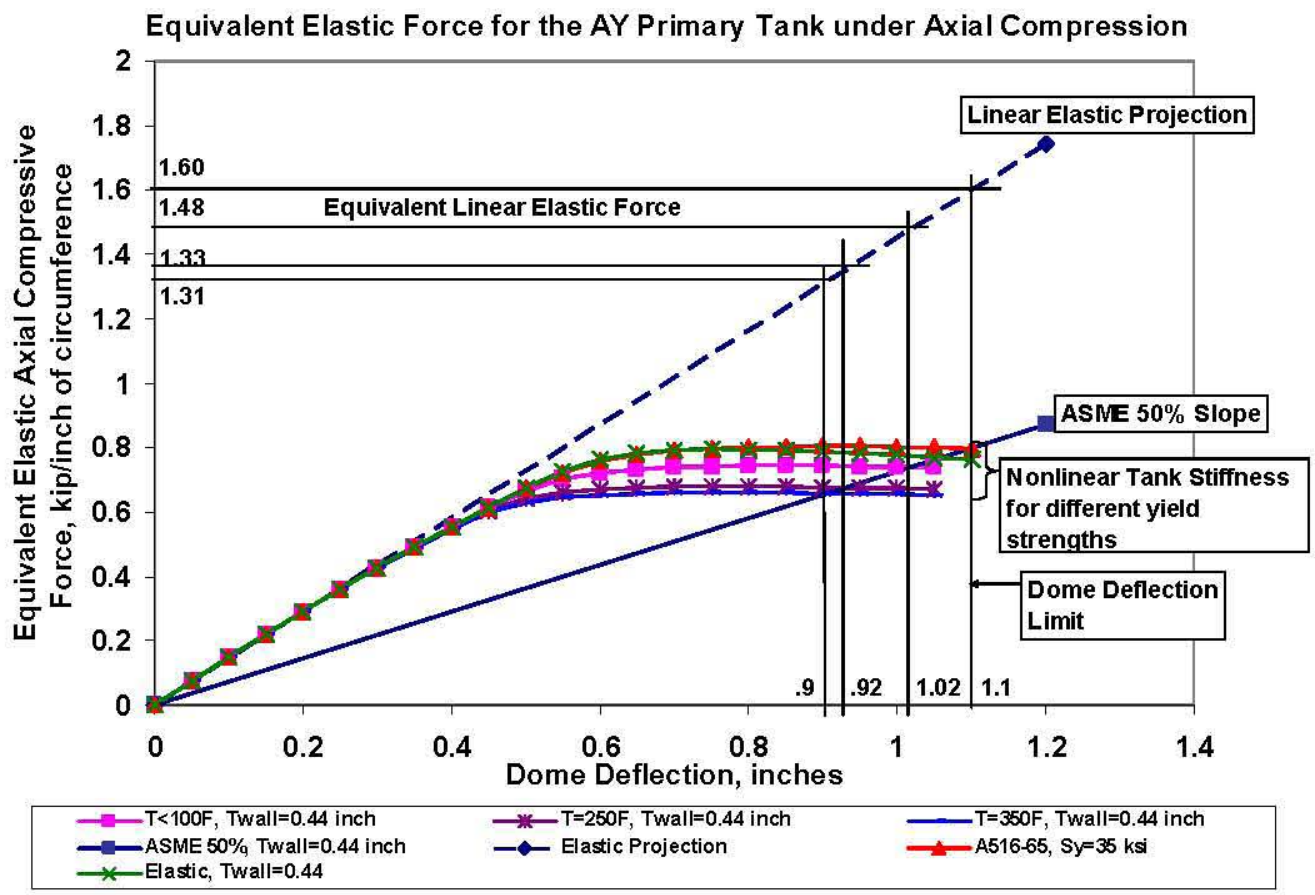

Figure 3-12. Nonlinear Load Deflection Curves for the AY Tank Plus the Linear Elastic Projected Stiffness, Showing the Definition of the Equivalent Linear Elastic Compressive Force 
RPP-RPT-28967, Rev. 2

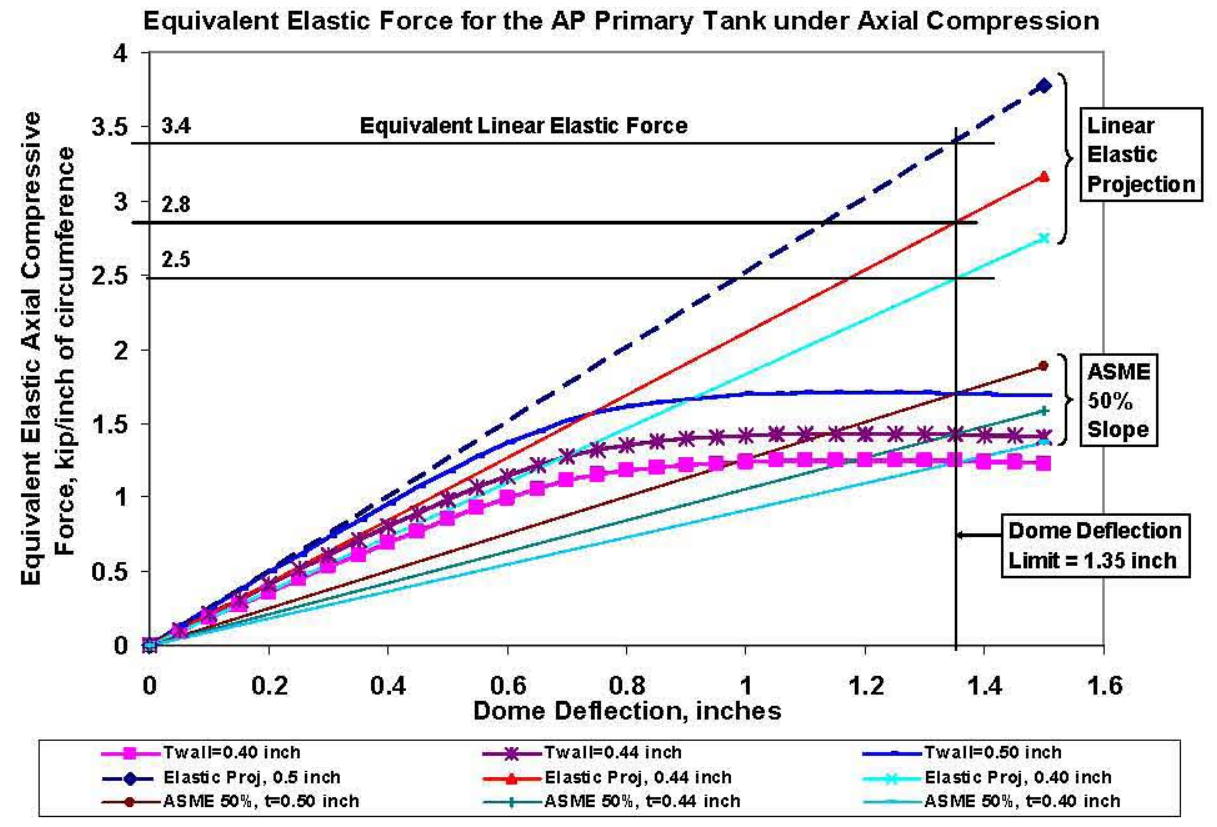

Figure 3-13. Nonlinear Load Deflection Curves for the AP Tank Plus the Linear Elastic Projected Stiffness, Showing the Definition of the Equivalent Linear Elastic Compressive Force

Tables 3-4 and 3-5 list the maximum axial force and its corresponding dome deflection plus the equivalent elastic force and its corresponding deflection for the AY and AP tanks, respectively. The tables show that the maximum axial force that the primary tank can support is roughly $50 \%$ of the equivalent linear elastic force. The maximum surface strains (in the haunch) are less than $0.5 \%$ for the limiting dome deflections in Tables 3-4 and 3-5.

Table 3-4. Summary of Maximum Dome Displacements and Maximum Equivalent Linear Elastic Compressive Forces for the AY Primary Tank

\begin{tabular}{|c|c|c|c|c|c|}
\hline Temp. & $\begin{array}{l}\text { Yield } \\
\text { Stress }\end{array}$ & $\begin{array}{l}\text { Dome } \\
\text { Displacement } \\
\text { at Max Force }\end{array}$ & $\begin{array}{c}\text { Maximum } \\
\text { Nonlinear } \\
\text { Force }\end{array}$ & $\begin{array}{c}\text { Dome } \\
\text { Displacement } \\
\text { Limit }\end{array}$ & $\begin{array}{c}\text { Equiv. Elastic } \\
\text { Force Limit }\end{array}$ \\
\hline${ }^{\circ} \mathrm{F}$ & ksi & inches & kip/inch & inches & kip/inch \\
\hline \multicolumn{6}{|c|}{ Twall $=0.500$ inches, Corrosion $=0.0$ inch } \\
\hline$\leq 100$ & 32.00 & 0.9 & 0.95 & 1.05 & 1.91 \\
\hline 250 & 28.75 & 0.85 & 0.86 & 0.95 & 1.73 \\
\hline 350 & 27.85 & 0.8 & 0.84 & 0.92 & 1.67 \\
\hline \multicolumn{6}{|c|}{ Twall $=0.440$ inches, Corrosion $=0.060$ inch } \\
\hline Elastic & $>36.6$ & 0.75 & 0.79 & 1.06 & 1.54 \\
\hline A516-65 & 35.00 & 0.9 & 0.80 & 1.10 & 1.60 \\
\hline$\leq 100$ & 32.00 & 0.85 & 0.74 & 1.02 & 1.48 \\
\hline 250 & 28.75 & 0.75 & 0.68 & 0.92 & 1.33 \\
\hline 350 & 27.85 & 0.75 & 0.66 & 0.90 & 1.31 \\
\hline \multicolumn{6}{|c|}{ Twall $=0.400$ inches, Corrosion $=0.100$ inch } \\
\hline$\leq 100$ & 32.00 & 0.8 & 0.62 & 1.00 & 1.22 \\
\hline 250 & 28.75 & 0.7 & 0.57 & 0.91 & 1.11 \\
\hline 350 & 27.85 & 0.7 & 0.55 & 0.89 & 1.09 \\
\hline
\end{tabular}


Table 3-5. Summary of Maximum Dome Displacements and Maximum Equivalent Linear Elastic Compressive Forces for the AP Primary Tank

\begin{tabular}{|c|c|c|c|c|c|}
\hline $\begin{array}{c}\text { Wall } \\
\text { Thickness }\end{array}$ & Corrosion & $\begin{array}{c}\text { Dome } \\
\text { Displacement } \\
\text { at Max Force }\end{array}$ & $\begin{array}{c}\text { Maximum } \\
\text { Nonlinear } \\
\text { Force }\end{array}$ & $\begin{array}{c}\text { Dome } \\
\text { Displacement } \\
\text { Limit }\end{array}$ & $\begin{array}{c}\text { Equiv. } \\
\text { Elastic } \\
\text { Force Limit }\end{array}$ \\
\hline inches & inches & inches & kip/inch & inches & kip/inch \\
\hline $\mathbf{0 . 5 0 0}$ & 0.000 & 1.20 & 1.71 & 1.35 & 3.39 \\
\hline $\mathbf{0 . 4 4 0}$ & 0.060 & 1.20 & 1.43 & 1.35 & 2.85 \\
\hline $\mathbf{0 . 4 0 0}$ & 0.100 & 1.20 & 1.25 & 1.35 & 2.47 \\
\hline
\end{tabular}

\subsection{Vacuum Limit Equations for the AY Primary Tank}

Figure 3-14 shows the AY vacuum limits that were calculated for waste heights from 0 to 300 inches and tank compressive displacements of 0 to 0.6 inches. The dome displacement of 0.6 inches gives compressive stresses in the AY and AP tanks that are above those predicted for the combined operating loads. These data points are for a corrosion allowance of 0.060 inch and a waste specific gravity of 1.7. The curve for axial compression of 0.3 inches give a similar initial stress to that predicted by the thermal and operating loads analysis (Rinker et al. 2004). These data points were curve fit and shifted upward to the vacuum limit for zero axial compression and zero waste height. (Note: The data points of the 0.3 inch axial compression were used for curve fitting because they give a slightly flatter curve with waste height and are thus slightly conservative compared to the data points for 0.0 inch axial compression). The predicted vacuum limit increases more rapidly at waste heights above 300 -inches and, therefore, a second

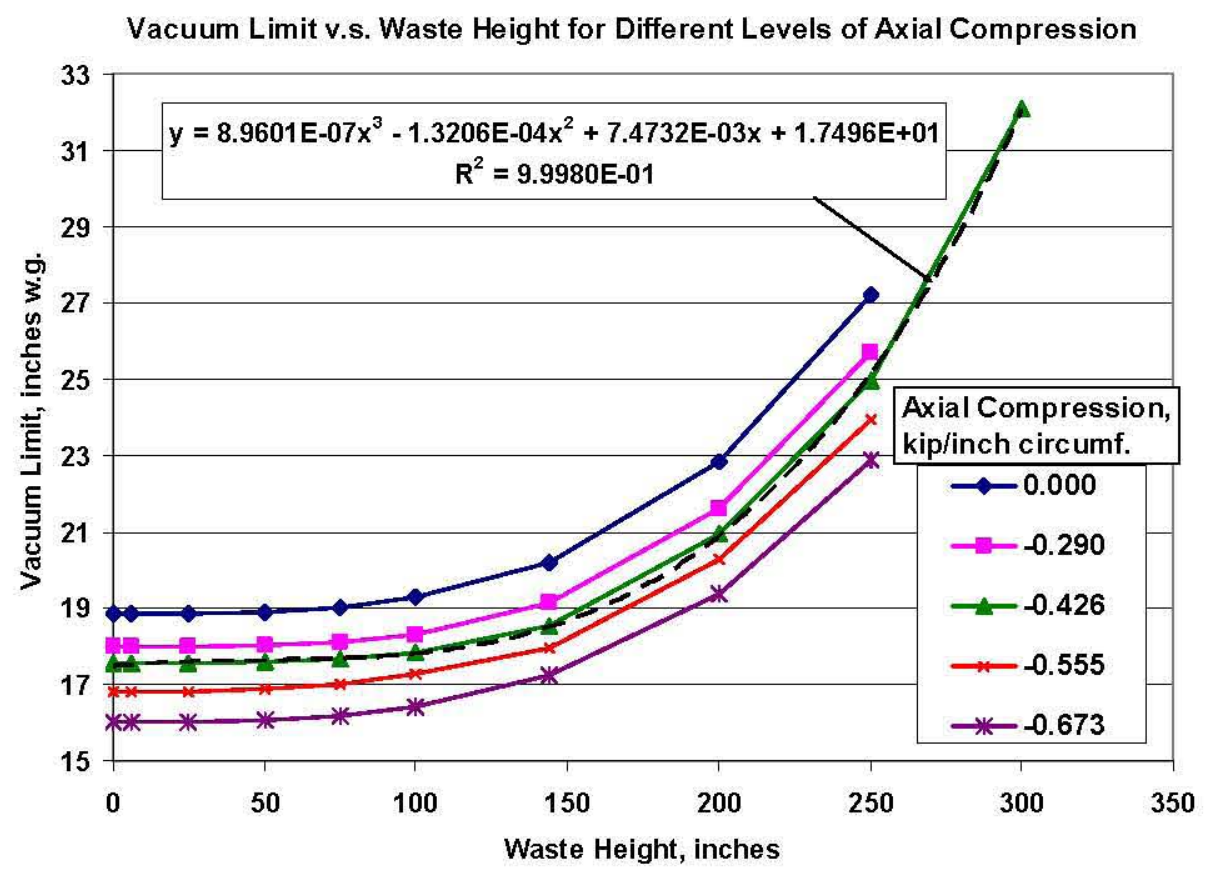

Figure 3-14. Calculated Vacuum Limit Versus Waste Heights for a Range of Axial Compressive Loads (These results are for the $\mathrm{AY}$ tank with waste $\mathrm{SpG}=1.7$ and corrosion allowance $=$ 0.060 inch.) 


\section{RPP-RPT-28967, Rev. 2}

linear projection was used to approximate the vacuum limits above 300 -inches of waste. The resulting equations for limit vacuum in the AY tank with zero axial compression is:

$$
\begin{aligned}
& \mathrm{P}_{\mathrm{V}_{\left(\mathrm{F}_{\varphi}=0\right)}}= 9.6251 \times 10^{-7} \mathrm{~h}^{3}-1.4185 \times 10^{-4} \mathrm{~h}^{2}+8.0271 \times 10^{-3} \mathrm{~h}+18.855 \\
& \text { for } \quad 0 \leq \mathrm{h} \leq 300-\text { inches } \\
& \mathrm{P}_{\mathrm{V}_{\left(\mathrm{F}_{\varphi}=0\right)}}=0.39530 \mathrm{~h}-84.104 \\
& \quad \text { for } 300 \leq \mathrm{h} \leq 460-\text { inches }
\end{aligned}
$$

Where $\mathrm{h}$ is the waste height in inches. The vacuum limit is expressed in inches of water gauge (inch w.g.).

The vacuum limits for a 6-inch waste depth and increasing compressive load were used to fit a scale factor to adjust the above curve for compressive load (Figure 3-15). The equivalent linear elastic force, $F_{\varphi}$, expressed in kips per inch of tank circumference, is used for the equation fitting because it is independent of the different thicknesses in the free-standing portion of the tank wall. The axial compressive force factor, $f\left(F_{\varphi}\right)$ is

$$
\mathrm{f}\left(\mathrm{F}_{\varphi}\right)=-0.01437 \mathrm{~F}_{\varphi}^{3}-0.17908 \mathrm{~F}_{\varphi}^{2}+0.08798 \mathrm{~F}_{\varphi}+0.9988
$$

Note that the equivalent linear elastic force, $F_{\varphi}$, is compressive and expressed as a negative quantity. This equation is valid for axial compressive forces up to the maximum equivalent linear elastic force, $F_{\varphi}(\max )$, which was defined in the previous section.

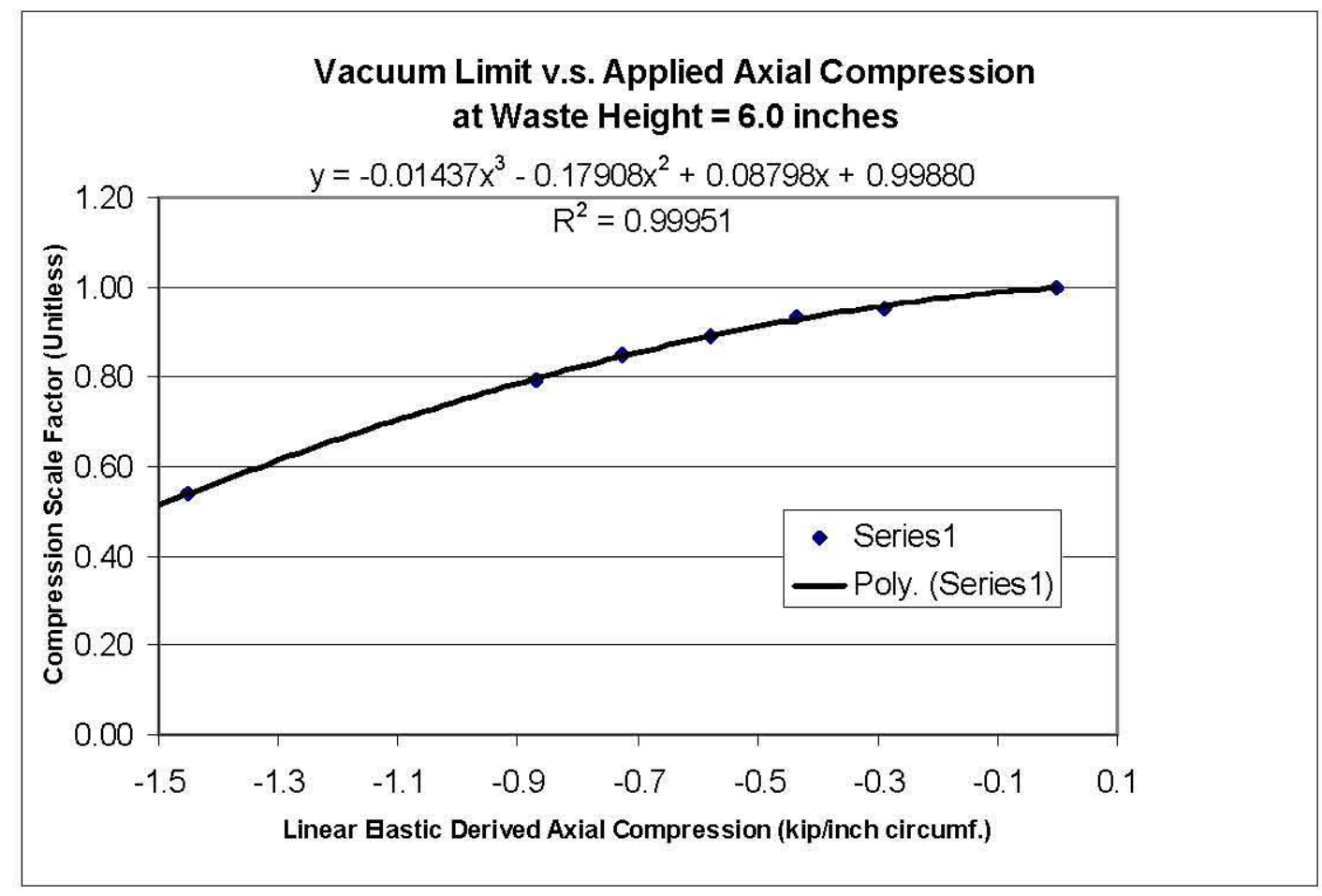

Figure 3-15. Axial Compression Scale Factor of Adjusting the Vacuum Limit for the AY Primary Tank 
Tank models with corrosion allowances of 0.0 to nearly 0.1 inches were also run to determine the sensitivity of the vacuum limit to reductions in the wall thickness. Figure 3-16 shows the relationship of the limit vacuum ratio (normalized by the limit vacuum for a wall thickness reduction of $0.060 \mathrm{inch}$ ) for the range of wall thicknesses that were analyzed. The data in Figure 3-16 were curve fit to give the wall thickness factor, $\mathrm{g}(\mathrm{t})$ as:

$$
g(t)=10.43255 t^{2}+12.025 t-1.753
$$

Where $\mathrm{t}$ is the 0.375 inch wall thickness of the AY upper tank wall minus the corrosion allowance. The minimum wall thickness in the upper wall of the tank was used for the scaling because this is where the buckling deformation occurs. Equation 3.3 is valid for corrosion allowanced from 0.0 to 0.1 inches.

The tank buckling model was also run with different specific gravities ranging from 1.0 to 2.0. Figure 3-17 shows the normalized vacuum limit as a function of specific gravity. These data were curve fit to give the specific gravity factor, $h(\mathrm{SpG})$, as

$$
\mathrm{h}(\mathrm{SpG})=-0.0344(\mathrm{SpG})^{2}+0.1758(\mathrm{SpG})+0.801
$$

The specific gravity, $\mathrm{SpG}$, is unitless. Equation 3.4 is valid for waste specific gravities from 1.0 to 2.0.

Finally, the vacuum limit, $P_{V}(F \varphi, t, S p G, h)$, can be calculated as the product of equations 3.1 through 3.4.

$$
\mathrm{P}_{\mathrm{V}}\left(\mathrm{F}_{\varphi}, \mathrm{t}, \mathrm{SpG}, \mathrm{h}\right)=\mathrm{f}\left(\mathrm{F}_{\varphi}\right) \mathrm{g}(\mathrm{t}) \mathrm{h}(\mathrm{SpG}) \mathrm{P}_{\mathrm{V}\left(\mathrm{F}_{\varphi}=0\right)}
$$

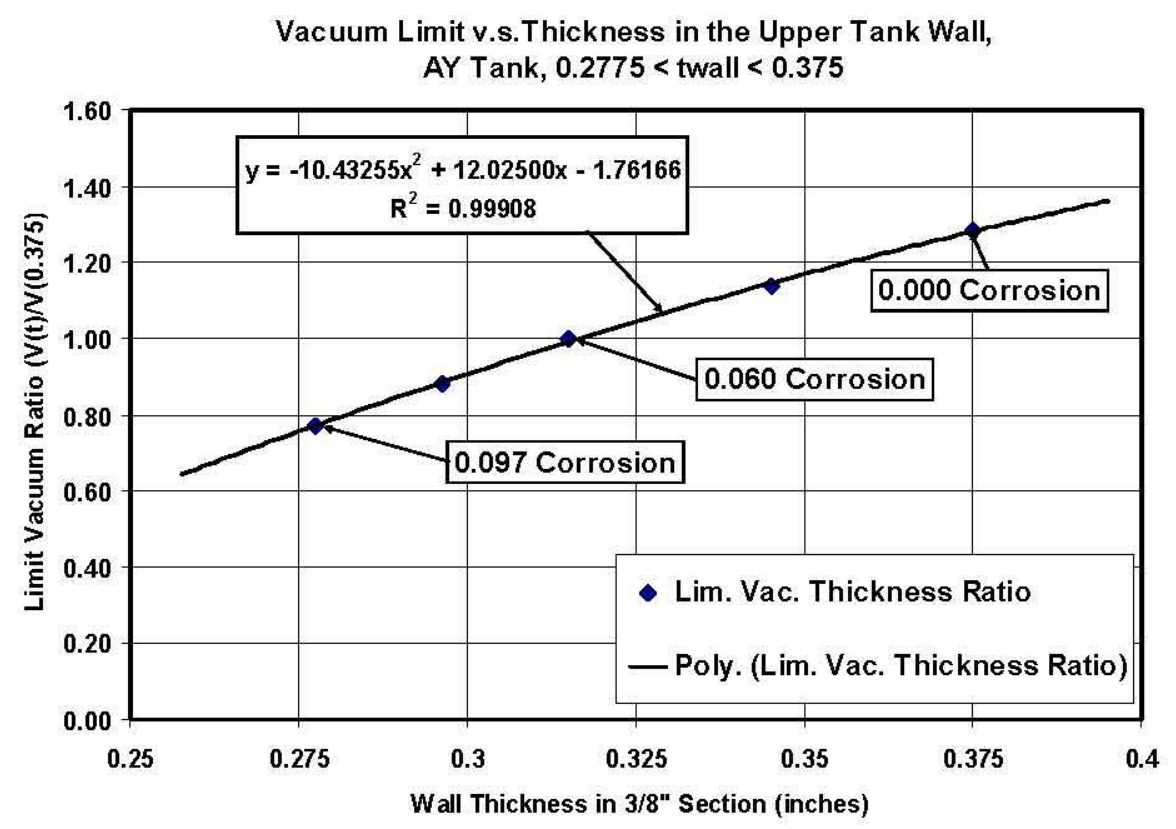

Figure 3-16. Wall Thickness Scale Factor for the AY Tank 
RPP-RPT-28967, Rev. 2

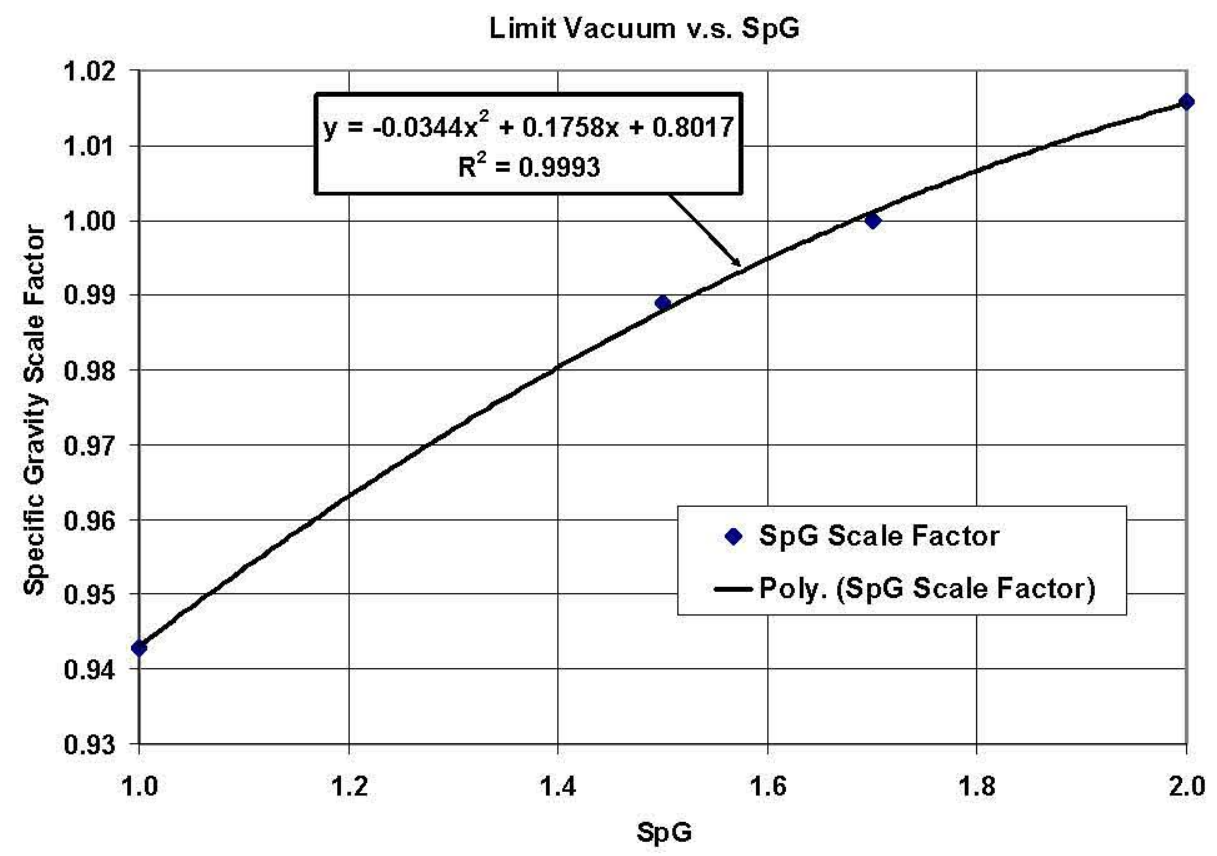

Figure 3-17. Specific Gravity Scale Factor for the AY Tank

The units for the vacuum limit are inches w.g. Figure 3-18 shows that the analytical equations fit the data in Table 3-1 quite well. A Microsoft Excel ${ }^{\circledR}$ spreadsheet (shown in Table 3-6 for the AY tank) was also constructed so that the vacuum limit can be easily calculated based on the parameters $F_{\varphi}, t, S p G$, and $h$.

Addition equations were fit to calculate the maximum equivalent linear elastic force, $F_{\varphi}(\max )$, as a function of the wall thickness and the yield strength. Figure 3-19 shows that a linear relationship exists between the equivalent linear elastic force and the wall thickness for the AY tank. Figure 3-20 shows a similar trend for the AP tank geometry. For the AY tank the equation for the limiting equivalent linear elastic force, $F_{\varphi}(\max )$, is:

$$
\mathrm{F}_{\varphi}(\max )=\sigma_{\mathrm{y}}(-0.21269 t+0.020025)
$$

Where $F_{\varphi}(\max )$ is in kips per inch of tank circumference, $\sigma_{y}$ is the yield strength at temperature, and $\mathrm{t}$ is the 0.375 inch thickness of the upper AY tank wall minus the corrosion allowance.

Figure 3-21 shows the axial displacements of the AY tank are concentrated in the dome and upper knuckle of the tank. The deformed shape of the AP tank is similar. Since the deformation is confined in the upper knuckle at the thinnest wall section, the axial compressive load limit is not significantly influenced by the waste height. 


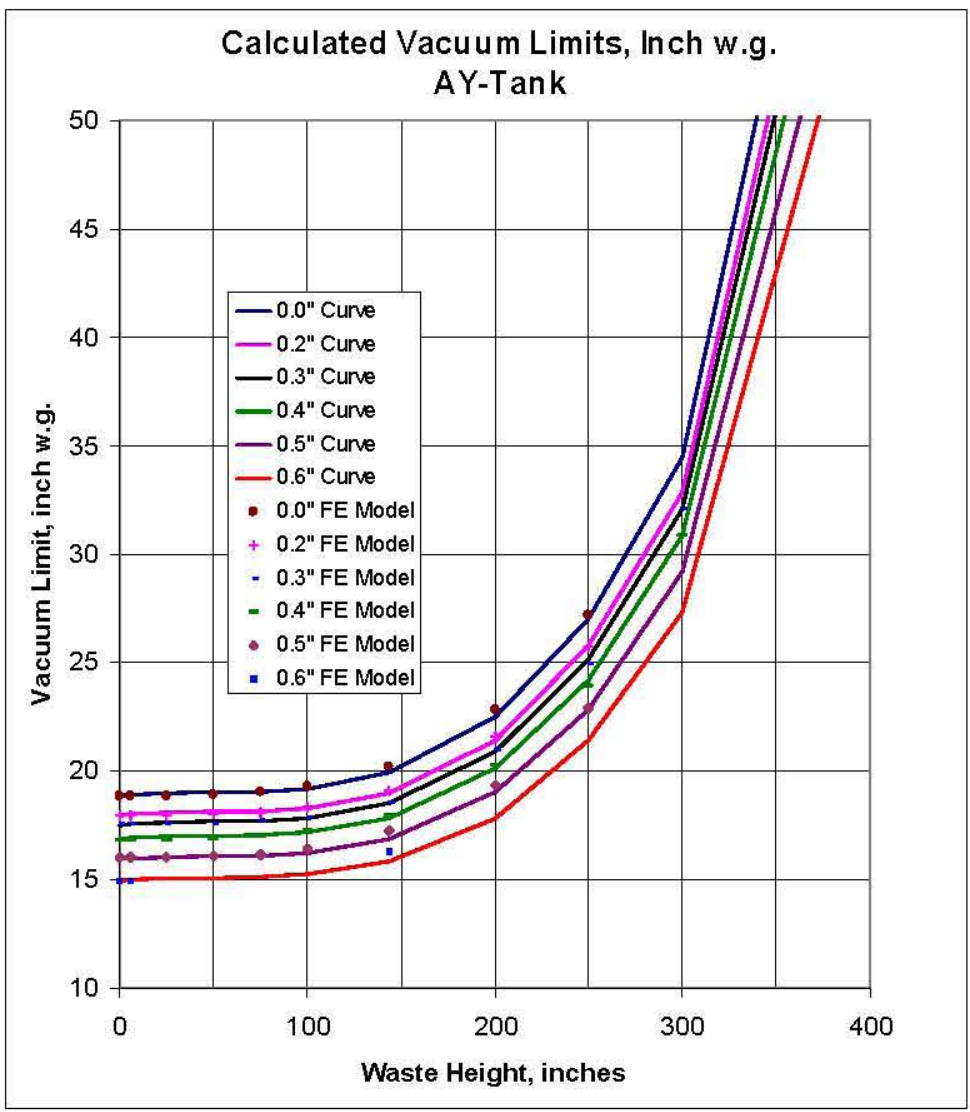

Figure 3-18. Comparison of the Analytical Equations for Vacuum Limit with the Discrete Valued Predicted with Large Deformation Finite Element Analysis

Table 3-6. Excel ${ }^{\circledR}$ Spreadsheet for Calculating the Vacuum Limit of the AY Primary Tank

\begin{tabular}{|c|c|c|c|c|c|c|c|c|}
\hline \multicolumn{9}{|c|}{ AY Vacuum Limits Calculated using the polynomial equations } \\
\hline $\begin{array}{r}\mathrm{SpG}= \\
\end{array}$ & 1.7 & $\mathrm{~h}(\mathrm{SpG})=$ & 1.000444 & & & & & \\
\hline Corrosion Allow= & 0.06 & $g(t)=$ & 0.999705226 & & & & & \\
\hline \multirow[t]{2}{*}{$\mathrm{t}(3 / 8)=$} & 0.315 & $h(S p G)^{*} g(t)$ & 1.000149095 & & & & & \\
\hline & & & & & & & & \\
\hline \multirow[t]{2}{*}{ Axl Stress, $\mathrm{t}=3 / 8^{\prime \prime}$} & psi & 0 & -317 & -635 & -952 & -1270 & -1587 & -3175 \\
\hline & & \multicolumn{6}{|c|}{ Equivalent Linear Elastic Axial Force (kip/in of circumference) $\rightarrow \longrightarrow$} & \\
\hline Lin. Axial Force, & $F($ kip/in) & 0.00 & -0.10 & -0.20 & -0.30 & -0.40 & -0.50 & -1.00 \\
\hline \multirow[t]{3}{*}{ Force Factor, } & $f(F)=$ & 0.999 & 0.988 & 0.974 & 0.957 & 0.936 & 0.912 & 0.746 \\
\hline & Waste $\mathrm{Ht}$. & & & & & & & \\
\hline & inches & \multicolumn{4}{|c|}{ Limit Vacuums, inches w.g. ----〉>> } & & & \\
\hline \multirow[t]{10}{*}{ 1st equation } & 0 & 18.84 & 18.64 & 18.37 & 18.04 & 17.65 & 17.20 & 14.07 \\
\hline & 6 & 18.88 & 18.68 & 18.41 & 18.08 & 17.69 & 17.23 & 14.10 \\
\hline & 25 & 18.96 & 18.76 & 18.49 & 18.16 & 17.77 & 17.31 & 14.16 \\
\hline & 50 & 19.00 & 18.80 & 18.53 & 18.20 & 17.80 & 17.35 & 14.19 \\
\hline & 75 & 19.05 & 18.84 & 18.58 & 18.24 & 17.85 & 17.39 & 14.23 \\
\hline & 100 & 19.18 & 18.98 & 18.71 & 18.37 & 17.97 & 17.51 & 14.33 \\
\hline & 144 & 19.92 & 19.71 & 19.43 & 19.08 & $\begin{array}{l}18.67 \\
\end{array}$ & 18.19 & 14.88 \\
\hline & 200 & 22.46 & 22.23 & 21.91 & 21.52 & 21.05 & 20.51 & 16.78 \\
\hline & 250 & 27.01 & 26.72 & 26.34 & 25.87 & 25.31 & 24.66 & 20.17 \\
\hline & 300 & 34.45 & 34.08 & 33.60 & 33.00 & 32.28 & 31.45 & 25.73 \\
\hline \multirow[t]{4}{*}{ 2nd equation } & 300 & 34.45 & 34.09 & 33.60 & 33.00 & 32.28 & 31.45 & 25.73 \\
\hline & 350 & 54.19 & 53.62 & 52.86 & 51.91 & 50.78 & 49.48 & 40.48 \\
\hline & 400 & 73.94 & 73.16 & 72.11 & 70.82 & 69.28 & 67.50 & 55.23 \\
\hline & 460 & 97.63 & 96.60 & 95.22 & 93.51 & 91.48 & 89.13 & 72.93 \\
\hline
\end{tabular}


RPP-RPT-28967, Rev. 2

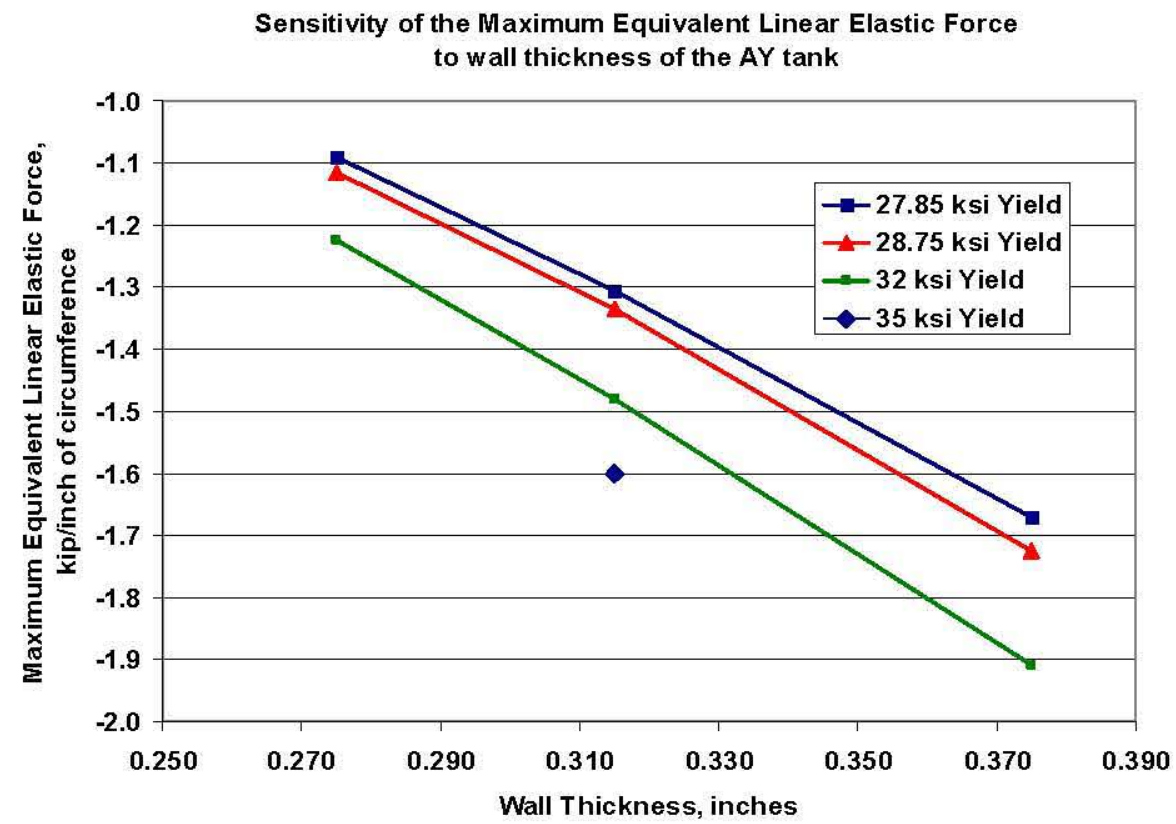

Figure 3-19. Effect of Wall Thickness and Yield Strength on the Axial Limit Load for the AY Primary Tank

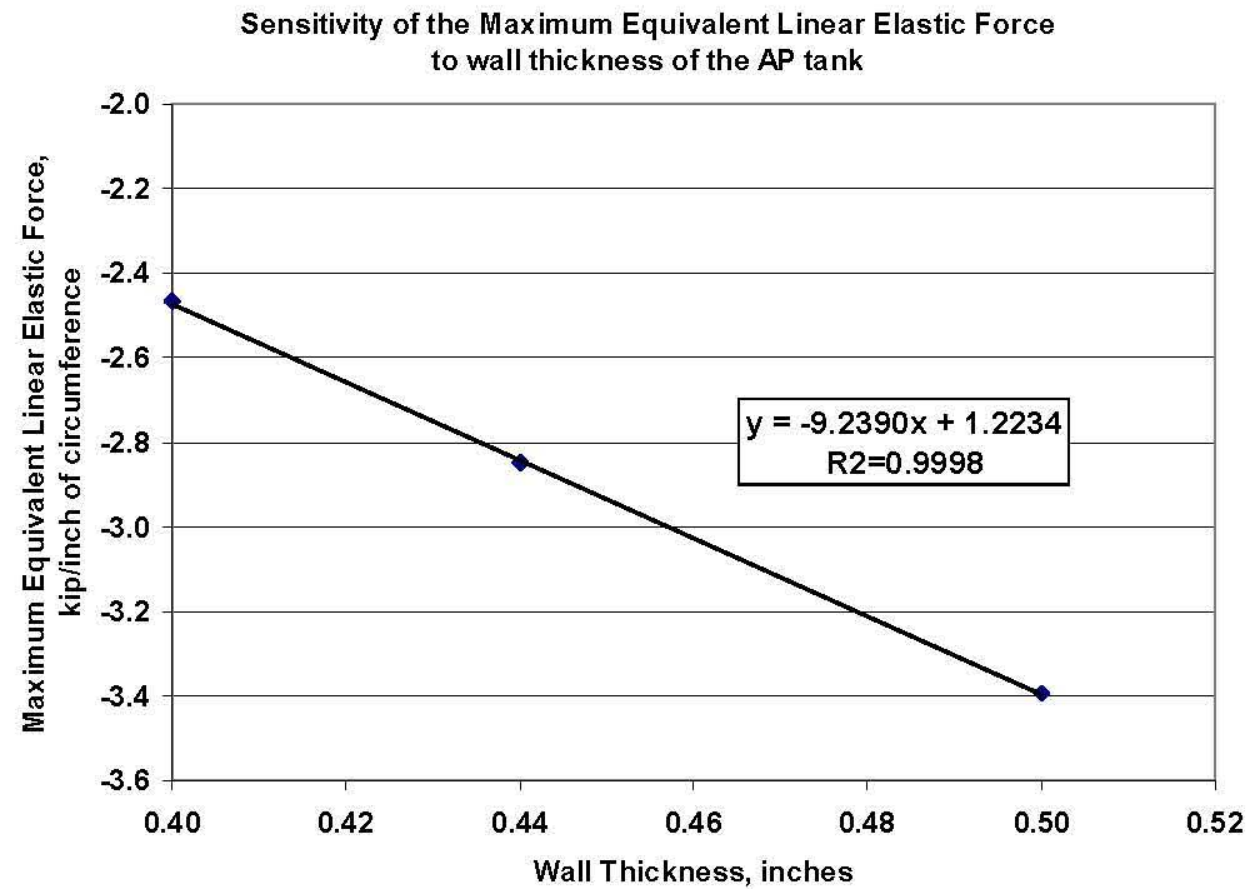

Figure 3-20. Effect of Wall Thickness on the Axial Limit Load for the AP Primary Tank 
RPP-RPT-28967, Rev. 2

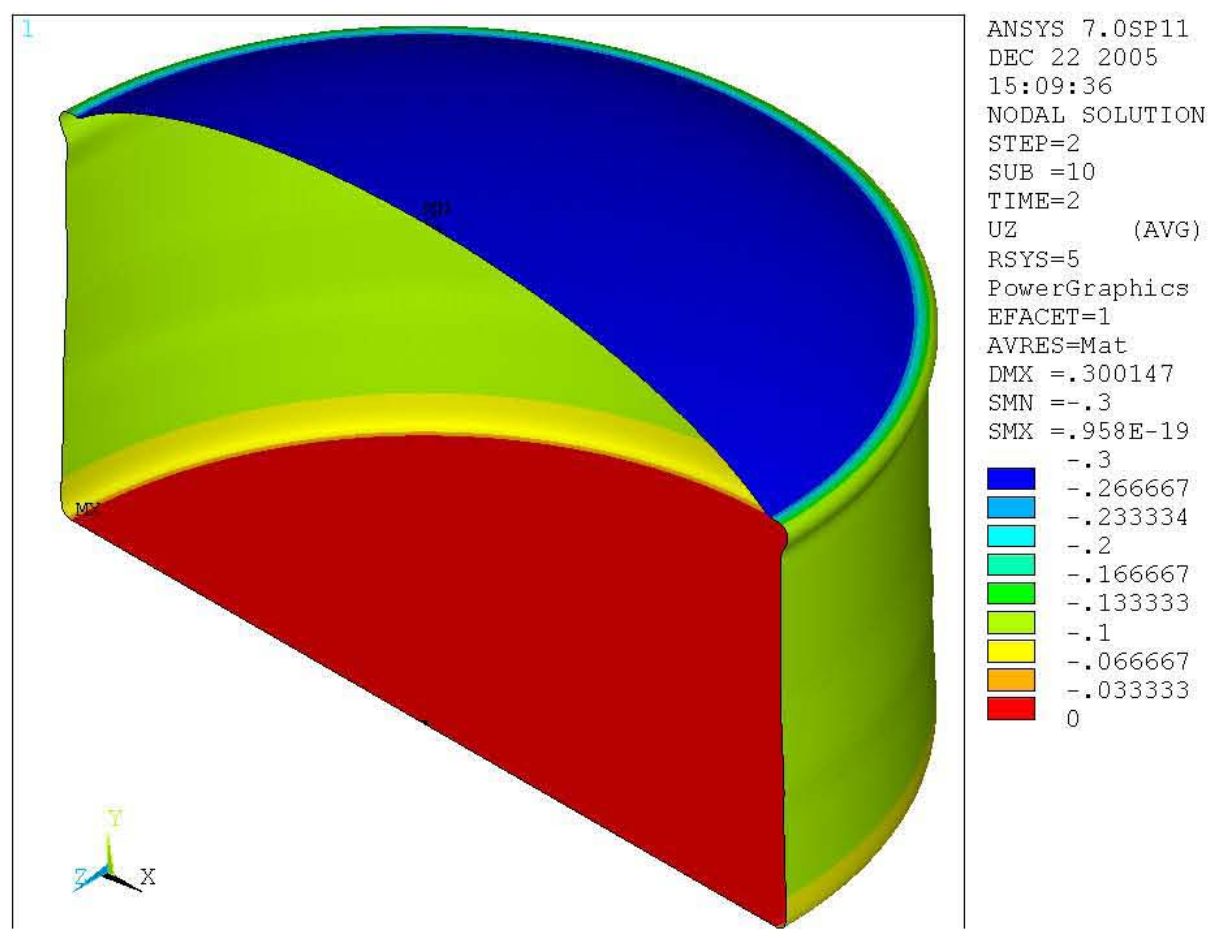

Figure 3-21. Typical Displacement Shape of the AY and AP Primary Tanks at the Axial Limit Load (The displacements have been magnified 50 times in the plot.)

\subsection{Vacuum Limit Equations for the AP Primary Tank}

Equations for calculating the vacuum limit of the AP primary tank were fit using the model results listed in Table 3-2. The equations for limit vacuum in the AP tank with zero axial compression are:

$$
\begin{aligned}
& \mathrm{P}_{\mathrm{V}\left(\mathrm{F}_{\varphi}=0\right)}= 1.2233 \times 10^{-6} \mathrm{~h}^{3}-2.2759 \times 10^{-4} \mathrm{~h}^{2}+1.5927 \times 10^{-2} \mathrm{~h}+20.5942 \\
& \text { for } \quad 0 \leq \mathrm{h} \leq 300-\text { inches } \\
& \mathrm{P}_{\mathrm{V}_{\left(\mathrm{F}_{\varphi}=0\right)}}=0.72364 \mathrm{~h}-179.172 \\
& \quad \text { for } 300 \leq \mathrm{h} \leq 460 \text {-inches }
\end{aligned}
$$

The axial compressive force factor, $\mathrm{f}\left(\mathrm{F}_{\varphi}\right)$, is given by

$$
f\left(F_{\phi}\right)=-0.01474 F_{\phi}^{3}-0.02956 F_{\phi}^{2}+0.10616 F_{\phi}+1.00025
$$

Where $F_{\varphi}$ is the equivalent linear elastic compressive force in the tank wall in kips/inch of the circumference. Again, the compressive force is negative.

The wall thickness factor, $\mathrm{g}(\mathrm{t})$ is given by

$$
g(t)=3.81011 t^{2}+1.0394 t-0.1949
$$


Where $\mathrm{t}$ is the 0.5 inch thickness of the AP upper tank wall minus the corrosion allowance. Equation 3.9 is valid for corrosion allowanced from 0.0 to 0.1 inches.

The specific gravity factor, $\mathrm{h}(\mathrm{SpG})$ is given by

$$
\mathrm{h}(\mathrm{SpG})=-0.0344(\mathrm{SpG})^{2}+0.1758(\mathrm{SpG})+0.801
$$

Equation 3.10 is valid for waste specific gravities from 1.0 to 2.0 .

Finally, the vacuum limit, $P_{V}\left(F_{\varphi}, t, S p G, h\right)$, is calculated as the product of equations 3.7 through 3.10 .

$$
P_{\mathrm{V}}\left(\mathrm{F}_{\varphi}, \mathrm{t}, \mathrm{SpG}\right)=\mathrm{f}\left(\mathrm{F}_{\varphi}\right) \mathrm{g}(\mathrm{t}) \mathrm{h}(\mathrm{SpG}) \mathrm{P}_{\mathrm{V}}\left(\mathrm{F}_{\varphi}=0\right)
$$

The units for the vacuum limit are again inches w.g. A Microsoft Excel ${ }^{\circledR}$ spreadsheet (shown in Table 3-7 for the AP tank) was constructed so that the vacuum limit can be easily calculated based on the parameters $F_{\varphi}, t, S p G$, and $h$.

From Figure 3-20, the equation for the maximum equivalent linear elastic force, $F_{\varphi}(\max )$, for the AP primary tank is:

$$
F_{\varphi}(\max )=-9.239 t+1.2234
$$

Where $F_{\varphi}(\max )$ is in kips per inch of tank circumference and $\mathrm{t}$ is the 0.500 inch thickness of the AP upper

\begin{tabular}{|c|c|c|c|c|c|c|c|c|}
\hline \multicolumn{9}{|c|}{ AP Vacuum Limits Calculated using the polynomial equations } \\
\hline $\mathrm{SpG}=$ & 1.7 & $\mathrm{~h}(\mathrm{SpG})=$ & 1.000444 & & & & & \\
\hline Corrosion Allow $=$ & 0.06 & $g(t)=$ & 1.000082096 & & & & & \\
\hline \multirow[t]{2}{*}{$\mathrm{t}(0.5)=$} & 0.44 & $\mathrm{~h}(\mathrm{SpG}){ }^{*} \mathrm{~g}(\mathrm{t})$ & 1.000526132 & & & & & \\
\hline & & & & & & & & \\
\hline \multirow{2}{*}{ Axl Stress, $\mathrm{t}=1 / 2$} & psi & \begin{tabular}{|r|}
-455 \\
\end{tabular} & -909 & -1364 & -1818 & -2273 & -2727 & -4773 \\
\hline & & \multicolumn{6}{|c|}{ Equivalent Linear Elastic Axial Force (kip/in of circumference) } & \\
\hline Axial Force, & $F(\mathrm{kip} / \mathrm{in})$ & -0.200 & -0.400 & -0.600 & -0.800 & -1.000 & -1.200 & -2.100 \\
\hline \multirow[t]{3}{*}{ Force Factor, } & $f(F)=$ & 0.980 & 0.956 & 0.931 & 0.906 & 0.882 & 0.858 & 0.786 \\
\hline & Waste $\mathrm{Ht}$. & & & & & & & \\
\hline & inches & \multicolumn{4}{|c|}{ Limit Vacuums, inches w.g. $\longrightarrow \gg \gg$} & & & \\
\hline \multirow[t]{10}{*}{ 1st equation } & 0 & 20.197 & 19.704 & 19.190 & 18.672 & 18.164 & 17.679 & 16.190 \\
\hline & 6 & 20.283 & 19.787 & 19.272 & 18.752 & 18.241 & 17.755 & 16.259 \\
\hline & 25 & 20.467 & 19.967 & 19.447 & 18.922 & 18.406 & 17.915 & 16.406 \\
\hline & 50 & 20.570 & 20.067 & 19.545 & 19.017 & 18.499 & 18.006 & 16.489 \\
\hline & 75 & 20.619 & 20.115 & 19.591 & 19.063 & 18.543 & 18.049 & 16.528 \\
\hline & 100 & 20.727 & 20.220 & 19.694 & 19.162 & 18.640 & 18.143 & 16.614 \\
\hline & 144 & 21.400 & 20.877 & 20.334 & 19.785 & 19.246 & 18.733 & 17.154 \\
\hline & 200 & 23.991 & 23.404 & 22.795 & 22.180 & 21.575 & 21.000 & 19.231 \\
\hline & 250 & 28.898 & 28.191 & 27.457 & 26.716 & 25.988 & 25.295 & 23.164 \\
\hline & 300 & 37.187 & 36.278 & 35.334 & 34.380 & 33.443 & 32.551 & 29.809 \\
\hline \multirow[t]{4}{*}{ 2nd equation } & 300 & 37.189 & 36.280 & 35.335 & 34.381 & 33.445 & 32.553 & 29.810 \\
\hline & 350 & 72.673 & 70.897 & 69.051 & 67.187 & 65.357 & 63.614 & 58.253 \\
\hline & 400 & 108.158 & 105.515 & 102.767 & 99.992 & 97.269 & 94.675 & 86.697 \\
\hline & 460 & 150.739 & 147.055 & 143.225 & 139.358 & 135.563 & 131.948 & 120.829 \\
\hline
\end{tabular}
tank wall minus the corrosion allowance.

Table 3-7. Excel $^{\circledR}$ Spreadsheet for Calculating the Vacuum Limit of the AP Primary Tank 


\subsection{Comparison of Buckling Evaluations Using ASME N-284-1 and the DST Primary Tank Specific Method}

Buckling evaluations were made for a DST primary tank using both the N-284-1 method and PNNL's tank-specific method described in Section 2.2. The AY tank was chosen with the conditions specified in Table 3-8. Three different cases were analyzed; two with different waste heights ( 6 inches and 144 inches) and the third with a waste height of 144 inches and the minimum wall thickness of the AY tank ( 0.375 inch minus the 0.060 inch corrosion allowance). The buckling length of the cylinder was assumed to be the vertical distance between the waste free surface and the tangent point between the upper knuckle and the dome. The wall thickness in cases 1 and 2 is the weighted average wall thickness over this length. Table 3-9 summarizes section properties and allowable stresses calculated using the N-284-1 methods. The allowable stresses from N-284-1 are defined as follows:

$\sigma_{\mathrm{xa}}=$ The allowable axial compressive stress, psi, for external radial pressure $=0.0$

$\sigma_{\mathrm{ra}}=$ The allowable external radial pressure, psi, for axial stress $=0.0$

$\sigma_{\text {ha }}=$ The allowable hydrostatic external pressure, psi, where the axial stress, $\sigma_{\text {axial }}=1 / 2 \sigma_{\text {hoop }}$ for a closed ended cylinder

Table 3-8. Buckling Evaluation Cases for Comparing the N-284-1 Method with the PNNL Large Displacement Buckling Evaluation Method

\begin{tabular}{|c|c|c|c|c|c|}
\hline $\begin{array}{c}\text { Case } \\
\text { No. }\end{array}$ & $\begin{array}{c}\mathbf{R}=\text { tank } \\
\text { radius, } \\
\text { inches }\end{array}$ & $\begin{array}{c}\text { h=waste } \\
\text { height, } \\
\text { inches }\end{array}$ & $\begin{array}{l}\text { Length, } L=460-h=\text { distance } \\
\text { from waste surface to dome } \\
\text { tangent, inches }\end{array}$ & $\begin{array}{c}t=\text { average wall } \\
\text { thickness above the } \\
\text { waste, inches } \\
\end{array}$ & $\begin{array}{c}\mathrm{E}=\text { elastic } \\
\text { modulus, } \\
\text { psi }\end{array}$ \\
\hline 1 & 450 & 6 & 454 & 0.507 & $29.5 \mathrm{E} 6$ \\
\hline 2 & 450 & 144 & 316 & 0.409 & $29.5 \mathrm{E} 6$ \\
\hline 3 & 450 & 144 & 316 & 0.315 & $29.5 \mathrm{E} 6$ \\
\hline
\end{tabular}

Table 3-9. ASME N-284-1 Calculated Section Properties and Allowable Stresses

\begin{tabular}{||c|c|c|c|c|c||}
\hline $\begin{array}{c}\text { Case } \\
\text { No. }\end{array}$ & $\mathbf{R} / \mathbf{t}$ & $\mathrm{M}=\frac{\mathrm{L}}{\sqrt{\mathrm{Rt}}}$ & $\begin{array}{c}\boldsymbol{\sigma}_{\mathrm{xa}}=\text { allowable } \\
\text { axial compressive } \\
\text { stress, psi }\end{array}$ & $\begin{array}{c}\boldsymbol{\sigma}_{\mathbf{r a}}=\text { allowable radial } \\
\text { only compressive } \\
\text { stress, psi }\end{array}$ & $\begin{array}{c}\boldsymbol{\sigma}_{\mathbf{h a}}=\text { allowable hydrostatic } \\
\text { compressive stress, psi } \\
\left(\boldsymbol{\sigma}_{\text {axial }}=\mathbf{1} / \mathbf{2} \mathbf{\sigma}_{\text {hoop }}\right)\end{array}$ \\
\hline \hline 1 & 888 & 30.45 & 4028 & 808 & 794 \\
\hline 2 & 1100 & 23.25 & 3250 & 860 & 840 \\
\hline 2 & 1429 & 26.54 & 2590 & 750 & 730 \\
\hline
\end{tabular}

Article 1713.1.1 of N-284-1 uses these three allowable loads to construct interaction diagrams for different combinations of axial compressive stress and external radial pressure. Figures 3-22 and 3-23 show interaction diagrams for the two different wastes with average wall thickness. Figure 3-24 shows similar results for the 144-inch waste height with the reduced wall thickness of the upper wall. In these plots the radial external pressure was converted to inches w.g. and the axial stress to kips/inch of tank circumference (by multiplying by the average wall thickness used in the N-284-1 calculations) for direct comparison with PNNL's large displacement buckling method. 
RPP-RPT-28967, Rev. 2

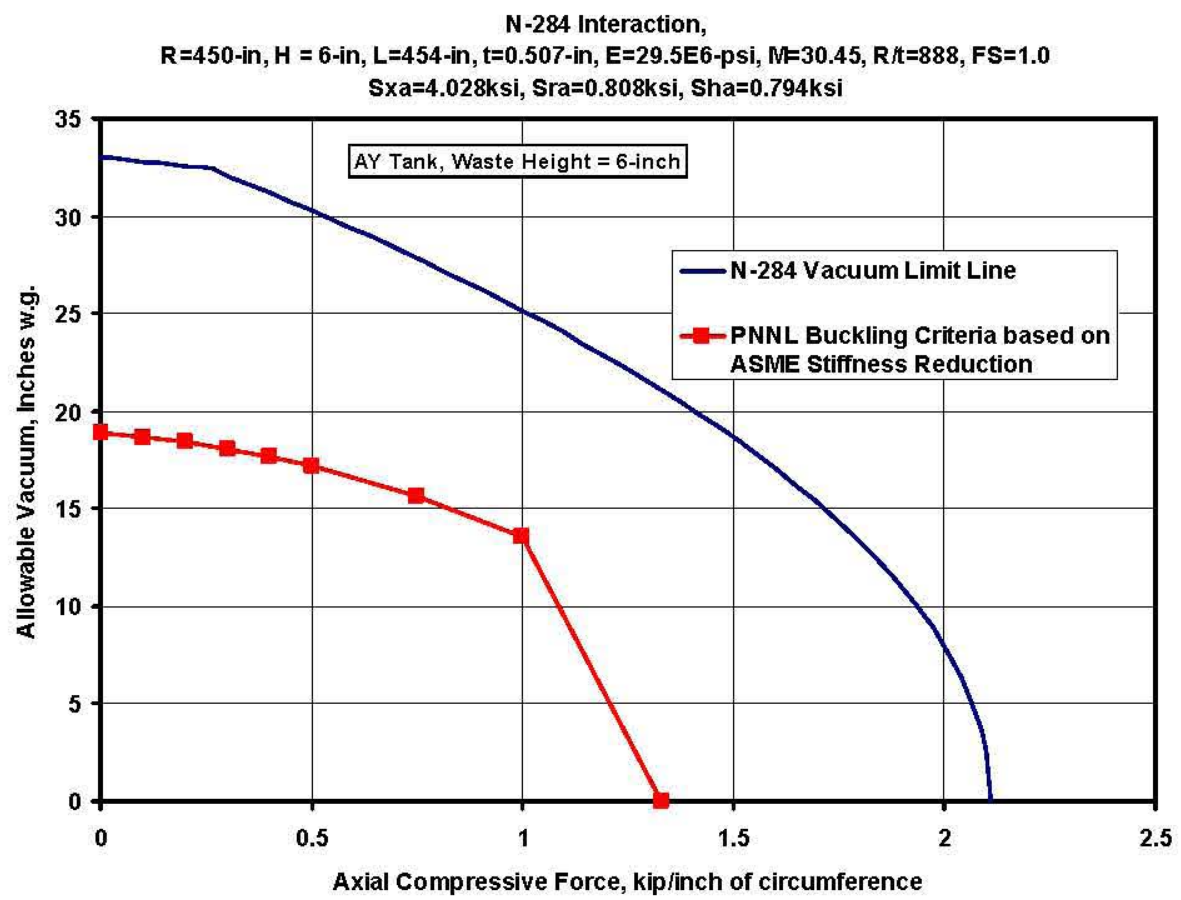

Figure 3-22. Comparison of the PNNL Large Displacement Buckling Evaluation Method with the ASME N-284-1 Method (The comparison is made for the AY tank with a waste height of 6 inches.)

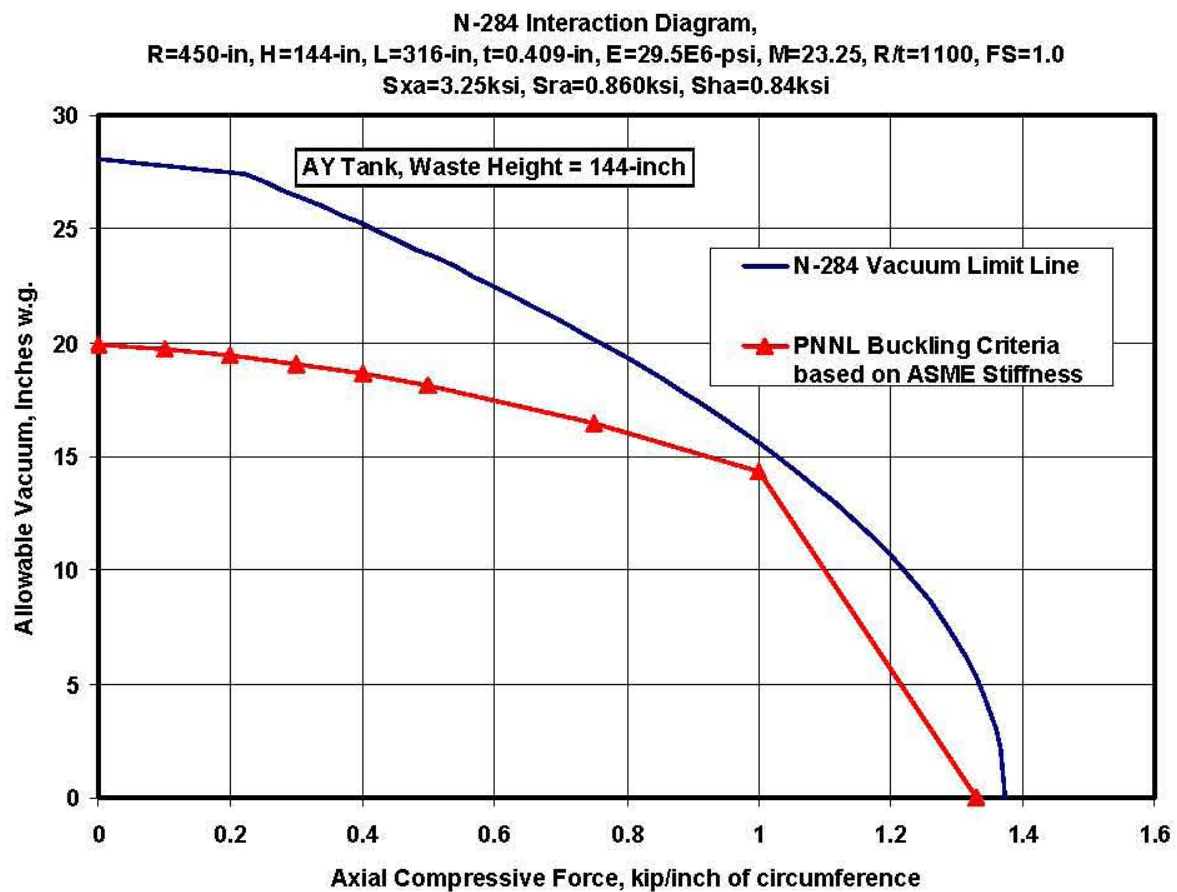

Figure 3-23. Comparison of the PNNL Large Displacement Buckling Evaluation Method with the ASME N-284-1 Method (The comparison is made for the AY tank with a waste height of 144 inches.) 
Figures 3-22 and 3-23 show that the PNNL results give nearly the same limit curves for both the waste heights. The vacuum limit for the 6-inch waste height is slightly smaller than the vacuum limit for the 144 inch waste height. This is reasonable because the buckling deformation (the basis for the vacuum limits) primarily occurs in the upper section of the tank above the waste height. It is also reasonable for the vacuum limit to decrease slightly with reduced waste height because the tank wall is supported less at the lower waste height. However, Figures 3-22 and 3-23 show that the N-284-1 evaluation (based on the free height above the waste and the corresponding average wall thickness) predicts the opposite trend with a considerably higher vacuum limit for the lower waste height. The $\mathrm{N}-284-1$ vacuum limit increases with decreasing waste height because it is a direct function of the thickness, and the average thickness increases as the waste height decreases. This is counter intuitive.

The third comparison case (Figure 3-24) shows the interaction diagram for the 144-inch waste height assuming that the average wall thickness is the minimum thickness of the upper section of the tank wall (0.315 inches). N-284-1 gives nearly the same vacuum limit as the PNNL method when using the minimum wall thickness. This is reasonable because the vacuum limit is proportional to the wall thickness and the finite element analysis has shown that the buckling deformation mode occurs primarily in the upper thin section of the tank wall. Although somewhat higher, the PNNL method gives a very comparable limit for the axial compression load. This is justifiable based on the detailed tank specific analysis that was performed and the understanding that the tank axial deformation is fully displacement controlled by the outer concrete structure.

In summary, the comparison cases presented here show that the PNNL tank-specific buckling method establishes buckling limits that are similar in magnitude to the limits calculated using the N-284-1 method. The PNNL method correctly accounts for the wall thickness effects and the confinement of the primary tank inside the concrete outer tank. These comparison cases support the validity of the buckling evaluation method developed by PNNL for the DST primary tanks.

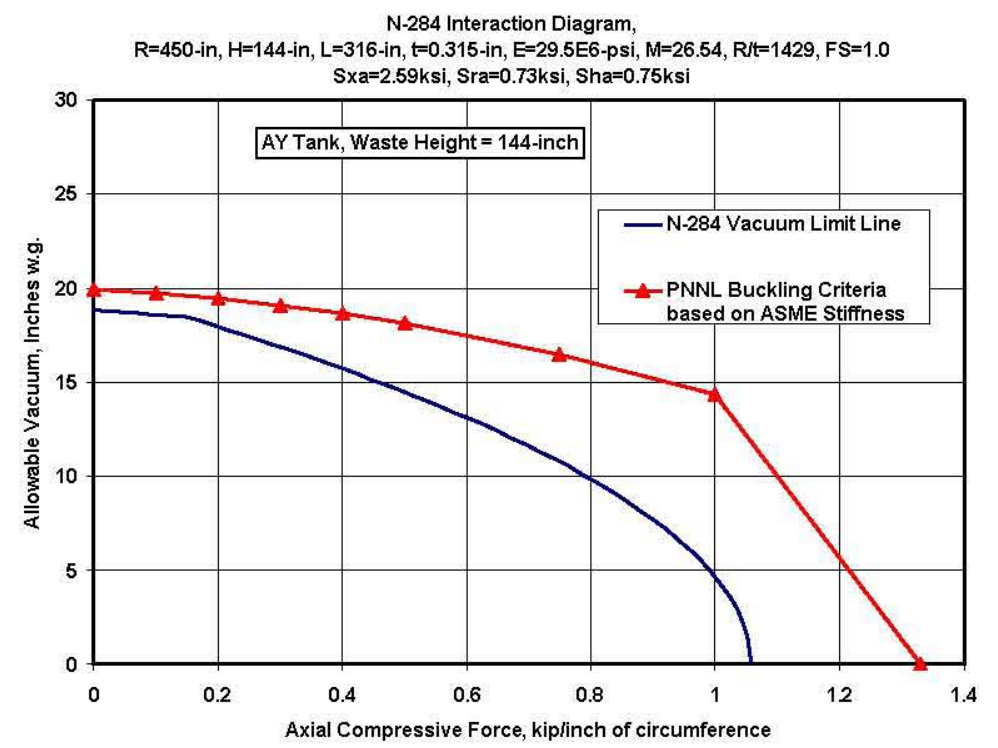

Figure 3-24. Comparison of the PNNL Large Displacement Buckling Evaluation Method with the ASME N-284-1 Method (The comparison is made for the AY tank with a waste height of 144 inches and an average wall thickness of 0.315 inches.) 



\subsection{ANSYS Thermal Model of the Double-Shell Waste Tanks}

The DST Thermal and Operating Loads Analysis (Rinker et al. 2004) used a TEMPEST thermal model to predict the temperature distributions for a single waste height and thermal transient. TEMPEST is a finite difference, thermal-hydraulics code developed at PNNL that has been used extensively for waste tank simulations (Antoniak and Recknagle 1995). The main benefit of using TEMPEST in the Thermal and Operating Loads Analysis was that an existing double-shell waste tank model was available. This model had been calibrated to match measured temperature distributions in the waste, and it could be easily modified to simulate the bounding waste tank geometry and the design basis waste temperature transient of the Thermal and Operating Loads Analysis.

However, the data mapping procedure used to transfer the TEMPEST temperature profiles to the ANSYS structural model made analyzing different waste heights and temperature transients difficult because of the different numerical grids that were used. Therefore, an ANSYS thermal model has been developed that is directly (node-to-node) compatible with the ANSYS DST structural model. This model supports the tank buckling analysis by allowing easy prediction of tank stresses due to different combinations of thermal and operating loads. This capability is required to calculate the allowable net vacuum loads as a function of the waste height and temperature. The ANSYS thermal model input files are listed in Appendix C.

\subsection{Comparison of Previous Double-Shell Tank Thermal Models}

The modeling features and methods used in previous waste tank thermal models were reviewed during the initial phase of the ANSYS thermal model development to ensure that the significant heat transfer mechanisms were accounted for in the ANSYS model. This section summarizes the main features of the TEMPEST model and other DST thermal models using the GOTH_SNF and P/THERMAL codes.

\subsubsection{TEMPEST Model}

The TEMPEST model by Antoniak and Recknagle (1995) includes conduction, radiation, and convection heat transfer effects on the transient tank temperatures. The model includes the following features:

- Convective (fully mixed) waste at a uniform temperature.

- Conduction from an upper non-convective waste layer to the convective waste below.

- Convection from the waste surface to the dome air, but no convection from the dome air to the dome.

- Convection from the tank wall to the annulus air, but no convection from the annulus air to the secondary tank wall.

- Radiation from the waste surface to the dome

- Radiation from the primary wall to the secondary wall.

The TEMPEST model is shown in Figure 4-1. 


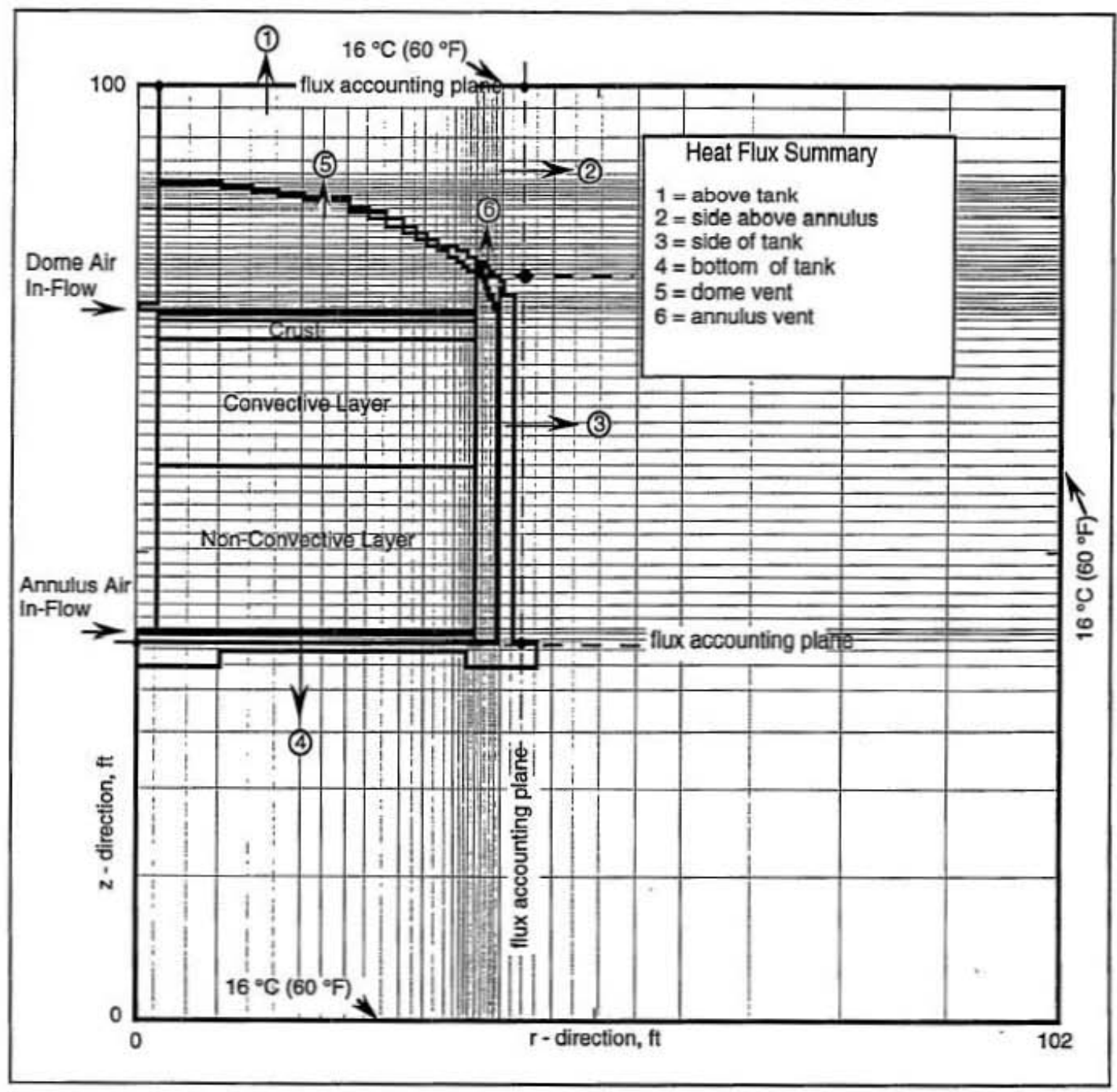

Figure 4-1. TEMPEST DST Model Configuration

\subsubsection{GOTH_SNF Model}

Crea, Sathyanarayana, and Ogden (2000) used the GOTH_SNF code to analyze the ability of the dome space and annulus ventilation systems to control the waste temperature during and following tank mixing. The GOTH model incorporates lumped-parameter and distributed parameter volumes, heat conductors, and flow and pressure boundary conditions to provide a one-dimensional model of tanks 241-AY-102 and 241-AZ-102. The GOTH_SNF model is shown in Figure 4-2, including the heat transfer volumes named below. Specific features of the model include:

- The tank volume is a distributed parameter volume with a 1-D (vertical) model of the waste, supernatant liquid, and the dome space (Volume 1s).

- The waste is modeled with eight sub-volumes, the supernatant with multiple sub-volumes, and the dome with one sub-volume.

- Evaporation from the liquid is accounted for in the dome space. 


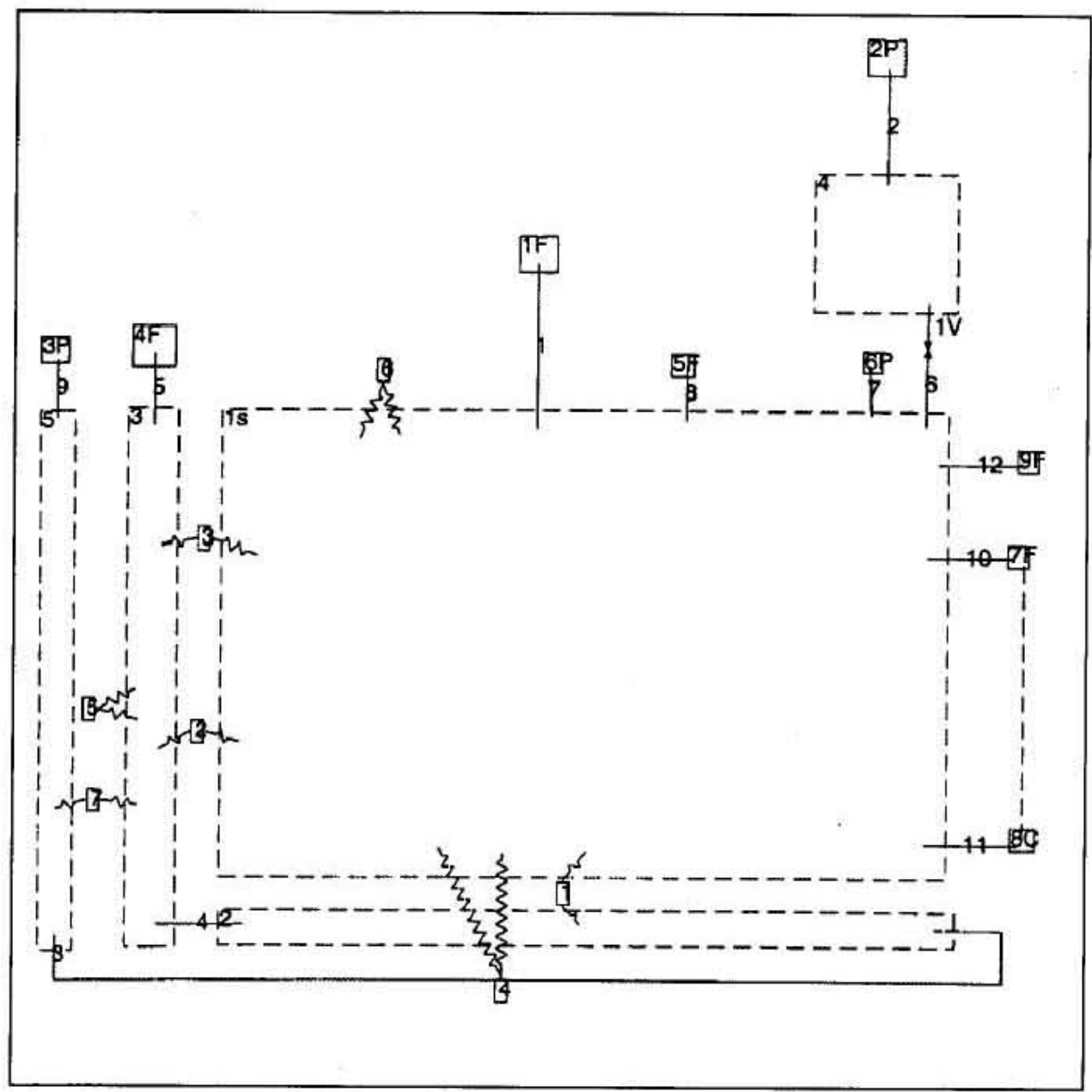

Figure 4-2. GOTH_SNF DST Model Configuration

- Convective heat transfer in the air flowing under the floor (lumped parameter, Vol. 2).

- Convective heat transfer in the air flowing in the annulus (distributed parameter, Vol. 3 ).

- Inlet annulus piping (Vol. 5).

- Downstream piping from the primary ventilation system (Vol. 4).

- Soil above the tank (1-D Thermal conductor 6).

- Soil surrounding the tank (Thermal tube conductor 5).

- Soil below the tank, $200 \mathrm{ft}$. (1-D Thermal conductor, 4).

- Steel tank bottom (1-D Thermal conductor, 1).

- Primary steel tank wall below waste surface (1-D Thermal conductor, 2).

- Primary steel tank wall above waste surface (1-D Thermal conductor, 3 ).

There is no mention of simulating radiation effects within the GOTH SNF model. Also, the model does not differentiate between the surrounding soil and the concrete. 
RPP-RPT-28967, Rev. 2

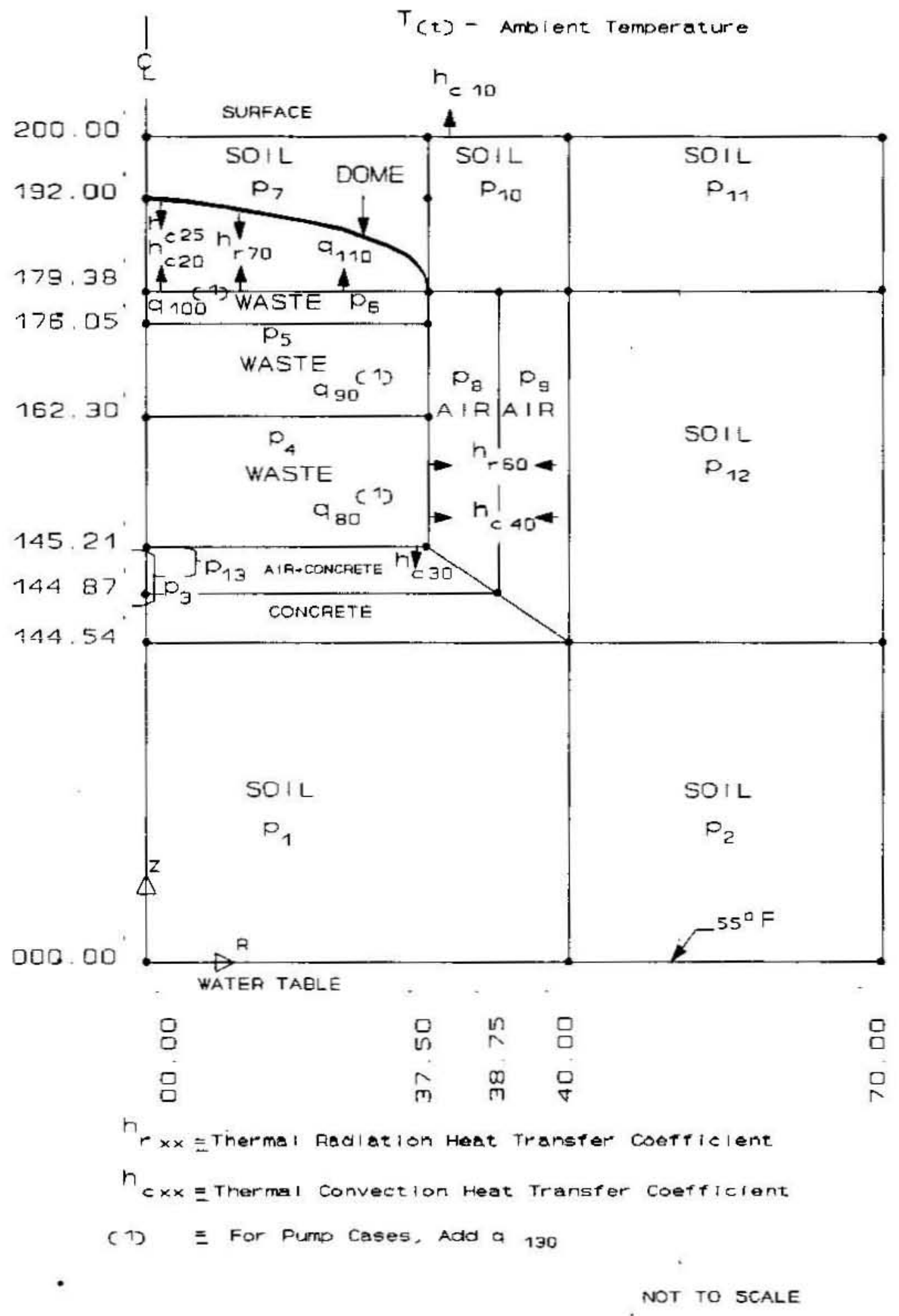

Figure 43. P/THERMAL DST Model Configuration 


\subsubsection{P/THERMAL Model}

Beaver et al. (1993) describes a DST thermal model that was developed using the P/THERMAL code to predict the average waste temperatures in tank 241-SY-101 over the 13-year operating period of the tank. The model was also used to evaluate four different combinations of tank ventilation and mixer pump operations to arrest the continued cool down of the tank waste. A relatively simple 2-D axisymmetric model (Figure 4-3) was used with the following features:

- The steel walls of the tank and surrounding concrete structure were not modeled because 1) the wall thicknesses and associated temperature drops are small and 2) the controlling thermal resistances were determined to be in the waste, the air spaces, and the surrounding soil.

- The insulating concrete pad was modeled including the annulus ventilation flow channels.

- The annular air space between the primary and secondary tanks was modeled.

- The tank dome space was also modeled.

- The tank waste was treated as three separate layers each with differing thermal heat generation rates and material properties.

- The conductivity of the crust and non-convecting layers were varied with time to match the recorded temperature history for tanks 241-SY-101.

- Heat flux between the primary and secondary tank walls was modeled as a combination of natural convection and thermal radiation.

- Heat loss through the bottom of the tank is modeled as conduction through the insulating concrete pad and convection to the air distribution slots.

- Heat loss from the surface of the waste includes convection, radiation (emissivity $=0.85$ ), and evaporation.

- A progressive tank filling model was calibrated against measured temperatures between April 1977 and November 1980 to establish the baseline soil and waste temperatures and improve the accuracy of the temperature predictions in the later years of operation.

\subsubsection{Summary of the Previous DST Thermal Models and the Objectives of the Buckling Analysis}

Several similarities exist between the above thermal modeling studies even though different analysis methods were used.

- The objective of each study was to predict the temperature distribution in the waste rather than in the tank structure. 
- The tank structure and the surrounding soil were included in the model to approximate the distribution of thermal mass and thermal resistance to better predict the waste temperature variation.

- The GOTH_SNF and P/Thermal models used a distributed heat flux in the waste whereas the TEMPEST model used a prescribed waste temperature history as the heat source.

- The waste was simulated in layers with different thermal and heat generation properties in order to better predict the measured temperature distributions.

- Many different assumptions were made regarding the input parameters and the relative importance of the competing heat transfer mechanisms, decay heat, conduction, convection, and radiation.

- Each study tuned the thermal properties to best match a set of measured temperatures in the waste column.

The major difference between these features and the thermal analysis supporting the DST structural analysis is the assumed heat source. The DST Thermal and Operating Loads Analysis is based on the operational temperature limits that are imposed on the tank structural. Therefore, specified waste temperature histories are applied as the heat source rather than a waste heat generation rate. This simulates an infinite heat source at a prescribed temperature, and it significantly affects the contribution of radiation and convection heat transfer on the tank temperatures compared to applying a waste heat generation rate. This effect is particularly significant in determining the steady state temperature of the tank dome, which approaches the temperature of the waste surface.

The TEMPEST model used in the Thermal and Operating Loads analysis included an upper nonconvecting waste layer that effectively attenuated the waste surface temperature to give realistic steady state dome temperatures including the effect of radiant heat transfer. The thickness of this layer was adjusted to give the maximum dome surface temperature $\left(235^{\circ} \mathrm{F}\right)$ from the ASA Phase III Structural Analysis (Rinker et al. 2004, Chapter 4 and Appendix A). However, using the estimated boiling temperature of the aqueous waste provides a much stronger physical basis for limiting the waste surface temperature. The high concentration of dissolved material in the supernate increases the boiling temperature from $212^{\circ} \mathrm{F}$ (boiling temperature of water) to upwards of $250^{\circ} \mathrm{F}$ depending on the specific waste chemistry of each tank. Operational experience at Hanford has shown that such temperatures are needed to achieve boiling in the evaporator units used to remove water and concentrate liquid wastes. In addition, calculations were perform by a Hanford chemist (D. Place) which estimated the boiling point of a saturated sodium nitrate solution to be $246^{\circ} \mathrm{F}(67.6 \%$ weight, or $12.2 \%$ molar concentration).

\subsection{ANSYS Thermal Model}

The ANSYS DST thermal model uses the boiling temperature as a rational limit on the waste surface temperature. The model applies different temperature histories to the bulk waste and surface waste throughout the thermal transient. Additional boundary conditions on the ANSYS thermal model include:

- Radiation from the waste surface to the dome.

- Convection to the dome for a prescribed film coefficient and conservatively assuming that the convective source is equal to the temperature of the waste surface. 
- Radiation from the primary tank to the secondary tank.

- Convection from the annulus air to the primary and secondary tanks conservatively assuming the bulk temperature of the waste.

The ANSYS model does not include the air spaces (in the dome or annulus) in the finite element mesh. Therefore, convective heat transfer is included using a convective film coefficient and a convective source temperature. In addition, the thermal link elements used to simulate radiation (from the waste free surface to the dome and from the primary tank to the secondary tank) do not include convective heat transfer loads. However, since the temperatures of the radiating body and incident surfaces are nearly the same on the absolute temperature scale, the radiant heat transfer is for all purposes linear with the temperature difference and the convection can be lumped with the radiation term. Radiant heat transfer from a constant temperature source can be calculated as:

$$
\mathrm{q}_{\mathrm{rad}}=\sigma \varepsilon\left(\mathrm{T}_{\mathrm{R}}^{4}-\mathrm{T}_{\mathrm{S}}^{4}\right)
$$

Where $\sigma$ is the Stefan-Boltzmann constant $\left(2.86 \mathrm{E}-10 \mathrm{Btu} /\right.$ day-in $\left.{ }^{2}-\mathrm{R}^{4}\right), \varepsilon$ is the surface emissivity $(0.7)$, $T_{R}$ is the radiating source temperature, and $T_{S}$ is the incident surface temperature. Note that absolute temperatures $\left({ }^{\circ} \mathrm{R}\right)$ must be used when calculating radiant heat transfer. When $T_{R}$ and $T_{S}$ are similar in absolute magnitude, equation 4.1 can be accurately approximated as:

$$
\begin{aligned}
\mathrm{q}_{\mathrm{rad}} & =\sigma \varepsilon\left(4 \mathrm{~T}_{\mathrm{R}}^{3}\right)\left(\mathrm{T}_{\mathrm{R}}-\mathrm{T}_{\mathrm{S}}\right)=\mathrm{h}_{\mathrm{rad}}\left(\mathrm{T}_{\mathrm{R}}-\mathrm{T}_{\mathrm{S}}\right), \\
\mathrm{h}_{\mathrm{rad}} & =\sigma \varepsilon\left(4 \mathrm{~T}_{\mathrm{R}}^{3}\right)
\end{aligned}
$$

Assuming the maximum temperature difference corresponding to $T_{R}=350^{\circ} \mathrm{F}\left(810^{\circ} \mathrm{R}\right)$ and $T_{S}=50^{\circ} \mathrm{F}$ $\left(510^{\circ} \mathrm{R}\right)$ gives only a $5 \%$ difference between equations 4.1 and $4.2\left(T_{R}=610^{\circ} \mathrm{R}\right.$ and $T_{S}=510^{\circ} \mathrm{R}$ gives only a $1 \%$ difference). Equation 4.2 was used to estimate the magnitude of the radiant heat transfer coefficient, $h_{\text {rad }}$, compared to the similar convective film coefficient, $h_{c}$. The surface emissivity, $\varepsilon$, was then scaled up in the ANSYS thermal model to account for both radiation and convection in the radiation term. This conservatively assumes that the convecting air temperature is equal to the radiating source temperature. In the tank analysis this means that the dome air is assumed to be equal to the waste surface temperature. In the annulus it means that the air temperature is equal to the primary tank wall temperatures. The primary wall temperature is equal to the bulk waste temperature at elevations below the free surface of the waste and it decreases toward the dome surface temperature at elevations above the waste.

Assuming $T_{R}=250^{\circ} \mathrm{F}\left(710^{\circ} \mathrm{R}\right)$ in the dome gives $h_{\text {rad }}=0.286 \mathrm{Btu} / \mathrm{day}-\mathrm{in}^{2}-^{\circ} \mathrm{R}$. The TEMPEST model

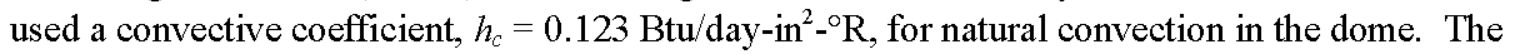
convective coefficient is about $43 \%$ of the radiant heat transfer coefficient. Therefore, the emissivity was increased by a factor of 1.4 to include the effect of dome space natural convection in the radiant heat transfer analysis.

Similarly, assuming $T_{R}=350^{\circ} \mathrm{F}\left(810^{\circ} \mathrm{R}\right)$ in the annulus gives $h_{\text {rad }}=0.425 \mathrm{Btu} /$ day-in ${ }^{2}{ }^{\circ} \mathrm{R}$. The TEMPEST model used a convective coefficient, $h_{c}=0.168 \mathrm{Btu} /$ day-in ${ }^{2}-{ }^{\circ} \mathrm{R}$, to represent forced convection in the annulus. This convective coefficient is about $40 \%$ of the radiant heat transfer coefficient. Therefore, the emissivity of the annulus surfaces was also increased by a factor of 1.4 to include the effect of forced convection in the annulus. Note that the adjusted emissivities should be recalculated for other temperature transients. 
RPP-RPT-28967, Rev. 2

\subsection{Comparison of the ANSYS and TEMPEST Results}

The ANSYS temperature predictions were compared with the TEMPEST results from the DST Thermal and Operating Loads Analysis to confirm the accuracy of the ANSYS modeling approach and to quantify the differences in the temperature and resulting stress distributions. The thermal properties recommended by Rinker et al. (2004) were used in the previous TEMPEST model and also in the current ANSYS analysis.

Figure 4-4 shows the temperature transient that was applied to the bulk waste in contact with the primary tank wall. Figure 4-4 also shows that the waste surface temperature was defined to follow the bulk waste temperature until the limiting surface temperature of $222^{\circ} \mathrm{F}$ was reached. This temperature limit gave the same temperature of the dome center as did the TEMPEST model. Figure 4-5 shows a temperature contour plot of the TEMPEST results as they were mapped onto the ANSYS structural model in the Thermal and Operating Loads Analysis. This is the steady state temperature distribution for the design basis transient. Figure 4-6 shows the steady state temperature distribution predicted with the ANSYS model. Comparing Figures 4-5 and 4-6 shows that the temperature distributions are very similar. Figure 4-7 shows a larger view of the near field temperature zone around the tank. Figure 4-8 shows the temperature distribution that is predicted when the waste level is reduced to 144 -inches.

Temperature path plots around the inside and outside surfaces of the concrete tank were also developed to provide a 1:1 comparison of the ANSYS and TEMPEST results. Figure 4-9 compares the TEMPEST and ANSYS temperature predictions along the inside surface of the concrete tank structure. The steady state condition at the maximum waste temperature of $350^{\circ} \mathrm{F}$ was again used for the comparison because this determines the maximum expected concrete degradation and creep. The ANSYS temperatures are slightly higher than the TEMPEST predictions everywhere except in the outer radius of the dome and haunch where they are about $20^{\circ} \mathrm{F}$ lower. The dome-to-haunch region is also where the mapping of the TEMPEST results onto the ANSYS mesh was more approximate. Figure 4-10 shows a similar plot of the outside surface temperatures. The ANSYS temperatures are again slightly higher than the TEMPEST values except at the very center of the dome.

Also of importance are the resulting meridional stresses in the primary tank wall because they determine the buckling response of the tank. In this case, the maximum stresses do not occur at the maximum steady state temperature condition, but rather during the increasing temperature part of the transient. In the buckling analysis in Rinker et al. (2004) the maximum compressive stresses in the tank occur in the analysis step designated $\mathrm{H} 4$ - just before the waste initially reaches the maximum temperature of $350^{\circ} \mathrm{F}$. Figure 4-11 shows that the temperatures from the ANSYS model produce a meridional stress distribution in the tank wall that is only slightly higher (about $60 \mathrm{psi}$ compression). This shows that the ANSYS thermal solution results in meridional stresses that are very close to those based on the TEMPEST thermal results. 
RPP-RPT-28967, Rev. 2

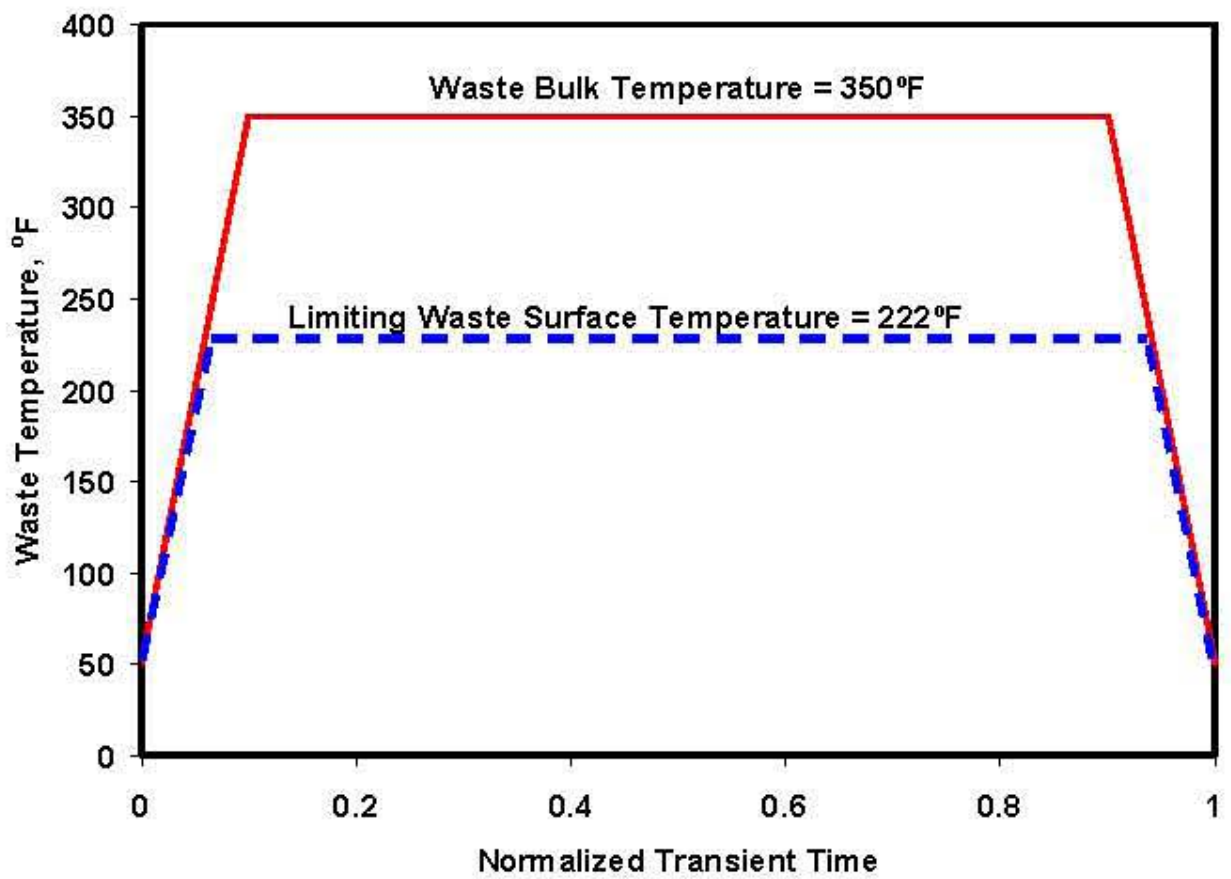

Figure 4-4. Example Waste Temperature Transient Showing the Limiting Waste Surface Temperature

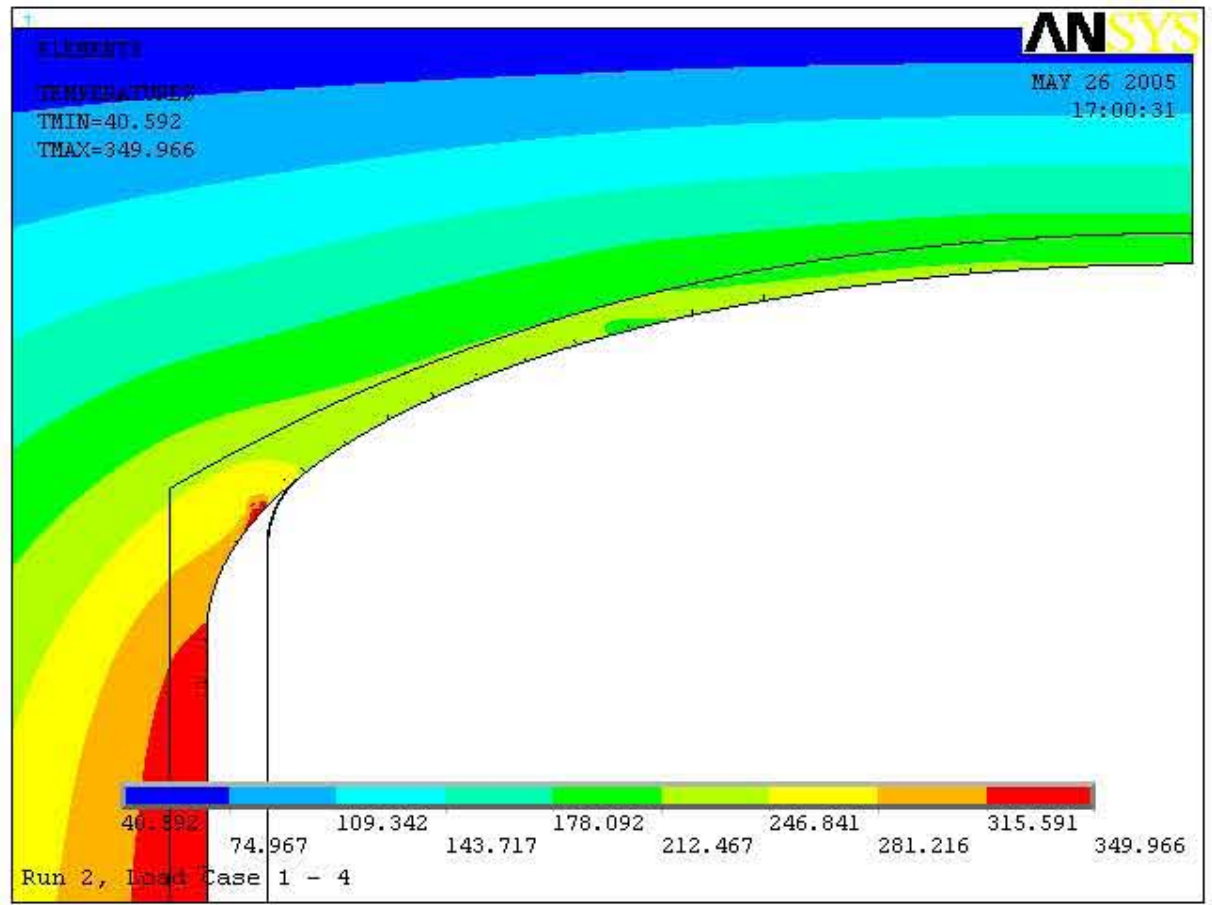

Figure 4-5. TEMPEST Temperatures Mapped onto the ANSYS DST Model (Steady State temperature solution, Waste Height $=422$ inches, Twaste $=350^{\circ} \mathrm{F}$.) 


\section{RPP-RPT-28967, Rev. 2}

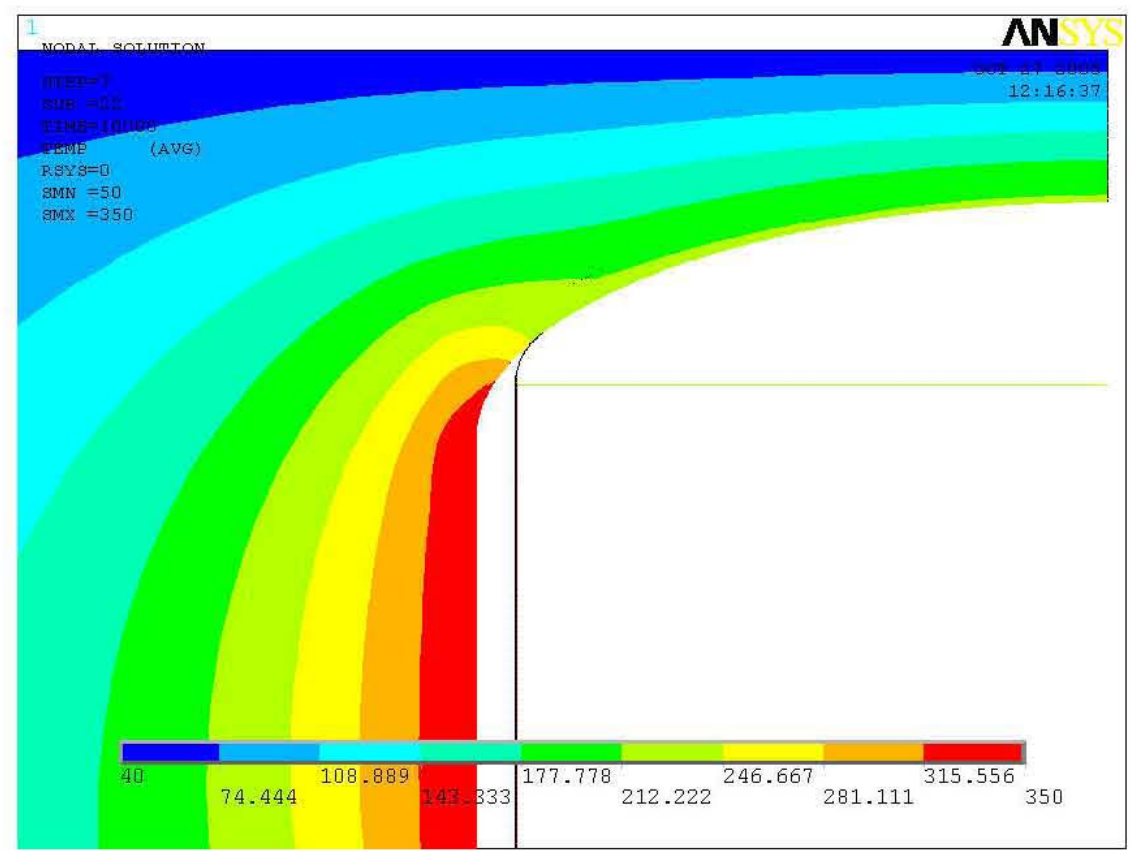

Figure 4-6. ANS YS Thermal Solution with Bulk Waste and Waste Surface Boundary Temperatures (Steady State temperature solution, Waste Height $=422$ inches, Twaste_bulk $=350^{\circ} \mathrm{F}$, Twaste_surface $=222^{\circ} \mathrm{F}$. Maximum temperature of the dome surface $=217^{\circ} \mathrm{F}$.)

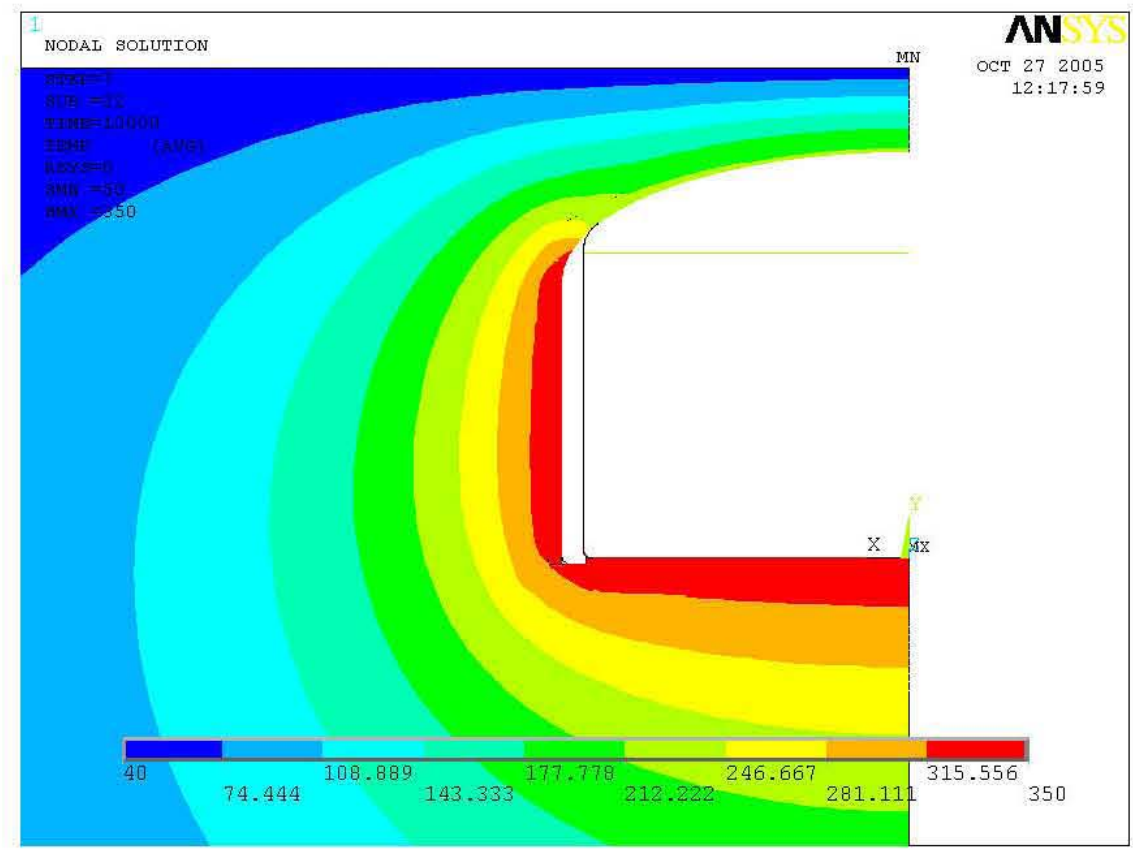

Figure 4-7. ANSYS Contour Plot Showing Temperatures Around and Beneath the Tank for a Waste Depth of 422 Inches (Bulk waste and waste surface boundary temperatures applied. Steady State, Twaste_bulk $=350^{\circ} \mathrm{F}$, Twaste_surface $=222^{\circ} \mathrm{F}$. Maximum temperature of the dome surface $=217^{\circ} \mathrm{F}$.) 


\section{RPP-RPT-28967, Rev. 2}

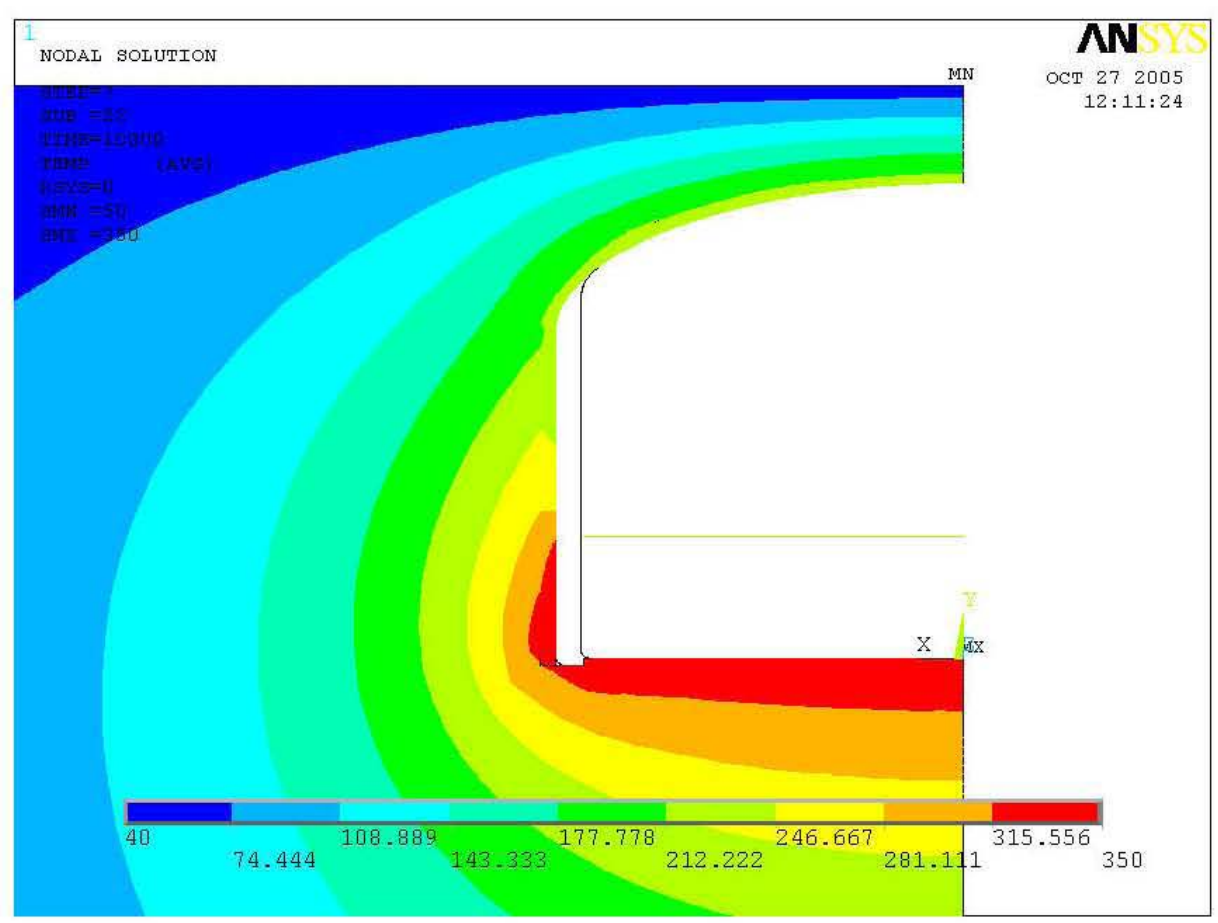

Figure 4-8. ANSYS Contour Plot Showing Temperatures Around and Beneath the Tank for a Waste Depth of 144 Inches (Bulk waste and waste surface boundary temperatures applied. Steady State, Twaste_bulk $=350^{\circ} \mathrm{F}$, Twaste_surface $=222^{\circ} \mathrm{F}$. Maximum temperature of the dome surface $=229^{\circ} \mathrm{F}$.)

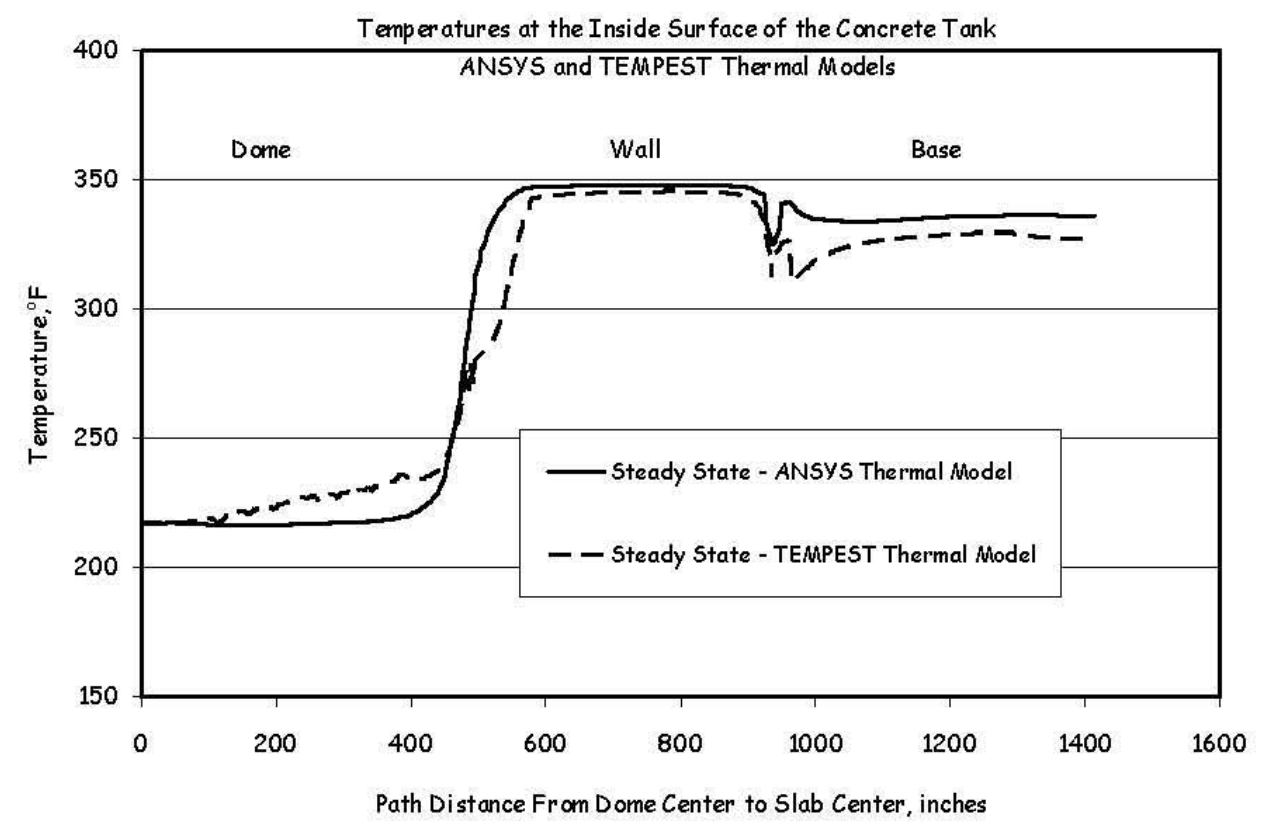

Figure 4-9. Comparison of the TEMPEST and ANSYS Temperature Predictions at the Inside Surface of the Concrete Tank (Steady State, Twaste_bulk $=350^{\circ} \mathrm{F}$, Twaste_surface $=222^{\circ} \mathrm{F}$. Temperature at the inside dome center $=244^{\circ} \mathrm{F}$.) 
RPP-RPT-28967, Rev. 2

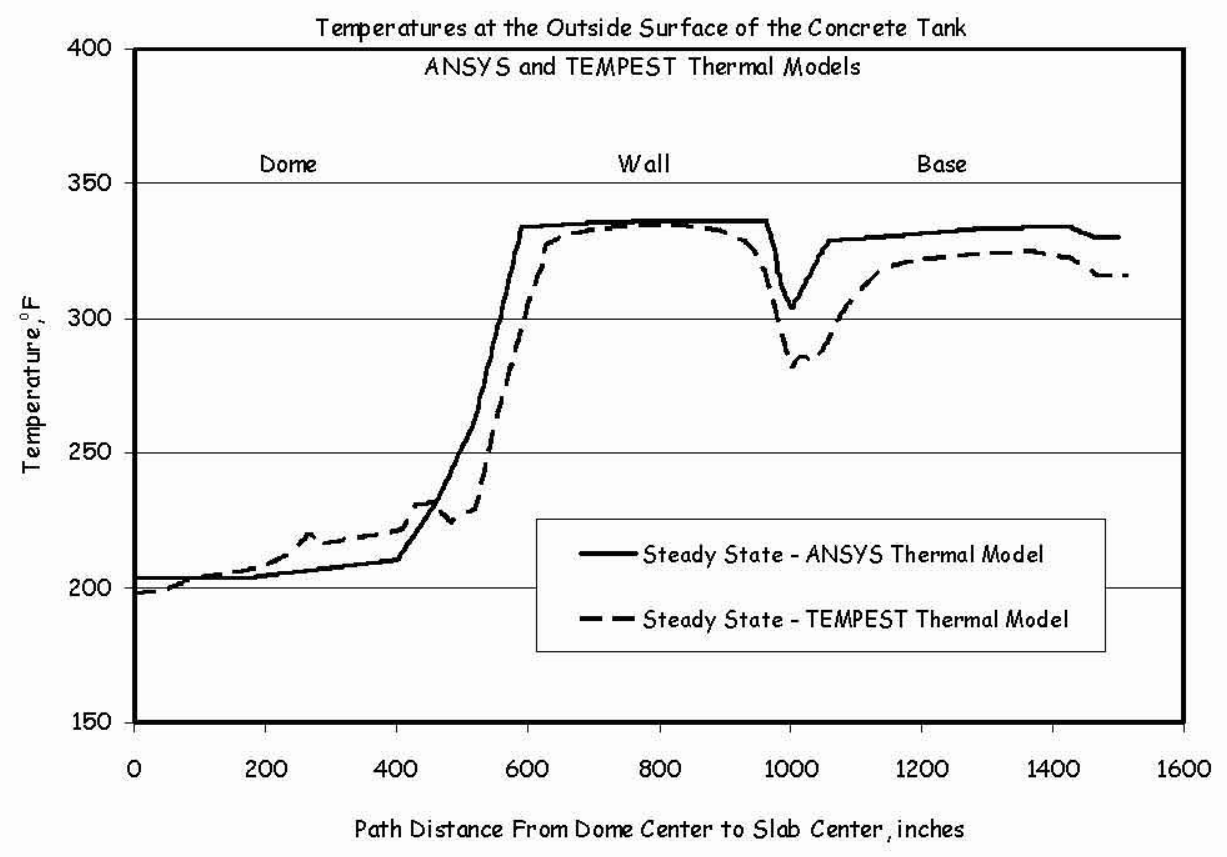

Figure 4-10. Comparison of the TEMPEST and ANSYS Temperature Predictions at the Outside Surface of the Concrete Tank (Steady State, Twaste bulk $=350^{\circ} \mathrm{F}$, Twaste surface $=222^{\circ} \mathrm{F}$. Temperature at the outside dome center $=244^{\circ} \mathrm{F}$.)

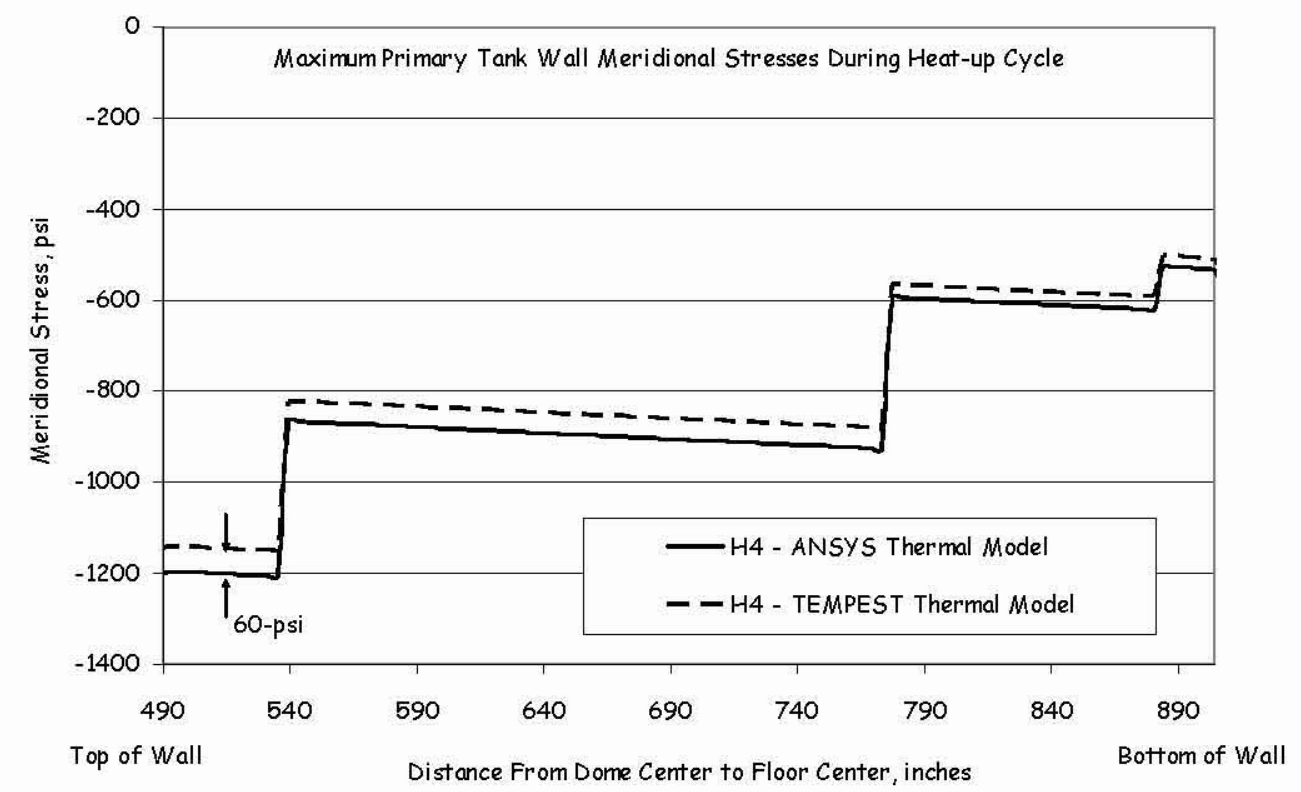

Figure 4-11. Comparison of Maximum Meridional Membrane Stresses During Heatup for the TEMPEST and ANSYS Temperature Distributions (Maximum stresses occur at heatup cycle H4.) 
RPP-RPT-28967, Rev. 2

\subsection{Calculated Boiling Temperatures for the Different Double-Shell Waste Tanks}

The wastes in each of the double-shell tanks have different concentrations and chemistry that determine the boiling temperature of the mixture. Therefore, it is important to use an appropriate boiling temperature limit for each of the different tanks. Appendix B of Ogden et al. (2002) provides vapor pressure versus temperature data for the waste in each of the 28 tanks that can be used to estimate the saturation (boiling) temperature of each specific tank. The vapor pressure data were calculated using version 6.4 of the Environmental Simulation Program (ESP) based on the Best Basis Inventory of the waste constituents and concentration in each of the tanks. Table 4-1 provides an example of the calculated data for tank AY-101 (the data for all of the other tanks are listed in Ogden et al. (2002) Appendix B).

Table 4-1. Example Vapor Pressure Data from Ogden et al. (2002) for Tank AY-102

\begin{tabular}{|c|c|c|c|c|}
\hline \multicolumn{4}{|c|}{ Tank AY-102 } & \multirow[b]{2}{*}{ Major Solids } \\
\hline \multirow{2}{*}{$\begin{array}{c}T \\
\text { deg-C }\end{array}$} & \multirow{2}{*}{$\begin{array}{c}\text { Waste } \\
\text { Pvapor } \\
\text { atm }\end{array}$} & \multirow{2}{*}{$\begin{array}{c}\mathrm{H}_{2} \mathrm{O} \\
\text { Pvapor } \\
\text { atm }\end{array}$} & \multirow{2}{*}{$\begin{array}{c}\text { Solid } \\
\text { Density } \\
\mathrm{Kg} / \mathrm{L}\end{array}$} & \\
\hline & & & & (weight Fraction) \\
\hline 25 & 0.0301 & 0.0313 & 3.013 & NALACO3OH2 (0.346), FEOOH (.339), ALOH3 (.171) \\
\hline 40 & 0.0699 & 0.0729 & 3.011 & NALACO3OH2 (0.350), FEOOH (.338), ALOH3 (.162) \\
\hline 55 & 0.1489 & 0.1555 & 3.008 & NALACO3OH2 (0.357), FEOOH (.337), ALOH3 (.153) \\
\hline 70 & 0.2943 & 0.3078 & 3.004 & NALACO3OH2 (0.366), FEOOH (.337), ALOH3 (.143) \\
\hline 85 & 0.5449 & 0.5707 & 3.000 & NALACO3OH2 (0.378), FEOOH (.339), ALOH3 (.131) \\
\hline 100 & 0.9535 & 1.0002 & 3.001 & NALACO3OH2 (0.397), FEOOH (.340), ALOH3 (.111) \\
\hline
\end{tabular}

The boiling temperature was estimated as the temperature at which the vapor pressure is $1.00 \mathrm{~atm}$. However, the vapor pressure calculations presented in Ogden et al. only go to $100^{\circ} \mathrm{C}$ where the waste vapor pressure is somewhat less than 1.00 . Therefore, the data were curve fit and the curve was extrapolated to estimate the boiling temperature of the waste at atmospheric pressure. Figure 4-12 shows this procedure for the Tank AY-102 data, where the boiling temperature was estimated to be $102^{\circ} \mathrm{C}$ $\left(216^{\circ} \mathrm{F}\right)$. This procedure was carried out for all 28 tanks, resulting in the estimated boiling temperatures listed in Table 4-2. Table 4- 2 shows that the estimated boiling temperature of $216^{\circ} \mathrm{F}$ for $\mathrm{AY}-102$ is higher than that of AY-101 and it is less than the limiting waste surface temperature $\left(222^{\circ} \mathrm{F}\right)$ that was used to reproduce the TEMPEST results from the Thermal and Operating Loads analysis. The $222^{\circ} \mathrm{F}$ limiting waste surface temperature is recommended for the bounding waste tank calculations to be consistent with the previous work. Other analyses of specific tanks should use the values in Table 4-2. 
RPP-RPT-28967, Rev. 2

Table 4-2. Estimated Boiling Temperature for the 28 Double-Shell Tanks

\begin{tabular}{|c|c|c|c|c|c|c|}
\hline \hline No & Tank & Boiling Temp, $^{\mathbf{0}} \mathbf{F}$ & & No & Tank & Boiling Temp, F \\
\hline \hline 1 & AN-101 & 225 & & 15 & AP-108 & 217 \\
\hline 2 & AN-102 & 230 & & 16 & AW-101 & 253 \\
\hline 3 & AN-103 & 234 & & 17 & AW-102 & 220 \\
\hline 4 & AN-104 & 229 & & 18 & AW-103 & 219 \\
\hline 5 & AN-105 & 244 & & 19 & AW-104 & 217 \\
\hline 6 & AN-106 & 235 & & 20 & AW-105 & 217 \\
\hline 7 & AN-107 & 230 & & 21 & AW-106 & 226 \\
\hline 8 & AP-101 & 226 & & 22 & AY-101 & 214 \\
\hline 9 & AP-102 & 223 & & 23 & AY-102 & 216 \\
\hline 10 & AP-103 & 212 & & 24 & AZ-101 & 221 \\
\hline 11 & AP-104 & 223 & & 25 & AZ-102 & 217 \\
\hline 12 & AP-105 & 226 & & 26 & SY-101 & 230 \\
\hline 13 & AP-106 & 216 & & 27 & SY-102 & 220 \\
\hline 14 & AP-107 & 213 & & 28 & SY-103 & 242 \\
\hline
\end{tabular}

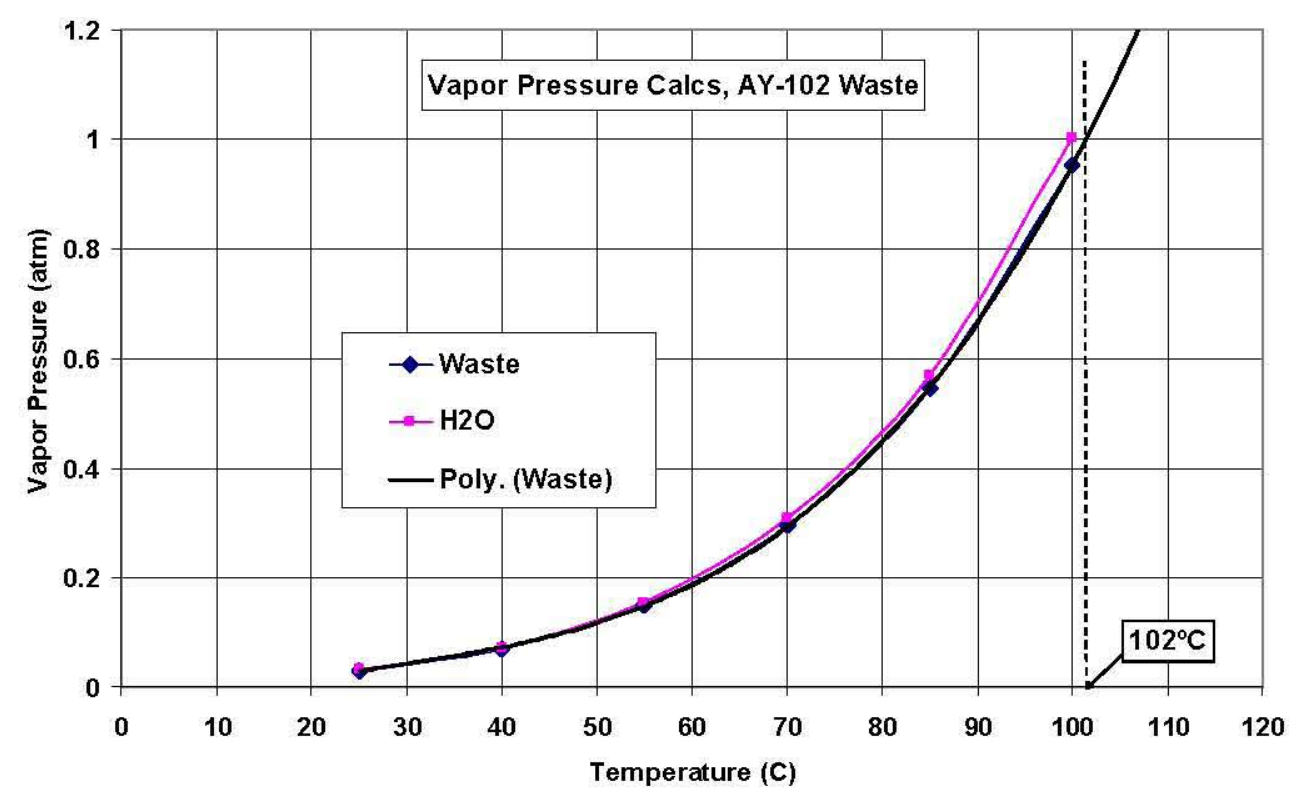

Figure 4-12. Vapor Pressure Data Used to Estimate the Boiling Temperature of Different Tank Wastes (The data for Tank AY-102 is shown.) 


\subsection{Influence Functions for Calculating the Applied Axial Force on the Primary Tank Wall}

This chapter presents influence functions that were developed to estimate the applied axial force in the primary tank wall, which is required for evaluating buckling of the primary tank. The DST thermal model (Chapter 4) was run to provide temperature distributions in the steel and concrete tank and the surrounding soil for different combinations of waste height and temperature. The temperature distributions were then applied to the DST structural model to calculate the axial force due to differential thermal expansion. A matrix of different waste heights and temperatures was simulated that covers the tank operating limits on waste height and temperature. The axial forces for these discrete load combinations were then curve fit to allow estimating the thermal expansion force for intermediate waste heights and temperatures. The axial force contributions from other applied loads were also evaluated, giving the total axial force as the sum of the following loads:

- Differential thermal expansion,

- Gravity,

- Surface loads,

- Concrete thermal degradation and creep,

- Seismic excitation, and the

- Effect of hydrostatic waste pressure on the confined axial force.

The baseline DST finite element model (Rinker et al. 2004) was used in the current study. (The input files for both the ANSYS thermal and structural models are listed in Appendix C.) Table 5-1 lists the loading conditions for this model. Two general classes of DST tanks were simulated: the AY tank and the AP tank. Although the baseline model was constructed using the specific dimensions of the AY tank, it also applies to the $\mathrm{AZ}, \mathrm{SY}, \mathrm{AW}$, and $\mathrm{AN}$ primary tanks since they have similar geometry and wall thickness distributions. Table 1-1 shows that the AP primary tank wall is somewhat thicker than the others in the upper section of the tank. Because the scope of the current study did not allow for constructing specific models of each different tank design, the AP tank was approximated by substituting the AP wall thickness distribution into the baseline model. This approximation is reasonable because the primary tank is the focus of the buckling analysis and the significant influence of the massive concrete over-structure and the surrounding soil is to confine the vertical displacement of the primary tank dome. The axial stiffness of the AP primary tank is only about $1 \%$ of the axial stiffness of the concrete tank walls.

Table 5-1. Load Conditions for the Baseline DST Analysis

\begin{tabular}{|l|l|l|}
\hline \multicolumn{1}{|c|}{ Design Load } & \multicolumn{1}{c|}{ Value } & \multicolumn{1}{c|}{ Notes } \\
\hline Design Life & $>50$ years & A 60-year design life is used. \\
\hline Maximum Corrosion Rate & $1 \mathrm{mil} / \mathrm{yr}$ & $\begin{array}{l}\text { A total corrosion allowance of } 0.060 \text { inch is applied to the } \\
\text { specified nominal thicknesses. }\end{array}$ \\
\hline Soil Cover & $8.5 \mathrm{ft} @, 125 \mathrm{lb} / \mathrm{ft}^{3}$ & Relative to dome apex. \\
\hline Concrete Density & $145 \mathrm{lb} / \mathrm{ft}^{3}$ & Average including reinforcements \\
\hline Surface Live Load & $40 \mathrm{lb} / \mathrm{ft}^{2}$ & Uniform over the dome \\
\cline { 2 - 4 } & $200,000 \mathrm{lb}$ & Concentrated \\
\hline
\end{tabular}




\subsection{Axial Compression in the Primary Tank Wall Due to Concrete Thermal Degradation and Creep}

Analytical models that describe the creep compliance and modulus degradation with time and temperature are given in Rinker et al. (2004) for the concrete used in the double-shell waste tanks. The creep compliance, $\mathrm{J}$, is modeled as a function of time and temperature as:

$$
\mathrm{J}(\mathrm{T}, \mathrm{t})=\varphi(\mathrm{T}) \mathrm{C}(\mathrm{t})
$$

where $C(t)$ is the specific creep function versus time, and $\varphi(T)$ adjusts the time dependency for temperature. A four-term exponential series describes the creep compliance as:

$$
C(t)=0.1936\left(1-e^{-0.069 t}\right)+0.280\left(1-e^{-0.0069 t}\right)+0.375\left(1-e^{-0.00069 t}\right)+0.348\left(1-e^{-0.000069 t}\right)
$$

where time, $\mathrm{t}$, is in days and $C(t)$ is in units of $10^{-6} \mathrm{in} / \mathrm{in}$ per $\mathrm{lbf} / \mathrm{in}^{2}$. The temperature shift is given by:

$$
\varphi(T)=226.09-0.00429 \mathrm{~T}+147.52 \mathrm{~T}^{-0.367}-309.26 \mathrm{~T}^{-0.044}
$$

where $\mathrm{T}$ is temperature in ${ }^{\circ} \mathrm{F}$ and $\varphi(T)$ is a unitless scaling factor.

The elastic modulus is described by the following equation:

$$
\mathrm{E}=5.3947+0.1233 \mathrm{~S}-0.006751 \mathrm{~T}-0.1786 \ln (\mathrm{t}+1) \mathrm{I}+\mathrm{E}_{\mathrm{b}}
$$

where: $\mathrm{E}=$ modulus of elasticity $\left(10^{6} \mathrm{psi}\right)$

$\mathrm{S}=$ nominal 28-day compressive strength (ksi), (valid range is $3 \leq \mathrm{S} \leq 4.5$ )

$\mathrm{T}=$ temperature $\left({ }^{\circ} \mathrm{F}\right)$

$\mathrm{t}=$ time at constant temperature (days)

I $=0$ for $\mathrm{T} \leq 200^{\circ} \mathrm{F}$

$=(\mathrm{T}-200) / 50$ for $200^{\circ} \mathrm{F}<\mathrm{T}<250^{\circ} \mathrm{F}$

$=1$ for $\mathrm{T}>250^{\circ} \mathrm{F}$

$\mathrm{E}_{\mathrm{b}}=$ uncertainty band width for modulus $\left(10^{6} \mathrm{psi}\right)$

$=0.00$ for best fit

$=+/-0.26$ for $95 \%$ confidence band

$=+/-0.76$ for $95 / 95 \%$ tolerance band

The equation for the modulus degradation with increasing temperature is:

$$
\mathrm{F}(\mathrm{T})=-0.39157 \ln (\mathrm{T})+2.80192
$$

The mean elastic modulus at $\mathrm{T}=100^{\circ} \mathrm{F}$ is used as the undegraded modulus, which is then scaled down for higher temperatures using the degradation factor, $F(T)$.

These models were used in spreadsheet calculations to estimate the compression in the primary tank due to creep and modulus degradation. The spreadsheet calculates the average compressive stress in the wall of the tank due to the weight of the tank walls, dome, overburden soil, and the surface loads. The tank 
wall is then separated into sections above and below the waste surface. The creep and modulus degradation below the waste surface is calculated assuming that the concrete tank is at the maximum waste temperature. The similar quantities above the waste surface are calculated assuming that the concrete tank is at the maximum estimated waste surface temperature. The surface temperature is limited to the estimated boiling temperature of the supernate $\left(222^{\circ} \mathrm{F}\right)$. The results of the ANSYS thermal models in Chapter 4 show that this is a reasonable approximation of the steady state temperature distribution in the concrete tank walls. The creep strains were calculated as the creep compliance times the applied stress. The strain due to modulus degradation was calculated as the applied stress divided by the undegraded modulus minus the stress divided by the degraded modulus. The foreshortening of the tank walls was then calculated as the individual strain components (for the creep and modulus reduction effects above and below the waste surface) times the height of the wall sections above and below the waste surface, respectively. Finally, the force in the tank wall was calculated using the tank axial stiffnesses that were calculated in Chapter 3 from the finite element models. Table 5-2 shows an example of the creep and thermal degradation calculations.

The axial compression due to concrete thermal degradation and creep is a function of each tank's operating history. Therefore, the available operating data were reviewed to define appropriate values of maximum waste height and temperature that bound the operating histories for each tank. Table 5-3 lists these tank-specific values along with the axial forces resulting from creep and thermal degradation (assuming a 60-year operating history and 0.060 inch corrosion). The forces due to modulus degradation are only $2 \%$ to $6 \%$ of the creep forces. The forces calculated for the AP tank are higher (for a specific temperature) because the axial stiffness of the AP primary tank is about $50 \%$ higher than the thinner AY tank. The values in Table 5-3 are of similar magnitude to previous results summarized in Table 3-12 of Rinker et al. (2004) from the Phase III analysis. The Phase III analysis showed the change in the primary tank axial stress with and without creep to be about $233 \mathrm{psi}$ ( $233 \mathrm{psi}$ times the average wall thickness of 0.5 inch $=0.117 \mathrm{kip} / \mathrm{inch}$ ) for the AY primary tank design. 
Table 5-2. Example Creep and Thermal Degradation Calculations

\begin{tabular}{|c|c|c|c|c|c|c|c|}
\hline \multicolumn{8}{|c|}{ Creep and Thermal Degradation of Concrete } \\
\hline \begin{tabular}{|l|l|} 
Tank height & \\
\end{tabular} & & & 460 & inches & & & \\
\hline \multicolumn{2}{|l|}{ Concrete Tank Thickness = } & & 18 & inches & & & \\
\hline \multicolumn{2}{|l|}{\begin{tabular}{|l|l|} 
Steel Modulus & \\
\end{tabular}} & & $2.80 \mathrm{E}+07$ & psi & & & \\
\hline & & & & & & & \\
\hline \multicolumn{8}{|l|}{ Load on Concrete Wall } \\
\hline Soil & & & 5613506 & & & & \\
\hline \multicolumn{8}{|c|}{980673} \\
\hline \multicolumn{8}{|l|}{$1 / 2$ Wall Weight } \\
\hline \multicolumn{8}{|l|}{ Surface Load } \\
\hline \multicolumn{8}{|l|}{$\begin{array}{l}\text { Concentrated Load } \\
\text { Total Load }\end{array}$} \\
\hline Total Load & & & 8116624 & $\mathrm{Ib}$ & & & \\
\hline \\
\hline Wall Area & & & 55305 & inch $^{\wedge} 2$ & & & \\
\hline \multicolumn{8}{|l|}{ Axial Stress in concrete } \\
\hline \multirow{2}{*}{\multicolumn{8}{|c|}{ Max Waste Temp, F }} \\
\hline & & & & & & & \\
\hline \multicolumn{8}{|l|}{$\begin{array}{l}\text { Waste surface Temp } \\
\text { truncated to } 222 \mathrm{~F}\end{array}$} \\
\hline Waste Height, inches & & & 370 & & & & \\
\hline \multicolumn{8}{|l|}{ Life, yrs } \\
\hline & & & & & & & \\
\hline \multicolumn{2}{|l|}{ ames and Rashid Model } & Above Waste & Below Waste & & & & \\
\hline \begin{tabular}{|l|} 
Creep Compliance \\
\end{tabular} & & Surface & \begin{tabular}{|l|} 
Surface \\
\end{tabular} & & & & \\
\hline & Temp, F & 222 & 250 & & & & \\
\hline Time & $\mathrm{Xi}(\mathrm{T})=$ & 1.621 & 1.905 & & & & \\
\hline days & Time Coeff & Crp Compl & Crp Compl & & & & \\
\hline & $C(t)$ & (1E-6 in/in/psi) & (1E-6 in/in/psi) & & & & \\
\hline 21900 & 1.1198 & 1.8148 & 2.1334 & & & & \\
\hline & & & & & & & \\
\hline Height of Tank Section & & 90 & 370 & & & & \\
\hline Creep Strain, in/in & & 0.000266 & 0.000313 & & & & \\
\hline & & & & & & & \\
\hline Degraded Elastic Modult & us v.s. tempe & rature & & & & & \\
\hline $\begin{array}{r}\text { Specifie } \\
\end{array}$ & d Minimum & Strength, $\mathbf{k s i}=$ & 3 & ksi & & & \\
\hline & degraded Me & ean Modulus $=$ & 5.0895 & $10^{\wedge} 6 \mathrm{psi}$ & & & \\
\hline & & Time & 0 & days & & & \\
\hline Temp, F & $\begin{array}{l}\text { Mean } \\
\text { degrad } \\
\text { Factors }\end{array}$ & \begin{tabular}{|l|} 
Lower \\
Bound E, \\
$\left(10^{\wedge} 6 \mathrm{psi}\right)$
\end{tabular} & $\begin{array}{l}\text { Mean E, } \\
\left(10^{\wedge} 6 \mathrm{psi}\right)\end{array}$ & $\begin{array}{l}\text { Upper } \\
\text { Bound E, } \\
\left(10^{\wedge} 6 \mathrm{psi}\right)\end{array}$ & & & \\
\hline 222 & 0.686 & 2.733 & 3.493 & 4.253 & & & \\
\hline 250 & 0.640 & \begin{tabular}{r|}
2.497 \\
\end{tabular} & $\begin{array}{r}3.257 \\
\end{array}$ & 4.017 & & & \\
\hline & & \begin{tabular}{|l|} 
Above Waste \\
\end{tabular} & \begin{tabular}{|l|} 
Below Waste \\
\end{tabular} & & & & \\
\hline Modulus Reduction & & Surface & Surface & & & & \\
\hline Height of Tank Section & & 90 & 370 & & & & \\
\hline Strain, at Low Temp Modul & & $2.88 \mathrm{E}-05$ & $2.88 \mathrm{E}-05$ & & & & \\
\hline Strain, at High Temp Modu & & $4.20 \mathrm{E}-05$ & $4.51 \mathrm{E}-05$ & & & & \\
\hline \begin{tabular}{|l|l|} 
Increase in Strain \\
\end{tabular} & & $1.32 \mathrm{E}-05$ & $1.62 \mathrm{E}-05$ & & & & \\
\hline & & & & & & & \\
\hline Creep+Degrad Strain & & $2.80 \mathrm{E}-04$ & $3.29 \mathrm{E}-04$ & & & & \\
\hline Tank Foreshortening & & 0.025156708 & 0.121851475 & inch & & & \\
\hline Tank Axial Stiffmesses fron & $\mathrm{nAY}$ and $\mathrm{AP}$ & Axial Compressio & on Model & & & & \\
\hline & & & & & & & \\
\hline & & AY Stiffnesses & & & AP Stiffnesses & & \\
\hline Corrosion, & , inches $=>$ & $0.000^{\prime \prime}$ & $0.060^{\prime \prime}$ & $0.100^{\prime \prime}$ & $0.000^{\prime \prime}$ & $0.060^{\prime \prime}$ & $0.100^{\prime \prime}$ \\
\hline Axl. Stiff, (kip/inch)/ir & nch defl $=>$ & 1.8175 & 1.45 & 1.2249 & 2.5758 & 2.14896 & 1.8844 \\
\hline For & reshortening & Axial Force & Axial Force & Axial Force & Axial Force & Axial Force & Axial Force \\
\hline \begin{tabular}{|l|} 
Above Waste \\
\end{tabular} & (inch) & (kip/inch) & (kip/inch) & (kip/inch) & (kip/inch) & (kip/inch) & (kip/inch) \\
\hline Creep Force & 0.024 & 0.044 & 0.035 & 0.029 & 0.062 & 0.052 & 0.045 \\
\hline Degrad Mod. Force & 0.001 & 0.002 & 0.002 & 0.001 & 0.003 & 0.003 & 0.002 \\
\hline \begin{tabular}{|l|} 
Below Waste \\
\end{tabular} & & & & & & & \\
\hline Creep Force & 0.116 & 0.211 & 0.168 & 0.142 & 0.298 & 0.249 & 0.218 \\
\hline Degrad Mod. Force & 0.006 & 0.011 & 0.009 & 0.007 & 0.015 & 0.013 & 0.011 \\
\hline Total Creep+Degrad & 0.147 & -0.267 & -0.213 & -0.180 & -0.379 & -0.316 & -0.277 \\
\hline & & & & & & & \\
\hline Stress in 0.44 inch wall, $p s$ & & -607 & -485 & -409 & -861 & -718 & -630 \\
\hline
\end{tabular}


Table 5-3. Estimated Axial Force Due to Creep and Thermal Degradation of the Elastic Modulus for a Range of Tank Waste Temperatures and Waste Heights (The force calculations assume a 0.060 inch corrosion allowance and a 60 -year operating history.)

\begin{tabular}{|l|c|c|c|c|}
\hline \multicolumn{1}{|c|}{ Description } & $\begin{array}{c}\text { Temperature } \\
{ }^{\mathbf{F}}\end{array}$ & $\begin{array}{c}\text { Waste } \\
\text { Height, } \\
\text { Inches }\end{array}$ & $\begin{array}{c}\text { Creep } \\
\text { Axial Force } \\
\text { (kip/in) }\end{array}$ & $\begin{array}{c}\text { Modulus Degradation } \\
\text { Axial Force } \\
\text { (kip/in) }\end{array}$ \\
\hline AY Bounding Analysis & 350 & 422 & -0.295 & -0.018 \\
\hline AY Specified Limits & 350 & 370 & -0.280 & -0.017 \\
\hline AY/AZ Operating History & 250 & 422 & -0.207 & -0.011 \\
\hline SY/AW/AN Operating History & 150 & 422 & -0.092 & -0.003 \\
\hline AP Operating History & 120 & 422 & -0.083 & -0.002 \\
\hline AP Specified Limits & 210 & 422 & -0.243 & -0.011 \\
\hline
\end{tabular}

\subsection{Differential Thermal Expansion Forces for Current Operating Conditions}

Table 5-4 lists the differential thermal expansion forces for the matrix of operating conditions that were simulated for the AY primary tank geometry. Both the thermal expansion forces at the end of the heatup cycle and at the steady state temperature distribution are listed. The thermal expansion force at the end of heatup (see Figure 4-4) is generally larger than the steady state value and it is used to calculate the maximum operating force in the tank wall. This is also when the maximum thermal expansion stresses were observed in the thermal and operating loads analysis (Rinker et al. 2004). The steady state thermal expansion force is slightly lower (5\% to $10 \%)$ and it is combined with the seismic force to calculate the total applied force during faulted or abnormal conditions. The differential thermal forces during heatup are plotted in Figure 5-1 along with curve fits of the form:

$$
\mathrm{F}_{\varphi}(\mathrm{h}, \mathrm{T})=\mathbf{a}(\mathrm{T}) \mathrm{h}+\mathrm{b}(\mathrm{T})
$$

where

$$
\begin{gathered}
a(T)=-2.015 \times 10^{-9} \mathrm{~T}^{2}-1.852 \times 10^{-6} \mathrm{~T}+8.513 \times 10^{-5} \\
\mathrm{~b}(\mathrm{~T})=1.189 \times 10^{-6} \mathrm{~T}^{2}-1.191 \times 10^{-3} \mathrm{~T}+6.394 \times 10^{-2}
\end{gathered}
$$

Equation 5.6 is also used for the AY steady state thermal expansion force, but the coefficients are

$$
\begin{gathered}
a(T)=-6.877 \times 10^{-9} \mathrm{~T}^{2}+6.773 \times 10^{-7} \mathrm{~T}-2.927 \times 10^{-5} \\
\mathrm{~b}(\mathrm{~T})=2.359 \times 10^{-6} \mathrm{~T}^{2}-1.687 \times 10^{-3} \mathrm{~T}+8.458 \times 10^{-2}
\end{gathered}
$$


Figure 5-2 shows how the curve fits match the steady state forces from the finite element analysis.

Table 5-5 lists the thermal expansion forces for the analyses of the AP primary tank. For the AP thermal expansion forces at the end of the heatup cycle, the temperature dependent coefficients, $a(T)$ and $b(T)$ are:

$$
\begin{aligned}
& a(T)=2.263 \times 10^{-8} \mathrm{~T}^{2}-8.946 \times 10^{-6} \mathrm{~T}+3.908 \times 10^{-4} \\
& \mathrm{~b}(\mathrm{~T})=-8.896 \times 10^{-6} \mathrm{~T}^{2}+1.062 \times 10^{-3} \mathrm{~T}-3.087 \times 10^{-2}
\end{aligned}
$$

Table 5-4. Matrix of Waste Tank Models That were Analyzed to Estimate the Axial Thermal Expansion Forces for the AY Tank Design (The table lists the thermal expansion forces at the end of the heatup cycle and at the steady state temperature distribution.)

\begin{tabular}{||c|c|c|c|c|}
\hline & \multicolumn{5}{|c|}{ Axial Thermal Expansion Force, kips/inch of circumference } \\
\hline Waste Height & Twaste $^{\mathbf{5}} \mathbf{5 0}^{\circ} \mathbf{F}$ & Twaste $=\mathbf{1 5 0}^{\circ} \mathbf{F}$ & Twaste $=\mathbf{2 5 0} \mathbf{}^{\circ} \mathbf{F}$ & Twaste $=\mathbf{3 5 0}^{\circ} \mathbf{F}$ \\
\hline \hline \multicolumn{5}{|c|}{ Thermal expansion force at end of heatup cycle } \\
\hline 100 & 0 & -0.093 & -0.227 & -0.281 \\
\hline 200 & 0 & -0.122 & -0.278 & -0.366 \\
\hline 300 & 0 & -0.147 & -0.319 & -0.447 \\
\hline 370 & 0 & -0.168 & -0.355 & -0.503 \\
\hline \multicolumn{7}{|c|}{ Steady state thermal expansion force } \\
\hline 100 & 0 & -0.109 & -0.234 & -0.276 \\
\hline 200 & 0 & -0.117 & -0.260 & -0.339 \\
\hline 300 & 0 & -0.134 & -0.284 & -0.404 \\
\hline 370 & 0 & -0.140 & & -0.450 \\
\hline
\end{tabular}

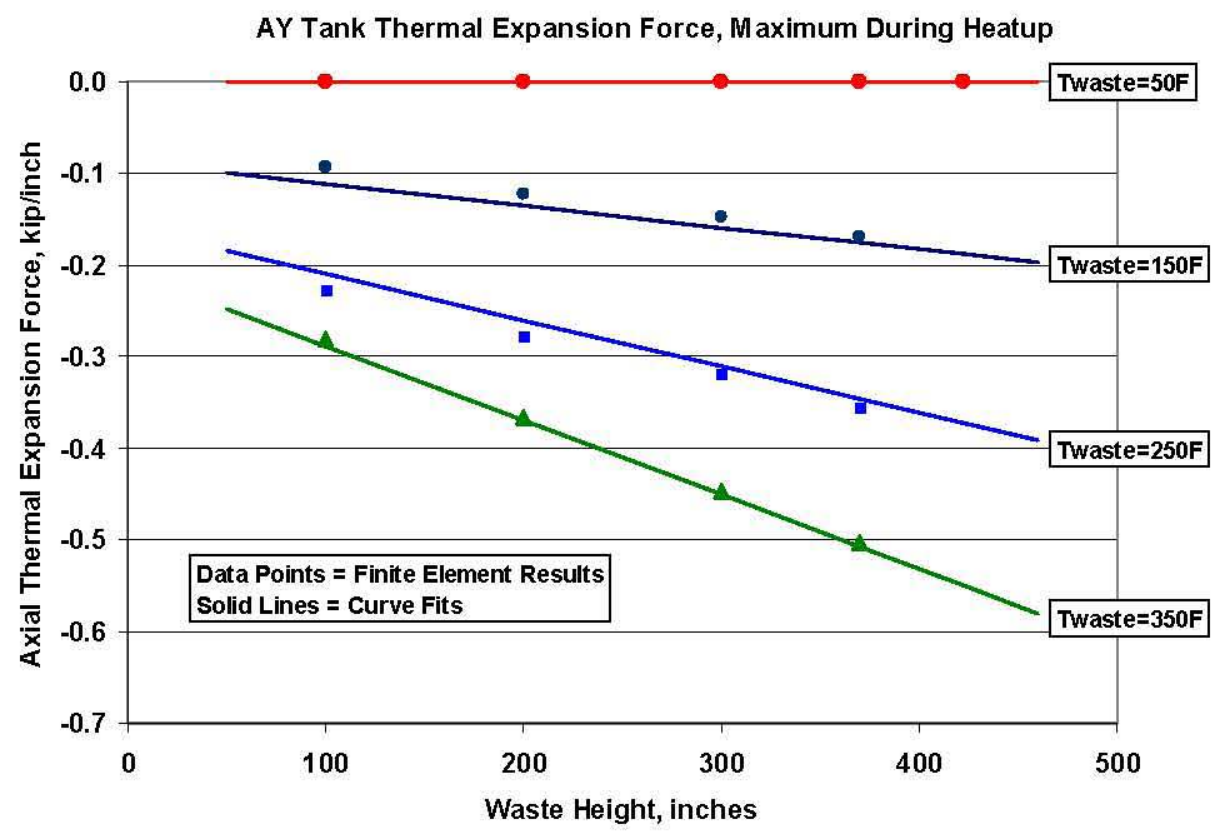

Figure 5-1. Relationship of Maximum Axial Thermal Expansion Force During the Heatup Cycle in the AY Primary Tank Wall for a Range of Waste Heights and Temperatures (The data point are the finite element results and the solid lines represent the curve fits of the data.) 
RPP-RPT-28967, Rev. 2

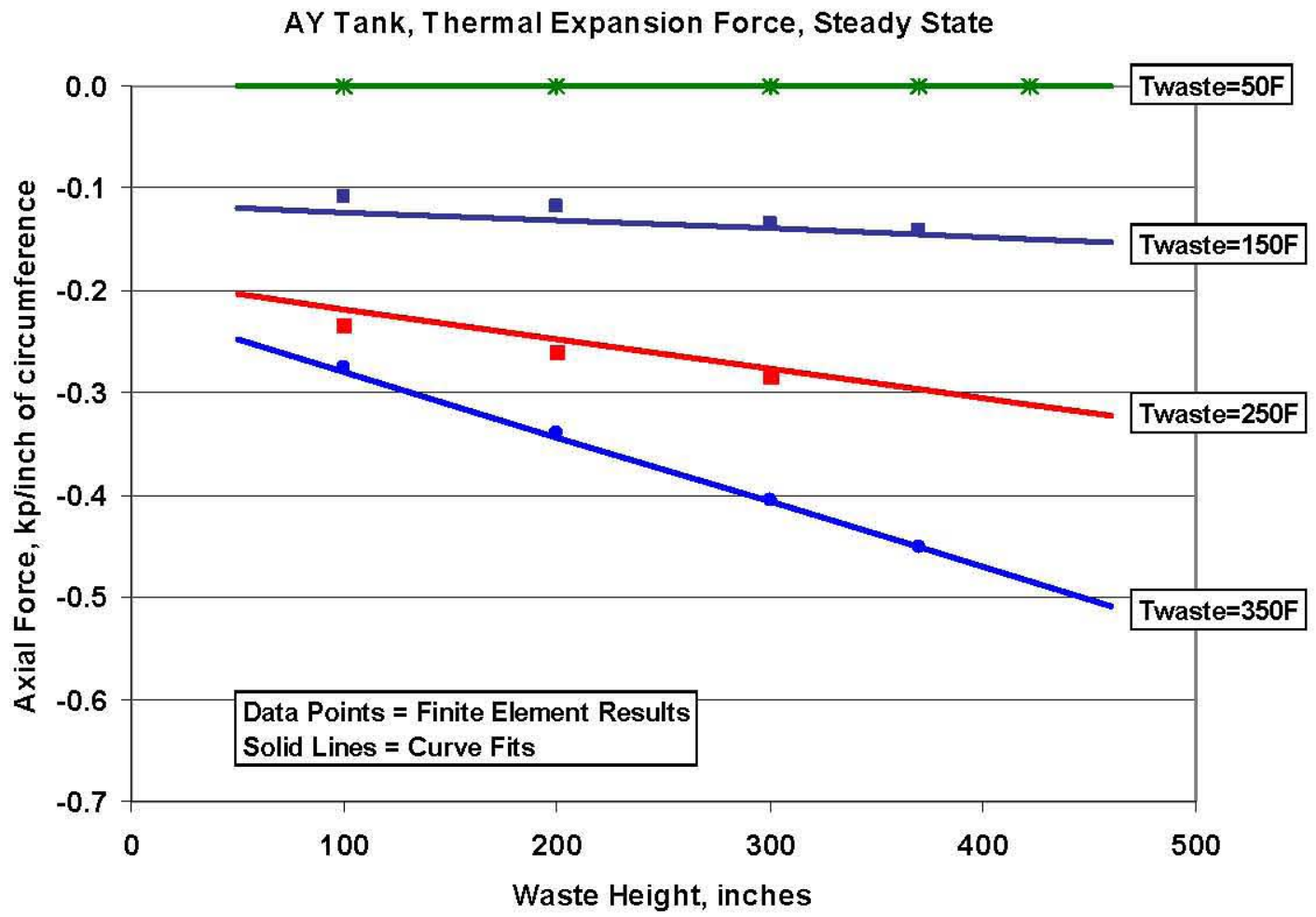

Figure 5-2. Relationship of the Steady State Axial Thermal Expansion Force in the AY Primary Tank Wall for a Range of Waste Heights and Temperatures (The data point are the finite element results and the solid lines represent the curve fits of the data.)

Table 5-5. Matrix of Waste Tank Models That were Analyzed to Estimate the Axial Thermal Expansion Forces for the AP Tank Design (The table lists the thermal expansion forces at the end of the heatup cycle and at the steady state temperature distribution.)

\begin{tabular}{|c|c|c|c|}
\hline & \multicolumn{4}{|c|}{ Axial Thermal Expansion Force, kips/inch of circumference } \\
\hline Waste Height & Twaste $=\mathbf{5 0}^{\circ} \mathbf{F}$ & Twaste $=\mathbf{1 5 0}^{\circ} \mathbf{F}$ & Twaste $=\mathbf{2 5 0 ^ { \circ } \mathbf { F }}$ \\
\hline \multicolumn{4}{|c|}{ Thermal expansion force at end of heatup cycle } \\
\hline 100 & 0 & -0.067 & -0.247 \\
\hline 200 & 0 & -0.103 & -0.302 \\
\hline 300 & 0 & -0.138 & -0.345 \\
\hline 370 & 0 & -0.164 & -0.382 \\
\hline \multicolumn{5}{|c|}{ Steady state thermal expansion force } \\
\hline 100 & 0 & -0.092 & -0.264 \\
\hline 200 & 0 & -0.105 & -0.283 \\
\hline 300 & 0 & -0.117 & -0.298 \\
\hline 370 & 0 & -0.123 & -0.313 \\
\hline
\end{tabular}




\section{RPP-RPT-28967, Rev. 2}

At the steady state temperature distribution, the coefficients are:

$$
\begin{aligned}
& a(T)=5.172 \times 10^{-9} T^{2}-2.388 \times 10^{-6} \mathrm{~T}+1.065 \times 10^{-4} \\
& b(T)=-4.122 \times 10^{-6} \mathrm{~T}^{2}-4.832 \times 10^{-4} \mathrm{~T}+3.447 \times 10^{-2}
\end{aligned}
$$

Figures 5-3 and 5-4 show the axial forces and the curve fits for the AP thermal expansion at the end of the heatup cycle and at the steady state temperature distribution, respectively.

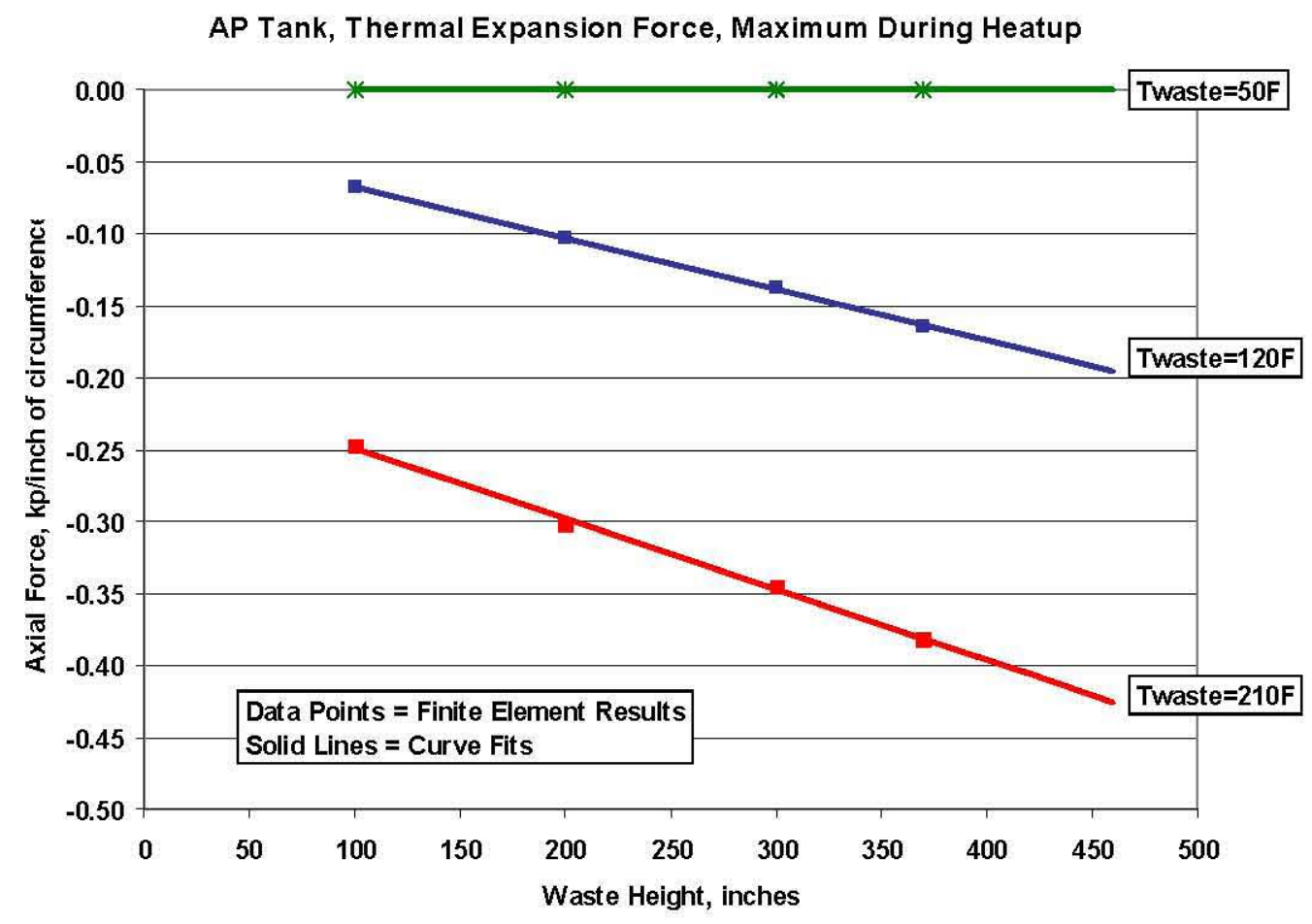

Figure 5-3. Relationship of the Maximum Axial Thermal Expansion Force During the Heatup Cycle in the AP Primary Tank Wall for a Range of Waste Heights and Temperatures (The data points are the finite element results and the solid lines represent the curve fits of the data.) 
RPP-RPT-28967, Rev. 2

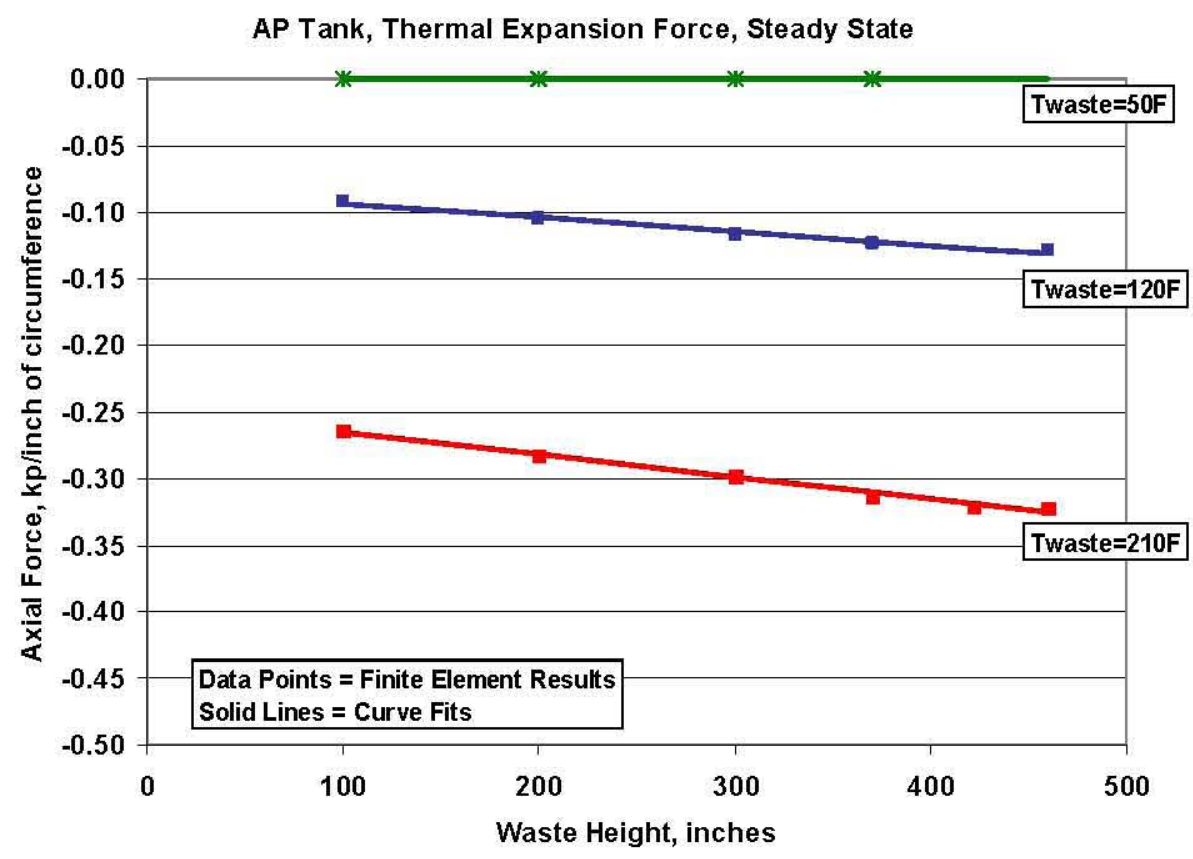

Figure 5-4. Relationship of the Steady State Axial Thermal Expansion Force in the AP Primary Tank Wall for a Range of Waste Heights and Temperatures (The data point are the finite element results and the solid lines represent the curve fits of the data.)

\subsection{Axial Load Components Due to Gravity}

The axial load component due to gravity considers the mass of the soil and the tank on loading the primary tank wall. Figures 5-5 and 5-6 show that the gravity component varies along the height of the tank. The values at 144 inches (the top of the $3 / 4$ inch tank wall section) are used here as a reasonable average. For the soil depth and densities listed in Table 5-1, the gravity loads for the AY and AP tanks are estimated to be $-0.135 \mathrm{kip} /$ inch and $-0.167 \mathrm{kip} / \mathrm{inch}$, respectively. The gravity component is greater for the AP tank because it has a higher axial stiffness than the AY tank.

The gravity load components reported here are an output from detailed finite element analysis of the tank and the surrounding soil. If the reader wishes to consider other soil densities or cover depths it is recommended that this effect be considered by scaling the surface load effect to account for the difference compared to the assumed conditions in Table 5-1.

\subsection{Axial Load Components Due to Surface Loads}

Figures 5-5 and 5-6 show that the surface loads contribute almost no load to the primary tank wall (-0.010 and $-0.005 \mathrm{kips} /$ inch for the AY and AP tanks, respectively). This is consistent with the results of the concentrated load analysis (Rinker et al. 2005) and with the discussion of the vacuum load on axial compression presented in Chapter 3. Later sections will show that this is about 1 to $2 \%$ of the total axial load on the tank wall. The current calculations include the contribution of surface loads for completeness; however, it is undoubtedly smaller than the uncertainty in either the thermal expansion or seismic force components. 


\section{RPP-RPT-28967, Rev. 2}

AY Tank, Axial Load Components, Design Basis Thermal Transient, Waste Height $=422$ in, Twaste $=350 \mathrm{~F}$

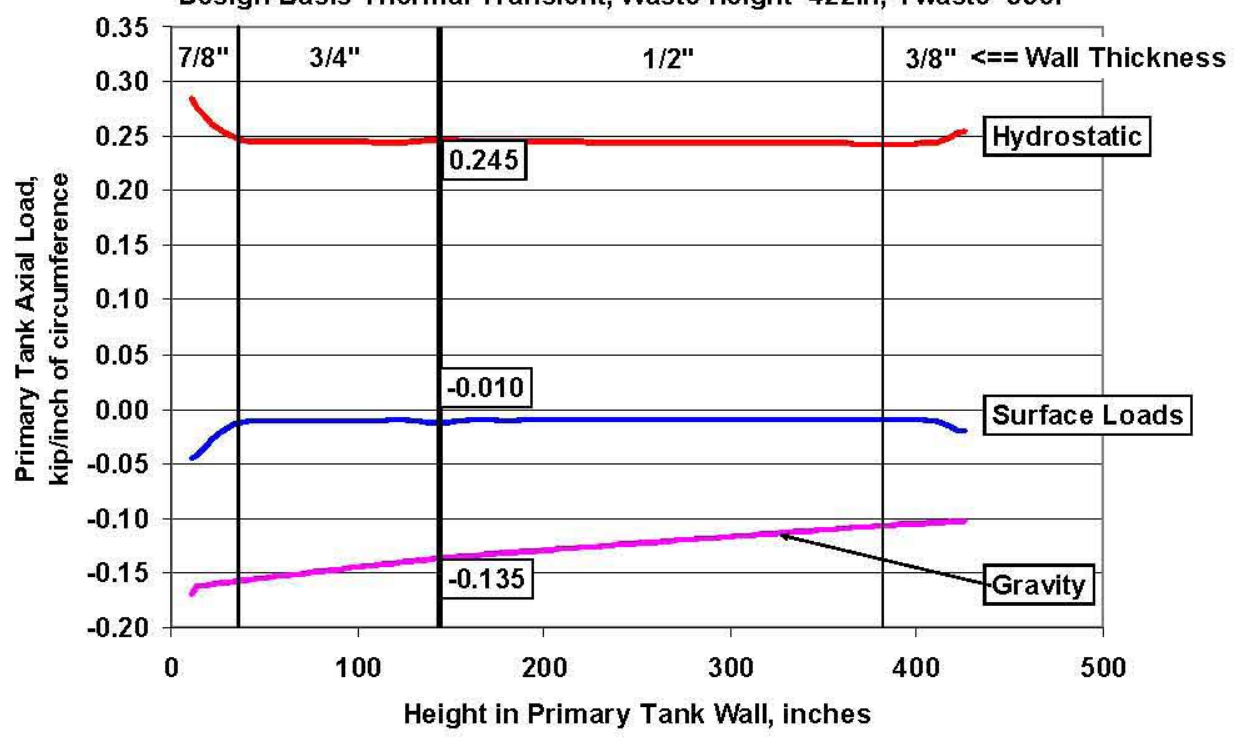

Figure 5-5. Comparison of the Axial Force Components in the AY Primary Tank Wall Due to the Different Tank Loads

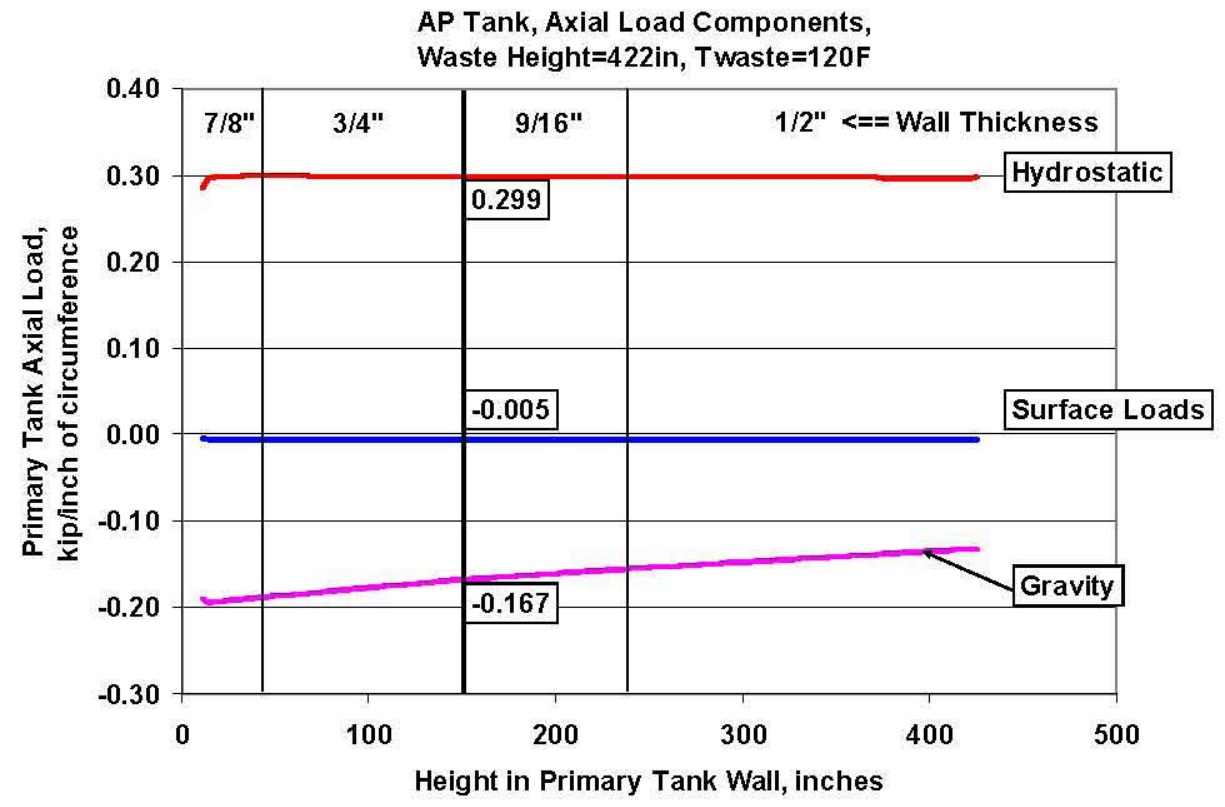

Figure 5-6. Comparison of the Axial Force Components in the AY Primary Tank Wall Due to the Different Tank Loads 
RPP-RPT-28967, Rev. 2

\subsection{Axial Load Component Due to Waste Hydrostatic Pressure}

The waste hydrostatic pressure contributes a tensile axial force due the Poisson's effect from the tensile hoop stress. This effect was quantified using the model results considering different waste heights that were used to calculate the vacuum limits in Chapter 3. Figure 5-7 shows the relationship of axial force with increasing waste height for both the AY and AP tanks for a waste specific gravity of 1.7. The equation for the $\mathrm{AY}$ axial force due to hydrostatic waste pressure is:

$$
\mathrm{F}_{\text {waste }}(\mathrm{h})=5.5322 \times 10^{-7} \mathrm{~h}^{2}+2.4877 \times 10^{-4} \mathrm{~h}-2.1662 \times 10^{-3}
$$

Where $h$ is the waste height in inches and $F_{\text {waste }}(h)$ is the axial force in kips/inch. Note that $F_{\text {waste }}(h)$ is positive.

The equation for the axial force due to hydrostatic waste pressure in the AP tank is:

$$
\mathrm{F}_{\text {wate }}(\mathrm{h})=7.2156 \times 10^{-7} \mathrm{~h}^{2}+3.3431 \times 10^{-4} \mathrm{~h}-3.168 \times 10^{-3}
$$

Both equations 5.15 and 5.16 can be modified for different waste specific gravities by multiplying by the equation:

$$
\mathrm{h}(\mathrm{SpG})=0.6072(\mathrm{SpG})-0.0318
$$

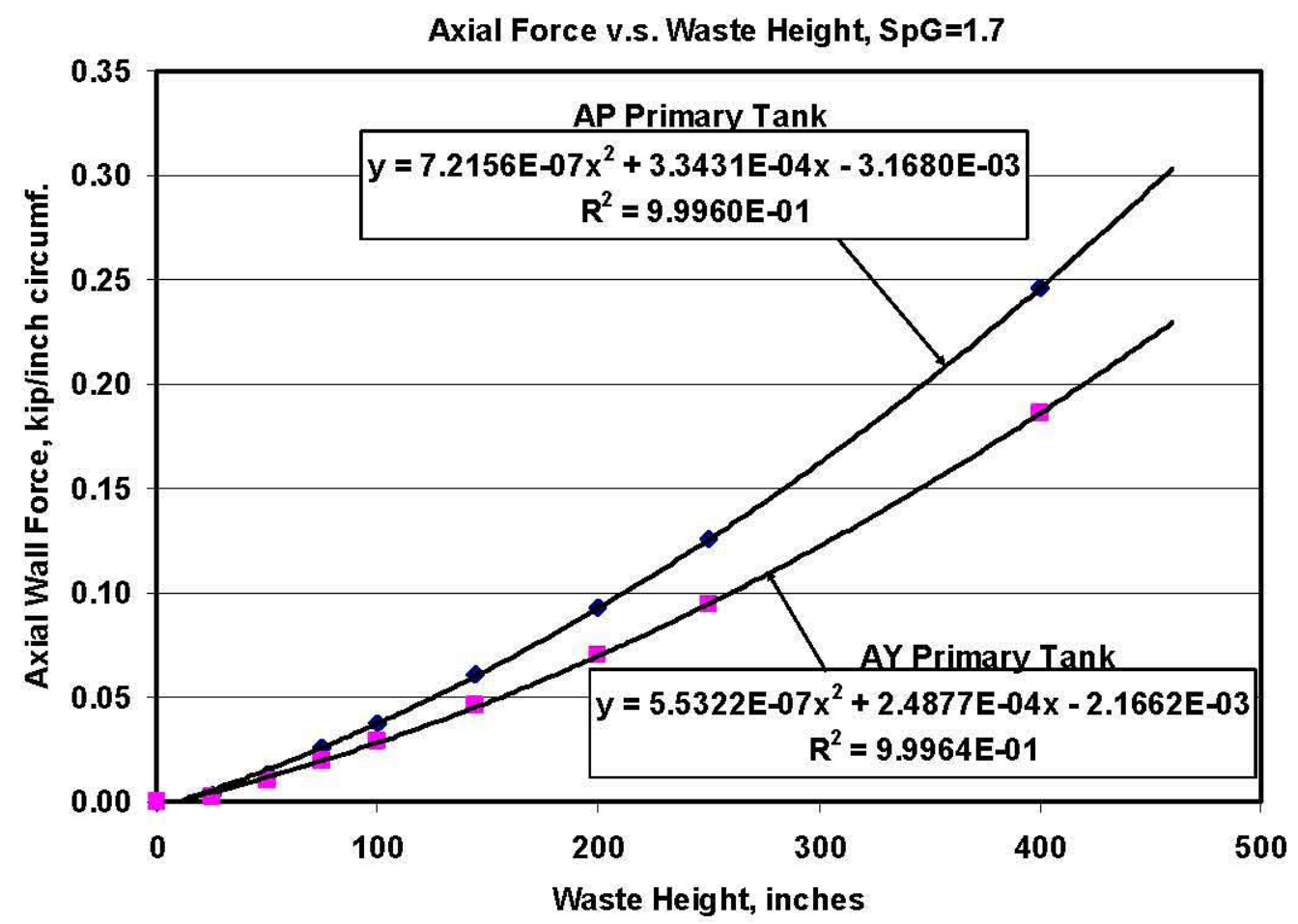

Figure 5-7. Axial Force in the Primary Tank Wall Due to Waste Hydrostatic Pressure

Figure 5-8 shows that this equation fits the AY axial force data for specific gravities from 1.0 to 2.0 . 
RPP-RPT-28967, Rev. 2

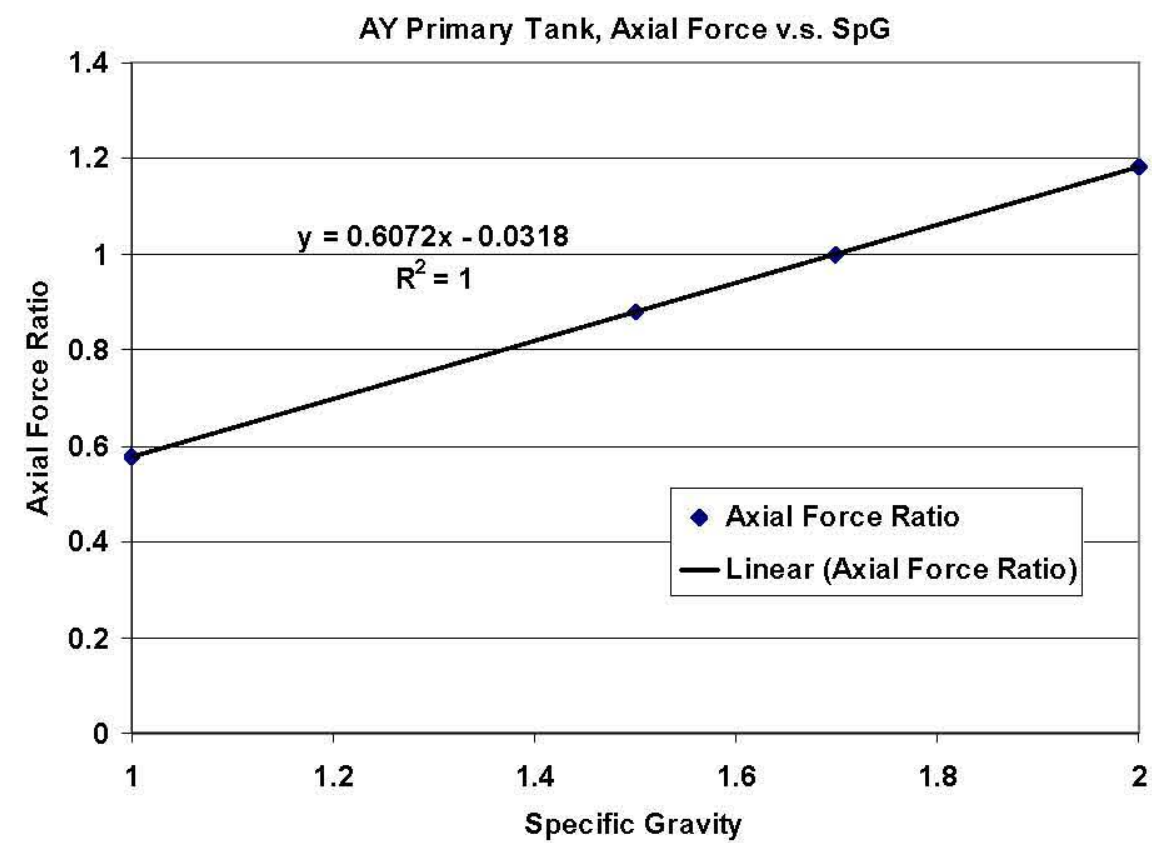

Figure 5-8. Effect of Specific Gravity on Axial Force in the AY Tank Wall

\subsection{Axial Load Component Due to Seismic Excitation}

Seismic motion will cause loads on the primary tank due to deformation of the concrete outer tank plus the impulsive load of the waste sloshing within the tank. The loads transmitted from the concrete tank will be directed axially to the primary tank wall, and they will be comprised of a rocking motion (positive on one side and negative on the other) plus a "breathing mode" that will exert uniform alternating tension and compression forces around the whole tank. The impulsive mode will primarily cause an increased hoop stress on one side of the tank and a reduced hoop stress on the other side. The seismic axial stress component is of interest to the buckling and anchor bolt evaluations of the primary tank.

A seismic analysis of the AY tank has been performed by Carpenter et al. (2006). The maximum amplitudes of the axial and hoop membrane stresses were compiled at each meridional node location in the finite element model by scanning the stress at each band of nodes in the circumferential direction of the half-symmetry model. The scan was performed throughout the transient dynamic analysis, and the maximum and minimum values were recorded. The seismic analysis was performed for four combinations of soil and concrete stiffness properties:

1. Best Estimate Soil - Best Estimate Concrete (BES-BEC)

2. Best Estimate Soil - Fully Cracked Concrete (BES-FCC)

3. Lower Bound Soil - Best Estimate Concrete (LBS-BEC)

4. Upper Bound Soil - Best Estimate Concrete (UBS-BEC)

Figure 5-9 shows the distribution of meridional membrane stresses in the free-standing portion on the AY tank wall for the four combinations of soil and concrete properties. The maximum force is $0.627 \mathrm{kip} / \mathrm{inch}$, but this occurs in the mid-section of the wall, not at the top of the wall where the buckle is 
expected to occur. Therefore, the local maximum of $0.43 \mathrm{kip} / \mathrm{inch}$ at the transition between the freestanding tank wall and the dome was used as a more realistic approximation of the seismically induced compressive force. The seismic force for the AP tank was estimated by scaling the AY forces by the ratio of the AP/AY tank stiffnesses (a factor of 1.429), giving an axial seismic force of $0.614 \mathrm{kip} / \mathrm{inch}$. Since the current evaluation considers the elastic buckling mode, no credit was taken for inelastic energy absorption [i.e., the $\mathrm{F}_{\mu}$ factor in IBC (2003)] reducing the seismic axial force.

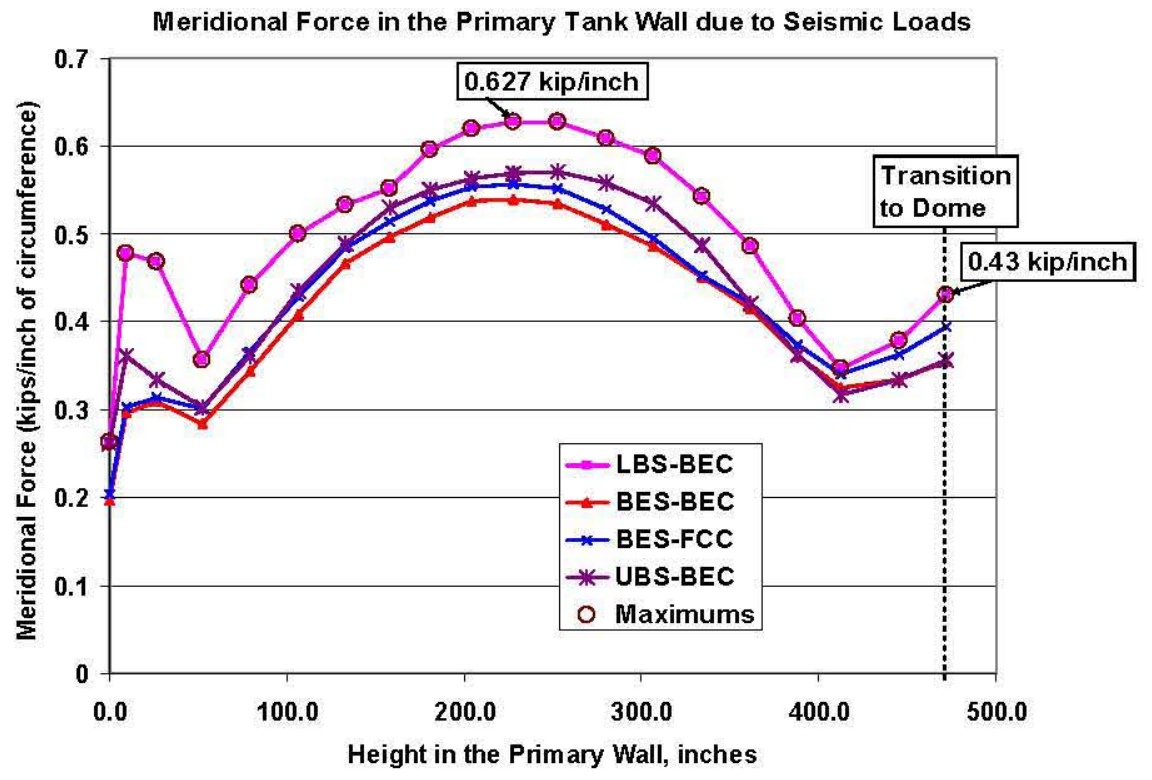

Figure 5-9. Meridional (axial) Membrane Stress in the AY Tank Wall for the Four Different Combinations of Soil and Concrete Properties

\subsection{The Total Axial Force in the Primary Tank Wall}

An Excel ${ }^{\circledR}$ spreadsheet was developed to calculate the total axial force in the primary tank wall based on the data and equations given in this chapter.

Assuming that the axial stress is primarily caused by the relative deformations of the primary tank and the outer concrete tank, then the axial stress for different corrosion allowances can be estimated by scaled by the ratio of the axial stiffnesses. As noted previously, this is a reasonable assumption because even the axial stiffness of the thicker AP tank is only about $1 \%$ of the axial stiffness of the concrete tank walls. Figure 5-10 shows this scaling method for the AY and AP tanks. The axial force scaling factor for the AY tank is:

$$
\mathrm{k}(\mathrm{c})=-4.093717 \mathrm{c}+1.250545
$$

Where $\mathrm{c}$ is the corrosion allowance and $k(c)$ is the multiplication factor on the axial force. The similar equation for the AP tank is:

$$
\mathrm{k}(\mathrm{c})=-3.259365 \mathrm{c}+1.193369
$$




\section{RPP-RPT-28967, Rev. 2}

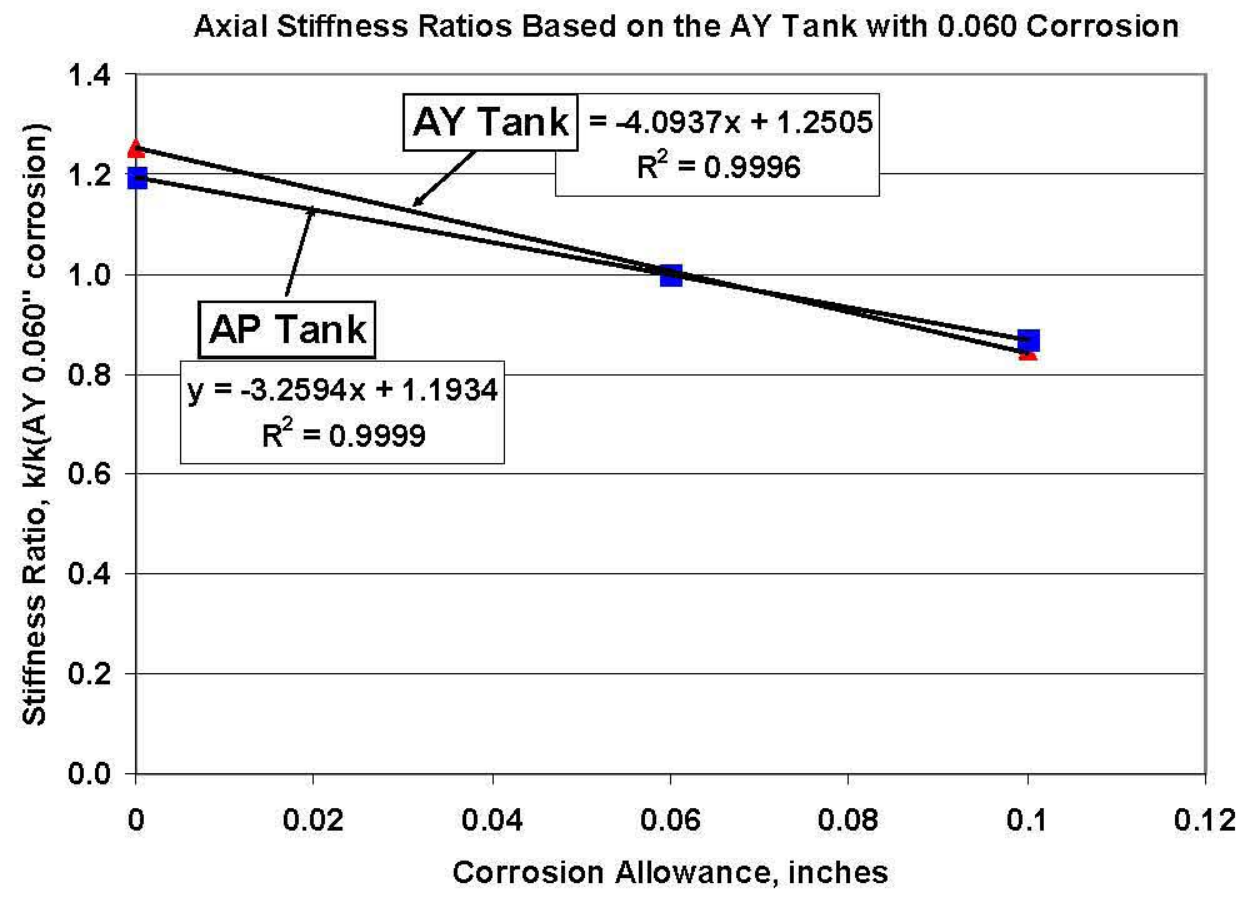

Figure 5-10. Stiffness Scale Factors to Estimate the Seismic Axial Force for the AY and AP Tanks with Different Corrosion Allowances 


\subsection{The Potential for Progressive Anchor Bolt Failure Under Thermal Operating and Seismic Loads}

The primary tank buckling analysis by Julyk (1997) was based on ASME Code Case N-284-1 (ASME 1995), which requires that the safety factor for local buckling be increased by 20 percent when local buckling would lead to a total collapse failure mode. Julyk (1997) did not use the higher safety factor because local tank buckling is not expected to lead to total tank collapse since the primary tank wall is supported by the anchor bolts embedded in the concrete dome. Furthermore, under operating loads (deadweight, thermal, and hydrostatic) the primary tank is in a state of displacement controlled vertical compression, and only a small amount of bowing in the tank wall is necessary to relieve the axial compression and limit the extent of the buckle.

However, the EH-22 safety review panel (see Chapter 1) postulated that the load path would initially be only through the outer ring of anchor-bolts and that the primary tank dome would likely peel away from the underside of the concrete dome due to the downward pull of the buckling sides. They further postulated that each succeeding inboard bolt circle would assume load only after the outboard bolts had failed. In this scenario the anchor bolts would fail progressively until the steel dome had completely detached from the concrete dome, causing total collapse of the primary tank. The EH-22 panel identified the anchor bolts as the unanalyzed weak link in the load path. They concluded that the factor of safety used by Julyk (1997) was potentially non-conservative with respect to the ASME Code Case requirements.

This chapter addresses the potential for progressive anchor bolt failure and what are the appropriate safety factors for evaluating local and global buckling. The analysis answers the following specific questions:

- Can the EH-22 scenario develop if the vacuum is limited to -6.6 inches w.g. by a relief valve?

- What is the appropriate factor of safety required to protect against buckling if the EH-22 scenario can develop?

- What is the appropriate factor of safety required to protect against buckling if the EH-22 scenario cannot develop?

\subsection{Anchor Bolt Evaluations for the Bounding (AY) and AP Tank Designs}

Detailed anchor bolt evaluations were performed for the AY bounding tank design (Deibler et al. 2008a) and for the AP tank design (Deibler et al. 2008b). These analyses established the maximum allowable waste temperature for combination with the operating and seismic loads summarized in Table 6-1. These analyses show that the maximum anchor bolt shear and axial displacements occur at the outer-most ring of anchors. When the steady state thermal and operating loads are combined with the transient seismic loads, the maximum waste temperatures in Table 6-1 give peak anchor bolt shear and axial displacements that are nearly equal to the anchor bolt capacities. Note that the maximum temperatures in Table 6-1 are above the current and future expected waste temperatures for the double shell tanks. In addition, waste temperature limits have been established for tank farm operations that ensure that these temperatures will not be exceeded during future waste processing and retrieval campaigns.

For the maximum temperatures in Table 6-1, the demand/capacity ratios for anchor shear are 0.81 for the bounding AY tank and 0.99 for the AP tank design. The corresponding demand/capacity ratios for anchor 
tension are very low; 0.15 for the bounding tank and 0.04 for the AP tank. This is significant because the "peeling away" behavior postulated by the EH-22 panel would require that the anchor tensile allowables be exceeded. The detailed anchor analysis shows that the combined thermal, deadweight, vacuum, and seismic loads account for less than $1 / 6$ of the tensile capacity of the anchors. Therefore, it is highly unlikely that the primary tank will peel away from the concrete dome.

Table 6-1. Maximum load conditions addressed in the AY and AP anchor bolt evaluations.

\begin{tabular}{|c|c|c|c|}
\hline Design Load & Bounding (AY) Tank & AP Tank & Notes \\
\hline Design Life & $>50$ years & $>50$ years & $\begin{array}{l}\text { A } 60 \text {-year design life is } \\
\text { used. }\end{array}$ \\
\hline $\begin{array}{l}\text { Maximum } \\
\text { Corrosion Rate }\end{array}$ & $1 \mathrm{mil} / \mathrm{yr}$ & $1 \mathrm{mil} / \mathrm{yr}$ & $\begin{array}{l}\text { Total corrosion of } 0.060 \\
\text { inch is applied to the } \\
\text { nominal thicknesses. }\end{array}$ \\
\hline Soil Cover & $8.3 \mathrm{ft} @ 125 \mathrm{lb} / \mathrm{ft}^{3}$ & $8.3 \mathrm{ft} @ 125 \mathrm{lb} / \mathrm{ft}^{3}$ & Relative to dome apex. \\
\hline $\begin{array}{l}\text { Hydrostatic } \\
\text { Waste Pressure }\end{array}$ & 422 inches @ $1.7 \mathrm{SpG}$ & 460 inches@1.83 SpG & \\
\hline $\begin{array}{l}\text { Primary Tank } \\
\text { Differential } \\
\text { Pressure }\end{array}$ & -12 in. $w g$ & -12 in. $\mathrm{wg}$ & $\mathrm{P}_{\text {primary }}-\mathrm{P}_{\text {annulus }}$ \\
\hline \multirow[t]{2}{*}{ Live Load } & $40 \mathrm{lb} / \mathrm{ft}^{2}$ & $40 \mathrm{lb} / \mathrm{ft}^{2}$ & Uniform \\
\hline & $200,000 \mathrm{lb}$. nominal & $200,000 \mathrm{lb}$. nominal & Concentrated \\
\hline $\begin{array}{l}\text { Maximum } \\
\text { Waste } \\
\text { Temperature }\end{array}$ & $\begin{array}{ll}\text { Supernatant } & 135^{\circ} \mathrm{F} \\
\text { Sludge } & 160^{\circ} \mathrm{F}\end{array}$ & $\begin{array}{ll}\text { Supernatant } & 135^{\circ} \mathrm{F} \\
\text { Sludge } & 135^{\circ} \mathrm{F}\end{array}$ & $\begin{array}{l}\text { Waste temperature for } \\
\text { demand/capacity }=1\end{array}$ \\
\hline $\begin{array}{l}\text { Seismic } \\
\text { Spectrum }\end{array}$ & $\begin{array}{l}\text { 2006 DST surface spectrum } \\
\text { (Rinker and Youngs, 2006) }\end{array}$ & $\begin{array}{l}\text { 2006 DST surface spectrum } \\
\text { (Rinker and Youngs, 2006) }\end{array}$ & $\begin{array}{l}\text { Based on the WTP design } \\
\text { spectrum (Rohay and } \\
\text { Reidel, 2005) }\end{array}$ \\
\hline $\begin{array}{l}\text { Anchor } \\
\text { Displacement } \\
\text { Demands and } \\
\text { Capacities }\end{array}$ & $\begin{array}{ll}\text { Axial Demand: } & 0.048 \text { inch } \\
\text { Axial Capacity: } & 0.330 \text { inch } \\
\text { Axial D/C ratio: } & 0.15 \\
\text { Shear Demand: } & 0.133 \text { inch } \\
\text { Shear Capacity: } & 0.165 \text { inch } \\
\text { Shear D/C ratio: } & 0.81\end{array}$ & $\begin{array}{ll}\text { Axial Demand: } & 0.014 \text { inch } \\
\text { Axial Capacity: } & 0.375 \text { inch } \\
\text { Axial D/C ratio: } & 0.04 \\
\text { Shear Demand: } & 0.164 \text { inch } \\
\text { Shear Capacity: } & 0.165 \text { inch } \\
\text { Shear D/C ratio: } & 0.99\end{array}$ & $\begin{array}{l}\text { AY J-Bolt limits defined } \\
\text { in Deibler et al. (2008a), } \\
\text { AP Headed Anchor limits } \\
\text { defined in Deibler et al. } \\
\text { (2008b) }\end{array}$ \\
\hline
\end{tabular}

\subsection{Does Initiation of Primary Tank Buckling Concentrate Anchor Bolt Loads?}

The anchor bolt evaluations summarized in Table 6.1 do not include the localizing effect of a buckle increasing the maximum anchor loads. Therefore, additional finite element model results are presented in this section to investigate if buckle initiation will significantly concentrate local anchor bolt loads and lead to progressive failure of the anchors.

The anchor bolt evaluations summarized in Table 6.1 establish the limiting waste temperatures that give anchor bolt demand/capacity ratios of nearly 1 when combined with the specified operating and seismic loads. Therefore, the focus of the current analysis is to assess the variation in anchor bolt loads in and near a local buckle compared to the baseline anchor loads outside of the local buckle. Figure 6-1 shows the primary tank model with the anchor bolts represented by short beam elements oriented normal to the 


\section{RPP-RPT-28967, Rev. 2}

tank shell. The remote ends of the beam elements were held fixed while the waste hydrostatic pressure was applied followed by increasing vacuum. The model includes a geometric imperfection (see Figure 31) to initiate the buckling instability under the radially symmetric vacuum load. The anchor bolt shear and normal forces were recorded as the vacuum load was increased to a maximum of $20 \mathrm{inch} \mathrm{w.g} \mathrm{(a}$ factor of 1.67 greater than the maximum specified vacuum of 12 inch w.g.). The anchor bolt study by Deibler et al. (2008a) used detailed finite element models of the DST anchors to estimate the appropriate axial and shear stiffnesses to use for the embedded concrete anchors. This work showed that the shear and axial stiffnesses are similar and that an appropriate lower-bound anchor stiffness is $23,500 \mathrm{lb} / \mathrm{inch}$. Therefore, the axial and shear displacement increments caused by localized buckling were calculated for a lower-bound anchor stiffness of $23,500 \mathrm{lb} / \mathrm{inch}$.

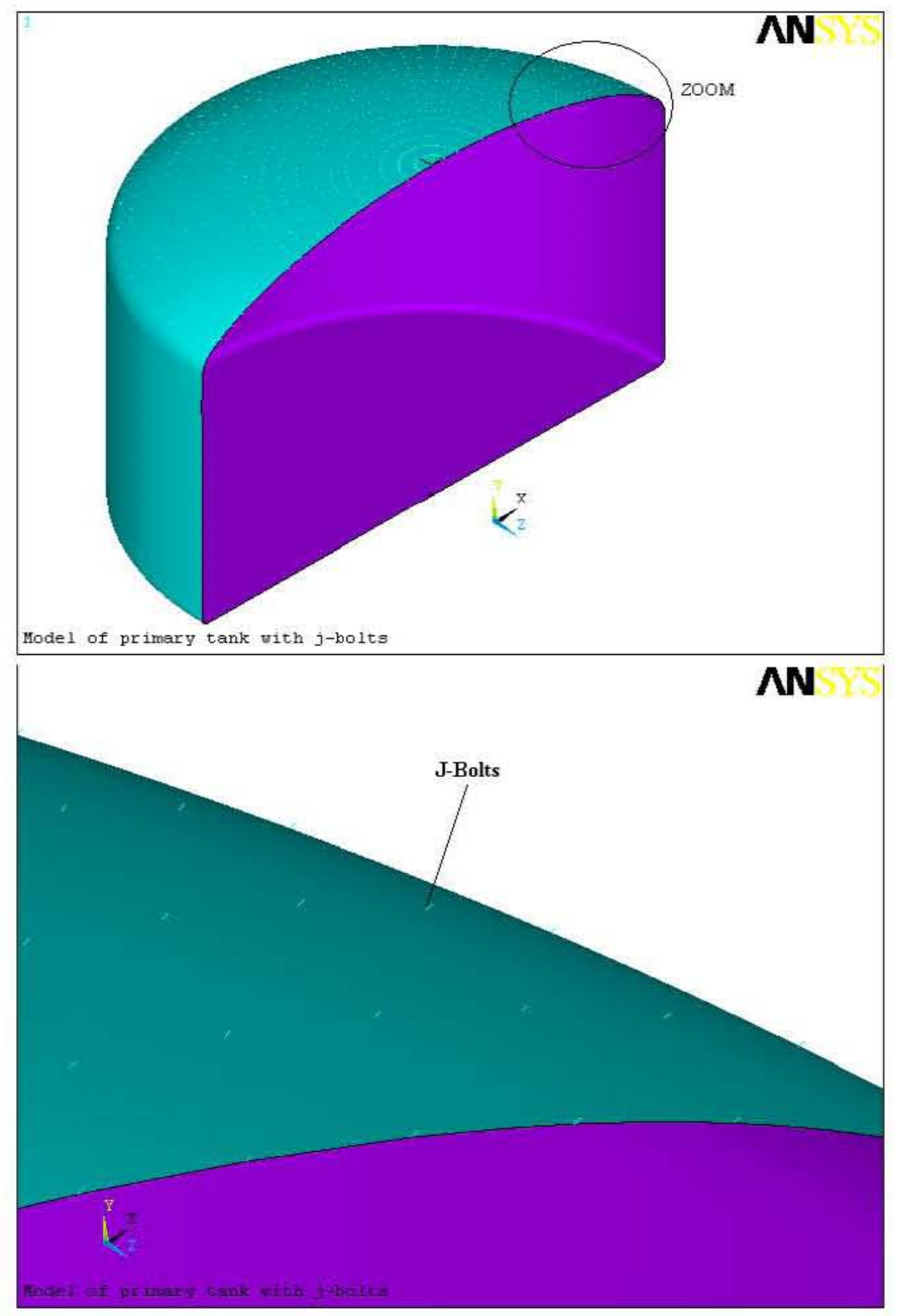

Figure 6-1. Buckling Model Showing the Location of the anchor bolts Attached to the Tank Dome 
Localization of anchor loads was evaluated for both the bounding (AY) tank design and the AP tank design. The anchor bolts were first evaluated at a low waste height of 25 inches because the tank is more susceptible to buckling at low waste heights (see Table 2-1). Additional cases with 400 inch waste height were also evaluated for both tank designs. Full tank conditions ( 422 inch for the bounding tank and 460 inch for the AP tank) were not evaluated because the hydrostatic pressure applied to the full height of the vertical wall effectively resists tank buckling at the low vacuums being considered.

\subsubsection{Anchor Load Sensitivity for the AY Tank Design}

The first anchor bolt evaluation considered the AY tank with a low waste height of 25 inches and vacuum increasing up to 20 inch w.g. Figures 6-2 and 6-3 show that for the outermost circumferential row of anchor bolts, the anchor bolt axial and shear displacements vary by less than 0.0002 inch and 0.001 inch, respectively, for a vacuum of 12.5 inch w.g. Figures 6-4 and 6-5 show similar results for the AY tank with a waste height of 400 inches. The variation in axial displacement is 0.0002 inch and the variation in shear displacement is less that 0.001 inch. These are very small compared to the allowable axial and shear displacements listed in Table 6-1 for the AY J-bolt anchors. Therefore, increasing the vacuum load to the maximum 12 inch w.g. will not concentrate the anchor loads and cause progressive anchor failure.

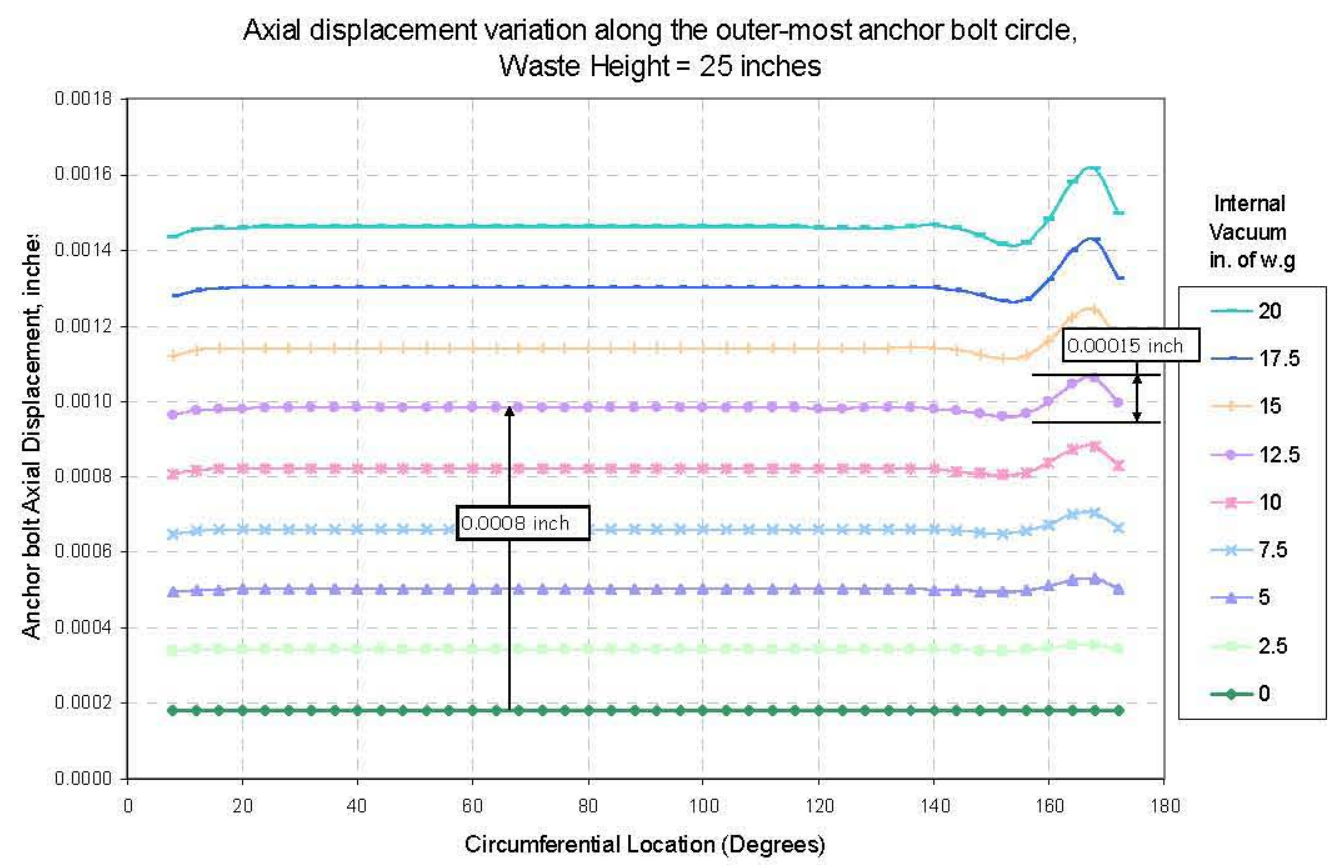

Figure 6-2. Axial Displacement Variation Along the Outermost Anchor Bolt Circle as a Function of Internal Vacuum. Bounding (AY) Tank with 25 Inch Waste Depth. 
RPP-RPT-28967, Rev. 2

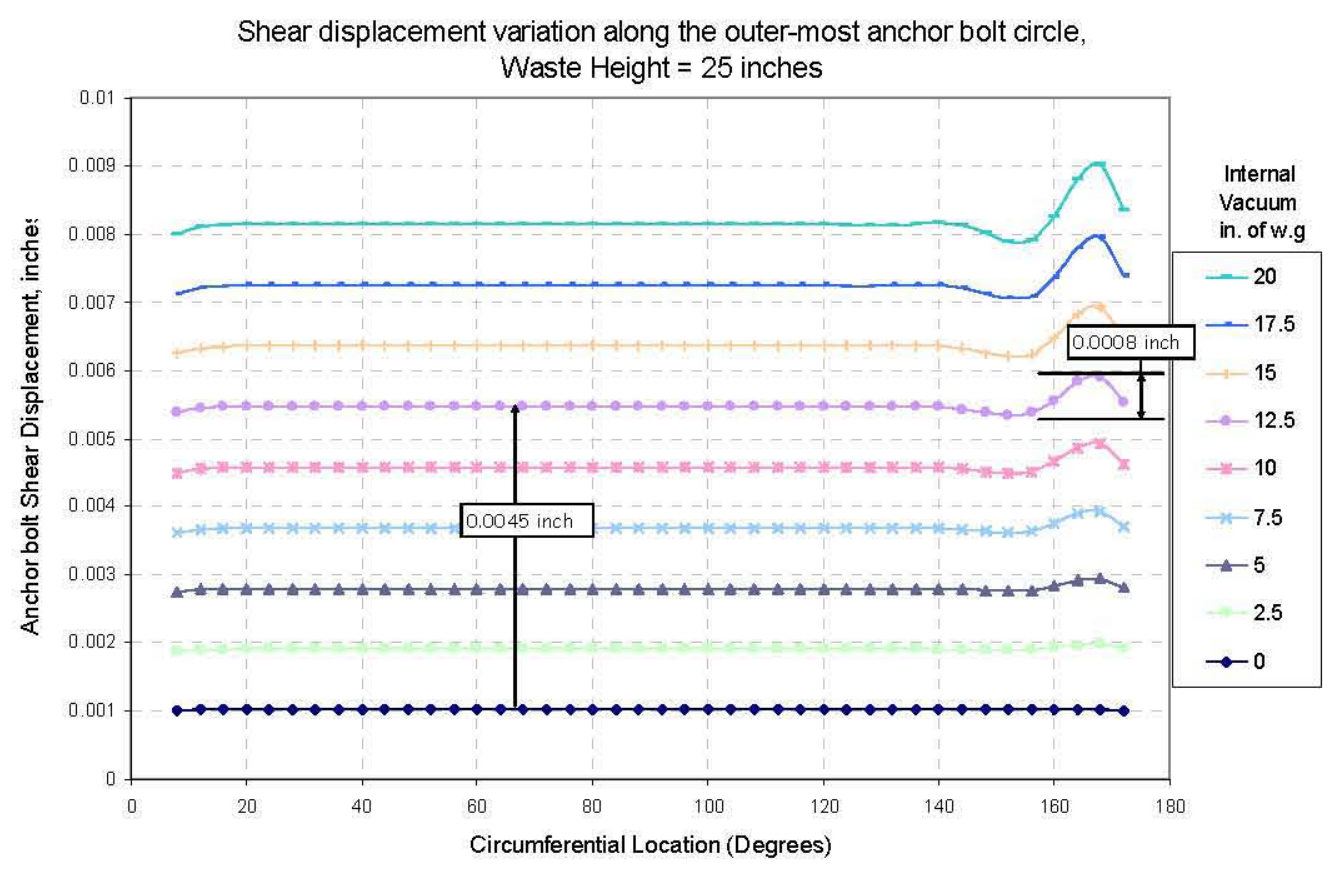

Figure 6-3. Shear Displacement Variation Along the Outermost Anchor bolt Circle as a Function of Internal Vacuum. Bounding (AY) Tank with 25 Inch Waste Depth.

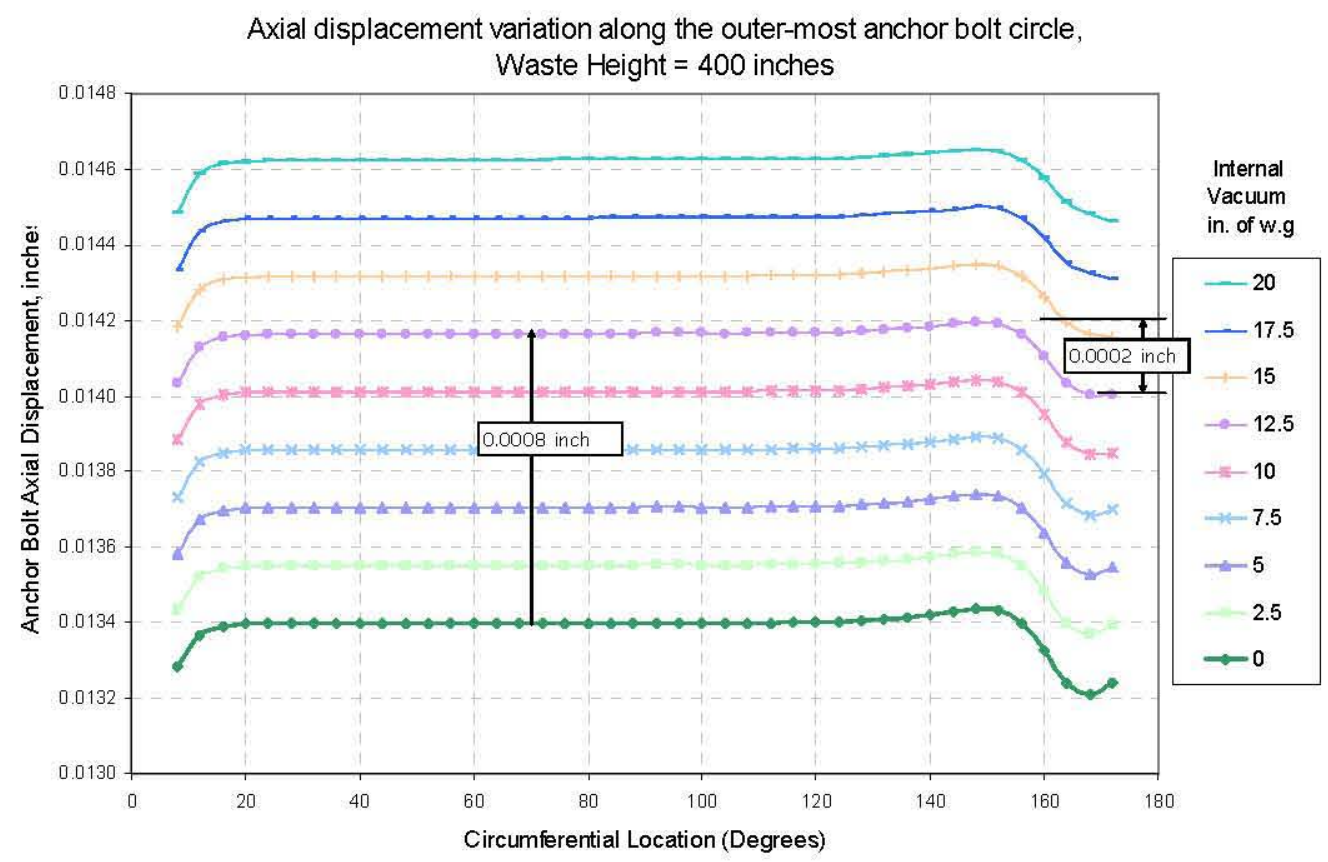

Figure 6-4. Axial Displacement Variation Along the Outermost Anchor Bolt Circle as a Function of Internal Vacuum. Bounding (AY) tank with 400 inch waste depth. 
RPP-RPT-28967, Rev. 2

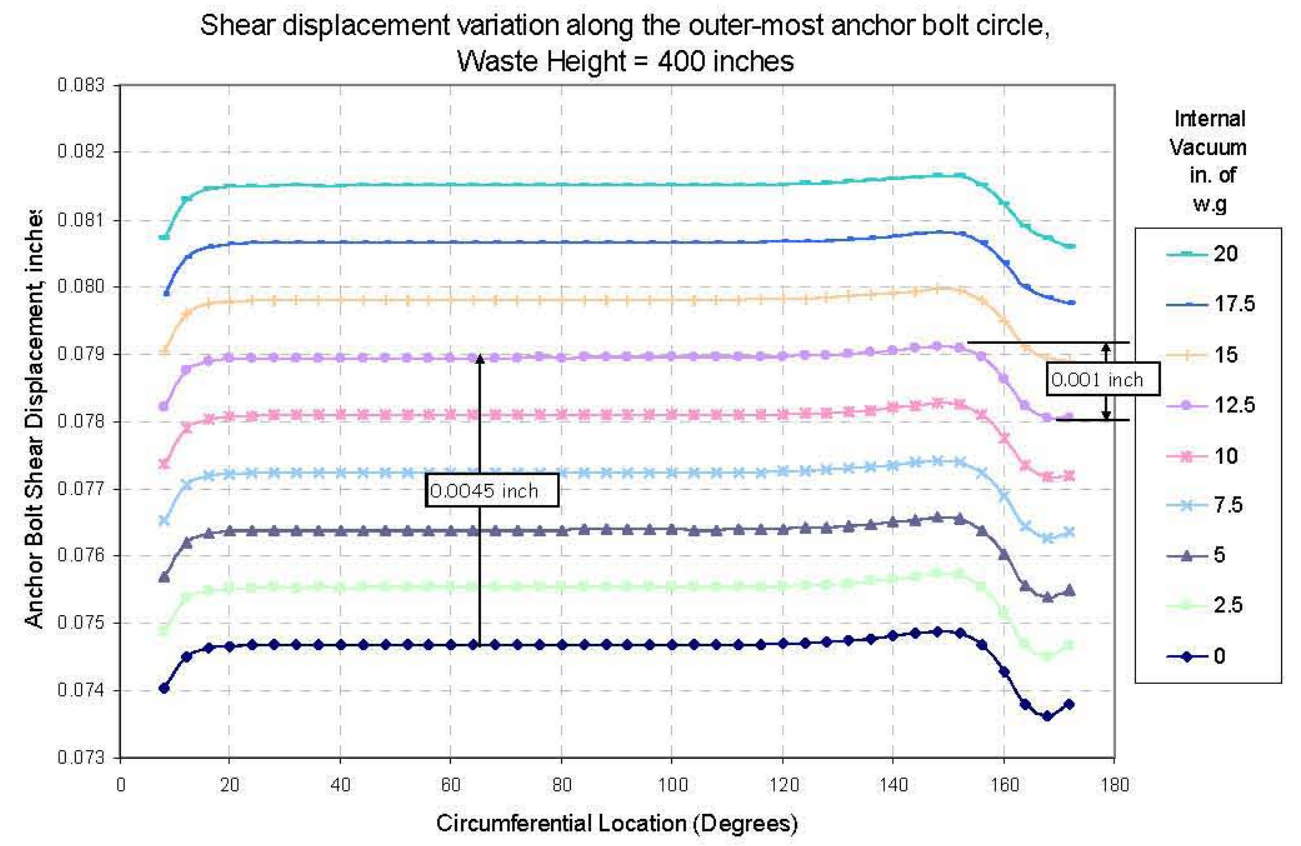

Figure 6-5. Shear Displacement Variation Along the Outermost Anchor bolt Circle as a Function of Internal Vacuum. Bounding (AY) tank with 400 inch waste depth.

\subsubsection{Anchor Load Sensitivity for the AP Tank Design}

Figures 6-6 and 6-7 show the sensitivity of the anchor bolt axial and shear displacements for the outermost circumferential row of anchor bolts for the AP tank design with a 25 inch waste height. The anchor axial and shear displacements vary by less than 0.0002 inch and 0.001 inch, respectively, for a vacuum of 12.5 inch w.g. At a waste depth of 400 inches, Figures 6-8 and 6-9 show that the axial and shear displacements vary by 0.0002 inch and 0.002 inch, respectively. These are very small compared to the allowable axial and shear displacements listed in Table 6-1 for the headed anchor studs used in the AP tanks. Therefore, increasing the vacuum load to the maximum 12 inch w.g. in the presence of a geometric imperfection in the tank wall will not significantly concentrate the anchor loads and cause progressive anchor failure. 
RPP-RPT-28967, Rev. 2

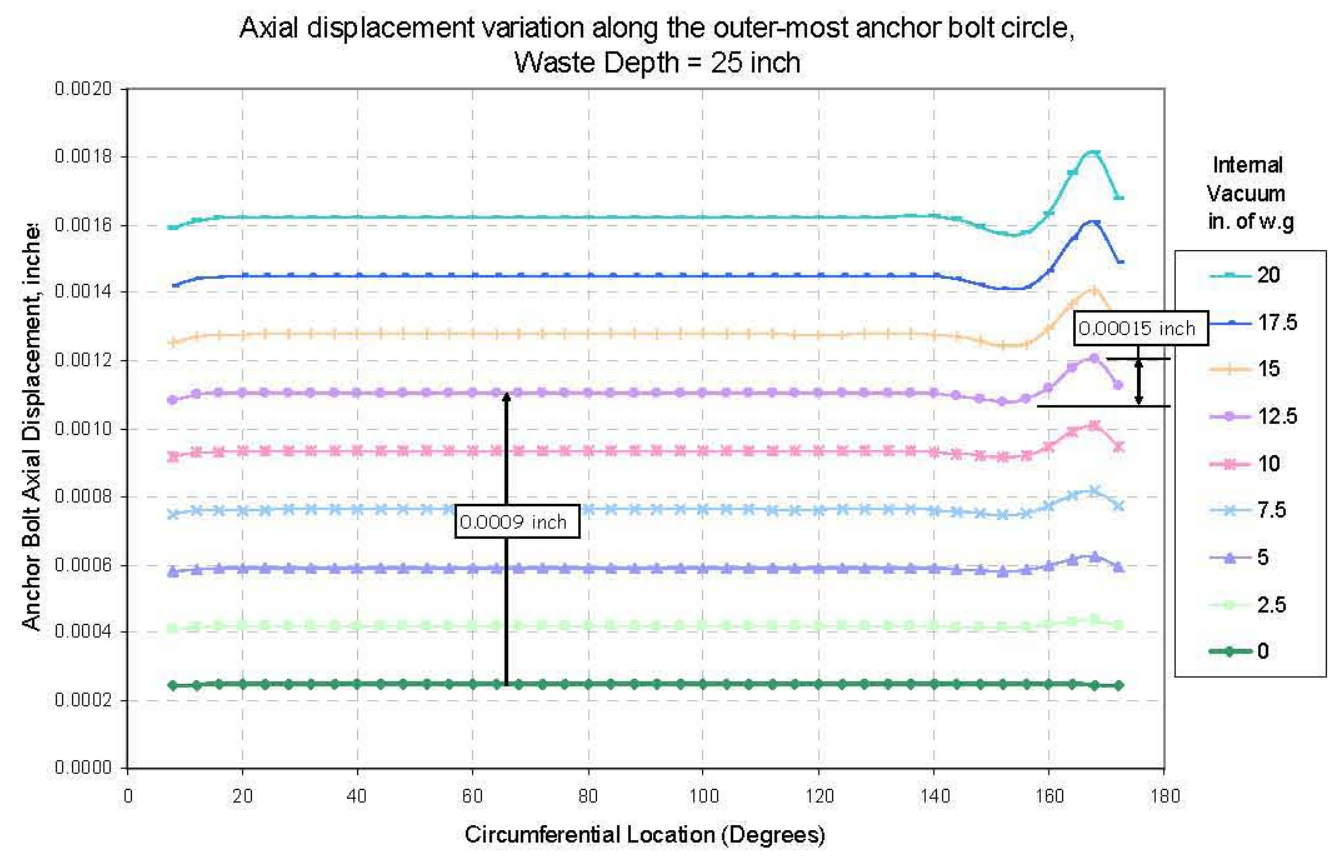

Figure 6-6. Axial Displacement Variation Along the Outermost Anchor Bolt Circle as a Function of Internal Vacuum. AP Tank with 25 Inch Waste Depth.

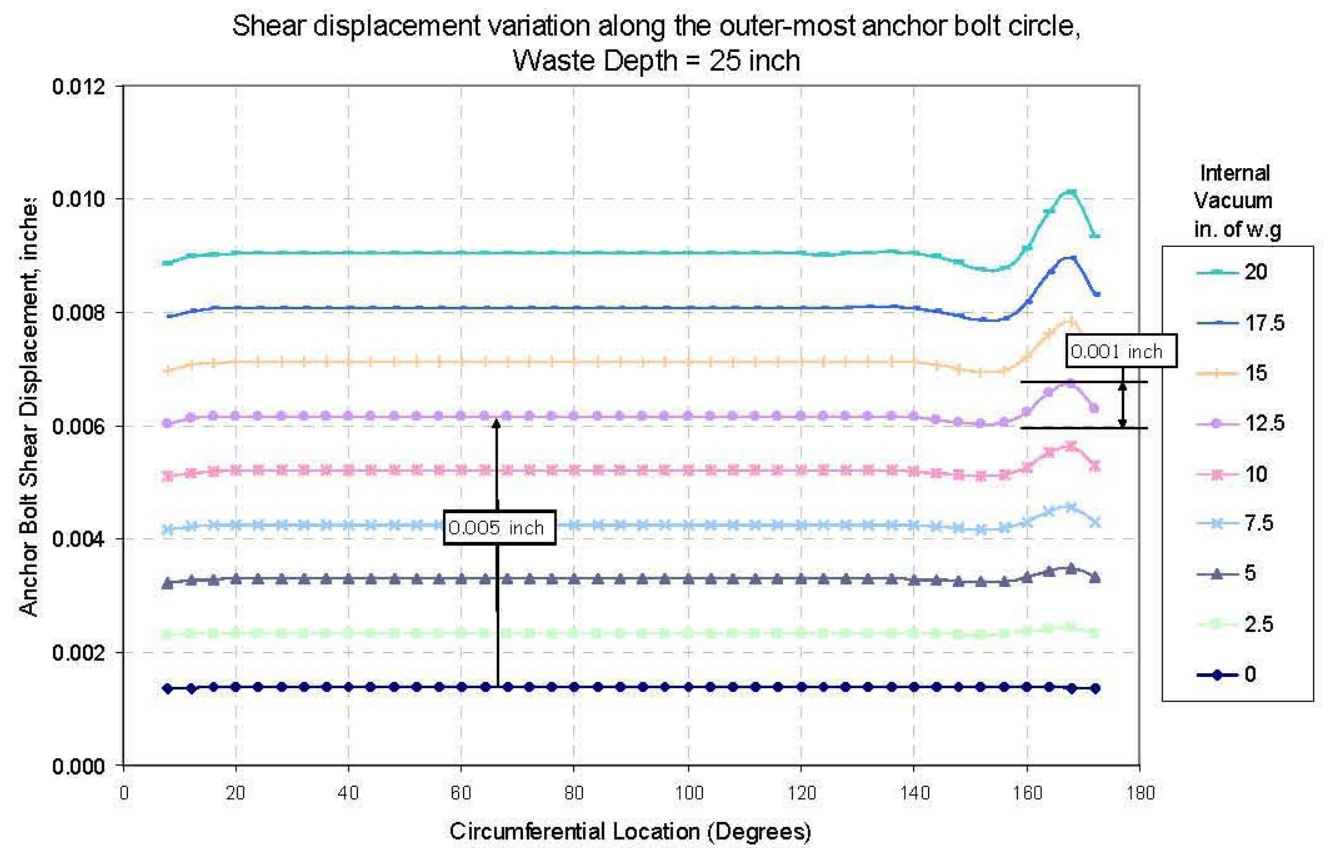

Figure 6-7. Shear Displacement Variation Along the Outermost Anchor bolt Circle as a Function of Internal Vacuum. AP Tank with 25 Inch Waste Depth. 
RPP-RPT-28967, Rev. 2

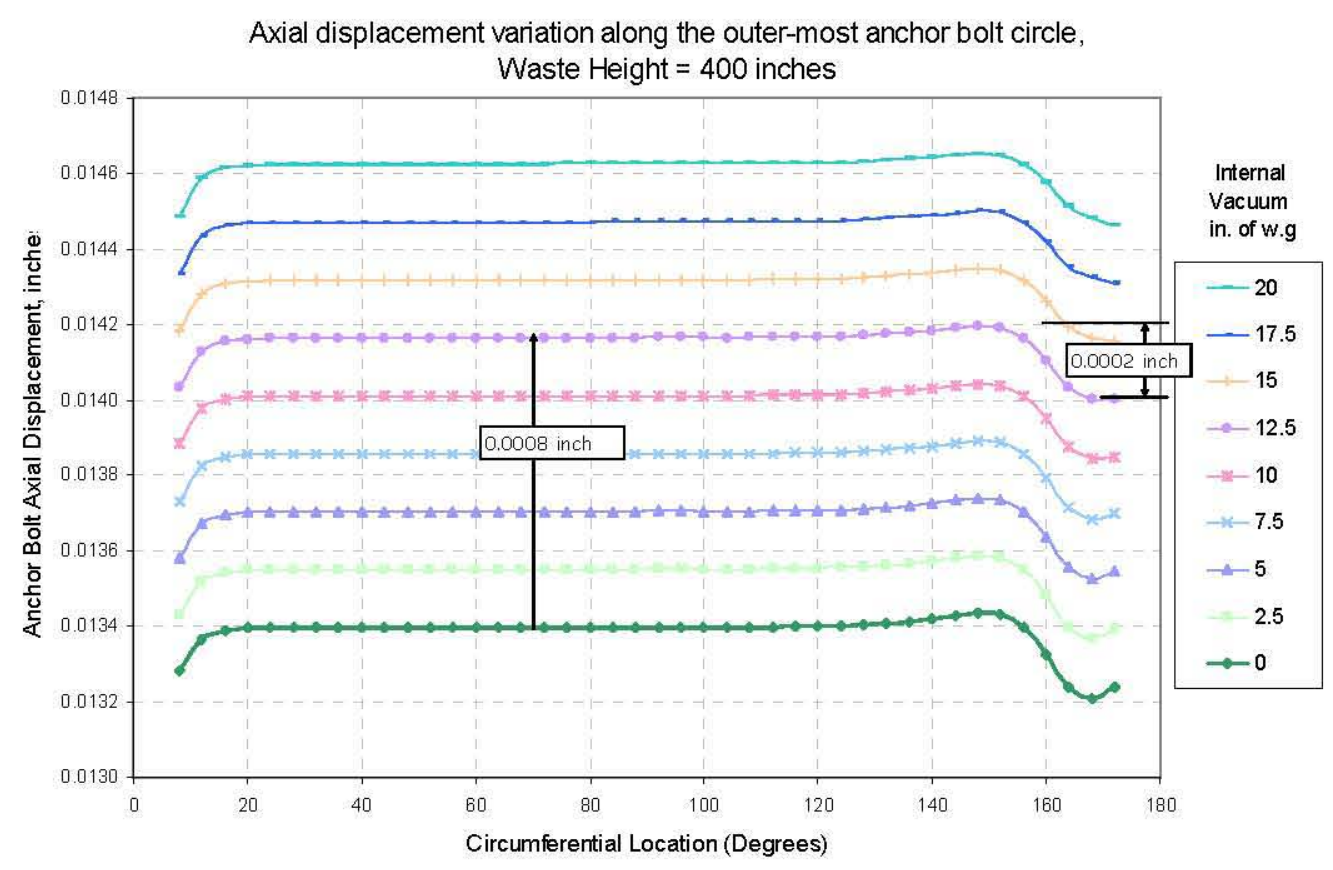

Figure 6-8. Axial Displacement Variation Along the Outermost Anchor Bolt Circle as a Function of Internal Vacuum. AP tank with 400 inch waste depth.

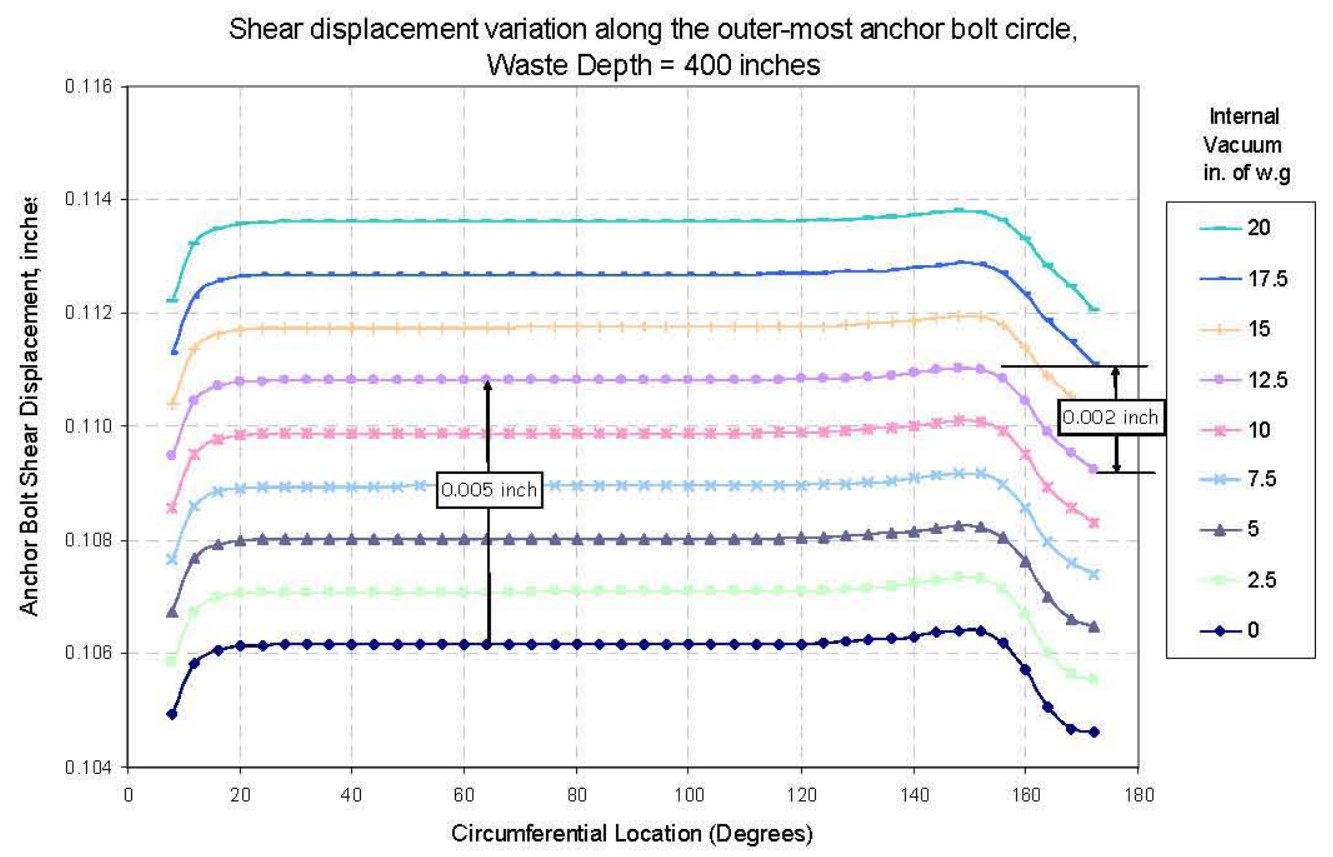

Figure 6-9. Shear Displacement Variation Along the Outermost Anchor bolt Circle as a Function of Internal Vacuum. AP tank with 400 inch waste depth. 


\subsection{Addressing the EH-22 Findings on the Potential for Progressive Anchor Bolt Failure and the Appropriate Safety Factors for Evaluating Local and Global Buckling}

This section answers the questions:

- Can the EH-22 scenario develop if the vacuum is limited to -6.6 in. water gage by a relief valve?

- What is the appropriate factor of safety required to protect against buckling if the EH-22 scenario can develop?

- What is the appropriate factor of safety required to protect against buckling if the EH-22 scenario cannot develop?

\subsubsection{Can the EH-22 Scenario Develop if the Vacuum is Limited to -6.6 Inch Water Gage by a Relief Valve?}

The anchor bolt analysis summarized in Section 6.1 shows that the anchors are structurally sound for vacuum loads up to 12-inches w.g. The sensitivity analysis in Section 6.2 shows that the application of vacuum in the primary tank does not significantly concentrate anchor loads such that progressive anchor failure would occur.

In addition, the finite element analyses in Chapter 3 that established the limiting vacuum and axial loads on the primary tank showed that the tank deformations are small at the unfactored limit vacuum and they increase stably at loads beyond this value. None of the analyses predicted that the tank dome would peel away from the concrete under increasing vacuum as was postulated by the EH-22 panel. This is true for vacuum loads up to and beyond the unfactored limits, which are at least a factor of 1.67 (i.e., the safety factor for global buckling with a service level $\mathrm{C}$ load) times the actual limits set on the tank vacuum. This is well below the gross tank wrinkling that would have to accompany the failure scenario postulated by the EH-22 panel.

Based on this review, anchor bolt failure is not expected, and thus it is very unlikely that the EH-22 scenario could occur.

\subsubsection{What is the Appropriate Factor of Safety Required to Protect Against Buckling if the EH-22 Scenario Can Develop?}

Based on the buckling and anchor bolt analyses presented in this report, it is very unlikely that the EH-22 scenario could occur. 


\subsubsection{What is the Appropriate Factor of Safety Required to Protect Against Buckling if the EH-22 Scenario Cannot Develop?}

The buckling calculations in Chapter 7 are conducted for four different service levels defined in Section III of the ASME Boiler and Pressure Vessel Code. Each service level has required factors of safety for local and global buckling:

\begin{tabular}{lcc} 
& \multicolumn{2}{c}{ Factors of Safety } \\
\cline { 2 - 3 } & Local Buckling & Global Buckling \\
\cline { 2 - 3 } Level A $=$ Normal operating conditions & 2.0 & 2.4 \\
Level B $=$ Upset conditions & 2.0 & 2.4 \\
Level C $=$ Emergency conditions & 1.67 & 2.0 \\
Level D $=$ Faulted conditions & 1.34 & 1.61
\end{tabular}

Attachment B of Julyk (2002) makes the argument that axial compression in the tank cylinder will be relieved by local bowing of the wall before the onset of general instability. This position is justified since the meridional (axial) compressive stresses are displacement-controlled as a result of differential thermal expansion and concrete creep-induced loads on the primary tank. The load deflection response of the large displacement finite element models used in the current buckling analysis confirms that the axial stress in the tank is self-limited by the deformation of the primary tank geometry (see Figures 3-12 and 3-13). This rationale leads to the following buckling criteria when combining the effects of axial and hoop loads on the allowable vacuum:

The allowable vacuum (net negative pressure) in the double-shell tanks is controlled by the minimum of two cases:

A. Local Buckling (with $\underline{\text { local }}$ buckling safety factors imposed) evaluated considering the interaction of the net internal vacuum load $(\Delta p)$ combined with the meridional compressive stress $\left(\sigma_{\phi}\right)$.

B. General Instability (with global buckling safety factors imposed) evaluated considering the net internal vacuum load $(\Delta \mathrm{p})$ acting alone. No interaction with the meridional compressive stress shall be considered $\left(\sigma_{\phi}=0\right)$.

These criteria were used by Julyk (2002) and they are also used in the current buckling evaluation. It is further assumed that the design basis loads used in the thermal and operating loads analysis conservatively represent Service Levels A, B, and C. This is consistent with the loading conditions assumed by Julyk (2002). Service Level D, however, requires that the incremental seismic stresses be added to the design basis stresses for evaluating the faulted condition.

Julyk (2002) states that activation of the tank relief valves at the limiting vacuum load should be classified as an ASME Service Level C (emergency) load condition. Service Level C loads are defined by the ASME Code, Section III, Division 1, NB-3113 (ASME 2004b) as:

"The total number of postulated occurrences for all specified service conditions for which Level C Limits are specified shall not cause more than 25 stress cycles having an $\mathrm{S}_{\mathrm{a}}$ value greater than that for $10^{6}$ cycles from the applicable fatigue design curves of Figures I-9.0."

Evidence is provided below that the alternating stress associated with these vacuum cycles is well below the allowable, $\mathrm{S}_{\mathrm{a}}$, and also that the total number of vacuum cycles between normal operating vacuum and the limit vacuum are expected to be less than the maximum number of 25 cycles. 
The AY primary tanks were constructed with A515 grade 60 steel, which has a minimum ultimate tensile strength, $S_{\text {ult, }}$ of $60 \mathrm{ksi}$. The allowable alternating stress, $\mathrm{S}_{\mathrm{a}}$, at $10^{6}$ cycles is $12,500 \mathrm{psi}$ for carbon steels with $\mathrm{S}_{\text {ult }} \leq 80 \mathrm{ksi}$ (ASME, 2004c). The alternating stress due to tank vacuum is the hoop stress corresponding to the limiting vacuum load. The maximum alternating stresses for the different tank designs are:

AY, SY, AN, AY, AZ: Tank Radius $=450$ inch, Pressure $=-6$ inch w.g. $(-0.217$ psi)

Minimum Wall Thickness $=0.375-0.060=0.315$ inch

Hoop Stress $=\mathrm{pr} / \mathrm{t}=(-0.217)(450) / 0.315 \quad \underline{\mathrm{S}}_{\underline{\mathrm{a}}}=310 \mathrm{psi}$

$\underline{\mathrm{AP}}$ :

Tank Radius $=450$ inch, Pressure $=-12$ inch w.g. $(-0.434$ psi $)$

Minimum Wall Thickness $=0.375-0.060=0.315$ inch

Hoop Stress $=\mathrm{pr} / \mathrm{t}=(-0.434)(450) / 0.315 \quad \underline{\mathrm{S}} \underline{\mathrm{a}}=620 \mathrm{psi}$

These alternating stresses are factors of 40 and 20 lower than the limiting value of $12,500 \mathrm{psi}$.

Tank farms operations staff recently reviewed all of the Occurrence Reports from 1990 to the 2006. This summary information will be released in the next revision of RPP-11413, Technical Basis for the

Ventilation Requirements Contained in Tank Farm Operating Specifications Documents, authored by

L. Payne. No incidents were found where the primary tank differential vacuum has exceeding the 6 inch w.g. maximum. There was a report of reaching a vacuum of 4 inch w.g. in the SY tank ventilation system, but the exhauster shut down on interlock. There was one incident in AW, but it was also limited to 4 inch w.g. or less. The incident that people remembered where a vacuum limit was exceeded was in the AN annulus system in 2005 (PER-2005-072). Note that this occurred in the annulus and not in the primary tank.

This review shows that there is no recorded evidence that the primary tank vacuum limits have ever been achieved during tank operation and even if they had the resulting cyclic stress would be insignificantly small. Therefore, it is very appropriate to define the occurrence of the maximum operating vacuum as an ASME Service Level C load condition. 

RPP-RPT-28967, Rev. 2

\subsection{Buckling Evaluation of the DST Primary Tanks}

This chapter presents both elastic and plastic buckling analyses of the DST primary tanks. The elastic buckling evaluation presents a method for evaluating the allowable vacuum limit for each of the DST primary tanks. The method estimates the axial force in the primary tank wall using the equations in Chapter 5, and then uses this force to calculate the unfactored vacuum limit for elastic buckling based on the equations in Chapter 3 . Once the unfactored axial force and vacuum limits are calculated, the safety factors for the ASME Section III service levels are applied to calculate the allowable tank vacuum limits. An independent review (Appendix B) was conducted to confirm the correct calculation of the axial tank force, the unfactored vacuum limit, and the application of the ASME safety factors. This chapter concludes with a plastic (elephant-foot) buckling evaluation of the tanks for the worst case loading conditions.

\subsection{Elastic Buckling}

An Excel ${ }^{\mathrm{TM}}$ spreadsheet was constructed using the equations of Chapters 3 and 5, and it applies the ASME Section III Service Level safety factors to calculate the vacuum allowables for the primary tanks. Tables 7-1 through 7-3 show an example of these calculations based on the AY tank geometry and operating conditions. Table 7-1 shows the input data to the spreadsheet (in light blue) and the calculated force components (in tan) plus the total axial force with and without the seismic axial force. Note that the thermal force during heatup is used to calculate the maximum operating force, but the steady state force is used when combining with the seismic load. This is to recognize the extremely low probability that the seismic force and the maximum transient thermal force would both occur at the same time. Table 7-1 also compares the total unfactored axial force with the limit value of the axial force. The hydrostatic force for the specified waste height is included in this comparison. Table 7-2 shows that the vacuum limits for three different axial forces (zero, total maximum operating force, and total steady state operating + seismic force) are used to calculate unfactored vacuum limits to evaluated the tank for local and global buckling. The hydrostatic force component for each increasing waste height is used in these calculations. Table 7-3 shows how these vacuum limits are reduced by the appropriate safety factors. The governing allowable vacuum limit listed in Table 7-3 is the minimum value of all the global and local buckling evaluations. This value assumes that the Service Level A\&B safety factors apply to the limit vacuum load. However, justification for classifying the vacuum load as a Service Level $\mathrm{C}$ load has been provided in Section 6.4.3. Therefore, a second governing vacuum load is listed that considers the limit vacuum as a Service Level C load. The vacuum limit calculated based on Service Level C safety factors is used for comparison with the existing vacuum limits for the double shell tanks (see the last line of Table 7-3).

The spreadsheet contains individual worksheets for evaluating each of the DST primary tanks. Table 7-4 summarizes the allowable vacuum calculations that are based on the current operating limits for waste temperature, waste height, and waste specific gravity. A corrosion allowance of 0.060 inch was assumed in these calculations. Table 7-4 shows that the calculated allowable vacuum limits are greater than the current vacuum limits for all of the tanks except the AP tanks. The current AP vacuum allowable is 12 inches w.g. compared to the calculated allowable of 10.53 inch w.g. This limit vacuum is based on global buckling assuming a minimum waste height of 12 inches. The calculations show that although the AP tank is slightly thicker in the upper tank wall, this is not sufficient to double the vacuum limit compared to the AY tank. The unfactored limit vacuum for the AY tank with 6 inches of waste is 
18.98 inches w.g. compared to 21.07 inches w.g. for the AP tank with 12 inches of waste. Both tanks have a very large $\mathrm{R} / \mathrm{t}$ ratio, which governs the vacuum limit for buckling.

Table 7-1. Calculation of Axial Applied Force for the AY Primary Tank

\begin{tabular}{|c|c|c|c|c|c|}
\hline \multicolumn{6}{|c|}{ Allowable Vacuum for the AY Primary Tank } \\
\hline & & & & & \\
\hline \multicolumn{6}{|c|}{ Summation of Applied Axial Tank Force Components } \\
\hline & & & & & Axial Force \\
\hline & & & & & Component \\
\hline & & Temp, F & Waste $\mathrm{Ht}$, in. & Time, yrs & kip/inch \\
\hline \multicolumn{6}{|l|}{ History Effect } \\
\hline \multicolumn{2}{|c|}{ AYIAZ History } & 250 & 370 & 60 & -0.213 \\
\hline & & & & & \\
\hline & & Temp & Waste Ht & SpG & \\
\hline Current Operation & & 350 & 370 & 1.77 & \\
\hline \multicolumn{2}{|c|}{ Yield Strength at Temp, ksi = } & 27.85 & & & \\
\hline \multicolumn{2}{|c|}{ Corrosion Allowance, inches $=$} & 0.060 & & & \\
\hline & & & & & \\
\hline \multicolumn{3}{|c|}{ Hydrostatic Axial Tension at operating waste height } & SpG factor $=$ & 1.042944 & 0.173 \\
\hline \multicolumn{6}{|c|}{ (Hydrostatic tension is added later in the lim. vac. v.s. waste height calc) } \\
\hline \multicolumn{3}{|c|}{ Max Operating Differential Thermal Exp. $=$} & $\mathrm{a}(\mathrm{T})=$ & $-8.099 \mathrm{E}-04$ & -0.507 \\
\hline & & & $\mathrm{b}(\mathrm{T})=$ & $-2.073 \mathrm{E}-01$ & \\
\hline \multicolumn{3}{|c|}{ Steady State Differential Thermal Exp. $=$} & $a(T)=$ & $-6.346 \mathrm{E}-04$ & -0.451 \\
\hline \multicolumn{2}{|c|}{ (Combine with Seismic) } & & $\mathrm{b}(\mathrm{T})=$ & $-2.166 \mathrm{E}-01$ & \\
\hline & & & & & \\
\hline \multirow[t]{2}{*}{ Gravity $=$} & & & & & -0.135 \\
\hline & & & & & \\
\hline \multirow[t]{2}{*}{ Surface Loads = } & & & & & -0.010 \\
\hline & & & & & \\
\hline \multicolumn{2}{|c|}{ Max. Seismic Axial Force $=$} & & & & -0.430 \\
\hline \multicolumn{2}{|c|}{\begin{tabular}{|l|l|} 
& \\
\end{tabular}} & & & & \\
\hline 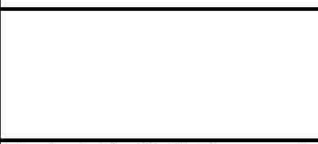 & & & & \begin{tabular}{|l|} 
Operating Force \\
(Service Levels \\
A, B, and C)
\end{tabular} & $\begin{array}{l}\text { Operating + } \\
\text { Seismic Force } \\
\text { (Service Level }\end{array}$ \\
\hline \multicolumn{4}{|c|}{ Total Axial Force in Empty Tank with 0.060 inch Corrosion } & -0.865 & -1.240 \\
\hline \multicolumn{2}{|c|}{ Corrosion Allowance, inches $=$} & 0.060 & \begin{tabular}{|l|} 
Corrosion \\
Factor $=$ \\
\end{tabular} & 1.005 & 1.005 \\
\hline \multicolumn{3}{|c|}{ Total Axial Force - empty tank, kip/inch } & & -0.870 & -1.246 \\
\hline & & & & & \\
\hline \multicolumn{4}{|c|}{ Total Axial Force at Specified Waste Height, kip/inch } & -0.696 & -1.073 \\
\hline \multicolumn{4}{|c|}{ Calculate Axial Force Limit in Primary Tank Wall } & & \\
\hline t_min $=$ & 0.315 & & & $F_{\varphi}(\max )=$ & -1.308 \\
\hline
\end{tabular}


RPP-RPT-28967, Rev. 2

Table 7-2. Calculation of Unfactored Vacuum Limit for the AY Primary Tank

\begin{tabular}{|c|c|c|c|c|c|}
\hline Calculate the Vacuu & Im limit bas & sed on the ap & plied axial fo & rce above & \\
\hline SpG $=$ & $\begin{array}{r}1.77 \\
\end{array}$ & $\mathrm{~h}(\mathrm{SpG})=$ & 1.00439424 & & \\
\hline Corrosion Allow= & 0.060 & $g(t)=$ & 0.999705226 & & \\
\hline $\mathrm{t}(3 / 8)=$ & 0.315 & $h(S p G){ }^{*} g(t)$ & 1.004098171 & & \\
\hline & & & & & \\
\hline & & & Axial force for & Axial force for & Axial force for \\
\hline & & & $\begin{array}{l}\text { Global Buckling } \\
\text { (Service Levels } \\
\text { A, B, and C) } \\
\end{array}$ & $\begin{array}{l}\text { Local Buckling } \\
\text { (Service Levels } \\
\text { A, B, and C) }\end{array}$ & $\begin{array}{l}\text { Local Buckling } \\
\text { Service Level D } \\
\text { Oper + Seismic } \\
\end{array}$ \\
\hline Equiv.AxI Stress, $\mathrm{t}=3 / 8^{\prime \prime}$ & psi & & 0 & -2761 & -3956 \\
\hline & & ForceFactor=> & 1.00 & 0.80 & 0.64 \\
\hline & SpGFactor=> & 1.042944 & $F(\mathrm{kip} / \mathrm{in})$ & $F($ kip/in) & $F(\mathrm{kip} / \mathrm{in})$ \\
\hline & & Hydrostatic & 0 & -0.87 & -1.25 \\
\hline & Waste $\mathrm{Ht}$. & Force & Limit Vacuum & Limit Vacuum & Limit Vacuum \\
\hline & inches & (kip/inch) & inch w.g. & inch w.g. & inch w.g. \\
\hline 1st equation & 6 & -0.001 & 18.98 & 15.10 & 12.12 \\
\hline & 12 & 0.001 & 19.01 & 15.14 & 12.15 \\
\hline & 25 & 0.005 & 19.06 & 15.21 & 12.22 \\
\hline & 50 & 0.012 & 19.10 & 15.29 & 12.31 \\
\hline & 75 & 0.021 & 19.14 & 15.39 & 12.41 \\
\hline & 100 & 0.030 & 19.28 & 15.56 & 12.58 \\
\hline & 144 & 0.047 & 20.03 & 16.29 & 13.23 \\
\hline & 200 & 0.073 & 22.58 & 18.57 & 15.18 \\
\hline & 250 & 0.099 & 27.15 & 22.56 & 18.57 \\
\hline & 300 & 0.128 & 34.63 & 29.12 & 24.12 \\
\hline 2nd equation & 300 & 0.128 & 34.63 & 29.12 & 24.12 \\
\hline & 370 & 0.174 & 62.41 & 53.40 & 44.70 \\
\hline & 422 & 0.211 & 83.05 & 72.03 & 60.78 \\
\hline & 460 & 0.240 & 98.13 & 85.97 & 72.99 \\
\hline
\end{tabular}

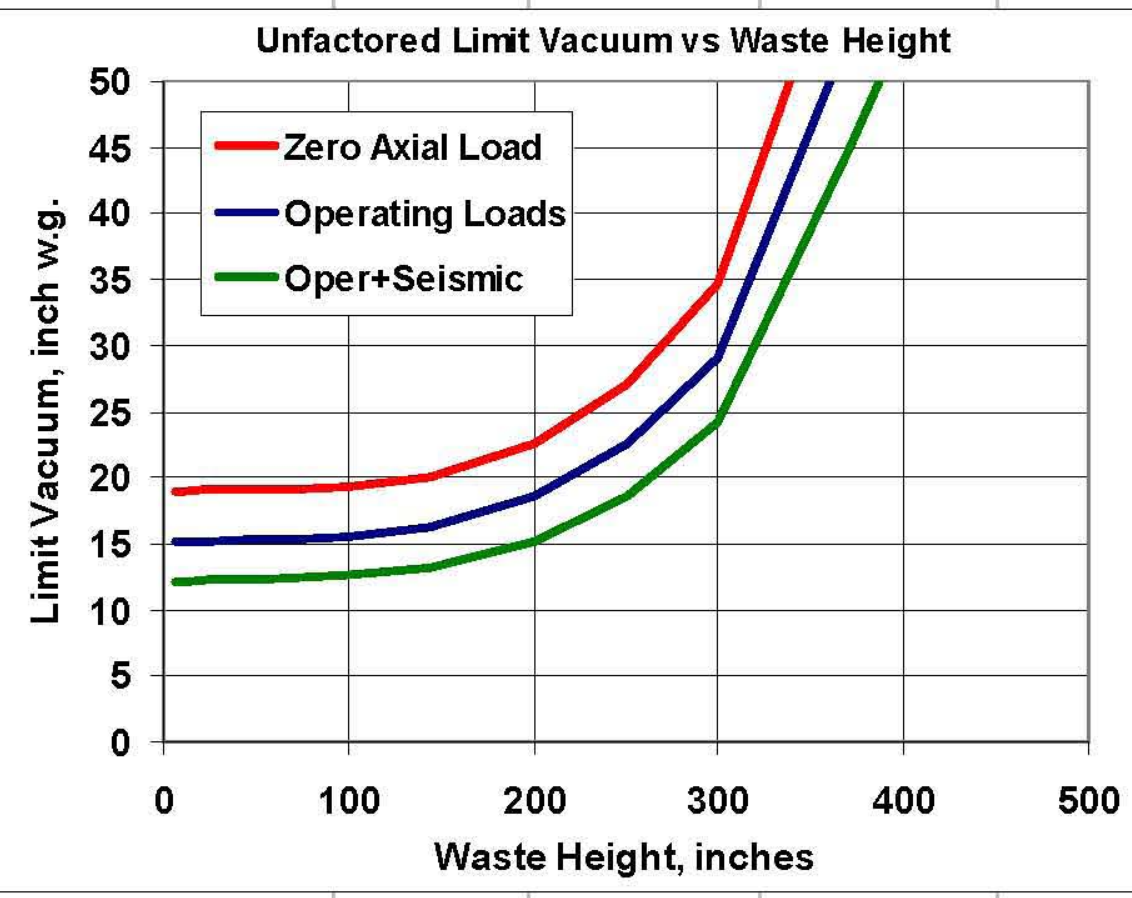


Table 7-3. Evaluation of the Allowable Vacuum Limit for the AY Tank Based on the ASME Section III Service Level Safety Factors

\begin{tabular}{|c|c|c|c|c|}
\hline \multicolumn{5}{|c|}{ Calculate Allowable Vacuum with ASME Section III Service Level Safety Factors } \\
\hline & & $\begin{array}{l}\text { Global Buckling } \\
\text { (Service Levels } \\
\text { A, B, and C) } \\
\end{array}$ & $\begin{array}{l}\text { Local Buckling } \\
\text { (Service Levels } \\
\text { A, B, and C) }\end{array}$ & $\begin{array}{l}\text { Local Buckling } \\
\text { Service Level D } \\
\text { Oper + Seismic }\end{array}$ \\
\hline \multirow[t]{2}{*}{$\begin{array}{l}\text { Unfactored Limit Vacuum } \\
\text { at } 6 \text { inch waste }\end{array}$} & & 18.98 & 15.10 & 12.12 \\
\hline & $\begin{array}{l}\text { Safety } \\
\text { Factor }\end{array}$ & $\begin{array}{l}\text { Unfactored } \\
\text { Vacuum }\end{array}$ & $\begin{array}{l}\text { Allowable } \\
\text { Vacuum }\end{array}$ & \\
\hline \multicolumn{5}{|l|}{ Local Buckling } \\
\hline Service Level A\&B & 2.00 & 15.10 & 7.55 & \\
\hline Service Level C & 1.67 & 15.10 & 9.04 & \\
\hline Service Level D & 1.34 & 12.12 & 9.04 & \\
\hline \multicolumn{5}{|l|}{ Global Buckling } \\
\hline Service Level A\&B & 2.40 & 18.98 & 7.91 & \\
\hline Service Level C & 2.00 & 18.98 & 9.49 & \\
\hline \multicolumn{2}{|c|}{ Governing Allowable Vacuum } & & 7.55 & inch w.g. \\
\hline \multicolumn{3}{|c|}{ Governing when vacuum = Level C load } & 9.04 & inch w.g. \\
\hline
\end{tabular}

As noted in Table 6-1, the anchor bolt structural limits reduce the maximum waste temperature to $160^{\circ} \mathrm{F}$ for the bounding tank design and $135^{\circ} \mathrm{F}$ for the AP tank designs. Since these temperatures are considerably below the maximum design temperatures used in Table 7-4, the buckling calculations were repeated using the lower temperatures and the vacuum limits are presented in Table 7-5. The lower waste temperatures significantly reduce the axial force due to differential thermal expansion, which slightly increases the allowable vacuum (about $0.5 \mathrm{psi}$ ) for the AY, AZ, AW, and AN tanks. Table 7-5 shows that global buckling with Service Level C safety factors is the governing case for all tanks with the lower temperatures. The slightly lower vacuum limits for the maximum design temperatures (Table 7-4) were adopted for further review.

The spreadsheet calculations were also performed for corrosion allowances ranging from 0.000 to 0.120 inch. Table 7-6 summarizes the calculated vacuum limits for these conditions, assuming that the limiting vacuum load is classified as a Service Level C Load. The upper half of Table 7-6 shows the results for the current temperature limits $\left(350^{\circ} \mathrm{F}\right.$ for all tanks except SY and AP). Scanning down the vacuum limits for all the tanks except $\mathrm{AP}$ shows that the vacuum limit first increases with increasing corrosion and then decreases for the highest corrosion allowances of $0.100,0.110$, and 0.120 inch. For each of these tanks the limit on local buckling governs and two competing wall thickness effects are at play. For a constant axial load the vacuum limit decreases with decreasing wall thickness; however, the axial load in the tank wall is also decreasing because the axial stiffness of the tank wall is lower for the thinner wall. The calculated vacuum limits for the AY, AZ, SY, AW, and AN tanks are above the current vacuum limit of 6 inch w.g. for all the cases. In comparison, the vacuum limits for the AP tank steadily decrease with decreasing wall thickness, because the global buckling criteria gives the limiting case (i.e., the axial force is not considered in the global buckling criteria). The calculated vacuum limit for the $\mathrm{AP}$ tank is above the current 12 inch w.g. limit for corrosion allowances of 0.000 to 0.025 inches. For 
corrosion greater than 0.025 inch, the calculated allowable vacuum is less than the current 12 inch w.g. limit.

Table 7-4. Summary of the DST Primary Tank Buckling Evaluations for the Specified Maximum Operating Conditions (corrosion allowance is 0.060 inches)

\begin{tabular}{|c|c|c|c|c|c|c|}
\hline & & & DST Prima & & & \\
\hline & AY & $\overline{A Z}$ & SY & AW & AN & AP \\
\hline \multicolumn{7}{|l|}{ Approx. Operating History } \\
\hline $\begin{array}{ll}\text { Temp, F } \\
\end{array}$ & 250 & 250 & 150 & 150 & 150 & 120 \\
\hline Hwaste, inch & 370 & 370 & 422 & 422 & 422 & 422 \\
\hline \multicolumn{7}{|l|}{ Operating Limits } \\
\hline Temp, F & 350 & 350 & 250 & 350 & 350 & 210 \\
\hline Hwaste, inch & 370 & 370 & 422 & 422 & 422 & 422 \\
\hline SpG & 1.77 & 1.77 & 1.70 & 1.70 & 1.70 & 2.00 \\
\hline Corrosion Allowance, inch & 0.060 & 0.060 & 0.060 & 0.060 & 0.060 & 0.060 \\
\hline Yield at Temp, ksi & 27.85 & 27.85 & 31.45 & 39 & 39 & 39.7 \\
\hline \multicolumn{7}{|l|}{ Calculated Axial Forces } \\
\hline Operating Axial Force, kip/inch & -0.696 & -0.696 & -0.413 & -0.590 & -0.590 & -0.349 \\
\hline Oper+Seismic Force, kip/inch & -1.073 & -1.073 & -0.784 & -0.958 & -0.958 & -0.875 \\
\hline Axial Force Limit, kip/inch & -1.308 & -1.308 & -1.477 & -1.719 & -1.719 & -2.842 \\
\hline \multicolumn{7}{|c|}{ Calculated AllowableVacuum Limits, inches w.g. } \\
\hline & & & & & & \\
\hline \multicolumn{7}{|l|}{ Local Buckling } \\
\hline Service Level A\&B & 7.55 & 7.55 & 8.32 & 7.78 & 7.78 & 9.70 \\
\hline Service Level C & 9.04 & 9.04 & 9.96 & 9.32 & 9.32 & 11.62 \\
\hline Service Level D & 9.04 & 9.04 & 10.60 & 9.56 & 9.56 & 13.48 \\
\hline \multicolumn{7}{|l|}{ Global Buckling } \\
\hline Service Level A\&B & 7.91 & 7.91 & 7.88 & 7.88 & 7.88 & 8.78 \\
\hline Service Level C & 9.49 & 9.49 & 9.45 & 9.45 & 9.45 & 10.53 \\
\hline $\begin{array}{l}\text { Governing } \\
\text { Allowable Vacuum, inch w.g. }\end{array}$ & 7.55 & 7.55 & 7.88 & 7.78 & 7.78 & 8.78 \\
\hline $\begin{array}{l}\text { Governing Allowable } \\
\text { when vacuum = Level C load }\end{array}$ & 9.04 & 9.04 & 9.45 & 9.32 & 9.32 & 10.53 \\
\hline Current Vacuum Limit, inches w.g. & 6 & 6 & 6 & 6 & 6 & 12 \\
\hline
\end{tabular}


Table 7-5. Summary of the DST Primary Tank Buckling Evaluations for the Reduced Maximum Waste Temperatures Based on Anchor Integrity (corrosion allowance is 0.060 inches)

\begin{tabular}{|c|c|c|c|c|c|c|}
\hline & & & DST Prim & & & \\
\hline & AY & $\mathbf{A Z}$ & SY & AW & AN & AP \\
\hline \multicolumn{7}{|l|}{ Approx. Operating History } \\
\hline Temp, F & 250 & 250 & 150 & 150 & 150 & 120 \\
\hline Hwaste, inch & 370 & 370 & 422 & 422 & 422 & 422 \\
\hline \multicolumn{7}{|l|}{ Operating Limits } \\
\hline Anchor Integrity Max Waste Temp, F & 160 & 160 & 160 & 160 & 160 & 135 \\
\hline Hwaste, inch & 370 & 370 & 422 & 422 & 422 & 422 \\
\hline SpG & 1.77 & 1.77 & 1.70 & 1.70 & 1.70 & 2.00 \\
\hline Corrosion Allowance, inch & 0.060 & 0.060 & 0.060 & 0.060 & 0.060 & 0.060 \\
\hline Yield at Temp, ksi & 27.85 & 27.85 & 31.45 & 39 & 39 & 39.7 \\
\hline \multicolumn{7}{|l|}{ Calculated Axial Forces } \\
\hline Operating Axial Force, kip/inch & -0.381 & -0.381 & -0.247 & -0.247 & -0.247 & -0.163 \\
\hline Oper+Seismic Force, kip/inch & -0.780 & -0.780 & -0.637 & -0.637 & -0.637 & -0.713 \\
\hline Axial Force Limit, kip/inch & -1.308 & -1.308 & -1.477 & -1.719 & -1.719 & -2.842 \\
\hline \multicolumn{7}{|c|}{ Calculated AllowableVacuum Limits, inches w.g. } \\
\hline & & & & & & \\
\hline \multicolumn{7}{|l|}{ Local Buckling } \\
\hline Service Level A\&B & 8.51 & 8.51 & 8.73 & 8.73 & 8.73 & 9.95 \\
\hline Service Level C & 10.19 & 10.19 & 10.46 & 10.46 & 10.46 & 11.92 \\
\hline Service Level D & 10.82 & 10.82 & 11.38 & 11.38 & 11.38 & 13.77 \\
\hline \multicolumn{7}{|l|}{ Global Buckling } \\
\hline Service Level A\&B & 7.91 & 7.91 & 7.88 & 7.88 & 7.88 & 8.78 \\
\hline Service Level C & 9.49 & 9.49 & 9.45 & 9.45 & 9.45 & 10.53 \\
\hline $\begin{array}{l}\text { Governing } \\
\text { Allowable Vacuum, inch w.g. }\end{array}$ & 7.91 & 7.91 & 7.88 & 7.88 & 7.88 & 8.78 \\
\hline $\begin{array}{l}\text { Governing Allowable } \\
\text { when vacuum = Level C load }\end{array}$ & 9.49 & 9.49 & 9.45 & 9.45 & 9.45 & 10.53 \\
\hline Current Vacuum Limit, inches w.g. & 6 & 6 & 6 & 6 & 6 & 12 \\
\hline
\end{tabular}


Table 7-6. Summary of DST Primary Tank Buckling Evaluations for a Range of Corrosion Allowances and Operating Conditions

\begin{tabular}{|c|c|c|c|c|c|c|}
\hline & \multicolumn{5}{|c|}{ Buckling Evaluation of the DST Primary Tanks } & \multirow[b]{2}{*}{ AP } \\
\hline & AY & AZ & SY & AW & AN & \\
\hline \multicolumn{7}{|l|}{ Approx. Operating History } \\
\hline Temp, F & 250 & 250 & 150 & 150 & 150 & 120 \\
\hline Hwaste, inch & 370 & 370 & 422 & 422 & 422 & 422 \\
\hline \multicolumn{7}{|c|}{ Maximum Specified Operating Conditions } \\
\hline Temp, F & 350 & 350 & 250 & 350 & 350 & 210 \\
\hline Hwaste, inch & 370 & 370 & 422 & 422 & 422 & 422 \\
\hline SpG & 1.77 & 1.77 & 1.70 & 1.70 & 1.70 & 2.00 \\
\hline Yield at Temp, ksi & 27.85 & 27.85 & 31.45 & 39 & 39 & 39.7 \\
\hline Corrosion Allowance, inch & 0.000 & & & & & \\
\hline Level C Vacuum Limit, inch w.g. & 8.86 & 8.86 & 11.77 & 9.85 & 9.85 & 13.45 \\
\hline Corrosion Allowance, inch & 0.010 & & & & & \\
\hline Level C Vacuum Limit, inch w.g. & 9.04 & 9.04 & 11.70 & 9.94 & 9.94 & 12.95 \\
\hline & & & & & & \\
\hline Corrosion Allowance, inch & 0.025 & & & & & \\
\hline Level C Vacuum Limit, inch w.g. & 9.20 & 9.20 & 11.13 & 9.98 & 9.98 & 12.20 \\
\hline Corrosion Allowance, inch & & & & & & \\
\hline Level C Vacuum Limit, inch w.g. & 9.04 & 9.04 & 9.45 & 9.32 & 9.32 & 1053 \\
\hline & & & & & & \\
\hline Corrosion Allowance, inch & 0.100 & & & & & \\
\hline Level C Vacuum Limit, inch w.g. & 7.26 & 7.26 & 7.23 & 7.23 & 7.23 & 8.75 \\
\hline & & & & & & \\
\hline Corrosion Allowance, inch & 0.110 & & & & & \\
\hline Level C Vacuum Limit, inch w.g. & 6.65 & 6.65 & 6.63 & 6.63 & 6.63 & 8.32 \\
\hline Corrosion Allowance, inch & 0.120 & & & & & \\
\hline Level C Vacuum Limit, inch w.g. & 6.03 & 6.03 & 6.00 & 6.00 & 6.00 & 7.90 \\
\hline \multicolumn{7}{|c|}{ Maximum Expected Future Operating Conditions } \\
\hline Temp, F & 250 & 250 & 250 & 250 & 250 & 210 \\
\hline Hwaste, inch & 370 & 370 & 422 & 422 & 422 & 422 \\
\hline SpG & 2.00 & 2.00 & 1.70 & 1.70 & 1.70 & 2.00 \\
\hline Yield at Temp, ksi & 27.85 & 27.85 & 31.45 & 39.00 & 39.00 & 39.70 \\
\hline Corrosion Allowance, inch & 0.000 & & & & & \\
\hline Level C Vacuum Limit, inch w.g. & 10.69 & 10.69 & 11.77 & 11.77 & 11.77 & 13.45 \\
\hline Corrosion Allowance, inch & 0.010 & & & & & \\
\hline Level C Vacuum Limit, inch w.g. & 10.71 & 10.71 & 11.70 & 11.70 & 11.70 & 12.95 \\
\hline & & & & & & \\
\hline Corrosion Allowance, inch & 0.025 & & & & & \\
\hline Level C Vacuum Limit, inch w.g. & 10.65 & 10.65 & 11.13 & 11.13 & 11.13 & 12.20 \\
\hline Corrosion Allowance, inch & 0.060 & & & & & \\
\hline Level C Vacuum Limit, inch w.g. & 9.49 & 9.49 & 9.45 & 9.45 & 9.45 & 10.53 \\
\hline Corrosion Allowance, inch & 0.100 & & & & & \\
\hline Level C Vacuum Limit, inch w.g. & 7.26 & 7.26 & 7.23 & 7.23 & 7.23 & 8.75 \\
\hline Corrosion Allowance, inch & 0.110 & & & & & \\
\hline Level C Vacuum Limit, inch w.g. & 6.65 & 6.65 & 6.63 & 6.63 & 6.63 & 8.32 \\
\hline Corrosion Allowance, inch & 0.120 & & & & & \\
\hline Level C Vacuum Limit, inch w.g. & 6.03 & 6.03 & 6.00 & 6.00 & 6.00 & 7.90 \\
\hline Current Vacuum Limit, inches w.g. & 6 & 6 & 6 & 6 & 6 & 12 \\
\hline
\end{tabular}


However, limiting general corrosion in the AP tank evaluation to 0.025 inch over the remaining life of the tank is reasonable because a recent inspection has shown that the measured wall thickness of the AP tanks is generally greater than the nominal design thickness (Jensen 2005). Similar work measuring the wall thicknesses of all the other double-shell tanks has shown that little or no general wall thinning has occurred throughout the years of operation. For example, only three locations of very localized pitting corrosion ( 0.154 inch maximum depth over an area of $\left.0.5 \mathrm{inch}^{2}\right)$ were found during the wall thickness assessment of tank AY-101 (Jensen 2003). In addition, the future operating temperature of the tanks is expected to be much lower than the current $350^{\circ} \mathrm{F}$ limit. Tests conducted on an aging waste tank (AZ-101) showed that the ventilation system maintained an average supernatant temperature of $190^{\circ} \mathrm{F}$ for a heat load of $4.7 \mathrm{mBTU} / \mathrm{hr}$ in the tank (Hoover 1990). This is about three times higher than the expected heat load in the future, based on extended operation of a pair of 300-HP mixer pumps in a single DST. The calculated heat load for the pair of mixer pumps is estimated to be $1.66 \mathrm{mBTU} / \mathrm{hr}$ (Keller 1997). The heat input from the tank radionuclide content in the future will be negligible compared to the mixer pump energy. Therefore, the waste temperature is not expected to exceed $200^{\circ} \mathrm{F}$ during future operations.

Other buckling cases were evaluated in Table 7-6 where the waste temperature limit for the AY, AZ, AW, and $\mathrm{AN}$ tanks was reduced to $250^{\circ} \mathrm{F}$ and the corrosion allowance was limited to $0.025 \mathrm{inch}$. The second half of Table 7-6 shows that the calculated allowable vacuums for these more reasonable operating conditions are greater than those for the more extreme combinations of design corrosion allowance and temperature.

Two additional cases are listed in Table 7-6 where the corrosion allowance was increased to the point where the calculated vacuum limit was nearly equal to the vacuum limit of 6.0 inch w.g. Table 7-6 estimates that the maximum allowable corrosion for the AY, AZ, SY, AW, and AN tanks is 0.120 inch. These calculated corrosion limits are the same for both the current waste temperature limit $\left(350^{\circ} \mathrm{F}\right)$ and the estimated maximum future waste temperature $\left(250^{\circ} \mathrm{F}\right)$ because global buckling governs and the difference in axial compressive stress is not considered in the calculation. Therefore, the minimum wall thickness for buckling in these tanks is estimated to be 0.255 inch in the thinnest upper section of the primary tank wall. These calculations conservatively assume uniform general corrosion.

The spreadsheet described in this section provides a convenient tool for quickly calculating the applied loads, the vacuum and axial load limits, and the code-based allowable vacuum loads. The buckling evaluation method contained in this work uses curve fitting to condense many detailed analyses into a quick evaluation tool. As such, it includes necessary conservatisms in the influence functions to ensure that the applied loads are not under-predicted or that the unfactored vacuum limit is not over-predicted for the range of input parameters that define the tanks. In addition, the ASME stiffness reduction method used to calculate the limiting vacuum and the axial loads is also judged to be conservative. The finite element results show that the unscaled tank deformations are barely visible on the tank geometry (see Figures 3-9 and 3-10) at the ASME limits for vacuum and axial loads. The models also predict that stable deformation will occur beyond these limits. Therefore, the buckling evaluation tool provides a conservative evaluation of the DST primary tanks. In cases where the calculated allowable vacuum is predicted to be below the current vacuum limit, then additional, more detailed analysis would be required to qualify the tank for the higher vacuum limit.

Based on the analysis contained in this report, the current limits on the maximum vacuum level of 6 inches w.g. for the AY, AZ, SY, AN, and AW tanks and 12 inches w.g. for the AP tanks are acceptable given the current lack of corrosion in the tanks and the expectation that the maximum waste temperature 


\section{RPP-RPT-28967, Rev. 2}

will not exceed $160^{\circ} \mathrm{F}$ in the $\mathrm{AY}, \mathrm{AZ}, \mathrm{SY}, \mathrm{AN}$, and $\mathrm{AW}$ tanks and $135^{\circ} \mathrm{F}$ in the AP tanks. These limits are predicated on maintaining the minimum allowable waste level at 6 inches for the AY, AZ, SY, AN, and AW tanks and 12 inches for the AP tanks to preclude bottom uplift from occurring.

\subsection{Plastic Buckling}

Since the ASME Code, Section III does not address the plastic elephant-foot mode of buckling, the DST structural acceptance criteria (Day et al. 1995) recommends using the compressive stress limit defined in the TSEP guidelines (Bandyopadhyay et al. 1995):

$$
\sigma_{b e}=\frac{0.6 \mathrm{E}_{\mathrm{t}}}{\mathrm{R} / \mathrm{t}_{\mathrm{tw}}}\left[1-\left(\frac{\mathrm{p}_{\mathrm{mx}} \mathrm{R}}{\mathrm{S}_{\mathrm{y}} \mathrm{t}_{\mathrm{tw}}}\right)^{2}\right]\left[1-\frac{1}{1.12+\mathrm{k}^{1.5}}\right]\left[\frac{\mathrm{k}+\left(\mathrm{S}_{\mathrm{y}} / 36\right)}{\mathrm{k}+1}\right]
$$

where: $\mathrm{k}=\mathrm{R} /\left(400 \mathrm{t}_{\mathrm{tw}}\right)$

$$
\begin{aligned}
R= & \text { Primary tank mean radius } \\
t_{t w}= & \text { Nominal tank wall thickness minus the corrosion allowance at the location of the } \\
& \text { cylindrical wall of interest. } \\
S_{y}= & \text { Yield strength }(\mathrm{ksi}) \text { of the material at the design temperature. } \\
E_{y}= & \text { Elastic modulus of the primary tank material at the design temperature. } \\
p_{m x}= & \text { Maximum net internal redial pressure coincident with the compressive stress at the } \\
& \text { location of the cylindrical wall of interest. }
\end{aligned}
$$

Under seismic loading

$$
\mathrm{p}_{\mathrm{mx}}=\mathrm{p}_{\mathrm{st}}+\mathrm{p}_{\mathrm{h}}+0.4 \mathrm{p}_{\mathrm{v}}
$$

where: $\quad \mathrm{p}_{\mathrm{st}}=$ Total static pressure equal to the sum of the vapor pressure and the hydrostatic pressure for the liquid waste at the location of interest.

$p_{h}=$ Hydrodynamic pressure due to lateral seismic motion at the location of interest.

$p_{v}=$ Hydrodynamic pressure due to vertical seismic motion at the location of interest.

Once $\sigma_{b e}$ is determined, the axial compressive membrane stress allowable can be calculated as:

$$
\sigma_{\mathrm{a}}=\frac{\sigma_{\mathrm{be}}}{\text { Factor_of_Safety }}
$$

Where the factors of safety are:

\begin{tabular}{|c|c|}
\hline Service Level & Factor of Safety \\
\hline A & 2 \\
\hline B & 2 \\
\hline C & $5 / 3$ \\
\hline D & $4 / 3$ \\
\hline
\end{tabular}

Plastic elephant-foot buckling can only develop near the lower knuckle of the tank where large hoop stresses occur and hoop expansion is constrained by the base plate of the tank. Therefore, the hoop and 
axial stresses near the base of the tank should be used in the elephant-foot buckling evaluation. The distributions of hoop stress from the combined seismic and deadweight analyses by Carpenter et al. (2006) are plotted in Figure 7-1. A local maximum hoop stress occurs at approximately 48 inches above the tank floor $(22,889$ psi). This occurs in the 0.75 -inch-thick wall section about 2 feet above the tangent point between the lower knuckle and the vertical tank wall.

Equation 7-1 was recast using the maximum hoop stress directly

$$
\sigma_{b e}=\frac{0.6 E_{t}}{R / t_{t w}}\left[1-\left(\frac{\sigma_{h o o p, \max }}{S_{y}}\right)^{2}\right]\left[1-\frac{1}{1.12+k^{1.5}}\right]\left[\frac{k+\left(S_{y} / 36\right)}{k+1}\right]
$$

Table 7-7 summarizes the plastic buckling evaluation of the different double-shell tank designs. The applied axial compressive stress in the tank wall was conservatively assumed to be the maximum reaction force that can be supported by the primary tank. The load deflection curve in Figure 3-11 shows that the maximum reaction force for the uncorroded AY primary tank is $0.95 \mathrm{kip} /$ inch of circumference.

Similarly, Figure 3-13 shows that the maximum reaction force is $1.7 \mathrm{kip} / \mathrm{inch}$ for the uncorroded AP tank. The right-most column in Table 7-6 gives the demand/capacity ratio as the maximum applied axial compressive stress divided by the maximum axial stress at the onset of plastic-buckling. Table 7-7 shows that the maximum demand/capacity ratio of 0.34 occurs for the AY/AZ tanks. This means that the maximum axial reaction load that can be exerted by the primary tank is only $34 \%$ of the axial load required to initiate plastic buckling. Therefore, plastic buckling of the DST primary tanks is not a credible failure mode for the seismic loads considered here.

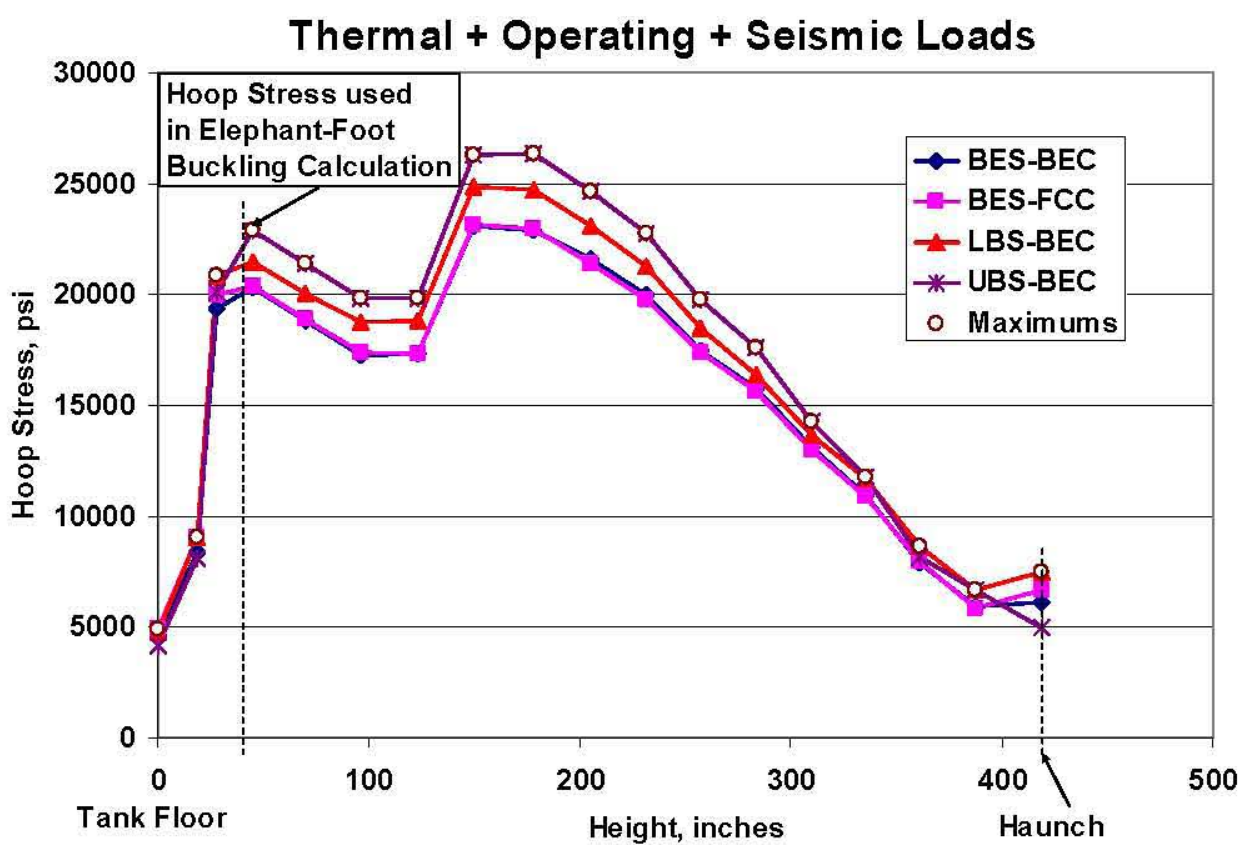

Figure 7-1. The Axial Distribution of Hoop Stress in the Primary Tank Wall Due to Thermal + Operating + Seismic Loads 
Table 7-7. Reevaluation of Plastic Buckling for the DST Primary Tanks

\begin{tabular}{|c|c|c|c|c|c|c|c|c|c|}
\hline \multicolumn{2}{|c|}{ AY / AZ Tanks } & & & & & & & & \\
\hline \multicolumn{2}{|c|}{ Tank Radius } & 450 & inch & \multicolumn{2}{|c|}{ Yield Strength } & 27850 & psi & & \\
\hline \multicolumn{2}{|c|}{ Waste Height } & 370 & inch & \multicolumn{2}{|c|}{ Corrosion Allowance } & 0.06 & inch & & \\
\hline SpG & & 1.77 & & \multicolumn{2}{|c|}{ Max. Axial Force } & 0.95 & kip/inch & & \\
\hline \multicolumn{2}{|c|}{ Temperature } & 350 & $\mathbf{F}$ & \multicolumn{2}{|c|}{ Max. Seismic Hoop S } & 22889 & psi & & \\
\hline \multicolumn{2}{|c|}{ Elastic Mod at Temp } & $2.85 \mathrm{E}+07$ & psi & & & & & & \\
\hline & & & & & & & Service & & \\
\hline & & & & & & & Level D & & \\
\hline & & & & & & & Safety & Smx $=$ & \\
\hline & & & & Max. & & & Factor $=$ & Max. & \\
\hline & & Nominal & Corroded & Seismic & & & \begin{tabular}{|l|}
1.33 \\
\end{tabular} & Axial & \\
\hline & & Thickness & Thickness & Shoop & $\mathbf{k}=$ & $\sigma_{\text {be }}$ & $\sigma_{\mathrm{a}}$ & Stress & Ratio \\
\hline ELEM & Height, in. & Inch & Inch & psi & $R /\left(400^{\star} t\right)$ & psi & psi & psi & Smx/oa \\
\hline \multirow[t]{4}{*}{1262} & \begin{tabular}{|l|}
48.38 \\
\end{tabular} & 0.750 & 0.69 & 22889 & 1.63 & 5348 & 4011 & 1377 & 0.34 \\
\hline & & & & & & & & & \\
\hline & & & & & & \multicolumn{3}{|c|}{ Maximum Ratio, $\mathbf{S m x} / \sigma_{\mathrm{a}}=$} & 0.34 \\
\hline & & & & & & & & & \\
\hline $\mathrm{AN} / \mathrm{AV}$ & Tanks & & & & & & & & \\
\hline Tank Rac & & 450 & inch & Yield Stren & & 39000 & psi & & \\
\hline Waste $\mathrm{He}$ & & 422 & inch & Corrosion & Ilowance & 0.06 & inch & & \\
\hline SpG & & 1.70 & & Max. Axial & Force & 0.95 & kip/inch & & \\
\hline Tempera & & 350 & $\mathbf{F}$ & Max. Seisn & ic Hoop S & 22889 & psi & & \\
\hline Elastic M & at Temp & $2.85 \mathrm{E}+07$ & psi & & & & & & \\
\hline & & & & & & & Service & & \\
\hline & & & & & & & Level D & & \\
\hline & & & & & & & \begin{tabular}{|l|} 
Safety \\
\end{tabular} & $\operatorname{smx}=$ & \\
\hline & & & & Max. & & & Factor $=$ & Max. & \\
\hline & & Nominal & Corroded & Seismic & & & \begin{tabular}{|l|}
1.33 \\
\end{tabular} & Axial & \\
\hline & & Thickness & Thickness & Shoop & $\mathbf{k}=$ & $\sigma_{\text {be }}$ & $\sigma_{\mathrm{a}}$ & Stress & Ratio \\
\hline ELEM & Height, in. & Inch & Inch & psi & $R /\left(400^{\star} t\right)$ & psi & psi & psi & Smx/oa \\
\hline 1262 & \begin{tabular}{|l|}
48.38 \\
\end{tabular} & 0.750 & 0.69 & 22889 & 1.63 & 12195 & 9146 & 1377 & 0.15 \\
\hline & & & & & & \begin{tabular}{|l} 
Maximum \\
\end{tabular} & Ratio $5 \mathrm{~m}$ & $y / \sigma_{-}=$ & 0.15 \\
\hline & & & & & & & & & \\
\hline SYTan & & & & & & & & & \\
\hline Tank Rac & & 450 & inch & Yield Stren & & 30500 & psi & & \\
\hline Waste $\mathrm{He}$ & & 422 & inch & Corrosion & Ilowance & 0.060 & inch & & \\
\hline SpG & & 1.70 & & Max. Axial & Force & 0.95 & kip/inch & & \\
\hline Tempera & & 250 & $\mathbf{F}$ & Max. Seisn & ic Hoop S & 22889 & psi & & \\
\hline Elastic M & at Temp & $2.85 \mathrm{E}+07$ & psi & & & & & & \\
\hline & & & & & & & Service & & \\
\hline & & & & & & & Level D & & \\
\hline & & & & & & & \begin{tabular}{|l|} 
Safety \\
\end{tabular} & Smx $=$ & \\
\hline & & & & Max. & & & Factor $=$ & Max. & \\
\hline & & Nominal & Corroded & Seismic & & & \begin{tabular}{|l|}
1.33 \\
\end{tabular} & Axial & \\
\hline & & Thickness & Thickness & Shoop & $\mathbf{k}=$ & $\sigma_{\text {be }}$ & $\sigma_{\mathrm{a}}$ & Stress & Ratio \\
\hline ELEM & Height, in. & Inch & Inch & psi & $R /\left(400^{\star} t\right)$ & psi & psi & psi & Smx/oa \\
\hline 1262 & 48.38 & 0.750 & 0.69 & 22889 & 1.63 & 7419 & 5564 & 1377 & 0.25 \\
\hline & & & & & & & & & \\
\hline & & & & & & Maximum & Ratio, Sm & $x / \sigma_{a}=$ & 0.25 \\
\hline & & & & & & & & & \\
\hline AP Tan & & & & & & & & & \\
\hline Tank Rac & & 450 & inch & Yield Stren & & 39700 & psi & & \\
\hline Waste $\mathrm{He}$ & & 422 & inch & Corrosion & Ilowance & 0.06 & inch & & \\
\hline SpG & & 1.70 & & Max. Axial & Force & 1.7 & kip/inch & & \\
\hline Tempera & & 210 & $\mathbf{F}$ & Max. Seisn & ic Hoop S & 22889 & psi & & \\
\hline Elastic M & at Temp & $2.85 \mathrm{E}+07$ & psi & & & & & & \\
\hline & & & & & & & Service & & \\
\hline & & & & & & & Level D & & \\
\hline & & & & & & & \begin{tabular}{|l|} 
Safety \\
\end{tabular} & Smx $=$ & \\
\hline & & & & Max. & & & Factor $=$ & Max. & \\
\hline & & Nominal & Corroded & Seismic & & & \begin{tabular}{|l|}
1.33 \\
\end{tabular} & Axial & \\
\hline & & Thickness & Thickness & Shoop & $\mathbf{k}=$ & $\sigma_{\text {be }}$ & $\sigma_{\mathrm{a}}$ & Stress & Ratio \\
\hline ELEM & Height, in. & Inch & Inch & psi & $R /\left(400^{\star} t\right)$ & psi & psi & psi & Smxioa \\
\hline 1262 & 48.38 & 0.750 & 0.69 & 22889 & 1.63 & 12508 & 9381 & 2464 & 0.26 \\
\hline & & & & & & & & & \\
\hline & & & & & & Maximum & Ratio, Sr & $x / \sigma_{a}=$ & 0.26 \\
\hline
\end{tabular}



RPP-RPT-28967, Rev. 2

\subsection{Summary and Conclusions}

This report documents a detailed buckling evaluation of the primary tanks in the Hanford double-shell waste tanks, which is part of a comprehensive structural review for the Double-Shell Tank Integrity Project. This work also provides information on tank integrity that specifically responds to concerns raised by the Office of Environment, Safety, and Health (ES\&H) Oversight (EH-22) during a review of work performed on the double-shell tank farms and the operation of the aging waste facility (AWF) primary tank ventilation system.

The current buckling review focuses on the following tasks:

- Evaluate the potential for progressive Anchor bolt failure and the appropriateness of the safety factors that were used for evaluating local and global buckling. The analysis will specifically answer the following questions:

- Can the EH-22 scenario develop if the vacuum is limited to -6.6 in. water gage by a relief valve?

- What is the appropriate factor of safety required to protect against buckling if the EH- 22 scenario can develop?

- What is the appropriate factor of safety required to protect against buckling if the EH-22 scenario cannot develop?

- Develop influence functions to estimate the axial stresses in the primary tanks for all reasonable combinations of tank loads based on detailed finite element analysis. The analysis must account for the variation in design details and operating conditions between the different DSTs. The analysis must also address the imperfection sensitivity of the primary tank to buckling.

- Perform a detailed buckling analysis to determine the maximum allowable differential pressure for each of the DST primary tanks at the current specified limits on waste temperature, height, and specific gravity.

Previous buckling evaluations of the double-shell primary tanks used the analysis method in ASME Code Case N-284-1, which is based on the buckling of a constant thickness cylindrical shell with unsupported length, L. The cylindrical shell of the DST primary tanks does not have constant wall thickness and it does not have clearly defined lines of support due to the varying wall thickness and the upper and lower knuckle geometries.

The present buckling analysis used large displacement finite element analysis to predict the limiting vacuum load for the DST primary tanks under combined axial and vacuum loads. The analysis included tank models that were specific to the geometry and thickness distributions of the AY and the AP tanks. The AY results are also representative of the AZ, SY, AW, and AN tanks because they have very similar wall thickness distributions. The current buckling evaluation method uses the well established ASME NB-3213.25 stiffness reduction method to conservatively estimate the vacuum and axial load limits on the primary tank. Comparison with N-284-1 calculations showed that PNNL's large displacement method better accounts for the effect of the wall thickness variation on the limiting vacuum and axial loads. The 
finite element analysis also predicts that the tank deformations are small at the limit loads and they increase stably at loads beyond the limit loads. A large matrix of analyses was run that covers the expected range of axial forces and vacuum loads on the primary tanks. Influence functions were fit to the limit load predictions to allow calculating the limiting vacuum and axial loads for all reasonable combinations of axial load, corrosion allowance, specific gravity, and waste height.

An ANSYS thermal model was developed that is directly node-to-node compatible with the ANSYS DST structural model. Previous thermal simulations for the thermal and operating loads analysis were performed using the TEMPEST finite difference code. A laborious data mapping step was required when transferring the TEMPEST thermal results to the ANSYS structural grid. The ANSYS thermal model supports the tank buckling analysis by allowing easy prediction of tank stresses due to different combinations of thermal and operating loads. This capability was required to calculate the allowable net vacuum loads as a function of the waste height and temperature. The ANSYS thermal model includes the effects of radiation and convection in the annulus and the dome space, and the thermal solution compared very closely with the previous TEMPEST thermal results. The two temperature solutions also give very similar stresses throughout the thermal transient.

Influence functions were also developed to estimate the applied axial force in the primary tank wall, which is required for evaluating buckling of the primary tank. The sequentially coupled ANSYS thermal and structural models were used to predict the axial thermal stresses in the wall of the primary tanks for a large matrix of waste height and temperature conditions. Analyses were conducted for both the AY and AP wall thickness distributions. The axial forces for the applied load components were curve fit to allow estimating the total equivalent linear elastic axial force as the sum of the following loads:

- Differential thermal expansion,

- Gravity,

- Surface loads,

- Concrete thermal degradation and creep,

- Seismic excitation, and the

- Effect of hydrostatic waste pressure on the confined axial force.

The variation in concrete anchor loads in and near a local buckle was calculated to address the concern of the EH-22 safety panel that an initiating buckle may locally overload some anchors in the outer ring and lead to progressive anchor failure and global buckling of the primary tank. The finite element analyses showed that a local buckle increases the maximum anchor axial displacement by no more than 0.0002 inch and the shear displacement increases by no more than 0.002 inch. These are very small variations compared to the baseline anchor displacements for the combined thermal operating and seismic loads (see Table 6-1). Therefore, the differential vacuum from the tank ventilation systems will not cause the anchor bolts to fail in or near a local buckle. Since the anchors are not expected to fail, then it is unlikely that the EH-22 scenario could occur.

Both elastic and plastic buckling analyses were performed for the DST primary tanks. The elastic buckling evaluation provides a method for evaluating the allowable vacuum limits for the DST primary tanks. The current method follows the previous tank buckling evaluations; however, the N-284-1 calculations were replaced with the large displacement method that was developed in the current work. The method calculates the axial force on the primary tank wall and then uses this force to calculate the unfactored limits on vacuum and axial load. The safety factors for the ASME Section III service levels 
are applied to calculate the allowable tank vacuum limits. Each service level has required factors of safety for local and global buckling:

Level $\mathrm{A}=$ Normal operating conditions

Level B $=$ Upset conditions

Level $\mathrm{C}=$ Emergency conditions

Level D $=$ Faulted conditions
Factors of Safety

\begin{tabular}{ccc}
\hline Local Buckling & & Global Buckling \\
2.0 & 2.4 \\
2.0 & 2.4 \\
1.67 & 2.0 \\
1.34 & 1.61
\end{tabular}

An Excel ${ }^{\mathrm{TM}}$ spreadsheet was constructed to perform the above calculations and apply the safety factors. The spreadsheet was used to evaluate each of the DST primary tanks for their current operating conditions (waste temperature, height, and $\mathrm{SpG}$ ) and corrosion allowances of $0.000,0.060$, and 0.100 inch.

Table 7-4 shows that the calculated allowable vacuum limits for the conservative baseline assumption of 0.060 inch corrosion are greater than the current vacuum limits for all of the tanks except the AP tanks. The current AP vacuum allowable is 12 inches w.g. compared to the calculated allowable of 10.53 inch w.g. This vacuum limit is based on global buckling assuming a minimum waste height of 12 inches. The calculations show that although the AP tank is slightly thicker in the upper tank wall, this is not enough to double the vacuum limit compared to the other tanks.

Additional cases were analyzed with corrosion levels from 0.000 to 0.120 inches and a more realistic maximum future waste temperature of $250^{\circ} \mathrm{F}$. The calculated allowable vacuum limits for the $\mathrm{AY}, \mathrm{AZ}$, $\mathrm{SY}, \mathrm{AW}$, and $\mathrm{AN}$ tanks are above the current vacuum limit of 6 inch w.g. for all the cases. The allowable vacuum limit for the AP tank is above the current 12 inch w.g. limit for corrosion allowances of 0.000 to 0.025 inches. Therefore, the minimum wall thickness for buckling in the AP tanks is estimated to be 0.475 inch in the upper section of the primary tank wall.

The corrosion allowance for the AY, AZ, SY, AW, and AN tanks was also increased to identify the maximum value where the calculated vacuum limit was nearly equal to the 6 inch w.g. vacuum limit. The maximum allowable corrosion for these tanks was estimated to be $0.120 \mathrm{inch}$. These calculated corrosion limits are the same for both the current waste temperature limit $\left(350^{\circ} \mathrm{F}\right)$ and the lower maximum future waste temperature $\left(250^{\circ} \mathrm{F}\right)$ because global buckling governs and the difference in axial compressive stress is not considered in the global buckling calculation. Therefore, the minimum uniform wall thickness for buckling in these tanks is estimated to be 0.255 inch in the thinnest upper section of the primary tank wall.

The spreadsheet described in this section provides a convenient tool for quickly calculating the applied loads, the vacuum and axial load limits, and the code-based allowable vacuum loads. The buckling evaluation method contained in this work uses curve fitting to condense many detailed analyses into a quick evaluation tool. As such, it includes necessary conservatisms in the influence functions to ensure that the applied loads are not under-predicted or that the unfactored vacuum limit is not over-predicted for the range of input parameters that define the tanks. In addition, the ASME stiffness reduction method used to calculate the limiting vacuum and the axial loads is also judged to be conservative. The finite element results show that the unscaled tank deformations are barely visible on the tank geometry (see Figures 3-9 and 3-10) at the ASME limits for vacuum and axial loads. The models also predict that stable deformation will occur beyond these limits. Therefore, the buckling evaluation tool provides a conservative evaluation of the DST primary tanks. In cases where the calculated allowable vacuum is predicted 
to be below the current vacuum limit then additional, more detailed analysis would be required to qualify the tank for the higher vacuum limit.

The tank farm occurrence reports from 1990 to the present were reviewed to identify the number of times that the vacuum limits have been challenged. This summary information will be released in the next revision of RPP-11413, Technical Basis for the Ventilation Requirements Contained in Tank Farm Operating Specifications Documents, authored by L. Payne. No incidents were found where the primary tank differential vacuum has exceeding the 6 inch w.g. maximum. There was a report of reaching a vacuum of 4 inch w.g. in the SY tank ventilation system, but the exhauster shut down on interlock. There was one incident in $\mathrm{AW}$, but it was also limited to 4 inch w.g. or less. The incident that people remembered where a vacuum limit was exceeded was in the AN annulus system in 2005 (PER-2005-072). Note that this occurred in the annulus and not in the primary tank.

Therefore, not only are the tanks able to withstand the expected loads without buckling, there are no recorded occurrences where the maximum vacuum has been achieved. There are also safety systems and operating procedures in place to ensure that the maximum vacuum loads are not achieved in future operations.

Based on the analysis contained in this report, the current limits on the maximum vacuum level of 6 inches w.g. for the AY, AZ, SY, AN, and AW tanks and 12 inches w.g. for the AP tanks are acceptable given the current lack of corrosion in the tanks and the expectation that the maximum waste temperature will not exceed $160^{\circ} \mathrm{F}$ in the $\mathrm{AY}, \mathrm{AZ}, \mathrm{SY}, \mathrm{AN}$, and $\mathrm{AW}$ tanks and $135^{\circ} \mathrm{F}$ in the $\mathrm{AP}$ tanks. These limits are predicated on maintaining the minimum allowable waste level at 6 inches for the AY, AZ, SY, AN, and $\mathrm{AW}$ tanks and 12 inches for the AP tanks to preclude bottom uplift from occurring. 


\section{RPP-RPT-28967, Rev. 2}

\subsection{References}

American Society of Mechanical Engineers. 1992. Section III, Division 2, Subsection CC, ASME Boiler and Pressure Vessel Code, American Society of Mechanical Engineers, New York.

American Society of Mechanical Engineers. 1995. Code Case N-284-1, 1995, Metal Containment Shell Buckling Design Method, Class MC, Section III, Division 1. ASME Boiler and Pressure Vessel Code, American Society of Mechanical Engineers, New York.

American Society of Mechanical Engineers. 2004a. Section III, Division 1, Subsection NB-3200 Design by Analysis, Article 3213.25 Plastic Analysis - Collapse Load. ASME Boiler and Pressure Vessel Code, American Society of Mechanical Engineers, New York.

American Society of Mechanical Engineers. 2004b. Section III, Division 1, Subsection NB-3113 Service Conditions. ASME Boiler and Pressure Vessel Code, American Society of Mechanical Engineers, New York.

American Society of Mechanical Engineers. 2004c. Section III, Division 1, Mandatory Appendix I, Design Stress Intensity Values, Allowable Stresses, Material Properties, and Design Fatigue Curves, Table I-9.1. ASME Boiler and Pressure Vessel Code, American Society of Mechanical Engineers, New York.

Antoniak ZI and KP Recknagle. 1995. Thermal Modeling of Tanks 241-AW-101 and 241-AN104 with the TEMPEST Code, PNL 10683, UC-510, Pacific Northwest Laboratory, Richland, Washington.

Bandyopadhyay K, A Cornell, C Costantino, R Kennedy, C Miller, and A Veletsos. 1995. Seismic Design and Evaluation Guidelines for the Department of Energy High Level Waste Tanks and Appurtenances. BNL 52361. Brookhaven National Laboratory. Associated Universities, Inc., Upton, New York.

Carpenter BG, C Hendrix, and FG Abatt. 2006. Hanford Double Shell Tank Thermal and Seismic Project - ANSYS Seismic Analysis of Hanford Double Shell Primary Tank. RPP-RPT-28966, Rev. 0. M\&D Professional Services, Richland, Washington.

CH2M HILL. 2002. Contract No. DE-AC27-99RL14047 - Final Report of Focused Review of CH2M HILL Hanford Group, Inc. (CHG) Integrated Safety Management System (ISMS). 0204443/02-QAO051. CHG Correspondence Control, CH2M HILL Hanford Group, Inc., Richland, Washington.

Deibler JE, KI Johnson, NK Karri, SP Pilli, MW Rinker, FG Abatt, BG Carpenter, and CA Hendrix. 2008a. Hanford Double-Shell Tank Thermal and Seismic Project-Summary of Combined Thermal and Operating Loads with Seismic Analysis, PNNL-15721, RPP-RPT-28968, Rev. 1. Pacific Northwest National Laboratory, Richland, Washington.

Deibler JE, KI Johnson, SP Pilli, MW Rinker, FG Abatt, NK Karri. 2008b. Hanford Double-Shell Tank Thermal and Seismic Project - Increased Liquid Level Analysis for 241-AP Tank Farms. PNNL-16372, RPP-RPT-32237, Rev. 1. Pacific Northwest National Laboratory, Richland, Washington. 


\section{RPP-RPT-28967, Rev. 2}

Day JP, AD Dyrness, LJ Julyk, CJ Moore, WS Peterson, MA Scott, HP Shrivastava, JS Shulman, and TN Watts. 1995. Structural Acceptance Criteria for the Evaluation of Existing Double-Shell Waste Storage Tanks Located at the Hanford Site, Richland, Washington. WHC-SD-WM-DGS-003. Westinghouse Hanford Company, Richland, Washington.

Hoover DA. 1990. Functional Design Criteria for the Tank Farm Ventilation Upgrade Project W-030. SD-600-FDC-001, Rev. 3. Westinghouse Hanford Company. Richland, Washington.

Jensen CE. 2003. Supplement 2 to Inspection Results for Double Shell Tank 241-AY-101 FY2003. RPP-15763. CH2M HILL Hanford Group, Inc., Richland, Washington.

Jensen CE. 2005. Ultrasonic Inspection Results for DST 241-AP-106 FY2005. RPP-RPT-23205. CH2M HILL Hanford Group, Inc., Richland, Washington.

Julyk LJ. 1997. Assessment of Project W-030 Relief Valve Pressure Setting on Internal Vacuum Specification Limits for $A Y$ and AZ Tank Farm Primary Tanks. HNF-1838. CH2M HILL Hanford Group, Inc., Richland, Washington.

Julyk LJ and HH Ziada. 2002. Assessment of Double-Shell Tank Internal Vacuum Specification Limits on Primary Tanks. HNF-1838, Rev. 0-A. CH2M HILL Hanford Group, Inc., Richland, Washington.

Keller C. 1997. Functional Design Criteria for the Tank Farm Ventilation Upgrade Project W-030. HNF-SD-600-FDC-001, Rev. 4. Numatec Hanford Company, Richland, Washington.

Ogden DM, MJ Thurgood, WE Bryan, GP Duncan, and DH Shuford. 2002. Engineering Evaluation of Double Shell Tank Vapor Space Condensation and Annulus Relative Humidity. RPP-12422, Rev 0, CH2M HILL Hanford Group, Inc., Richland, Washington.

Rinker MW, JE Deibler, KI Johnson, SP Pilli, CE Guzman-Leong, and OD Mullen. 2004. Hanford Double-Shell Tank Thermal and Seismic Project - Thermal and Operating Load Analysis.

RPP-RPT-23308, Rev. 0. Pacific Northwest National Laboratory, Richland, Washington.

Rinker MW, JE Deibler, KI Johnson, and SP Pilli. 2005. Hanford Double-Shell Tank Thermal and Seismic Project - Increased Concentrated Load Analysis. RPP-RPT-25608, Rev. 0. Pacific Northwest National Laboratory, Richland, Washington.

Rinker MW and RR Youngs. 2006. Development of PC2 Surface Spectra for Double-Shell Tank Facilities, DOE Hanford Site in Washington State. PNNL-15607, RPP-RPT-27570, Rev. 0. Pacific Northwest National Laboratory, Richland, Washington.

Rohay AC and SP Reidel. 2005. Site-specific seismic site response model for the Waste Treatment Plant, Hanford, Washington: Report prepared by Pacific Northwest National Laboratory for the U.S. Department of Energy, Office of River Protection, under Contract DE-AC05-76RL01830. PNNL-15089, Pacific Northwest National Laboratory, Richland, Washington. 
RPP-RPT-28967, Rev. 2

\section{Appendix A}

\section{Analysis Files Used in the Chapter 2 Assessment of Buckling Evaluation Methods}




\section{Appendix A}

\section{Analysis Files Used in the Chapter 2 Assessment of Buckling Evaluation Methods}

This appendix contains examples of all of the ANSYS model input files. To conserve space and avoid duplication of the same data multiple times, some of the files listed will be used multiple times, but they are only included one time in this document. The input files are listed in this following order.

\section{Analysis Files Used in Buckling Evaluation Methods}

- Uniform Cylinder ANSYS Models

- Eigenvalue buckling analysis for Axial Loads

- Eigenvalue buckling analysis for Hoop Loads

- Eigenvalue buckling analysis for Axial and Hoop Loads

- Primary Tank ANSYS Models

- Eigenvalue buckling analysis for Axial Loads

- Eigenvalue buckling analysis for Hoop Loads

- Eigenvalue buckling analysis for Axial and Hoop Loads

Analysis Files Used in Imperfection Sensitivity Analysis

- Uniform Cylinder ANSYS Models

- One Imperfection Eigenvalue buckling analysis for Axial Loads

- One Imperfection Eigenvalue buckling analysis for Hoop Loads

- One Imperfection Eigenvalue buckling analysis for Axial and Hoop Loads

- Two Imperfections Eigenvalue buckling analysis for Axial Loads

- Two Imperfections Eigenvalue buckling analysis for Hoop Loads

- Two Imperfections Eigenvalue buckling analysis for Axial and Hoop Loads

- Four Imperfections Eigenvalue buckling analysis for Axial Loads

- Four Imperfections Eigenvalue buckling analysis for Hoop Loads

- Four Imperfections Eigenvalue buckling analysis for Axial and Hoop Loads

- Primary Tank ANSYS Models

- One Imperfection Eigenvalue buckling analysis for Axial Loads

- One Imperfection Eigenvalue buckling analysis for Hoop Loads

- One Imperfection Eigenvalue buckling analysis for Axial and Hoop Loads

- Two Imperfections Eigenvalue buckling analysis for Axial Loads

- Two Imperfections Eigenvalue buckling analysis for Hoop Loads

- Two Imperfections Eigenvalue buckling analysis for Axial and Hoop Loads

- Four Imperfections Eigenvalue buckling analysis for Axial Loads

- Four Imperfections Eigenvalue buckling analysis for Hoop Loads

- Four Imperfections Eigenvalue buckling analysis for Axial and Hoop Loads 
!*******************************************)!!

!!Buckling Evaluation Methods ANSYS Models!!

!****************************************!!!

\section{!!!Uniform Cylinder Models!!!}

Input File: Uniform Cylinder - Eigenvalue buckling analysis for Axial Loads

fini

/cle

/fil,uc-pft-a

/title,perfect Uniform tank Under Axial Pressure

/com,Fixed Top \& Bottom Rings (Disp only), 180-deg

prep 7

et, 1,181

i

\section{*afun,deg}

!**** Materials

mp,ex, $1,29.5 \mathrm{e} 6$

mp, dens, $1,490 / 1728$

mp,prxy, $1, .3$

tb, biso, 1

tbdata, $1,36000, .01 * 27.7 \mathrm{e} 6$

!*** Shell thickness

$\mathrm{t}=0.507 \quad$ ! wall thickness, inch

$\mathrm{R}, 1, \mathrm{t} \quad$ ! shell Thickness

real, 1

!*** Tank Dimensions

$r=450.0 \quad$ ! tank radius, inch

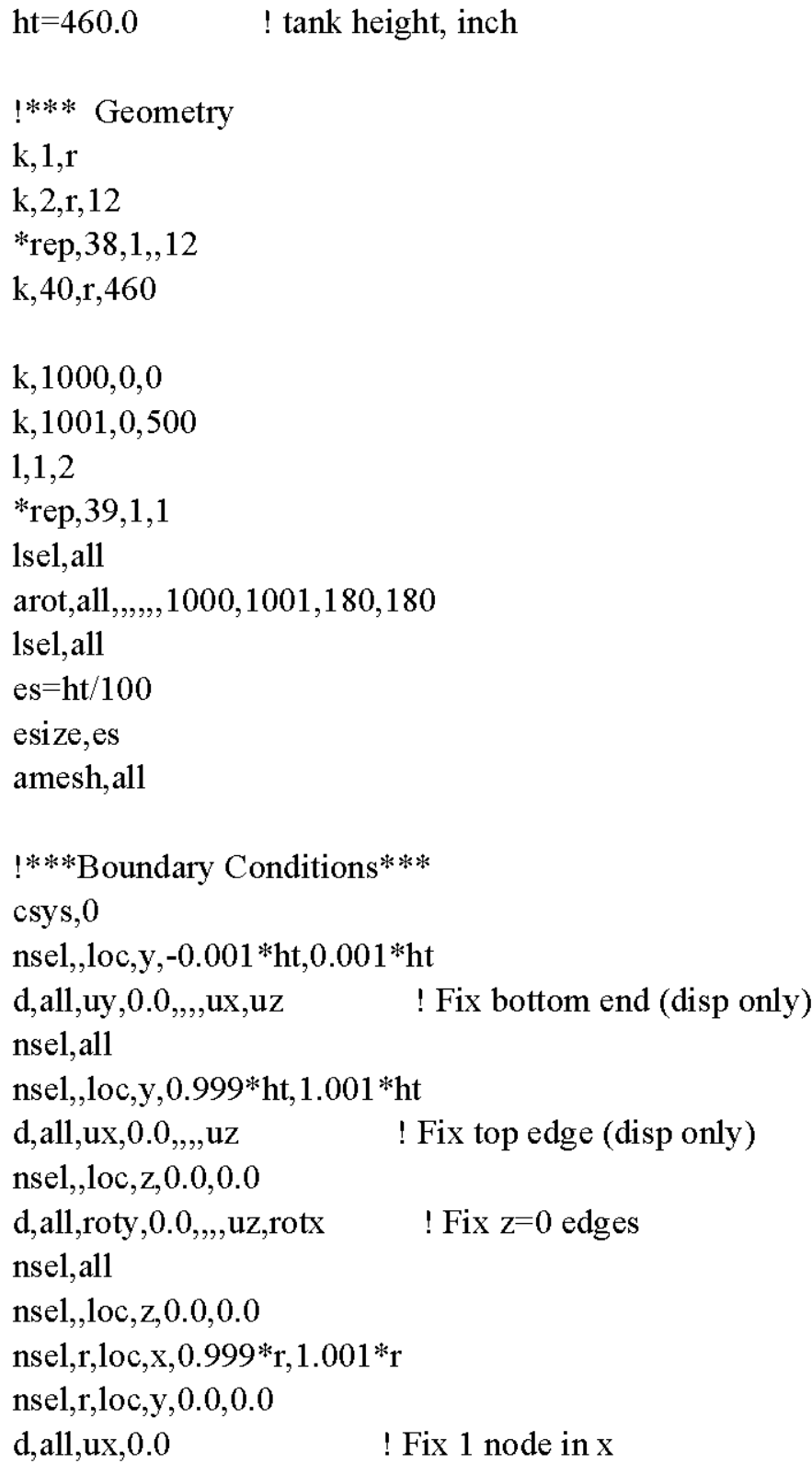




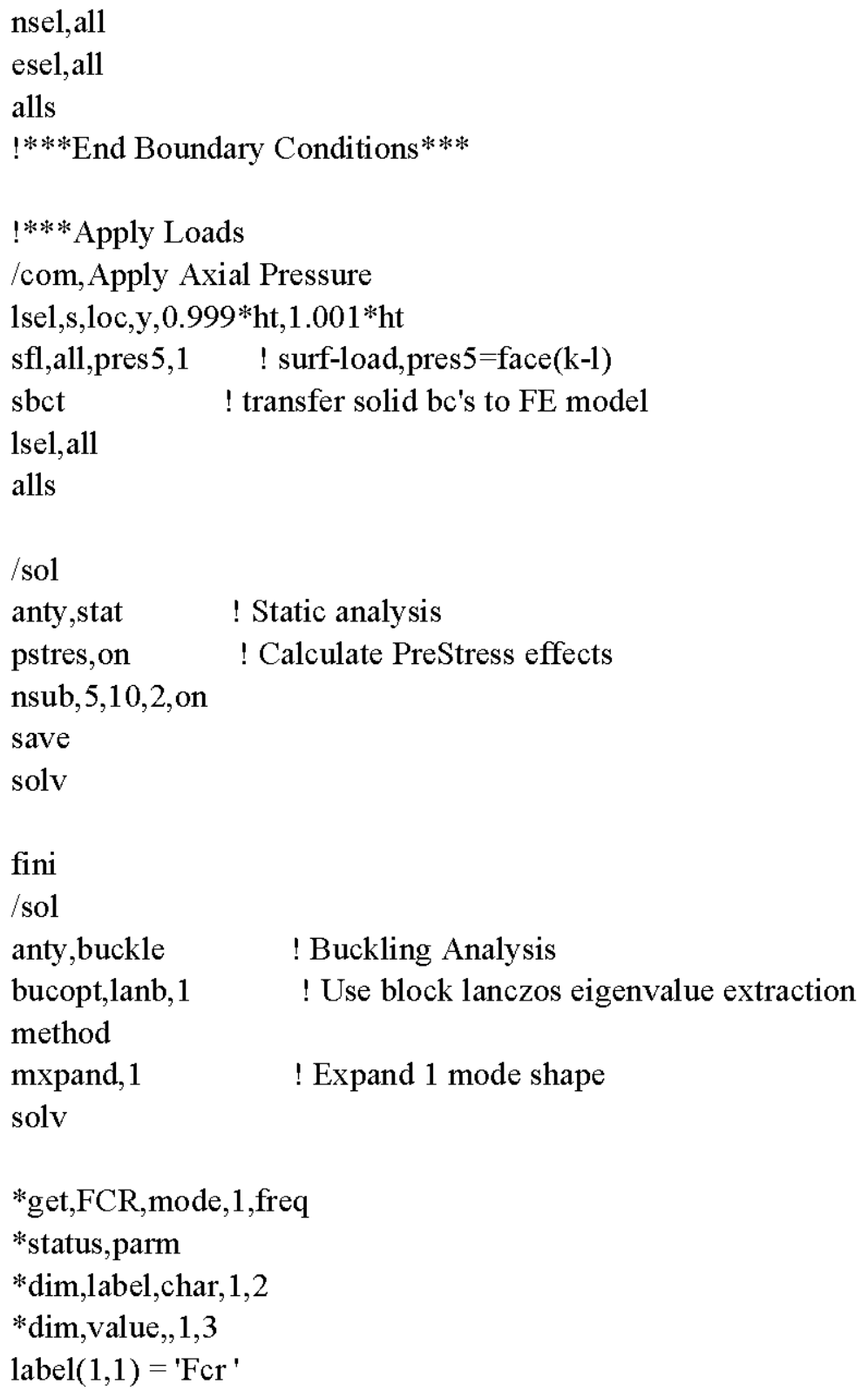

nsel,all

esel,all

alls

!***End Boundary Conditions***

!***Apply Loads

/com,Apply Axial Pressure

1sel,s,loc,y, 0.999*ht, $1.001 * \mathrm{ht}$

sfl,all,pres5,1 ! surf-load,pres5=face(k-1)

sbct ! transfer solid bc's to FE model

1sel,all

alls

/sol

anty,stat ! Static analysis

pstres, on ! Calculate PreStress effects

nsub, $5,10,2$, on

solv

fini

/sol

anty,buckle ! Buckling Analysis

bucopt,lanb,1 ! Use block lanczos eigenvalue extraction

method

mxpand, 1

! Expand 1 mode shape

solv

*get,FCR,mode, 1, freq

*status,parm

*dim,label,char, 1,2

*dim,value, 1,3

label $(1,1)=$ 'Fcr'

$>$ save label $(1,2)={ }^{\prime} 1 b^{\prime}$

Input File: Uniform Cylinder - Eigenvalue buckling analysis for Hoop Loads

fini

/cle

/fil,uc-pft-v

title,perfect Uniform tank Under VAcuum

/com,Fixed Top \& Bottom Rings (Disp only), 180-deg

/prep7

et, 1,181

*afun, deg

!*** Materials

$\mathrm{mp}, \mathrm{ex}, 1,29.5 \mathrm{e} 6$

mp,dens, $1,490 / 1728$

mp,prxy, 1,3

tb, biso, 1

tbdata, $1,36000, .01 * 27.7 \mathrm{e} 6$

!*** Shell thickness

$\mathrm{t}=0.507 \quad$ ! wall thickness, inch

$\mathrm{R}, 1, \mathrm{t} \quad$ ! shell Thickness

real,1

!*** Tank Dimensions

$\mathrm{r}=450.0 \quad$ ! tank radius, inch

$\mathrm{ht}=460.0 \quad$ ! tank height, inch

!*** Geometry

$\mathrm{k}, 1, \mathrm{r}$ 


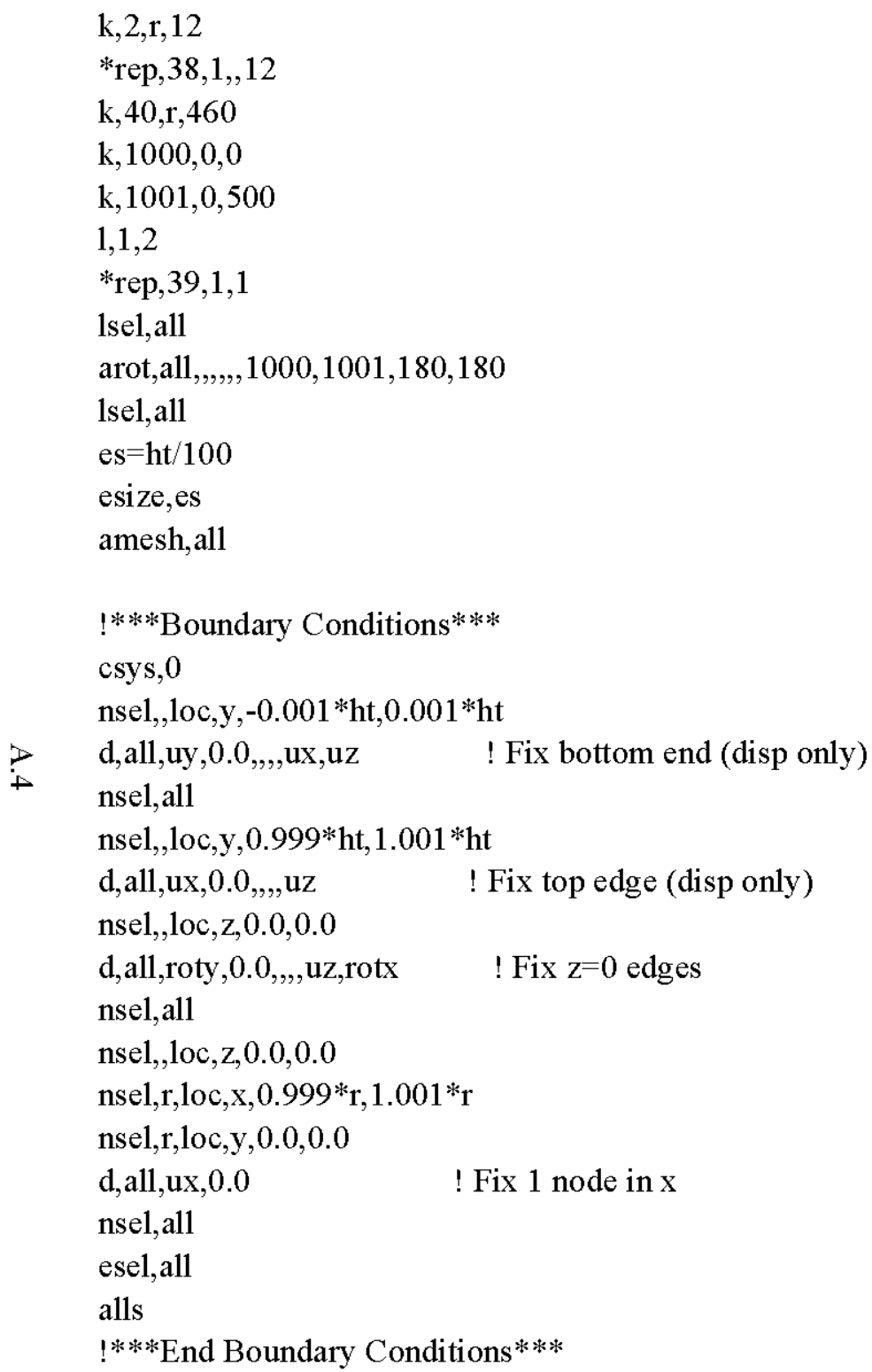

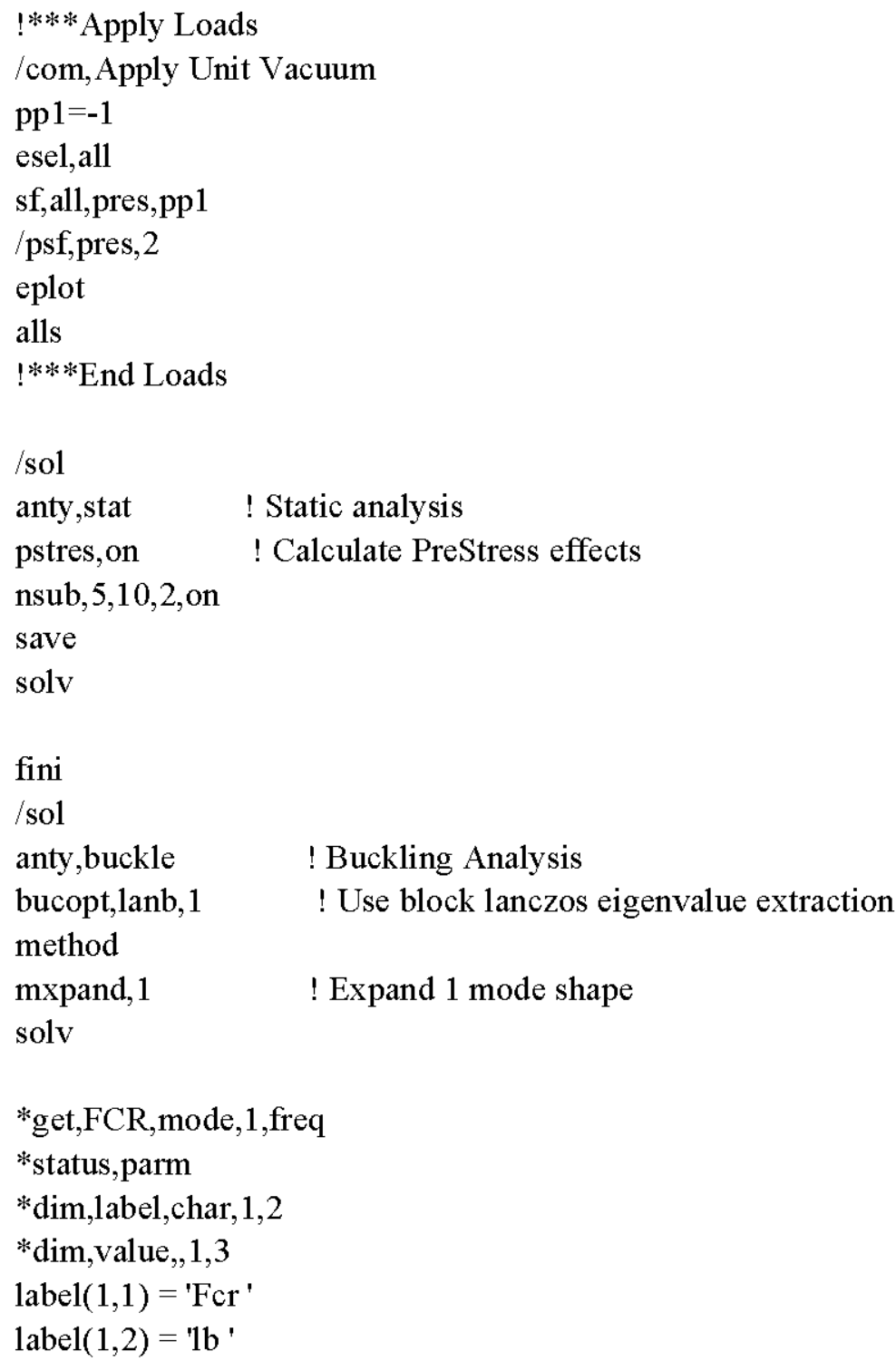


Input File: Uniform Cylinder - Eigenvalue buckling analysis for Axial and Hoop Loads

fini

cle

/fil,uc-pft-v

/title,perfect Uniform tank Under Combined Load

/com,Fixed Top \& Bottom Rings (Disp only), 180-deg

/prep7

et, 1,181

*afun, deg

!*** Materials

$\mathrm{mp}, \mathrm{ex}, 1,29.5 \mathrm{e} 6$

mp, dens, $1,490 / 1728$

mp,prxy, $1, .3$

tb, biso, 1

tbdata, $1,36000, .01 * 27.7 \mathrm{e} 6$

!*** Shell thickness

$\mathrm{t}=0.507 \quad$ ! wall thickness, inch

$\mathrm{R}, 1, \mathrm{t}$ ! shell Thickness

real,1

!*** Tank Dimensions

$\mathrm{r}=450.0 \quad$ ! tank radius, inch

$\mathrm{ht}=460.0 \quad$ ! tank height, inch

!*** Geometry

$\mathrm{k}, 1, \mathrm{r}$

$\mathrm{k}, 2, \mathrm{r}, 12$

*rep, 38, 1,12 $\mathrm{k}, 40, \mathrm{r}, 460$

$\mathrm{k}, 1000,0,0$

$\mathrm{k}, 1001,0,500$

$1,1,2$

*rep, 39,1,1

1sel,all

arot,all,,,,,,1000,1001,180,180

1sel,all

es $=h t / 100$

esize, es

amesh,all

!***Boundary Conditions****

csys, 0

nsel,,loc,y, $-0.001 *$ ht, $0.001 *$ ht

$\mathrm{d}, \mathrm{all}, \mathrm{uy}, 0.0,,, \mathrm{ux}, \mathrm{uz} \quad$ ! Fix bottom end (disp only)

nsel, all

nsel, loc,y, 0.999*ht, $1.001 *$ ht

$\mathrm{d}, \mathrm{all}, \mathrm{ux}, 0.0,,, \mathrm{uz} \quad$ ! Fix top edge (disp only)

nsel, loc, z, $0.0,0.0$

$\mathrm{d}$, all,roty, $0.0,,$, ,uz,rotx $\quad$ ! Fix $\mathrm{z}=0$ edges

nsel, all

nsel, loc, $\mathrm{z}, 0.0,0.0$

nsel,r,loc, $\mathrm{x}, 0.999 *^{*} \mathrm{r}, 1.001 *_{\mathrm{r}}$

nsel,r,loc, $\mathbf{y}, 0.0,0.0$

$\mathrm{d}, \mathrm{all}, \mathrm{ux}, 0.0 \quad$ ! Fix 1 node in $\mathrm{x}$

nsel,all

esel,all

alls

!***End Boundary Conditions***

!***Apply Loads

/com, Apply Unit Vacuum 


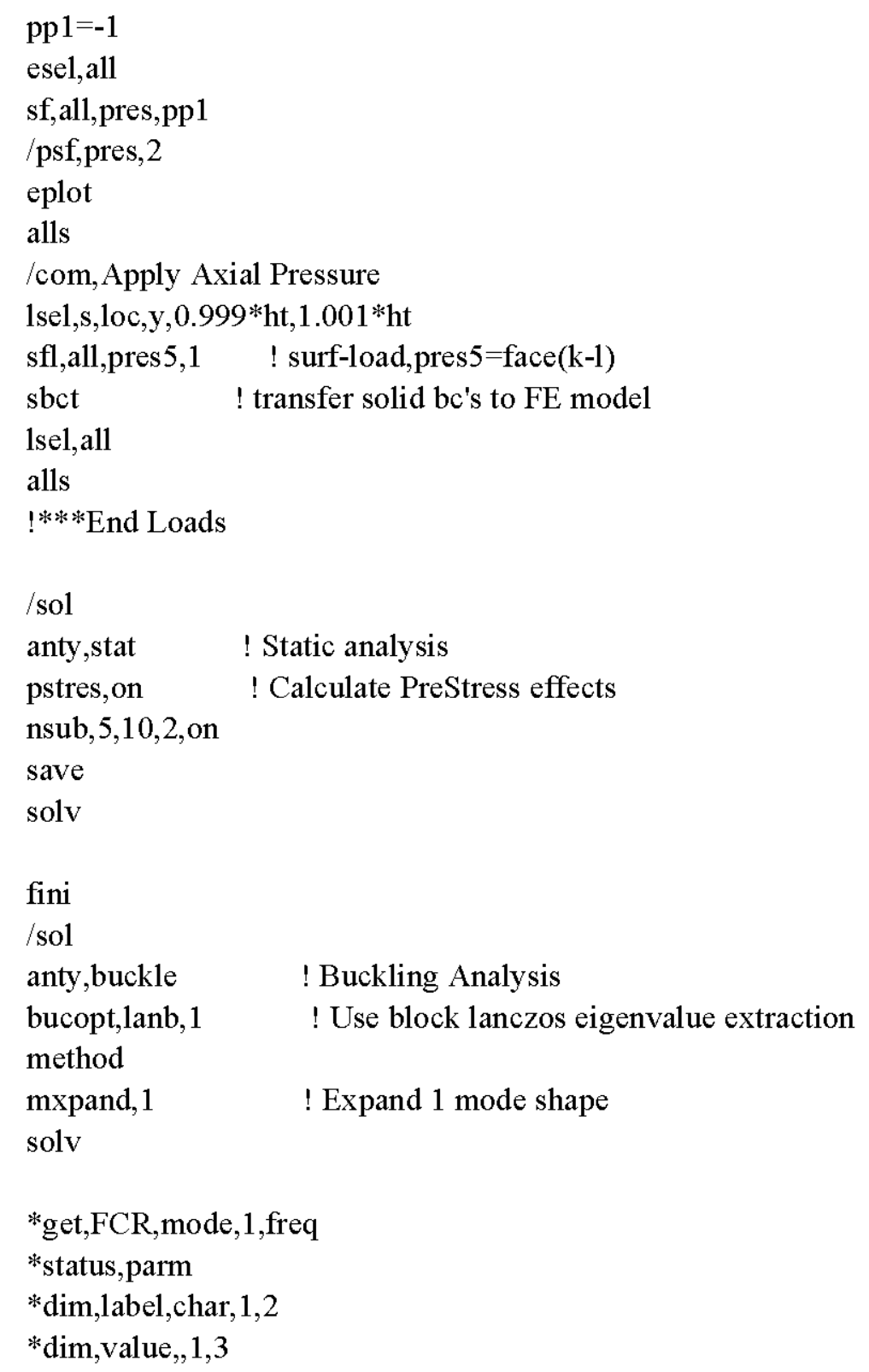




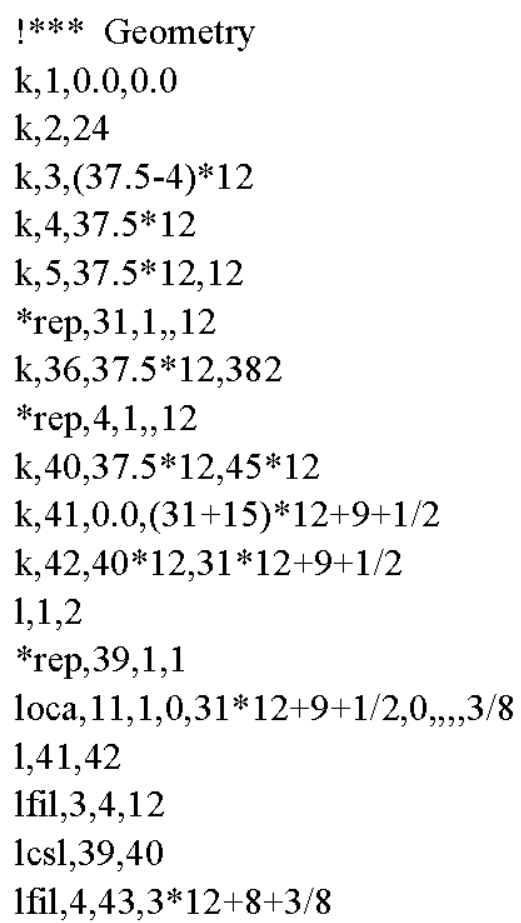

1 del $, 42,44,1$

1del, 1,3,1

csys,defa

1sel,all

arot,all, ,,,,, $1,41,180,180$

1sel, all

$\mathrm{ht}=459$

rbtm $=438$ ! radius at bottom knuckle tangent.

$\mathrm{t}=3 / 8-0.06 \quad$ ! thickness at top of shell where pressure applied. es $=\mathrm{ht} / 100$

fnode $=-1 *$ es $* 1$ ! nodal force, $y$-direction

fends $=$ fnode $/ 2$ ! nodal force at ends, $y$-direction esize,es

amesh,all

!***Thickness assignments

csys, 5

nsel, loc, $x, 402,500$

nsel,r,loc,z,0,36

esln,, 1

emod,all,real,3

nsel, loc, $, 3,36,144$

esln, 1

emod,all,real, 4

nsel, loc, z, 144,382

esln, 1

emod,all,real, 5

nsel,,loc,z,382,561.5

esln, 1

esel,r,type,,1

emod,all,real, 2

allsel

!***Boundary Conditions***

csys, 0

nsel, loc, $, \mathrm{y},-0.001 * \mathrm{ht}, 0.001 * \mathrm{ht}$

$\mathrm{d}$, all,uy, $0.0,,, \mathrm{ux}, \mathrm{uz} \quad$ ! Fix bottom end (disp only)

nsel,all

nsel, loc, y, 0.999*ht, $1.001 *$ ht

$\mathrm{d}, \mathrm{all}, \mathrm{ux}, 0.0,,, \mathrm{uz} \quad$ ! Fix top edge (disp only)

nsel, loc, z, $0.0,0.0$

d,all,roty, $0.0,,$, uz,rotx $\quad$ ! Fix $z=0$ edges

nsel, all

nsel,s,loc, z, $0.0,0.0$

nsel,r,loc, $\mathrm{x}, 0.999 * \mathrm{rbtm}, 1.001 * \mathrm{rbtm}$ 
nsel,r,loc,y,0.0,0.0

d,all,ux, 0.0

! Fix 1 node in $\mathrm{x}$

nsel,all

!****End Boundary Conditions $* * * *$

!***Apply Loads

/com, Apply Axial Load

nsel, s, loc,y, 0.999*ht, 1.001*ht

$\mathrm{f}$, all,fy,fnode

nsel,r,loc, z, $0.0,0.0$

$\mathrm{f}$,all,fy,fends

nsel,all

!****End Loads

/sol

anty,stat ! Static analysis

pstres, on ! Calculate PreStress effects

nsub, $5,10,2$,on

save

solv

fini

/sol

anty,buckle ! Buckling Analysis

bucopt,lanb, 1 ! Use block lanczos eigenvalue extraction

method

mxpand,1 ! Expand 1 mode shape

solv

*get,FCR,mode, 1 ,freq

*status,parm *dim,label,char, 1,2

*dim,value, 1,3

label $(1,1)=$ 'Fcr'

label $(1,2)={ }^{\prime} 1 b^{\prime}$

\section{Input File: Primary Tank - Eigenvalue buckling analysis for} Hoop Loads

fini

/cle

/fil,dst-pft-v

/title,perfect DST tank Under Vacuum

/com, AY Primary Tank, Fixed Top \& Bottom Rings (Disp only),

$180-$ deg

$/ \operatorname{prep} 7$

et, 1,181

*afun,deg

! **** Materials

mp,ex, 1,29.5e6

mp, dens, $1,490 / 1728$

mp,prxy, $1, .3$

tb, biso, 1

tbdata, $1,36000, .01 * 27.7 \mathrm{e} 6$

!**** Shell thickness

!*** 0.060 corrosion allowance

r, 1,1-.06

r, 2,3/8-.06

r, 3, 7/8-.06

r, 4,3/4-.06 
r,5,1/2-.06

!*** Geometry

$\mathrm{k}, 1,0.0,0.0$

$\mathrm{k}, 2,24$

$\mathrm{k}, 3,(37.5-4)^{*} 12$

$\mathrm{k}, 4,37.5 * 12$

$\mathrm{k}, 5,37.5 * 12,12$

*rep, $31,1,12$

$\mathrm{k}, 36,37.5 * 12,382$

*rep, $4,1,12$

$\mathrm{k}, 40,37.5 * 12,45 * 12$

$\mathrm{k}, 41,0.0,(31+15) * 12+9+1 / 2$

$\mathrm{k}, 42,40 * 12,31 * 12+9+1 / 2$

$1,1,2$

*rep, 39, 1,1

loca $, 11,1,0,31 * 12+9+1 / 2,0,,, 3 / 8$

$1,41,42$

1fil, $3,4,12$

$1 \mathrm{csl}, 39,40$

1 fil $, 4,43,3 * 12+8+3 / 8$

1 del, $42,44,1$

1del, $1,3,1$

csys,defa

1sel,all

arot,all,,,,,, $1,41,180,180$

1sel, all

$\mathrm{ht}=459$

rbtm $=438$ ! radius at bottom knuckle tangent.

$\mathrm{t}=3 / 8-0.06 \quad$ ! thickness at top of shell where pressure applied.

es $=\mathrm{ht} / 100$

esize,es

amesh,all
!***Thickness assignments

csys, 5

nsel, $, 10 c, x, 402,500$

nsel,r,loc, z,0,36

esln, 1

emod,all,real,3

nsel,,loc,z,36,144

esln, 1

emod,all,real, 4

nsel,,loc,z,144,382

esln, 1

emod,all,real, 5

nsel,,loc,z,382,561.5

esln, 1

esel,r,type,,1

emod,all,real, 2

allsel

!****B Boundary Conditions $* * * *$

csys, 0

nsel, loc, y, $-0.001 *$ ht,, $0.001 *$ ht

$\mathrm{d}, \mathrm{all}, \mathrm{uy}, 0.0,,, \mathrm{ux}, \mathrm{uz} \quad$ ! Fix bottom end (disp only)

nsel, all

nsel, loc,y, $0.999 * \mathrm{ht}, 1.001 * \mathrm{ht}$

$\mathrm{d}, \mathrm{all}, \mathrm{ux}, 0.0,,, \mathrm{uz}$

! Fix top edge (disp only)

nsel, loc, $\mathrm{z}, 0.0,0.0$

$\mathrm{d}$,all,roty, $0.0,,$, ,uz,rotx $\quad$ ! Fix z $=0$ edges

nsel, all

nsel,s,loc, z, 0.0,0.0

nsel,r,loc, $x, 0.999 *$ rbtm, $1.001 *$ rbtm

nsel,r,loc,y, $0.0,0.0$ 


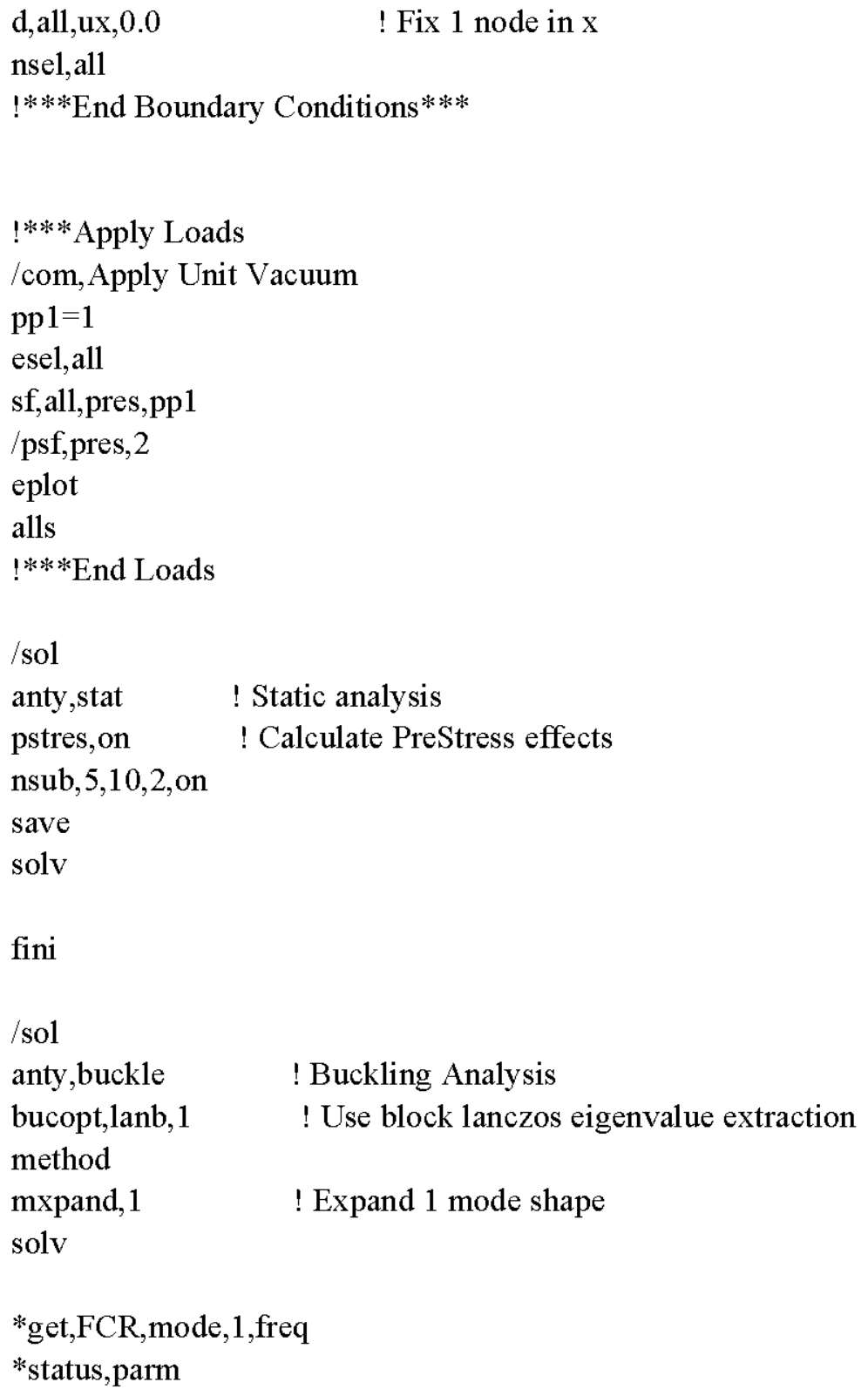

*dim,label,char, 1,2

*dim,value, 1,3

label $(1,1)=$ 'Fcr'

label $(1,2)={ }^{\prime} l b^{\prime}$

Input File: Primary Tank - Eigenvalue buckling analysis for Axial and Hoop Loads

fini

/cle

/fil,dst-pft-c

title,perfect DST tank Under Combined Loads

/com, AY Primary Tank, Fixed Top \& Bottom Rings (Disp only), 180-deg

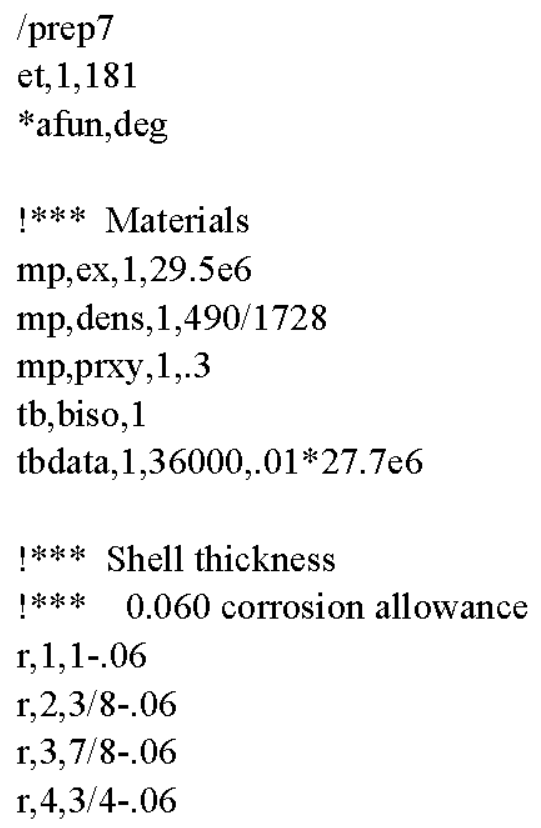


r,5,1/2-.06

!*** Geometry

$\mathrm{k}, 1,0.0,0.0$

$\mathrm{k}, 2,24$

$\mathrm{k}, 3,(37.5-4)^{*} 12$

$\mathrm{k}, 4,37.5^{*} 12$

$\mathrm{k}, 5,37.5^{*} 12,12$

*rep, $31,1,12$

$\mathrm{k}, 36,37.5 * 12,382$

*rep, $4,1,12$

$\mathrm{k}, 40,37.5 * 12,45 * 12$

$\mathrm{k}, 41,0.0,(31+15) * 12+9+1 / 2$

$\mathrm{k}, 42,40 * 12,31 * 12+9+1 / 2$

$1,1,2$

*rep, 39, 1,1

loca, $11,1,0,31 * 12+9+1 / 2,0,,, 3 / 8$

$\geq \quad 1,41,42$

= $1 \mathrm{fil}, 3,4,12$

$1 \mathrm{cs} 1,39,40$

1fil $, 4,43,3 * 12+8+3 / 8$

1del, $42,44,1$

1del, $1,3,1$

csys,defa

1sel,all

arot,all,,,,,,1,41,180,180

1sel, all

$\mathrm{ht}=459$

rbtm $=438$ ! radius at bottom knuckle tangent.

$\mathrm{t}=3 / 8-0.06 \quad$ ! thickness at top of shell where pressure applied.

es $=\mathrm{ht} / 100$

fnode $=-1 *$ es $* 1$ ! nodal force, $y$-direction

fends $=$ fnode $/ 2$ ! nodal force at ends, $y$-direction esize,es

amesh,all

!***Thickness assignments

csys, 5

nsel, loc, $x, 402,500$

nsel,r,loc,z,0,36

esln,, 1

emod,all,real, 3

nsel,,loc,z,36,144

esln, 1

emod,all,real, 4

nsel, loc, z, 144,382

esln, 1

emod,all,real,5

nsel,,loc,z,382,561.5

esln, 1

esel,r,type,,1

emod,all,real,2

allsel

!***Boundary Conditions***

csys, 0

nsel, loc, $, \mathrm{y},-0.001 * \mathrm{ht}, 0.001 * \mathrm{ht}$

d,all,uy, $0.0,,, \mathrm{ux}, \mathrm{uz} \quad$ ! Fix bottom end (disp only)

nsel,all

nsel, loc, y, 0.999*ht, $1.001 *$ ht

$\mathrm{d}, \mathrm{all}, \mathrm{ux}, 0.0,,, \mathrm{uz} \quad$ ! Fix top edge (disp only)

nsel, loc,, , $0.0,0.0$

$\mathrm{d}$, all,roty, $0.0,,$, ,uz,rotx $\quad$ ! Fix $\mathrm{z}=0$ edges

nsel,all

nsel,s,loc, z, $0.0,0.0$

nsel,r,loc, $\mathrm{x}, 0.999 * \mathrm{rbtm}, 1.001 * \mathrm{rbtm}$ 
nsel,r,loc,y,0.0,0.0

$$
\mathrm{d}, \text { all, ux, } 0.0
$$

! Fix 1 node in $x$

$$
\text { nsel,all }
$$

!***End Boundary Conditions $* * * *$

$$
\text { !***Apply Loads }
$$

/com, Apply Unit Vacuum

pp $1=1$

esel,all

sf,all,pres,pp1

/psf,pres, 2

eplot

alls

\section{/com, Apply Axial Load}

nsel, s,loc,y, 0.999*ht, 1.001*ht

f,all,fy,fnode

nsel,r,loc, z, $0.0,0.0$

i f,all,fy,fends

nsel,all

!****End Loads

/sol

anty, stat ! Static analysis

pstres, on ! Calculate PreStress effects

nsub, 5, 10,2, on

save

solv

fini

/sol

anty,buckle

\author{
bucopt,lanb, 1 \\ method \\ mxpand, 1 \\ solv \\ *get,FCR,mode,1,freq \\ *status,parm \\ *dim,1abel,char, 1,2 \\ *dim,value, 1,3 \\ label $(1,1)=$ 'Fcr' \\ label $(1,2)=$ ' $1 \mathrm{~b}$ '
}

! Use block lanczos eigenvalue extraction

$\lfloor * * * * * * * * * * * * * * * * * * * * * * * * * * * * * * * * * * * * * * * * * * * * * * * * !$

!!***Input files for Imperfection Sensitivity Analysis*** !!

!*************************************************!

!!!Uniform Cylinder One Imperfection Models!!!

Input File: Uniform Cylinder with one ASME or Tank

Fabrication specifications - by changing the comment line $\{(1 / 10)$

times, 1 times, 10 times, by changing the comment line\}

imperfection - Eigenvalue buckling analysis for Axial Loads

fini

/cle

/fil,uc-impft-1asme-1-a

/title, UNIFORM tank with one imperfection Under Axial Pressure

/com,Fixed Top \& Bottom Rings (Disp only), 180-deg

$/ \operatorname{prep} 7$

et, 1,181

*afun,deg 
!*** Materials

mp, ex, 1,29.5e6

mp, dens, $1,490 / 1728$

mp,prxy, $1, .3$

tb, biso, 1

tbdata, $1,36000, .01 * 27.7 \mathrm{e} 6$

!**** Shell thickness

$\mathrm{t}=0.507$ ! wall thickness, inch

$\mathrm{R}, 1, \mathrm{t}$ ! shell Thickness

real, 1

!*** Tank Dimensions

$r=450.0 \quad !$ tank radius, inch

$\mathrm{ht}=460.0 \quad$ ! tank height, inch

!*** Geometry

$\mathrm{k}, 1, \mathrm{r}$

ш $\mathrm{k}, 2, \mathrm{r}, 12$

*rep, $38,1,12$

$\mathrm{k}, 40, \mathrm{r}, 460$

$\mathrm{k}, 1000,0,0$

$\mathrm{k}, 1001,0,500$

$1,1,2$

*rep, 39, 1, 1

1sel,all

arot,all,,,,, 1000,1001,180,180

1sel,all

!***ASME NE-4220 specs

$\mathrm{W}=9.75 * 12$

$! h=0.05 \quad !(1 / 10)$ times ASME imperfection

$\mathrm{h}=0.5 \quad ! 1 *$ ASME imperfection

\section{$! h=5 \quad ! 10$ times ASME imperfection}

!***Tank-Fabrication specs

! $\mathrm{w}=7 * 12$

$! h=0.1 \quad !(1 / 10)$ times Tank Fab imperfection

$! h=1 \quad ! 1^{*}$ Tank Fab imperfection

$! h=10 \quad$ ! 10 times Tank Fab imperfection

$\mathrm{pi}=22 / 7$

impang $=(\mathrm{w} / 450)^{*}(180 / \mathrm{pi})$

n1=nint(impang/1/2) !! nearest integer

$*_{\text {if, }}(\mathrm{n} 1 * 1 * 450 * \mathrm{pi} / 180), \mathrm{ge},(\mathrm{w} / 2)$, then !<check if ' $\mathrm{n} 1$ ' spreads for ' $\mathrm{w}$ ' or not>

$\mathrm{n}=\mathrm{n} 1$

*else

$\mathrm{n}=\mathrm{n} 1+1$

*endif

!***imperfection $@$ the upper section of the tank *****

csys, 5

*do,i, 1,n, 1

ksel, loc, $x, 450$

,r,loc,y,(180-((i-1)*1))

,r,loc, z,370,430

*get,numkp,kp, count

*do,j,1,numkp, 1

*get,a,kp,0,num,max

*get,x1,kp,a,loc, $\mathrm{x}$

*get,y1,kp,a,loc,y

*get,z1,kp,a,loc, z

kmodif, a, $x 1+\sin \left((\mathrm{j}-1)^{*} 45\right)^{*}\left(\mathrm{~h} *\left(1-(\mathrm{i}-1)^{*} 1 / \mathrm{n}\right)\right), \mathrm{y} 1, \mathrm{z} 1$

ksel,u,kp, a 
*enddo

*enddo

!***end imperfection****

es $=h t / 100$

esize, es

amesh,all

!***Boundary Conditions***

csys, 0

nsel,,loc,y,-0.001*ht, $0.001 *$ ht

d,all,uy, $0.0,,$, ,ux,uz ! Fix bottom end (disp only)

nsel,all

nsel, loc, y, 0.999*ht, $1.001 * \mathrm{ht}$

$\mathrm{d}$, all, ux, $0.0,,, \mathrm{uz} \quad$ ! Fix top edge (disp only)

nsel, loc, z, $0.0,0.0$

d,all,roty, $0.0,,$, uz,rotx $\quad$ ! Fix z $=0$ edges

nsel, all

nsel, loc, z, $0.0,0.0$

$\mp$ nsel,r,loc, $\mathrm{x}, 0.999 * \mathrm{r}, 1.001 * \mathrm{r}$

nsel,r,loc,y, $0.0,0.0$

d,all,ux, 0.0

! Fix 1 node in $\mathrm{x}$

nsel,all

esel,all

alls

!***End Boundary Conditions***

!***Apply Loads

/com, Apply Axial Pressure

1sel,s,loc,y, 0.999*ht,1.001*ht

sfl,all,pres5,1 ! surf-load,pres5=face(k-1)

sbct ! transfer solid bc's to FE model

1sel,all

alls

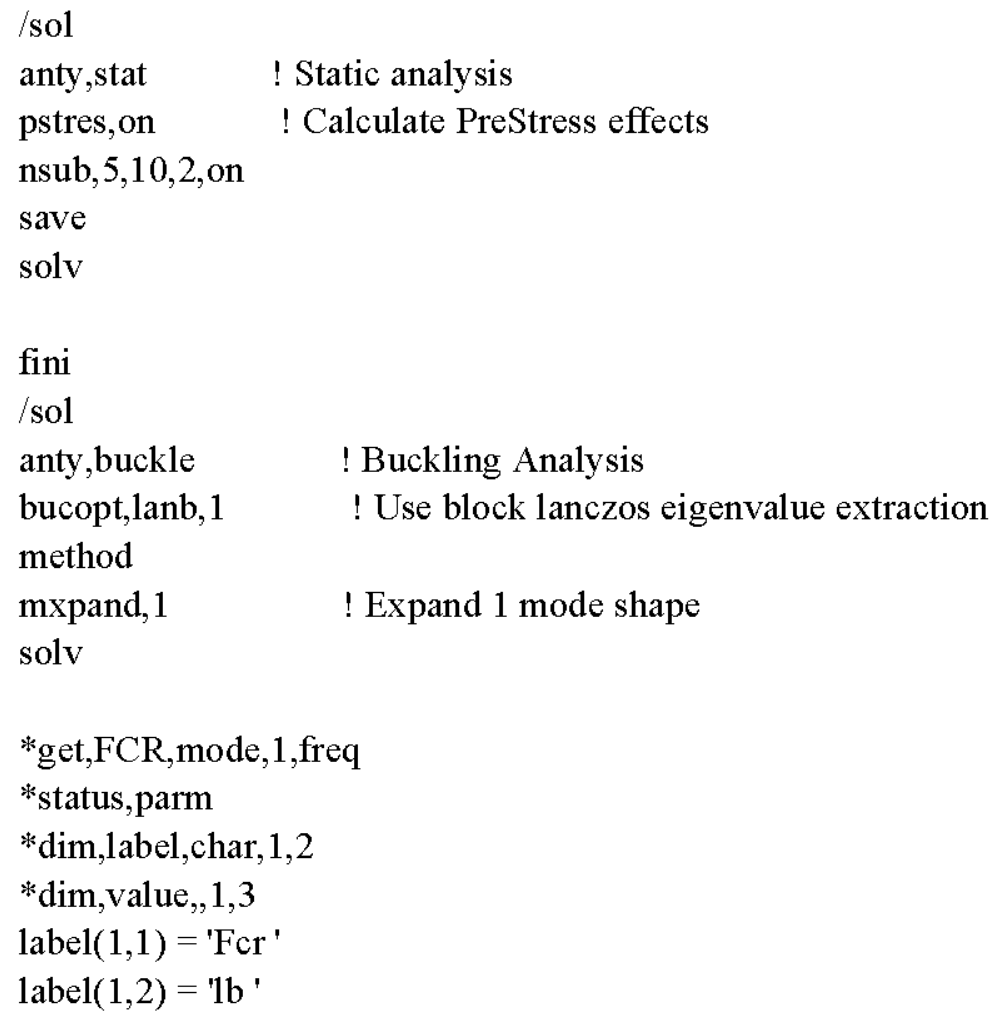

Input File: Uniform Cylinder with one ASME or Tank

Fabrication specifications - by changing the comment line $\{(1 / 10)$ times, 1 times, 10 times, by changing the comment line\} imperfection - Eigenvalue buckling analysis for Hoop Loads fini

/cle

/fil,uc-impft-1asme-1-v

/title, UNIFORM tank with one imperfection Under Vacuum /com,Fixed Top \& Bottom Rings (Disp only), 180-deg 


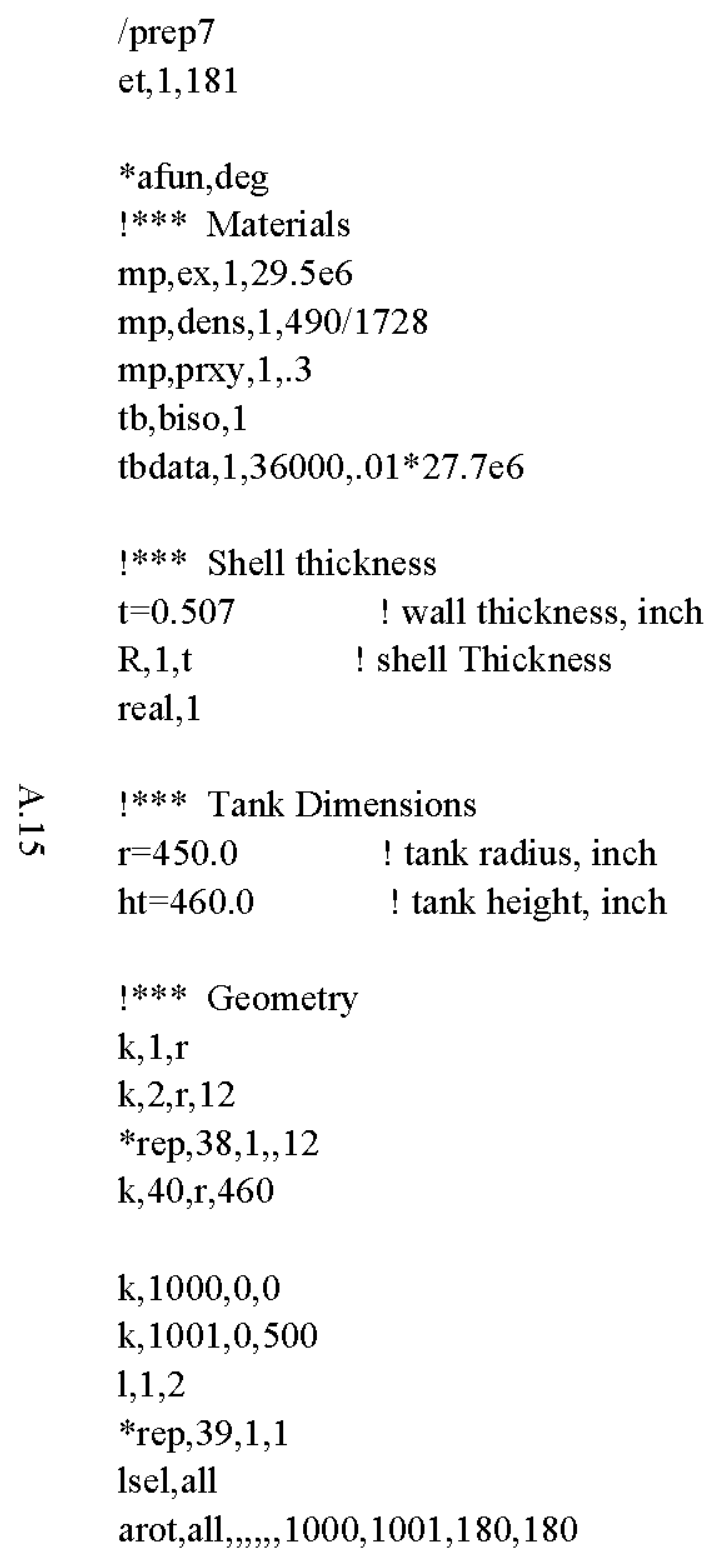

1sel,all

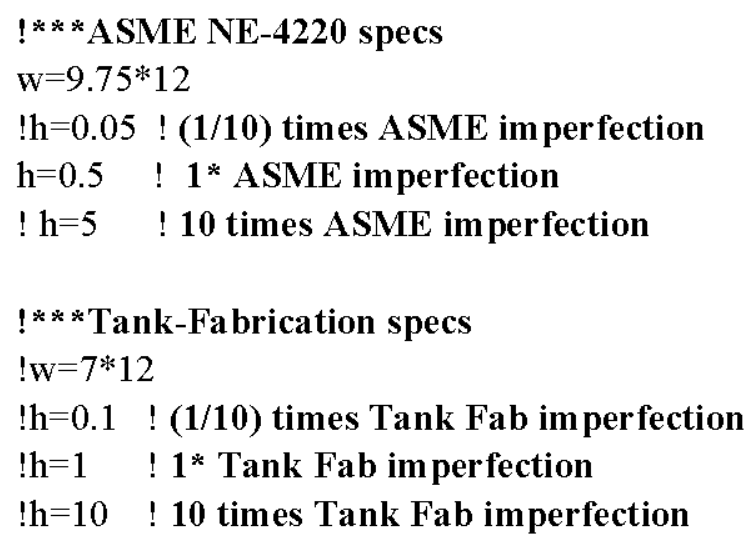


*do, $, 1,1$, numkp, 1

*get, a,kp,0,num,max

*get,x1,kp,a,loc, $x$

*get,y 1,kp,a,loc,y

*get,z1,kp,a,loc, z

kmodif, $, \mathrm{x} 1+\sin \left((\mathrm{j}-1)^{*} 45\right)^{*}\left(\mathrm{~h} *\left(1-(\mathrm{i}-1)^{*} 1 / \mathrm{n}\right)\right), \mathrm{y} 1, \mathrm{z} 1$

$\mathrm{ksel}, \mathrm{u}, \mathrm{kp},, \mathrm{a}$

*enddo

*enddo

!***end imperfection $* * * *$

es $=\mathrm{ht} / 100$

esize,es

amesh, all

!***Boundary Conditions***

csys, 0

nsel, loc, $,-0.001 * \mathrm{ht}, 0.001 * \mathrm{ht}$

o nsel,all

nsel, loc,y,0.999*ht, 1.001*ht

$\mathrm{d}$, all, ux, $0.0,,, \mathrm{uz}$

nsel, ,loc, z, $0.0,0.0$

d,all,roty, $0.0,,$, uz,rotx $\quad$ ! Fix $z=0$ edges

nsel,all

nsel, loc, $\mathrm{z}, 0.0,0.0$

nsel,r,loc, $\mathrm{x}, 0.999^{*} \mathrm{r}, 1.001 *^{*} \mathrm{r}$

nsel,r,loc,y, $0.0,0.0$

d,all,ux, 0.0

! Fix 1 node in $\mathrm{x}$

nsel,all

esel,all

alls

!***End Boundary Conditions****

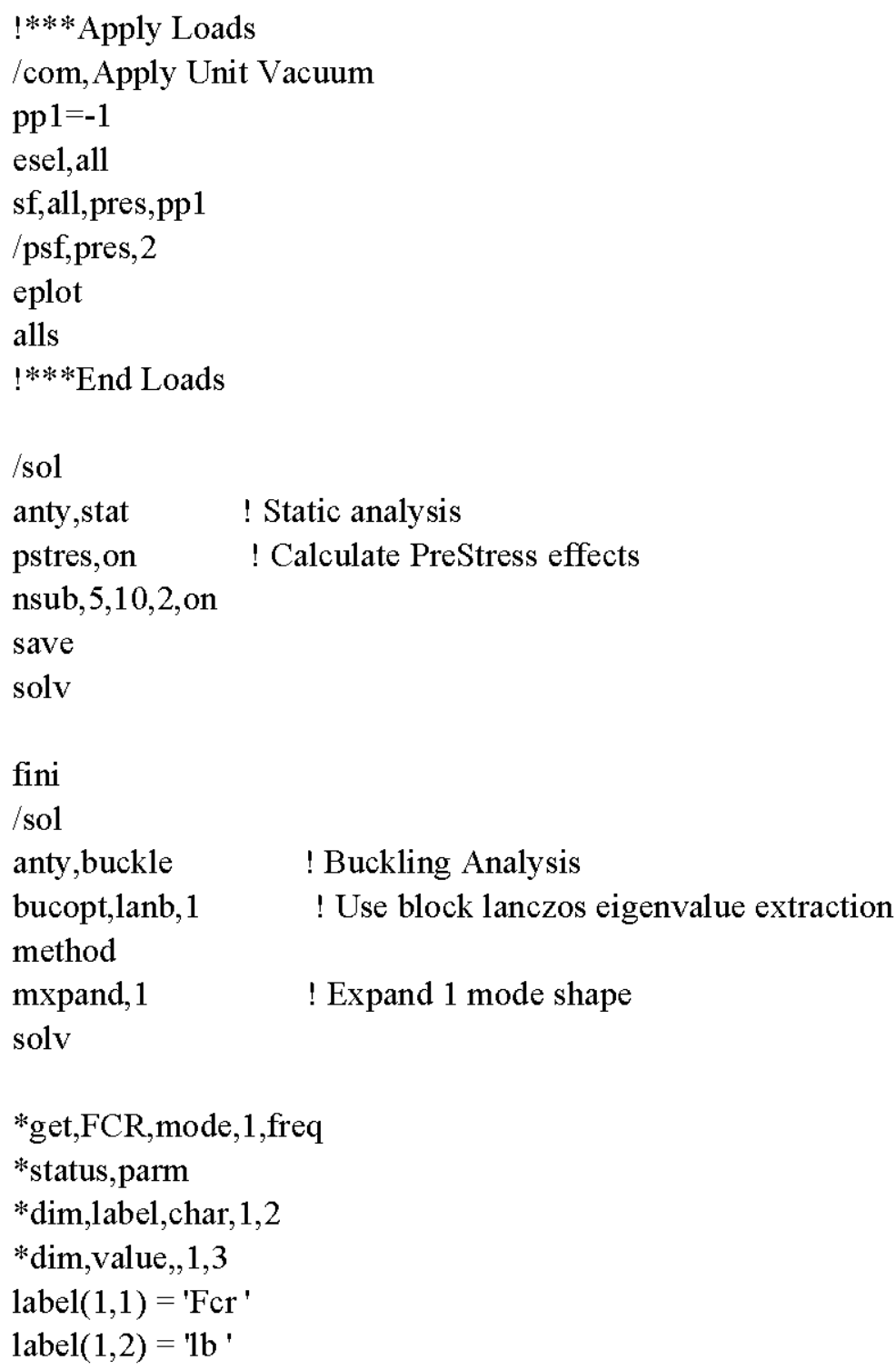


Input File: Uniform Cylinder with one ASME or Tank

Fabrication specifications - by changing the comment line $\{(1 / 10)$

times, 1 times, 10 times, by changing the comment line\}

imperfection - Eigenvalue buckling analysis for Axial and Hoop

Loads

fini

/cle

/fil,uc-impft-1asme-1-c

/title,Imperfect UNIFORM tank with one imperfection Under Combined Load

/com,Fixed Top \& Bottom Rings (Disp only), 180-deg

/prep 7

et, 1,181

*afun,deg

!*** Materials

mp,ex, $1,29.5 \mathrm{e} 6$

mp, dens, $1,490 / 1728$

mp,prxy, $1, .3$

tb, biso, 1

tbdata, $1,36000, .01 * 27.7 \mathrm{e} 6$

!*** Shell thickness

$\mathrm{t}=0.507 \quad$ ! wall thickness, inch
$\mathrm{R}, 1, \mathrm{t}$
real, 1

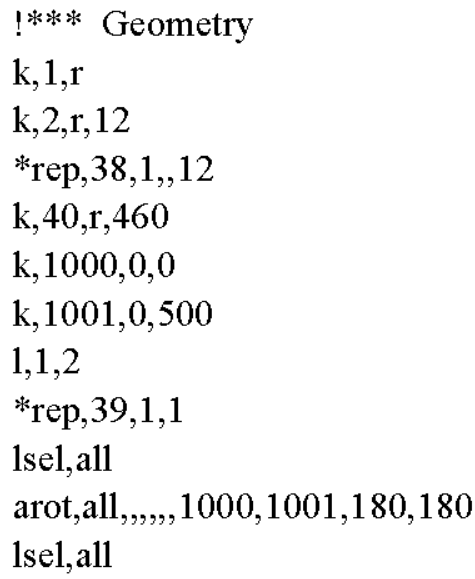


nsub, $5,10,2$, on

save

solv

\section{fini}

/sol

anty,buckle

bucopt,lanb, 1

method

mxpand,1

solv

! Buckling Analysis

! Use block lanczos eigenvalue extraction

! Expand 1 mode shape

*get,FCR,mode, 1 ,freq

*status,parm

*dim,label,char, 1,2

*dim,value, 1,3

label $(1,1)=$ 'Fcr'

label $(1,2)={ }^{\prime} l b^{\prime}$

\section{!!!Uniform Cylinder Two Imperfection Models!!!}

Input File: Uniform Cylinder with two ASME or Tank

Fabrication specifications - by changing the comment line $\{(1 / 10)$

times, 1 times, 10 times, by changing the comment line\}

imperfections - Eigenvalue buckling analysis for Axial Loads

fini

/cle

/fil,uc-impft-1asme-2-a

/title, UNIFORM tank with 2 imperfections Under Axial Pressure /prep7

et, 1,181 *afun, deg

!*** Materials

$\mathrm{mp}, \mathrm{ex}, 1,29.5 \mathrm{e} 6$

mp,dens, $1,490 / 1728$

mp,prxy, 1,3

tb, biso, 1

tbdata, $1,36000, .01 * 27.7 \mathrm{e} 6$

!*** Shell thickness

$\mathrm{t}=0.507 \quad$ ! wall thickness, inch

$\mathrm{R}, 1, \mathrm{t} \quad$ ! shell Thickness

real,1

!*** Tank Dimensions

$\mathrm{r}=450.0 \quad$ ! tank radius, inch

$\mathrm{ht}=460.0 \quad$ ! tank height, inch

!*** Geometry

$\mathrm{k}, 1, \mathrm{r}$

$\mathrm{k}, 2, \mathrm{r}, 12$

*rep, 38, 1,12

$\mathrm{k}, 40, \mathrm{r}, 460$

$\mathrm{k}, 1000,0,0$

$\mathrm{k}, 1001,0,500$

$1,1,2$

*rep, 39, 1,1

1 sel,all

arot,all,,,,,,1000,1001,180,180

1sel,all

! * * ASME NE-4220 specs

$\mathrm{w}=9.75 * 12$

$! h=0.05 !(1 / 10)$ times ASME imperfection 
$\mathrm{h}=0.5 \quad ! \quad 1 *$ ASME imperfection

$! \mathrm{h}=5 \quad ! 10$ times ASME imperfection

\section{!***Tank-Fabrication specs}

! $\mathrm{w}=7 * 12$

$! h=0.1 \quad !(1 / 10)$ times Tank Fab imperfection

!h=1 ! 1* Tank Fab imperfection

$! h=10 \quad ! 10$ times Tank Fab imperfection

\section{$\mathrm{pi}=22 / 7$}

impang $=(\mathrm{w} / 450)^{*}(180 / \mathrm{pi})$

n1 =nint(impang $/ 1 / 2)$ !! nearest integer

*if,(n1* $1 * 450 * \mathrm{pi} / 180), \mathrm{ge},(\mathrm{w} / 2)$,then !<check if ' $\mathrm{n} 1$ ' spreads for ' $\mathrm{w}$ ' or not>

$\mathrm{n}=\mathrm{n} 1$

*else

in $\mathrm{n} 1+1$

o *endif

!***imperfection @ the upper section of the tank **** csys, 5

*do,i, $1, \mathrm{n}, 1$

ksel, ,loc, $\mathrm{x}, 450$

,r,loc,y, $\left(180-\left((\mathrm{i}-1)^{*} 1\right)\right)$

,r,loc, z,370,430

*get,numkp,kp,,count

*do,j, 1, numkp, 1

*get, a,kp, , , num,max

*get, $\mathrm{x} 1, \mathrm{kp}, \mathrm{a}, \mathrm{loc}, \mathrm{x}$

*get,y1,kp,a,loc,y

*get, z1,kp, a,loc, z

kmodif, $\mathrm{a}, \mathrm{x} 1+\sin ((\mathrm{j}-1) * 45) *(\mathrm{~h} *(1-(\mathrm{i}-1) * 1 / \mathrm{n})), \mathrm{y} 1, \mathrm{z} 1$ $\mathrm{ksel}, \mathrm{u}, \mathrm{kp}, \mathrm{a}$

*enddo

*enddo

!***end imperfection****

!***imperfection @ mid wall of the tank ****

$*$ do, $\mathrm{i}, 1, \mathrm{n}, 1$

ksel, loc, $x, 450$

,r,loc,y,,$\left(180-\left((\mathrm{i}-1)^{*} 1\right)\right)$

,r,loc, z,190,241

*get,numkp,kp,,count

*do, $\mathrm{j}, 1$, numkp, 1

*get,a,kp, 0, num,max

*get,x1,kp,a,loc,x

*get,y1,kp,a,loc,y

*get, z1,kp,a,loc, $\mathrm{z}$

kmodif, $\mathrm{a}, \mathrm{x} 1+\sin \left((\mathrm{j}-1)^{*} 45\right) *(\mathrm{~h} *(1-(\mathrm{i}-1) * 1 / \mathrm{n})), \mathrm{y} 1, \mathrm{z} 1$

$\mathrm{ksel}, \mathrm{u}, \mathrm{kp}, \mathrm{a}$

*enddo

*enddo

!***end imperfection $* * * *$

es $=h t / 100$

esize,es

amesh,all

!***Boundary Conditions***

csys, 0

nsel,loc,, , $-0.001 *$ ht, $0.001 *$ ht

d,all,uy, 0.0, ,, ux, uz $\quad$ ! Fix bottom end (disp only)

nsel, all

nsel,,loc,y, 0.999*ht, 1.001*ht

d,all,ux, $0.0,,$, , uz $\quad$ : Fix top edge (disp only) 
nsel, $, 10 c, z, 0.0,0.0$

$\mathrm{d}$,all,roty, $0.0,,$, ,uz,rotx $\quad$ ! Fix $\mathrm{z}=0$ edges

$$
\text { nsel,all }
$$

nsel, loc, z, 0.0,0.0

nsel,r,loc, $\mathrm{x}, 0.999 * \mathrm{r}, 1.001 * \mathrm{r}$

nsel,r,loc,y, $0.0,0.0$

$\mathrm{d}, \mathrm{all}, \mathrm{ux}, 0.0$

! Fix 1 node in $\mathrm{x}$

nsel,all

esel,all

alls

!***End Boundary Conditions***

!***Apply Loads

/com, Apply Axial Pressure

1sel,s,loc,y,0.999*ht, 1.001*ht

sfl,all,pres5,1 ! surf-load,pres5=face(k-1)

sbct ! transfer solid bc's to FE model

i 1sel,all

alls

/sol

anty,stat ! Static analysis

pstres, on ! Calculate PreStress effects

nsub, $5,10,2$,on

save

solv

fini

/sol

\section{anty,buckle}

bucopt,lanb, 1

method

mxpand, 1
! Buckling Analysis

! Use block lanczos eigenvalue extraction

! Expand 1 mode shape solv

*get,FCR,mode, 1 ,freq

*status,parm

*dim,label,char,1,2

*dim,value, ,1,3

label $(1,1)=$ 'Fcr '

label $(1,2)={ }^{\prime} l b^{\prime}$

Input File: Uniform Cylinder with two ASME or Tank

Fabrication specifications - by changing the comment line $\{(1 / 10)$

times, 1 times, 10 times, by changing the comment line\}

imperfections - Eigenvalue buckling analysis for Hoop Loads

fini

/cle

/fil,uc-impft-1asme-2-v

/title, UNIFORM tank with two imperfections Under Vacuum

/com,Fixed Top \& Bottom Rings (Disp only), 180-deg

/prep7

et, 1,181

*afun, deg

!*** Materials

mp, ex, $1,29.5 \mathrm{e} 6$

mp,dens, $1,490 / 1728$

mp,prxy, $1, .3$

tb, biso, 1

tbdata, $1,36000, .01 * 27.7 \mathrm{e} 6$

!*** Shell thickness

$\mathrm{t}=0.507 \quad$ ! wall thickness, inch 


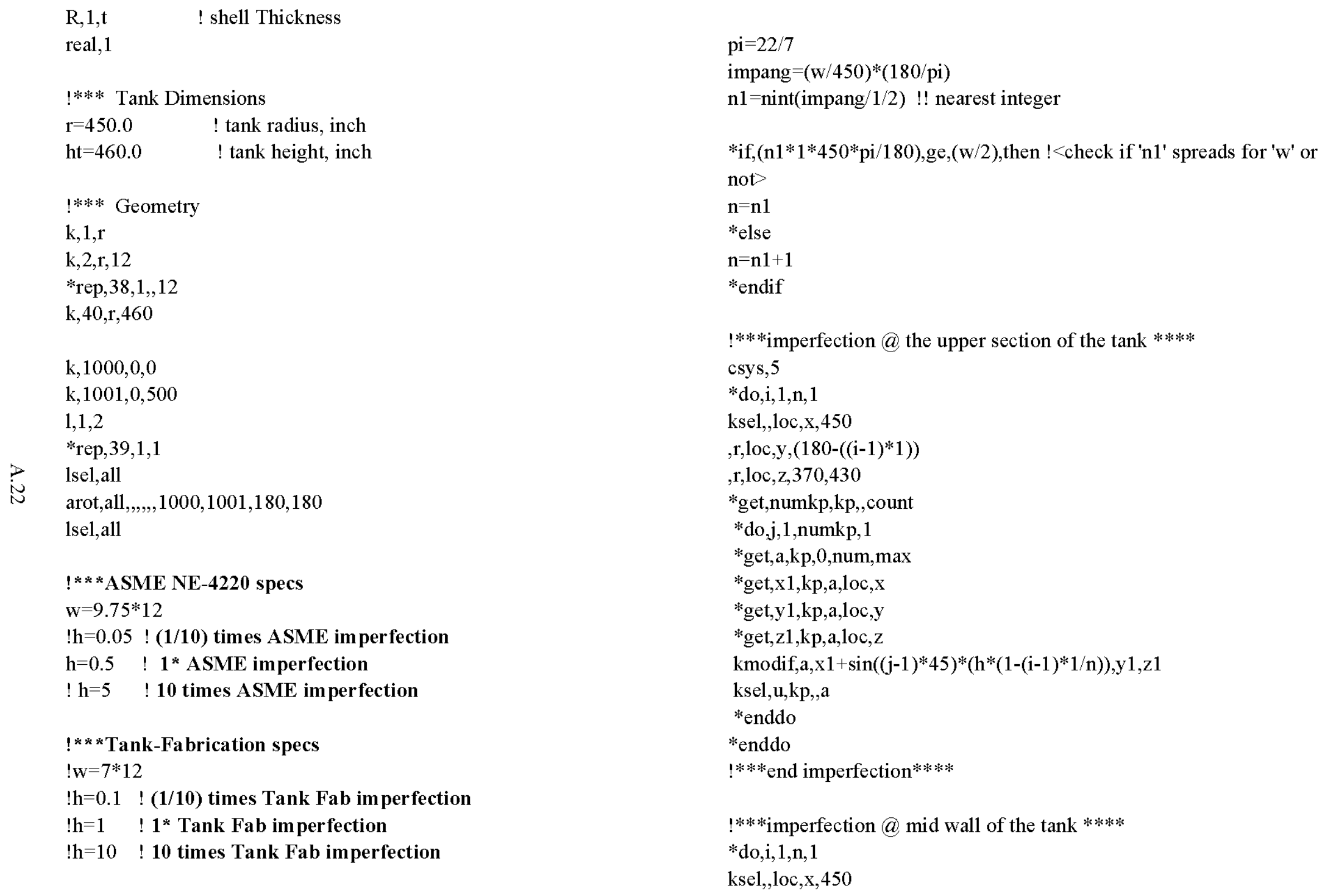


,r,loc,y, $\left(180-\left((\mathrm{i}-1)^{*} 1\right)\right)$

,r,loc, z, 190,241

*get,numkp,kp,,count

*do, $, 1,1$, numkp, 1

*get,a,kp,0,num,max

*get, $\mathrm{x} 1, \mathrm{kp}, \mathrm{a}, \mathrm{loc}, \mathrm{x}$

*get,y1,kp,a,loc,y

*get, z1,kp,a,loc, z

kmodif, $, \mathrm{x}, \mathrm{x} 1+\sin \left((\mathrm{j}-1)^{*} 45\right) *\left(\mathrm{~h} *\left(1-(\mathrm{i}-1)^{*} 1 / \mathrm{n}\right)\right), \mathrm{y} 1, \mathrm{z} 1$

$\mathrm{ksel}, \mathrm{u}, \mathrm{kp},, \mathrm{a}$

*enddo

*enddo

!***end imperfection****

es $=h t / 100$

esize,es

amesh,all

!***Boundary Conditions***

csys, 0

nsel, ,loc,y,-0.001*ht, $0.001 * \mathrm{ht}$

$\mathrm{d}$, all,uy, $0.0,,, \mathrm{ux}, \mathrm{uz} \quad$ ! Fix bottom end (disp only)

nsel, all

nsel, loc,y, 0.999*ht, 1.001*ht

$\mathrm{d}, \mathrm{all}, \mathrm{ux}, 0.0,,, \mathrm{uz}$

! Fix top edge (disp only)

nsel, loc,, , $, 0.0,0.0$

d,all,roty, $0.0,,$, uz,rotx $\quad !$ Fix $z=0$ edges

nsel, all

nsel, ,loc, z, $0.0,0.0$

nsel, $r, 10 c, x, 0.999 * r, 1.001 * r$

nsel,r,loc,y, $0.0,0.0$

$\mathrm{d}, \mathrm{all}, \mathrm{ux}, 0.0$

! Fix 1 node in $x$

nsel,all esel,all

alls

!***End Boundary Conditions***

!***Apply Loads

/com,Apply Unit Vacuum

pp $1=-1$

esel,all

sf,all,pres,pp1

/psf,pres,2

eplot

alls

!***End Loads

/sol

anty,stat ! Static analysis

pstres, on ! Calculate PreStress effects

nsub, $5,10,2$,on

save

solv

fini

/sol

anty,buckle ! Buckling Analysis

bucopt,lanb,1 ! Use block lanczos eigenvalue extraction

method

mxpand,1 ! Expand 1 mode shape

solv

*get,FCR,mode, 1 ,freq

*status,parm

*dim,label,char, 1,2

*dim,value, ,1,3 


$$
\begin{aligned}
& \text { label }(1,1)=\text { 'Fcr' } \\
& \operatorname{label}(1,2)=\text { 'lb ' }
\end{aligned}
$$

Input File: Uniform Cylinder with two ASME or Tank

Fabrication specifications - by changing the comment line $\{(1 / 10)$

times, 1 times, 10 times, by changing the comment line\}

imperfections - Eigenvalue buckling analysis for Axial and Hoop Loads

fini

/cle

/fil,uc-impft-1asme-2-c

/title,UNIFORM tank with two imperfections Under Combined Load /com,Fixed Top \& Bottom Rings (Disp only), 180-deg

/prep7

et, 1,181

*afun, deg

!*** Materials

mp, ex, $1,29.5 \mathrm{e} 6$

mp,dens, $1,490 / 1728$

mp,prxy, $1, .3$

tb, biso, 1

tbdata, $1,36000, .01 * 27.7 \mathrm{e} 6$

!*** Shell thickness

$\mathrm{t}=0.507 \quad$ ! wall thickness, inch

$\mathrm{R}, 1, \mathrm{t} \quad$ ! shell Thickness

real,1

!*** Tank Dimensions

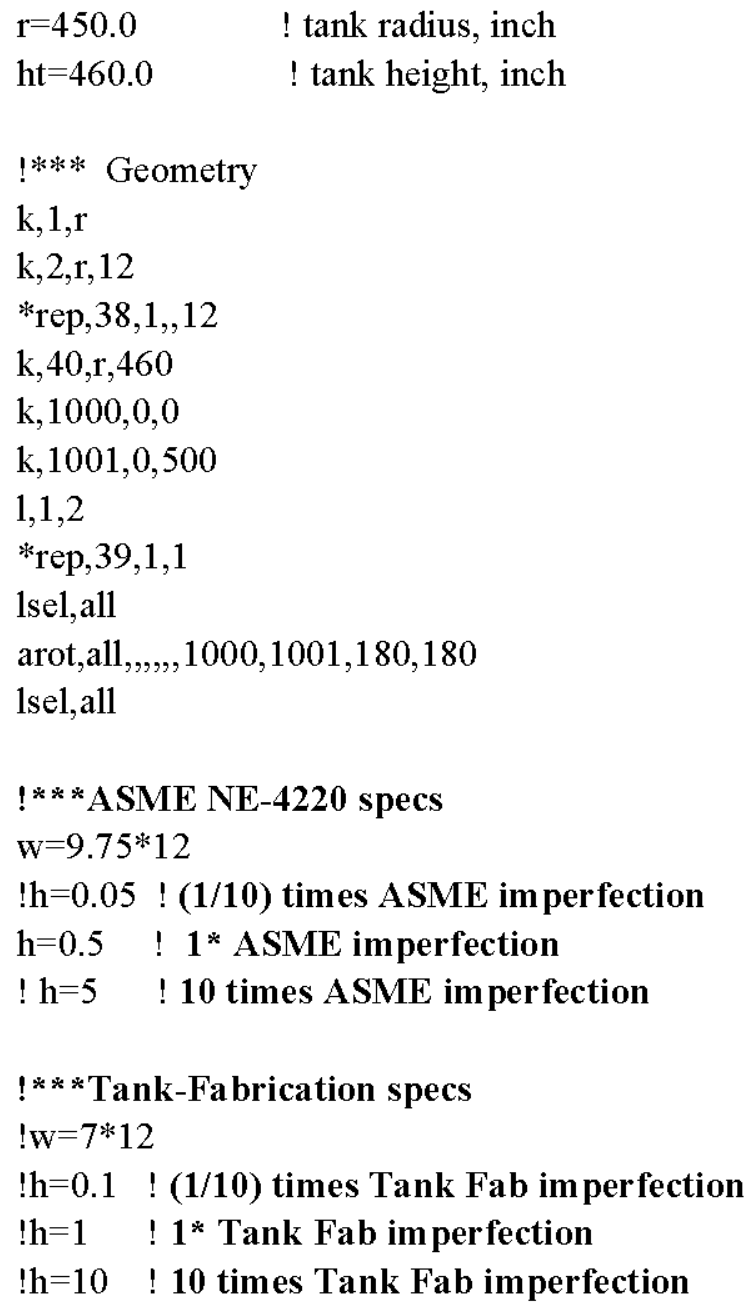


*if,(n1*1*450*pi/180),ge,(w/2),then !<check if 'n1' spreads for ' $\mathrm{w}$ ' or not>

$\mathrm{n}=\mathrm{n} 1$

*else

$\mathrm{n}=\mathrm{n} 1+1$

*endif

!***imperfection@ the upper section of the tank **** csys, 5

$*$ do, $, 1,1, n, 1$

ksel, $, 10 c, x, 450$

$, \mathrm{r}, 1 \mathrm{loc}, \mathrm{y},\left(180-\left((\mathrm{i}-1)^{*} 1\right)\right)$

,r,loc, z, 370,430

*get,numkp,kp,,count

*do,j,1,numkp, 1

*get, a,kp,0,num,max

*get,x1,kp,a,loc, $\mathrm{x}$

* *get,y1,kp,a,loc,y

*get,z1,kp,a,loc, z

kmodif, $\mathrm{a}, \mathrm{x} 1+\sin ((\mathrm{j}-1) * 45) *(\mathrm{~h} *(1-(\mathrm{i}-1) * 1 / \mathrm{n})), \mathrm{y} 1, \mathrm{z} 1$

$\mathrm{ksel}, \mathrm{u}, \mathrm{kp},, \mathrm{a}$

*enddo

*enddo

!***end imperfection****

!***imperfection @ mid wall of the tank ****

$*$ do, $\mathrm{i}, 1, \mathrm{n}, 1$

ksel, loc, $x, 450$

,r,loc,y, $\left(180-\left((\mathrm{i}-1)^{*} 1\right)\right)$

,r,loc, z, 190,241

*get,numkp,kp,, count

*do,j, 1, numkp, 1

*get,a,kp,0,num,max *get, $\mathrm{x} 1, \mathrm{kp}, \mathrm{a}, \mathrm{loc}, \mathrm{x}$

*get,y1,kp,a,loc,y

*get,z1,kp,a,loc, z

kmodif,a, $\mathrm{x} 1+\sin ((\mathrm{j}-1) * 45) *(\mathrm{~h} *(1-(\mathrm{i}-1) * 1 / \mathrm{n})), \mathrm{y} 1, \mathrm{z} 1$

$\mathrm{ksel}, \mathrm{u}, \mathrm{kp}, \mathrm{a}$

*enddo

*enddo

!***end imperfection****

es $=h t / 100$

esize,es

amesh,all

!***B Boundary Conditions***

csys, 0

nsel, loc, y, $-0.001 *$ ht, $0.001 * \mathrm{ht}$

d,all,uy, $0.0,,, \mathrm{ux}, \mathrm{uz} \quad$ ! Fix bottom end (disp only)

nsel, all

nsel, loc, y, 0.999*ht, $1.001 *$ ht

$\mathrm{d}, \mathrm{all}, \mathrm{ux}, 0.0,,, \mathrm{uz} \quad$ ! Fix top edge (disp only)

nsel, ,loc, z, $0.0,0.0$

$\mathrm{d}$,all,roty, $0.0,,$, uz,rotx $\quad$ ! Fix $\mathrm{z}=0$ edges

nsel,all

nsel, loc, $, 0.0,0.0$

nsel,r,loc, $\mathrm{x}, 0.999 * \mathrm{r}, 1.001 * \mathrm{r}$

nsel,r,loc,y, $0.0,0.0$

$\mathrm{d}, \mathrm{all}, \mathrm{ux}, 0.0$

! Fix 1 node in $\mathrm{x}$

nsel,all

esel, all

alls

!***End Boundary Conditions***

!***Apply Loads 
/com, Apply Axial Pressure

1sel,s,loc,y, 0.999*ht, 1.001*ht

sfl,all,pres5,1 ! surf-load,pres5=face (k-1)

sbct ! transfer solid bc's to FE model

1sel,all

alls

/com, Apply Unit Vacuum

$\mathrm{pp} 1=-1$

esel,all

sf,all,pres,pp1

/psf,pres, 2

eplot

alls

!***End Loads

/sol

$\underset{\sim}{\text { anty,stat }} \begin{array}{ll}\text { ! Stres,on } & \text { ! Calculate PreStress effects }\end{array}$

nsub, $5,10,2$, on

save

solv

fini

/sol

\section{anty,buckle}

bucopt,lanb, 1

method

mxpand, 1

solv

! Buckling Analysis

! Use block lanczos eigenvalue extraction

*get,FCR,mode,1,freq

*status,parm *dim,label,char, 1,2

*dim,value, 1,3

label $(1,1)=$ 'Fcr'

label $(1,2)=$ ' $1 b^{\prime}$

!!!Uniform Cylinder Four Imperfections Models!!!

Input File: Uniform Cylinder with Four ASME or Tank

Fabrication specifications - by changing the comment line $\{(1 / 10)$

times, 1 times, 10 times, by changing the comment line\}

imperfections - Eigenvalue buckling analysis for Axial Loads

fini

/cle

/fil,uc-impft-1asme-3-a

/title, UNIFORM tank with 4 imperfections Under Axial Pressure

/prep7

et, 1,181

*afun, deg

!*** Materials

$\mathrm{mp}, \mathrm{ex}, 1,29.5 \mathrm{e} 6$

mp, dens, $1,490 / 1728$

mp,prxy, 1,3

tb, biso, 1

tbdata, $1,36000, .01 * 27.7 \mathrm{e} 6$

!*** Shell thickness

$\mathrm{t}=0.507 \quad$ ! wall thickness, inch

R, $1, \mathrm{t} \quad$ ! shell Thickness

real,1

!*** Tank Dimensions 


$$
\begin{array}{ll}
\mathrm{r}=450.0 & ! \text { tank radius, inch } \\
\mathrm{ht}=460.0 & \text { ! tank height, inch }
\end{array}
$$$$
\text { !*** Geometry }
$$$$
\mathrm{k}, 1, \mathrm{r}
$$$$
\mathrm{k}, 2, \mathrm{r}, 12
$$$$
\text { *rep, } 38,1,12
$$$$
\mathrm{k}, 40, \mathrm{r}, 460
$$$$
\mathrm{k}, 1000,0,0
$$$$
\mathrm{k}, 1001,0,500
$$

$1,1,2$

*rep, 39,1,1

1sel,all

arot,all, $,,,, 1000,1001,180,180$

1sel,all

\section{!***ASME NE-4220 specs}

$\mathrm{w}=9.75 * 12$

บ $! h=0.05 !(1 / 10)$ times ASME imperfection

$\mathrm{h}=0.5 \quad ! \quad 1^{*}$ ASME imperfection

$! h=5 \quad ! 10$ times ASME imperfection

\section{!***Tank-Fabrication specs}

$! \mathrm{w}=7 * 12$

!h=0.1 ! (1/10) times Tank Fab imperfection

$! h=1 \quad ! 1^{*}$ Tank Fab imperfection

!h=10 ! 10 times Tank Fab imperfection

$\mathrm{pi}=22 / 7$

impang $=(\mathrm{w} / 450) *(180 / \mathrm{pi})$

n1=nint(impang $/ 1 / 2)$ !! nearest integer *if,(n1*1*450*pi/180),ge,(w/2),then !<check if ' $n 1$ ' spreads for ' $\mathrm{w}$ ' or not>

$\mathrm{n}=\mathrm{n} 1$

*else

$\mathrm{n}=\mathbf{n} 1+\mathbf{1}$

*endif

!***imperfection @ the upper section of the tank **** csys, 5

*do, $\mathrm{i}, 1, \mathrm{n}, 1$

ksel, $, 10 c, x, 450$

$, \mathrm{r}, 1 \mathrm{loc}, \mathrm{y},\left(180-\left((\mathrm{i}-1)^{*} 1\right)\right)$

,r,loc, z,370,430

*get,numkp,kp, count

*do, $, 1,1$, numkp, 1

*get,a,kp,0,num,max

*get, $\mathrm{x} 1, \mathrm{kp}, \mathrm{a}, \mathrm{loc}, \mathrm{x}$

*get,y1,kp,a,loc,y

*get, z1,kp,a,loc, $\mathrm{z}$

kmodif, $\mathrm{a}, \mathrm{x} 1+\sin \left((\mathrm{j}-1)^{*} 45\right)^{*}(\mathrm{~h} *(1-(\mathrm{i}-1) * 1 / \mathrm{n})), \mathrm{y} 1, \mathrm{z} 1$

$\mathrm{ksel}, \mathrm{u}, \mathrm{kp}, \mathrm{a}$

*enddo

*enddo

!***end imperfection****

!***imperfection @ mid wall of the tank ****

$*$ do, $\mathrm{i}, 1, \mathrm{n}, 1$

ksel, loc, $x, 450$

,r,loc,y,(180-((i-1)*1))

,r,loc, z, 190,241

*get,numkp,kp, count

*do,j, 1 ,numkp, 1

*get, a,kp,0,num,max 
*get, $\mathrm{x} 1, \mathrm{kp}, \mathrm{a}, \mathrm{loc}, \mathrm{x}$

*get,y1,kp,a,loc,y

*get, z1,kp, a,loc, z

kmodif, $\mathrm{a}, \mathrm{x} 1+\sin \left((\mathrm{j}-1)^{*} 45\right) *\left(\mathrm{~h} *\left(1-(\mathrm{i}-1)^{*} 1 / \mathrm{n}\right)\right), \mathrm{y} 1, \mathrm{z} 1$

$\mathrm{ksel}, \mathrm{u}, \mathrm{kp}, \mathrm{a}$

*enddo

*enddo

!***end imperfection****

!***Third imperfection@ @ lower level of the tank ****

*do,i, $1, \mathrm{n}, 1$

ksel, $, 10 c, x, 450$

$, \mathrm{r}, 1 \mathrm{loc}, \mathrm{y},\left(140-\left((\mathrm{i}-1)^{*} 1\right)\right)$

,r,loc, z, 110,170

*get,numkp,kp,,count

$*$ do, $, 1,1$, numkp, 1

i *get,a,kp,0,num,max

*get, $\mathrm{x} 1, \mathrm{kp}, \mathrm{a}, \mathrm{loc}, \mathrm{x}$

*get,y1,kp,a,loc,y

*get, z1,kp,a,loc, z

kmodif, $\mathrm{a}, \mathrm{x} 1+\sin \left((\mathrm{j}-1)^{*} 45\right) *\left(\mathrm{~h} *\left(1-(\mathrm{i}-1)^{*} 1 / \mathrm{n}\right)\right), \mathrm{y} 1, \mathrm{z} 1$

$\mathrm{ksel}, \mathrm{u}, \mathrm{kp}, \mathrm{a}$

*enddo

*enddo

$*$ do,i,2,n, 1

ksel, $, 10 c, x, 450$

$, \mathrm{r}, 1 \mathrm{loc}, \mathrm{y},(140+((\mathrm{i}-1) * 1))$

,r,loc, z, 110,170

*get,numkp,kp,,count

$*$ do, $, 1,1$, numkp, 1

*get, a,kp,0,num,max *get, $\mathrm{x} 1, \mathrm{kp}, \mathrm{a}, \mathrm{loc}, \mathrm{x}$

*get,y1,kp,a,loc,y

*get,z1,kp,a,loc, z

kmodif, $\mathrm{a}, \mathrm{x} 1+\sin ((\mathrm{j}-1) * 45) *(\mathrm{~h} *(1-(\mathrm{i}-1) * 1 / \mathrm{n})), \mathrm{y} 1, \mathrm{z} 1$

$\mathrm{ksel}, \mathrm{u}, \mathrm{kp}, \mathrm{a}$

*enddo

*enddo

!***end imperfection $* * * *$

es $=\mathrm{ht} / 100$

esize,es

amesh,all

!***Boundary Conditions***

csys, 0

nsel, loc, y, $-0.001 *$ ht, $0.001 *$ ht

d,all,uy, $0.0,,$, ux, uz $\quad$ ! Fix bottom end (disp only)

nsel, all

nsel,,loc,y, 0.999*ht, $1.001 *$ ht

$\mathrm{d}, \mathrm{all}, \mathrm{ux}, 0.0,,, \mathrm{uz} \quad$ ! Fix top edge (disp only)

nsel, loc, $\mathrm{z}, 0.0,0.0$

$\mathrm{d}$, all,roty, $0.0,,$, ,uz,rotx $\quad$ ! Fix $\mathrm{z}=0$ edges

nsel,all

nsel, loc, $\mathrm{z}, 0.0,0.0$

nsel,r,loc, $\mathrm{x}, 0.999 * \mathrm{r}, 1.001 * \mathrm{r}$

nsel,r,loc,y, $0.0,0.0$

$\mathrm{d}$, all, $\mathrm{ux}, 0.0 \quad$ ! Fix 1 node in $\mathrm{x}$

nsel, all

esel, all

alls

!***End Boundary Conditions***

!***Apply Loads 
/com, Apply Axial Pressure

1sel,s,loc,y,0.999*ht, 1.001*ht

sfl,all,pres5,1 ! surf-load,pres5=face (k-1)

sbct ! transfer solid bc's to FE model

1sel,all

alls

$$
\text { /sol }
$$

anty,stat ! Static analysis

pstres, on ! Calculate PreStress effects

nsub, $5,10,2$, on

save

solv

fini

/sol

anty,buckle

! Buckling Analysis

bucopt,lanb,1 ! Use block lanczos eigenvalue extraction

method

mxpand, 1

solv

! Expand 1 mode shape

*get,FCR,mode, 1 ,freq

*status,parm

*dim,label,char, 1,2

*dim,value, $, 1,3$

label $(1,1)=$ 'Fcr'

label $(1,2)=' b^{\prime}$

Input File: Uniform Cylinder with Four ASME or Tank

Fabrication specifications - by changing the comment line $\{(1 / 10)$

times, 1 times, 10 times, by changing the comment line\}

imperfections - Eigenvalue buckling analysis for Hoop Loads fini

/cle

/fil,uc-impft-1asme-3-v

/title, UNIFORM tank with Four imperfections Under Vacuum

/com,Fixed Top \& Bottom Rings (Disp only), 180-deg

/prep7

et, 1,181

*afun, deg

!*** Materials

$\mathrm{mp}, \mathrm{ex}, 1,29.5 \mathrm{e} 6$

mp, dens, $1,490 / 1728$

mp,prxy, 1,3

tb, biso, 1

tbdata, $1,36000, .01 * 27.7 \mathrm{e} 6$

!*** Shell thickness

$\mathrm{t}=0.507 \quad$ ! wall thickness, inch

R, 1,t ! shell Thickness

real,1

!*** Tank Dimensions

$\mathrm{r}=450.0 \quad$ ! tank radius, inch

ht $=460.0 \quad$ ! tank height, inch

!*** Geometry

$\mathrm{k}, 1, \mathrm{r}$

$\mathrm{k}, 2, \mathrm{r}, 12$

*rep, 38, 1,12

$\mathrm{k}, 40, \mathrm{r}, 460$ 
$\mathrm{k}, 1000,0,0$

$\mathrm{k}, 1001,0,500$

$1,1,2$

*rep, 39,1,1

1sel,all

arot,all, ,,, , 1000,1001,180,180

1sel,all

\section{!***ASME NE-4220 specs}

$\mathrm{w}=9.75^{*} 12$

$! h=0.05 \quad !(1 / 10)$ times ASME imperfection

$\mathrm{h}=0.5 \quad ! 1 *$ ASME imperfection

$! \mathrm{h}=5 \quad ! 10$ times ASME imperfection

\section{!***Tank-Fabrication specs}

! $\mathrm{w}=7 * 12$

$! h=0.1 \quad !(1 / 10)$ times Tank Fab imperfection

th $\quad ! 1^{*}$ Tank Fab imperfection

o $! \mathrm{h}=10 \quad ! 10$ times Tank Fab imperfection

$\mathrm{pi}=22 / 7$

impang $=(\mathrm{w} / 450)^{*}(180 / \mathrm{pi})$

$\mathrm{n} 1=\operatorname{nint}(\mathrm{impang} / 1 / 2)$ !! nearest integer

$*$ if,(n1* $1 * 450 * \mathrm{pi} / 180), \mathrm{ge},(\mathrm{w} / 2)$, then !<check if 'n1' spreads for ' $\mathrm{w}$ ' or not>

$\mathrm{n}=\mathrm{n} 1$

*else

$\mathrm{n}=\mathrm{n} 1+\mathbf{1}$

*endif

!***imperfection $@$ the upper section of the tank **** csys, 5

$* \mathrm{do}, \mathrm{i}, 1, \mathrm{n}, 1$

$\mathrm{ksel}, 1 \mathrm{loc}, \mathrm{x}, 450$

,r,loc,y,(180-((i-1)*1))

,r,loc, z,370,430

*get,numkp,kp, count

*do,j,1,numkp, 1

*get,a,kp,0,num,max

*get, $\mathrm{x} 1, \mathrm{kp}, \mathrm{a}, \mathrm{loc}, \mathrm{x}$

*get,y1,kp,a,loc,y

*get,z1,kp,a,loc, z

kmodif, a, $x 1+\sin \left((\mathrm{j}-1)^{*} 45\right)^{*}\left(\mathrm{~h}^{*}\left(1-(\mathrm{i}-1)^{*} 1 / \mathrm{n}\right)\right), \mathrm{y} 1, \mathrm{z} 1$

$\mathrm{ksel}, \mathrm{u}, \mathrm{kp}, \mathrm{a}$

*enddo

*enddo

!***end imperfection*****

!***imperfection $@$ mid wall of the tank ****

*do, $\mathrm{i}, 1, \mathrm{n}, 1$

$\mathrm{ksel}, \mathrm{loc}, \mathrm{x}, 450$

,r,loc,y, (180-((i-1)*1))

,r,loc, z, 190,241

*get,numkp,kp, count

*do,j,1,numkp, 1

*get,a,kp,0,num,max

*get,x1,kp,a,loc, $\mathrm{x}$

*get,y1,kp,a,loc,y

*get, z1,kp,a,loc, $\mathrm{z}$

kmodif,a, $\mathrm{x} 1+\sin \left((\mathrm{j}-1)^{*} 45\right)^{*}\left(\mathrm{~h} *\left(1-(\mathrm{i}-1)^{*} 1 / \mathrm{n}\right)\right), \mathrm{y} 1, \mathrm{z} 1$

$\mathrm{ksel}, \mathrm{u}, \mathrm{kp}, \mathrm{a}$

*enddo

*enddo

!***end imperfection**** 
!***Third imperfection $@$ lower level of the tank ****

$*$ do, $\mathrm{i}, 1, \mathrm{n}, 1$

ksel, loc, $x, 450$

,r,loc,y,,$\left(140-\left((\mathrm{i}-1)^{*} 1\right)\right)$

,r,loc, z, 110,170

*get,numkp,kp,,count

*do,j,1,numkp, 1

*get, a,kp, 0,num,max

*get, $x 1, \mathrm{kp}, \mathrm{a}, 1 \mathrm{loc}, \mathrm{x}$

*get,y1,kp,a,loc,y

*get,z1,kp,a,loc, z

kmodif, $\mathrm{a}, \mathrm{x} 1+\sin \left((\mathrm{j}-1)^{*} 45\right) *(\mathrm{~h} *(1-(\mathrm{i}-1) * 1 / \mathrm{n})), \mathrm{y} 1, \mathrm{z} 1$

$\mathrm{ksel}, \mathrm{u}, \mathrm{kp}, \mathrm{a}$

*enddo

*enddo

$\vec{\omega}_{\omega}$

$*$ do,, , $2, \mathrm{n}, 1$

ksel, $, 10 c, x, 450$

$, \mathrm{r}, \mathrm{loc}, \mathrm{y},\left(140+\left((\mathrm{i}-1)^{*} 1\right)\right)$

,r,loc, z, 110,170

*get,numkp,kp,, count

$*$ do, $, 1,1$, numkp, 1

*get, a,kp,0,num,max

*get,x1,kp,a,loc, $x$

*get,y1,kp,a,loc,y

*get,z1,kp,a,loc, z

kmodif, a, $\mathrm{x} 1+\sin ((\mathrm{j}-1) * 45) *(\mathrm{~h} *(1-(\mathrm{i}-1) * 1 / \mathrm{n})), \mathrm{y} 1, \mathrm{z} 1$

$\mathrm{ksel}, \mathrm{u}, \mathrm{kp}, \mathrm{a}$

*enddo

*enddo

!***end imperfection**** es $=h t / 100$

esize,es

amesh,all

!***Boundary Conditions****

csys, 0

nsel, $, 10 c, y,-0.001 * h t, 0.001 *$ ht

d,all,uy, $0.0,,$, ux,uz $\quad$ ! Fix bottom end (disp only)

nsel, all

nsel,,loc,y, 0.999*ht, 1.001*ht

$\mathrm{d}, \mathrm{all}, \mathrm{ux}, 0.0,,, \mathrm{uz} \quad$ ! Fix top edge (disp only)

nsel, ,loc, z, $0.0,0.0$

d,all,roty, $0.0,,$, ,uz,rotx $\quad$ ! Fix $z=0$ edges

nsel,all

nsel, loc, z, $0.0,0.0$

nsel,r,loc, $\mathrm{x}, 0.999 * \mathrm{r}, 1.001 * \mathrm{r}$

nsel,r,loc,y, $0.0,0.0$

$\mathrm{d}$, all,ux, $0.0 \quad$ ! Fix 1 node in $\mathrm{x}$

nsel, all

esel,all

alls

!***End Boundary Conditions***

!***Apply Loads

/com, Apply Unit Vacuum

pp $1=-1$

esel,all

sf,all,pres,pp1

/psf,pres, 2

eplot

alls

!***End Loads 


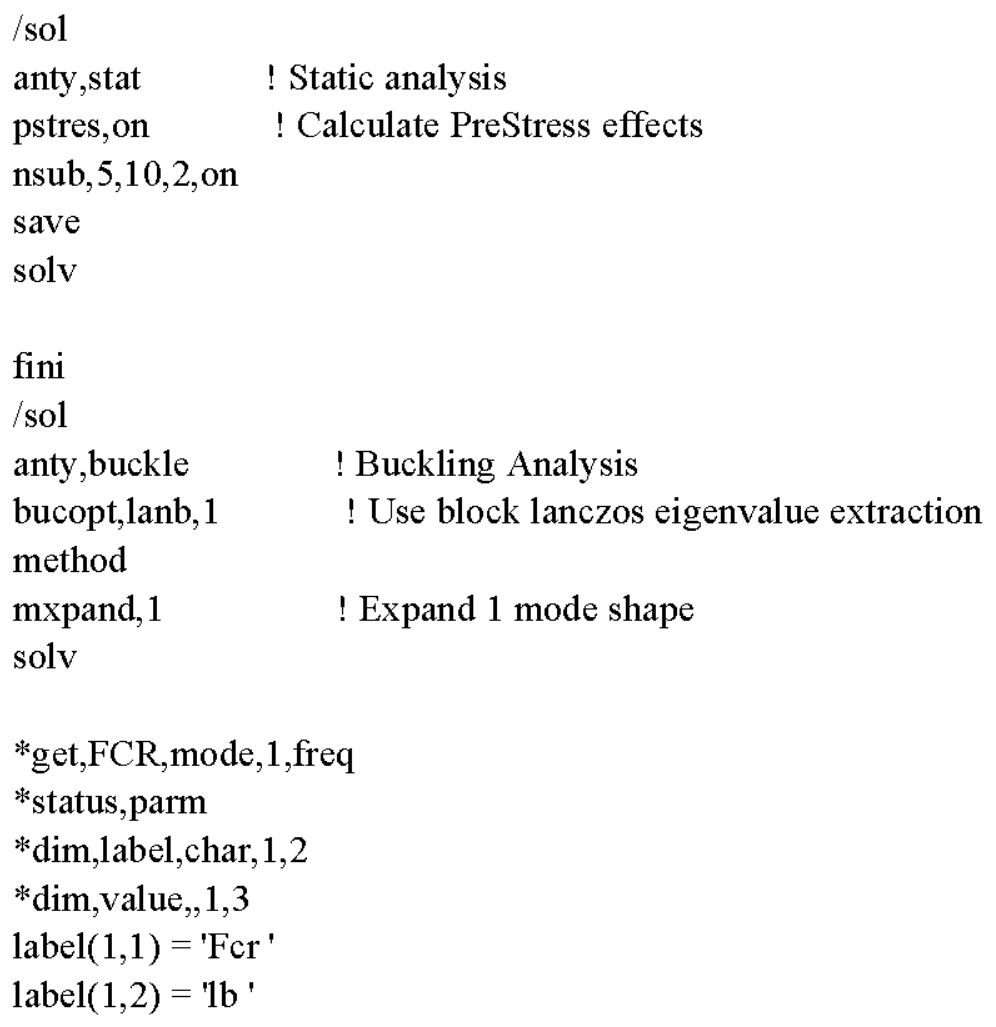

Input File: Uniform Cylinder with Four ASME or Tank

Fabrication specifications - by changing the comment line $\{(1 / 10)$ times, 1 times, 10 times, by changing the comment line\}

imperfections - Eigenvalue buckling analysis for Axial and Hoop Loads

fini
$/$ cle

/fil,uc-impft-1asme-3-c
/title,UNIFORM tank with Four imperfections Under Combined Load

/com,Fixed Top \& Bottom Rings (Disp only), 180-deg

/prep7

et, 1,181

*afun, deg

!*** Materials

$\mathrm{mp}, \mathrm{ex}, 1,29.5 \mathrm{e} 6$

mp, dens, $1,490 / 1728$

mp,prxy, $1, .3$

tb, biso, 1

tbdata, $1,36000, .01 * 27.7 \mathrm{e} 6$

!*** Shell thickness

$\mathrm{t}=0.507 \quad$ ! wall thickness, inch

$\mathrm{R}, 1, \mathrm{t} \quad$ ! shell Thickness

real,1

!*** Tank Dimensions

$\mathrm{r}=450.0 \quad$ ! tank radius, inch

$\mathrm{ht}=460.0 \quad$ ! tank height, inch

!*** Geometry

$\mathrm{k}, 1, \mathrm{r}$

$\mathrm{k}, 2, \mathrm{r}, 12$

*rep, $38,1,12$

$\mathrm{k}, 40, \mathrm{r}, 460$

$\mathrm{k}, 1000,0,0$

$\mathrm{k}, 1001,0,500$

$1,1,2$

*rep, 39, 1,1 
1 sel, all

arot,all,,,,,, $1000,1001,180,180$

lsel,all

! ** ASME NE-4220 specs

$\mathrm{w}=9.75 * 12$

!h $=0.05 !(1 / 10)$ times ASME imperfection

$\mathrm{h}=0.5 \quad ! 1 *$ ASME imperfection

$! \mathrm{h}=5 \quad ! 10$ times ASME imperfection

!***Tank-Fabrication specs

! $\mathrm{w}=7 * 12$

!h=0.1 ! (1/10) times Tank Fab imperfection

!h=1 ! 1* Tank Fab imperfection

$! h=10 \quad ! 10$ times Tank Fab imperfection

pi $\quad$ i $22 / 7$

$\omega \quad$ impang $=(\mathrm{w} / 450) *(180 / \mathrm{pi})$

n1 $=$ nint(impang $/ 1 / 2)$ !! nearest integer

$*$ if, $(\mathrm{n} 1 * 1 * 450 * \mathrm{pi} / 180)$, ge,(w/2), then !<check if ' $\mathrm{n} 1$ ' spreads for ' $\mathrm{W}$ ' or not>

$\mathrm{n}=\mathrm{n} 1$

*else

$\mathrm{n}=\mathrm{n} 1+1$

*endif

!***imperfection @ the upper section of the tank ****

csys, 5

$*$ do, $\mathrm{i}, 1, \mathrm{n}, 1$

ksel, $, 10 c, x, 450$

$, \mathrm{r}, 1 \mathrm{loc}, \mathrm{y},\left(180-\left((\mathrm{i}-1)^{*} 1\right)\right)$ ,r,loc, z,370,430

*get,numkp,kp, count

*do,j,1,numkp, 1

*get,a,kp,0,num,max

*get, $\mathrm{x} 1, \mathrm{kp}, \mathrm{a}, \mathrm{loc}, \mathrm{x}$

*get,y $1, \mathrm{kp}, \mathrm{a}, \mathrm{loc}, \mathrm{y}$

*get,z1,kp,a,loc, z

kmodif, $, \mathrm{x} 1+\sin ((\mathrm{j}-1) * 45) *(\mathrm{~h} *(1-(\mathrm{i}-1) * 1 / \mathrm{n})), \mathrm{y} 1, \mathrm{z} 1$

$\mathrm{ksel}, \mathrm{u}, \mathrm{kp}, \mathrm{a}$

*enddo

*enddo

!***end imperfection****

!***imperfection $@$ mid wall of the tank ****

$*$ do, $\mathrm{i}, 1, \mathrm{n}, 1$

ksel, loc, $\mathrm{x}, 450$

,r,loc,y, $\left(180-\left((\mathrm{i}-1)^{*} 1\right)\right)$

,r,loc, z,190,241

*get,numkp,kp,,count

*do,j, 1, numkp, 1

*get,a,kp,0,num,max

*get, $\mathrm{x} 1, \mathrm{kp}, \mathrm{a}, 1 \mathrm{loc}, \mathrm{x}$

*get,y1,kp,a,loc,y

*get,z1,kp,a,loc, z

kmodif, $\mathrm{a}, \mathrm{x} 1+\sin \left((\mathrm{j}-1)^{*} 45\right)^{*}\left(\mathrm{~h} *\left(1-(\mathrm{i}-1)^{*} 1 / \mathrm{n}\right)\right), \mathrm{y} 1, \mathrm{z} 1$

$\mathrm{ksel}, \mathrm{u}, \mathrm{kp}, \mathrm{a}$

*enddo

*enddo

!***end imperfection $* * * *$

!***Third imperfection@ @ lower level of the tank ****

$*$ do, $\mathrm{i}, 1, \mathrm{n}, 1$ 
ksel, loc, $\mathrm{x}, 450$

$, \mathrm{r}, 1 \mathrm{loc}, \mathrm{y},\left(140-\left((\mathrm{i}-1)^{*} 1\right)\right)$

,r,loc, z,110,170

*get,numkp,kp,,count

*do,j, 1, numkp, 1

*get,a,kp,0,num,max

*get, $\mathrm{x} 1, \mathrm{kp}, \mathrm{a}, \mathrm{loc}, \mathrm{x}$

*get,y1,kp,a,loc,y

*get,z1,kp,a,loc, z

kmodif, a, $\mathrm{x} 1+\sin ((\mathrm{j}-1) * 45) *(\mathrm{~h} *(1-(\mathrm{i}-1) * 1 / \mathrm{n})), \mathrm{y} 1, \mathrm{z} 1$

$\mathrm{ksel}, \mathrm{u}, \mathrm{kp}, \mathrm{a}$

*enddo

*enddo

$*$ do,, , $2, n, 1$

ksel, loc, $\mathrm{x}, 450$

,r,loc,y, $\left(140+\left((\mathrm{i}-1)^{*} 1\right)\right)$

is,loc, z, 110,170

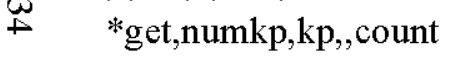

*do,j, 1, numkp, 1

*get,a,kp,0,num,max

${ }^{*}$ get, $x 1, k p, a, 1 o c, x$

*get,y 1,kp,a,loc,y

*get,z1,kp,a,loc, z

kmodif,a, $x 1+\sin ((\mathrm{j}-1) * 45) *(\mathrm{~h} *(1-(\mathrm{i}-1) * 1 / \mathrm{n})), \mathrm{y} 1, \mathrm{z} 1$

$\mathrm{ksel}, \mathrm{u}, \mathrm{kp},, \mathrm{a}$

*enddo

*enddo

!***end imperfection****

es $=h t / 100$

esize, es

amesh, all
!***Boundary Conditions****

csys, 0

nsel, loc, $,-0.001 * \mathrm{ht}, 0.001 * \mathrm{ht}$

d,all,uy, $0.0,,$, ux, uz $\quad$ ! Fix bottom end (disp only)

nsel,all

nsel, loc, y, 0.999*ht, $1.001 * \mathrm{ht}$

$\mathrm{d}, \mathrm{all}, \mathrm{ux}, 0.0,,, \mathrm{uz} \quad$ ! Fix top edge (disp only)

nsel, loc, z, $0.0,0.0$

$\mathrm{d}$,all,roty, $0.0,,$, ,uz,rotx $\quad$ ! Fix $z=0$ edges

nsel, all

nsel, ,loc, z, $0.0,0.0$

nsel,r,loc, $x, 0.999 * \mathrm{r}, 1.001 * \mathrm{r}$

nsel,r,loc,y, $0.0,0.0$

$\mathrm{d}, \mathrm{all}, \mathrm{ux}, 0.0 \quad$ ! Fix 1 node in $\mathrm{x}$

nsel,all

esel,all

alls

!***End Boundary Conditions***

!***Apply Loads.

/com, Apply Axial Pressure

1sel,s,loc,y, 0.999*ht,1.001*ht

sfl,all,pres5,1 ! surf-load,pres5=face (k-1)

sbct ! transfer solid bc's to FE model

1sel,all

alls

/com, Apply Unit Vacuum

pp1 $1=-1$

esel,all

sf,all,pres,pp1

/psf,pres, 2 
eplot

alls

!***End Loads

/sol

anty,stat ! Static analysis

pstres, on ! Calculate PreStress effects

nsub, $5,10,2$, on

save

solv

fini

/sol

anty,buckle

bucopt,lanb, 1

method

mxpand, 1

solv

*get,FCR,mode, 1 ,freq

*status,parm

*dim,label,char, 1,2

*dim,value, 1,3

label $(1,1)=$ 'Fcr'

label $(1,2)=' b^{\prime}$

\section{!!!DST Primary Tank One Imperfection Models!!!}

Input File: Primary Tank with one ASME or Tank Fabrication specifications - by changing the comment line $\{(1 / 10)$ times, 1 times, 10 times, by changing the comment line $\}$ imperfection Eigenvalue buckling analysis for Axial Loads fini
$/ \mathrm{cle}$

/fil,dst-impft-1 asme-1-a

/title,Imperfect DST primary tank with one imperfection Under Axial Pressure

/com, AY Primary Tank, Fixed Top \& Bottom Rings (Disp only),

180-deg

/prep7

et, 1,181

*afun,deg

!*** Materials

mp,ex, $1,29.5 \mathrm{e} 6$

mp,dens, $1,490 / 1728$

mp,prxy, $1, .3$

tb,biso, 1

tbdata, $1,36000, .01 * 27.7 \mathrm{e} 6$

!*** Shell thickness

!*** 0.060 corrosion allowance

r, 1,1-.06

r, $2,3 / 8-.06$

$\mathrm{r}, 3,7 / 8-.06$

$\mathrm{r}, 4,3 / 4-.06$

r, $5,1 / 2-.06$

!*** Geometry

$\mathrm{k}, 1,0.0,0.0$

$\mathrm{k}, 2,24$

$\mathrm{k}, 3,(37.5-4)^{*} 12$

$\mathrm{k}, 4,37.5 * 12$

$\mathrm{k}, 5,37.5^{*} 12,12$ 
*rep, $31,1,12$

$\mathrm{k}, 36,37.5 * 12,382$

*rep, $4,1,12$

$\mathrm{k}, 40,37.5 * 12,45 * 12$

$\mathrm{k}, 41,0.0,(31+15) * 12+9+1 / 2$

$\mathrm{k}, 42,40 * 12,31 * 12+9+1 / 2$

$1,1,2$

*rep, $39,1,1$

loca $, 11,1,0,31 * 12+9+1 / 2,0,,, 3 / 8$

$1,41,42$

1 fil $, 3,4,12$

$1 \mathrm{csl}, 39,40$

1fil $, 4,43,3 * 12+8+3 / 8$

1del, $42,44,1$

1del, $1,3,1$

csys, defa

1sel,all

i arot,all, ,,, $, 1,41,180,180$

lsel, all

$\mathrm{ht}=459$

rbtm $=438$ ! radius at bottom knuckle tangent.

$\mathrm{t}=3 / 8-0.06 \quad$ ! thickness at top of shell where pressure applied.

es $=\mathrm{ht} / 100$

!***Specify the width (w) and deviation (h) of the dent

!***ASME NE-4220 specs

$\mathrm{W}=9.75 * 12$

$! h=0.05 \quad !(1 / 10)$ times ASME imperfection

$\mathrm{h}=0.5 \quad$ ! $1 *$ ASME imperfection

$! h=5 \quad ! 10$ times ASME imperfection

\section{!***Tank-Fabrication specs \\ ! $\mathrm{w}=7 * 12$ \\ $! h=0.1 \quad !(1 / 10)$ times Tank Fab imperfection \\ $! h=1 \quad !$ 1* Tank Fab imperfection \\ $! h=10 \quad ! 10$ times Tank Fab imperfection}

$\mathrm{pi}=22 / 7$

impang $=(\mathrm{w} / 450)^{*}(180 / \mathrm{pi})$

$\mathrm{n} 1=\operatorname{nint}(\mathrm{impang} / 1 / 2)$ !! nearest integer

$*$ if, $(\mathrm{n} 1 * 1 * 450 * \mathrm{pi} / 180), \mathrm{ge},(\mathrm{w} / 2)$, then !<check if ' $\mathrm{n} 1$ ' spreads for ' $\mathrm{w}$ ' or not>

$\mathrm{n}=\mathrm{n} 1$

*else

$\mathrm{n}=\mathbf{n} 1+\mathbf{1}$

*endif

!***imperfection $@$ the upper thin section of the tank **** csys, 5

*do, $\mathrm{i}, 1, \mathrm{n}, 1$

ksel, loc, $x, 450$

,r,loc,y,(180-((i-1)*1))

,r,loc, z,340,423

*get,numkp,kp, count

*do,j,1,numkp, 1

*get,a,kp,0,num,max

*get,x1,kp,a,loc, $\mathrm{x}$

*get,y1,kp,a,loc,y

*get,z1,kp,a,loc, $\mathrm{z}$

kmodif,a, $x 1+\sin \left((\mathrm{j}-1)^{*} 30\right)^{*}\left(\mathrm{~h} *\left(1-(\mathrm{i}-1)^{*} 1 / \mathrm{n}\right)\right), \mathrm{y} 1, \mathrm{z} 1$

$\mathrm{ksel}, \mathrm{u}, \mathrm{kp}, \mathrm{a}$

*enddo

*enddo 
!***end imperfection*****

esize,es

amesh, all

!***Thickness assignments

\section{csys, 5}

nsel, ,loc, $x, 402,500$

nsel,r,loc, z,0,36

esln, 1

emod,all,real, 3

nsel,,loc, z,36,144

esln,, 1

emod,all,real,4

nsel,,loc, z,144,382

esln, 1

emod,all,real, 5

nsel,,loc, z,382,561.5

w esln, 1

esel,r,type, ,1

emod,all,real, 2

allsel

!***Boundary Conditions***

\section{csys, 0}

nsel, loc, $, \mathrm{y},-0.001 * \mathrm{ht}, 0.001 * \mathrm{ht}$

$\mathrm{d}$,all,uy, $0.0,,, \mathrm{ux}, \mathrm{uz} \quad$ ! Fix bottom end (disp only)

nsel,all

nsel, loc,y, $0.999 * \mathrm{ht}, 1.001 * \mathrm{ht}$

d,all,ux, $0.0,,$, uz

! Fix top edge (disp only)

nsel, ,loc, z, 0.0,0.0

d,all,roty, $0.0,,$, uz,rotx $\quad$ ! Fix $z=0$ edges

nsel,all

nsel,s,loc, z, $0.0,0.0$ nsel,r,loc, $x, 0.999 *$ rbtm, 1.001*rbtm

nsel,r,loc,y, $0.0,0.0$

d,all,ux, $0.0 \quad$ ! Fix 1 node in $\mathrm{x}$

nsel,all

!***End Boundary Conditions***

!***Apply Loads

/com, Apply Axial Load

fnode $=-1 *$ es* 1 ! nodal force, y-direction

fends $=$ fnode $/ 2$ ! nodal force at ends, y-direction

nsel,s,loc,y, 0.999*ht, 1.001*ht

f,all,fy,fnode

nsel,r,loc, z, $0.0,0.0$

$\mathrm{f}$,all,fy,fends

nsel,all

alls

!***End Loads

/sol

anty,stat ! Static analysis

pstres, on ! Calculate PreStress effects

nsub, $5,10,2$, on

save

solv

fini

/sol

anty,buckle ! Buckling Analysis

bucopt,lanb,1 ! Use block lanczos eigenvalue extraction

method

mxpand,1 ! Expand 1 mode shape 
solv

*get,FCR,mode, 1 ,freq

*status,parm

*dim,label,char, 1,2

*dim,value, 1,3

label $(1,1)=$ 'Fcr'

label $(1,2)={ }^{\prime} 1 b^{\prime}$

Input File: Primary Tank with one ASME or Tank Fabrication specifications - by changing the comment line $\{(1 / 10)$ times, 1

times, 10 times, by changing the comment line $\}$ imperfection Eigenvalue buckling analysis for Hoop Loads

fini

/cle

/fil,dst-impft-1 asme-1-a

/ /title,Imperfect DST primary tank with one imperfection Under

/com, AY Primary Tank, Fixed Top \& Bottom Rings (Disp only), 180-deg

prep 7

et, 1,181

*afun,deg

!**** Materials

mp,ex, 1,29.5e6

mp,dens, $1,490 / 1728$

mp,prxy, $1, .3$

tb, biso, 1

tbdata, $1,36000, .01 * 27.7 \mathrm{e} 6$

!**** Shell thickness

!*** 0.060 corrosion allowance

r, 1, 1-.06

r, 2,3/8-.06

$\mathrm{r}, 3,7 / 8-.06$

r, 4,3/4-.06

r, 5, 1/2-.06

!*** Geometry

$\mathrm{k}, 1,0.0,0.0$

$\mathrm{k}, 2,24$

$\mathrm{k}, 3,(37.5-4)^{*} 12$

$\mathrm{k}, 4,37.5 * 12$

$\mathrm{k}, 5,37.5 * 12,12$

*rep, $31,1,, 12$

$\mathrm{k}, 36,37.5 * 12,382$

*rep, $4,1,12$

$\mathrm{k}, 40,37.5 * 12,45 * 12$

$\mathrm{k}, 41,0.0,(31+15)^{*} 12+9+1 / 2$

$\mathrm{k}, 42,40 * 12,31 * 12+9+1 / 2$

$1,1,2$

*rep, 39,1,1

loca $, 11,1,0,31 * 12+9+1 / 2,0,,, 3 / 8$

$1,41,42$

1fil, $3,4,12$

$1 \mathrm{cs} 1,39,40$

1 fil $, 4,43,3 * 12+8+3 / 8$

1del, $42,44,1$

1del, $1,3,1$

csys, defa

1sel,all

arot,all,,,,,, 1,41,180,180

1sel,all 


\section{$\mathrm{ht}=459$}

rbtm $=438$ ! radius at bottom knuckle tangent.

$\mathrm{t}=3 / 8-0.06 !$ thickness at top of shell where pressure applied.

es $=$ ht $/ 100$

!***Specify the width (w) and deviation (h) of the dent

\section{!***ASME NE-4220 specs}

\section{$\mathrm{W}=9.75^{*} 12$}

$! h=0.05 \quad !(1 / 10)$ times ASME imperfection

$\mathrm{h}=0.5 \quad$ ! 1 * ASME imperfection

$! h=5 \quad ! 10$ times ASME imperfection

\section{!***Tank-Fabrication specs}

!w $=7 * 12$

$! h=0.1 \quad !(1 / 10)$ times Tank Fab imperfection

!h=1 ! 1* Tank Fab imperfection

$! h=10 \quad ! 10$ times Tank Fab imperfection

\section{$\mathrm{pi}=22 / 7$}

impang $=(\mathrm{w} / 450)^{*}(180 / \mathrm{pi})$

$\mathrm{n} 1=$ nint(impang $/ 1 / 2)$ !! nearest integer

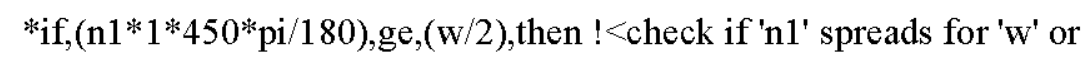
not>

$\mathrm{n}=\mathrm{n} 1$

*else

$\mathrm{n}=\mathrm{n} 1+1$

*endif

!***imperfection $@$ the upper thin section of the tank **** csys, 5

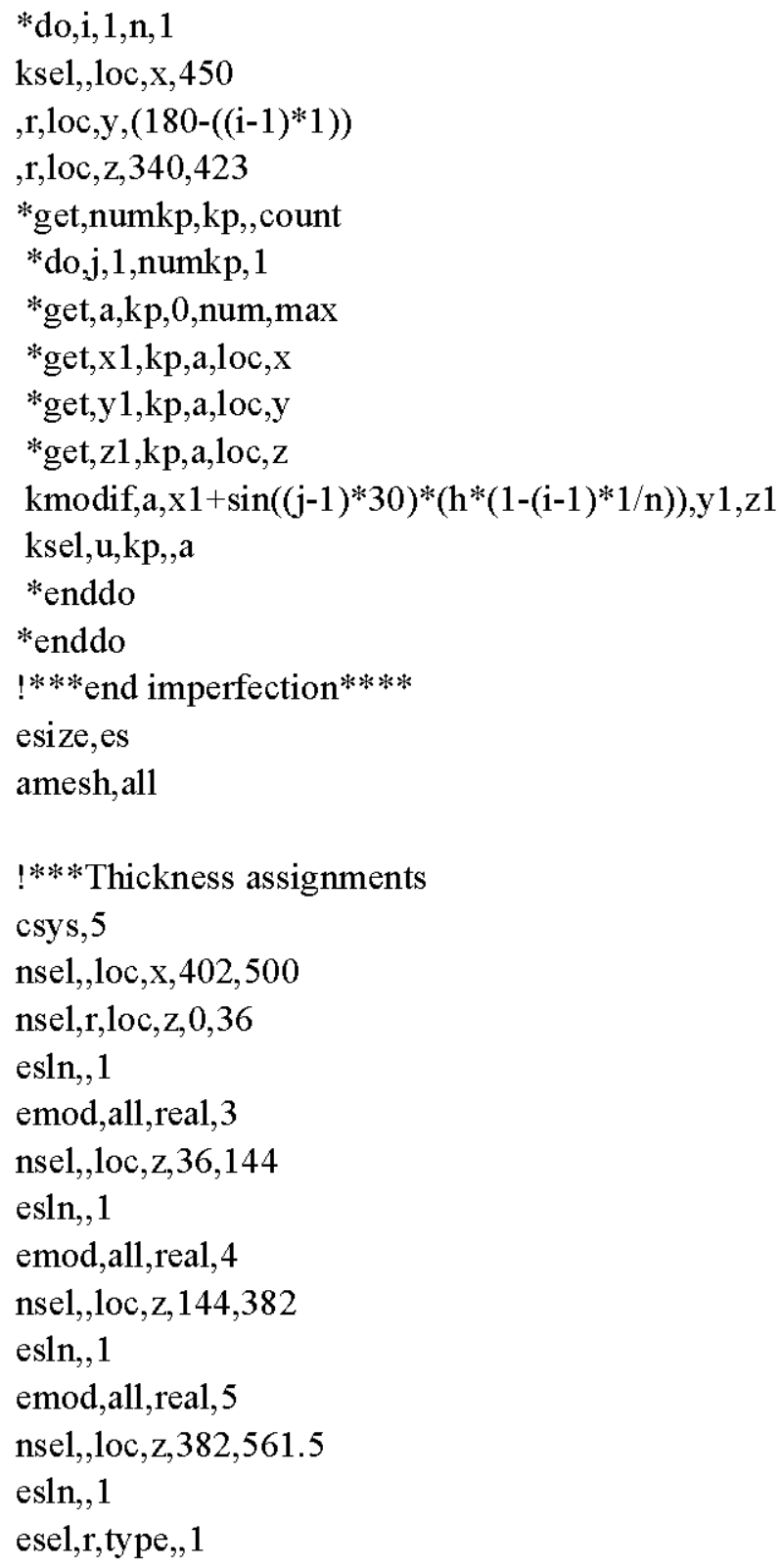


emod,all,real,2

allsel

!***Boundary Conditions***

csys, 0

nsel, loc,y, $-0.001 * \mathrm{ht}, 0.001 * \mathrm{ht}$

$\mathrm{d}$, all,uy, $0.0,,, \mathrm{ux}, \mathrm{uz} \quad$ ! Fix bottom end (disp only)

nsel, all

nsel, loc,y, 0.999*ht, 1.001*ht

$\mathrm{d}, \mathrm{all}, \mathrm{ux}, 0.0,,, \mathrm{uz}$

! Fix top edge (disp only)

nsel, loc, z, $0.0,0.0$

d,all,roty, $0.0,,$, uz,rotx $\quad$ ! Fix z $=0$ edges

nsel,all

nsel,s,loc, z, $0.0,0.0$

nsel,r,loc,, $0.099 *$ rbtm, $1.001 * \mathrm{rbtm}$

nsel,r,loc,y, $0.0,0.0$

$\mathrm{d}$,all, $\mathrm{ux}, 0.0 \quad$ ! Fix 1 node in $\mathrm{x}$

nsel,all

f !***End Boundary Conditions $* * *$

!***Apply Loads

/com, Apply Unit Vacuum

$\mathrm{pp} 1=1$

esel,all

sf,all,pres,pp1

/psf,pres, 2

eplot

alls

!***End Loads

/sol

anty,stat

! Static analysis

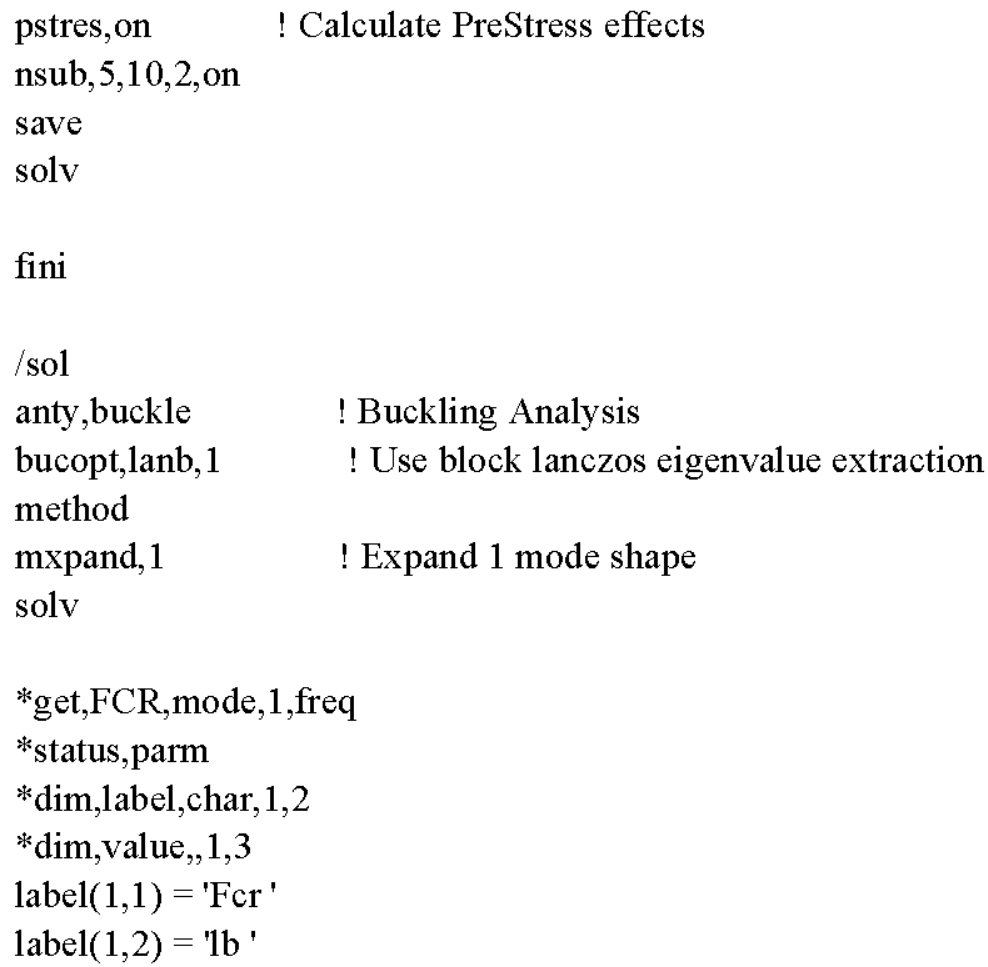

Input File: Primary Tank with one ASME or Tank Fabrication specifications - by changing the comment line $\{(1 / 10)$ times, 1 times, 10 times, by changing the comment line $\}$ imperfection Eigenvalue buckling analysis for Axial and Hoop Loads fini

/cle

/fil,dst-impft-1 asme-1-a

/title,Imperfect DST primary tank with one imperfection Under Combined Load

/com, AY Primary Tank, Fixed Top \& Bottom Rings (Disp only), 180-deg 


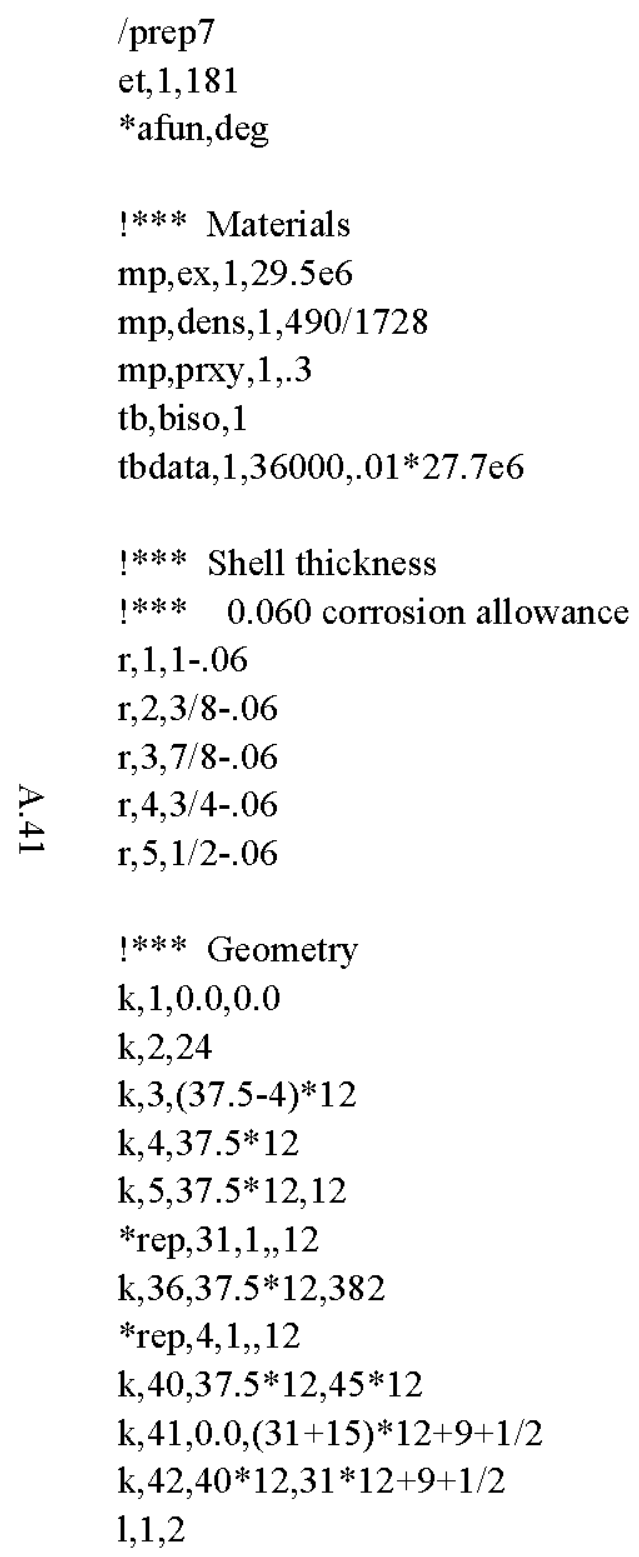


impang $=(\mathrm{w} / 450)^{*}(180 / \mathrm{pi})$

$\mathrm{n1}=\operatorname{nint}(\mathrm{impang} / 1 / 2)$ !! nearest integer

$*$ if, $(\mathrm{n} 1 * 1 * 450 * \mathrm{pi} / 180), \mathrm{ge},(\mathrm{w} / 2)$, then !<check if ' $\mathrm{n} 1$ ' spreads for ' $\mathrm{w}$ ' or

not>

$\mathrm{n}=\mathrm{n} 1$

*else

$\mathrm{n}=\mathrm{n} 1+\mathbf{1}$

*endif

!***imperfection $@$ the upper thin section of the tank ****

csys, 5

*do,i, 1,n, 1

ksel, loc, $x, 450$

,r,loc,y,(180-((i-1)*1))

,r,loc,z,340,423

*get,numkp,kp, count

$?$ do, j, 1, numkp, 1

*get,a,kp,0,num,max

*get,x1,kp,a,loc, $\mathrm{x}$

*get,y1,kp,a,loc,y

*get, z1,kp,a,loc, $\mathrm{z}$

kmodif, a, $x 1+\sin ((\mathrm{j}-1) * 30) *(\mathrm{~h} *(1-(\mathrm{i}-1) * 1 / \mathrm{n})), \mathrm{y} 1, \mathrm{z} 1$

ksel,u,kp,a

*enddo

*enddo

!***end imperfection $* * * *$

esize, es

amesh,all

!***Thickness assignments

csys, 5

nsel,, 1 loc, $x, 402,500$ nsel,r,loc, z,0,36

esln, 1

emod,all,real, 3

nsel, loc, z,36,144

esln, 1

emod,all,real, 4

nsel, loc, z, 144,382

esln, 1

emod,all,real, 5

nsel,,loc, z,382,561.5

esln, 1

esel,r,type, 1

emod,all,real, 2

allsel

!****B Boundary Conditions****

csys, 0

nsel, loc, y, $-0.001 *$ ht, $0.001 *$ ht

d,all,uy, $0.0,,, u x, u z \quad$ ! Fix bottom end (disp only)

nsel, all

nsel, loc,y, 0.999*ht, $1.001 * \mathrm{ht}$

d,all,ux,0.0,, ! I Fix top edge (disp only)

nsel, $, 10 c, \mathrm{z}, 0.0,0.0$

d,all,roty, $0.0,,$, uz,rotx $\quad !$ Fix $z=0$ edges

nsel,all

nsel, s,1oc, z, 0.0,0.0

nsel,r,loc, $\mathrm{x}, 0.999 * \mathrm{rbtm}, 1.001 * \mathrm{rbtm}$

nsel,r,loc,y,0.0,0.0

$\mathrm{d}$, all, $\mathrm{ux}, 0.0$

! Fix 1 node in $\mathrm{x}$

nsel,all

!***End Boundary Conditions $* * *$

!***A Apply Loads 
/com, Apply Axial Load

fnode $=-1$ *es 1 ! nodal force, $y$-direction

fends $=$ fnode $/ 2 \quad$ ! nodal force at ends, $y$-direction

nsel,s,loc,y, $0.999 * \mathrm{ht}, 1.001 * \mathrm{ht}$

f,all,fy,fnode

nsel,r,loc,z,0.0,0.0

$\mathrm{f}$, all,fy,fends

nsel,all

alls

/com, Apply Unit Vacuum

$\mathrm{pp} 1=1$

esel,all

sf,all,pres,pp1

/psf,pres, 2

eplot

alls

!***End Loads

/sol

anty,stat ! Static analysis

pstres, on ! Calculate PreStress effects

nsub, $5,10,2$, on

save

solv

fini

/sol

\section{anty,buckle}

bucopt,lanb, 1

method

mxpand, 1 solv

*get,FCR,mode, 1 ,freq

*status,parm

*dim,label,char, 1,2

*dim,value, 1,3

label $(1,1)=$ 'Fcr'

label $(1,2)={ }^{\prime} l b '$

\section{!!!DST Primary Tank Two Imperfections Models!!!}

Input File: Primary Tank with two ASME or Tank Fabrication specifications - by changing the comment line $\{(1 / 10)$ times, 1

times, 10 times, by changing the comment line $\}$ imperfections -

Eigenvalue buckling analysis for Axial Loads

fini

/cle

/fil,dst-impft-1 asme-1-a

/title,Imperfect DST primary tank with two imperfections Under Axial Pressure

/com, AY Primary Tank, Fixed Top \& Bottom Rings (Disp only), 180-deg

/prep7

et, 1,181

*afun,deg

!*** Materials

$\mathrm{mp}, \mathrm{ex}, 1,29.5 \mathrm{e} 6$

mp, dens, $1,490 / 1728$

mp,prxy, $1, .3$
! Buckling Analysis

! Use block lanczos eigenvalue extraction

! Expand 1 mode shape 
tb, biso, 1

tbdata, $1,36000, .01 * 27.7 \mathrm{e} 6$

!*** Shell thickness

!*** 0.060 corrosion allowance

$\mathrm{r}, 1,1-.06$

$\mathrm{r}, 2,3 / 8-.06$

r,3,7/8-.06

r, $4,3 / 4-.06$

r, 5,1/2-.06

!*** Geometry

$\mathrm{k}, 1,0.0,0.0$

$\mathrm{k}, 2,24$

$\mathrm{k}, 3,(37.5-4)^{*} 12$

$\mathrm{k}, 4,37.5^{*} 12$

$\mathrm{k}, 5,37.5 * 12,12$

*rep, $31,1,12$

$\pm \quad \mathrm{k}, 36,37.5^{*} 12,382$

*rep, $4,1,12$

$\mathrm{k}, 40,37.5 * 12,45 * 12$

$\mathrm{k}, 41,0.0,(31+15) * 12+9+1 / 2$

$\mathrm{k}, 42,40 * 12,31 * 12+9+1 / 2$

$1,1,2$

*rep, $39,1,1$

loca, $11,1,0,31 * 12+9+1 / 2,0,,, 3 / 8$

$1,41,42$

1 fil $, 3,4,12$

$1 \mathrm{cs} 1,39,40$

1fil $, 4,43,3 * 12+8+3 / 8$

1del, $42,44,1$

1 del, $1,3,1$

csys, defa 1sel,all

arot,all,,,,,,1,41,180,180

1sel,all

$\mathrm{ht}=459$

rbtm $=438$ ! radius at bottom knuckle tangent.

$\mathrm{t}=3 / 8-0.06 \quad$ ! thickness at top of shell where pressure applied.

es $=\mathrm{ht} / 100$

!***Specify the width (w) and deviation (h) of the dent

!***ASME NE-4220 specs

$\mathrm{w}=9.75 * 12$

!h $=0.05 \quad !(1 / 10)$ times ASME imperfection

$\mathrm{h}=0.5 \quad ! \quad 1^{*}$ ASME imperfection

$! \mathrm{h}=5 \quad ! 10$ times ASME imperfection

!***Tank-Fabrication specs

$! \mathrm{w}=7 * 12$

!h=0.1 ! (1/10) times Tank Fab imperfection

!h=1 ! 1* Tank Fab imperfection

!h=10 ! 10 times Tank Fab imperfection

$\mathrm{pi}=22 / 7$

impang $=(\mathrm{w} / 450)^{*}(180 / \mathrm{pi})$

n1=nint(impang $/ 1 / 2)$ !! nearest integer

$* \mathrm{if},(\mathrm{n} 1 * 1 * 450 * \mathrm{pi} / 180), \mathrm{ge},(\mathrm{w} / 2)$, then $!<$ check if 'n1' spreads for ' $\mathrm{w}$ ' or not>

$\mathrm{n}=\mathrm{n} 1$

*else

$\mathrm{n}=\mathrm{n} 1+1$

*endif 
!***imperfection $@$ the upper thin section of the tank $* * * *$ csys, 5

$*$ do, $, 1,1, \mathrm{n}, 1$

ksel, loc, $x, 450$

$, \mathrm{r}, 1 \mathrm{loc}, \mathrm{y},\left(180-\left((\mathrm{i}-1)^{*} 1\right)\right)$

,r,loc, z,340,423

*get,numkp,kp,,count

$*$ do, $, 1,1$, numkp, 1

*get, a,kp, , num,max

*get, $\mathrm{x} 1, \mathrm{kp}, \mathrm{a}, 1 \mathrm{loc}, \mathrm{x}$

*get,y1,kp,a,loc,y

*get,z1,kp,a,loc, z

kmodif, $, \mathrm{x} 1+\sin ((\mathrm{j}-1) * 30) *(\mathrm{~h} *(1-(\mathrm{i}-1) * 1 / \mathrm{n})), \mathrm{y} 1, \mathrm{z} 1$

$\mathrm{ksel}, \mathrm{u}, \mathrm{kp}, \mathrm{a}$

*enddo

*enddo

! $\quad * *$ end imperfection $* * * *$

!***imperfection @ mid wall of the tank ****

$*$ do, $, 1,1, \mathrm{n}, 1$

ksel,,loc, $x, 450$

$, \mathrm{r}, \mathrm{loc}, \mathrm{y},\left(180-\left((\mathrm{i}-1)^{*} 1\right)\right)$

,r,loc, z, 190,241

*get,numkp,kp,,count

*do, $, 1,1$, numkp, 1

*get,a,kp,0,num,max

*get, $\mathrm{x} 1, \mathrm{kp}, \mathrm{a}, \mathrm{loc}, \mathrm{x}$

*get,y1,kp,a,loc,y

*get, z1,kp, a,loc, z

kmodif, $\mathrm{a}, \mathrm{x} 1+\sin ((\mathrm{j}-1) * 45) *(\mathrm{~h} *(1-(\mathrm{i}-1) * 1 / \mathrm{n})), \mathrm{y} 1, \mathrm{z} 1$ $\mathrm{ksel}, \mathrm{u}, \mathrm{kp}, \mathrm{a}$

*enddo

*enddo

!***end imperfection****

esize,es

amesh,all

!***Thickness assignments

csys, 5

nsel, loc, $x, 402,500$

nsel,r,loc, z, 0,36

esln,, 1

emod,all,real,3

nsel,,loc,z,36,144

esln, 1

emod,all,real, 4

nsel,,loc, z, 144,382

esln,, 1

emod,all,real, 5

nsel, loc, z,382,561.5

esln, 1

esel,r,type,,1

emod,all,real,2

allsel

$! * * *$ Boundary Conditions***

csys, 0

nsel, loc,y, $-0.001 *$ ht, $0.001 *$ ht

d,all,uy, 0.0, ,, ux, uz $\quad$ ! Fix bottom end (disp only)

nsel, all

nsel, loc, y, 0.999*ht, $1.001 * \mathrm{ht}$

$\mathrm{d}, \mathrm{all}, \mathrm{ux}, 0.0,,, \mathrm{uz} \quad$ ! Fix top edge (disp only)

nsel, ,loc, $, 0.0,0.0$ 


\author{
d,all,roty, $0.0,,$, uz,rotx $\quad$ ! Fix $z=0$ edges \\ nsel,all \\ nsel,s,loc, z, $0.0,0.0$ \\ nsel,r,loc, $\mathrm{x}, 0.999 * \mathrm{rbtm}, 1.001 * \mathrm{rbtm}$ \\ nsel,r,loc,y, $0.0,0.0$ \\ $\mathrm{d}, \mathrm{all}, \mathrm{ux}, 0.0 \quad$ ! Fix 1 node in $\mathrm{x}$ \\ nsel,all \\ !***End Boundary Conditions***
}

!***Apply Loads

/com, Apply Axial Load

fnode $=-1 *$ es* 1 ! nodal force, $y$-direction

fends $=$ fnode $/ 2$ ! nodal force at ends, $y$-direction

nsel,s,loc,y, 0.999*ht, 1.001*ht

$\mathrm{f}$, all,fy, fnode

nsel,r,loc, z, $0.0,0.0$

f,all,fy,fends

क nsel,all

alls

!****End Loads

/sol

anty,stat ! Static analysis

pstres, on ! Calculate PreStress effects

nsub, $5,10,2$, on

save

solv

fini

/sol

anty, buckle

! Buckling Analysis

\author{
bucopt,lanb, 1 \\ method \\ solv \\ *get,FCR,mode, 1 ,freq \\ *status,parm \\ *dim,1abel,char, 1,2 \\ *dim,value, 1,3 \\ label $(1,1)=$ 'Fcr' \\ label $(1,2)={ }^{\prime} \mathrm{lb}$ '
}

mxpand,1 ! Expand 1 mode shape

Input File: Primary Tank with two ASME or Tank Fabrication specifications - by changing the comment line $\{(1 / 10)$ times, 1

times, 10 times, by changing the comment line $\}$ imperfections -

Eigenvalue buckling analysis for Hoop Loads

fini

/cle

/fil,dst-impft-1 asme-1-a

/title,Imperfect DST primary tank with two imperfections Under

Vacuum

/com, AY Primary Tank, Fixed Top \& Bottom Rings (Disp only),

180-deg

/prep7

et, 1,181

*afun, deg

!*** Materials

mp,ex, $1,29.5 \mathrm{e} 6$

mp, dens, $1,490 / 1728$ 


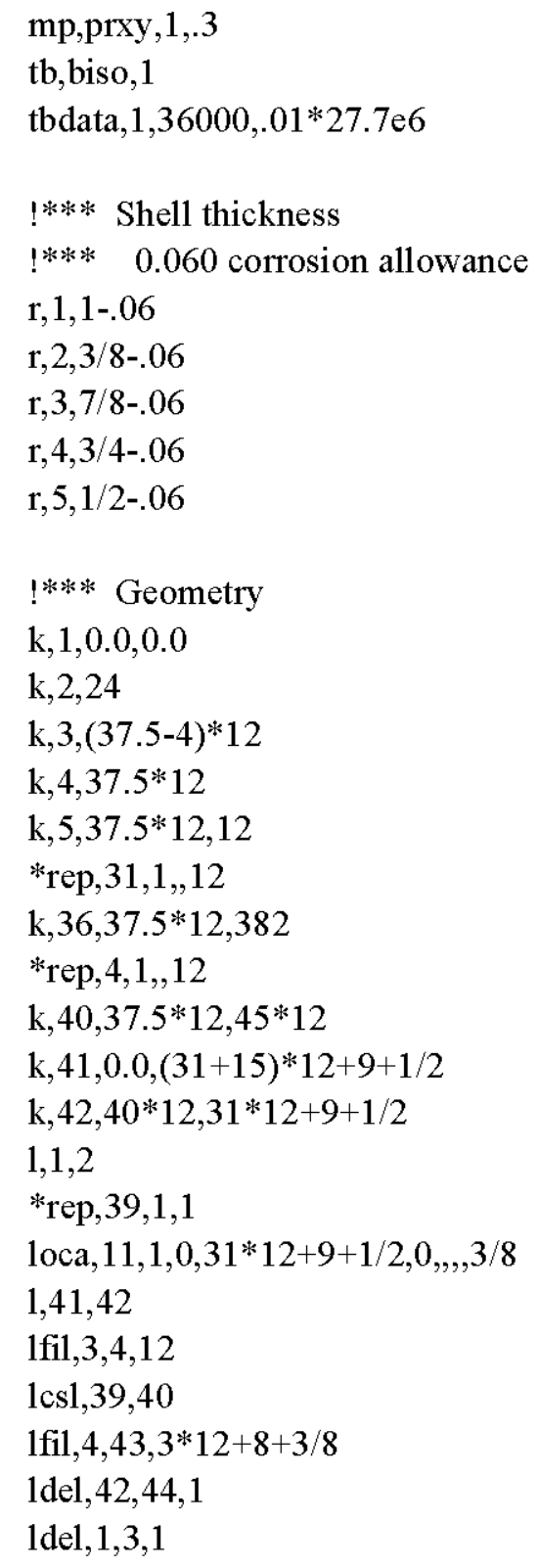


*endif

!***imperfection @ the upper thin section of the tank **** csys, 5

*do,i, $1, \mathrm{n}, 1$

ksel, $, 10 c, x, 450$

$, \mathrm{r}, 1 \mathrm{loc}, \mathrm{y},\left(180-\left((\mathrm{i}-1)^{*} 1\right)\right)$

,r,loc, z,340,423

*get,numkp,kp,,count

$*$ do, $, 1,1$, numkp, 1

*get, a,kp,0,num,max

*get,x1,kp,a,loc, $\mathrm{x}$

*get,y1,kp,a,loc,y

*get,z1,kp,a,loc, z

kmodif, $, \mathrm{x} 1+\sin ((\mathrm{j}-1) * 30) *\left(\mathrm{~h} *\left(1-(\mathrm{i}-1)^{*} 1 / \mathrm{n}\right)\right), \mathrm{y} 1, \mathrm{z} 1$

ksel, u,kp,,a

*enddo

$>\quad$ *enddo

$+\infty \quad$ !***end imperfection $* * * *$

!***imperfection $@$ mid wall of the tank *****

*do, $\mathrm{i}, 1, \mathrm{n}, 1$

ksel, loc, $x, 450$

,r,loc,y,(180-((i-1)*1))

,r,loc, z, 190,241

*get,numkp,kp, count

*do,j,1,numkp, 1

*get,a,kp,0,num,max

*get,x1,kp,a,loc, $x$

*get,y1,kp,a,loc,y

*get,z1,kp,a,loc, $\mathrm{z}$ kmodif,a, $\mathrm{x} 1+\sin \left((\mathrm{j}-1)^{*} 45\right)^{*}\left(\mathrm{~h} *\left(1-(\mathrm{i}-1)^{*} 1 / \mathrm{n}\right)\right), \mathrm{y} 1, \mathrm{z} 1$

$\mathrm{ksel}, \mathrm{u}, \mathrm{kp}, \mathrm{a}$

*enddo

*enddo

!***end imperfection*****

esize,es

amesh,all

!***Thickness assignments

csys, 5

nsel, 1 loc, $\mathrm{x}, 402,500$

nsel,r,loc, z, 0,36

esln, 1

emod,all,real,3

nsel,,loc, z, 36,144

esln, 1

emod,all,real, 4

nsel, loc, z, 144,382

esln, 1

emod,all,real, 5

nsel,,loc,z,382,561.5

esln, 1

esel,r,type, 1

emod,all,real, 2

allsel

!***B Boundary Conditions***

csys, 0

nsel, 1 loc,y, $-0.001 *$ ht, $0.001 * h t$

d,all,uy, $0.0,,, u x, u z \quad !$ Fix bottom end (disp only)

nsel,all

nsel, loc,y, 0.999*ht, 1.001*ht

d,all,ux, $0.0,,, \mathrm{uz} \quad$ ! Fix top edge (disp only) 
nsel, loc, $\mathrm{z}, 0.0,0.0$

d,all,roty, $0.0,,$, ,uz,rotx $\quad$ ! Fix z $=0$ edges

$$
\text { nsel,all }
$$

nsel,s,loc, z, $0.0,0.0$

nsel,r,loc, $x, 0.999 * \mathrm{rbtm}, 1.001 * \mathrm{rbtm}$

nsel,r,loc,y, $0.0,0.0$

$\mathrm{d}, \mathrm{all}, \mathrm{ux}, 0.0$

! Fix 1 node in $\mathrm{x}$

nsel,all

!***End Boundary Conditions***

\section{!***Apply Loads}

/com, Apply Unit Vacuum

$\mathrm{pp} 1=1$

esel,all

sf,all,pres,pp1

/psf,pres, 2

eplot

alls

$\rightarrow \quad$ !***End Loads

/sol

anty,stat ! Static analysis

pstres, on ! Calculate PreStress effects

nsub, $5,10,2$, on

save

solv

fini

$$
\text { /sol }
$$

anty,buckle

bucopt,lanb, 1

! Buckling Analysis

method mxpand,1 ! Expand 1 mode shape

solv

*get,FCR,mode,1,freq

*status,parm

*dim,label,char, 1,2

*dim,value, $, 1,3$

label $(1,1)=$ 'Fcr'

label $(1,2)={ }^{\prime} \mathrm{lb}^{\prime}$

Input File: Primary Tank with two ASME or Tank Fabrication specifications - by changing the comment line $\{(1 / 10)$ times, 1 times, 10 times, by changing the comment line $\}$ imperfections Eigenvalue buckling analysis for Axial and Hoop Loads fini

/cle

/fil,dst-impft-1 asme-1-a

/title,Imperfect DST primary tank with two imperfections Under Combined Load

/com, AY Primary Tank, Fixed Top \& Bottom Rings (Disp only), 180-deg

/prep7

et, 1,181

*afun,deg

!*** Materials

mp,ex, $1,29.5$ e6

mp,dens, $1,490 / 1728$

mp,prxy, $1, .3$

tb, biso, 1 
tbdata, $1,36000, .01 * 27.7 \mathrm{e} 6$

!*** Shell thickness

!*** 0.060 corrosion allowance

r, 1, 1-.06

r, 2,3/8-.06

r, 3, 7/8-.06

r, 4,3/4-.06

r, 5, 1/2-.06

!*** Geometry

$\mathrm{k}, 1,0.0,0.0$

$\mathrm{k}, 2,24$

$\mathrm{k}, 3,(37.5-4) * 12$

$\mathrm{k}, 4,37.5^{*} 12$

$\mathrm{k}, 5,37.5^{*} 12,12$

*rep, $31,1,12$

k, 36,37.5*12,382

है *rep, $4,1,12$

$\mathrm{k}, 40,37.5 * 12,45 * 12$

$\mathrm{k}, 41,0.0,(31+15) * 12+9+1 / 2$

$\mathrm{k}, 42,40 * 12,31 * 12+9+1 / 2$

$1,1,2$

*rep, $39,1,1$

loca $, 11,1,0,31 * 12+9+1 / 2,0,,, 3 / 8$

$1,41,42$

1fil, $3,4,12$

$1 \mathrm{cs} 1,39,40$

1fil, $4,43,3 * 12+8+3 / 8$

1del, $42,44,1$

ldel, $1,3,1$

csys, defa

1sel,all arot,all,,,,, $1,41,180,180$

1sel,all

ht $=459$

rbtm $=438$ ! radius at bottom knuckle tangent.

$\mathrm{t}=3 / 8-0.06 \quad$ ! thickness at top of shell where pressure applied.

es $=$ ht $/ 100$

!***Specify the width (w) and deviation (h) of the dent

!***ASME NE-4220 specs

$\mathrm{W}=9.75^{*} 12$

!h=0.05 ! (1/10) times ASME imperfection

$\mathrm{h}=0.5 \quad ! 1 *$ ASME imperfection

$! h=5 \quad ! 10$ times ASME imperfection

!***Tank-Fabrication specs

!w $=7 * 12$

$! h=0.1 \quad !(1 / 10)$ times Tank Fab imperfection

$! h=1 \quad !$ 1* Tank Fab imperfection

$! h=10 \quad$ ! 10 times Tank Fab imperfection

$\mathrm{pi}=22 / 7$

impang $=(\mathrm{w} / 450)^{*}(180 / \mathrm{pi})$

$\mathrm{n} 1=\operatorname{nint}(\mathrm{impang} / \mathbf{1} / 2)$ !! nearest integer

$*$ if,(n1* $1 * 450 * \mathrm{pi} / 180), \mathrm{ge},(\mathrm{w} / 2)$, then $!<$ check if ' $\mathrm{n} 1$ ' spreads for ' $\mathrm{w}$ ' or not>

$\mathrm{n}=\mathrm{n} 1$

*else

$\mathrm{n}=\mathrm{n} \mathbf{1}+\mathbf{1}$

*endif 
!***imperfection @ the upper thin section of the tank ****

csys, 5

$*$ do, $\mathrm{i}, 1, \mathrm{n}, 1$

ksel, $, 10 c, x, 450$

,r,loc,y, $\left(180-\left((\mathrm{i}-1)^{*} 1\right)\right)$

,r,loc, z,340,423

*get,numkp,kp,,count

*do,j, 1, numkp, 1

*get, a,kp,0,num,max

*get, $x 1, \mathrm{kp}, \mathrm{a}, 1 \mathrm{loc}, \mathrm{x}$

*get,y1,kp,a,loc,y

*get,z1,kp,a,loc, z

kmodif, $\mathrm{a}, \mathrm{x} 1+\sin ((\mathrm{j}-1) * 30) *(\mathrm{~h} *(1-(\mathrm{i}-1) * 1 / \mathrm{n})), \mathrm{y} 1, \mathrm{z} 1$

ksel,u,kp,,a

*enddo

*enddo

!***end imperfection****

in

!***imperfection @ mid wall of the tank****

$*$ do, $\mathrm{i}, 1, \mathrm{n}, 1$

ksel, loc, $x, 450$

,r,loc,y, $\left(180-\left((\mathrm{i}-1)^{*} 1\right)\right)$

,r,loc, z, 190,241

*get,numkp,kp,,count

*do, j, 1, numkp, 1

*get, a,kp,0,num,max

*get, $x 1, \mathrm{kp}, \mathrm{a}, \mathrm{loc}, \mathrm{x}$

*get,y1,kp,a,loc,y

*get,z1,kp, a,loc, $\mathrm{z}$

kmodif,a, $x 1+\sin \left((\mathrm{j}-1)^{*} 45\right)^{*}\left(\mathrm{~h} *\left(1-(\mathrm{i}-1)^{*} 1 / \mathrm{n}\right)\right), \mathrm{y} 1, \mathrm{z} 1$

ksel,u,kp, ,a *enddo

*enddo

!***end imperfection****

esize, es

amesh, all

!***Thickness assignments

csys, 5

nsel, $10 \mathrm{loc}, \mathrm{x}, 402,500$

nsel,r,loc, z, 0,36

esln, 1

emod,all,real,3

nsel,,loc, z,36,144

esln, 1

emod,all,real, 4

nsel, loc, z, 144,382

esln, 1

emod,all,real, 5

nsel,,loc,z,382,561.5

esln, 1

esel,r,type,,1

emod,all,real, 2

allsel

!***Boundary Conditions****

csys, 0

nsel, loc,y, $-0.001 *$ ht, $0.001 *$ ht

$\mathrm{d}$, all,uy, $0.0,,, \mathrm{ux}, \mathrm{uz} \quad$ ! Fix bottom end (disp only)

nsel,all

nsel,,loc,y, 0.999*ht, 1.001*ht

$\mathrm{d}, \mathrm{all}, \mathrm{ux}, 0.0,,, \mathrm{uz}$

! Fix top edge (disp only)

nsel, ,loc, $, 0.0,0.0$

$\mathrm{d}$,all,roty, $0.0,,$, ,uz,rotx $\quad$ ! Fix $z=0$ edges 


\section{nsel, all}

nsel,s,loc, z, 0.0,0.0

nsel,r,loc, $\mathrm{x}, 0.999 * \mathrm{rbtm}, 1.001 * \mathrm{rbtm}$

nsel,r,loc,y, $0.0,0.0$

$\mathrm{d}, \mathrm{all}, \mathrm{ux}, 0.0 \quad$ ! Fix 1 node in $\mathrm{x}$

nsel,all

!***End Boundary Conditions***

!***Apply Loads

/com, Apply Axial Load

fnode $=-1 *$ es* 1 ! nodal force, $y$-direction

fends $=$ fnode $/ 2$ ! nodal force at ends, y-direction

nsel,s,loc, y, 0.999*ht, 1.001*ht

f,all,fy,fnode

nsel,r,loc, $, 0.0,0.0$

$\mathrm{f}$,all,fy,fends

nsel,all

alls

/com, Apply Unit Vacuum

$\mathrm{pp} 1=1$

esel,all

sf,all,pres,pp1

/psf,pres, 2

eplot

alls

!***End Loads

\section{/sol}

anty,stat

! Static analysis

pstres, on

! Calculate PreStress effects

nsub, $5,10,2$, on

save solv

fini

/sol

anty,buckle ! Buckling Analysis

bucopt,lanb, 1 ! Use block lanczos eigenvalue extraction

method

mxpand,1 ! Expand 1 mode shape

solv

*get,FCR,mode, 1 ,freq

*status,parm

*dim,label,char, 1,2

*dim,value, ,1,3

label $(1,1)=$ 'Fcr'

label $(1,2)={ }^{\prime} l b^{\prime}$

\section{!!!DST Primary Tank Four Imperfections Models!!!}

Input File: Primary Tank with Four ASME or Tank Fabrication specifications - by changing the comment line $\{(1 / 10)$ times, 1 times, 10 times, by changing the comment line $\}$ imperfections Eigenvalue buckling analysis for Axial Loads

fini

/cle

/fil,dst-impft-1 asme-1-a

/title,Imperfect DST primary tank with Four imperfections Under Axial Pressure

/com, AY Primary Tank, Fixed Top \& Bottom Rings (Disp only), 180-deg 


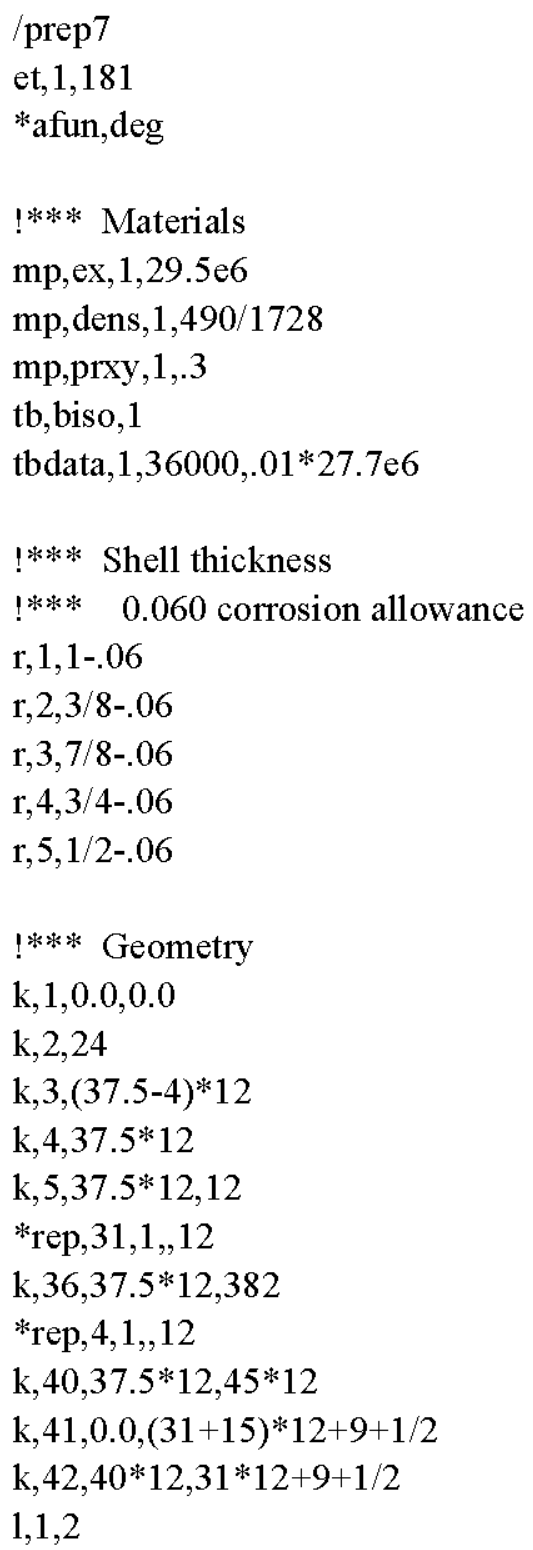


impang $=(\mathrm{w} / 450)^{*}(180 / \mathrm{pi})$

$\mathrm{n} 1=\operatorname{nint}(\mathrm{impang} / 1 / 2)$ !! nearest integer

$*$ if, $(\mathrm{n} 1 * 1 * 450 * \mathrm{pi} / 180), \mathrm{ge},(\mathrm{w} / 2)$, then !<check if ' $\mathrm{n} 1$ ' spreads for ' $\mathrm{w}$ ' or

not>

$\mathrm{n}=\mathrm{n} 1$

*else

$\mathrm{n}=\mathrm{n} 1+\mathbf{1}$

*endif

!***imperfection $@$ the upper thin section of the tank ****

csys, 5

*do, i, $1, \mathrm{n}, 1$

$\mathrm{ksel}, 1 \mathrm{loc}, \mathrm{x}, 450$

,r,loc,y, (180-((i-1)*1))

r,loc, z, 340,423

*get,numkp,kp, count

*do,j,1,numkp, 1

*get, a,kp,0,num,max

*get, $x 1, k p, a, 10 c, x$

*get,y1,kp,a,loc,y

*get,z1,kp,a,loc, $\mathrm{z}$

kmodif, a, $x 1+\sin ((\mathrm{j}-1) * 30) *(\mathrm{~h} *(1-(\mathrm{i}-1) * 1 / \mathrm{n})), \mathrm{y} 1, \mathrm{z} 1$

ksel,u,kp,a

*enddo

*enddo

!***end imperfection*****

!***imperfection $@$ mid wall of the tank ****

*do,i, 1,n, 1

$\mathrm{ksel}, 1 \mathrm{loc}, \mathrm{x}, 450$ ,r,loc,y,(180-((i-1)*1))

,r,loc, z, 190,241

*get,numkp,kp, count

*do,j, 1, numkp, 1

*get,a,kp,0,num,max

*get,x1,kp,a,loc, $\mathrm{x}$

*get,y1,kp,a,loc,y

*get,z1,kp,a,loc, z

kmodif,a, $x 1+\sin \left((\mathrm{j}-1)^{*} 45\right)^{*}\left(\mathrm{~h}^{*}\left(1-(\mathrm{i}-1)^{*} 1 / \mathrm{n}\right)\right), \mathrm{y} 1, \mathrm{z} 1$

$\mathrm{ksel}, \mathrm{u}, \mathrm{kp}, \mathrm{a}$

*enddo

*enddo

!***end imperfection****

!***imperfection $@$ worst height level of the tank *****

*do, $\mathrm{i}, 1, \mathrm{n}, 1$

ksel, 1 loc, $x, 450$

,r,loc,y,(140-((i-1)*1))

,r,loc, z, 110,170

*get,numkp,kp, count

*do,j,1,numkp, 1

*get,a,kp,0,num,max

*get,x1,kp,a,loc, $x$

*get,y1,kp,a,loc,y

*get,z1,kp,a,loc, z

kmodif,a, $x 1+\sin \left((\mathrm{j}-1)^{*} 45\right)^{*}\left(\mathrm{~h}^{*}\left(1-(\mathrm{i}-1)^{*} 1 / \mathrm{n}\right)\right), \mathrm{y} 1, \mathrm{z} 1$

$\mathrm{ksel}, \mathrm{u}, \mathrm{kp}, \mathrm{a}$

*enddo

*enddo

*do, $\mathrm{i}, 2, \mathrm{n}, 1$

ksel, loc, $x, 450$ 
$, \mathrm{r}, 10 \mathrm{loc}, \mathrm{y},\left(140+\left((\mathrm{i}-1)^{*} 1\right)\right)$

,r,loc, z, 110,170

*get,numkp,kp,,count

*do,j, 1, numkp, 1

*get, a,kp,0,num,max

*get,x1,kp,a,loc, $\mathrm{x}$

*get,y1,kp,a,loc,y

*get,z1,kp,a,loc, z

kmodif, $\mathrm{a}, \mathrm{x} 1+\sin \left((\mathrm{j}-1)^{*} 45\right) *\left(\mathrm{~h} *\left(1-(\mathrm{i}-1)^{*} 1 / \mathrm{n}\right)\right), \mathrm{y} 1, \mathrm{z} 1$

ksel, u,kp,,a

*enddo

*enddo

!***end imperfection****

esize,es

amesh, all

! $\quad$ ***Thickness assignments

csys, 5

nsel, $, 10 c, x, 402,500$

nsel,r,loc, z, 0,36

esln, 1

emod,all,real,3

nsel, loc, z,36,144

esln,, 1

emod,all,real, 4

nsel,,loc, z, 144,382

esln,, 1

emod,all,real, 5

nsel,,loc, z,382,561.5

esln,, 1

esel,r,type, 1

emod,all,real,2 allsel

!***B Boundary Conditions $* * * *$

csys, 0

nsel, loc, y, $-0.001 *$ ht, $0.001 *$ ht

d,all,uy, $0.0,,, u x, u z \quad$ ! Fix bottom end (disp only)

nsel,all

nsel, loc,y,0.999*ht, 1.001*ht

$\mathrm{d}, \mathrm{all}, \mathrm{ux}, 0.0, \mathrm{n}, \mathrm{uz} \quad$ ! Fix top edge (disp only)

nsel, $, 10 c, \mathrm{z}, 0.0,0.0$

d,all,roty, $0.0,$, , uz,rotx $\quad !$ Fix z $=0$ edges

nsel,all

nsel, s,loc, $\mathrm{z}, 0.0,0.0$

nsel,r,loc, $x, 0.999 * \mathrm{rbtm}, 1.001 * \mathrm{rbtm}$

nsel,r,loc,y,0.0,0.0

$\mathrm{d}$, all, $\mathrm{ux}, 0.0 \quad$ ! Fix 1 node in $\mathrm{x}$

nsel,all

!***End Boundary Conditions****

!****Apply Loads

/com, Apply Axial Load

fnode $=-1$ *es*1 ! nodal force, $y$-direction

fends $=$ fnode $/ 2$ ! nodal force at ends, $y$-direction

nsel, s, loc,y, $0.999^{*}$ ht, $1.001 *$ ht

$\mathrm{f}$, all,fy,fnode

nsel,r,loc, z, $0.0,0.0$

f,all,fy,fends

nsel,all

alls

!**** End Loads

/sol 


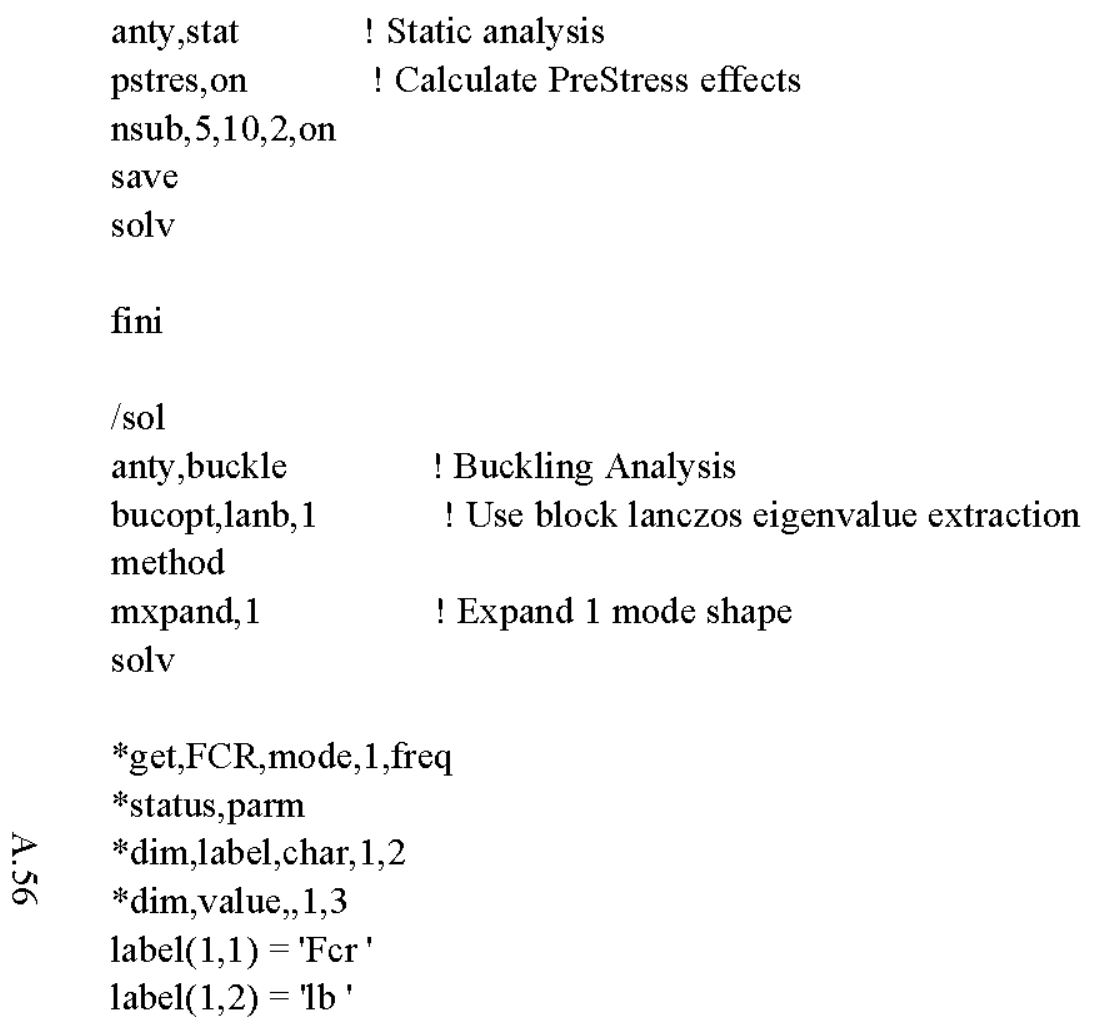

Input File: Primary Tank with Four ASME or Tank Fabrication specifications - by changing the comment line $\{(1 / 10)$ times, 1 times, 10 times, by changing the comment line $\}$ imperfections Eigenvalue buckling analysis for Hoop Loads fini

/cle

/fil,dst-impft-1 asme-1-a /title,Imperfect DST primary tank with Four imperfections Under Vacuum /com, AY Primary Tank, Fixed Top \& Bottom Rings (Disp only), 180-deg

/prep7

et, 1,181

*afun, deg

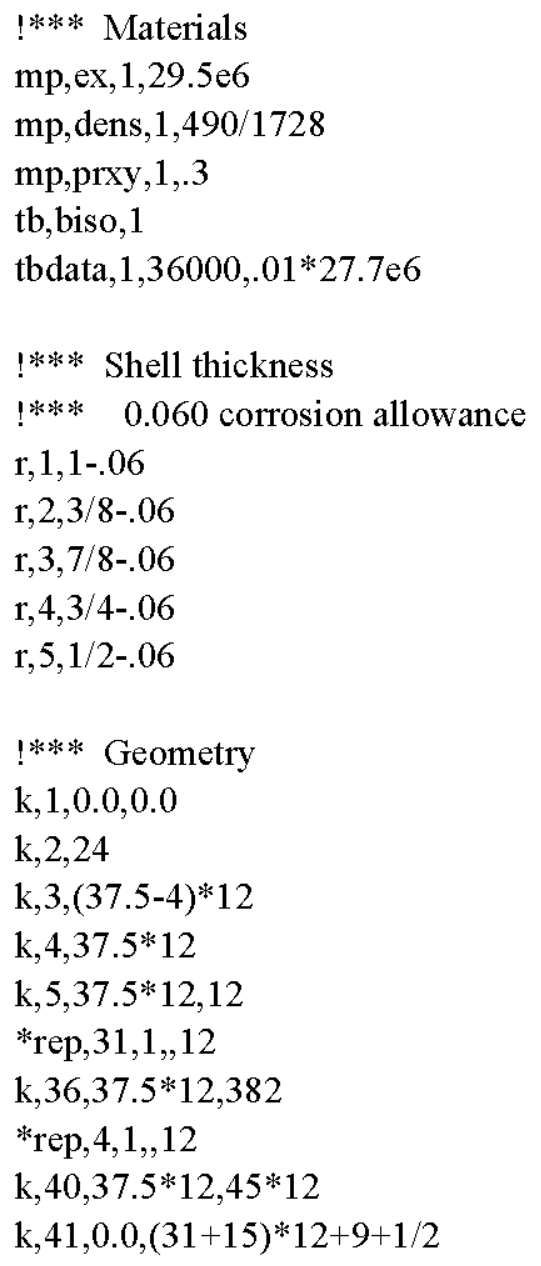


$\mathrm{k}, 42,40 * 12,31 * 12+9+1 / 2$

$1,1,2$

*rep, 39,1,1

loca $, 11,1,0,31 * 12+9+1 / 2,0,,, 3 / 8$

$1,41,42$

1 fil $, 3,4,12$

$1 \mathrm{cs} 1,39,40$

1 fil $, 4,43,3 * 12+8+3 / 8$

1del, $42,44,1$

ldel, $1,3,1$

csys,defa

1sel,all

arot,all,,,,,, 1,41,180,180

1sel,all

$\mathrm{ht}=459$

rbtm $=438$ ! radius at bottom knuckle tangent.

in $\mathrm{t}=3 / 8-0.06$ ! thickness at top of shell where pressure applied.

es $=\mathrm{ht} / 100$

!***Specify the width (w) and deviation (h) of the dent

\section{!***ASME NE-4220 specs}

$\mathrm{W}=9.75^{*} 12$

!h $=0.05 \quad$ ! (1/10) times ASME imperfection

$\mathrm{h}=0.5 \quad ! 1 *$ ASME imperfection

$! h=5 \quad ! 10$ times ASME imperfection

!***Tank-Fabrication specs

!w $=7 * 12$

$! h=0.1 \quad !(1 / 10)$ times Tank Fab imperfection

$! h=1 \quad ! 1 *$ Tank Fab imperfection

$! h=10 \quad$ ! 10 times Tank Fab imperfection

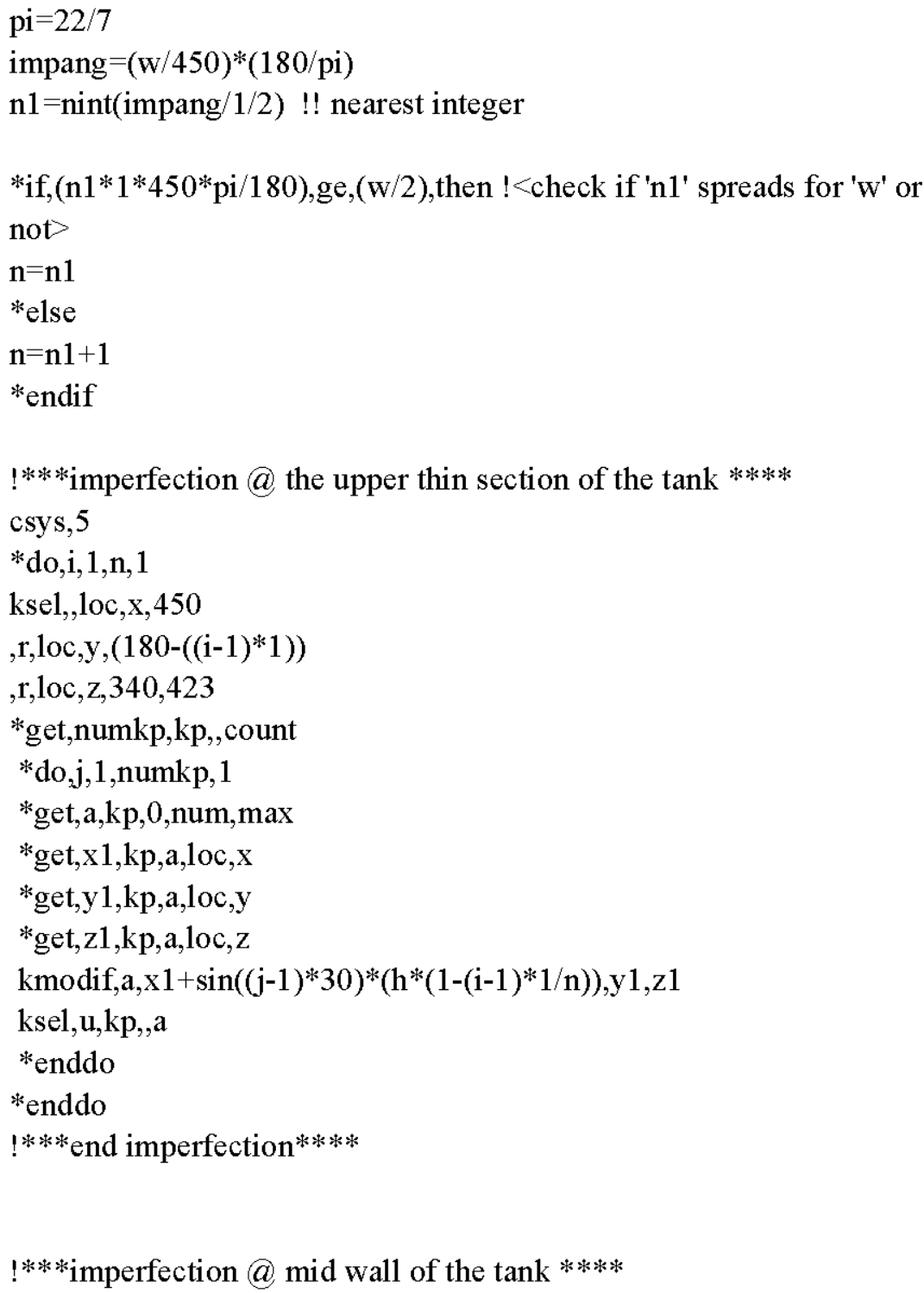


*do, $\mathrm{i}, 1, \mathrm{n}, 1$

ksel, ,loc, $\mathrm{x}, 450$

,r,loc,y, $\left(180-\left((\mathrm{i}-1)^{*} 1\right)\right)$

,r,loc, z,190,241

*get,numkp,kp,,count

*do,j,1,numkp, 1

*get,a,kp,0,num,max

*get, $x 1, \mathrm{kp}, \mathrm{a}, \mathrm{loc}, \mathrm{x}$

*get,y1,kp,a,loc,y

*get, z1,kp,a,loc,z

kmodif, $\mathrm{a}, \mathrm{x} 1+\sin \left((\mathrm{j}-1)^{*} 45\right)^{*}\left(\mathrm{~h} *\left(1-(\mathrm{i}-1)^{*} 1 / \mathrm{n}\right)\right), \mathrm{y} 1, \mathrm{z} 1$

ksel, u,kp,,a

*enddo

*enddo

!***end imperfection****

!***imperfection @ worst height level of the tank ****

$\infty$

*do,i, $1, \mathrm{n}, 1$

ksel, $, 10 c, x, 450$

,r,loc,y,,$\left(140-\left((\mathrm{i}-1)^{*} 1\right)\right)$

,r,loc, z, 110,170

*get,numkp,kp,, count

*do,j, 1, numkp, 1

*get, a,kp,0,num,max

*get,x1,kp,a,loc, $x$

*get,y1,kp,a,loc,y

*get, z1,kp,a,loc,z

kmodif,a, $\mathrm{x} 1+\sin \left((\mathrm{j}-1)^{*} 45\right)^{*}\left(\mathrm{~h} *\left(1-(\mathrm{i}-1)^{*} 1 / \mathrm{n}\right)\right), \mathrm{y} 1, \mathrm{z} 1$

ksel, u,kp,,a

*enddo

*enddo *do, i, $2, \mathrm{n}, 1$

ksel, ,loc, $\mathrm{x}, 450$

,r,loc,y, $\left(140+\left((\mathrm{i}-1)^{*} 1\right)\right)$

,r,loc, z, 110,170

*get,numkp,kp,, count

*do,j,1,numkp, 1

*get,a,kp,0,num,max

*get,x $1, \mathrm{kp}, \mathrm{a}, \mathrm{loc}, \mathrm{x}$

*get,y1,kp,a,loc,y

*get,z1,kp,a,loc, z

kmodif, $\mathrm{a}, \mathrm{x} 1+\sin \left((\mathrm{j}-1)^{*} 45\right)^{*}\left(\mathrm{~h} *\left(1-(\mathrm{i}-1)^{*} 1 / \mathrm{n}\right)\right), \mathrm{y} 1, \mathrm{z} 1$

ksel,u,kp,,a

*enddo

*enddo

!***end imperfection****

esize,es

amesh,all

!***Thickness assignments

csys, 5

nsel, $, 10 c, x, 402,500$

nsel,r,loc, z,0,36

esln, 1

emod,all,real,3

nsel,,loc,z,36,144

esln,, 1

emod,all,real, 4

nsel, loc,, , 144,382

esln, 1

emod,all,real, 5

nsel,loc, z,382,561.5

esln,, 1 


\section{esel,r,type,, 1}

emod,all,real, 2

allsel

!***Boundary Conditions***

csys, 0

nsel,,loc,y,-0.001*ht, $0.001 *$ ht

$\mathrm{d}, \mathrm{all}, \mathrm{uy}, 0.0,,, \mathrm{ux}, \mathrm{uz} \quad$ ! Fix bottom end (disp only)

nsel,all

nsel, loc, y, 0.999*ht, 1.001*ht

$\mathrm{d}, \mathrm{all}, \mathrm{ux}, 0.0,,, \mathrm{uz}$

! Fix top edge (disp only)

nsel,,loc, z, $0.0,0.0$

d,all,roty, $0.0,,$, uz,rotx $\quad$ ! Fix z $=0$ edges

nsel, all

nsel,s,loc, z, 0.0,0.0

nsel,r,loc, $\mathrm{x}, 0.999 * \mathrm{rbtm}, 1.001 * \mathrm{rbtm}$

nsel,r,loc,y, $0.0,0.0$

$\mathrm{d}, \mathrm{all}, \mathrm{ux}, 0.0 \quad$ ! Fix 1 node in $\mathrm{x}$

nsel,all

!***End Boundary Conditions***

/com, Apply Unit Vacuum

$\mathrm{pp} 1=1$

esel,all

sf,all,pres,pp1

/psf,pres, 2

eplot

alls

!***End Loads

/sol

anty,stat

! Static analysis

pstres, on

! Calculate PreStress effects nsub, $5,10,2$, on

save

solv

fini

/sol

anty,buckle ! Buckling Analysis

bucopt,lanb, 1 ! Use block lanczos eigenvalue extraction

method

mxpand, $1 \quad$ ! Expand 1 mode shape

solv

*get,FCR,mode, 1 ,freq

*status,parm

*dim,label,char, 1,2

*dim,value, 1,3

label $(1,1)=$ 'Fcr'

label $(1,2)=' 1 b$ '

Input File: Primary Tank with Four ASME or Tank Fabrication specifications - by changing the comment line $\{(1 / 10)$ times, 1 times, 10 times, by changing the comment line $\}$ imperfections Eigenvalue buckling analysis for Axial and Hoop Loads fini

/cle

/fil,dst-impft-1 asme-1-a

/title,Imperfect DST primary tank with Four imperfections Under Combined Load

/com, AY Primary Tank, Fixed Top \& Bottom Rings (Disp only), 180-deg 


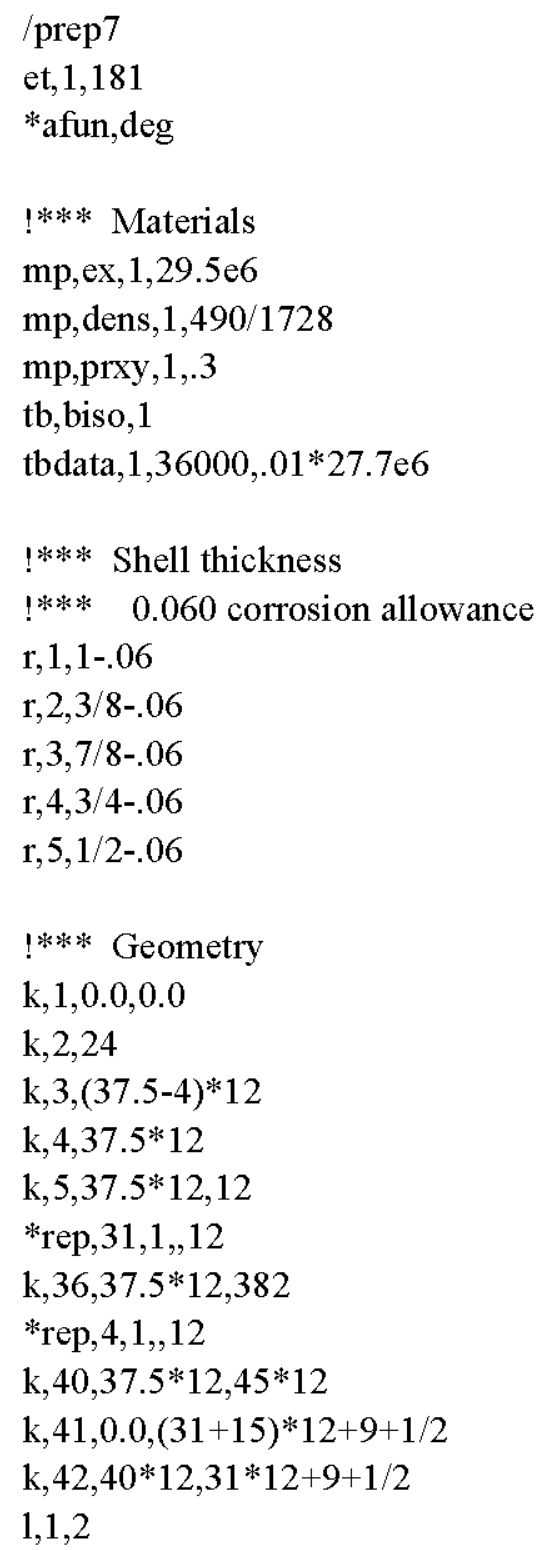


impang $=(\mathrm{w} / 450)^{*}(180 / \mathrm{pi})$

$\mathrm{n} 1=\operatorname{nint}(\mathrm{impang} / 1 / 2)$ !! nearest integer

$*$ if, $(\mathrm{n} 1 * 1 * 450 * \mathrm{pi} / 180), \mathrm{ge},(\mathrm{w} / 2)$, then !<check if ' $\mathrm{n} 1$ ' spreads for ' $\mathrm{w}$ ' or

not>

$\mathrm{n}=\mathrm{n} 1$

*else

$\mathrm{n}=\mathrm{n} 1+\mathbf{1}$

*endif

!***imperfection $@$ the upper thin section of the tank ****

csys, 5

*do, i, $1, \mathrm{n}, 1$

$\mathrm{ksel}, 1 \mathrm{loc}, \mathrm{x}, 450$

,r,loc,y, (180-((i-1)*1))

r,loc, z, 340,423

*get,numkp,kp, count

*do,j,1,numkp, 1

*get,a,kp,0,num,max

*get,x1,kp,a,loc, $\mathrm{x}$

*get,y1,kp,a,loc,y

*get, z1,kp,a,loc, z

kmodif, a, $x 1+\sin ((\mathrm{j}-1) * 30) *(\mathrm{~h} *(1-(\mathrm{i}-1) * 1 / \mathrm{n})), \mathrm{y} 1, \mathrm{z} 1$

ksel,u,kp,a

*enddo

*enddo

!***end imperfection*****

!***imperfection $@$ mid wall of the tank ****

*do,i, 1,n, 1

ksel, loc, $x, 450$

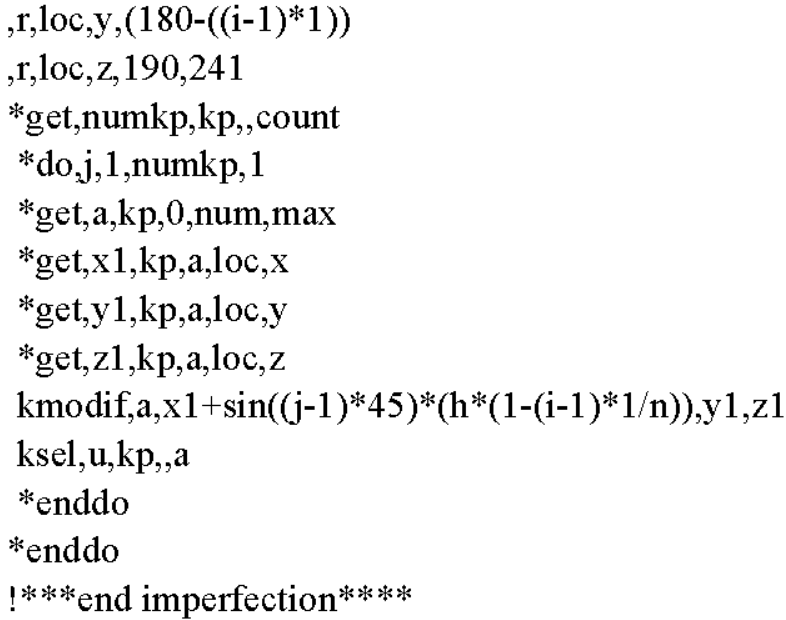

*do, $\mathrm{i}, 2, \mathrm{n}, 1$

$\mathrm{ksel}, \mathrm{loc}, \mathrm{x}, 450$ 
$, \mathrm{r}, 10 \mathrm{loc}, \mathrm{y},\left(140+\left((\mathrm{i}-1)^{*} 1\right)\right)$

,r,loc, z, 110,170

*get,numkp,kp,,count

*do,j, 1, numkp, 1

*get, a,kp,0,num,max

*get,x1,kp,a,loc, $\mathrm{x}$

*get,y1,kp,a,loc,y

*get,z1,kp,a,loc, z

kmodif, $\mathrm{a}, \mathrm{x} 1+\sin \left((\mathrm{j}-1)^{*} 45\right) *\left(\mathrm{~h} *\left(1-(\mathrm{i}-1)^{*} 1 / \mathrm{n}\right)\right), \mathrm{y} 1, \mathrm{z} 1$

ksel, u,kp,,a

*enddo

*enddo

!***end imperfection****

esize,es

amesh, all

!***Thickness assignments

csys, 5

nsel, $, 10 c, x, 402,500$

nsel,r,loc, z, 0,36

esln,, 1

emod,all,real,3

nsel, loc,z,36,144

esln,, 1

emod,all,real, 4

nsel,,loc, z, 144,382

esln, 1

emod,all,real, 5

nsel,,loc, z,382,561.5

esln, 1

esel,r,type, ,1

emod,all,real,2 allsel

!***B Boundary Conditions****

csys, 0

nsel, loc,y, $-0.001 *$ ht, $0.001 *$ ht

d,all,uy, $0.0,,, u x, u z \quad$ ! Fix bottom end (disp only)

nsel,all

nsel, loc,y,0.999*ht, 1.001*ht

d,all,ux,0.0,,,uz ! Fix top edge (disp only)

nsel, $, 10 c, \mathrm{z}, 0.0,0.0$

d,all,roty, 0.0, , , uz,rotx $\quad !$ Fix $z=0$ edges

nsel,all

nsel,s,loc, $\mathrm{z}, 0.0,0.0$

nsel,r,loc, $\mathrm{x}, 0.999 * \mathrm{rbtm}, 1.001 * \mathrm{rbtm}$

nsel,r,loc,y,0.0,0.0

$\mathrm{d}$, all,ux, 0.0

! Fix 1 node in $\mathrm{x}$

nsel,all

!***End Boundary Conditions****

!****Apply Loads

/com, Apply Axial Load

fnode $=-1 *$ es $^{*} 1$ ! nodal force, $y$-direction

fends $=$ fnode $/ 2$ ! nodal force at ends, $y$-direction

nsel,s,loc,y, 0.999*ht, 1.001*ht

$\mathrm{f}$,all,fy,fnode

nsel,r,loc, z, $0.0,0.0$

$\mathrm{f}$,all,fy,fends

nsel,all

alls

/com, Apply Unit Vacuum

pp $1=1$

esel,all 


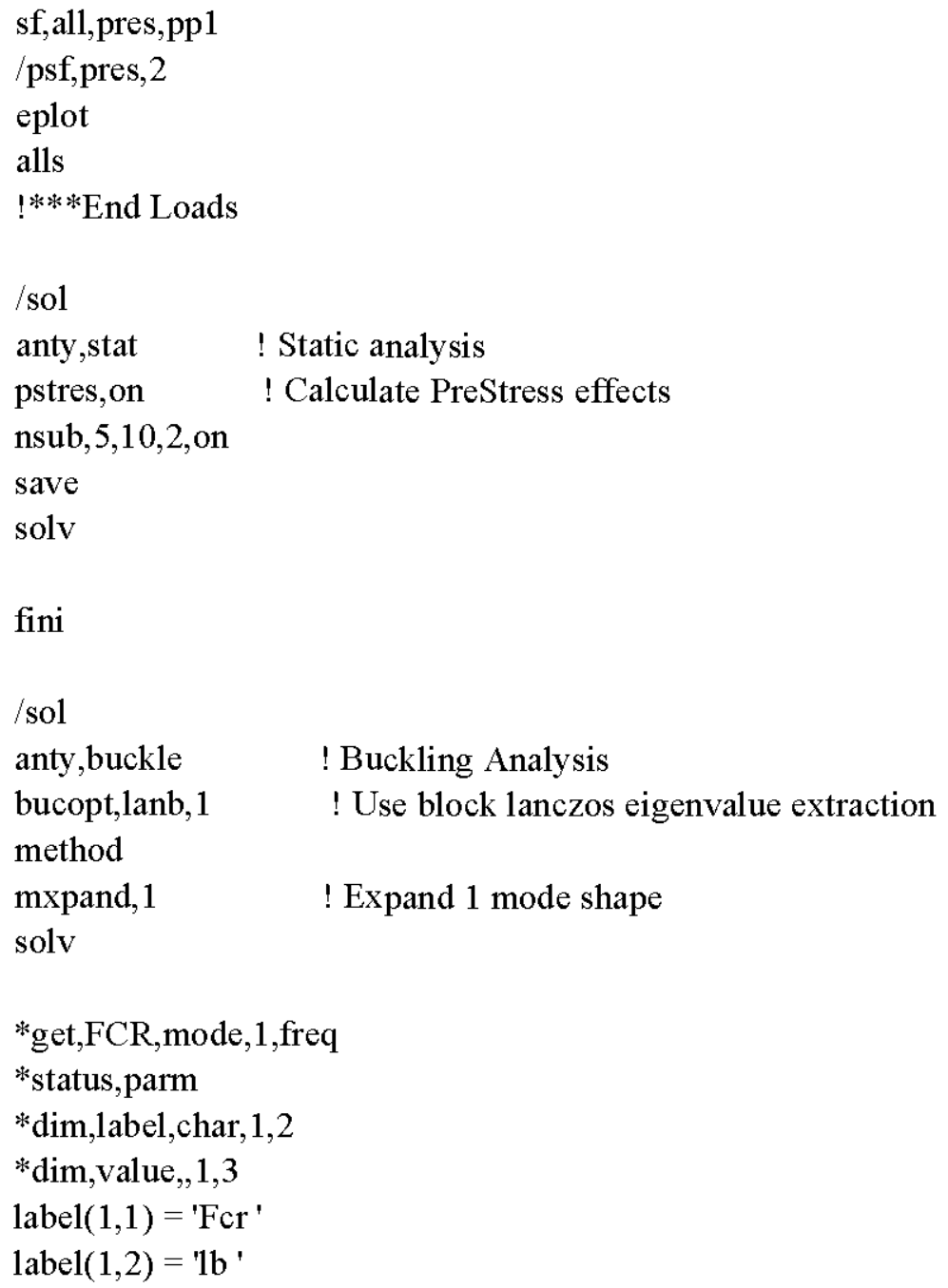


RPP-RPT-28967, Rev. 2

\section{Appendix B}

\section{ANSYS Input and Post Processing Files for Buckling Analysis}




\section{Appendix B}

\section{ANSYS Input and Post Processing Files for Buckling Analysis}

\section{B.1 Introduction}

This section contains input and post processing files for buckling analysis of the AP and AY primary tanks under under combined axial compression and vacuum loads. There are two main input analysis files for each case. One is for studying the affect of differential thermal expansion and other dead loads (applied as equivalent downward displacement to the dome) on buckling of the tank wall under axial load only. The other file is for estimating the buckling collapse load under increased vacuum load at a constant compression load. Variations of these finite element models were used to studying the influence of the different tank operating parameters (waste height, temperature, specific gravity, corrosion allowance, dome displacement) on the collapse loads.

Appendix B Contents:

\begin{tabular}{|l|c|}
\hline \multicolumn{1}{|c|}{ Section } & \multicolumn{1}{c|}{ Title / File Name } \\
\hline B.1 & Introduction \\
\hline B.2 & AY Tank Input Files \\
\hline B.2.1 & AYCompressionOnlyElastic.inp \\
\hline B.2.2 & AyU1miso50F.inp (Compression only Plastic) \\
\hline B.2.3 & AYbuckling.inp \\
\hline B.3 & AY Tank Post Processing Files \\
\hline B.3.1 & Post1_MerStress_wall elem hist.inp \\
\hline B.3.2 & Post2_KnuckSurfStress_elem hist.inp \\
\hline B.3.3 & 1Post-UXVsLS_Nodehist.inp \\
\hline B.4 & AP Tank Input Files \\
\hline B.4.1 & APcompressionOnlyElstic.inp \\
\hline B.4.2 & APelastPlasict210F.inp \\
\hline B.4.3 & APbuckling.inp \\
\hline B.5 & AP Post Processing Files \\
\hline B.5.1 & Post_MerStress_wall elem hist.inp \\
\hline B.5.2 & Post_KnuckSurfStress_elem hist.inp \\
\hline B.5.3 & 1Post-UXVsLS_Nodehist.inp \\
\hline
\end{tabular}




\section{B.2 AY Tank Input Files}

\section{B.2.1 Input file: AYCompressionOnlyElastic.inp}

! AY Compression only model with Bilinear-Elastic material properties.

! Input file for studying the variation in meridional stress in the tank wall with increased compression loading on dome for AY tank.

! Elastic model (bilinear stress-strain curve)

fini

/clear

$!===========$ PARAMATRS $============================$

DomeDisp $=-1.5$ ! Dome vertical

displacement

Corrosion $=0.06 \quad$ ! corrosion allowance

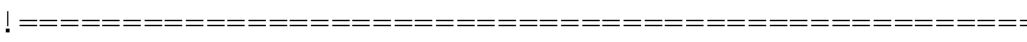

Ifilname, NowasteCor0u1_5! Change filename according to above paramaters

/tit, No waste, DomeDispon" DomeDispl,

응orrosiono" corrosion

/triad, lbot

/prep7

et, $1,181,, 2$

!*** Materials

$\mathrm{mp}, \mathrm{ex}, 1,29.5 \mathrm{e} 6$

mp, dens, 1,490/1728

mp, prxy, $1, .3$

tbo, biso, 1

tbdata, $1,36000, .01 * 27.7 e 6$

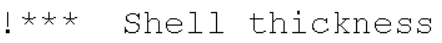

r,101,1-Corrosion

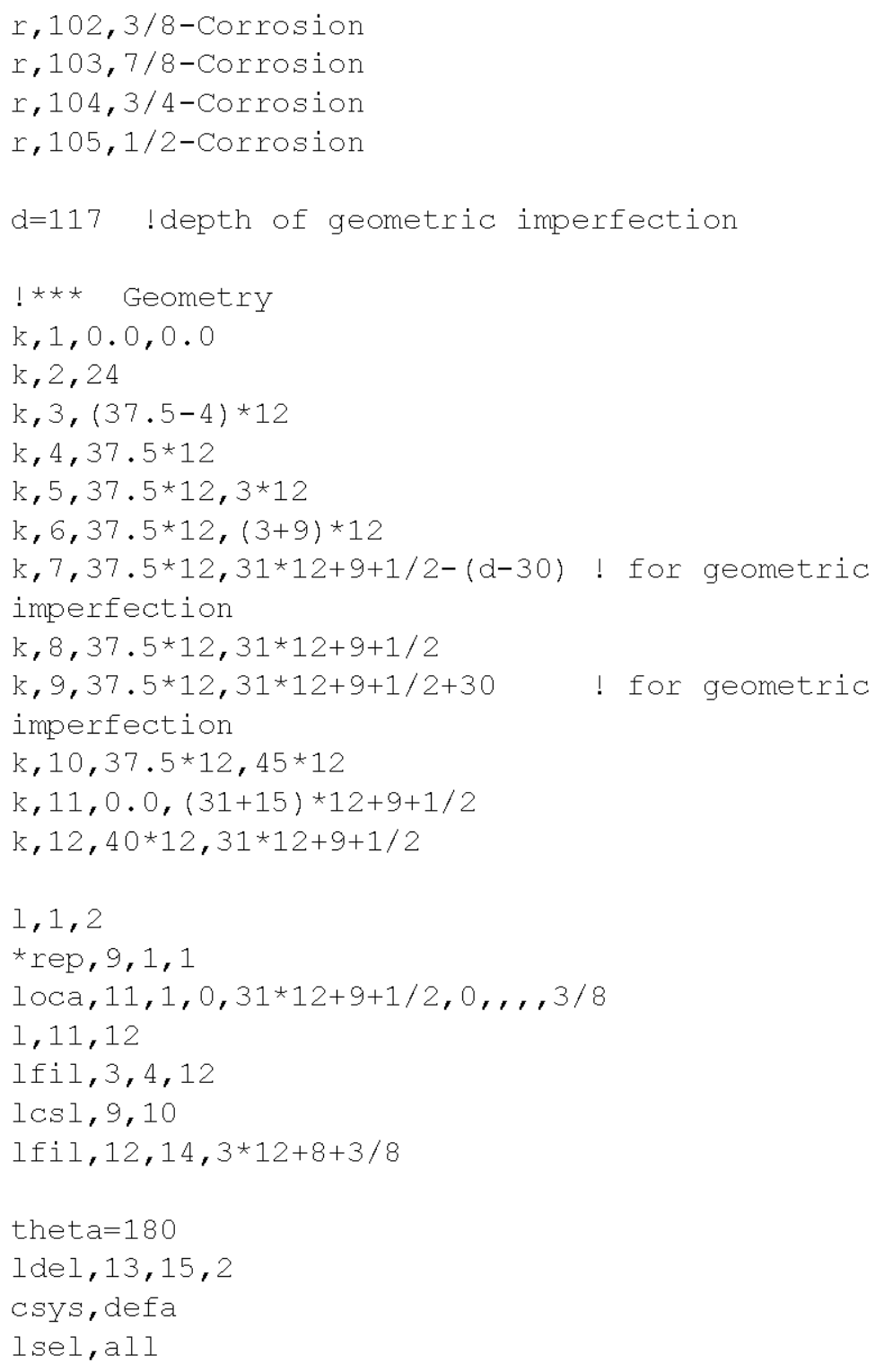


*get, L14length, LINE, 14, LENG

lsel, , line, , 14

! lesi,all, 24

ldiv,all, ,L14length/24! 2' Approx, Divides to

nearest integer value

lsel, , line, 13,26

lsel, a, line, 10

lcomb, all

lsel, , line, , 1

lesi, all, 4

lsel, , line, 2

lesi, all, , 20,-2

lsel, , line, 3

lesi, all, , 6, 1/1.5

lsel, , line, 11

lesi,all, 4

lsel, , line, 4

lesi,all, 4

lsel, , line, 5

lesi,all, , 15, 3

lsel, , line, 6

lesi, all, , 10,-1.5

lsel, , line,, 7

lesi,all, , 12,1/2.8

lsel, , line, 8

lesi, all, , 8, 1/1.4

lsel, , line, , 12

lesi,all, 4

lsel, , line, 9

lesi, all, 4

lsel, , line, , 30

lesi,all, 4

lsel, , line, 29

lesi, all, , 5, 1/1.4

lsel, , line, , 28

lesi,all, , 3,1/1.5 1sel, 1 ine,, 27

lesi, all, , 2, 1/1.4

lsel, , line, 10

lesi,all, 24

lsel, all

arot, all, , , , ,1,11, theta, 45

lsel, , line, , 737, 1397, 15

lesiz,all, , 1

! one

element

lsel, , line, , 738, 1398, 15

lsel, a, line, , 739,1399, 15

lsel, a, line, , 740,1400,15

lsel, a, line, , 741,1401, 15

lsel, a, line, , 742,1402,15

lsel, a, line, , 743,1403,15

lsel, a, line, , 744,1404,15

lsel, a, line, , 745,1405, 15

lsel,a, line, , 746,1406,15

lsel,a, line, , 747,1407,15

lsel,a, line, , 748,1408,15

lsel, a, line, , 749,1409, 15

lsel, a, line, , 750,1410,15

lsel, a, line, , 751, 1411, 15

lesiz, all, , 1

! one

degree angle

lsel, all

loca $, 12,1,0,0,0,-90$

csys, 12

!***Specify the width (w) and deviation (h) of the dent

$W=7 * 12$

$\mathrm{h}=1$

$\mathrm{pi}=22 / 7$

impang $=w / p i / 450 * 180$

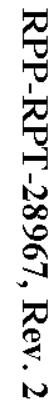


*do, $i, 1,3,1$

ksel, , loc, $z, 382$

$, r, 10 \mathrm{c}, \mathrm{y},(180-((i-1) \star 4))$

* get, $a, k p, 0, n u m, \max$

*get, $\mathrm{x} 1, \mathrm{kp}, \mathrm{a}, \mathrm{loc}, \mathrm{x}$

*get, $\mathrm{Y} 1, \mathrm{kp}, \mathrm{a}, \mathrm{loc}, \mathrm{Y}$

*get, $\mathrm{z} 1, \mathrm{kp}, \mathrm{a}, 1 \circ \mathrm{c}, \mathrm{z}$

kmodif, $a, x 1+(h *(1-(i-1) * 4 / i m p a n g)), y 1, z 1$

*enddo

esiz, 24

amesh, all

save

!***Thickness assignments

nsel, , loc, $x, 0,24$

nsel, r, loc, z, 0

esln, 1

emod, all, real, 101

nsel, , loc, x, 24, 402

nsel, r, loc, z, 0

esln, 1

emod, all, real, 102

nsel, , 1oc, x, 402, 450

nsel, r, loc, z, 0,36

esln, 1

emod, all, real, 103

nsel, , loc, z, 36, 144

esln, 1

emod, all, real, 104

nsel, , loc, z, 144,382

esln, 1

emod, all, real, 105 nsel, , loc, z, 382, 561.5

esln

esel, r, type, , 1

emod,all, real, 102

allsel

!LOOP FOR SELECTING ONLY j-BOLT NODES to apply displacements later

csYs, 5

nsel, NONE

*do, i, 0,180.0,4.0

nsel, a, loc, y, i

*enddo

nsel, r, loc, z, 459,600

nsel, u, loc, $x, 350,371$

nsel, u, loc, $x, 372,392$

nsel, u, loc, x, 394,412

nsel, u, loc, $x, 414,432$

$\mathrm{cm}$, Dome JBNodes, NODE

!STORE THE NODE NUMBERS OF SELECTED NODES FOR BEAM ELEMENT CREATION LATER

* get, NoJB, Node, , COUNT

* dim, JBnodeNum, array, NoJB, 1

* do , i, 1, NoJB

* get, number, NODE, , NUM, MIN

JBnodeNum $(i, 1)=$ number

nsel, u, NODE, number

*enddo

! Generate additional set of nodes for Beam elements

cmsel, , DomeJBNodes, NODE 
LOCAL, $15,2,0,381.5,0,0,0,0,0.375$

NROTat, ALL

ngen, 2,20000, all, , , 1

! Total

16107 nodes already defined.

I JB nodes

may be numbered between 20000,20000+16107

\section{Create Beam elements for J-Bolts}

et, 11, BEAM18 8

$\mathrm{MP}, \mathrm{EX}, 11,100 \mathrm{e} 6$

MP, NUXY, 11, 0.25

SECTYPE, 11, BEAM, CSOLID, JBSEC

SECDATA, $0.25,1,1$ ! Bolt Radius

! SECPLOT, 11

CSYS

N, 99999,500,500 !Dummy node for beam orientations TYPE, 11

$\varpi$

MAT, 11

SECNUM, 11

$\star$ do, i, 1, NoJB

E, JBnodeNum $(i, 1), \operatorname{JBnodeNum}(i, 1)+20000,99999$

*enddo

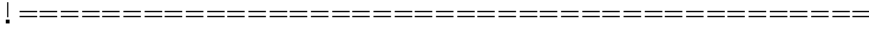

allsel

csys, 12 ! same as csys 5

nrot, all

/rep

nsel, s, loc, z, 0

$\mathrm{d}, \mathrm{all}, \mathrm{uz}, 0.0$

$\mathrm{d}, \mathrm{all}, \operatorname{rot} \mathrm{x}, 0$

d, all, roty, 0

d, all, rotz, 0
! FIX Bottom of Tank nsel, all

nsel, , loc, y, 0

Symmetry

nsel, a, loc, y, 180

nsel, u, node, , 99999

d, all, uy, 0.0

d, all, rotx, 0

d, all, rotz, 0

nsel, all

nsel, , loc, $x, 0$

nsel, r, loc, z, 0

! Fix center node

d, all, ux, 0.0

nsel, all

nsel, , loc, z, 459.17, 600

Fix rotations of the

Tank Dome + beam end nodes

$d, \operatorname{all}, \operatorname{rot} x, 0$

d,all, roty, 0

d, all, rotz, 0

nsel, all

allsel

finish

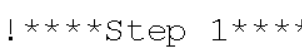

I sol

anty, stat

nlgeom, on

nsel, node, 20000,40000 ! Only J-bolt top end nodes

d,all,uz, DomeDisp

nsel, all

allsel

nsub, $30,100,30$ 
outr, all, all

save

$\mathrm{s} O \mathrm{lv}$

\section{B.2.2 File Name: AyU1miso50F.inp}

! AY Compression only model with Elastic-Plastic material properties.

Input file for studying the affect of increased dome displacement on meridional stress with Elastic-Plastic material properties for AY primary at $50 \mathrm{~F}$.

fini

/clear

$\begin{array}{ll}l========\text { PARAMARS } & ===================== \\ \text { DomeDisp }=-1.0 & \text { ! Dome vertical displacement } \\ \text { Corrosion=0 } & \text { !corrosion allowance }\end{array}$

/filname, AYU1miso

/tit, No waste, 1.0" Disp, No vacuum / triad, lbot

/prep7

et, $1,181,, 2$

mpte, 1,50

mpda, ex, 1, 1,29.5e6

mpda, alpx, 1, 1, $5.73 e-6$

mp, prxy, $1,0.3$

mp, dens, 1,490/1728

!** tb, temp, 50

to, miso, $1,1,6$

tbpt, , 32/29.5e3, 32000

tbpt, $, 0.0025,35000$

tbpt, , 0.01,42000

tbpt, $, 0.02,49000$ tbpt, , $0.03,55000$

tbpt, $, 0.04,59000$

!*** Shell thickness

r,101,1-Corrosion

$r, 102,3 / 8$-Corrosion

r, 103,7/8-Corrosion

r,104,3/4-Corrosion

r,105,1/2-Corrosion

$d=117$ !depth of geometric imperfection

!*** Geometry

$\mathrm{k}, 1,0.0,0.0$

$\mathrm{k}, 2,24$

$k, 3,(37.5-4) * 12$

$\mathrm{k}, 4,37.5 * 12$

$k, 5,37.5 * 12,3 * 12$

$\mathrm{k}, 6,37.5 * 12,(3+9) * 12$

$\mathrm{k}, 7,37.5 * 12,31 * 12+9+1 / 2-(\mathrm{d}-30)$ ! for geometric

imperfection

$\mathrm{k}, 8,37.5 * 12,31 * 12+9+1 / 2$

$\mathrm{k}, 9,37.5 * 12,31 * 12+9+1 / 2+30$ ! for geometric

imperfection

$\mathrm{k}, 10,37.5 * 12,45 * 12$

$\mathrm{k}, 11,0.0,(31+15) * 12+9+1 / 2$

$\mathrm{k}, 12,40 * 12,31 * 12+9+1 / 2$

$1,1,2$

*rep, $9,1,1$

loca $, 11,1,0,31 * 12+9+1 / 2,0,1,3 / 8$

$1,11,12$

lfil, 3, 4, 12

lCsl, 9,10

lfil, $12,14,3 * 12+8+3 / 8$ 
thet $\mathrm{a}=180$

ldel, 13,15, 2

csys, defa

lsel, all

*get, L14 length, LINE, 14 , LENG

lsel, , line, , 14

! lesi, all, 24

ldiv, all, ,L14length/24 ! 2'Approx, Divides to

nearest integer value

lsel, , line, , 13, 26

lsel, a, line, 10

lcomb, all

lsel, , line, , 1

lesi,all, 4

lsel, , line, 2

lesi,all, ,20,-2

lsel, , line, 3

lesi,all, , 6, 1/1.5

lsel, , line, , 11

lesi,all, 4

lsel, , line, 4

lesi,all, 4

lsel, , line, 5

lesi, all, , 15, 3

lsel, , line, 6

lesi,all, , 10, -1.5

lsel, , line, 7

lesi,all, , 12,1/2.8

lsel, 1 ine, 8

lesi,all, , 8, 1/1.4

lsel, , line, , 12

lesi,all, 4

lsel, 1 ine, 9

lesi,all, 4

lsel, , line, , 30 lesi,all, 4

lsel, , line, 29

lesi,all, , $5,1 / 1.4$

lsel, , line, 28

lesi,all, , 3,1/1.5

lsel, , line, 27

lesi, all, , 2, 1/1.4

lsel, , line, 10

lesi,all, 24

lsel, all

arot, all, , , , 1, 11, theta, 45

lsel, , line, $, 737,1397,15$

lesiz,all, , 1

! one element

lsel, , line, $, 738,1398,15$

lsel, a, line, , 739,1399, 15

lsel, a, line, , 740,1400,15

lsel, a, line, , 741,1401,15

lsel, a, line, , 742,1402,15

lsel, a, line, , 743,1403, 15

lsel,a, line, , 744,1404,15

lsel,a, line, , 745,1405, 15

lsel, a, line, , 746,1406,15

lsel, a, line, , 747,1407,15

lsel, a, line, , 748,1408,15

lsel, a, line, , 749,1409, 15

lsel, a, line, , 750,1410,15

lsel, a, line, ,751,1411, 15

lesiz, all, 1

lsel, all

loca $, 12,1,0,0,0,-90$

CSYs, 12

!***Specify the width (w) and deviation (h) of the dent

$\mathrm{W}=7 * 12$

$h=1$ 
$\mathrm{p} i=22 / 7$

impang $=\mathrm{w} / \mathrm{pi} / 450 * 180$

$\star$ do, $i, 1,3,1$

ksel, , loc, $\mathrm{z}, 382$

$, r, 10 \mathrm{C}, \mathrm{Y},(180-((\mathrm{i}-1) * 4))$

*get, a, kp, 0, num, max

*get, $\mathrm{x} 1, \mathrm{kp}, \mathrm{a}, \mathrm{loc}, \mathrm{x}$

* get, $\mathrm{Y} 1, \mathrm{kp}, \mathrm{a}, \mathrm{loc}, \mathrm{Y}$

*get, $z 1, \mathrm{kp}, \mathrm{a}, \mathrm{loc}, \mathrm{z}$

kmodif, $a, x 1+(h *(1-(i-1) * 4 /$ impang $)), y 1, z 1$

*enddo

esiz, 24

amesh, all

save

! ***Thickness assignments

nsel, , loc, $x, 0,24$

$\infty$

$\infty$

nsel, r, loc, z, 0

esln, 1

emod, all, real, 101

nsel, , 1oc, $x, 24,402$

nsel, r, loc, $z, 0$

esln, 1

emod, all, real, 102

nsel, , 10c, $x, 402,450$

nsel, r, loc, z, 0,36

esln, 1

emod,all, real, 103

nsel, , loc, z, 36, 144

esln, 1

emod, all, real, 104 nsel, , loc, $\mathrm{z}, 144,382$

esln, 1

emod, all, real, 105

nsel, , loc, z, 382, 561.5

esln

esel, r, type, 1

emod, all, real, 102

allsel

!LOOP FOR SELECTING ONLY j-BOLT NODES to apply displacements later

c.sYs, 5

nsel, NONE

*do, i, 0,180.0,4.0

nsel, a, loc, y, i

*enddo

nsel, r, loc, z, 459,600

nsel, $u, 10 c, x, 350,371$

nsel, u, loc, x, 372, 392

nsel, u, loc, $x, 394,412$

nsel, u, loc, $x, 414,432$

$\mathrm{cm}$, Dome JBNodes, NODE

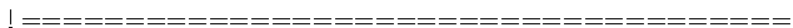

!STORE THE NODE NUMBERS OF SELECTED NODES FOR BEAM ELEMENT CREATION LATER

* get, NouB, Node, , COUNT

*dim, JBnodeNum, array, NoJB, 1

*do, i, 1, NoJB

*get, number, NODE, , NUM, MIN

JBnodeNum $(i, 1)=$ number

nsel, u, NODE, number

*enddo 
! Generate additional set of nodes for Beam

elements

cmsel, , DomeJBNodes, NODE

LOCAL, $15,2,0,381.5,0,0,0,0,0.375$

NROTat, ALI

ngen, 2,20000, all, ,

! Total

16107 nodes already defined.

may be numbered between 20000,20000+16107

\section{! Create Beam elements for J-bolts}

et, 11, BEAM18 8

$\mathrm{MP}, \mathrm{EX}, 11,100 \mathrm{e} 6$

MP, NUXY, 11, 0.25

SECTYPE, 11, BEAM, CSOLID, JBSEC

SECDATA, $0.25,1,1$ ! Bolt Radius

! SECPLOT, 11

N,99999,500,500 !Dummy node for beam orientations TYPE, 11

$\mathrm{MAT}, 11$

SECNUM, 11

* do, $i, 1, \mathrm{NoJB}$

E, JBnodenum (i, 1), JBnodeNum (i, 1) +20000,99999

*enddo

allsel

csys, 12 ! same as csys 5

nrot, a 11

/rep

nsel, s, loc, z, 0

! FIX Bottom of Tank d, all, $\operatorname{rot} x, 0$

d, all, roty, 0

d, all, rotz, 0

nsel, all

nsel, , loc, y, 0

symmetry

nsel, a, loc, y, 180

nsel, u, node, , 99999

d, all, uy, 0.0

$\mathrm{d}, \mathrm{all}, \operatorname{rot} \mathrm{x}, 0$

d, all, rotz, 0

nsel, all

nsel, , loc, $x, 0$

nsel, r, loc, z,

! Fix center node

d, all, ux, 0.0

nsel, all

nsel, , loc, z, 459.17,600

Fix rotations of the

Tank Dome + beam end nodes

d, all, rotx, 0

d, all, roty, 0

d, all, rotz, 0

nsel, all

allsel

finish

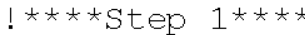

/ sol

anty, stat

nlgeom, on

nsel, node, 20000,40000 ! Only J-bolt top end

nodes

d, all, uz, DomeDisp

a, all, uz, 0.0 
nsel, all

allsel

nsub, $20,100,20$

outr, all, all

save

solv

\section{B.2.3 File Name: AYbuckling.inp}

! AY Increased vacuum model at constant

compression.

! Main input file for studying the influence of various parameters on buckling collapse load for AY Tank

! Parameters include Waste height, Dome displacement (Meridional stress), Spacific gravity, Corrosion allowance(Wall thickness) ! Pressure Ramped from 0 to 50" W.G in the third load step. Increase this for waste levels above $300 "$

fini

/clear

l $===========$ PARAMATERS $============================$

$=====$

WasteHt $=06$

! Waste Height in Inches

$\mathrm{SpG}=1.7$

Corrosion $=0$

! Specific Gravity

60 years

DomeDisp=-1

! Dome vertical displacement

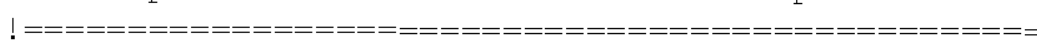

/filname, WH06Coro U1

! Change filename

according to above paramaters

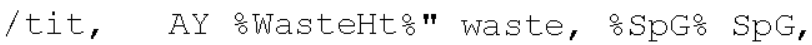

응 DomeDisp응 DomeDispl, 응 corrosion응 corrosion

/triad, lbot /prep 7

et, $1,181,, 2$

!*** Materials

mp,ex, 1,29.5e6 !Young's Modulus of Primary

Liner material

mp, dens,1,490/1728 !Density of Primary Liner

material

mp,prxy, 1,.3! !Poisson's Ration of Primary

Liner material

tb,biso,1 !Material Behaviour/data

todata, $1,36000, .01 * 27.7 e 6$

!** Shell thickness

$r, 101,1$-Corrosion

r,102,3/8-Corrosion

$r, 103,7 / 8$-Corrosion

r,104,3/4-Corrosion

r,105,1/2-Corrosion

$d=117$ !depth of geometric imperfection

!*** Geometry

$\mathrm{k}, 1,0.0,0.0$

$\mathrm{k}, 2,24$

$\mathrm{k}, 3,(37.5-4) * 12$

$\mathrm{k}, 4,37.5 * 12$

$\mathrm{k}, 5,37.5 * 12,3 * 12$

$k, 6,37.5 * 12,(3+9) * 12$

$\mathrm{k}, 7,37.5 * 12,31 * 12+9+1 / 2-(\mathrm{d}-30)$ ! for geometric imperfection

$\mathrm{k}, 8,37.5 * 12,31 * 12+9+1 / 2$

$\mathrm{k}, 9,37.5 * 12,31 * 12+9+1 / 2+30$ ! for geometric

imperfection

$\mathrm{k}, 10,37.5 * 12,45 * 12$

$k, 11,0.0,(31+15) * 12+9+1 / 2$ 
$\mathrm{k}, 12,40 * 12,31 * 12+9+1 / 2$

$1,1,2$

*rep, $9,1,1$

loca $, 11,1,0,31 * 12+9+1 / 2,0,1,3 / 8$

$1,11,12$

$1 \mathrm{fil}, 3,4,12$

$1 \mathrm{Cs} 1,9,10$

lfil, $12,14,3 * 12+8+3 / 8$

thet $a=180$

ldel, 13,15, 2

csys, defa

lsel, all

* get, L14length, LINE, 14 , LENG

lsel, , line, 14

! lesi, all, 24

ldiv,all, ,L14length/24! 2'Approx, Divides to

$\varpi$ nearest integer value

= lsel, , line, 13,26

lsel, a, line, 10

lcomb, all

lsel, , line, 1

lesi,all, 4

lsel, , line, 2

lesi,all, , 20,-2

lsel, , line, 3

lesi,all, , 6, 1/1.5

lsel, , line, , 11

lesi, all, 4

lsel, , line, , 4

lesi,all, 4

lsel, , line, 5

lesi, all, , 15, 3

lsel, , line, 6

lesi,all, , 10, -1.5 lsel, , line, 7

lesi, all, , 12,1/2.8

lsel, , line, 8

lesi,all, , 8, 1/1.4

lsel, , line, 12

lesi,all, 4

lsel, , line, 9

lesi,all, 4

lsel, , line, 30

lesi,all, 4

lsel, , line,, 29

lesi,all, , 5, 1/1.4

lsel, , line,, 28

lesi,all, , 3,1/1.5

lsel, , line,, 27

lesi,all, , 2,1/1.4

lsel, , line, 10

lesi,all, 24

lsel, all

arot, all, , , , 1, 11, theta, 45

lsel, , line, , 737, 1397, 15

lesiz,all, , 1

one

element

lsel, , line, , 738, 1398, 15

lsel, a, line, , 739,1399, 15

lsel, a, line, , 740,1400,15

lsel, a, line, , 741,1401,15

lsel, a, line, , 742,1402,15

lsel, a, line, , 743,1403,15

lsel, a, line, , 744,1404, 15

lsel, a, line, , 745,1405, 15

lsel,a, line, , 746,1406,15

lsel,a, line, , 747,1407,15

lsel, a, line, , 748,1408, 15

lsel, a, line, , 749,1409,15

lsel, a, line, , 750,1410,15 
lsel, a, line, ,751,1411,15

lesiz, all, 1

! one

degree angle

1 sel, all

loca $, 12,1,0,0,0,-90$

Csys, 12

!***Specify the width $(w)$ and deviation (h) of the dent

$W=7 * 12$

$\mathrm{h}=1$

$\mathrm{p} i=22 / 7$

impang $=\mathrm{w} / \mathrm{pi} / 450 * 180$

*do, $i, 1,3,1$

ksel, , loc, z, 382

$, r, 100, y,(180-((i-1) * 4))$

* get, $a, k p, 0$, num, max

*get, $\mathrm{x} 1, \mathrm{kp}, \mathrm{a}, \mathrm{loc}, \mathrm{x}$

* get, $\mathrm{Y} 1, \mathrm{kp}, \mathrm{a}, \mathrm{loc}, \mathrm{Y}$

*get, z1, kp, a , loc, z

kmodif, $a, x 1+(h *(1-(i-1) * 4 /$ impang $)), y 1, z 1$

*enddo

esiz, 24

amesh, all

save

!***Thickness assignments

nsel, , loc, $x, 0,24$

nsel, r, loc, $z, 0$

esln, 1

emod, all, real, 101

nsel, , 1oc, $x, 24,402$

nsel, r, loc, z, 0

esln, 1 emod, all, real, 102

nsel, , loc, $x, 402,450$

nsel, r, loc, z, 0,36

esln, 1

emod, all, real, 103

nsel, , loc, z, 36, 144

esln, 1

emod, all, real, 104

nsel, , loc, z, 144, 382

esln, 1

emod, all, real, 105

nsel, , loc, z, 382, 561.5

$\operatorname{esln}$

esel, r, type, 1

emod, all, real, 102

allsel

!LOOP FOR SELECTING ONLY j-BOLT NODES to applY displacements later (mainly above IMPEREECTION) CSYs, 5

nsel, NONE

*do, $i, 0,180.0,4.0$

nsel, a, loc, y, i

tenddo

nsel, r, loc, z, 459,600

nsel, u, loc, $x, 350,371$

nsel, u, loc, x, 372, 392

nsel, u, loc, x, 394,412

nsel, u, loc, x, 414, 432

$\mathrm{cm}$, Dome JBNodes, NODE

$!================================$
!STORE THE NODE NUMBERS OF SELECTED NODES FOR BEAM ELEMENT CREATION LATER 
* get, NoJB, Node, , COUNT

*dim, JBnodeNum, array, NoJB, 1

* do, i, 1, NoJB

* get, number, NODE, , NUM, MIN

JBnodeNum $(i, 1)=$ number

nsel, u, NODE, , number

*enddo

! Generate additional set of nodes for Beam

elements

cmsel, , Dome JBNodes, NODE

LOCAL , 15, 2, 0, 381.5, 0, 0, 0, 0, 0.375

NROTat, ALL

ngen, 2,20000, all, , 1

! Total

16107 nodes already defined.

! JB nodes

may be numbered between 20000,20000+16107

\section{! Create Beam elements for J-Bolts}

et, 11, BEAM188

$\mathrm{MP}, \mathrm{EX}, 11,100 \mathrm{e} 6$

MP, NUXY, $11,0.25$

SECTYPE, 11, BEAM, CSOLID, JBSEC

SECDATA, 0.25,1,1 ! Bolt Radius

! SECPLOT, 11

CSYS

N, 99999,500,500 !Dummy node for beam orientations TYPE, 11

MAT, 11

SECNUM, 11

*do, i, 1, NoJB

E, JBnodeNum (i, 1), JBnodeNum (i, 1) +20000,99999

*enddo allsel

csys, 12 ! same as csys 5

nrot, all

rep

! pressure loads

Pvac $=0$

! Internal Pressure,

Inch W. $\mathrm{g}$.

pp1=Pvac/12*62.4/144 ! internal pressure,

psi

hw=WasteHt

! Waste Height, inches

Wdens=SpG*62.4/1728 ! Waste Density,

$1 \mathrm{~b} / \mathrm{in}^{\wedge} 3$

pp $2=p p 1+h w * w d e n s$

tank, psi

! Pressure at bottom of

!primary liner - below waste level

! Not applied in first load step for waste

hydrostatic effect on primary meridional stress

!primary liner - below waste level

nsel, s, loc, z, 0 , hw

esln, s, 1, all

sfgrad,pres, 12, z, hw, (pp1-pp2)/hw

sf,all,pres,pp1

alls

sfgrad,pres! reset pressure gradient

/rep

nsel, s, loc, z, 0

! FIX Bottom of Tank

$\mathrm{d}, \mathrm{all}, \mathrm{uz}, 0.0$

d, all, rotx, 0

d, all, roty, 0

d, all, rotz, 0

nsel, all 


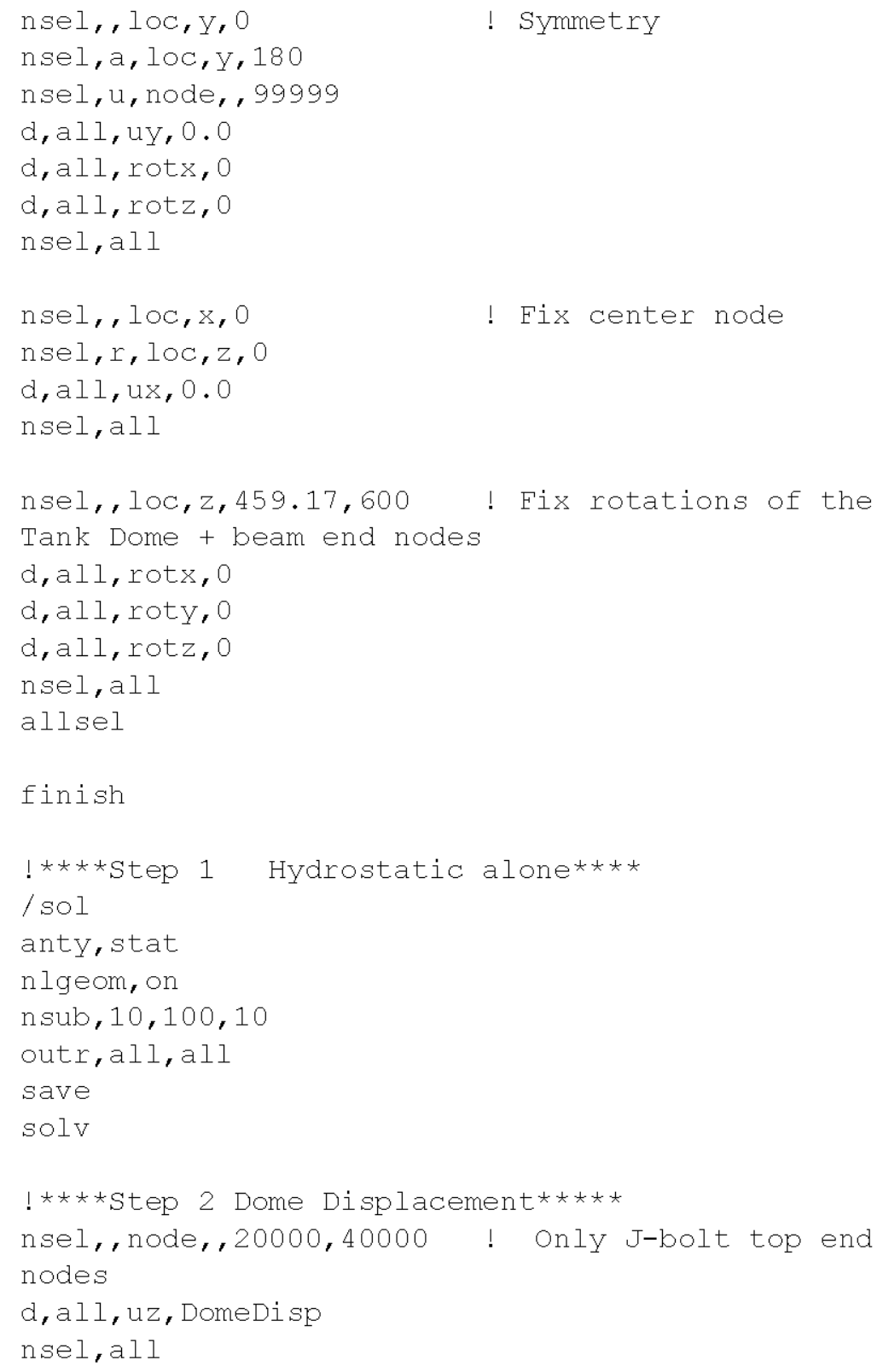

allsel

nsub $, 10,100,10$

outr,all, all

save

solv

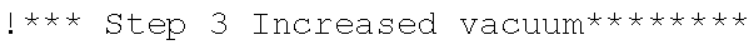

Pvac $=-50$

! Internal Pressure,

Inch w.g.

pp1=Pvac/12*62.4/144! internal pressure,

psi

pp2=pp1+hw*Wdens

tank, psi

! Pressure at bottom of

!primary liner - Below waste level

nsel, s, loc, z, 0, hw

esln, s, 1, all

sfgrad,pres, 12, z, hw, (pp1-pp2)/hw

sf,all,pres,pp1

allsel

sfgrad,pres!reset pressure gradient so not applied above waste

!primary liner - above waste level

nsel, s, loc, z, hw, 562

nsel, u, node, ,20000, 40000

nsel, u, node, , 99999

esln, s, 1, all

ESEL, R, TYPE, , 1

sf, all, pres, pp1

alls

$\mathrm{kbc}, 0$

nsub, 20,100,20

outr, all, all

save

solv 


\section{B.3 AY Tank Post Processing Files}

\section{B.3.1 File Name: Post1_MerStress_wall elem hist.inp}

! Mac for variation of meridional stress with increased compression in the thinnest wall section

/POST1

CSYS, 5

esel, , elem, , 1044

rsys, solu

\section{$\angle \mathrm{PAGE}$, , , 500}

/header, off, off, off, off, off, off

loutput, 41Postmerstrs05thik, lis, , append

$\star$ do, $i, 1,30$

$\varpi$ set, $1, i$

Wr $\quad$ get, CurTime, ACTIVE, 0, SET, TIME

shell,mid

etab, eloc, cent, z

etab, smm, s, y

! esort, etab, eloc

! *status, curTime

*enddo

pret, etab, eloc, smm

/OUTPUT

\section{B.3.2 File Name: Post2_KnuckSurfStress_elem hist.inp}

! Macro for monitoring surface stresses in the knuckle region under increased compression (away from imperfection)

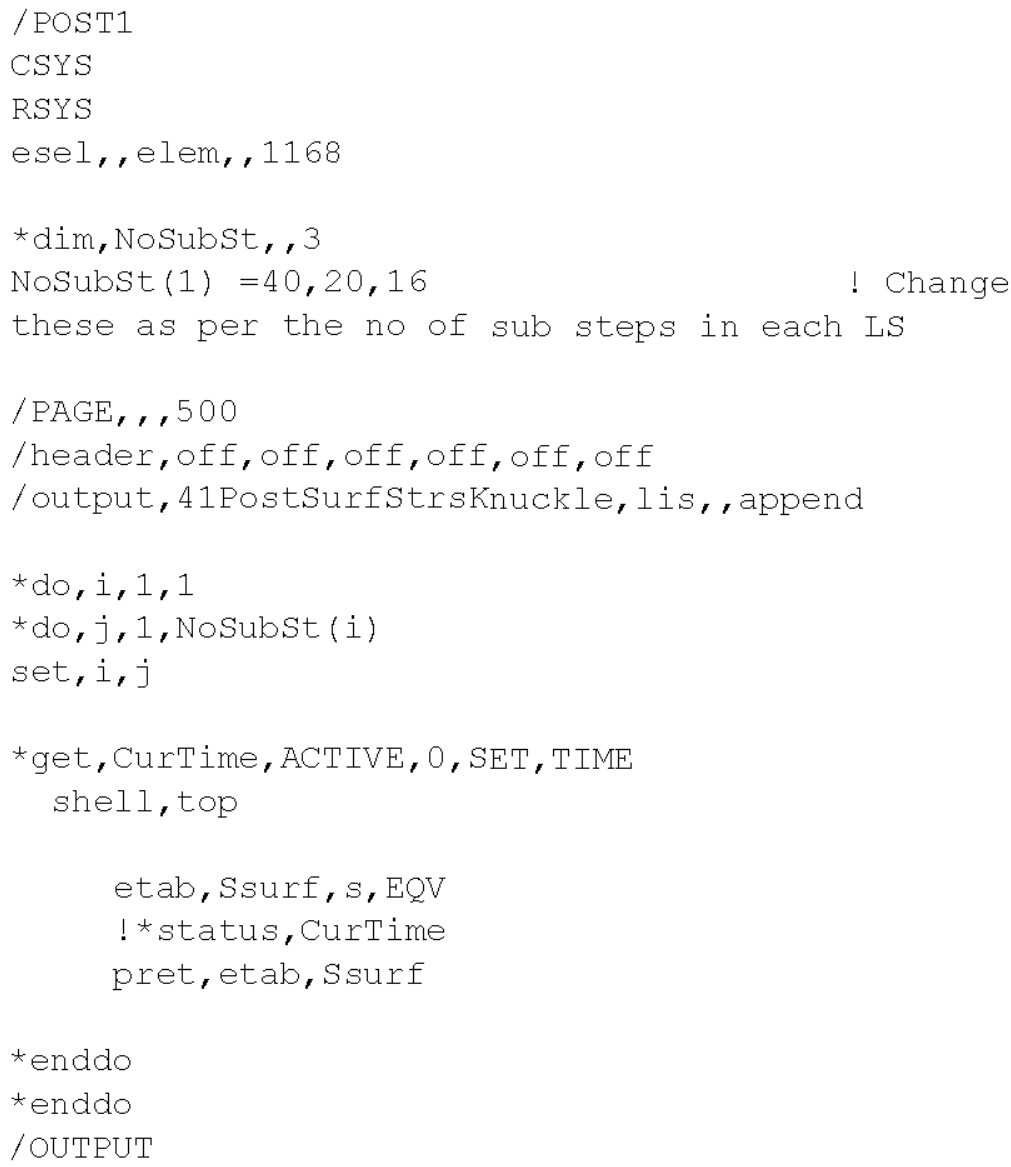

RSYS

esel, , elem, , 1168

*dim, Nosubst, 3

NoSubst $(1)=40,20,16$ ! Change

these as per the no of sub steps in each LS

/PAGE, , , 500

/header, off, off, off, off, off, off

loutput, 41Postsurfstrsknuckle, lis, , append

$\star$ do, $i, 1,1$

* do, $j, 1$, NoSubst $(i)$

set, $i, j$

*get, CurTime, ACTIVE, 0, SET, TIME

shell, top

$$
\begin{aligned}
& \text { etab, Ssurf, s, EQV } \\
& \text { ! *status, CurTime } \\
& \text { pret, etab, ssurf }
\end{aligned}
$$

*enddo

*enddo

/OUTPUT

\section{B.3.3 File Name: 1Post-UXVsLS_Nodehist.inp}

! AP Compression only model with Bilinear-Elastic material properties.

! MACRO FOR MONITORING DISPLACEMENT(UX IN RSYS 5) IN ESTIMATION OF BUCKLING COLLAPSE LOAD AS PER ASME COLLAPSE METHOD. 
set, last

set, prev

*get, LS3NOSS, ACTIVE, 0, SET, SBST

*dim, NoSubst,, 3

NoSubst (1) $=1,1$, LS3NoSS

these as per the no of sub steps in each Ls

Vtot=NoSubst (1) +NoSubst (2)+NoSubst (3)

*dim, UXminHist, , vtot, 2

row $=0$

rsys, 5

*do, $i, 1,3$

only 3rd LS for ASME Collapse

line

* do, j, 1, Nosubst (i)

ț $\quad * i f, i$, eq, 1 , then

allsel

rsys

*mwrite, UXminHist, o RunNoPostuXNODEHist, lis, ,jik, 2 , row

$(\mathrm{F} 15.9,5 \mathrm{x}, \mathrm{F} 15.9)$

\section{B.4 AP Tank Input Files}

\section{B.4.1 File Name: APcompressionOnlyElstic.inp}

! AP Compression only model with Elastic-Plastic material properties.

! Input file for studying the variation in meridional stress in the tank wall with increased compression loading for AP Tank.

! Elastic model (bilinear)

fini

/clear

$\begin{array}{cr}l========\text { PARAMARS } & ============= \\ \text { DomeDi } \mathrm{sp}=-1.0 & \text { ! Dome vertical }\end{array}$

displacement

Corrosion $=0.0 \quad$ !corrosion allowance

Ifilname, ApNovacCor0 U1 ! change file name as per above paramaters

tit, AP No waste, 1" Disp, No vacuum

/triad, lbot

/prep 7

et, $1,181,, 2$

!*** Materials

mp, ex, 1,29.5e6

mp, dens, 1,490/1728

mp, prxy, $1, .3$

tb, biso, 1 
tbdata, $1,36000, .01 * 27.7 e 6$

\section{!*** Shell thickness}

r,101,1-Corrosion

r, 102,1/2-Corrosion

r, 103,7/8-Corrosion

r,104,15/16-Corrosion

r,105,3/4-Corrosion

r,106,9/16-Corrosion

r, 107,3/8-Corrosion

$\mathrm{d}=117$ !depth of geometric imperfection

!** Geometry

$\mathrm{k}, 1,0.0,0.0$

$\mathrm{k}, 2,24$

$\mathrm{k}, 3,(37.5-4) * 12$

$\mathrm{k}, 4,37.5 * 12$

$\mathrm{k}, 5,37.5 * 12,3 * 12$

$k, 6,37.5 * 12,(3+9) * 12$

$\mathrm{k}, 7,37.5 * 12,31 * 12+9+1 / 2-(\mathrm{d}-30)$ ! for geometric imperfection

$\mathrm{k}, 8,37.5 * 12,31 * 12+9+1 / 2$

$\mathrm{k}, 9,37.5 * 12,31 * 12+9+1 / 2+30$ ! for geometric

imperfection

$\mathrm{k}, 10,37.5 * 12,45 * 12$

$\mathrm{k}, 11,0.0,(31+15) * 12+9+1 / 2$

$\mathrm{k}, 12,40 * 12,31 * 12+9+1 / 2$

$1,1,2$

*rep, $9,1,1$

loca $, 11,1,0,31 * 12+9+1 / 2,0,1,3 / 8$

$1,11,12$

lfil, $3,4,12$

lasl, 9,10

lfil, $12,14,3 * 12+8+3 / 8$ thet $\mathrm{a}=180$

ldel, 13,15, 2

csys, defa

lsel, all

*get, L14 length, LINE, 14 , LENG

lsel, , line, 14

! lesi, all, 24

ldiv,all, ,L14length/24! 2'Approx, Divides to nearest integer value

lsel, , line, , 13, 26

lsel, a, line, , 10

lcomb, all

lsel, , line, , 1

lesi,all, 4

lsel, , line, , 2

lesi,all, , 20,-2

lsel, , line, 3

lesi, all, , 6, 1/1.5

lsel, , line, 11

lesi,all, 4

lsel, , line, , 4

lesi,all, 4

lsel, , line, , 5

lesi, all, , 15, 3

lsel, , line, 6

lesi,all, , 10,-1.5

lsel, , line, 7

lesi, all, , 12,1/2.8

1 sel, 1 ine,, 8

lesi,all, , 8, 1/1.4

lsel, , line, 12

lesi,all, 4

lsel, , line, , 9

lesi,all, 4

lsel, , line,, 30 


\section{lesi,all, 4}

lsel, ,line, 29

lesi,all, , 5, 1/1.4

lsel, , line,, 28

lesi,all, ,3,1/1.5

lsel, , line, 27

lesi,all, ,2,1/1.4

lsel, , line, , 10

lesi,all,24

lsel,all

arot, all, , , ,1,11, theta, 45

lsel, , line, , 737, 1397, 15

lesiz,all, , 1

! one

element

lsel, , line, , 738,1398,15

lsel,a, line, , 739,1399,15

lsel,a, line, ,740,1400,15

lsel, a, line, , 741,1401,15

lsel,a, line, ,742,1402,15

$\square \quad l s e l, a, l i n e,, 743,1403,15$

$\infty \quad$ lsel, $a$, line, , 744,1404,15

lsel,a, line, ,745,1405,15

lsel,a, line, , 746,1406,15

lsel,a, line, ,747,1407,15

lsel,a, line, , 748,1408,15

lsel,a,line, , 749,1409,15

lsel,a, line, , 750,1410,15

lsel,a, line, , 751,1411,15

lesiz,all, 1

degree angle

lsel, all

loca, 12,1,0,0,0, -90

CsYs, 12

!***Specify the width (w) and deviation ( $h$ ) of the dent

$\mathrm{W}=7 * 12$ $\mathrm{h}=1$

$\mathrm{p} i=22 / 7$

impang $=\mathrm{w} / \mathrm{pi} / 450 * 180$

$\star$ do, $i, 1,3,1$

ksel, , loc, z, 382

$, r, 100, y,(180-((i-1) * 4))$

* get, a, kp, 0, num, max

* get, $x 1, \mathrm{kp}, \mathrm{a}, \mathrm{loc}, \mathrm{x}$

* get, $\mathrm{y} 1, \mathrm{kp}, \mathrm{a}, \mathrm{loc}, \mathrm{y}$

*get, $\mathrm{z} 1, \mathrm{kp}, \mathrm{a}, \mathrm{loc}, \mathrm{z}$

kmodif $, \mathrm{a}, \mathrm{x} 1+(\mathrm{h} *(1-(\mathrm{i}-1) * 4 / \mathrm{impang})), \mathrm{y} 1, \mathrm{z} 1$

*enddo

esiz,24

amesh, all

save

!***Thickness assignments

nsel, , loc, $x, 0,24$

nsel, r, loc, $z, 0$

esln, 1

emod, all, real, 101

nsel, loc, x, 24, 401.0625

nsel, r, loc, z, 0

esln

emod,all, real, 102

nsel, , 10c, x, $401.0625,438$

nsel, r, loc, z, 0

esln, 1

emod,all, real, 103

nsel, , loc, $x, 438,450$

nsel, r, loc, $z, 0,12$

esln, 1

emod, all, real, 104

nsel, , loc, z, 12, 36.875

esln, 1

emod, all, real,103

nsel, , loc, z, 36.875, 144.875 


\section{esln}

emod, all, real, 105

nsel, , loc, z, 144.875, 237.375

esln, 1

emod, all, real, 106

nsel, , loc, z, 237.375, 468.5

esln, 1

emod, all, real, 102

nsel, , loc, z, $468.5,561.5$

nsel, u, loc, $x, 0,72$

esln

emod, all, real, 107

nsel, , loc, z, $468.5,561.5$

nsel, R, loc, $x, 0,72$

esln, 1

emod, all, real, 102

allsel

! LOOP FOR SELECTING ONLY j-BOLT NODES to apply

$\varpi$ displacements later (mainly above IMPEREECTION)

ம $\quad$ csys, 5

nsel, NONE

$\star$ do, i, $0,180.0,4.0$

nsel, a, loc, y, i

*enddo

nsel, r, loc, z, 459,600

nsel, u, loc, $x, 350,371$

nsel, u, loc, $x, 372,392$

nsel, u, loc, x, 394, 412

nsel, u, loc, $x, 414,432$

$\mathrm{cm}$, Dome JBNodes, NODE

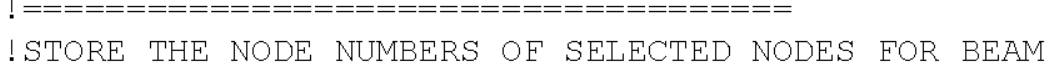
ELEMENT CREATION LATER

* get, NoJB, Node, , COUNT

*dim, JBnodeNum, array, NoJB, 1

$\star$ do, i, 1, NoJB *get, number, NODE, , NUM, MIN

JBnodeNum $(i, 1)=$ number

nsel, u, NODE, number

*enddo

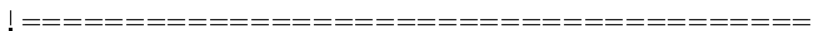

! Generate additional set of nodes for Beam

elements

cmsel, , Dome JBNodes, NODE

LOCAL, $15,2,0,381.5,0,0,0,0,0.375$

NROTat, ALL

ngen, 2,20000, all, , 1

16107 nodes already defined.

may be numbered between 20000,20000+16107

!Create Beam elements

et, 11, BEAM188

$\mathrm{MP}, \mathrm{EX}, 11,100 \mathrm{e} 6$

MP, NUXY, $11,0.25$

SECTYPE, 11, BEAM, CSOLID, JBSEC

SECDATA, $0.25,1,1$ ! Bolt Radius

! SECPLOT, 11

CSYS

N, 99999,500,500 !Dummy node for beam orientations TYPE, 11

MAT, 11

SECNUM, 11

* do, $i, 1$, NoJB

E, JBnodeNum (i, 1), JBnodeNum (i, 1) +20000,99999

*enddo

allsel

csys, 12 ! same as csys 5 


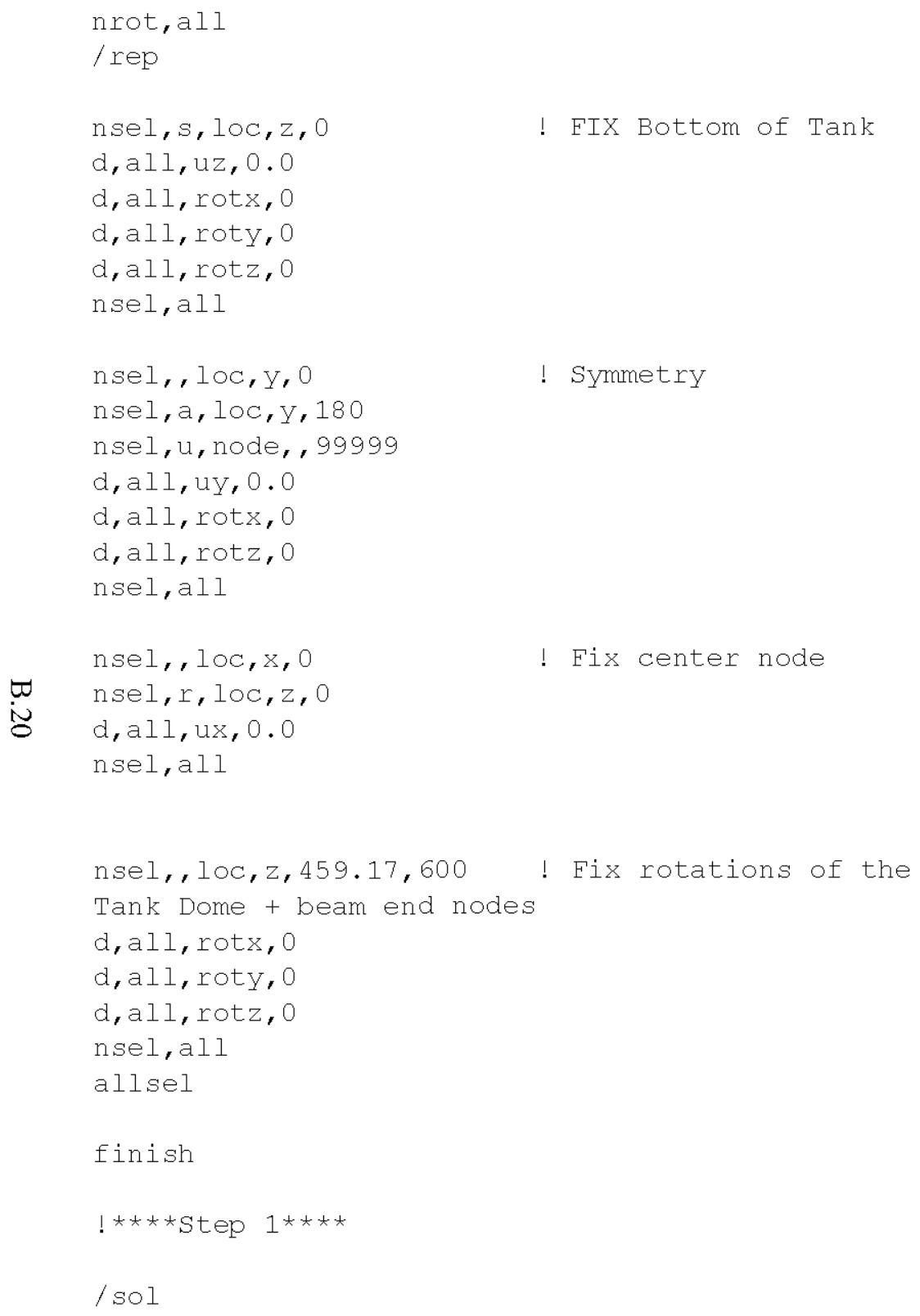

! Fix rotations of the Tank Dome + beam end nodes

d, all, $\operatorname{rot} x, 0$

d, all, roty, 0

d, all, rotz, 0

nsel,all

allsel

finish

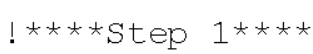

/ sol

! FIX Bottom of Tank

! Symmetry

! Fix center node 
!*** Materials

mp, ex, $1,29.5 e 6$

mp, dens, $1,490 / 1728$

mp, prxy, $1, .3$

! to, temp, 210

tb, miso, $1,1,6$

tbpt, , 39.69/29.5e3, 39690

tbpt, $, 0.0025,35000 *(39.69 / 32)$

tbpt, $, 0.01,42000 *(39.69 / 32)$

tbpt, $, 0.02,49000 *(39.69 / 32)$

tbpt, $, 0.03,55000 *(39.69 / 32)$

tbpt, $, 0.04,59000 *(39.69 / 32)$

!*** Shell thickness

r,101,1-Corrosion

$r, 102,1 / 2$-Corrosion

r,103,7/8-Corrosion

$\forall \quad r, 104,15 / 16$-Corrosion

N r,105,3/4-Corrosion

r,106,9/16-Corrosion

r,107,3/8-Corrosion

$\mathrm{d}=117$ !depth of geometric imperfection

!*** Geometry

$\mathrm{k}, 1,0.0,0.0$

$\mathrm{k}, 2,24$

$\mathrm{k}, 3,(37.5-4) * 12$

$\mathrm{k}, 4,37.5 * 12$

$\mathrm{k}, 5,37.5 * 12,3 * 12$

$\mathrm{k}, 6,37.5 * 12,(3+9) * 12$

$k, 7,37.5 * 12,31 * 12+9+1 / 2-(d-30)$ ! for geometric imperfection

$\mathrm{k}, 8,37.5 * 12,31 * 12+9+1 / 2$ $k, 9,37.5 * 12,31 * 12+9+1 / 2+30$ ! for geometric

imperfection

$\mathrm{k}, 10,37.5 * 12,45 * 12$

$\mathrm{k}, 11,0.0,(31+15) * 12+9+1 / 2$

$\mathrm{k}, 12,40 * 12,31 * 12+9+1 / 2$

$1,1,2$

* rep, 9, 1, 1

loca $, 11,1,0,31 * 12+9+1 / 2,0,1,3 / 8$

$1,11,12$

lfil, 3, 4, 12

lasl $, 9,10$

lfil, $12,14,3 * 12+8+3 / 8$

thet $\mathrm{a}=180$

ldel, 13, 15, 2

csys, defa

lsel, all

*get, L14 length, LINE, 14 , LENG

lsel, , line, , 14

! lesi, all, 24

ldiv,all, ,L14length/24! 2'Approx, Divides to nearest integer value

lsel, , line, , 13, 26

lsel, a, line, , 10

lcomb, all

lsel, , line, , 1

lesi,all, 4

lsel, , line, 2

lesi,all, , 20,-2

1 sel, , line, 3

lesi,all, , 6, 1/1.5

lsel, , line, , 11

lesi,all, 4

lsel, , line, , 4 


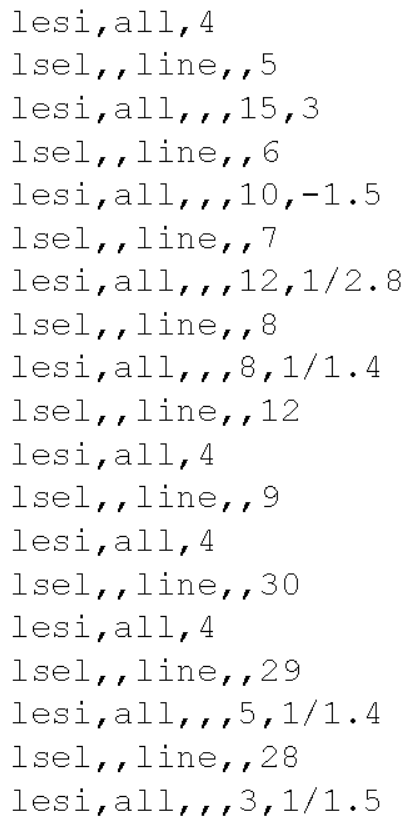

lsel, a, line, 746,1406,15

lsel,a, line, , 747,1407,15

lsel,a, line, , 748,1408,15

lsel,a, line, , 749,1409,15

lsel,a, line, ,750,1410,15

lsel,a, line, , 751,1411,15

lesiz,all, 1

degree angle

lsel,all

loca, 12,1,0,0,0, ,-90

Csys, 12

!***Specify the width (w) and deviation ( $h$ ) of the dent

$w=7 * 12$

$h=1$

$\mathrm{pi}=22 / 7$

impang $=\mathrm{w} / \mathrm{pi} / 450 * 180$

$\star$ do, $i, 1,3,1$

ksel, , loc, z, 382

, r, loc, $y,(180-((i-1) * 4))$

* get, a, kp, 0, num, max

* get, $\mathrm{x} 1, \mathrm{kp}, \mathrm{a}, \mathrm{loc}, \mathrm{x}$

* get, $\mathrm{y} 1, \mathrm{kp}, \mathrm{a}, \mathrm{loc}, \mathrm{y}$

* get, z1, kp, a, loc, z

kmodif, $a, x 1+(h *(1-(i-1) * 4 /$ impang $)), y 1, z 1$ 
nsel, , 1oc, x, 24, 401.0625

nsel, r, loc, $z, 0$

esln

emod, all, real, 102

nsel, , loc, x, $401.0625,438$

nsel, r, loc, $z, 0$

esln, 1

emod, all, real,103

nsel, $100, x, 438,450$

nsel, r, loc, $z, 0,12$

esln, 1

emod, all, real, 104

nsel, , loc, z, 12, 36.875

esln, 1

emod, all, real, 103

nsel, , loc, z, 36.875, 144.875

esln

emod, all, real, 105

nsel, loc, z, 144.875, 237.375

esln, 1

emod,all, real,106

nsel, , loc, z, $237.375,468.5$

esln, 1

emod, all, real, 102

nsel, , loc, z, $468.5,561.5$

nsel, u, loc, $x, 0,72$

esln

emod, all, real, 107 nsel, loc, z, 468.5, 561.5

nsel, R, loc, $x, 0,72$

esln, 1

emod, all, real, 102

allsel

!LOOP FOR SELECTING ONLY j-BOLT NODES to apply displacements later (mainly above IMPERFECTION)

cSYs, 5

nsel, NONE

*do, $i, 0,180.0,4.0$

nsel, a, loc, y, i

*enddo

nsel, r, loc, z, 459,600

nsel, u, loc, $x, 350,371$

nsel, u, loc, $x, 372,392$

nsel, u, loc, x, 394, 412

nsel, u, loc, $x, 414,432$

$\mathrm{cm}$, Dome JBNodes, NODE

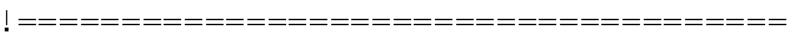

!STORE THE NODE NUMBERS OF SELECTED NODES FOR BEAM ELEMENT CREATION LATER

* get, NoJB, Node, , COUNT

* dim, JBnodeNum, array, NoJB, 1

*do, $i, 1$, NoJB

*get, number, NODE, , NUM, MIN

JBnodeNum $(i, 1)=$ number

nsel, u, NODE, , number

*enddo

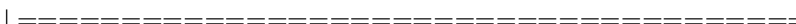

! Generate additional set of nodes for Beam

elements

cmsel, , DomeJBNodes, NODE

LOCAL $, 15,2,0,381.5,0,0,0,0,0.375$

NROTat, ALL 
ngen, 2,20000, all, , 1

! Total

16107 nodes already defined.

! JB nodes

may be numbered between $20000,20000+16107$

\section{lCreate Beam elements for J-bolts}

et, 11, BEAM188

$\mathrm{MP}, \mathrm{EX}, 11,100 \mathrm{e} 6$

MP, NUXY, 11, 0.25

SECTYPE, 11, BEAM, CSOLID, JBSEC

SECDATA, 0.25,1,1 ! Bolt Radius

! SECPLOT, 11

CSYS

N, 99999,500,500 !Dummy node for beam orientations TYPE, 11

MAT, 11

SECNUM, 11

$\star$ do, $i, 1$, NoJB

E, JBnodeNum (i, 1), JBnodeNum (i, 1) +20000,99999

*enddo

allsel

csys, 12 ! same as csys 5

nrot, all

/rep

! pressure loads

Pvac $=-6$

! Internal Pressure,

Inch W. $g$.

pp1=Pvac/12*62.4/144 ! internal pressure,

psi

hw=6 ! Waste Height, inches

SpG $=1.70$ ! Waste Spec. Gravity

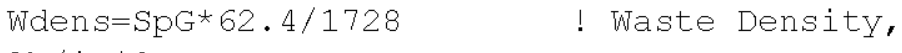
$1 \mathrm{~b} / \mathrm{in}^{\wedge} 3$

pp2=pp1+hw*wdens ! Pressure at bottom of tank, psi

!primary liner - below waste level

nsel, s, loc, z, 0, hw

esln, s, 1, all

sfgrad, pres, 12, z, hw, (pp1-pp 2)/hw

sf,all,pres,ppl

alls

sfgrad,pres ! reset pressure gradient

lrep

nsel, s, loc, z, 0

! FIX Bottom of Tank

d, all, uz, 0.0

d, all, rotx, 0

d, all, roty, 0

d, all, rotz, 0

nsel, all

nsel, , loc, y, 0

! symmetry

nsel, a, loc, y, 180

nsel, u, node, , 99999

d, all, uy, 0.0

d, all, rotx, 0

d, all, rotz, 0

nsel, all

nsel, , loc, $x, 0$

nsel, r, loc, $z, 0$

d, all, ux, 0.0

nsel, all

nsel, , loc, z, 459.17,600

! Fix rotations of the

Tank Dome + beam end nodes

$\mathrm{d}, \operatorname{all}, \operatorname{rot} x, 0$ 


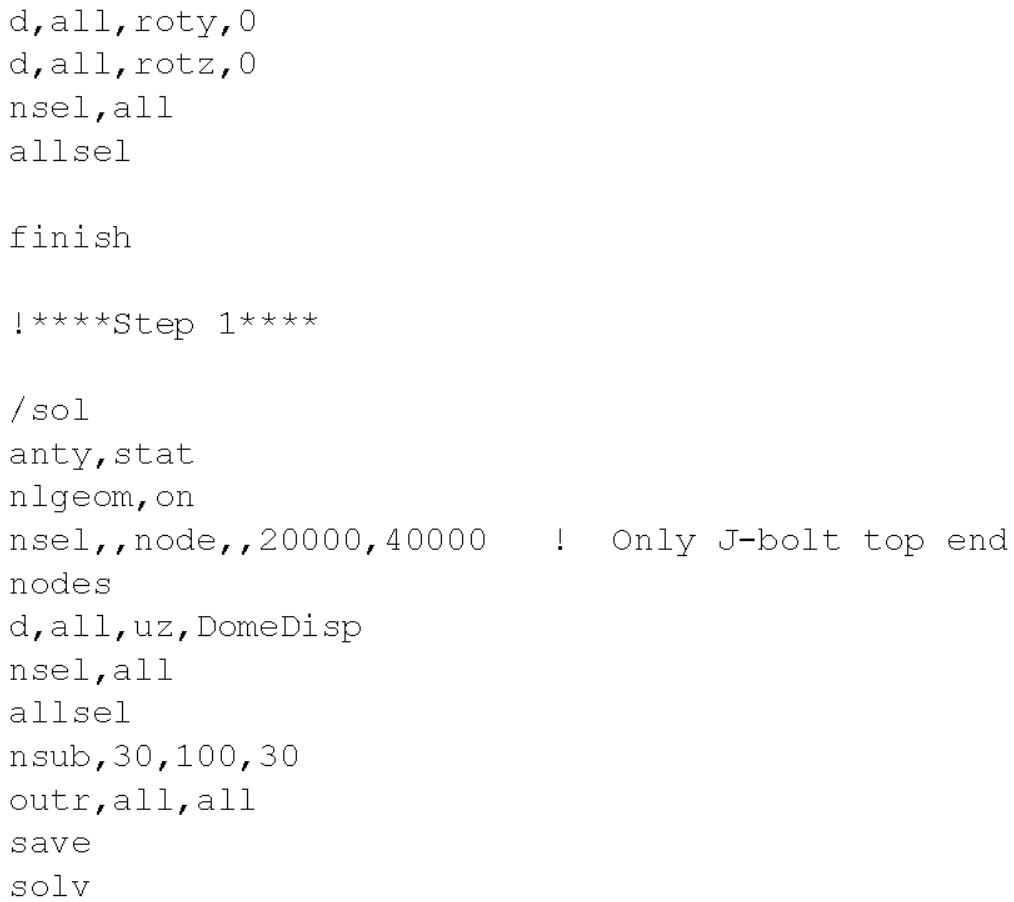

\section{B.4.3 File Name: APbuckling.inp}

! AP Increased vacuum model at constant

compression.

! Main input file for studying the infleunce of various parameters on buckling collapse load

! Parameters include waste height, Dome

displacement (Meridional stress), Spacific gravity, Corrosionn allowance(Wall thickness)

! Pressure Ramped for 0 to 50 " W. G in the third load step. Increase this for waste levels above $300 "$

fini

/clear

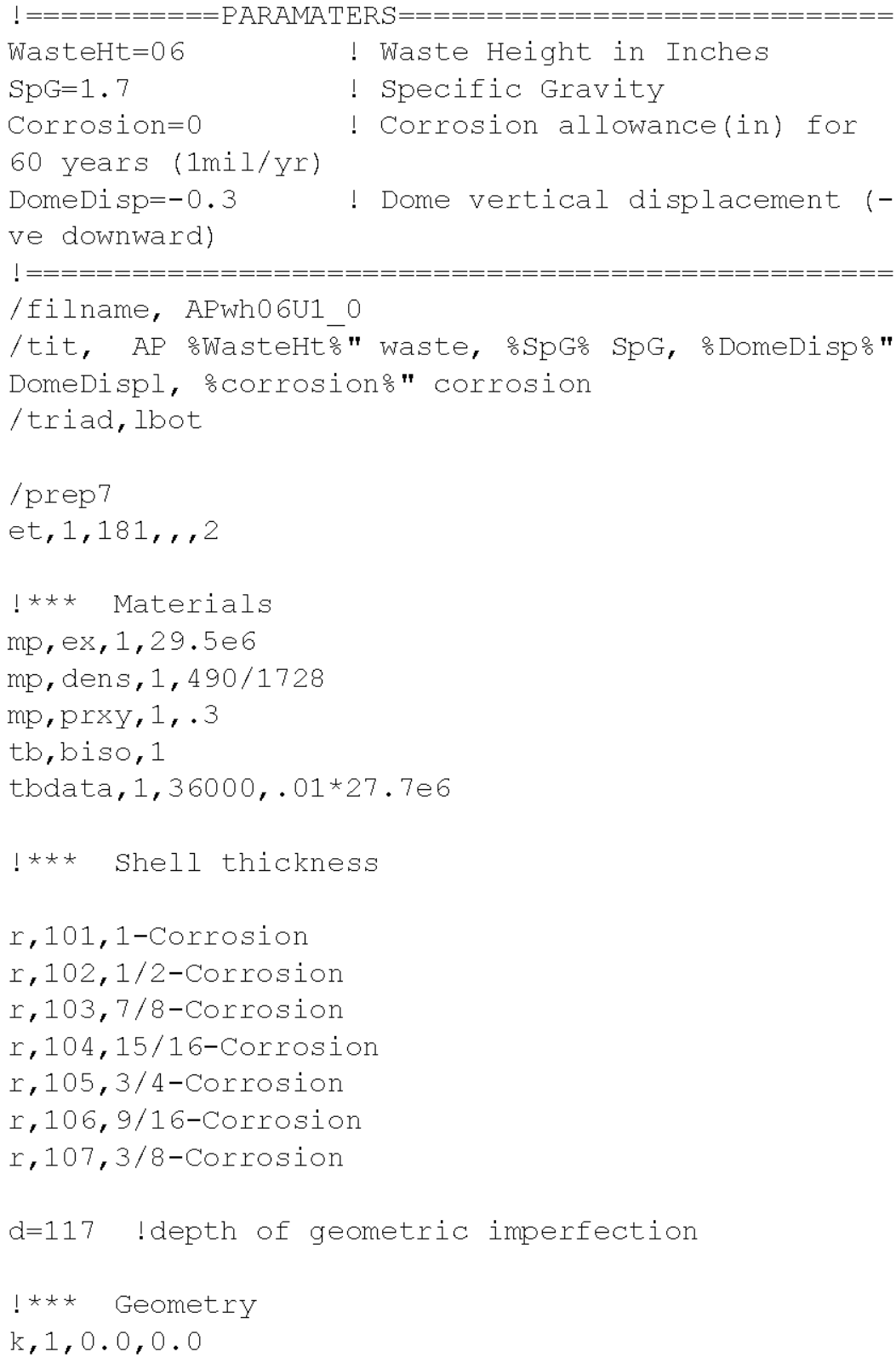




\section{$\mathrm{k}, 2,24$}

$k, 3,(37.5-4) * 12$

$\mathrm{k}, 4,37.5 * 12$

$k, 5,37.5 * 12,3 * 12$

$k, 6,37.5 * 12,(3+9) * 12$

$\mathrm{k}, 7,37.5 * 12,31 * 12+9+1 / 2-(\mathrm{d}-30)$ ! for geometric imperfection

$\mathrm{k}, 8,37.5 * 12,31 * 12+9+1 / 2$

$k, 9,37.5 * 12,31 * 12+9+1 / 2+30$

imperfection

$\mathrm{k}, 10,37.5 * 12,45 * 12$

$\mathrm{k}, 11,0.0,(31+15) * 12+9+1 / 2$

$\mathrm{k}, 12,40 * 12,31 * 12+9+1 / 2$

$1,1,2$

* rep $, 9,1,1$

loca $, 11,1,0,31 * 12+9+1 / 2,0,1,3 / 8$

$1,11,12$

lfil, $3,4,12$

$\varpi 1 \mathrm{csl}, 9,10$

N 1 fil, $12,14,3 * 12+8+3 / 8$

thet $\mathrm{a}=180$

ldel, 13,15,2

csys, defa

lsel, all

* get, L14length, LINE, 14 , LENG

lsel, , line, , 14

!lesi, all, 24

ldiv, all, ,L14length/24 ! 2'Approx, Divides to nearest integer value

lsel, , line, 13,26

lsel, a, line, 10

lcomb, all

lsel, , line, 1 lesi,all, 4

lsel, , line, 2

lesi, all, , $20,-2$

lsel, , line, 3

lesi, all, , $6,1 / 1.5$

lsel, , line, , 11

lesi,all, 4

lsel, , line, , 4

lesi,all, 4

lsel, , line, 5

lesi, all, , 15, 3

lsel, , line, 6

lesi, all, , 10, -1.5

lsel, , line, 7

lesi,all, , 12,1/2.8

lsel, , line, , 8

lesi,all, , 8, 1/1.4

lsel, , line, 12

lesi,all, 4

lsel, , line, 9

lesi,all, 4

lsel, , line,, 30

lesi,all, 4

lsel, , line,, 29

lesi,all, , $5,1 / 1.4$

lsel, , line,, 28

lesi, all, $, 3,1 / 1.5$

lsel, , line, 27

lesi,all, ,2,1/1.4

lsel, , line, , 10

lesi, all, 24

lsel, all

arot, all, , , , , 1, 11, theta, 45

lsel, , line, , 737, 1397, 15

lesiz,all, , 1

element

lsel, , line, , 738, 1398, 15 
lsel, a, line, ,739,1399, 15

lsel, a, line, , 740,1400,15

lsel, a, line, , 741,1401, 15

lsel,a, line, , 742,1402,15

lsel,a, line, , 743,1403,15

lsel,a, line, , 744,1404,15

lsel, a, line, , 745,1405, 15

lsel,a, line, , 746,1406,15

lsel,a, line, , 747,1407, 15

lsel,a, line, , 748,1408,15

lsel, a, line, , 749,1409, 15

lsel, a, line, ,750,1410,15

lsel, a, line, , 751,1411, 15

lesiz,all, 1

degree angle

lsel, all

loca $, 12,1,0,0,0,-90$

csys, 12

!***Specify the width (w) and deviation (h) of the dent

$w=7 \star 12$

$h=1$

$\mathrm{p} i=22 / 7$

impang $=\mathrm{w} / \mathrm{pi} / 450 * 180$

$\star$ do $, i, 1,3,1$

ksel, , loc, z, 382

$, r, 1 \circ \mathrm{C}, \mathrm{y},(180-((i-1) * 4))$

*get, $a, \mathrm{kp}, 0$, num, max

*get, $x 1, \mathrm{kp}, \mathrm{a}, \mathrm{loc}, \mathrm{x}$

*get, $\mathrm{Y} 1, \mathrm{kp}, \mathrm{a}, \mathrm{loc}, \mathrm{Y}$

*get, $\mathrm{z} 1, \mathrm{kp}, \mathrm{a}, \mathrm{loc}, \mathrm{z}$

kmodif, $a, x 1+(h *(1-(i-1) * 4 /$ impang $)), y 1, z 1$

*enddo esiz, 24

amesh, all

save

!***Thickness assignments

nsel, $10 \mathrm{c}, \mathrm{x}, 0,24$

nsel, r, loc, $\mathrm{z}, 0$

esln, 1

emod, all, real, 101

nsel, , loc, x, 24, 401.0625

nsel, r, loc, z, 0

esln

emod, all, real, 102

nsel, , loc, x, $401.0625,438$

nsel, r, loc, z, 0

esln, 1

emod, all, real, 103

nsel, $100, x, 438,450$

nsel, r, loc, z, 0,12

esln, 1

emod, all, real, 104

nsel, , loc, z, 12, 36.875

esln, 1

emod, all, real, 103

nsel, , loc, z, 36.875, 144.875

esin

emod, all, real, 105

nsel, , loc, z, 144.875, 237.375

esln, 1

emod, all, real, 106 
nsel, , loc, z, $237.375,468.5$

esln, 1

emod, all, real, 102

nsel, , loc, z, $468.5,561.5$

nsel, u, loc, $x, 0,72$

esln

emod, all, real, 107

nsel, , loc, z, $468.5,561.5$

nsel, R, loc, $x, 0,72$

esln, 1

emod, all, real, 102

allsel

!LOOP FOR SELECTING ONLY j-BOLT NODES to apply displacements later(mainly above IMPEREECTION) Csys, 5

$\varpi$ nsel, NONE

$\infty \quad \star$ do, i, $0,180.0,4.0$

nsel, a, loc, y, i

*enddo

nsel, r, loc, z, 459,600

nsel, u, loc, x, 350,371

nsel, u, loc, $x, 372,392$

nsel, u, loc, $x, 394,412$

nsel, u, loc, x, 414,432

$\mathrm{cm}$, Dome JBNodes, NODE

!STORE THE NODE NUMBERS OF SELECTED NODES FOR BEAM ELEMENT CREATION LATER

*get, NoJB, Node, , COUNT

*dim, JBnodeNum, array, NoJB, 1

*do, i, 1, NoJB

*get, number, NODE, , NUM, MIN
JBnodeNum $(i, 1)=$ number

nsel, $u$, NODE, , number

*enddo

! Generate additional set of nodes for Beam elements

cmsel, , DomeJBNodes, NODE

LOCAL, $15,2,0,381.5,0,0,0,0,0.375$

NROTat, ALL

ngen, 2,20000, all, , , 1

16107 nodes already defined.

may be numbered between 20000,20000+16107

lCreate Beam elements

et, 11, BEAM188

$\mathrm{MP}, \mathrm{EX}, 11,100 \mathrm{e} 6$

MP, NUXY, 11, 0.25

SECTYPE, 11, BEAM, CSOLID, JBSEC

SECDATA, 0.25,1,1! Bolt Radius

!SECPLOT, 11

CSYS

N, 99999,500,500 !Dummy node for beam orientations TYPE, 11

MAT, 11

SECNUM, 11

*do, $i, 1$, NoJB

E, JBnodeNum (i, 1), JBnodeNum (i, 1) +20000, 99999

*enddo

allsel

csys, 12 ! same as csys 5

nrot, all 
! pressure loads

Pvac $=-0$

Inch $w \cdot g$.

$\mathrm{pp} 1=\mathrm{Pvac} / 12 * 62.4 / 144$

psi

hw= WasteHt

$\mathrm{SpG}=1.70$

! Internal Pressure,

! internal pressure,

den $\mathrm{S}=\mathrm{SpG}^{*} 62.4 / 1728$ ! Waste Density,

$1 \mathrm{~b} / \mathrm{in}^{\wedge} 3$

pp2=pp1+hw*wdens! Pressure at bottom of tank, psi

!primary liner - below waste level

nsel, s, loc, z, 0, hw

esln, s, 1, all

sfgrad, pres, 12, z, hw, (pp1-pp2)/hw

sf, all, pres, ppl

$$
\text { alls }
$$

sfgrad,pres ! reset pressure gradient

/rep

nsel, s, loc, z, 0

$\mathrm{d}, \mathrm{all}, \mathrm{uz}, 0.0$

d, all, $\operatorname{rot} x, 0$

d, all, roty, 0

d, all, rotz, 0

nsel, all

nsel, , loc, $y, 0$

nsel, a, loc, y, 180

! symmetry

nsel, u, node, , 99999

$\mathrm{d}, \mathrm{all}, \mathrm{uy}, 0.0$

$d$, all, $\operatorname{rot} x, 0$

d, all, rotz, 0

nsel, all nsel, , loc, $x, 0$

? Fix center node

nsel, r, loc, $z, 0$

d, all, ux, 0.0

nsel, all

nsel, , 1oc, z, 459.17,600

Fix rotations of the

Tank Dome + beam end nodes

d, all, rot $x, 0$

d,all, roty, 0

d, all, rotz, 0

nsel, all

allsel

finish

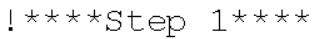

/ sol

anty, stat

nlgeom, on

nsub, 10,100,10

!outr,all, all

save

solv

!****Step 2*****

nsel, node, 20000,40000 ! Only J-bolt top end nodes

d, all, uz, DomeDisp

nsel, all

allsel

nsub, 10,100,10

!outr, all, all

save

solv

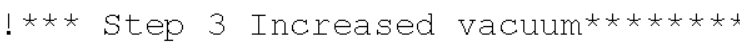




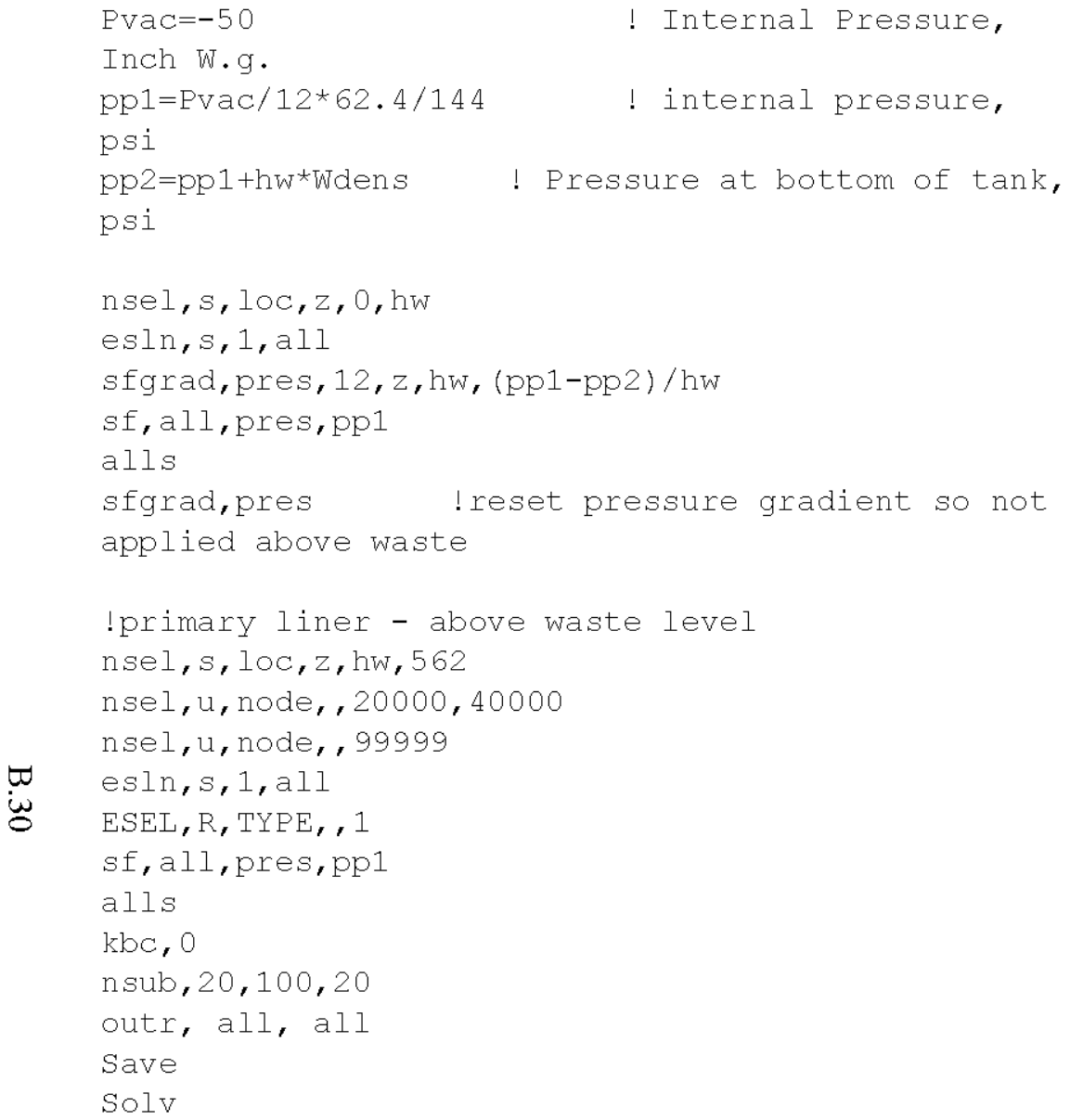

\section{B.5 AP Post Processing Files}

\section{B.5.1 File Name: Post_MerStress_wall elem hist.inp}

! Mac for meridional stress history at selected thickness (elem)

/ POST1

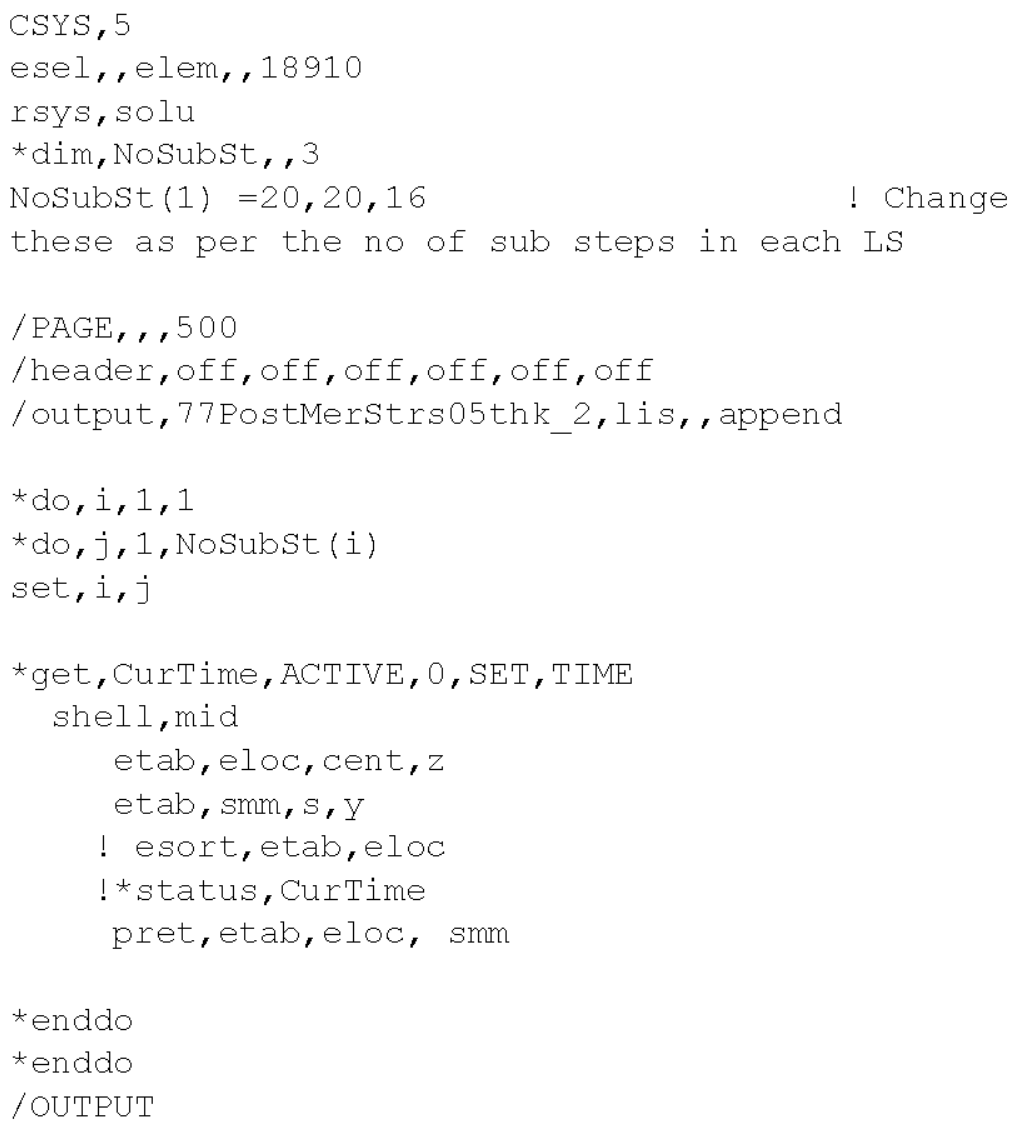

\section{B.5.2 File Name: Post_KnuckSurfStress_elem hist.inp}

! Macro for monitoring surface stresses in the knuckle region under increased compression (away from imperfection)

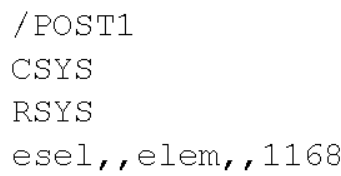


*dim, Nosubst, , 3

NoSubst (1) $=40,20,16$

! Change

these as per the no of sub steps in each LS

$/ \mathrm{PAGE}$, , , 500

/header, off, off, off, off, off, off

/ output, 41PostSurfStrsKnuckle, lis, , append

$\star$ do, $i, 1,1$

*do, $j, 1$, NoSubst (i)

set, $i, j$

* get, CurTime, ACTIVE, 0, SET, TIME

shell, top

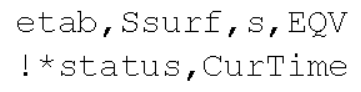

*enddo

$\forall \quad *$ enddo

$\omega \quad$ /OUTPUT

B.5.3 File Name: 1Post-UXVsLS Nodehist.inp

! MACRO FOR MONITORING DISPLACEMENT(UX IN RSYS 5)

IN THE ESTIMATION OF BUCKLING COLLAPSE LOAD AS PER ASME COLLAPSE METHOD.

/post1

set, last

set, prev

*get, LS3NoSS, ACTIVE, 0, SET, SBST

*dim, NoSubst,, 3

NoSubst $(1)=1,1$, LS3NOSS

! Change

these as per the no of sub steps in each LS

vtot=NoSubst (1) +NoSubst (2) +NoSubst (3)

*dim, UXminHist, , vtot, 2 row $=0$

rsys, 5

$\star$ do $, i, 1,3$

! only

3 rd LS for ASME Collapse line

*do, j, 1, NoSubst (i)

*if, i, eq, 1, then $j=10$

stored for Load steps 1,2

*endif

*if, i, eq, 2, then

$j=10$

*endif

set, $i, j$

*get, Lstime, ACTIVE, 0, SET, TIME

$\mathrm{Xdi}$ spMin=UX (18964)

row $=$ row +1

UXminHist (row, 1) =Lstime

UXminHist (row, 2) =XdispMin

*enddo

*enddo

allsel

cisys

rsys

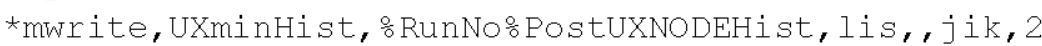
, row

(F15.9, 5x, F15.9 
RPP-RPT-28967, Rev. 2

\title{
Appendix C
}

\begin{abstract}
ANSYS Input and Post Processing Files for Thermal, Hydrostatic and Dead Load Stress Contributions to Primary Meridional Stress
\end{abstract}




\section{Appendix C}

\section{ANSYS Input and Post Processing Files for Thermal, Hydrostatic and Dead Load Stress Contributions to Primary Meridional Stress}

\section{C.1 Introduction}

This appendix includes ANSYS model input files for estimating the individual contributions of various load components (gravity, surface loads, hydrostatic loads and differential thermal expansion loads) to the total meridional stress in the tank wall. The first input file (AY350tr222WH422.inp) is for transient thermal analysis to obtain the temperature distribution in the tank and surrounding soil. To run this thermal model a data base file (dsttherm.db) needs to be resumed that contains the 2-D geometry of the tank (AY or AP). This data base file defines the thermal and operating loads model and it can be generated using the files in Appendix G of Rinker et al. (2004). The temperatures obtained from this analysis are applied to the analogous ANSYS structural model. The thermal transient calculations are run for one year to get the maximum and steady state thermal stress components using the second input file (set_sliceb.inp). This thermal stress model also uses a database file to define the structural model of the AY or AP tanks. This database file is built using 26 macro files, most of which are the same as the files used in the Thermal and Operating Load Analysis (TOLA, Rinker et al. 2004). The only files that were modified for the current analysis are included in this appendix. These input files are applicable to both the AY and AP tank specifications as the resumed database file will contain the corresponding tank structural data (wall thicknesses for the AP tank).

The post processing files to generate nodal temperatures and to estimate the meridional stress components are also included.

Appendix C Contents:

\begin{tabular}{|l|c|}
\hline \multicolumn{1}{|c|}{ Section } & Title / File Name \\
\hline C.1 & Introduction \\
\hline C.2 & ANSYS Thermal Model Input Files \\
\hline C. 2.1 & AY350tr222WH422.inp \\
\hline C.3 .1 & Thermal Mode1 Post Processing Files \\
\hline C. 3.1 & ExtractTempData.inp \\
\hline C.4 & One Year Runs Input Files \\
\hline C. 4.1 & set_materials.mac \\
\hline C. 4.2 & Pet_sliceb.inp \\
\hline C.5 5 Processing Files for One Year Runs \\
\hline C.5.1 & Post-PriMerdCycle.inp \\
\hline
\end{tabular}




\section{C.2 ANSYS Thermal Model Input Files}

\section{C.2.1 File Name: AY350tr222WH422.inp}

! Ansys thermal model for estimating temperatures to map on to the structural model later

! The transient temperatures and times should be changed according to the maximum waste

temperatures

/fil, dsttherm

resu

/fil,AY350tr222wh422

Parameter $\mathrm{s}========$

WasteHt $=422$

Waste $\mathrm{Tmp}=350$

CrustTmp $=222$

i

/prep 7

!*** Clean up 2D model

csys

vsel, all

vcle, all

asel, , loc, z

asel, inve

acle, all

cmse, , area prim

a, area secon

lsla

lsel, inve

lcle, all

alls

etde, 1,32

$, 60,61$ mpde, all, 1, 40

, al1,61,199

tode, all, all

ddel, all

cpde, 1, 3000

nrot, all

CSYs, 5

ngen, 2, 0, all, , , 180

CSYs

et, 45,32

$, 46,32$

! esel, , type, , 41, 44

! ensy, 0,0, all

!** Assign primary liner Reals

esel, type, 45

$\mathrm{cm}, \mathrm{epl}$, elem

* get, nple, elem, , count

*do, i, 1, nple

nsle

*if, i, 1t, 200, then

ncurn $=$ node $(0,800,0)$

*else

ncurn $=$ node $(600,800,0)$

tendif

nsel, , , ncurn

esln

esel, r, type, , 45

,$u$, , ecurn

nsle

*get, ecurn, elem, , num, max

*if, i, lt, 24 , then

tpl $=0.5-60 * 0.001$ ! $1 / 2-60$ years corrosion

*elseif, i, 1t, 173, then

$\mathrm{tpl}=0.375-60 * 0.001$

*elseif,i, lt, 200, then

$\mathrm{tpl}=0.5-60 * 0.001$ ! $1 / 2-60$ years corrosion 
*elseif,i,1t,260, then

tpl $=0.75-60 * 0.001 ! 3 / 4-60$ years corrosion

*elseif,i,lt, 286, then

tpl $=0.875-60 * 0.001$

*elseif,i, lt, 404 , then

$\mathrm{tpl}=0.375-60 * 0.001$

! $7 / 8$ - 60 years corrosion

! $3 / 8$ - 60 years corrosion

telse

$\mathrm{tpl}=1.00-60 * 0.001$

*endif

r, $600+i, \operatorname{abs}(2 * \mathrm{p} i * \operatorname{centrx}(\operatorname{ecurn}) * \operatorname{tpl})$

emod, all, real, $600+i$

cmse, , epl

esel, u, , ecurn

$\mathrm{cm}$, epl, elem

*enddo

!** Assign secondary liner Reals

esel, , type, , 46

$\mathrm{cm}$, esl, elem

$\Omega \quad{ }^{\prime}$ get, slen, elem, count

*do, i, 1, slen

nsle

ncurn $=$ node $(600,800,0)$

nsel, , , ncurn

esln

esel, r, type, 46

,$u$, , ecurn

nsle

*get, ecurn, elem, , num, max

*if, i, lt, 42, then

$\mathrm{tpl}=0.25$

*else

tpl $=0.375$

*endif

$r, 1100+i, \operatorname{abs}\left(2 * \mathrm{p} i{ }^{*} \operatorname{centrx}(e c u r n) * \operatorname{tpl}\right)$

emod, all, real, $1100+i$

cmse, , esl esel, u, , ecurn

$\mathrm{cm}, \mathrm{esl}, \mathrm{elem}$

*enddo

alls

!*** Element types (for reference)

!** et, $41,55,1,1$ ! Concrete wall \& dome

!** et, $42,55,, 1$ ! Slab

!** et, 43,55, , 1 ! Insulating concrete

!** et, 44,55, , 1 !Soil

!** et, 45,3 ! Primary liner - change to 32 after defining contact

!** et, 46,3 ! Secondary liner - change to 32 after defining contact

!** et, 47,32 !Link32s define rad at end

of insul concrete

!** et, 48,50

superelements

!** et, 50,169

!** et, $51,171,2$

!** et, $52,14,8$

!** et, 53,32

for Rad HT

! Radiation matrix

! Target

! Contact

! Thermal spring

!Waste Surface Elements

! Model Units

! Length = inches

! Time $=$ days

! Temp $=\mathrm{F}$ ( $\mathrm{R}=\mathrm{F}+460$ for radiation $)$

! Heat $=$ Btu

! Mass $=1 \mathrm{bm}$

!*** Material properties - check units!!!

!*** Ken Johnson input same props as TEMPEST model used in DST TOLA analysis

$\mathrm{mp}, \mathrm{kxx}, 41,0.9 / 12 * 24 \quad$ ! Concrete, Btu/day-in-F

mp, c, 41,0.235 ! Spec Heat, Btu/lb-F

mp, dens, $41,145 / 1728$ 
$m p, k x x, 43,0.13 / 12 * 24$

! *Insulating

concrete, Btu/day-in-F

mp, c, $43,0.2$

mp, dens, $43,50 / 1728$

$\mathrm{mp}, \mathrm{kxx}, 44,0.5 / 12 * 24$

$m p, c, 44,0.2$

mp, dens, $44,110 / 1728$

$m p, k x x, 45,24.2 / 12 * 24$

F

$m p, c, 45,0.114$

mp, dens, $45,490 / 1728$

! define contact thermal conductivity

$r, 81$

rmore,

rmore, 1 e8 thermal film coefficient

$r, 82$

rmore,

rmore, 1 e8 ! thermal film coefficient

$r, 83$

rmore,

rmore, 1 e8 !hermal film coefficient

$r, 84$

rmore,

rmore, 1 e8 !hermal film coefficient

$r, 85$

rmore,

rmore, 1 e8 ! thermal film coefficient

save

! WASTE HEIGHT, INCHES

hwaste=WasteHt !Waste Height, inches

! Generate waste surface Layer
! dummy material properties for meshing the link32 surface elements

$m p, k x x, 53,24.2 / 12 * 24 \quad$ ! ${ }^{*}$ Steel, Btu/day-in-

$m p, c, 53,0.001$

mp, dens, 53,10/1728

et, 53,32

! generate nodes starting at 30,001

numstr, node, 30001

numstr, $\mathrm{kp}, 4001$

numstr, line, 2101

$\mathrm{k}, \mathrm{,}, \mathrm{\text {hwaste }}$

$\mathrm{k}, 450$, hwaste

$1,4001,4002$

type, 53

mat 53

! Crust Layer

esize, 450/60

lmesh, 2101

! commands to show element coord system

! / psy, esys, 1

! eplo

esel, s, type,, 53

cm, Wastesurf, elem ! element surface set for radiation viewfactor calcs

! Modify contact elements to enforce bonded contact

keyopt, $51,12,5$ !bonded always

! make extra surface links to close off bottom of annulus for radiation

! extra link32s at end of insul concr !***

et, 47,32!*link32, end of insul concrete close annulus rad vol 
$m p, k x x, 47,0.2 / 12 * 24$

! *insul concrete

properties

$m p, c, 47,0.2$

mp, dens, 47,50/1728

$r, 47,1$

! *dummy cross-section area

type, 47

real, 47

e,20679,20820

e, 20820,20821

e,20821,20819

e,20819,20824

e,20824,20825

e, 20825,20260

!*** define primary tank radiating surface in annulus

esel, s, type, , 45

nsle

nsel, r, loc, $x, 432.9,451$

i

nsel, r, loc, $\mathrm{Y},-1,459.2$

esln

esel, r, type, 45

esel, u, elem, ,43934,43935

$\mathrm{cm}$, prim an, elem

!*** flip element orientations for rad to

secondary liner

ensym, 0, 0,43934,43935

ensym, 0, , 0,43944,44047

ensym, 0, 0,44059

!*** define secondary tank radiating surface in annulus

esel, s, type, 46

nsle

nsel, r, loc, $x, 432.9,481$

nsel, u, loc, y, 459.13,600

esln esel, r, type, 46

esel, u, elem, ,44344, 44348

cm, second_an, elem

!*** flip element orientations for rad to primary

$\tan k$

ensym, 0, 0,44360

ensym, $0,0,44367$

ensym, $0,0,44374$

ensym, 0, 0,44453,44459

ensym, $0,0,44499$

ensym, 0, 0,44505,44507

ensym, 0, , 0,44511,44515

fini

!*** Generate Radiation Matrix with AUX12

/ aus12

!***select elements and nodes for annulus

radiation primary $\langle-\rangle$ secondary

cmse, s, prim an

cmse, a, second an

esel, a, type, $\overline{4} 7$ ! add link32s at end of

insul concr

nsle

geom, 1,50 ! 2D geom, 50 divisions (same as

VM1 4 7)

! Increase Emissivities to approx convection

emis, $45,0.70 * 1.4$

emis, $46,0.70 * 1.4$

emis, $47,0.70 * 1.4$

! stef, $0.119 e-10$

! Stefan-Boltzmann

constant (Btu/hr-in^2-R^4)

stef, $(0.119 e-10) * 24$

! Stefan-Boltzmann

constant (Btu/day-in^2-R^4)

vtype, 0, ! Use Hidden-line method to calc

viewfactors.

mprint, 1 ! Print view factor matrix 
write, view an, sub ! write view factor matrix for the annulus radiation.

fini

/prep 7

allsel

!*** define primary tank dome space radiating surface

esel, s, type, 45

nsle

ensym, 0, 0, 44141,44174

ensym, 0, 0,44081,44084

ensym,0, 0,prim_an !flip back prim elems at

annulus for rad in dome

nsel, r, loc, y, hwaste, 1000

! keep only elements

above waste height, hwaste

$\mathrm{cm}$, dome nodes, node! dome-nodes for applying

surface convection

esln

esel, r, type, 45

$\mathrm{cm}$, dome_inside, elem

fini

!*** Generate Radiation Matrix for Dome Space with AUX 12

$1 \operatorname{aux} 12$

!***select elements and nodes for Waste to Dome radiation

cmse, s, dome inside

cmse, a, wastesurf

nsle

geom, 1,50 ! 2D geom, 50 divisions (same as

VM14 7)

! Increase Emissivities to approx convection

emis,53,0.90*1.4 !Waste surf emissivity

emis, $45,0.70 * 1.4$ ! tank surf emissivity stef, $0.119 e-10$

! Stefan-Boltzmann

constant (Btu/hr-in^2-R^4)

! stef, $0.119 e-10$

! Stefan-Boltzmann

constant (Btu/hr-in^2-R^4)

stef, $(0.119 e-10) * 24$ ! Stefan-Boltzmann

constant (Btu/day-in^2-R^4)mprint,1 ! Print

view factor matrix

write, view domein, sub ! write view factor matrix for the annulus radiation.

fini

/prep7

allsel

Toffst, 460

! $\mathrm{T}$ offset $=460$ for deg-F system

tunif, 50

uniform initial temperature

! Fixed Temperature Boundary Conditions

nsel, loc, $y,-2109,-2108$ ! Bottom soil

boundary

nsel,a, loc,y,676.09,676.11 ! top soil boundary nsel, $a, 10 \mathrm{c}, \mathrm{x}, 2880$ ! remote $\mathrm{x}$-boundary of

soil

d, all, temp, 50

allsel

! Delete link32 elements generated only to create radiation matrices

esel,s, type, 47 ! link32s at end of insul

concr

edele, all

allsel

!** substitute the superelement matrix

et, $48,50,1$

radiation superelement

type, 48

se, view an, sub

! rad superelem for

annulus radiation 
se, view domein, sub

! rad superelem for dome

space radiation

!*** contact elements complaining about no mat 62 !*** fix by defining dummy density of matl 62

mp, dens, 62,1

$1 \mathrm{l}=\mathrm{=}=\mathrm{=}=\mathrm{=}=\mathrm{=}=\mathrm{=}=\mathrm{=}=\mathrm{=}=\mathrm{=}=\mathrm{=}=\mathrm{=}=\mathrm{=}=\mathrm{=}=\mathrm{=}=\mathrm{=}=\mathrm{=}=\mathrm{=}=\mathrm{=}=\mathrm{=}=\mathrm{=}=\mathrm{=}=\mathrm{=}=\mathrm{=}=\mathrm{=}$

/PREP7

CSYS

ESEL, , TYPE, , 45

NSLE

! TOP CORNER- PRIMARY WALL TO DOME

lOCAL, $210,1,450-44.375,424.26$

NSEL, R, LOC, X, 44.375

NGEN, 2,20000,ALL, , , 0.5

$\Omega \quad \mathrm{CM}$, PrDmCorn, NODE

! WALL

NSLE

CSYS

NSEL, R, NODE, , 22038, 22140

NGEN, 2, 20000, ALL, , , -0.5

CM, PrimWal, NODE

! BOTTOM CORNER-PRIMARY WALL TO SLAB

NSLE

1OCAL, $211,1,450-12,12$

NSEL, R, LOC, $X, 12$

NGEN, 2, 20000, ALL, , , - 0.5

$\mathrm{CM}, \mathrm{PrSlCOrn}, \mathrm{NODE}$

! BOTTOM CORNER-SECONDARY WALL TO SLAB

ESEL, , TYPE , 46

NSLE

1OCAL $, 212,1,468,-8.125+12$
NSEL, R, LOC, $\mathrm{X}, 12$

NSEL, U, LOC, Y, 0, 270,270

! REMOVE 270,270 LATER

NGEN , 2,20000, ALL, , ,-0.5

CM, SCSlCorn, NODE

CMSE, A, PrDmCorn

CMSE, A, Primwal

CMSE, A, PrSlCorn

NPLOT

ET, 54, PLANE5 5

$\mathrm{MP}, \mathrm{KXX}, 54,0$

MP, DENS , 54,0

TYPE, 54

$\mathrm{E}, 42190,22190,21386,41386$

$\mathrm{E}, 41386,21386,22152,42152$

$\mathrm{E}, 42152,22152,22153,42153$

* REP $, 10,1,1,1,1$

$\mathrm{E}, 42162,22162,22037,42037$

$\mathrm{E}, 42037,22037,22140,42140$

$\mathrm{E}, 42140,22140,22139,42139$

$\star \mathrm{REP}, 102,-1,-1,-1,-1$

$\mathrm{E}, 42038,22038,21925,41925$

$\mathrm{E}, 41925,21925,21926,41926$

$\star \operatorname{REP}, 7,1,1,1,1$

$\mathrm{E}, 41932,21932,21780,41780$

! DUMMY ELEMENTS FOR SECONDARY WALL-SLAB CORNER

$\mathrm{E}, 42778,22778,22777,42777$

* REPEAT, $4,-1,-1,-1,-1$

ESEL, , TYPE, , 54

NSLE

CM, DumyNods, NODE 
*GET, DumNdCt, NODE, 0 , COUNT

$\star \mathrm{DO}, \mathrm{J}, 1$, DumNdCt $/ 2$

CMSEL, , DumyNods, NODE

*GET, DumNNUM, NODE, 0 , NUM, MIN

NSEL, , NODE, , DumNNUM, DumNNUM+20000, 20000

CP, NEXT, TEMP, ALI

CMSEL, , DumyNods, NODE

NSEL, U, NODE, , DuMNNUM

CM, DumyNods, NODE

$\star$ ENDDO

CSYS

NROT, ALL

! NSEL, , , , 4465

! NGEN, 2,40000, ALL, , , 0.5

! TYPE, 54

! E, $44465,4465,22778,42778$

! NSEL, , , , 4465, 44465,40000

! CP , NEXT, TEMP , ALL

ALLSEL

/titl, Radiation + Convection, waste

Height $=\frac{\circ}{\circ}$ WasteHto", Bulk Tmax $=\frac{\circ}{0}$ WasteTmpof , Crust tmax $=\circ$ Crust Tmp $\% \mathrm{~F}$

! Thermal Transient definition

/ solu

antype, trans

kbc, 0 ! ramped load

autots, on

deltim, 0.010

!*** Thermal load - Initial ramp

!*** Time in days
Twaste $=125$

Tsurf $=125$

fhrt $=7.5 / 24$

time, fhrt

! LS 2 in DST TOLA

analysis

!*ᄎ夫

!**t Fast heat to $125 \mathrm{~F}$

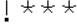

!*** fix temp of prim liner nodes up to waste

level

esel,s,type, 45 ! Prim tank elements

nsle

nsel, r, loc, y, -9, hwaste !apply waste temp up to

top of waste layer

cm, wbulktemp, node ! create node - temp applied for

transient

d, all, temp, Twaste

allsel

cmse, s, Wastesurf ! select waste surf elements

nsle ! select nodes of waste surf elements

cm, wsurftemp, node

d, all, temp, Tsurf

allsel

! nsub, 3,10,2

deltim,0.01,0.001,10.0 ! starting, minimum, and maximum time steps

!*** Add Radiation to Dome based on Waste Surface temperature

solv

time, $3+$ fhrt

! LS 3

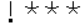

!** First of four steps to $350 \mathrm{~F}$

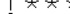

Twaste $=181.3$

Tsurf $=181$.

!** bulk waste temperature 
cmse, s, wbulktemp

d, all, temp, Twaste

!** Surface WAste Temperature

cmse, s, wsurftemp

d, all, temp, Tsurf

allsel

! nsub,20,100,6 ! number of substeps, max num, min num

solv

time, 6+fhrt

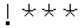

!*** Second of four steps to $350 \mathrm{~F}$

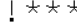

Twaste $=237.5$

Tsurf $=222$

!** bulk waste temperature

cmse, s, wbulktemp

d, all, temp, Twaste

!** Surface WAste Temperature

cmse, s, wsurftemp

d, all, temp, Tsurf

allsel

! nsub, 20,100,6

solv

time, $9+$ fhrt

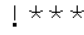

!*** Third of four steps to $350 \mathrm{~F}$

$! \star \star \star ~$

Twaste $=293.8$

Tsurf $=222$

!** bulk waste temperature

cmse, s, wbulktemp

d, all, temp, Twaste

!** Surface WAste Temperature

cmse, s, wsurftemp d, all, temp, Tsurf

allsel

! nsub, 20,100,6

solv

time, $11.25+$ fhrt

! LS 6

!***

!*** Four of four steps to $350 \mathrm{~F}$

$! * \star \star$

Twaste $=350$

Tsurf $=222$

!** bulk waste temperature

cmse, s, wbulktemp

d, all, temp, Twaste

!** Surface WAste Temperature

cmse, s, wsurftemp

d, all, temp, Tsurf

allsel

! nsub, 20,100,6

$\mathrm{solv}$

time, 30

! LS 7 SS step in

Tempest

!*** $350 \mathrm{~F}$

Twaste $=350$

Tsurf $=222$

!** bulk waste temperature

cmse, s, wbulktemp

d, all, temp, Twaste

!** Surface WAste Temperature

cmse, s, wsurftemp

d, all, temp, Tsurf

allsel

! nsub, 20,100,6

solv 
time, 10000

! LS 8

SS1

step in Tempest

!*** $350 \mathrm{~F}$

Twaste $=350$

Tsurf $=222$

match Tempest temperature

!** bulk waste temperature

cmse, s, wbulktemp

d, all, temp, Twaste

!** Surface WAste Temperature

cmse, s, wsurftemp

d, all, temp, Tsurf

allsel

delt, $0.1,0.01,2000$

solv

ILS 9 Hold for 1

year step in TOLA - Not included

! Ls 10

Material Property change step

- Not included

time, 10003

! LS 11

!*** Cool to ambient

$! * \star \star$

!*** First of four steps to $125 \mathrm{~F}$

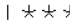

Twaste $=293.8$

Tsurf $=222$

!** bulk waste temperature

cmse, s, wbulktemp

d, all, temp, Twaste

!** Surface WAste Temperature

cmse, s, wsurftemp

d, all, temp, Tsurf

allsel deltim, 0.01,0.001,10.0

Same as statring ..continues to end

solv

time, 10006

! LS 12

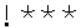

!*t* Second of four steps to $125 \mathrm{~F}$

!*夫

Twaste $=237.5$

Tsurf $=222$

!** bulk waste temperature

cmse, s, wbulktemp

d, all, temp, Twaste

!*t Surface WAste Temperature

cmse, s, wsurftemp

d, all, temp, Tsurf

allsel

! nsub, 15,200,5

SOLV

time, 10009

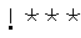

!*** Third of four steps to $125 \mathrm{~F}$

$! * \star$

Twaste $=181.3$

Tsurf $=181.3$

!** bulk waste temperature

cmse, s, wbulktemp

d, all, temp, Twaste

!** Surface WAste Temperature

cmse, s, wsurftemp

d, all, temp, Tsurf

allsel

!nsub, 15,200,5

solv

time, 10011.25

! LS 14 
$! * \star \star$

!*** Four of four steps to $125 \mathrm{~F}$

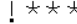

Twaste $=125$

Tsurf $=125$

!** bulk waste temperature

cmse, s, wbulktemp

d, all, temp, Twaste

!** Surface WAste Temperature

cmse, s, wsurftemp

d, all, temp, Tsurf

allsel

!nsub, 15,200, 5

solv

time, 10011.5625

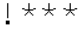

!*** Fast cool down to $50 \mathrm{~F}$

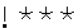

$\Omega \quad$ Twaste $=50$

= Tsurf=50

!** bulk waste temperature

cmse, s, wbulktemp

d, all, temp, Twaste

!** Surface WAste Temperature

cmse, s, wsurftemp

d, all, temp, Tsurf

allsel

! nsub, 7,100, 3

! deltim, $0.003125,0.3125 / 500,0.3125 / 10$

$\mathrm{s} O \mathrm{lV}$

time, 10012.5625

$! * \star \star$

!** Tank cool down transient to $50 \mathrm{~F}$

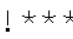

Twaste $=50$

Tsurf $=50$

!** bulk waste temperature

cmse, s, wbulktemp

d, all, temp, Twaste

!** Surface WAste Temperature

cmse, s, wsurftemp

d, all, temp, Tsurf

allsel

!nsub, 5, 100,2

solv

time, 10014

! LS 17

!*** Uniform $50 \mathrm{~F}$

\section{C.3.1 File Name: ExtractTempData.inp}

! Macro to generate temperatures files at various load steps that will be later mapped on to the structural model

! Needs node files of front and back sections of the 3-D DST tank model used in TOLA.

/post1

CSYS

*get, totLS, ACTIVE, 0, SET, NSET 


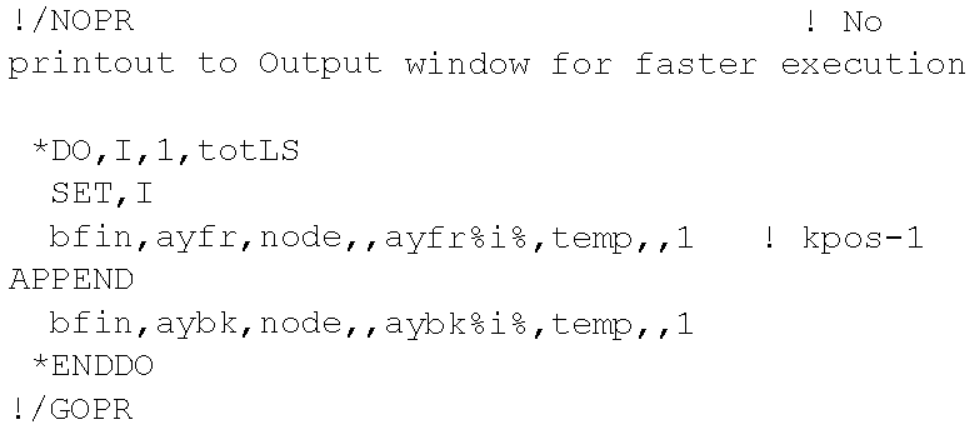

\section{C.4 One Year Runs Input Files}

* Refer to TOLA report for other macro files the were not modified

\section{C.4.1 File Name: set_materials.mac}

!****

!specify all material properties

/prep 7

![1] steel (for liner, jbolts, studs, anchors, bearing plates) steel_alpx $=$ steel_alpx*1e-6 6 in $/$ in $/ \mathrm{F}$ steel_dens $=$ steel_gamma/1728 !lb/in`3

mpte

mpte, $1,50,70,100,125,150,175$

mpte, $7,200,225,250,275,300,325$

mpte, 13,350

mpda,ex,mat_liner, 1,29.5e6,29.5e6,29.34e6,29.20e6,29.07e6,28.93e mpda,ex,mat_liner, 7,28.8e6,28.68e6,28.55e6,28.43e6,28.3e6,28.15e 6

mpda,ex,mat liner, $13,28.0 \mathrm{e} 6$

mp,dens,mat_liner,steel_dens

mp,prxy,mat_liner,steel_prxy

mpda,alpx,mat liner, $1,5.73 \mathrm{e}-6,5.73 \mathrm{e}-6,5.73 \mathrm{e}-6,5.82 \mathrm{e}-6,5.91 \mathrm{e}-6,6.0 \mathrm{e}-$ 6

mpda,alpx,mat_liner,7,6.09e-6,6.18e-6,6.27e-6,6.35e-6,6.43e6,6.51e-6

mpda,alpx,mat_liner,13,6.59e-6

tb,biso,mat_liner

tbdata,1,steel_yield,steel_tan*steel_ex

![2] structural concrete

conc_alpx $=$ conc_alpx* $* 1 \mathrm{e}-6$

conc_dens $=$ conc_gamma $/ 1728$

$\operatorname{lin} / \mathrm{in} / \mathrm{F}$

$\mathrm{mp}$, ex, mat conc, $5.083 \mathrm{e} 6$

mp,dens,mat_conc,conc_dens

mp,prxy,mat_conc,conc_prxy

mp,alpx,mat_conc,conc_alpx

![3] rebar

rebar_alpx $=$ rebar_alpx*1e-6

rebar_dens $=$ rebar_gamma/ 1728

mp,ex,mat_rebar,rebar_ex

! $1 \mathrm{~b} / \mathrm{in}^{\wedge} 3$

mp,dens,mat_rebar,rebar_dens

mp,prxy,mat_rebar,rebar_prxy

mp,alpx,mat_rebar,rebar_alpx

tb,miso,mat_rebar, 4,4

tbte, 100,1

tbpt, 2069e-6,60000

,3770e-6,67331

,,9555e-6,73035 $\operatorname{lin} /$ in $/ F$

!lb-sec ${ }^{\wedge} 2 /$ in $^{\wedge}$ 
,20129e-6,76967

tbte, 200,2

tbpt,,1896e-6,54978

,3770e-6,61720

$, 9555 \mathrm{e}-6,66882$

,20129e-6,70582

tbte, 300,3

tbpt,,1896e-6,53304

,3770e-6,59850

,9555e-6,64831

,20129e-6,68453

tbte, 400,4

tbpt,,1780e-6,51630

,3770e-6,57979

,9555e-6,62780

,20129e-6,66325

$\because \quad$ ![4] insulating concrete

insul_alpx=insul_alpx* $1 \mathrm{e}-6$

insul_dens $=$ insul_gamma $/ 1728$

!in $/ \mathrm{in} / \mathrm{F}$

mp,ex,mat_insul,insul_ex

mp,dens,mat_insul,insul_dens

mp,prxy,mat_insul,insul_prxy

mp,alpx,mat_insul,insul_alpx

!tb,concr,mat_insul

!tbda,1,insul_open,insul_closed,insul_crack,-1

![5] soil

! These soil properties for material 5 are overwritten later

!soil_ex $=575000$

!soil_prxy $=0.1$

!Poisson ratio

!soil_alpx $=0$

!thermal expansion coefficient !soil_gamma $=125$

!soil_cohesion $=0$

small number) [psi]

!soil_friction $=35.4$

!soil_dilat $=35.4$

!soil_alpx $=$ soil_alpx*1e-6

!soil_dens $=$ soil_gamma $/ 1728$

!unit weight $\left[1 \mathrm{bf} / \mathrm{ft}^{\wedge} 3\right]$

!drucker-prager constant (assume

!internal friction angle [deg]

!mp,ex,mat_soil,soil_ex

!mp,dens,mat_soil,soil_dens

!mp,prxy,mat_soil,soil_prxy

!mp,alpx,mat_soil,soil_alpx

!tb,dp,mat_soil

!tbdata,1,soil_cohesion,soil_friction,soil_dilat

!set mat_haunch materials equal to mat_conc material

vsel,s,mat,,mat_haunch

eslv

emodif,all,mat,mat_conc

mpdele,all,mat_haunch

!set slab rebar material properties

vsel,s,mat,mat rebar

eslv

nsle

nsel,r,loc,y,-999,-8.125

esln, 1

esel,r,mat,,mat_rebar

mat_srebar $=6$

emodif,all,mat,mat_srebar

![6] slab rebar

srebar_alpx $=$ srebar_alpx* $1 \mathrm{e}-6 \quad$ !in $/ \mathrm{in} / \mathrm{F}$

srebar_dens $=$ srebar_gamma $/ 1728 \quad ! 1 \mathrm{~b} / \mathrm{in}^{\wedge} 3$

$[\mathrm{me} / \mathrm{F}]$ 
mp,ex,mat_srebar,srebar_ex

mp,dens,mat_srebar,srebar_dens mp,prxy,mat_srebar,srebar_prxy mp,alpx,mat_srebar,srebar_alpx tb,miso,mat_srebar, 4,4

tbte, 100,1

tbpt, $1379 \mathrm{e}-6,40000$

$, 2513 \mathrm{e}-6,44887$

$, 6370 \mathrm{e}-6,48690$

$, 13419 \mathrm{e}-6,51311$

tbte, 200,2

tbpt, $1264 \mathrm{e}-6,36652$

$, 2513 \mathrm{e}-6,41147$

$, 6370 \mathrm{e}-6,44588$

$, 13419 \mathrm{e}-6,47055$

tbte, 300,3

tbpt, 1225e-6,35536

$, 2513 \mathrm{e}-6,39900$

$, 6370 \mathrm{e}-6,43221$

$,, 13419 \mathrm{e}-6,45636$

tbte, 400,4

tbpt, 1187e-6,34420

$, 2513 \mathrm{e}-6,38653$

$, 6370 \mathrm{e}-6,41853$

$, 13419 \mathrm{e}-6,44217$

allsel

esel,s,mat, 3

esel,a,mat, 6

emodif,all,mat,2

allsel

C.4.2 Filename: set_sliceb.inp
! Input file for running one year thermalstructural model with temperatures mapped from the ansys transient thermal model.

! Requires the database file (set_slice_0.db), - emat and .esav files generated by running set_slice_a.inp.

! Requires . temp files generated from ansys

transient thermal model.

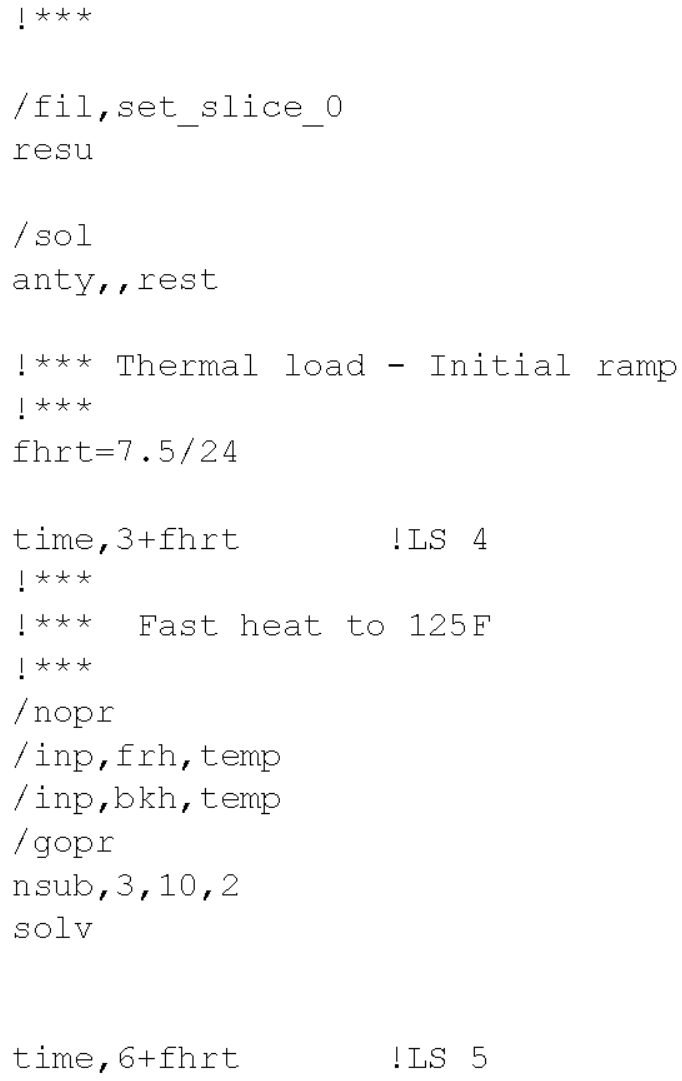

time, $6+f h r t$ 


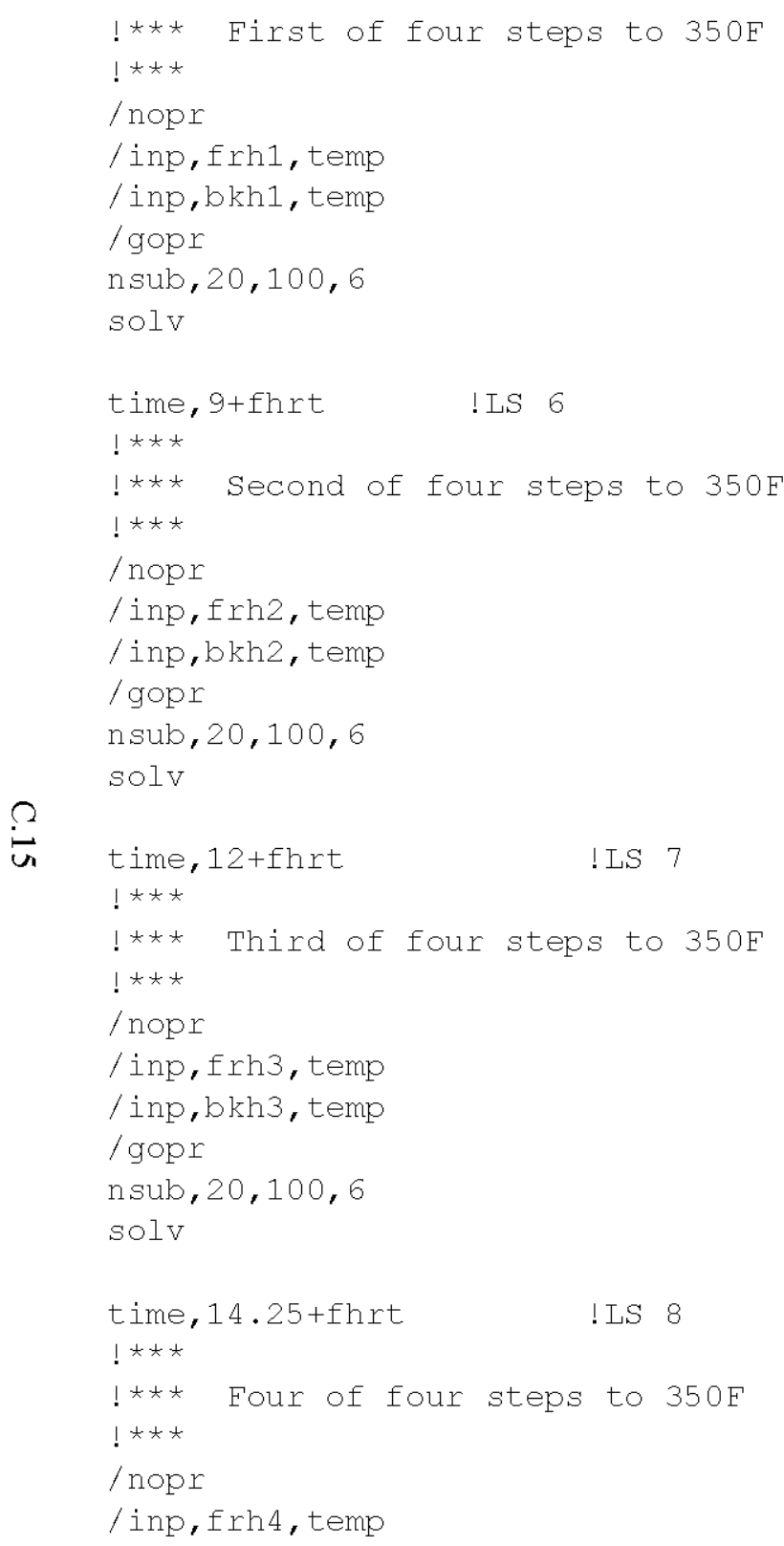

time,353!LS 11

!*** Hold for 1 Year

nsub, $300,10000,10$

save

solv

\section{C.5 Post Processing Files for One Year Runs}

\section{C.5.1 File Name: Post-PriMerdCycle.inp}

! Macro for meridional stresses in the primary liner wall section in all load steps 
/fil, set_slice_o

resume

/ POST1

CSYS

esel, , real, $, 50,54$

esel, a, real, $, 57,58$

nsle

nsel, r, loc, x, $-450.001,-450$

esln

rsys, solu

/PAGE, , , 500

loutput, PristrsMrMidTcAllLs, lis, , append

SET, FIRST

*GET, FirstLSno, ACTIVE, 0, SET, LSTP

SET, LAST

*GET, LastLSno, ACTIVE, 0, SET, LSTP
! *GET, totLS, ACTIVE, 0, SET, NSET

Total Number of Loadsteps

*do,j, Firstlsno, LastLsno

set, j

*get, CurTime, ACTIVE, 0, SET, TIME

shel, mid

etab, elocth, cent, y

etab, smm, s, y

esor, etab, elocth

*status, j

*status, CurTime

pret, etab, elocth, smm

*enddo

/OUTPUT
! Get the

Check This

a 
RPP-RPT-28967, Rev. 2

\section{Appendix D}

\section{Reviewer Comments and Discussion}




\section{Appendix D}

\section{Reviewer Comments and Discussion}

An independent review of the Double Shell Tanks (DST) Thermal and Operating Load (TOLA) and Seismic analyses was conducted by Dr. Robert P. Kennedy of RPK Structural Mechanics Consulting and Dr. Anestis S. Veletsos of Rice University. Their comments are reported below. Comment responses regarding the buckling analysis are found in the Executive Summary and Sections 5.6, 6.3, 6.4.1, 6.4.3, $7.1,7.2$, and 8.0 of the main report. 


\title{
Reviewer Comments
}

\author{
Additional Comments and Recommendations Concerning \\ Seismic Evaluation of Hanford Double-Shell Tanks \\ by \\ R.P. Kennedy and A.S. Veletsos \\ May 2006
}

\section{Introduction}

Our initial comments and recommendations regarding the seismic evaluation of the Hanford Double-Shell Tanks (DSTs) were presented in Ref. 1 based on our review of the studies reported through July 2005. Our present input refers to the additional studies conducted since then, and it is based on:

- Our review of Refs. 2 through 7; and

- The presentations and ensuing discussions at the Review Meeting of March 20 and 21, 2006, in which we participated to provide an independent oversight and comment on the adequacy and completeness of the approach being used.

Our views and recommendations are presented under the following six topic headings.

\section{Use of ANSYS for Soil-Structure Interaction Analyses}

The methodology used to evaluate the soil-structure interaction (SSI) effects for the DSTs is described in Ref. 2. It involves the use of the ANSYS computer program in which the analysis is implemented directly in the time domain. Unlike the more commonly used SASSI program which is limited to the analysis of linear, elastic systems, the ANSYS program can also be used to assess the effects of nonlinear, hysteretic actions.

Reference 2 presents the results of a number of comparative analyses implemented using both ANSYS and SASSI. The results obtained by the two approaches are in quite good agreement for system frequencies less than about $10 \mathrm{~Hz}$, but for the higher frequencies, the ANSYS predictions are generally higher than the SASSI. In as much as the natural frequencies of the tank-liquid systems that contribute materially to the desired responses are less than $10 \mathrm{~Hz}$, however, the conservative bias of the ANSYS results is of no practical consequence.

We, therefore, concur with the appropriateness and reliability of the ANSYS program to evaluate the SSI effects of the DSTs, and of the methodology described in Ref. 3. However, we do not concur that it was necessary to have performed the Ref. 3 analyses using ANSYS, but do respect an analyst's preference for and right to use any acceptable approach to a desired end.

The rationale for using ANSYS was to make it possible to account for the effects of potential sliding at the interface of the concrete vault and surrounding soil, and more importantly, the interface of the base of the primary tank and the insulating concrete basemat. Since these effects - as might have been 
anticipated by simple, exploratory analyses - did not prove to be of practical importance, the SSI analyses could have been performed using the SASSI or some other linear program.

Specifically, starting with a simplified, single-degree-of-freedom idealization of the waste-containing tank, the response of the tank-vault-soil system could have been evaluated using the SASSI program. The resulting response history of the concrete vault could then have been used as input to a refined model of the waste-containing tank, and its response determined either by ANSYS, making due provision for localized nonlinear actions, or by the DYTRAN program.

In the methodology described in Ref. 3, the waste-containing tank, concrete vault, and surrounding soil were analyzed as a single interacting system using the ANSYS program. As noted in Section 6 of Ref. 1, this one-step approach leads to a highly complex model that imposes practical limits to the degree of refinement with which critical regions of the system may be modeled. We believe that the two-step approach referred to above - even when implement exclusively with ANSYS - would have been preferable, as it would have permitted the use of more refined but simpler subsystems which might have led to improved solutions in regions of rapid pressure variation or high stress concentration.

Incidentally, its is not clear why, in the simplified analysis described in Section 7 of Ref. 2, the simplemass-spring systems used to model the waste-containing tank were attached to the concrete vault at 5 feet from its top. Considering that the tank is supported laterally at both the top and base of the concrete vault, the approximating system should have been similarly supported at the two levels. The appropriate approach is comparable to the one used in Section 8.1.1 of the same reference to evaluate the fluidstructure interaction effects.

\section{Fluid-Structure Interaction Analyses of Primary Tanks}

References 4 and 5 present the results of fluid-structure interaction (FSI) analyses for the primary tank using the ANSYS and Dytran program, respectively. Solutions for waste heights of both 424 or 422 inches and 460 inches are presented. The results of the two approaches for each of the two waste levels considered are discussed separately in the following subsections.

3.1 ANSYS Results for 424-inch Waste Level. With the exception noted in the following, the solutions for both the rigid and flexible tanks reported in Ref. 4 are in reasonable agreement with the corresponding theoretical solutions. The exception refers mainly to the surface sloshing action of the waste. The ANSYS model severely underpredicts this action; it leads to a maximum slosh-height of only 8 inches, while the corresponding theoretical value is 23.7 inches. This underprediction also adversely affects the accuracy of the hydrodynamic pressures in a shallow region around the top of the primary tank, as these effects are dominated by the sloshing action of the waste.

There are also differences between the theoretical and ANSYS solutions of the impulsive components of response, but these are generally limited to about 13 percent, the ANSYS results being consistently higher than the theoretical.

It is extremely important in our view to understand the reasons for these differences, especially the severe underprediction of the surface slosh-height. Parts of these differences may well be due to differences in the damping values used in the two approaches. 
Considering first the impulsive effects, it should be noted that the theoretical solutions for the horizontally excited flexible tank presented in Appendix B of Ref. 4 are for a fundamental impulsive modal damping of 4 percent critical. By contrast, the corresponding damping determined from the decay rate of the free vibrational phase of the impulsive response of the ANSYS solution shown in Fig. 5-3 of Ref. 4 is 2.7 percent critical. The larger damping in the theoretical solution will naturally reduce the response, but the reduction may partly be offset by differences in the natural frequencies of the models used in the two solutions.

Whereas the fundamental natural frequency of the impulsive mode in the theoretical solution presented in Appendix B of Ref. 4 is $7.0 \mathrm{~Hz}$, that of the ANSYS model was determined to be about $7.5 \mathrm{~Hz}$. The response spectrum in Fig. 2-22 of Ref. 4 shows that the spectral pseudo-acceleration and hence the system response at $7.0 \mathrm{~Hz}$ is indeed higher than at $7.5 \mathrm{~Hz}$. As a result, the effect of the difference in frequencies is opposite to that of the difference in damping, and the combined effect is expected to be a reduced level of impulsive response and improved agreement between the theoretical predictions and those arrived at by the ANSYS program.

Regarding the convective components of response, it should be noted that whereas the theoretical solution in Appendix B of Ref. 4 is based on a damping value of 0.5 percent critical for the fundamental convective mode, the corresponding damping determined from the free vibrational phase of the response of the ANSYS model in Fig. 5-2 of Ref. 4 is 17 percent of critical. The severe underprediction of the slosh height in the ANSYS solution is clearly due, at least in part, to the higher damping of the ANSYS model.

An additional factor that may contribute to the underestimation of the sloshing action may be the extent to which the waste in ANSYS is modeled as an incompressible, practically inviscid liquid. Additional studies are needed to determine whether the ANSYS code can indeed accurately predict the convective, sloshing action of the waste.

To address this issue, it is recommended that the ANSYS analysis for the horizontally excited flexible tank with the 424-inch waste height be repeated using the following values for the coefficients $\alpha$ and $\beta$ in the expression for the Rayleigh-form of damping.

$$
\alpha=0.00930 \text { and } \beta=0.00169
$$

These values correspond to a damping of 0.5 percent critical for the fundamental convective mode of $0.184 \mathrm{~Hz}$, and of 4.0 percent critical for the fundamental impulsive mode of $7.5 \mathrm{~Hz}$. The resulting solution should, of course, be compared with the corresponding theoretical solution.

It would also be desirable to assess the sensitivity of the ANSYS solutions to the approximations involved in the modeling of the waste as an incompressible, inviscid liquid. The relevant analyses should preferably be implemented for a flexible tank with an open top and a waste level of 424 inches.

Despite the fact that the ANSYS model for the tank considered in Ref. 4 does not adequately predict the slosh-height of the contained waste, it does predict reasonably the total hydrodynamic reactions and associated wall pressures, except, of course, for the pressures on a small segment of the tank wall around the waste surface that are dominated by the sloshing action. Shown in Table 1-2 and Fig. 5-11 of Ref. 4, 
the ANSYS results are overpredicted by less than 15 percent compared to their theoretical counterparts, the degree of overprediction being almost identical to that of the impulsive component of response referred to earlier.

For the tank with the 424-in waste height considered in this section, there is no indication from any of the solutions obtained that the sloshing waste will interact with the concrete dome at the top. It is relevant to note in this regard that the radial distribution of the maximum vertical surface displacements of the oscillating waste in the solution presented in Fig. 5-19 of Ref. 4 is in good agreement with the theoretical distribution for a tank with an open top. This is, of course, not true of the comparable solution shown in Fig. 4-18 of the same reference for a tank with the 460-in waste height.

In summary, the approach used in Ref. 4 to evaluate the seismic response of the primary tank with the 424-inch waste height is acceptable in our view. However, we still feel the need for the recommended additional studies to determine the reason or reasons for the severe overestimation of the surface sloshing action in the ANSYS solution.

3.2 Dytran Results for 422-inch Waste Level. For the indicated waste height, the results of the Dytran analyses for both rigid and flexible tanks are generally in very good agreement with the corresponding theoretical solutions, and better than those obtained with the ANSYS program. Satisfactory agreement was achieved for the fundamental natural frequencies of both the impulsive and convective modes, the maximum slosh-height, the total hydrodynamic reaction, as well as the magnitude and distribution of the associated wall pressures. The best agreement was achieved for Case $2 \mathrm{c}$ damping, which corresponds to a damping coefficient $\alpha=2$ and a damping factor of 1 percent critical for the fundamental convective mode

Apart from demonstrating the accuracy of the Dytran results for the conditions considered, the information presented also demonstrates the advantage of our preferred two-step approach that permits the use of different means for analyzing the components of the complex system involved in the present study.

3.3 Results for 460 -inch Waste Level. If the waste in the tanks is raised to the 460 -inch level, the concern is that the roof will partially suppress the surface sloshing action, reducing the portion of the waste mass that acts convectively and increasing the portion that acts impulsively. Considering that the natural frequencies of the impulsive modes are normally much higher than of the convective, the net effect of this constraining action would be an increase in the maximum values of the total hydrodynamic wall pressures and associated reactions over the values computed for the same tanks with an open top.

The portion of the waste mass being transformed from convective to impulsive, and the resulting increase in the overall response, clearly depend on the area of the roof being impacted by the sloshing waste. This area, in turn, depends on the available clearance between the waste surface and the roof. For a tank with a rigid, horizontal roof located immediately over the waste surface, the entire mass of the waste would respond in the impulsive mode, and the maximum values of the resulting hydrodynamic wall pressures and reactions would be significantly larger than those for an open-top tank.

Both the ANSYS and Dytran solutions for the maximum hydrodynamic pressures and reactions presented in Refs. 4 and 5 for the domed-tank with the 460 -inch waste height are similar to the corresponding theoretical solutions obtained for a tank with an open top. If correct, these results would indicate that, for 


\section{RPP-RPT-28967, Rev. 2}

the waste level considered, the dome does not materially constrain the sloshing action of the waste, and that either program may also be used to evaluate the response of the tank with the 460 -inch waste level. At this time, however, we are not convinced of the validity of this conclusion.

As already noted in Subsection 3.1, the ANSYS model does not accurately predict the surface sloshing action of the waste for an open-top tank. As a result, it is unlikely that it would accurately predict the constraining effect of the dome. It may be possible, however, to correct this deficiency by modifying the $\alpha$ and $\beta$ parameters in the expression for the Rayleigh-form of damping, as suggested in Subsection 3.1. If this adjustment does lead to an acceptable solution for the tank with the 424-inch waste level, our confidence in the appropriateness of the ANSYS model for the FSI analysis of the tank with the 460 -inch waste height will improve significantly.

Although of high accuracy for the tank with the 422-inch waste height, the results of the Dytran analyses for the 460-inch height also are suspect. In the solution displayed in Fig. 6-25 of Ref. 5, the waste around the tank periphery prior to the seismic excitation appears to have risen about 8 to 10 inches under gravity load. This obvious deficiency must be corrected before one can have confidence in the Dytran results. We suspect that a more refined mesh may be required to adequately model the waste in regions of potential interaction with the dome.

In summary, we feel that the effects of waste-roof interaction need to be further studied. In addition to the analyses with the indicated adjustments referred to above, it is recommended that

- Solutions be obtained for a flexible tank with a rigid, horizontal roof located at different distances above the waste surface; and that

- These solutions, along with those for the tank with the spherical dome, be compared with the predictions of the simple, approximate procedures described in Appendix D of Ref. 8 and in Ref. 9.

\section{Forces Resisted by J-Bolts}

The axial and shearing forces induced by the gravity and seismic loads at the interface of the concreteand underlying steel-domes are resisted mainly by the interconnecting J-bolts. Both sets of forces, as shown in Figs. 6-36 and 6-41 of Ref. 3, are largest along the outermost ring of bolts. The maximum values of the tensile forces, $T_{b}$, and of the corresponding shearing forces, $V_{b}$, were determined to be

$$
T_{b}=2.61 \mathrm{kips} / \mathrm{bolt} \text { and } V_{b}=4.54 \mathrm{kips} / \mathrm{bolt}
$$

for the 'Upper Bound Soil - Best Estimate Concrete' case, and

$$
T_{b}=2.35 \mathrm{kips} / \mathrm{bolt} \text { and } V_{b}=5.40 \mathrm{kips} / \mathrm{bolt}
$$

for the 'Best Estimate Soil - Fully Cracked Concrete' case. These values are lower than the Abnormal (operating plus seismic) Load Allowables of

$$
T_{b A}=3.93 \mathrm{kips} / \mathrm{bolt} \text { and } V_{b A}=11.71 \mathrm{kips} / \mathrm{bolt}
$$

presented in Table 6-4 of Ref. 7.

Neither of us is familiar with the basis of the acceptance criteria for the reported allowables. Furthermore, we do not have sufficient information regarding the Nelson Internally Threaded Studs used to 
attach the J-bolts to the steel tank so that we may assess the appropriateness of the indicated allowables. However, we do question the accuracy of the reported demands.

The maximum forces in the bolts were computed on the assumption that the shear at the interface of the concrete and steel domes is resisted partly by friction, and a value of 0.4 was used for the coefficient of friction which is, of course, appropriate only for a non-sliding surface.

While we do agree that the frictional resistance at the interface of the two domes should not be ignored, considering that the seismic action is likely to induce at least some slippage at this interface, we feel that a lower value for the coefficient of friction than the one used would be more appropriate.

To gain some insight into the sensitivity of the results to the uncertainties involved in this issue, it is recommended that the analysis for the 'Best Estimate Soil - Fully Cracked Concrete' case, which leads to the maximum shear for the outermost ring of bolts, be repeated using the zero and 0.2 values for the coefficient of friction. In our judgment, the use of the sliding friction coefficient of 0.2 would be appropriate for the final solution.

In the J-bolt evaluation presented in Chapter 6 of Ref. 7, it appears that the shear forces considered were only those induced by the axial force in the wall of the primary tank. The analysis does not appear to have provided for the effect of the horizontal hydrodynamic reaction at the top of the primary tank, which is expected to the dominant contributor to the shear forces in the outermost ring of J-bolts. Unless we have misinterpreted the reported solutions, this deficiency must be corrected.

\section{Buckling Evaluations}

Reference 7 presents the results of a series of evaluations for the buckling of the primary tanks due to the axial forces induced by static and seismic effects, concrete creep, differential thermal expansion, and internal vacuum. Because of our lack of detailed familiarity with several of the analyses presented, and the fact that some of the reported results are not described in sufficient detail for an independent check, we comment on only a few of the issues addressed in this reference.

5.1 Local Bowing and Global Buckling. We concur that, as indicated in Fig. 3-5 of Ref. 7, the upper knuckle region of the tank is the critical region for the development of localized, radial bowing in the tank wall due to the combined effects of axial forces and internal vacuum. We further concur with the adequacy of the ASME reduced stiffness approach for determining the critical or limiting levels of these effects.

In evaluating the contribution of the seismic effects, however, it should be kept in mind that the axial force in the tank wall is not uniformly distributed over its height. It is unduly conservative, therefore, to use the maximum value of the axial force, which for the top-supported tank considered occurs near midheight, in evaluating the bowing action near the upper knuckle. Instead, the value in the region of the upper knuckle should be used.

As indicated in Figs. 3-11 through 3-13 of Ref. 7, global buckling of the primary tank cannot be induced by differential axial deformation between the tank and concrete vault. The compressive axial forces due to such deformation are self-limiting as a result of the local bowing action referred to above. 
Furthermore, as long as the J-bolts interconnecting the steel and concrete domes do not fail, the tank can displace axially only by an amount equal to the axial displacement of the concrete vault.

5.2 Elephant-Foot Buckling. Plastic elephant-foot buckling can occur only near the lower knuckle of the tank where, in addition to the compressive axial stresses, the circumferential tensile stresses are large and radial expansion is constrained by the base plate. This is the only location for which such buckling needs to be checked. The appropriate axial force for this evaluation is, of course, the force near the lower knuckle. As indicated in connection with the estimation of the bowing action in the upper knuckle region, it is unduly conservative to use the maximum value of the axial force which, for the top-supported tanks considered, occurs near midheight. Conversely, the seismically induced hoop stresses should not be reduced by the inelastic factor $F_{\mu}=1.67$, because the hoop stresses continue to be in their elastic range at the onset of elephant-foot buckling.

We concur that elephant-foot buckling is not an issue for the tanks of interest. As long as the J-bolts interconnecting the steel and concrete domes do not fail and the tank is supported both laterally and vertically at the top and bottom, any localized bowing that may develop will relieve the axial force in the tank wall, and will prevent the bowing action from progressing to severe buckling.

The compressive axial force for the onset of elephant-foot buckling in Ref. 7 was determined by application of Eq. 7-1 in that reference, which is effectively an approximate, empirical equation. This force could also in that reference, have been determined by the method used to evaluate the localized bowing in the upper knuckle region. A relatively simple model, involving only the lower segment of the tank along with the appropriate conditions of support along its upper boundary, could have been used for this purpose.

\section{A Concluding Comment}

In the seismic analyses of the Hanford DSTs conducted so far - as in all previous analyses of wastecontaining tanks that we are aware of - the waste was effectively modeled as a homogeneous, incompressible, practically inviscid liquid. As already noted in our earlier review (Ref. 1), there are fundamental uncertainties in this idealization, and it would be highly desirable to assess their effect on critical tank responses.

To this end, it was recommended that the ANSYS program be used to evaluate the response of a representative tank with the waste modeled more realistically as a deformable medium of low shearing resistance and finite energy dissipating capacity, and that a range of likely values be used for the latter properties. We conclude by repeating this recommendation, as the hydrodynamic effects for a tank storing a solid-like material may be materially larger than for a liquid-containing tank.

\section{References}

1. Kennedy, R.P. and A.S. Veletsos, Comments and Recommendations Concerning Seismic Evaluation of Hanford Double-Shell Tanks, Sept. 2005

2. Rinker, M.W., F.G. Abatt, B.G. Carpenter and C.A. Hendrix, Hanford Double-Shell Tank Thermal and Seismic Project-Establishment of Methodology for Time Domain Soil-Structure Interaction 


\section{RPP-RPT-28967, Rev. 2}

Analysis of a Hanford Double-Shell Tank, RPP-RPT-28964, Rev. 0, Pacific Northwest National Laboratory, Jan. 2006

3. Carpenter, B.G., C. Hendrix and F.G. Abatt, ANSYS Seismic Analysis of Hanford Double-Shell Primary Tank, M\&D-2008-004-CALC-001, Rev. 0A, Draft, M\&D Professional Services, Inc., Jan 2006

4. Rinker, M.W., B.G. Carpenter and F. G. Abatt, Hanford Thermal and Seismic Project-ANSYS Benchmark Analysis of Seismically Induced Fluid-Structure Interaction in a Hanford Double-Shell Primary Tank, RPP-RPT-28965, Rev. 0, Pacific Northwest National Laboratory, Jan 2006

5. Rinker, M.W. and F.G. Abatt, Hanford Thermal and Seismic Project-Dytran Analysis of Seismically Induced Fluid-Structure Interaction on a Hanford Double-Shell Primary Tank, RPP-RPT-28963, Rev. 0, Pacific Northwest National Laboratory, Jan. 2006

6. Rinker, M.W., et al., Hanford Double-Shell Tank Thermal and Seismic Project-Summary of Combined Thermal and Operating Loads with Seismic Analysis, RPP-RPT-xxxxx, Rev. 0, Jan. 2006

7. Johnson, K.I., et al., Hanford Double-Shell Tank Thermal and Seismic Project-Buckling Evaluation Methods and Results for the Primary Tanks, prepared for CH2M Hill Hanford Group, Feb. 2006

8. Bandyopadhyay, K. et al., Seismic Design and Evaluation Guidelines for the Department of Energy High-Level Waste Storage Tanks and Appurtenances, BNL 52361, Brookhaven National Laboratory, Upton, N.Y., Oct. 1995

9. Malhotra, P.K., Sloshing Loads in Liquid-Storage Tanks with Insufficient Freeboard, Earthquake Spectra, Vol. 23, No. 4, pp. 1185-1192, Nov. 2005. 
RPP-RPT-28967, Rev. 2

\section{Appendix E}

Independent Confirmation of PNNL's Use of N-284-1 Safety

Factors in Computing the Double Shell Primary Tank Allowable Vacuum Level Governed by Buckling 


\section{Appendix E}

\section{Independent Confirmation of PNNL's Use of N-284-1 Safety Factors in Computing the Double Shell Primary Tank Allowable Vacuum Level Governed by Buckling}

This appendix contains an independent review (conducted in October 2006) of the methods used to calculate the buckling loads on the double shell waste primary tanks. The review specifically confirms the correct calculation of the axial tank force, the unfactored vacuum limit at incipient buckling, and the application of the safety factors for the ASME Service Levels A, B, C, and D. 


\title{
Independent Confirmation of PNNL's Use of N-284-1 Safety Factors in Computing the Double Shell Primary Tank Allowable Vacuum Level Governed by Buckling
}

\author{
R.P. Kennedy \\ October 14, 2006
}

\section{Review Performed}

I have independently checked the vacuum load capacity calculations presented in Tables 7-1 through 7-3 of Ref. $1^{*}$ for the AY tank with 6-inch waste depth, and similar tables provided to me by PNNL for the AP tank with 12-inch waste depth. These are the minimum waste depths considered and thus control the reported vacuum load capacity of the AY and AP tanks. Furthermore, I confirmed that the use of zero waste depth would have resulted in negligible reduction in the reported vacuum load capacity.

I have confirmed that the unfactored limit vacuum reported in Table 7-2 and 7-3 of Ref. 1 for the AY tank with 6-inch waste depth and on similar tables for the AP tank with 12-inch waste depth have been computed in accordance with the vacuum capacity equations in Sections 3.1 and 3.2 of Ref. 1 . Therefore, these reported unfactored limit vacuums satisfy the nonlinear limit deformation approach of ASME and represent conservative estimates of the vacuum capacity of these tanks.

Next the safety factors shown in Table 7-3 of Ref. 1 have been applied to these unfactored limit vacuums to obtain the allowable vacuums for both local and global buckling. These safety factors have been defined in accordance with Section 1400 of ASME Code Case N-284-1 for Service Levels A, B, C, and $\mathrm{D}$ for both Local and Global buckling. The required $20 \%$ increase in the safety factors for Global buckling has been properly included.

The Governing Allowable Vacuum Levels reported in Table 7-4 of Ref. 1 have been computed using the appropriate safety factors defined in accordance with Section 1400 of ASME Code Case N-284-1.

The Governing Allowable Vacuum Levels are reported separately for when Operating Conditions are assigned to Service Level A \& B versus being assigned to Service Level C. Since I don't know how often these vacuum limits are approached during the service life, I have no comment on whether Operating Conditions should be assigned to Service Level A \& B or to Service level C.

The case where Seismic Loads are included are assigned to Service Level D. However, since these tanks cannot be taken out of service after a seismic event, it is debatable whether the Seismic Load case should be assigned to Service Level C or D. If the Seismic Load case had been assigned to Service Level C, the Governing Allowable Vacuum for the AY tanks would have been reduced to 6.15 -inch w.g. No reduction would occur for the Governing Allowable Vacuum for the AP tanks.

\footnotetext{
${ }^{*}$ Ref. 1: Johnson, K.I., et. al., Hanford Double-Shell Tank Thermal and Seismic Project-Buckling Evaluation Methods and Results for the Primary Tanks, PNNL, Feb. 2006
} 


\section{Conclusions}

The Safety factors have been appropriately defined in accordance with Section 1400 of ASME Code Case N-284-1 for the various Service Levels. The Allow able Vacuum Limits have been appropriately determined for the assigned Service Levels. It is open to some debate as to what is the appropriate Service Level that should be assigned to the various Load Cases. This assignment of Service Levels will affect the reported Governing Allowable Vacuum. It is outside of my review to review the assigned Service Levels. However, the reported Governing Allowable Vacuums have been correctly determined for the assigned Service Levels. 
RPP-RPT-28967, Rev. 2

\section{Appendix F}

\section{Buckling Resistance of the DST Primary Tanks Under} Internal Vacuum When in the Full Condition 


\section{Appendix F}

\section{Buckling Resistance of the DST Primary Tanks Under Internal Vacuum When in the Full Condition}

This appendix summarizes buckling evaluations from the body of this report (RPP-RPT-28967, Rev. 2) that address the resistance of the Hanford double-shell tank (DST) primary tanks to buckling when in the full condition. These results were compiled in response to a question by CH2M HILL staff regarding the potential for primary tank buckling to occur when the tank is full and being drawn down during waste treatment efforts.

Section 1 presents the background justification for using the ASME Code Case N-284-1 method for evaluating buckling of the primary tanks under combined axial compression and internal vacuum loads. Section 1 also presents information that was used to justify classifying the limit vacuum load as an ASME Service Level C emergency load condition for DST operations.

Section 2 presents the results of the buckling analysis for a range of waste heights from the minimum allowable waste height to the full tank condition. The increased waste height acts to stabilize the primary tank wall against buckling. The results in Section 2 show that the vacuum limits of the full tanks are more than a factor of two times the vacuum limits at the minimum waste height.

Section 3 summarizes the anchor bolt analyses for the bounding AY tank and the AP tank designs. These analyses were performed for the full tank conditions, and they showed that the anchor bolts were within allowable tensile and shear displacements for waste temperatures that exceed the current and future expected waste temperatures.

The conclusion from this review is that the buckling resistance of the DST primary tanks increases significantly with increased waste height and that the anchor bolts are equally able to withstand the increased vacuum load. 


\section{F.1 Justification for Using the ASME Code Case N-284-1 Method for Evaluating DST Primary Tank Buckling}

Buckling of the primary tank is of concern because of compressive stresses that occur in both the meridional and hoop directions. Meridional (axial) compression results from differential thermal expansion between the primary tank and the concrete over-structure, plus creep-down of the concrete structure over time. Hoop compression results from net vacuum loads in the tank. These loading conditions (displacement controlled in the meridional direction and load controlled in the hoop direction) are unique compared to the vacuum-induced stresses in typical free-standing storage tanks, and are a direct result of the unique design of the underground double-shell waste storage tanks.

The buckling evaluation method defined in Code Case N-284-1, Metal Containment Shell Buckling Design Methods, of the American Society of Mechanical Engineers (ASME) Boiler and Pressure Vessel Code, Section III, Division 1 (ASME 1995) has been used in previous evaluations of the DST primary tanks because it considers the interaction of independent levels of compressive stress in both the meridional and hoop directions. By comparison, the ASME Code Case N-530 method (ASME 1994) that is described in the Brookhaven report, BNL 52361, (Bandyopadhyay et al. 1997) only addresses buckling of thin-walled tanks loaded with hoop tension. The N-530 method is not applicable to tanks subjected to vacuum loads.

The N-284-1 method provides an acceptance criteria with respect to buckling instability for defining the allowable loads for a given tank design. The method is based on theoretical critical buckling loads (hoop and axial limit stresses) that are adjusted by knockdown factors to account for geometric imperfections, the height of the tank, the radius-to-thickness ratio, and material plasticity. The intent of these calculations is to accurately estimate the actual bifurcation buckling load for a specific tank geometry. These loads are then reduced by safety factors (specified for four different service levels) to set the allowable combination of axial compressive load and tank vacuum. The bifurcation buckling solutions and knockdown factors used in N-284-1 are for simplified geometries that are intended to conservatively apply to typical storage tank geometries. This section reviews the analytical basis for N-284-1 and compares the solutions with finite element models that include the specific geometric features of the DST primary tanks.

Although the DST designs vary somewhat between tank farms, the primary tanks typically consist of a 75 -ft-diameter by $34-\mathrm{ft}-\mathrm{high}$ cylindrical portion that is connected to a flat bottom through a 1-ft-radius lower knuckle (Figure F-1). The wall thickness of the tank cylinder is graduated to counteract the hydrostatic stress of the contained waste (see Table F-1). The tanks are capped by a shallow spherical dome that transitions to the cylindrical section through a radiused upper knuckle. The dome is attached to the concrete over-structures with anchor bolts that are imbedded in the concrete. The total height of the tank is approximately $46.8 \mathrm{ft}$.

The formulas presented in Section 1710 of ASME Code Case N-284-1 are based on the buckling of a constant thickness cylindrical shell with an unsupported length, L. The length, L, is defined between "lines of support that provide sufficient stiffness to act as bulkheads." In previous analyses, L has been defined as the vertical distance from the waste-free surface to the tangent point between the upper knuckle and the dome. The wall thickness used in the N-284-1 equations was then calculated as the weighted 


\section{RPP-RPT-28967, Rev. 2}

average over this length. However, the primary tank cylindrical shell does not have a constant wall thickness and it does not have clearly defined lines of support due to the upper and lower knuckles.

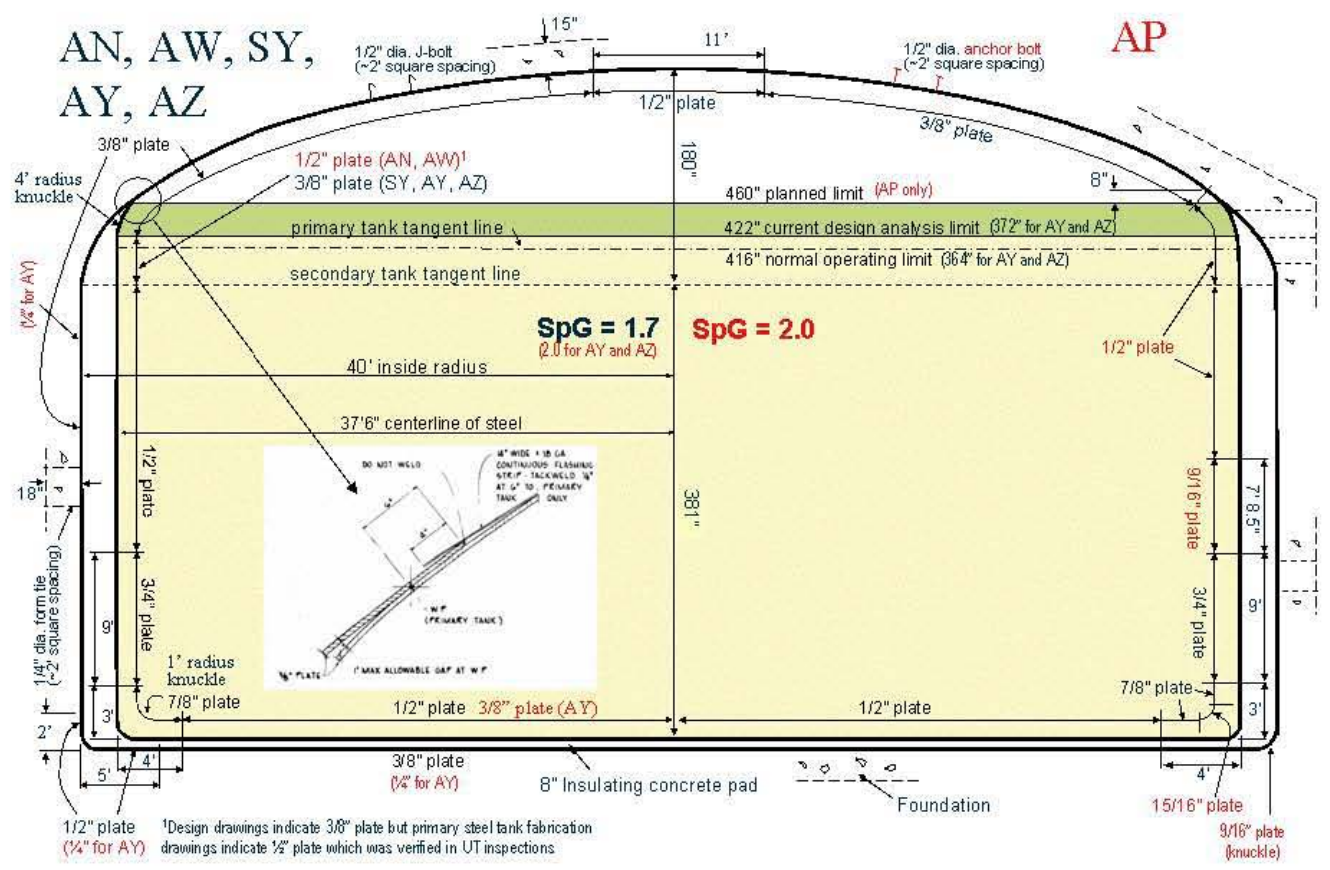

Figure F-1. Cross-Section View of the Hanford DST Primary Tank Designs

Table F-1. Summary of Design Data and Operating Limits for the DST Primary Tanks

\begin{tabular}{|c|c|c|c|c|}
\hline & \multicolumn{4}{|c|}{ The Diffe rent Tank Farm Designs } \\
\hline De sign Data and Operating Limits & AYIAZ & $\mathbf{S Y}$ & AWIAN & AP \\
\hline \multicolumn{5}{|l|}{ Primary Tank Thickness, inches } \\
\hline Upper Haunch & 0.375 & 0.375 & 0.375 & 0.5 \\
\hline Vertical Wall, Top & 0.375 & 0.375 & 0.5 & 0.5 \\
\hline Vertical Wall, Mid & 0.5 & 0.5 & 0.5 & 0.563 \\
\hline Vertical Wall, Bottom & 0.75 & 0.75 & 0.75 & 0.75 \\
\hline Lower Knuckle & 0.875 & 0.875 & 0.875 & 0.9375 \\
\hline & & & & \\
\hline Max Allowable Waste Temp., F & 350 & 250 & 350 & 210 \\
\hline Max Historical Waste Temp, F & $247 / 263$ & 155 & $135 / 150$ & 118 \\
\hline & & & & \\
\hline Yleld strength $Q$ Room lemp, Ksi & 32 & 35 & 50 & 45 \\
\hline Ultimate Strength, ksi & 60 & 65 & 70 & 70 \\
\hline Sm at Max. Allow Temp, ksi & 18.6 & 21 & 21.3 & 21.7 \\
\hline Sm at Max Hist Temp, ksi & 19.2 & 21.4 & 21.7 & 21.7 \\
\hline Specified Max. Waste Height, inch & 370 & 422 & 422 & 422 \\
\hline Maximum Specific Gravity & 1.77 & 1.7 & 1.7 & 2 \\
\hline
\end{tabular}

Therefore, the present buckling analysis used large displacement finite element analysis to predict the limiting vacuum load for the specific DST primary tank geometries under combined axial and vacuum loads. The detailed finite element analysis included models of the AY and the AP tanks. The AY results are also representative of the $\mathrm{AZ}, \mathrm{SY}, \mathrm{AW}$, and $\mathrm{AN}$ tanks because they have very similar wall thickness 
distributions (Table F-1). The current buckling evaluation method uses the ASME NB-3213.25 stiffness reduction method to conservatively estimate the vacuum and axial load limits on the primary tank. Comparison with N-284-1 calculations showed that the large displacement finite element method better accounts for the effect of the wall thickness variation on the limiting vacuum and axial loads. The finite element analysis also predicts that the tank deformations are small at the limit loads and they increase stably at loads beyond the limit loads. A large matrix of analyses was run that covers the expected range of axial forces and vacuum loads on the primary tanks.

\section{F.1.1 The N-284-1 Factors of Safety to Protect Against Buckling}

The buckling evaluation was conducted for four different service levels defined in ASME Code Case N-284-1. Each service level has required factors of safety for local and global buckling.

Factors of Safety

$$
\begin{aligned}
& \text { Level A }=\text { Normal operating conditions } \\
& \text { Level B }=\text { Upset conditions } \\
& \text { Level C }=\text { Emergency conditions } \\
& \text { Level D }=\text { Faulted conditions }
\end{aligned}
$$

\begin{tabular}{cc}
\multicolumn{2}{c}{ Factors of Safety } \\
\hline Local Buckling & Global Buckling \\
\hline 2.0 & 2.4 \\
2.0 & 2.4 \\
1.67 & 2.0 \\
1.34 & 1.61
\end{tabular}

Attachment B of Julyk (2002) makes the argument that axial compression in the tank cylinder will be relieved by local bowing of the wall before the onset of general instability. This position is justified since the meridional (axial) compressive stresses are displacement controlled as a result of differential thermal expansion and concrete creep induced loads on the primary tank. The load deflection response of the large displacement finite element models used in the current buckling analysis confirm that the axial stress in the tank is self-limited by the deformation of the primary tank geometry. This rationale leads to the following buckling criteria when combining the effects of axial and hoop loads on the allowable vacuum:

The allowable vacuum (net negative pressure) in the double shell tanks is controlled by the minimum of two cases,

A. Local Buckling (with $\underline{\text { local }}$ buckling safety factors imposed) evaluated considering the interaction of the net internal vacuum load $(\Delta \mathrm{p})$ combined with the meridional compressive stress $\left(\sigma_{\phi}\right)$.

B. General Instability (with global buckling safety factors imposed) evaluated considering the net internal vacuum load $(\Delta \mathrm{p})$ acting alone. No interaction with the meridional compressive stress shall be considered $\left(\sigma_{\phi}=0\right)$.

These criteria were used by Julyk (2002) and they are also used in the current buckling evaluation. It is further assumed that the design basis loads used in the thermal and operating loads analysis conservatively represent Service Levels A, B, and C. This is consistent with the loading conditions assumed by Julyk (2002). Service Level D, however, requires that the incremental seismic stresses be added to the design basis stresses for evaluating the faulted condition. 
RPP-RPT-28967, Rev. 2

\section{F.1.2 Justification for Classifying Limit Level Vacuum loads as a Service Level C Emergency Occurrence}

Julyk (2002) states that activation of the tank relief valves at the limiting vacuum load should be classified as an ASME Service Level C (emergency) load condition. Service Level C loads are defined by the ASME Code, Section III, Division 1, NB-3113 (ASME 2004a) as:

"The total number of postulated occurrences for all specified service conditions for which Level C Limits are specified shall not cause more than 25 stress cycles having an $\mathrm{S}_{\mathrm{a}}$ value greater than that for $10^{6}$ cycles from the applicable fatigue design curves of Figures I-9.0."

Evidence is provided below that the alternating stress associated with these vacuum cycles is well below the allowable, $\mathrm{S}_{\mathrm{a}}$, and also that the total number of vacuum cycles between normal operating vacuum and the limit vacuum are expected to be less than the maximum number of 25 cycles.

The AY primary tanks were constructed with A515 grade 60 steel, which has a minimum ultimate tensile strength, $\mathrm{S}_{\mathrm{ult}}$, of $60 \mathrm{ksi}$. The allowable alternating stress, $\mathrm{S}_{\mathrm{a}}$, at $10^{6}$ cycles is $12,500 \mathrm{psi}$ for carbon steels with $\mathrm{S}_{\text {ult }} \leq 80 \mathrm{ksi}$ (ASME, 2004b). The alternating stress due to tank vacuum is the hoop stress corresponding to the limiting vacuum load. The maximum alternating stresses for the different tank designs are:

$\begin{aligned} \mathrm{AY}, \mathrm{SY}, \mathrm{AN}, \mathrm{AY}, \mathrm{AZ:} & \text { Tank Radius }=450 \text { inch, Pressure }=-6 \text { inch w.g. }(-0.217 \mathrm{psi}) \\ & \text { Minimum Wall Thickness }=0.375-0.060=0.315 \mathrm{inch} \\ & \text { Hoop Stress }=\mathrm{pr} / \mathrm{t}=(-0.217)(450) / 0.315 \quad \underline{\mathrm{S}}_{\underline{a}}=310 \mathrm{psi}\end{aligned}$

AP:

$$
\begin{aligned}
& \text { Tank Radius }=450 \text { inch, Pressure }=-12 \text { inch w.g. }(-0.434 \mathrm{psi}) \\
& \text { Minimum Wall Thickness }=0.375-0.060=0.315 \text { inch } \\
& \text { Hoop Stress }=\text { pr } / \mathrm{t}=(-0.434)(450) / 0.315 \quad \underline{\mathrm{S}}_{\mathrm{a}}=620 \mathrm{psi}
\end{aligned}
$$

These alternating stresses are factors of 40 and 20 lower than the limiting value of 12,500 psi.

Tank farms operations staff recently reviewed all of the Occurrence Reports from 1990 to the present. This summary information will be released in the next revision of RPP-11413, Technical Basis for the Ventilation Requirements Contained in Tank Farm Operating Specifications Documents, authored by L. Payne. No incidents were found where the primary tank differential vacuum has exceeding the 6 inch w.g. maximum. There was a report of reaching a vacuum of 4 inch w.g. in the SY tank ventilation system, but the exhauster shut down on interlock. There was one incident in AW, but it was also limited to 4 inch w.g. or less. The incident that people remembered where a vacuum limit was exceeded was in the AN annulus system in 2005 (PER-2005-072). Note that this occurred in the annulus and not in the primary tank.

This review shows that there is no recorded evidence that the primary tank vacuum limits have ever been achieving during tank operation and even if they had the resulting cyclic stress would be insignificantly small. Therefore, it is very appropriate to define the occurrence of the maximum operating vacuum as an ASME Service Level C emergency load condition. 


\section{F.2 Evaluation of Tank Buckling for Variable Waste Height}

The buckling evaluations described in Chapter 7 of this report calculate the unfactored vacuum limits for the total range of waste heights. Figures F-2 through F-5 show the relationship of unfactored vacuum limit versus waste height for each of the different tank farms at the design limit loads of waste temperature, waste height, and specific gravity. These plots show that the unfactored vacuum limit increases dramatically as the waste height increases. The increased hydrostatic pressure provides increased hoop stability plus the associated Poisson's effect reduces the meridional compressive stress in the wall of the primary tank as the hoop stress increases. However, to establish conservative vacuum limits for the tanks, the unfactored limit vacuums at the minimum waste height were used when applying the N-284-1 safety factors in Chapter 7. Therefore, from a tank buckling standpoint Figures F-2 through F-5 show that the full tanks could withstand vacuum loads that are more than double the current limits based on the minimum waste height condition. Section 3 evaluates the anchor bolts and their ability to withstand a higher downward load due to increased vacuum.

\section{F.3 Evaluation of the Anchor Bolts for a Full Tank}

Detailed anchor bolt evaluations were performed for the AY bounding tank design (Deibler et al. 2008a) and for the AP tank design (Deibler et al. 2008b). The maximum waste heights of 422 inches for the AY tank and 460 inches for the AP tank designs were considered in these analyses. The purpose of the work was to establish the maximum allowable waste temperatures for combination with the operating and seismic loads. Table F-2 (Table 6-1 reproduced from the body of this report) lists these maximum load conditions and the resulting anchor bolt demand/capacity ratios. Note that a differential vacuum of 12 inches of water was conservatively assumed in both the AY and AP analyses.

The anchor bolt analyses show that the maximum anchor bolt shear and axial displacements occur at the outer-most ring of anchors. When the steady state thermal and operating loads are combined with the transient seismic loads, the maximum waste temperatures in Table F-2 give peak anchor bolt shear and axial displacements that approach the anchor bolt capacities. Note that the maximum temperatures in Table F-2 are above the current and future expected waste temperatures for the double shell tanks. In addition, waste temperature limits have been established for tank farm operations that ensure that these temperatures will not be exceeded during future waste processing and retrieval campaigns.

For the maximum temperatures listed in Table F-2, the demand/capacity ratios for anchor shear are 0.81 for the bounding AY tank and 0.99 for the AP tank design. The corresponding demand/capacity ratios for anchor tension are very low; 0.15 for the bounding tank and 0.04 for the AP tank. This is significant because the "peeling away" behavior postulated by the EH-22 panel would require that the anchor tensile allowables be exceeded. The detailed anchor analysis shows that the combined thermal, deadweight, vacuum, and seismic loads account for less than $1 / 6$ of the tensile capacity of the anchors. Therefore, the maximum load combinations will not exceed the specified allowable shear and tensile displacements for the anchor bolts. 
RPP-RPT-28967, Rev. 2

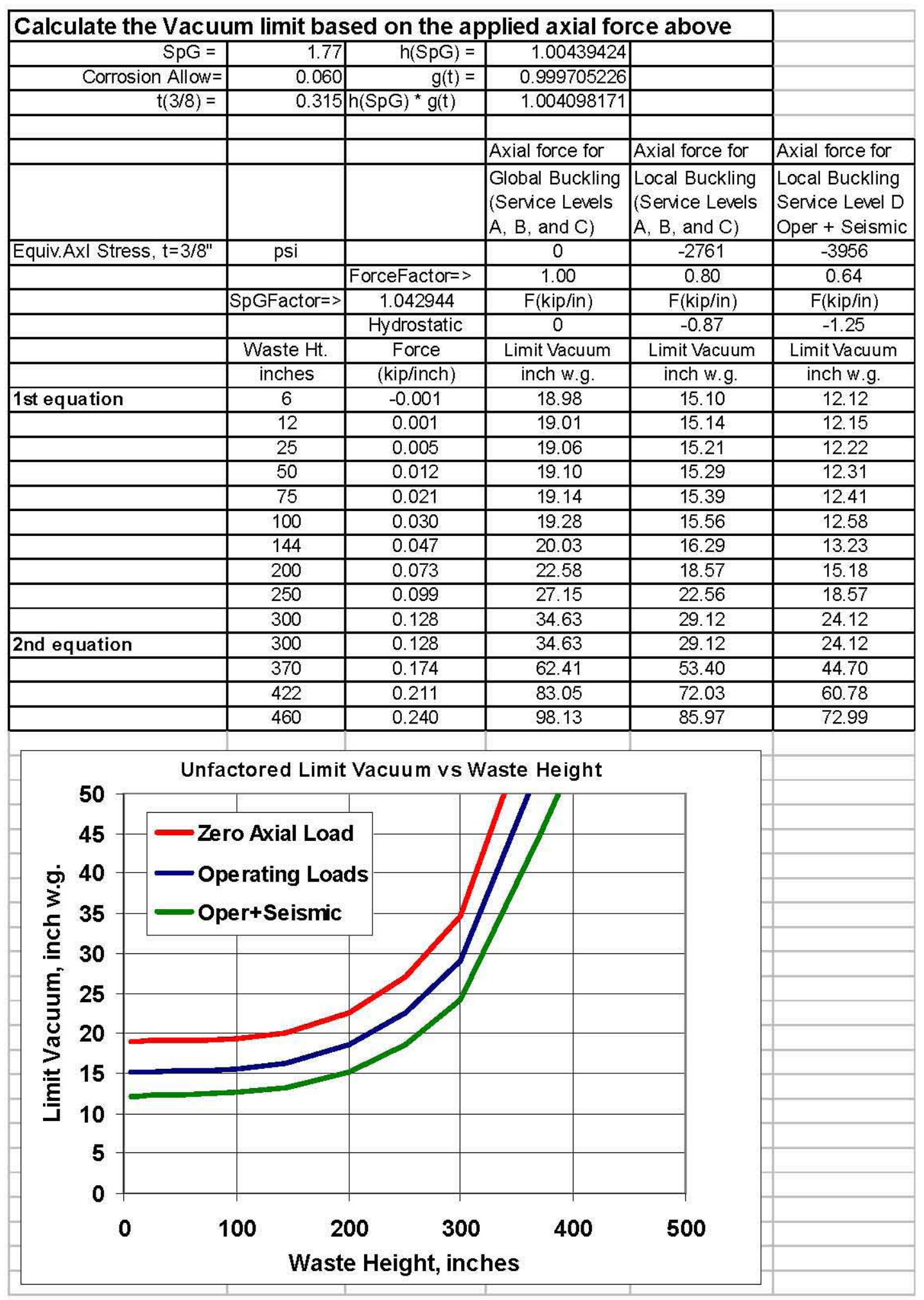

Figure F-2. Unfactored Buckling Limit Vacuum as a Function of Waste Height for the AY and AZ DSTs (Note: To calculate the factored vacuum limits, one must divide by the appropriate safety factors in the table of Section 2.1.) 
RPP-RPT-28967, Rev. 2

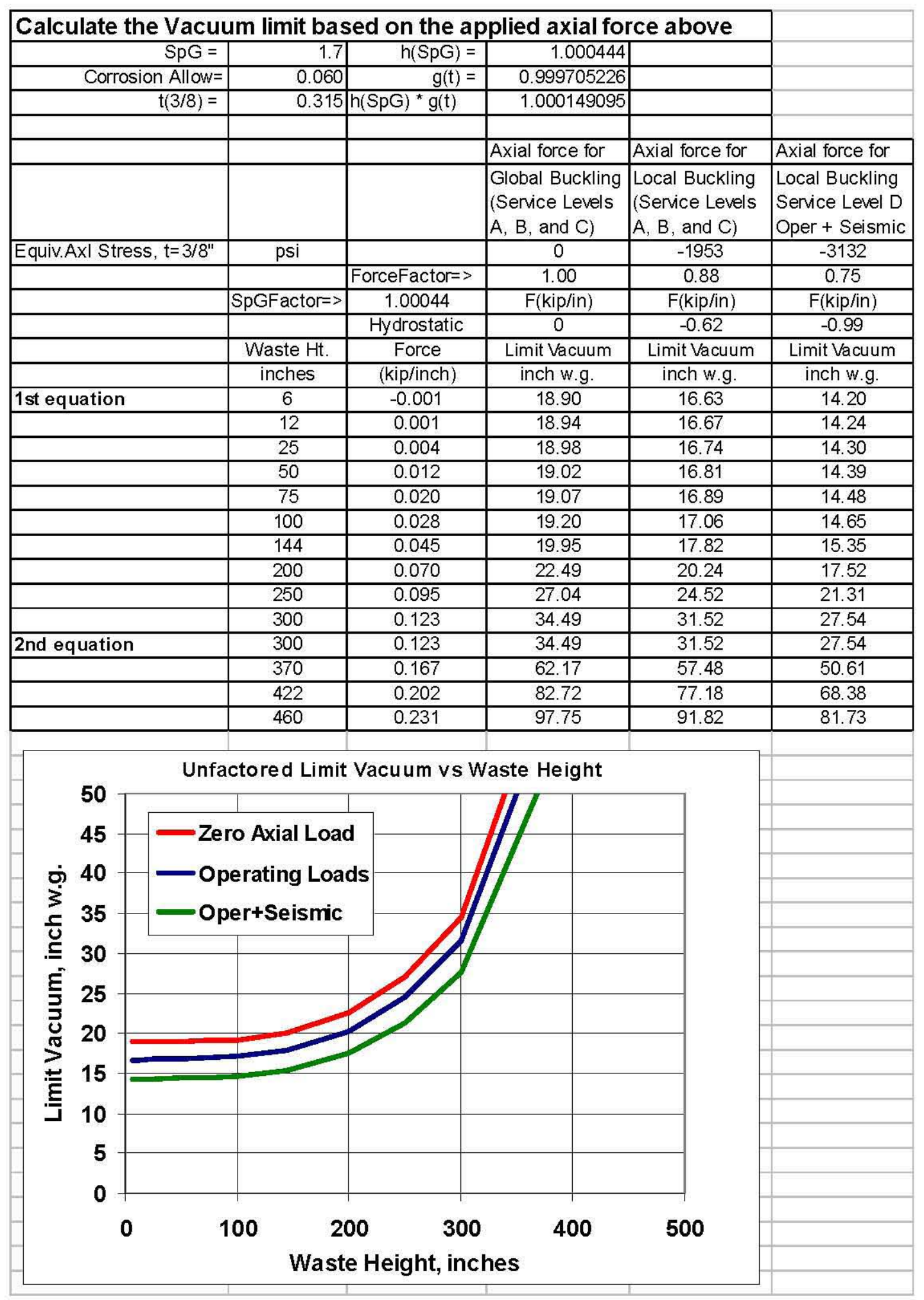

Figure F-3. Unfactored Buckling Limit Vacuum as a Function of Waste Height for the SY DSTs (Note: To calculate the factored vacuum limits, one must divide by the appropriate safety factors in the table of Section 2.1.) 
RPP-RPT-28967, Rev. 2

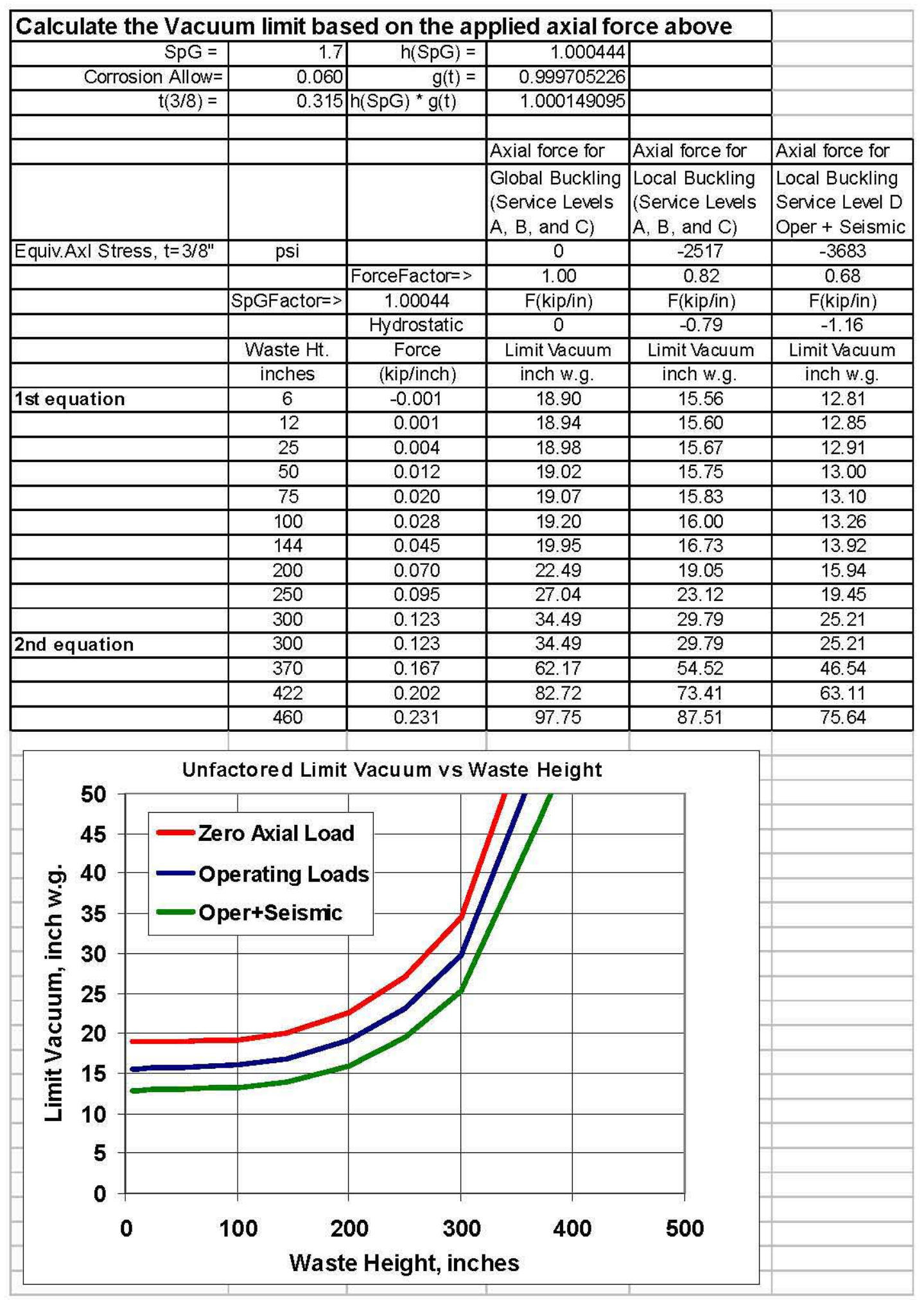

Figure F-4. Unfactored Buckling Limit Vacuum as a Function of Waste Height for the AN and AW DSTs (Note: To calculate the factored vacuum limits, one must divide by the appropriate safety factors in the table of Section 2.1.) 
RPP-RPT-28967, Rev. 2

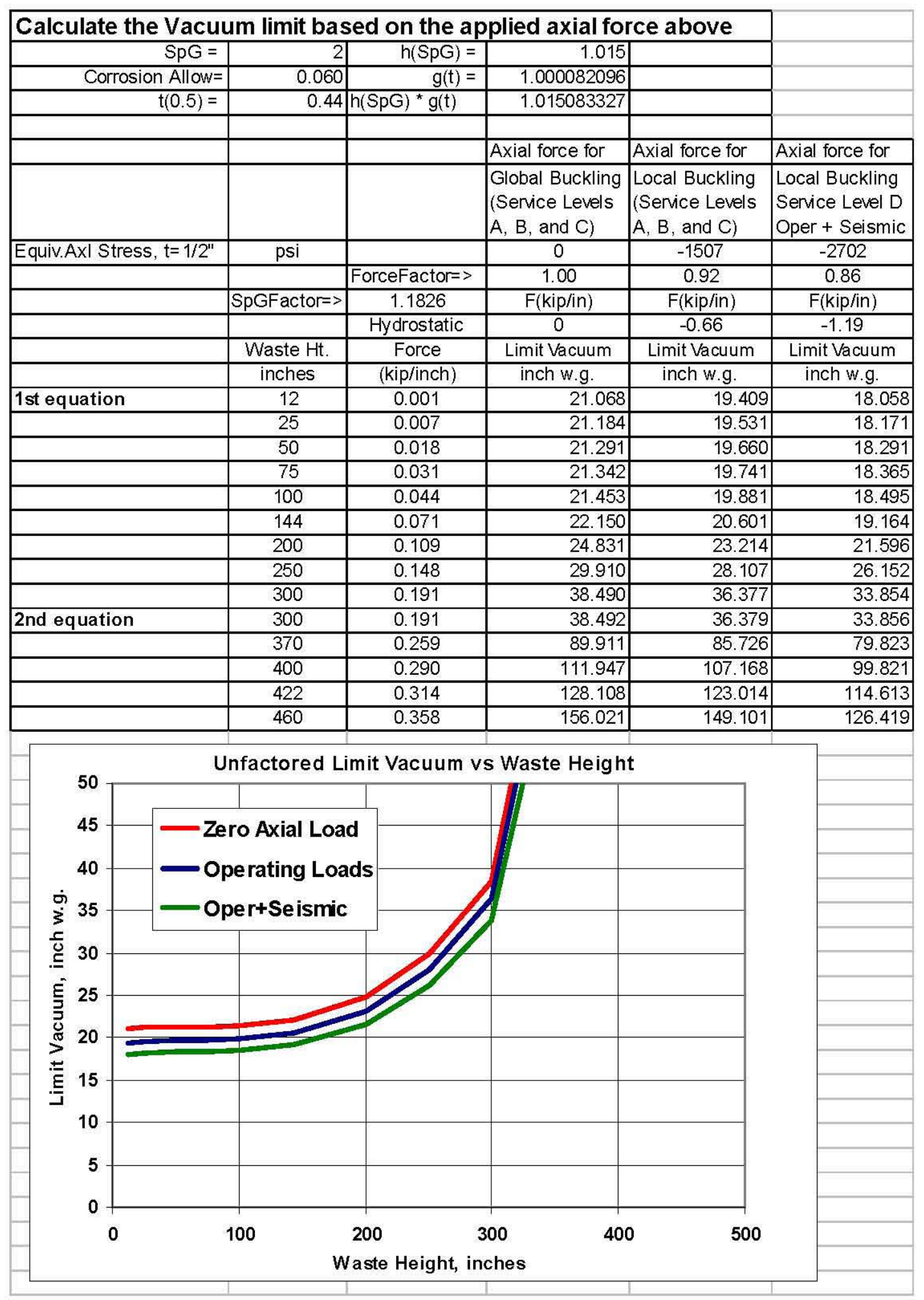

Figure F-5. Unfactored Buckling Limit Vacuum as a Function of Waste Height for the AP DSTs )Note: To calculate the factored vacuum limits, one must divide by the appropriate safety factors in the table of Section 2.1.) 
RPP-RPT-28967, Rev. 2

Table F-2. Maximum load conditions addressed in the AY and AP anchor bolt evaluations.

\begin{tabular}{|c|c|c|c|}
\hline Design Load & Bounding (AY) Tank & AP Tank & Notes \\
\hline Design Life & $>50$ years & $>50$ years & $\begin{array}{l}\text { A } 60 \text {-year design life is } \\
\text { used. }\end{array}$ \\
\hline $\begin{array}{l}\text { Maximum } \\
\text { Corrosion Rate }\end{array}$ & $1 \mathrm{mil} / \mathrm{yr}$ & $1 \mathrm{mil} / \mathrm{yr}$ & $\begin{array}{l}\text { Total corrosion of } 0.060 \\
\text { inch is applied to the } \\
\text { nominal thicknesses. }\end{array}$ \\
\hline Soil Cover & $8.3 \mathrm{ft} @ 125 \mathrm{lb} / \mathrm{ft}^{3}$ & $8.3 \mathrm{ft} @ 125 \mathrm{lb} / \mathrm{ft}^{3}$ & Relative to dome apex. \\
\hline $\begin{array}{l}\text { Hydrostatic } \\
\text { Waste Pressure }\end{array}$ & 422 inches @ $1.7 \mathrm{SpG}$ & 460 inches@1.83 SpG & \\
\hline $\begin{array}{l}\text { Primary Tank } \\
\text { Differential } \\
\text { Pressure } \\
\end{array}$ & -12 in. $w g$ & -12 in. $\mathrm{wg}$ & $\mathrm{P}_{\text {primary }}-\mathrm{P}_{\text {annulus }}$ \\
\hline \multirow[t]{2}{*}{ Live Load } & $40 \mathrm{lb} / \mathrm{ft}^{2}$ & $40 \mathrm{lb} / \mathrm{ft}^{2}$ & Uniform \\
\hline & $200,000 \mathrm{lb}$. nominal & 200,000 lb. nominal & Concentrated \\
\hline $\begin{array}{l}\text { Maximum } \\
\text { Waste } \\
\text { Temperature }\end{array}$ & $\begin{array}{ll}\text { Supernatant } & 135^{\circ} \mathrm{F} \\
\text { Sludge } & 160^{\circ} \mathrm{F}\end{array}$ & $\begin{array}{ll}\text { Supernatant } & 135^{\circ} \mathrm{F} \\
\text { Sludge } & 135^{\circ} \mathrm{F}\end{array}$ & $\begin{array}{l}\text { Waste temperature for } \\
\text { demand } / \text { capacity }=1\end{array}$ \\
\hline $\begin{array}{l}\text { Seismic } \\
\text { Spectrum }\end{array}$ & $\begin{array}{l}\text { 2006 DST surface spectrum } \\
\text { (Rinker and Youngs, 2006) }\end{array}$ & $\begin{array}{l}\text { 2006 DST surface spectrum } \\
\text { (Rinker and Youngs, 2006) }\end{array}$ & $\begin{array}{l}\text { Based on the WTP design } \\
\text { spectrum (Rohay and } \\
\text { Reidel, 2005) }\end{array}$ \\
\hline $\begin{array}{l}\text { Anchor } \\
\text { Displacement } \\
\text { Demands and } \\
\text { Capacities }\end{array}$ & $\begin{array}{ll}\text { Axial Demand: } & 0.048 \text { inch } \\
\text { Axial Capacity: } & 0.330 \text { inch } \\
\text { Axial D/C ratio: } & 0.15 \\
\text { Shear Demand: } & 0.133 \text { inch } \\
\text { Shear Capacity: } & 0.165 \text { inch } \\
\text { Shear D/C ratio: } & 0.81\end{array}$ & $\begin{array}{ll}\text { Axial Demand: } & 0.014 \text { inch } \\
\text { Axial Capacity: } & 0.375 \text { inch } \\
\text { Axial D/C ratio: } & 0.04 \\
\text { Shear Demand: } & 0.164 \text { inch } \\
\text { Shear Capacity: } & 0.165 \text { inch } \\
\text { Shear D/C ratio: } & 0.99\end{array}$ & $\begin{array}{l}\text { AY J-Bolt limits defined } \\
\text { in Deibler et al. (2008a), } \\
\text { AP Headed Anchor limits } \\
\text { defined in Deibler et al. } \\
(2008 \mathrm{~b})\end{array}$ \\
\hline
\end{tabular}

\section{F.4 References}

American Society of Mechanical Engineers. 1994. Code Case N-530, Provisions for Establishing Allowable Axial Compressive Membrane Stresses in the Cylindrical Walls of 0-15 psi Storage Tanks, Classes 2 and 3, Section III, Division 1. ASME Boiler and Pressure Vessel Code, American Society of Mechanical Engineers, New York, New York.

American Society of Mechanical Engineers. 1995. Code Case N-284-1, 1995, Metal Containment Shell Buckling Design Method, Class MC, Section III, Division 1. ASME Boiler and Pressure Vessel Code, American Society of Mechanical Engineers, New York, New York.

American Society of Mechanical Engineers. 2004a. Section III, Division 1, Subsection NB-3113 Service Conditions. ASME Boiler and Pressure Vessel Code, American Society of Mechanical Engineers, New York.

American Society of Mechanical Engineers. 2004b. Section III, Division 1, Mandatory Appendix I, Design Stress Intensity Values, Allowable Stresses, Material Properties, and Design Fatigue Curves, Table I-9.1. ASME Boiler and Pressure Vessel Code, American Society of Mechanical Engineers, New York. 


\section{RPP-RPT-28967, Rev. 2}

Bandyopadhyay K, A Cornell, C Costantino, R Kennedy, C Miller, and A Veletsos. 1995. Seismic Design and Evaluation Guidelines for the Department of Energy High Level Waste Tanks and Appurtenances. BNL 52361. Brookhaven National Laboratory. Associated Universities, Inc., Upton, New York.

Deibler JE, KI Johnson, NK Karri, SP Pilli, MW Rinker, FG Abatt, BG Carpenter, and CA Hendrix. 2008a. Hanford Double-Shell Tank Thermal and Seismic Project-Summary of Combined Thermal and Operating Loads with Seismic Analysis, PNNL-15721, RPP-RPT-28968, Rev. 1. Pacific Northwest National Laboratory, Richland, Washington.

Deibler JE, KI Johnson, SP Pilli, MW Rinker, FG Abatt, NK Karri. 2008b. Hanford Double-Shell Tank Thermal and Seismic Project - Increased Liquid Level Analysis for 241-AP Tank Farms. PNNL-16372, RPP-RPT-32237, Rev. 1. Pacific Northwest National Laboratory, Richland, Washington.

CH2M HILL. 2004. Operability/Technical Evaluation for DST Primary Tank Ventilation Systems. OE-04-0002. CH2M HILL Hanford Group, Inc., Richland, Washington.

Julyk, LJ and HH Ziada. 2002. Assessment of Double-Shell Tank Internal Vacuum Specification Limits on Primary Tanks. HNF-1838, Rev. 0-A. CH2M Hill Hanford Group, Inc., Richland, Washington.

Rinker MW and RR Youngs. 2006. Development of PC2 Surface Spectra for Double-Shell Tank Facilities, DOE Hanford Site in Washington State. PNNL-15607, RPP-RPT-27570, Rev. 0. Pacific Northwest National Laboratory, Richland, Washington.

Rohay AC and SP Reidel. 2005. Site-specific seismic site response model for the Waste Treatment Plant, Hanford, Washington: Report prepared by Pacific Northwest National Laboratory for the U.S. Department of Energy, Office of River Protection, under Contract DE-AC05-76RL01830. PNNL-15089, Pacific Northwest National Laboratory, Richland, Washington. 
RPP-RPT-28967, Rev. 2

\section{Appendix G}

\section{Reviewer Comments and Discussion on}

Revision 1 of RPP-RPT-28967 
RPP-RPT-28967, Rev. 2

\section{Appendix G}

\section{Reviewer Comments and Discussion on}

\section{Revision 1 of RPP-RPT-28967}

An independent review of the Double Shell Tanks (DST) Thermal and Operating Load (TOLA) and Seismic analyses was conducted by Dr. Robert P. Kennedy of RPK Structural Mechanics Consulting and Dr. Anestis S. Veletsos of Rice University. Section 3 of their comments address concerns about the anchor bolt evaluation methods, which impact the buckling analysis contained in RPP-RPT-28967, Rev. 1. 


\title{
Reviewer Comments
}

\author{
Comments Regarding Seismic Evaluation of \\ Hanford Double-Shell Tanks and Effect of Increased \\ Liquid Level in 241-AP Tank Farms
}

by

R.P. Kennedy and A. S. Veletsos

July 2007

\section{Introduction}

Based on our review of the seismic response analyses of the Hanford Double-Shell Tanks (DSTs) reported through February 2006, we provided in Ref. 1 comments on the reported information and recommendations for requisite additional studies. In response to this input, previously reviewed reports ( Refs. 2, 4 and 5 ) have been modified and comprehensive Appendices have been added to them. In addition, a benchmark study (Ref. 3) of seismically induced fluid-structure interaction in flat-top tanks has been performed using the DYTRAN computer program. Lastly, two reports (Refs. 6 and 7) evaluating the effects of increasing the waste in the 241-AP tanks to the 460 -inch level have been prepared.

Our present input refers to the additional studies conducted since then, and it is based on:

- $\quad$ Our review of Refs. 2 through 7; and

- The presentations and ensuing discussions at the Review Meeting of June 7 and 8, 2007, in which we participated to provide an independent oversight and comment on the adequacy and completeness of the approach being used.

Our views and recommendations are presented under the following six topic headings.

\section{Fluid-Structure Interaction Analyses of Primary Tanks}

\subsection{DYTRAN Analyses}

Refs. 2 and 3 present a series of fluid-structure interaction analyses performed using computer program DYTRAN. The problem with the DYTRAN solution identified in Section 3.3 of Ref. 1 has been addressed by using a more refined mesh in the tank region for which the fluid comes in contact with the roof.

We consider the DYTRAN fluid-structure interaction solutions obtained with the refined mesh to represent a good representation of the behavior of a homogeneous, incompressible, practically inviscid liquid in the tanks. 


\section{RPP-RPT-28967, Rev. 2}

\subsection{ANSYS Analyses}

The ANSYS model continues to be used for the combined soil-structure-fluid interaction seismic evaluation of the tanks. As previously noted in Section 3.1 of Ref. 1, this model conservatively overestimates the impulsive mode component of the hydrodynamic effects on the primary tank and underestimates the convective component of the effects. Because the impulsive mode of response dominates the fluid effects on the primary tank and because the ANSYS results are generally slightly higher than the DYTRAN results, we concur that the ANSYS model can continue to be used for the seismic evaluation of the soil-structure-fluid system. However, wherever critical, the convective and dome constrained fluid pressures near the surface of the liquid should be obtained from the DYTRAN solutions.

\subsection{Modeling of Waste}

In the seismic analyses of the Hanford DSTs conducted so far - as in all previous analyses of waste-containing tanks that we are aware of - the waste was effectively modeled as a homogeneous, incompressible, practically inviscid liquid. There are fundamental uncertainties in this idealization, and it would be highly desirable to assess their effect on critical responses.

We recommend that, as a minimum, a qualitative discussion be provided as to why it is considered acceptable to model the waste as a homogeneous liquid. From discussions on this issue during the June 7 and 8 meetings, we understand that the waste may appropriately be represented as:

1. Liquid with a specific gravity (SG) of 1.3 to 1.5 over at least the upper $2 / 3$ of the waste height; and

2. Sludge with the consistency of over-saturated soil with a low angle of repose and a SG of 1.5 to 1.83 over the lower portion of the tank.

Based on this description, we concur that it is probably reasonable, as a first approximation, to model the waste as an incompressible liquid with a SG of at least 1.7. However, this aspect of the system modeling is likely to continue being of concern to some, especially in light of the currently available computational capabilities.

In defense of criticism that may legitimately be voiced on this issue, it is recommended that the critical responses of a simplified model of the tank-waste system (for example, one that does not provide for the effects of soil-structure interaction or the impact effects of the sloshing surface of the waste with the superimposed dome) be evaluated by representing the waste as a uniform, deformable solid with the properties of the lower portion of the waste. The computed responses must then be compared with those obtained for the liquid-like idealization of the waste.

A more realistic modeling of the waste and of the tank itself would be warranted only if the differences in the critical responses computed for the liquid-like and proposed representations of the waste are shown to be of practical significance.

\subsection{Comparison of DYTRAN Results With Approximate Results Obtained Using Method of BNL Tank Report (Ref. 8)}


For the condition under which the sloshing liquid impacts the tank roof, Refs 2 and 3 compare the DYTRAN-computed pressures and reactions with those estimated by the approximate method presented in Appendix D of the BNL tank report (Ref. 8). However, both in Refs. 2 and 3, this appendix, particularly in sections dealing with wall pressures, has been misinterpreted.

Appendix D of Ref. 8 provides the following equations for estimating the hydrodynamic pressures induced on the tank wall:

- $\quad$ Constrained impulsive pressure $p_{i c}$, defined by Eqn. (D.5)

- Unconstrained impulsive pressure $p_{i u}$, defined by Eqn. (D.6)

- Unconstrained convective pressure $p_{c u}$, defined by Eqn. (D.7)

For liquid that is constrained by the roof within the angle $|\theta| \leq \theta_{0}$, Appendix D approximates the hydrodynamic wall pressure $\mathrm{p}$ by:

$$
\begin{aligned}
& \frac{\text { for }|\theta| \leq \Theta_{0}}{p=p_{i c}} \\
& \underline{\text { for }|\theta|>\theta_{0}} \\
& \mathbf{p}=\left[p_{i u}^{2}+p_{c u}^{2}\right]^{0.5}
\end{aligned}
$$

Instead, Refs. 2 and 3 have incorrectly used the expression:

$$
\frac{\text { for }|\theta| \leq \underline{\theta}_{\underline{o}}}{p=p_{i c}+p_{i u}+p_{c u}}
$$

which leads to a substantial overestimation of the wall pressures.

For example, for the 480-inch liquid level results shown in Figure 4-9 of Ref. 3, the correct values of the maximum absolute pressures determined by the approach of Appendix D of Ref. 8 vary from 54.3 psi at the bottom to $23.9 \mathrm{psi}$ at the top of the waste height. Similarly, the maximum gage pressure on the wall determined by this approach is $39.6 \mathrm{psi}$, which is in close agreement with the DYTRAN result of $37.8 \mathrm{psi}$. These results are only slightly greater than the DYTRAN computed maximum pressures.

Ref. 3 also incorrectly computes the minimum pressures corresponding to $\quad \theta=180^{\circ}$ by subtracting the incorrectly defined pressure p obtained by application of Eqn. (2.4.3) from the hydrostatic pressure. The correct hydrodynamic pressure that must be subtracted from the static pressure is given by Eqn. (2.4.2). The resulting minimum pressure determined by the approach of Appendix D of Ref. 8 is identical to the open top minimum pressure. Again, there is close agreement between the results computed by DYTRAN and those obtained by the approach of Appendix D.

A lesser problem exists with the peak horizontal reaction forces $P$ reported in Refs 2 and 3 based on the approach of Appendix D of Ref. 8. The reaction forces, in the later approach should be determined from the expressions: 


$$
\begin{aligned}
& \mathrm{P}_{\mathrm{ic}}=\varepsilon\left(\frac{\mathrm{H}_{\mathrm{t}}}{\mathrm{H}_{\ell}}\right) \mathrm{m}_{\ell}\left(\mathrm{S}_{\mathrm{A}}\right)_{\mathrm{i}} \\
& \mathrm{P}_{\mathrm{iu}}=(1-\varepsilon) \mathrm{P}_{\mathrm{i}} \\
& \mathrm{P}_{\mathrm{cu}}=(1-\varepsilon) \mathrm{P}_{\mathrm{c}} \\
& \mathrm{P}=\left[\left(\mathrm{P}_{\mathrm{ic}}+\mathrm{P}_{\mathrm{iu}}\right)^{2}+\mathrm{P}_{\mathrm{cu}}^{2}\right]^{0.5}
\end{aligned}
$$

where $\mathrm{m}_{\ell}$ is the total liquid mass, $\left(\mathrm{S}_{\mathrm{A}}\right)_{\mathrm{i}}$ is the spectral acceleration for the impulsive mode of response, $\mathrm{H}_{\mathrm{t}}$ is the roof height, $\mathrm{H}_{\ell}$ is the liquid height, $\varepsilon$ is the fraction of the liquid that is constrained by the roof, and $\mathrm{P}_{\mathrm{i}}$ and $\mathrm{P}_{\mathrm{c}}$ are respectively the impulsive and convective components of the reactions for an open top (unconstrained) liquid surface.

For example, for the 480 -inch liquid level, the peak horizontal reaction force $\mathrm{P}$ obtained by the approach of Appendix D should be $4.14 \times 10^{6} \mathrm{lbs}$ as opposed to the $4.47 \times 10^{6} \mathrm{lbs}$ reported in Fig. 4.1 and Table 4.1 of Ref. 3.

Furthermore, Appendix D of Ref. 8 does not provide a method for estimating the peak value of the convective component of the reaction following the decay of the impulsive component. Neither $\mathrm{P}_{\mathrm{cu}}$ (shown in Refs 2 and 3) nor $\mathrm{P}_{\mathrm{c}}$ are intended to represent the peak horizontal convective reaction force. It is therefore recommended that no results be reported in tables such as Table 4-1 and figures such as Figure 4-2 of Ref. 3 for the peak value of the convective component of the horizontal force obtained by the approach of Appendix D.

The maximum roof pressure of 16.2 psi gage reported in Table 4-1 of Ref. 3 for the DYTRAN results is believed to be for the midheight of the top outermost fluid element closest to the wall-roof junction. However, in Fig. 4-9 of Ref. 3, the corresponding wall pressure for the same element is only about 26.7 psi absolute (corresponding to about 12.0 psi gage). Please explain why there is such a large difference between the roof pressure and wall pressure for this same fluid element.

We recommend that the results obtained by the approach of Appendix D of Ref. 8 shown in Sections 4 and 5 and Appendix B of Ref. 3, and in Appendices C and D of Ref. 2 be corrected so as not to lead others astray when using the approximate method. Correcting these results will also help to demonstrate the reasonableness of the DYTRAN results.

\section{Anchorage of Primary Tank Steel Dome to Concrete Vault Dome}

Shearing forces and tensile forces between the primary tank steel dome and the concrete vault dome are transferred by $1 / 2$-inch diameter anchors. These anchors consist of either 6 -inch long headed anchor bolts or 6-inch long J-bolts with a $180^{\circ} \mathrm{J}$-hook at their upper end. These anchor bolts are screwed into $3 / 4$ inch diameter by 1.375 -inch high Nelson tapped welding studs welded to the steel dome. 
The tensile loads on these anchors are small. However, the shear loads are significant.

In Ref. 1 we stated that:

Neither of us is familiar with the basis of the acceptance criteria for the reported allowables. Furthermore, we do not have sufficient information regarding the Nelson Internally Threaded Studs used to attach the J-bolts to the steel tank so that we may assess the appropriateness of the indicated allowables.

The basis for the tension and shear allowables for these anchors has now been provided in Section 6.1 of Ref. 4 and Section E. 3 of Ref. 5.

Based on our review of these sections, we have concerns about the allowable capacities assigned to the anchors. We also wish to comment on the demands computed for these anchors.

\subsection{Allowable Anchor Bolt Capacities}

From Table 6-3 of Ref. 4, the allowable anchor tension $T_{a}$ and shear $V_{a}$ are defined by the following expressions:

For Normal (Operating) Loads

$$
\begin{aligned}
& \mathrm{T}_{\mathrm{a}}=0.33 \mathrm{~T}_{\mathrm{u}} \\
& \mathrm{V}_{\mathrm{a}}=0.33 \mathrm{~V}_{\mathrm{u}}
\end{aligned}
$$

For Abnormal (Operating + Seismic) Loads

$$
\begin{aligned}
\mathrm{T}_{\mathrm{a}} & =0.5 \mathrm{~T}_{\mathrm{u}} \\
\mathrm{V}_{\mathrm{a}} & =0.5 \mathrm{~V}_{\mathrm{u}}
\end{aligned}
$$

where $T_{u}$ and $V_{u}$ represent the nominal ultimate tensile and shear capacities of the anchors, respectively. We understand that the tank criteria document specifies the use of these ASME code factors of 0.33 and 0.5. These factors are lower (more conservative) than the strength reduction factors $\phi$ in both the AISC Code (Ref. 9) for steel and the ACI Code (Ref. 10) for concrete.

\subsubsection{Nominal Ultimate Tensile Strength for Headed Bolts}

Table 6-3 of Ref. 4 bases the nominal ultimate tensile capacity of the anchors on:

$$
T_{u}=(2 / 3) A_{b} f_{u}
$$

where $A_{b}=0.1963$ inch $^{2}$ is the cross-sectional area of the bolt shank, and $f_{u}=60 \mathrm{ksi}$ is the ultimate strength of the bolt material. Thus:

$$
\mathrm{T}_{\mathrm{u}}=7.85 \mathrm{kips}
$$




\section{RPP-RPT-28967, Rev. 2}

which is slightly less (more conservative) than the nominal $T_{u}$ computed in accordance with AISC (Ref. 9) or ACI (Ref. 10).

However, Refs. 4 and 5 do not check the anchor tensile capacity as governed by the concrete breakout strength $\mathrm{T}_{\mathrm{ub}}$ :

$$
\mathrm{T}_{\mathrm{ub}}=24\left(\mathrm{f}_{\mathrm{c}}^{\prime}\right)^{0.5} \mathrm{~h}^{1.5}
$$

where $f_{c}^{\prime}=4860 p s i$ is the concrete strength, and $h=6$ inches is the bolt length. Neither is the concrete pullout strength, $\mathrm{T}_{\mathrm{up}}$, defined by:

$$
\mathrm{T}_{\text {up }}=8 \mathrm{f}_{\mathrm{c}}^{\prime} \mathrm{A}_{\mathrm{brg}}
$$

checked, where $A_{b r g}=0.2959$ inch is the bearing area of the head on a $1 / 2$ inch bolt. The values obtained from Eqns. (3.1.5) and (3.1.6) are:

$$
\begin{aligned}
& \mathrm{T}_{\mathrm{ub}}=24.6 \mathrm{kips} \\
& \mathrm{T}_{\mathrm{up}}=11.5 \mathrm{kips}
\end{aligned}
$$

These concrete failure modes do not control the nominal ultimate tensile capacity $T_{u}$ for the headed anchor bolts. Even so, these concrete failure mode tensile capacities should be computed.

In conclusion, the tensile capacity $T_{u}=7.85$ kips presented in Table $6-3$ of Ref. 4 is considered to be reasonable for the headed anchor bolts. 


\subsubsection{Nominal Ultimate Tensile Strength for J-Bolt Anchors}

J-Bolt anchors are not permitted by either AISC or ACI for positive tensile anchorage. See, for example, page 14-10 of Ref. 9. Therefore, no approach is provided in either Ref. 9 or 10 for computing the ultimate tension capacity of J-Bolt anchors.

A criterion for determining the nominal ultimate capacity of J-bolt anchors is provided in older versions of the British Standard CP110 (Ref. 11). Based on this Standard, the ultimate bond tensile capacity $\mathrm{T}_{\mathrm{ub}}$ for $\mathrm{J}$-Bolt anchors is defined by:

$$
\mathrm{T}_{\mathrm{ub}}=\pi \mathrm{d}_{\mathrm{b}} \mathrm{f}_{\mathrm{bs}} \ell_{\mathrm{e}}
$$

where $d_{b}$ is the bar diameter, $f_{b s}$ is the concrete bond strength for a smooth-bar, and $\ell_{e}$ is the effective bar length given by:

$$
\begin{aligned}
& \ell_{\mathrm{e}}=\ell_{\mathrm{s}}+\ell_{\mathrm{h}} \\
& \ell_{\mathrm{h}} \leq 24 \mathrm{~d}_{\mathrm{b}}
\end{aligned}
$$

where $\ell_{\mathrm{s}}$ is the straight bar length to the start of the hook, and $\ell_{\mathrm{h}}$ is the inside radius length of the hook plus any straight extension beyond the hook, provided $\ell_{\mathrm{h}}$ is limited to not more than $24 \mathrm{~d}_{\mathrm{b}}$. For concrete with $f_{c}^{\prime}$ greater than $4600 \mathrm{psi}, \mathrm{CP} 110$ limits the smooth-bar bond-strength to:

$$
\mathrm{f}_{\mathrm{bs}}=275 \mathrm{psi}
$$

We suggest that the bond-slip capacity of the J-Bolt anchors might control their ultimate tensile capacity $T_{u}$ rather than the steel bolt shank capacity $T_{u}=7.85$ kips given by Eqn. (3.1.4). One possible approach for estimating the bond-slip capacity is to use Eqns. (3.1.9) through (3.1.12).

\subsubsection{Nominal Ultimate Shear Strength for Anchor Bolts}

In Table 6-3 of Ref. 4, ultimate shear strength values $V_{u}$ based both on a steel failure limit and on a concrete failure limit were computed using the following expressions:

For Steel Failure Limit

$$
\mathrm{V}_{\mathrm{us}}=0.9 \mathrm{~A}_{\mathrm{s}} \mathrm{f}_{\mathrm{u}}
$$

\section{For Concrete Failure Limit}

$$
\mathrm{V}_{\mathrm{uc}}=5.66 \mathrm{~A}_{\mathrm{s}} \mathrm{f}_{\mathrm{c}}^{0.3} \mathrm{E}_{\mathrm{c}}^{0.44}
$$

In Table 6-3 of Ref. 4 the full cross-sectional area $A_{s}=0.442$ in $^{2}$ of the $3 / 4$ inch diameter Nelson tapped welding stud was used in both Eqns (3.1.13) and (3.1.14) to obtain: 


$$
\begin{aligned}
& \mathrm{V}_{\mathrm{us}}=23.86 \mathrm{kips} \\
& \mathrm{V}_{\mathrm{uc}}=23.42 \mathrm{kips}
\end{aligned}
$$

In our judgement, it is inappropriate to use $A_{s}=0.442 \mathrm{in}^{2}$ in Eqn. (3.1.14) for the concrete failure limit $\mathrm{V}_{\mathrm{uc}}$. This equation was based on extensive test data for headed studs with a length of at least four stud diameters and is unconservative for lesser bearing lengths. For a $3 / 4$ inch diameter stud, the required length is 3.0 inches. However, the Nelson tapped welding stud is only 1.375 inch long. Over the remainder of the required 3.0 inch length, the concrete bears against a $1 / 2$ inch bolt instead of a $3 / 4$ inch stud.

The required bearing area $A_{\text {bear }}$ to obtain the $V_{u c}$ capacity is:

$\underline{\text { Required }}$

$$
\mathrm{A}_{\text {bear }}=4(3 / 4 \text { in })^{2}=2.25 \text { in }^{2}
$$

However, the available bearing area in the 3 inch length is only:

$\underline{\text { Available }}$

$$
\mathrm{A}_{\text {bear }}=1.375 \mathrm{in}(3 / 4 \mathrm{in})+1.625 \mathrm{in}(1 / 2 \mathrm{in})=1.844 \mathrm{in}^{2}
$$

Conservatively assuming a uniform bearing pressure over the required 3 inch length, $\mathrm{V}_{\mathrm{uc}}$ should be reduced to:

$$
\mathrm{V}_{\mathrm{uc}}=(1.844 / 2.25)(23.42)=19.19 \mathrm{kips}
$$

for an average bearing pressure on the concrete of:

$$
\mathrm{f}_{\text {bear }}=\frac{19.19}{1.844}=10.4 \mathrm{ksi}
$$

It is undoubtedly conservative to assume a uniform bearing pressure over the 3 inch length. In reality, bearing pressure will be concentrated closer to the base and this concentration will lead to in a higher $V_{u c}$ than that given by Eqn. (3.1.19). However, for a $4.86 \mathrm{ksi}$ concrete, it is not clear how much higher than $10.4 \mathrm{ksi}$ the bearing pressure can become without crushing the concrete.

It is also not appropriate to use the full $\mathrm{A}_{\mathrm{s}}=0.442 \mathrm{in}^{2}$ to determine the steel failure limit $\mathrm{V}_{\mathrm{us}}$. Immediately above the base, the cross-sectional area of the 3/4-inch Nelson tapped welding stud is reduced by the tapped threaded hole. Using the diameter midway between the minor and pitch diameter of the threaded hole, the reduction in cross-sectional area becomes 0.1416 inch. Thus, the effective shear area $\mathrm{A}_{\mathrm{se}}$ of the welding stud is:

$$
\mathrm{A}_{\mathrm{se}}=0.4418-0.1416=0.300 \mathrm{in}^{2}
$$




\section{RPP-RPT-28967, Rev. 2}

and with $\mathrm{f}_{\mathrm{u}}=60 \mathrm{ksi}$, Eqn (3.1.13) yields:

$$
\mathrm{V}_{\mathrm{us}}=0.9(0.300)(60)=16.2 \mathrm{kips}
$$

Another location that might control the ultimate shear capacity of the anchorage is the $1 / 2 \mathrm{inch}$ anchor bolt shaft at its junction with the Nelson tapped welding stud. Based on Eqn. (3.1.13), the shear capacity $\mathrm{V}_{\mathrm{ub}}$ for the bolt shank is:

$$
\mathrm{V}_{\mathrm{ub}}=0.9\left(0.1963 \mathrm{in}^{2}\right)(60 \mathrm{ksi})=10.60 \mathrm{kips}
$$

Conservatively assuming a uniform bearing pressure $\mathrm{f}_{\text {bear }}=10.4 \mathrm{ksi}$ and a bearing area $A_{\text {bear }}=1.375(3 / 4)=1.031 \mathrm{in}^{2}$ for the welding stud, the corresponding ultimate shear capacity at the base of the welding stud is:

$$
\mathrm{V}_{\text {usb }}=\mathrm{V}_{\mathrm{ub}}+\mathrm{f}_{\text {bear }} A_{\text {bear }}=21.3 \mathrm{kips}
$$

which is not the controlling capacity.

The ultimate shear capacity, $V_{u}$, of the anchors seems to be controlled by the $V_{u s}$ value determined from Eqn. (3.1.22). Thus:

$$
\mathrm{V}_{\mathrm{u}}=16.2 \mathrm{kips}
$$

which is only $69 \%$ of the value reported in Table 6-3 of Ref. 4 for these anchors.

\subsection{Recommendation for Finite Element Analysis of Anchor Bolts}

We recommend that a detailed nonlinear finite element model be developed for an anchor in the concrete dome so as to determine its load-deformation relationship in shear. The model must include: (1) a realistic stress-strain relationship for the Nelson welding stud and stud bolt, (2) realistic nonlinear constitutive properties for compression, shear, and tension in the concrete, (3) a bond shear limit between the anchor and concrete of no more than $250 \mathrm{psi}$, and (4) a coefficient of friction between the anchor and concrete of no more than 0.2 , with friction induced stresses not being additive to the bond induced stresses since friction activates after the bond is broken.

It is unlikely that this finite element analysis would justify the use of an ultimate shear strength higher than the 16.2 kips value, since the shear area is reduced by the tapped hole in the Nelson welding stud and the bolt does not extend to the bottom of this tapped hole. However, the analysis is likely to show significant shear distortions at an allowable shear load $\mathrm{V}_{\mathrm{a}}=0.5 \mathrm{~V}_{\mathrm{u}}=8.1 \mathrm{kips}$. The results of this analysis could be then used to determine if a lower shear stiffness than that currently considered for the anchors would be appropriate to use in the demand analyses.

As shown in Figs. 6-25 and 6-26 of Ref. 4, the reported demand analyses indicate the total shear between the primary tank steel dome and the concrete vault roof is heavily concentrated on the outermost anchor bolts. We expect that reducing the shear stiffness of the anchors below the level used in the 
demand evaluations presented so far will redistribute the shear to more anchors and will reduce the shear demands on the outermost anchors.

\subsection{Other Comments on Anchor Bolt Demand}

\subsubsection{Anchor Bolt Demand for 422 inch Waste Level}

In Ref. 12, the shear demand in the outermost anchor bolts for the combination of gravity and seismic loads was reported to be:

$$
\mathrm{V}_{\mathrm{bs}}=5.4 \mathrm{kips} / \mathrm{bolt}
$$

for the 'Best Estimate Soil-Fully Cracked Concrete' (BES-FCC) Case. This value was obtained from an analysis in which the coefficient of friction, $\mathrm{COF}$, between the steel and concrete was taken as 0.4 .

In Ref. 1 we commented that a COF value of 0.4 was too high to use once sliding was initiated and the anchor bolts begin to pick-up shear load. Therefore, the seismic analysis was rerun with $\mathrm{COF}=0$ for 'Best-Estimate Soil-Best Estimate Concrete' (BES-BEC) Case which is not the critical BES-FCC Case that we had recommended to be considered. For the BES-BEC Case, the shear $\mathrm{V}_{\mathrm{bs}}$ increased from 4.052 kips for $\mathrm{COF}=0.4$ to 4.591 kips for $\mathrm{COF}=0$, or by a factor of 1.133 . Applying the same amplification factor to the BES-FCC Case leads to:

\section{$\underline{B E S-F C C ~ C a s e ~}(\mathrm{COF}=0)$}

$$
\mathrm{V}_{\mathrm{bs}}=5.4(1.133)=6.1 \mathrm{kips}
$$

However, in Section 6.3 of Ref. 4 the seismically induced shear demand $V_{b s}=4.6$ kips was used to evaluate the Demand to Capacity ratio $(\mathrm{D} / \mathrm{C})$ of the anchors. We believe that the appropriate seismic shear demand should have been $V_{b s}=6.1$ kips.

The seismic shear demand $V_{b s}=4.6$ kips in Ref. 4 was then combined with the shear demand $V_{b c}$ on the outermost anchor induced by axial compression in the tank wall resulting from thermal expansion of the steel tank and axial shortening of the concrete vault due to concrete creep. The maximum permissible axial compressive force was then determined from the permissible $\mathrm{V}_{\mathrm{bc}}=\mathrm{V}_{\mathrm{a}}-\mathrm{V}_{\mathrm{bs}}=11.7 \mathrm{kips}-4.6 \mathrm{kips}=7.1$ kips.

Increasing $\mathrm{V}_{\mathrm{bs}}$ from 4.6 kips to 6.1 kips and decreasing $\mathrm{V}_{\mathrm{a}}$ from 11.7 kips to 8.1 kips will substantially reduce the allowable axial compression in the tank wall due to temperature and creep effects since $V_{b c}$ is reduced to 8.1 kips- $6.1 \mathrm{kips}=2.0$ kips.

However, the temperature and creep induced axial compression in the tank wall occurs only when significant compressive normal forces exist between the primary tank dome and the concrete vault roof. Under these conditions, even a low COF value of 0.2 , which we previously accepted in Ref. 1 , is likely to reduce the $\mathrm{V}_{\mathrm{bc}}$ demand. 
In summary, we do not concur with the $\mathrm{D} / \mathrm{C}$ evaluation of the J-bolt anchors presented in Sections 6.1 through 6.3 of Ref. 4 and summarized in Section 6.6 of Ref. 5 because:

1. The reported ultimate shear capacity $V_{u}$ of the anchors appears to be significantly unconservative; and

2. Both conservative and unconservative aspects appear to exist in the anchorage demand evaluations.

\subsubsection{Anchor Bolt Demand for 460 inch Waste Level}

For the anchorage of the steel dome to the concrete roof and the combination of gravity and seismic loads, Ref. 6 reports a shear demand $V_{b s}$ in the outermost anchors of 9.0 kips. This $V_{b s}$ represents an approximate factor of 1.5 increase resulting from increasing the waste height from 422 inches to 460 inches and increasing the waste SG from 1.7 to 1.83 . This increase seems reasonable, because with the increased waste level, a greater fraction of the total seismically induced horizontal reaction gets transferred to the concrete vault roof.

For the waste level considered, it is not clear how the temperatures and creep induced shear, $\mathrm{V}_{\mathrm{bc}}$, is combined with $V_{b s}$ in Section 6.6 of Ref. 7. No explanation is provided on how the total shear demand $V_{b}$ on the outermost anchor bolts was obtained. However, based on an allowable $\mathrm{V}_{\mathrm{a}}=11.7 \mathrm{kips}$, the maximum $\mathrm{D} / \mathrm{C}$ ratio is shown in Fig. $6-86$ of Ref. 7 to be about 0.88 , which would correspond to a combined total shear demand:

$$
\mathrm{V}_{\mathrm{b}}=0.88(11.71 \mathrm{kips})=10.3 \mathrm{kips}
$$

This combined shear demand is only 1.3 kips higher than the value of $\mathrm{V}_{\mathrm{bs}}=9.0$ kips obtained for gravity and seismic loads only. The small effect of the $\mathrm{V}_{\mathrm{bc}}$ in this case does not appear to be consistent with the result reported in Section 6.3 of Ref. 4 for the 422 inch waste level.

A seismic shear demand of $V_{b s}=9.0$ kips compounds the issues that arise if the ultimate shear capacity $V_{u}$ is reduced to 16.2 kips and the allowable shear capacity $V_{a}$ is reduced to 8.1 kips. The computed seismic shear demand alone for the outermost anchor exceeds this allowable shear capacity.

One should reconsider whether it is really necessary to define the allowable shear:

$$
\mathrm{V}_{\mathrm{a}}=0.5 \mathrm{~V}_{\mathrm{u}}
$$

as is currently required by the project criteria for Abnormal (Operating + Seismic) Loads. Both AISC (Ref. 9) and ACI (Ref. 10) would permit the use of a strength reduction factor $\phi=0.75$, which would increase the allowable $\mathrm{V}_{\mathrm{a}}$ for a given $\mathrm{V}_{\mathrm{u}}$ by a factor of 1.5 .

\section{Buckling Evaluations}


We concur with the approach for the buckling evaluation of the tank wall presented in Ref. 4 and summarized in Section 6.4 of Ref. 5 for a generic tank. The same approach and results are summarized in Section 6.4 of Ref. 7 for the AP tanks with the increased waste height.

\section{Seismic Induced Stressed in Lower Knuckle of Primary Tank}

The lower knuckle of the primary tank is too crudely modeled in the global analysis of the soilstructure-waste system to accurately define the peak values of the stresses induced in it. To provide for this inadequacy, the maximum values of the stresses determined in the global analysis for this region were increased by a factor of 2.0. We understand that this factor was based on the increase in maximum stresses determined for a refined model of the knuckle considering the effects of the hydrostatic pressures only.

While this amplification factor may indeed be adequate for the hydrostatic effects, we are concerned that it may not be adequate for the seismically induced effects. As the seismic loading, unlike the hydrostatic, induces a substantive axial force in the tank-wall, we expect the increase of the bending stresses in the knuckle to be larger for the seismic loading than for the hydrostatic.

We recommend that the stresses in the refined local model of the lower knuckle be determined using the maximum values of the boundary forces and of the associated pressures computed in the seismic analysis of the global model. A comparison of the absolute maximum values of the resulting stresses with those obtained by the global model would then provide a more defensible estimate of the amplification factor that should be applied to the seismically induced effects determined with the global model.

Alternatively - although this option is not as desirable - an approximate estimate of the requisite amplification factor may be determined by a static analysis similar to the one used, provided the vertical and circumferential distributions of the pressures considered are representative of those of the impulsive component of the seismically induced pressures.

Considering that some of the reported analyses indicate the absolute maximum stresses to occur in the base plate, slightly beyond the lower end of the knuckle, it is important that the local model does include this region.

\section{Comments in Inelastic Factor and Nonlinear Response}

So long as these tanks are considered to be PC\#2 structures, we concur with the use of a Response Modification Factor $\mathrm{R}=2.5$ coupled with an Importance Factor $\mathrm{I}=1.5$ which results in an Inelastic Factor:

$$
\mathrm{F}_{\mu} \frac{\mathrm{R}}{\mathrm{I}}=1.67
$$

For ductile failure modes, the computed seismic demands can be reduced by $\mathrm{F}_{\mu}=1.67$ before being combined with non-seismic demands. For brittle failure modes such as J-bolt anchorage failure and buckling, no credit should be taken for the Inelastic Factor (i.e., $\mathrm{F}_{\mu}=1.0$ ). 


\section{RPP-RPT-28967, Rev. 2}

In addition, wherever credit is taken for the Inelastic Factor $\mathrm{F}_{\mu}=1.67$, the ASME Code allowable stresses defined by Eqns. (6.1) through (6.4) of Ref. 5 should be limited to:

$$
\begin{aligned}
& \mathrm{kS}_{\mathrm{m}} \leq \mathrm{S}_{\mathrm{y}} \\
& 1.5 \mathrm{k} \mathrm{S}_{\mathrm{m}} \leq 1.5 \mathrm{~S}_{\mathrm{y}} \\
& 3 \mathrm{~S}_{\mathrm{m}} \leq 1.5 \mathrm{~S}_{\mathrm{y}}
\end{aligned}
$$

where $S_{y}$ is the yield stress. These limits should be applied to insure that the effect of inelastic behavior is not double-counted.

However, we are concerned with the statements on Pages i, 6.16, and 7.1 that primary stresses remain below yield, and that gross plastic deformation does not occur. The use of $F_{\mu}=1.67$ automatically implies that gross plastic deformation has occurred during the transient seismic response. In fact, in order to develop an $F_{\mu}$ of 1.67 , the gross deformation (elastic + plastic) during transient seismic response needs to be about 1.5 to 2.0 times the yield deformation of the structure (i.e., transient gross plastic deformations are about 0.5 to 1.0 times the yield deformation). At the end of the seismic event some residual stresses will remain in the yielding elements of the structure. However, it is not expected that the further operability or future seismic margin will appreciably be impaired by this level of inelastic response, although the potential for future stress-controlled cracking may increase.

If it is necessary to prevent gross plastic deformation, a value of $F_{\mu}=1.0$ should be used. In this case, the limits imposed by Eqns. (6.2) through (6.4) would no longer be necessary.

Lastly, we do not recommend the use of the $\mathrm{R}=3$ factor discussed in the second paragraph on Page 6.17 of Ref. 5 . We consider $\mathrm{R}=2.5$ to be reasonable, but not conservative. We further believe that it would

be difficult to defend the view that there is sufficient inelastic energy dissipation capability in these tanks so as to justify the use of $\mathrm{R}=3$ (i.e., $\mathrm{F}_{\mu}=2.0$ ).

\section{$\underline{\text { References }}$}

1. Kennedy, R.P. and Veletsos, A.S., Additional Comments and Recommendations Concerning Seismic Evaluation of Hanford Double-Shell Tanks, May 2006

2. Rinker, M.W. and Abatt, F. G., Hanford Thermal and Seismic Project-DYTRAN Analysis of Seismically Induced Fluid-Structure Interaction on a Hanford Double-Shell Primary Tank,RPP-RPT28963, Rev. 0A, Pacific Northwest National Laboratory, Nov. 2006

3. Abatt, F.G. and Rinker, M.W., Hanford Double-Shell Tank Thermal and Seismic Project-DYTRAN Benchmark Analysis of Seismically Induced Fluid-Structure Interaction in Flat-Top Tanks, RPPRPT-30807, Rev. 0, Pacific Northwest National Laboratory, Jan. 2007

4. Johnson, K.I. et al, Hanford Double-Shell Tank Thermal and Seismic Project-Buckling Evaluation Methods and Results for the Primary Tanks, RPP-RPT-28967, Rev. 1, Pacific Northwest National Laboratory, Jan. 2007 


\section{RPP-RPT-28967, Rev. 2}

5. Deibler, J.E., et al., Hanford Double-Shell Tank Thermal and Seismic Project-Summary of Combined Thermal and Operating Loads with Seismic Analysis, RPP-RPT-28968, Rev. O-A, Pacific Northwest National Laboratory, Jan. 2007

6. Abatt, F.G., Carpenter, B.G., and Rinker, M.W., Hanford Double-Shell Tank Thermal and Seismic Project-Seismic Analysis in Support of Increased Liquid Level in 241-AP Tank Farms, RPP-RPT32239, Rev.0, Pacific Northwest National Laboratory, Jan. 2007

7. Diebler, J.E., et al., Hanford Double-Shell Tank Thermal and Seismic Project-Increased Liquid Level Analysis for 241-AP Tank Farms, RPP-RPT-32237, Rev. 0, Pacific Northwest National Laboratory, Jan. 2007

8. Bandyopadhyay, K., et al., Seismic Design and Evaluation Guidelines for the Department of Energy High-Level Waste Storage Tanks and Appurtenances, BNL 52361, Brookhaven National Laboratory, Upton, N.Y., Oct. 1995

9. AISC, Steel Construction Manual, Thirteenth Edition, 2005

10. ACI 349-01, Code Requirements for Nuclear Safety Relayed Concrete Structures, 2001

11. British Standards Institution, The Structural Use of Concrete Part 1: Design, Materials, and Workmanship, London, CP110 Part 1, 1972, as amended in November 1980

12. Carpenter, B.G., C. Hendrix and G. G. Abatt, ANSYS Seismic Analysis of Hanford Double-Shell Primary Tank, M\&D-2008-004-CALC-001, Rev. 0A, Draft, M\&D Professional Services, Inc., Jan. 2006 